Marc Richard

\title{
Kapitalschutz der Aktiengesellschaft
}

Eine rechtsvergleichende und ökonomische Analyse deutscher und US-amerikanischer Kapitalschutzsysteme 


\section{Kapitalschutz der Aktiengesellschaft}

Das in der EU für Aktiengesellschaften kodifizierte Kapitalschutzsystem ist unter Rechtfertigungsdruck geraten und steht vor tiefgreifenden Veränderungen. Es sieht bisher neben der Aufbringung eines Mindestkapitals vielfältige Kapitalaufbringungs- und Kapitalerhaltungsregeln vor, die auf vom Vorsichtsprinzip geprägte Rechnungslegungsdaten im Einzelabschluss zurückgreifen. Auf der Annahme basierend, dass sich der Trend zur IFRS-Bilanzierung in Europa in den nächsten Jahren fortsetzen und zunehmend auch den Einzelabschluss betreffen wird, sind Vorschläge zur Reform des tradierten Gläubigerschutzsystems durch bilanzielle Kapitalerhaltung vorgelegt worden, die sich weitgehend an US-amerikanischen Kapitalschutzregulierungen orientieren. Nach den Plänen der EU-Kommission könnte es möglicherweise bereits $2009 \mathrm{zu}$ einem Systemwechsel kommen. Vor diesem Hintergrund werden in dieser Arbeit unter anderem die Kapitalschutzregeln des Model Business Corporations Act und der Kapitalgesellschaftsrechte Delawares und Kaliforniens detailliert analysiert und aus ökonomischer Sicht kritisch beurteilt.

Marc Richard, geboren 1974 in Herne, studierte von 1995 bis 2000 Wirtschaftswissenschaft an der Ruhr-Universität Bochum. Nach dem Abschluss als Diplom-Ökonom arbeitete er bis zu seiner Promotion im Frühjahr 2006 als Wissenschaftlicher Mitarbeiter am Lehrstuhl für Internationale Unternehmensrechnung an der Ruhr-Universität Bochum. Seit der Promotion ist er Mitarbeiter im Bereich Audit Commercial Clients einer großen Wirtschaftsprüfungsgesellschaft in Düsseldorf. 
Kapitalschutz der Aktiengesellschaft 


\section{BOCHUMER BEITRÄGE ZUR UNTERNEHMENSFÜHRUNG}

Herausgegeben von

Prof. Dr. Michael Abramovici, Prof. Dr. Dr. h.c. mult. Walther Busse von Colbe,

Prof. Dr. Dr. h.c. Werner H. Engelhardt, Prof. Dr. Roland Gabriel,

Prof. Dr. Gert Laßmann, Prof. Dr. Wolfgang Maßberg,

Prof. Dr. Bernhard Pellens, Prof. Dr. Mario Rese, Prof. Dr. Marion Steven,

Prof. Dr. Rolf Wartmann, Prof. Dr. Brigitte Werners

Herausgegeben

vom Direktorium des Instituts für Unternehmensführung

der Ruhr-Universität Bochum

Band 74

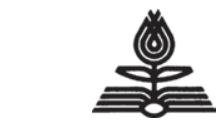

PETER LANG

Frankfurt am Main - Berlin - Bern - Bruxelles - New York - Oxford - Wien 


\section{Marc Richard}

\section{Kapitalschutz der Aktiengesellschaft}

Eine rechtsvergleichende und ökonomische Analyse deutscher und US-amerikanischer Kapitalschutzsysteme

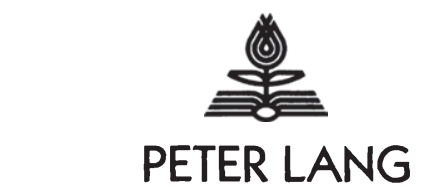

Europäischer Verlag der Wissenschaften 
Bibliografische Information der Deutschen Nationalbibliothek

Die Deutsche Nationalbibliothek verzeichnet diese Publikation in der

Deutschen Nationalbibliografie; detaillierte bibliografische

Daten sind im Internet über <http://www.d-nb.de> abrufbar.

Open Access: The online version of this publication is published on www.peterlang.com and www.econstor.eu under the international Creative Commons License CC-BY 4.0. Learn more on how you can use and share this work: http://creativecommons.org/licenses/by/4.0.

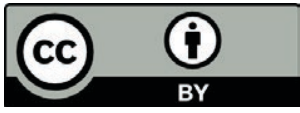

This book is available Open Access thanks to the kind support of ZBW - Leibniz-Informationszentrum Wirtschaft.

Zugl.: Bochum, Univ., Diss., 2006

Gedruckt auf alterungsbeständigem, säurefreiem Papier.

\author{
D 294 \\ ISSN 1860-479X \\ ISBN 3-631-56066-4 \\ ISBN 978-3-631-75501-3 (eBook) \\ (c) Peter Lang $\mathrm{GmbH}$ \\ Europäischer Verlag der Wissenschaften \\ Frankfurt am Main 2007 \\ Alle Rechte vorbehalten.
}

Das Werk einschließlich aller seiner Teile ist urheberrechtlich geschützt. Jede Verwertung außerhalb der engen Grenzen des

Urheberrechtsgesetzes ist ohne Zustimmung des Verlages unzulässig und strafbar. Das gilt insbesondere für Vervielfältigungen, Übersetzungen, Mikroverfilmungen und die Einspeicherung und Verarbeitung in elektronischen Systemen.

Printed in Germany 123467

www.peterlang.de 
Meinen Eltern

Marc Richard - 978-3-631-75501-3

Downloaded from PubFactory at 01/11/2019 04:06:06AM

via free access 
Marc Richard - 978-3-631-75501-3

Downloaded from PubFactory at 01/11/2019 04:06:06AM

via free access 


\section{Geleitwort}

Das in der Europäischen Union für die Aktiengesellschaft und ihr entsprechende Rechtsformen kodifizierte Kapitalschutzsystem ist unter Rechtfertigungsdruck geraten und steht vor möglichen tiefgreifenden Veränderungen. Es sieht bisher neben der Aufbringung eines Mindestkapitals vielfältige detaillierte Kapitalaufbringungs- und Kapitalerhaltungsregeln vor, die auf vom Vorsichtsprinzip geprägte Rechnungslegungsdaten im Einzelabschluss zurückgreifen. Auch das europäische Bilanzrecht ist im Wandel. Seit 2005 müssen alle kapitalmarktorientierten Mutterunternehmen ihren Konzernabschluss nach IFRS aufstellen und veröffentlichen. Es kann davon ausgegangen werden, dass sich der Trend zur IFRS-Bilanzierung in den nächsten Jahren fortsetzen und zunehmend auch den Einzelabschluss betreffen wird. Vor diesem Hintergrund hat die von der EU-Kommission eingesetzte High Level Group 2002 einen Vorschlag zur Reform des tradierten Gläubigerschutzsystems durch bilanzielle Kapitalerhaltung vorgelegt, der sich weitgehend an US-amerikanischen Kapitalschutzregulierungen orientiert. Neben der Abschaffung des festen Mindestkapitals soll ein wesentliches Kernelement des vorgeschlagenen Alternativsystems eine Solvenzprüfung sein, die aus einem Bilanztest und einer Liquiditätsprüfung besteht. Nach den Plänen der EU-Kommission könnte ein neues Kapitalschutzkonzept möglicherweise bereits 2009 umgesetzt werden.

Marc Richard untersucht in seiner Dissertation, ob die US-amerikanischen Kapitalschutzregeln für Europa eine Vorbildfunktion übernehmen können. Dazu analysiert er zum einen die in den USA bestehenden Regulierungen ausführlich und rechtsvergleichend. Zum anderen beurteilt er die verschiedenen Vorschriften kritisch aus ökonomischer Sicht. Hierfür hat er das Delaware General Corporation Law und den California Corporations Code auswählt. Darüber hinaus beleuchtet er die Vorschriften des Model Business Corporation Act, die von vielen Bundesstaaten der USA in ihr Gesellschaftsrecht übernommen worden sind.

Die vorliegende Arbeit beeindruckt durch eine umfassende und systematische Darstellung der US-amerikanischen Kapitalschutzsysteme und der vielfältigen in Europa diskutierten Reformvorschläge zur Kapitalerhaltung. Besonders hervorzuheben ist, dass sie auf Basis eines breiten Studiums der US-amerikanischen Primärliteratur, der Gesetzestexte und Gerichtsentscheidungen erfolgt. Herr Richard kommt zu dem Ergebnis, dass ein Solvenztest als Gläubigerschutzinstrument grundsätzlich geeignet ist, die unveränderte Übernahme des US-amerikanischen equity insolvency test jedoch für Europa nicht empfohlen werden kann. Er entwickelt daraufhin Kriterien, die ein Solvenztest erfüllen sollte, um Gläubiger wirksam zu schützen. Die in der deutschen Literatur bislang noch vorherrschende Ablehnung eines Solvenztests wird von Herrn Richard relativiert. Er zeigt weiterhin, dass ein zusätzlich zum Solvenztest durchzuführender Bilanztest grundsätzlich überflüssig erscheint. Die Untersuchung stellt damit einen wesentlichen Beitrag zur aktuellen Diskussion hinsichtlich der Reform des europäischen Kapitalschutzsystems dar. 
Marc Richard - 978-3-631-75501-3

Downloaded from PubFactory at 01/11/2019 04:06:06AM

via free access 


\section{Vorwort}

Die vorliegende Arbeit wurde im Februar 2006 von der Fakultät für Wirtschaftswissenschaft der Ruhr-Universität Bochum als Dissertation angenommen. Sie entstand während meiner Tätigkeit als wissenschaftlicher Mitarbeiter am Lehrstuhl für Internationale Unternehmensrechnung an der Ruhr-Universität Bochum. An dieser Stelle möchte ich denjenigen danken, die zum Gelingen der Arbeit beigetragen haben.

Mein besonderer Dank gilt meinem Doktorvater und akademischen Lehrer, Herrn Prof. Dr. Bernhard Pellens, der mich bereits zu Beginn meiner Assistentenzeit für das spannende Thema der Ausschüttungsregulierung begeistert hat. Ich danke ihm nicht nur für die engagierte und konstruktive Betreuung meiner Arbeit, sondern auch für die vielfältigen und abwechslungsreichen Projekte, an denen ich im Rahmen meiner Lehrstuhltätigkeit teilnehmen durfte. An dieser Stelle danke ich auch Herrn Prof. Dr. Hannes Streim für die Übernahme des Korreferats und seine konstruktiven Hinweise bei der Begutachtung.

Dem Direktorium des Instituts für Unternehmensführung (ifu) und dem Peter Lang Verlag bin ich für die Aufnahme meiner Arbeit in diese Schriftenreihe zu Dank verpflichtet. Zudem gilt mein Dank der KPMG Düsseldorf und der Alwin Reemtsma-Stiftung für die freundliche finanzielle Unterstützung während meiner Promotionszeit.

Ein besonderes Dankeschön geht an meine ehemaligen Kolleginnen und Kollegen am Lehrstuhl für Internationale Unternehmensrechnung: Holger Amshoff, Kerstin Basche, Dr. Andreas Bonse, Eva Brandt, Dr. Nils Crasselt, Karsten Detert, Prof. Dr. Rolf Uwe Fülbier, Prof. Dr. Joachim Gassen, Stefan Jannett, Dirk Jödicke, Ralf Jödicke, Stefan Neuhaus, Uwe Nölte, Beate Preuß, Dr. Franca Ruhwedel, André Schmidt, Dr. Ralf Schremper, Dr. Thorsten Sellhorn und Markus Weinreis. Sie alle haben dazu beigetragen, dass ich meine Lehrstuhlzugehörigkeit als eine wunderbare Zeit in Erinnerung behalten werde. Hervorheben möchte ich insbesondere Dr. Andreas Bonse, der mir während der gesamten Promotionszeit stets als angenehmer Diskussionspartner zur Verfügung stand und meine Arbeit in verschiedenen Phasen kritisch gelesen hat. Seine zahlreichen hilfreichen Anmerkungen und Tipps während dieser Zeit möchte ich nicht missen müssen. Dr. Nils Crasselt danke ich für das überaus zügige Lesen meiner Arbeit in der Schlussphase und die vielen konstuktiven Hinweise. Auch Eva Brandt danke ich herzlich für das Korrekturlesen meiner Arbeit. Ohne ihre große Unterstützung im Oktober 2005 hätte ich den Herbsttermin für die Abgabe der Dissertation nicht einhalten können. Stefan Neuhaus danke ich für die überaus professionelle und zeitintensive Unterstützung bei Fragen zum Layout und bei der Druckerstellung der Arbeit.

Auch außerhalb des Lehrstuhls ist mir große Hilfe zuteil geworden. Eine ganze Reihe von US-amerikanischen Professoren hat mir ausfürlich und in unkomplizierter Weise auf viele Fragen zum US-amerikanischen Gesellschaftsrecht geantwortet. Bedanken möchte ich mich dafür insbesondere bei Alan J. Barton, Barbara Black, Richard A. Booth, William J. Carney, Jesse H. Choper, James D. Cox, James J. Hanks, Alan R. Palmiter, Larry D. Spurgeon, Terry D. Warfield und Stephen Zeff. Zusätzlich zu der Tatsache, dass ich mich auch von Deutschland aus mit der US-amerikanischen Fachliteratur eindecken konnte, haben ihre Antworten leider auch dazu geführt, dass ein Forschungsaufenthalt beispielsweise im schönen Kalifornien nicht notwendig war. 
In meinem privaten Umfeld danke ich für viele sehr gute Anmerkungen Dr. Lars Micker, der sich trotz seines eigenen Dissertationsprojekts und der Vorbereitungen auf sein zweites juristisches Staatsexamen die Zeit genommen hat, meine Arbeit kritisch zu lesen. Für Hinweise zum Grundlagenteil meiner Arbeit danke ich auch Dr. Tina Koziol.

Abschließend und in besonderer Weise danke ich meinen Eltern Ursula und Dr. Harald Richardt. Auch sie haben meine Arbeit gelesen und mir viele hilfreiche Ratschläge gegeben. Ich danke ihnen aber vor allem dafür, dass sie mich - nicht nur während der Promotionszeit in jeder Hinsicht unterstützt haben und immer für mich da sind. Ohne sie wären alle meine Anstrengungen sinnlos gewesen. Diese Arbeit habe ich daher meinen Eltern gewidmet. 


\section{Inhaltsverzeichnis}

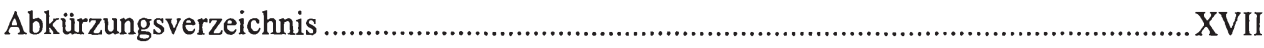

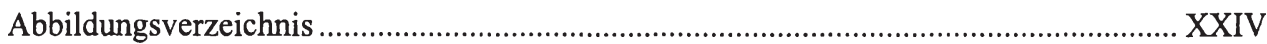

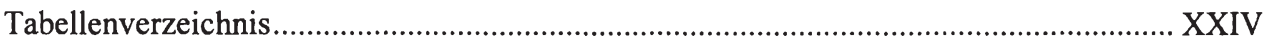

Kapitel I: Einführung.................................................................................................................1

1 Problemstellung und Ziel der Untersuchung .............................................................. 1

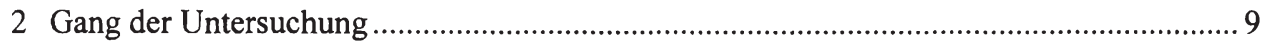

\section{Kapitel II: Rechtliche Ausgestaltung der Aktiengesellschaft in} Deutschland und der Corporation in den USA..........................12

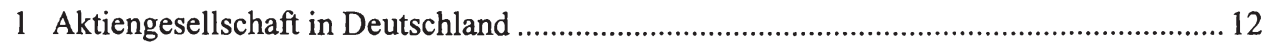

1.1 Einordnung der Aktiengesellschaft in die Rechtsformen unternehmerischer

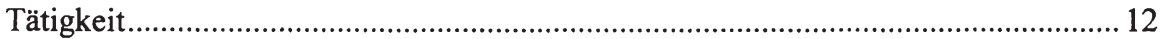

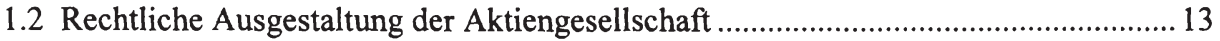

1.2.1 Gesellschafts- und Kapitalmarktrecht als Regulierungsgrundlage .................... 13

1.2.2 Zuständigkeiten der Organe ...................................................................... 18

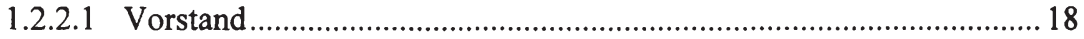

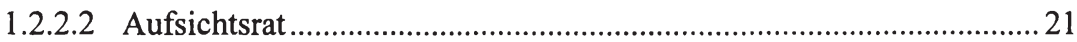

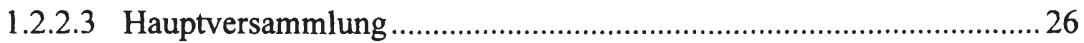

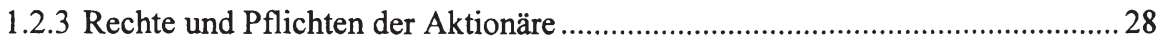

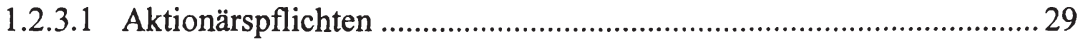

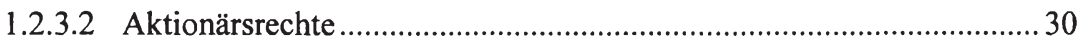

1.2.3.2.1 Herrschaftsrechte............................................................... 30

1.2.3.2.2 Informationsrechte ….................................................. 34

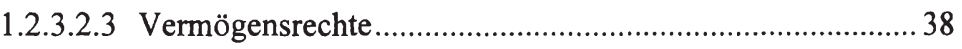

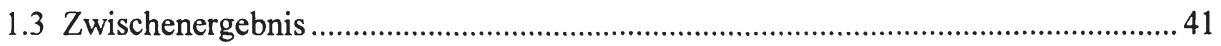




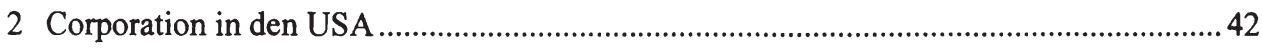

2.1 Einordnung der Corporation in die Rechtsformen unternehmerischer Tätigkeit ........ 42

2.2 Rechtliche Ausgestaltung der Corporation............................................................. 45

2.2.1 Gesellschafts- und Kapitalmarktrecht als Regulierungsgrundlage .................... 45

2.2.2 Zuständigkeiten der Organe ...................................................................... 52

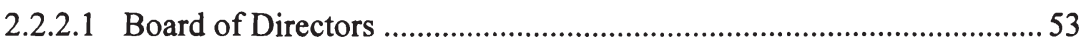

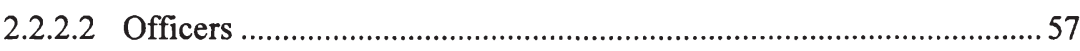

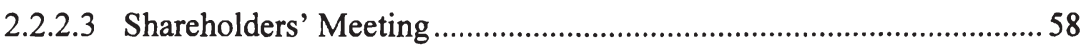

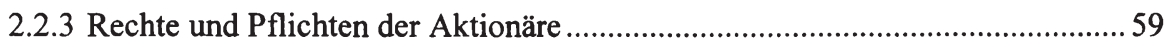

2.2.3.1 Aktionärspflichten .......................................................................... 59

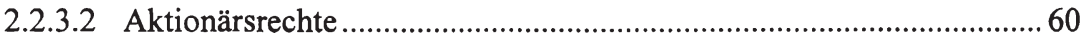

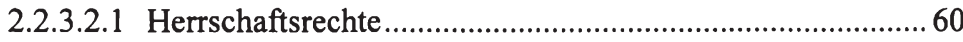

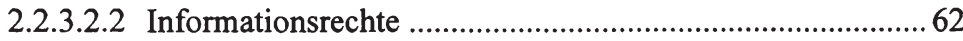

2.2.3.2.3 Vermögensrechte........................................................ 63

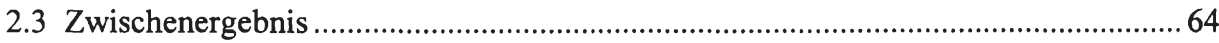

Kapitel III: Kapitalschutzsysteme in Deutschland und in den USA ............66

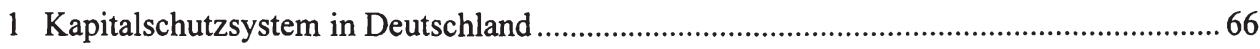

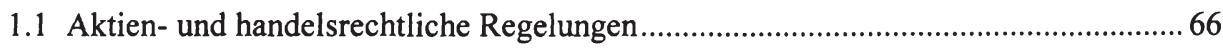

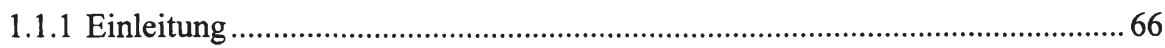

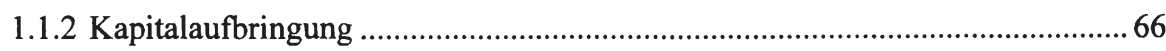

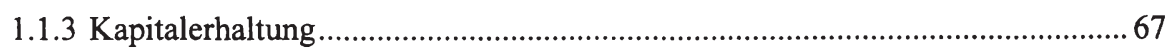

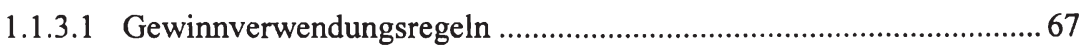

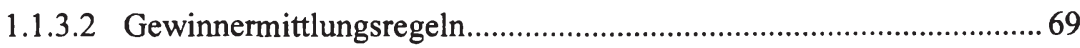

1.1.3.2.1 Zwecke des handelsrechtlichen Jahresabschlusses ............. 69

1.1.3.2.2 Auswirkungen der Grundsätze ordnungsmäßiger Buchführung auf den ausschüttungsfähigen Gewinn ........... 71

1.1.3.2.3 Auswirkungen der Verknüpfung von handels- und steuerrechtlicher Bilanzierung........................................ 74

1.1.3.3 Besonderheiten im Konzern............................................................ 75 


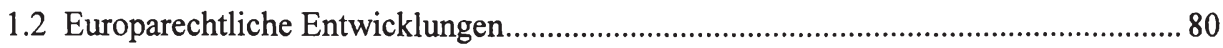

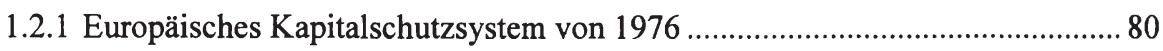

1.2.1.1 Aufbau und Anwendungsbereich der Kapitalrichtlinie ....................... 80

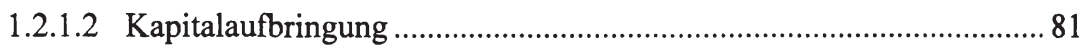

1.2.1.3 Kapitalerhaltung ........................................................................ 82

1.2.1.3.1 Auschüttungsrestriktionen.................................................... 82

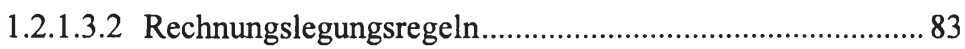

1.2.1.4 Gewinnverwendungskompetenz ...................................................... 86

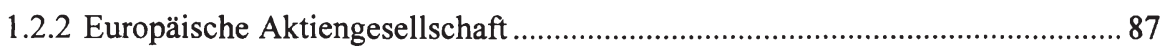

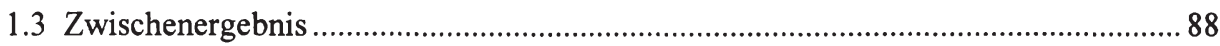

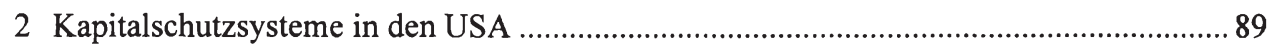

2.1 Common Law und Rechtsprechung ..................................................................... 89

2.2 Harmonisierungstendenzen durch Model Acts und Bundesgesetze............................. 94

2.2.1 Model Business Corporation Act..................................................................... 94

2.2.1.1 Ursprünge und ältere Model Business Corporation Acts ..................... 94

2.2.1.2 Kapitalaufbringung ........................................................................ 97

2.2.1.3 Kapitalerhaltung ............................................................................ 97

2.2.1.3.1 Ausschüttungsrestriktionen ................................................. 97

2.2.1.3.1.1 Equity Insolvency Test...................................98

2.2.1.3.1.2 Balance Sheet Test ........................................ 100

2.2.1.3.2 Rechnungslegungsregeln................................................ 101

2.2.1.3.3 Zeitpunkt der Durchführung der Testverfahren ................ 102

2.2.1.4 Haftungsregeln bei unzulässigen Dividendenzahlungen ................... 103

2.2.1.4.1 Haftungsregeln für Directors.............................................. 103

2.2.1.4.2 Haftungsregeln für Aktionäre........................................... 106

2.2.2 Kapitalschutzregeln anderer Model Acts und Gesetze .................................... 106

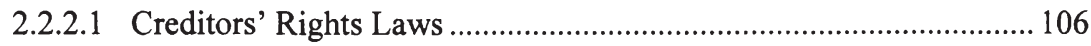

2.2.2.2 Accumulated Earnings Tax des Internal Revenue Code .................... 110 
2.3 Kapitalschutzsysteme bedeutender Inkorporationsstaaten ................................... 111

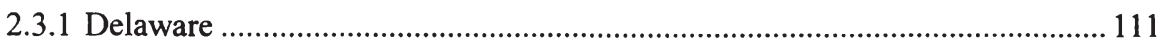

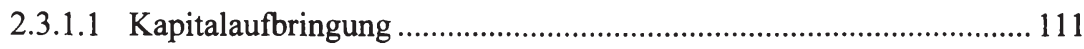

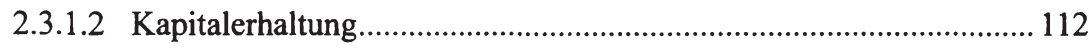

2.3.1.2.1 Ausschüttungsrestriktionen .......................................... 112

2.3.1.2.1.1 Surplus Test.............................................. 112

2.3.1.2.1.2 Kapitalherabsetzung.................................. 114

2.3.1.2.1.3 Net Profits Test (Nimble Dividends) ........... 115

2.3.1.2.2 Sonderregeln für Wasting Asset Corporations .................. 116

2.3.1.3 Haftungsregeln bei unzulässigen Dividendenzahlungen .................. 118

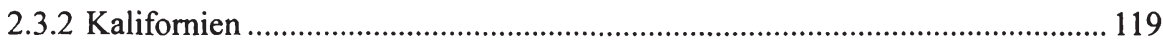

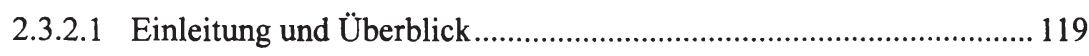

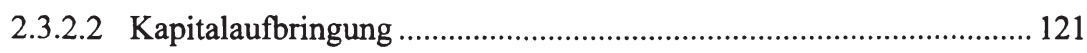

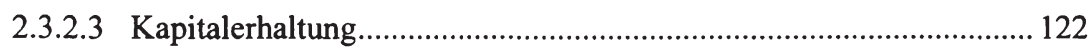

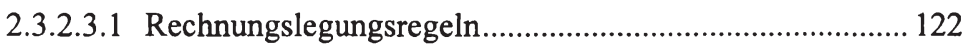

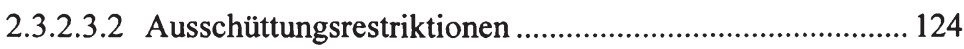

2.3.2.3.2.1 Equity Insolvency Test.............................. 125

2.3.2.3.2.2 Retained Earnings Test .............................. 126

2.3.2.3.2.3 Balance Sheet Tests ................................... 127

2.3.2.3.2.3.1 Quantitative Solvency Test.... 128

2.3.2.3.2.3.2 Liquidity Test........................ 129

2.3.2.3.3 Zeitpunkt der Durchführung der Testverfahren ............... 130

2.3.2.3.4 Besonderheiten bei Vorzugsaktien................................. 132

2.3.2.4 Haftungsregeln bei unzulässigen Dividendenzahlungen .................. 133

2.3.2.4.1 Haftungsregeln für Directors......................................... 133

2.3.2.4.2 Haftungsregeln für Aktionäre........................................ 135

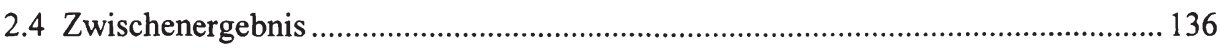

Kapitel IV: Reformvorschläge für das Kapitalsystem in Europa ..............139

1 Notwendigkeit einer Reform durch die Internationalisierung der Rechnungslegung ...... 139

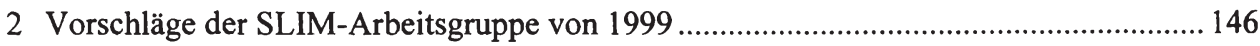

2.1 Aufgabe und Überblick zu den Ergebnissen ......................................................... 146

2.2 Vorschläge zur Reform der Kapitalrichtlinie ...................................................... 147 


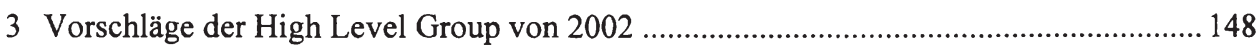

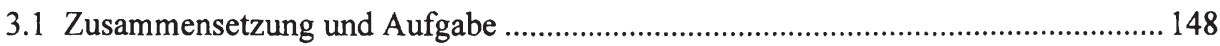

3.2 Vorschläge zur Reform der Kapitalrichtlinie .................................................. 149

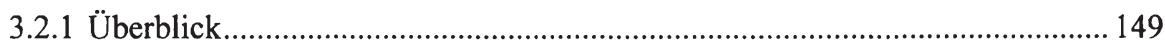

3.2.2 Kurzfristige Reformvorschläge („SLIM-Plus“) .......................................... 150

3.2.3 Langfristige Entwicklung eines alternativen Kapitalsystems ........................ 152

4 Aktionsplan der Europäischen Kommission vom 21.05.2003 ….................................... 154

5 Richtlinienvorschlag zur Änderung der Kapitalrichtlinie vom 21.09.2004 ................... 155

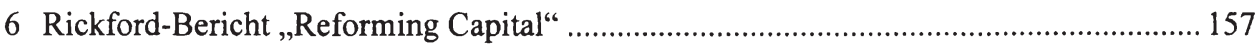

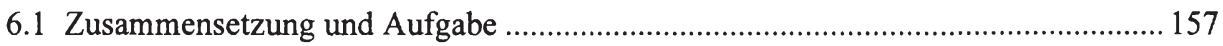

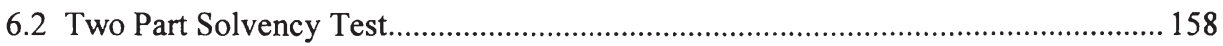

7 Vorschläge des Arbeitskreises „Kapital in Europa“....................................................... 159

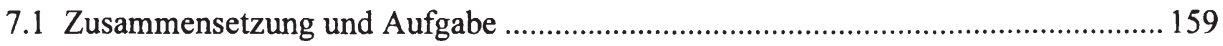

7.2 Vorschläge zur Reform der Kapitalrichtlinie ................................................... 160

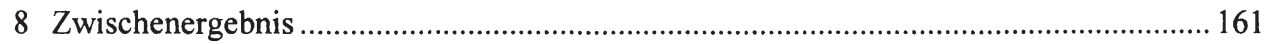

Kapitel V: Ökonomische Analyse der Kapitalschutzregeln und Schlussfolgerungen für deren Reform .........................................163

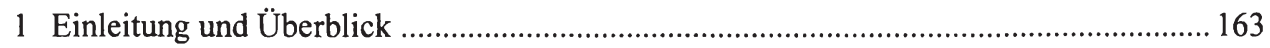

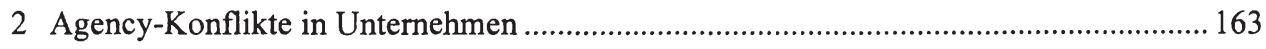

3 Analyse von Kapitalschutzregeln auf Basis ausgewählter Theorieansätze ..................... 167

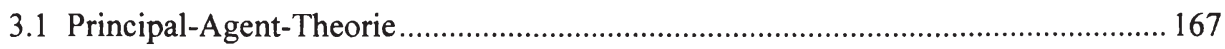

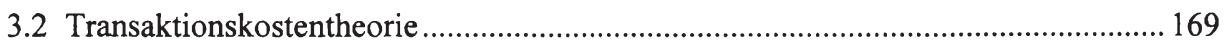

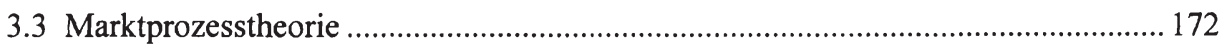

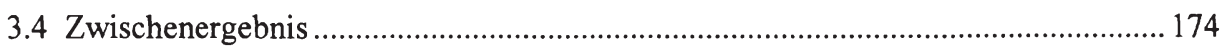

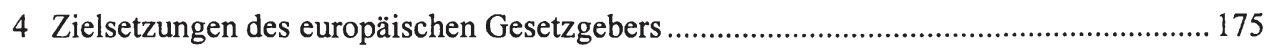

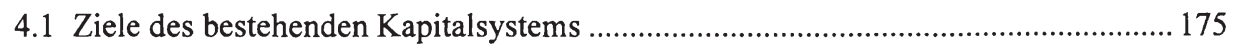

4.2 Ziele der eingeleiteten Reformmaßnahmen des Kapitalsystems ............................. 177

5 Ökonomische Analyse des europäischen Kapitalsystems .......................................... 178 


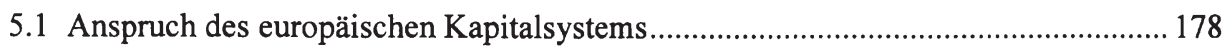

5.2 Infragestellung der Argumente zugunsten des europäischen Kapitalsystems............ 181

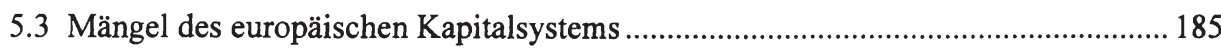

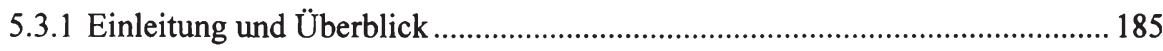

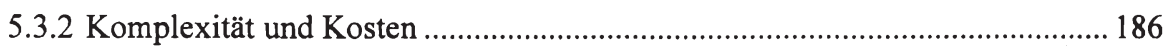

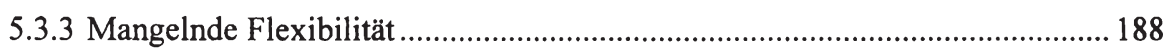

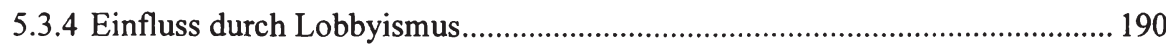

5.3.5 Probleme des Zusammenspiels von Auschüttungsregeln und

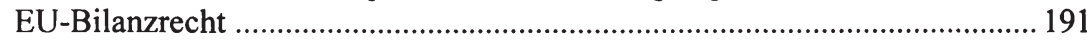

5.4 Selbstschutzmöglichkeiten verschiedener Gläubigergruppen ................................. 193

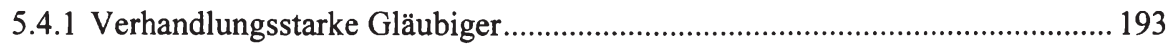

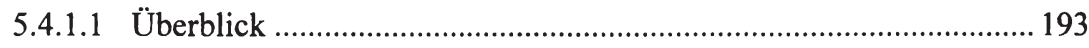

5.4.1.2 Covenants als Vertragsbestandteil ................................................ 196

5.4.1.3 Empirische Verbreitung von Covenants ......................................... 198

5.4.1.4 Kritische Würdigung................................................................... 200

5.4.2 Verhandlungsschwache Gläubiger................................................................. 203

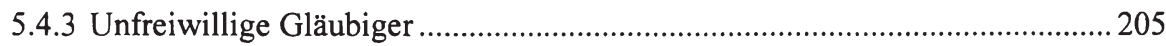

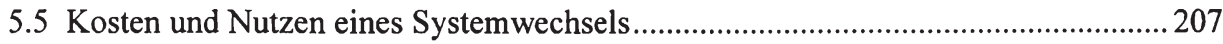

6 Ökonomische Analyse von alternativen Kapitalschutzregeln ...................................210

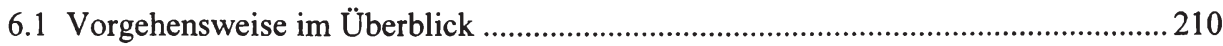

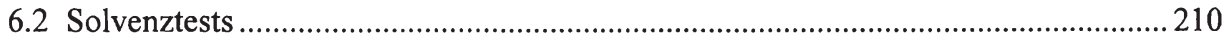

6.3 Model Business Corporation Act ....................................................................... 216

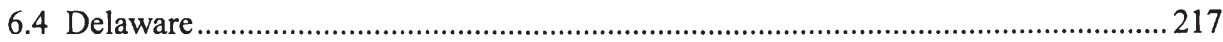

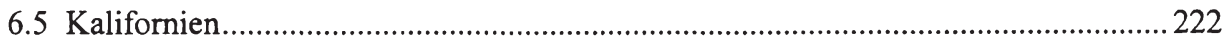

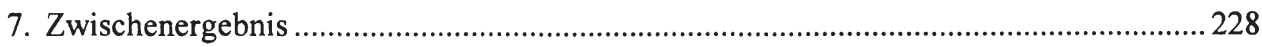

Kapitel VI: Zusammenfassung und Ausblick....................................................231

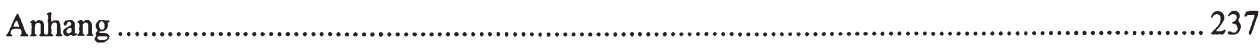

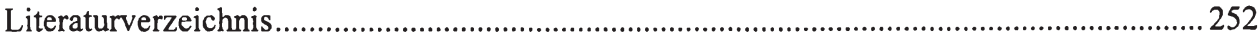

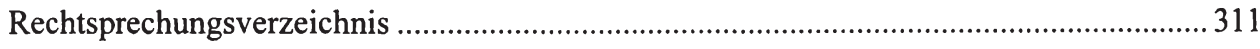




\section{Abkürzungsverzeichnis}

A.

a.A.

Abb.

$\mathrm{ABl}$.

ABR

Abs.

abzgl.

AER

AG

AGB

$\mathrm{AH}$

AICPA

AJCL

AKEU

Akron L. Rev.

AktG

aktiv.

Alb. L. Rev.

ALER

Ann.

AnSVG

AO

APAG

App.

AR

Art.

A.2d

Aufl.

BaFin

Bankr.D...

BAR

BAV

BB

BetrVG

BFH

BFuP

BG

BGB

BGBI.

BGH

$\mathrm{BGHZ}$

BilKoG

BilMoG

BilReG

BilRL

\author{
Atlantic Reporter \\ anderer Ansicht \\ Abbildung \\ Amtsblatt \\ Accounting and Business Research \\ Absatz \\ abzüglich \\ American Economic Review
}

Aktiengesellschaft / Die Aktiengesellschaft (Zeitschrift)

Allgemeine Geschäftsbedingungen

Accounting Horizons (Zeitschrift)

American Institute of Certified Public Accountants

Australian Journal of Corporate Law

Arbeitskreis Externe Unternehmensrechnung der SchmalenbachGesellschaft

Akron Law Review

Aktiengesetz

aktivierte

Albany Law Review

American Law and Economics Review

Annotated

Anlegerschutzverbesserungs-Gesetz

Abgabenordnung

Abschlussprüferaufsichtsgesetz

Appendix

The Accounting Review

Artikel

Atlantic Reporter, Second Series

Auflage

Bundesanstalt für Finanzdienstleistungsaufsicht

Bankruptcy Court for the District of .....(Bundesstaat)

British Accounting Review

Bundesaufsichtsamt für das Versicherungswesen

Betriebs-Berater (Zeitschrift)

Betriebsverfassungsgesetz

Bundesfinanzhof

Betriebswirtschaftliche Forschung und Praxis (Zeitschrift)

Bilanzgewinn

Bundesgesetzbuch

Bundesgesetzblatt

Bundesgerichtshof

Amtliche Sammlung der Rechtssprechung des Bundesgerichtshofes in Zivilsachen

Bilanzkontrollgesetz

Bilanzrechtsmodernisierungsgesetz

Bilanzrechtsreformgesetz

Bilanzrichtlinie 
BMJ

$\mathrm{BO}$

BörsG

BörsZulV

B.R.

BRD

BS

Bus. Law

bzw.

ca.

C.A.

Cal.Corp.Code

Cal. L. Rev.

Cal. Rptr.

CAR

CCA

CEO

Ch.

Cir.

CML Rev.

Colum. L. Rev.

Cornell L. Rev.

Corp.

DAI

DAV

DAX

DB

DBW

DCF

DCGK

DDR

Del.GCL

Denv. J. Int'l L. \& Pol'y

D\&O

DrittelbG

DSGV

DStR

DSW

DTI

EBIT

EAR

EBLR

EBOR

E-DRS

E.E.C.

e.G.

EG
Bundesministerium der Justiz

Börsenordnung

Börsengesetz

Börsenzulassungsverordnung

Bankruptcy Reporter

Bundesrepublik Deutschland

Bilanzsumme

Business Lawyer

beziehungsweise

circa

Court of Appeal(s)

California Corporations Code

California Law Review

California Reporter

Contemporary Accounting Research

Capital Consumption Adjustment

Chief Executive Officer

Chapter

Circuit

Common Market Law Review

Columbia Law Review

Cornell Law Review

Corporation

Deutsches Aktieninstitut

Deutscher Anwaltverein

Deutscher Aktienindex

Der Betrieb (Zeitschrift)

Die Betriebswirtschaft (Zeitschrift)

Discounted Cashflow

Deutscher Corporate Governance Kodex

Deutsche Demokratische Republik

Delaware General Corporation Law

Denver Journal of International Law and Policy

Director and Officer Liability Insurance

Drittelbeteiligungsgesetz

Deutscher Sparkassen- und Giroverband

Deutsches Steuerrecht (Zeitschrift)

Deutsche Schutzvereinigung für Wertpapierbesitz

Department of Trade and Industry

Earnings Before Interest and Taxes

European Accounting Review

European Business Law Review

European Business Organization Law Review

Deutscher Rechnungslegungsstandard (Entwurf)

European Economic Community

eingetragene Genossenschaft

Europäische Gemeinschaft 
EGV

EHUG

EK

EStG

et al.

EWG

e.V.

EU

$\mathrm{EuGH}$

EuR

EuroEG

EWS

FASB

FAZ

FB

ff.

FMC AG

Fn.

FS

F.2d

F.Supp.

F.3d

GAAP
GbR
GD
gem.
GesRZ
GmbH
GmbHG
GmbHR
GoA
GoB
GoF
GoU
GoÜ
GRL
GVV

Halbs.
Harv. L. Rev.
HGB
Hrsg.
hrsg.
HV

Vertrag zur Gründung der Europäischen Gemeinschaft

Gesetz über elektronische Handelsregister und Genossenschaftsregister sowie das Unternehmensregister

Eigenkapital

Einkommensteuergesetz

et alii

Europäische Wirtschaftsgemeinschaft

eingetragener Verein

Europäische Union

Europäischer Gerichtshof

Europarecht (Zeitschrift)

Euro-Einführungsgesetz

Europäisches Wirtschafts- und Steuerrecht (Zeitschrift)

Financial Accounting Standards Board

Frankfurter Allgemeine Zeitung

Finanzbetrieb (Zeitschrift)

folgende

Fresenius Medical Care AG

Fußnote

Festschrift

Federal Reporter, Second Series

Federal Supplement

Federal Reporter, Third Series

Generally Accepted Accounting Principles

Gesellschaft bürgerlichen Rechts

Generaldirektion

gemäß

Der Gesellschafter, Zeitschrift für Gesellschafts- und Unternehmensrecht

Gesellschaft mit beschränkter Haftung

GmbH-Gesetz

GmbH-Recht (Zeitschrift)

Grundsätze ordnungsmäßiger Abschlussprüfung

Grundsätze ordnungsmäßiger Buchführung

Grundsätze ordnungsmäßiger Unternehmensführung

Grundlagen und Systemstruktur von Führungsgrundsätzen für die Unternehmensleitung

Grundsätze ordnungsmäßiger Überwachung

Gewinnrücklagen

Gewinnverwendungsvorschlag

Halbsatz

Harvard Law Review

Handelsgesetzbuch

Herausgeber

herausgegeben

Hauptversammlung 
IAS

IASB

IAS-VO

IDW

IFRS

Inc.

Int. Rev. L. Econ.

IRC

IRS

i.V.m.

JA

$\mathrm{JAaE}$

JAAF

JAR

Jg.

JIBFL

JIBL

JITE

J.L. \& Econ.

J. Legal Stud.

JoA

JoCBL

JoFE

JR

JW

$\mathrm{JZ}$

$\mathrm{KA}$

KAGG

KapAEG

KapMuG

KapRL

$\mathrm{KG}$

$\mathrm{KGaA}$

KOM

KonTraG

KoR

KPMG

kurzfr.

KWG

L.A.B.J.

LLC

LLP

Loy. L.A. L. Rev.

LSE

LT

It.

Ltd.
International Accounting Standards

International Accounting Standards Board

IAS-Verordnung

Institut der Wirtschaftsprüfer

International Financial Reporting Standards

Incorporated

International Review of Law and Economics

Internal Revenue Code

Internal Revenue Service

in Verbindung mit

Juristische Arbeitsblätter (Zeitschrift)

Journal of Accounting and Economics

Journal of Accounting, Auditing and Finance

Journal of Accounting Research

Jahrgang

Butterworths Journal of International Banking and Financial Law

Journal of International Banking Law

Journal for Institutional and Theoretical Economics

Journal of Law and Economics

Journal of Legal Studies

Journal of Accountancy

The Journal of Commercial Bank Lending

Journal of Financial Economics

Juristische Rundschau (Zeitschrift)

Juristische Wochenschrift (Zeitschrift)

Juristenzeitung

Konzernabschluss

Gesetz über Kapitalanlagegesellschaften

Kapitalaufnahmeerleichterungsgesetz

Kapitalmarktinformationshaftungsgesetz

Kapitalrichtlinie

Kommanditgesellschaft

Kommanditgesellschaft auf Aktien

Kommission

Gesetz zur Verbesserung von Kontrolle und Transparenz im Unternehmensbereich

Zeitschrift für Kapitalmarktorientierte Rechnungslegung

Klynveld, Peat, Marwick, Goerdeler

kurzfristige

Kreditwesengesetz

Los Angeles Business Journal

Limited Liability Company

Limited Liablilty Partnership

Loyola of Los Angeles Law Review

London Stock Exchange

Liquidity Test

laut

Limited 
Mass.

$\max$.

MBCA

MDAX

MD\&A

MindestKapG

Minn.

Mio.

MitbestG

MitbestErgG

Mod. L. Rev.

MoMiG

MontanMitbestG

MontanMitbestErgG

Mrd.

m.w.N.

NASDAQ

NCCUSL

N.E.

NEMAX

N.E.2d

n.F.

NJW

No.

NPA

NPAEs

$\mathrm{Nr}$.

N.W.2d

Nw. U. L. Rev.

N.Y. BCL

NYCPA

NYSE

N.Y.S.2d

N.Y. Sup. Ct.

NZA

NZG

o.

OCBOA

OHG

o.V.

$P$

$\mathrm{Pa}$.
Massachusetts

maximal

Model Business Corporation Act

Mid Cap DAX

Management's Discussion and Analysis of Financial Condition and Results of Operations

Gesetz zur Neuregelung des Mindestkapitals der GmbH

Minnesota

Millionen

Mitbestimmungsgesetz

Mitbestimmungsergänzungsgesetz

Modern Law Review

Gesetzes zur Modernisierung des GmbH-Rechts und zur Bekämpfung von Missbräuchen

Montan-Mitbestimmungsgesetz

Montan-Mitbestimmungsergänzungsgesetz

Milliarden

mit weiteren Nachweisen

National Association of Securities Dealers Automated Quotation System

National Conference of Commissioners on Uniform State Laws

North Eastern Reporter

Neuer Markt Index

North Eastern Reporter, Second Series

neue Fassung

Neue Juristische Wochenschrift

Number

The National Public Accountant

Non-Publicly Accountable Entities

Nummer

North Western Reporter, Second Series

Northwestern University Law Review

New York Business Corporation Law

New York Certified Public Accountant (Zeitschrift)

New York Stock Exchange

West's New York Supplement, Second Series

New York Supreme Court of Judicature

Neue Zeitschrift für Arbeitsrecht

Neue Zeitschrift für Gesellschaftsrecht

ohne

Other Comprehensive Basis of Accounting

Offene Handelsgesellschaft

ohne Verfasser

Pacific Reporters

Pennsylvania 
Pac. L.J.

PCAOB

P.2d

PublG

PwC

QJE

QST

RablesZ

RAP

RIW

RK.

Rs.

RSDA

RST

S.

SA

SDAX

SE

SEA

SEC

SE-RL

S.E. $2 d$

SFAC

SFAS

Slg.

SLIM

SMEs

Sp.

Stan. L. Rev.

StGB

StuB

StückAG

StuW

S.W.2d

SZW

Tab.

Tex. L. Rev.

TIL

TransPuG

Tsd.

TU

Tz.

u.a.

U.C. Davis L. Rev.
Pacific Law Journal

Public Company Accounting Oversight Board

Pacific Reporter, Second Series

Publizitätsgesetz

PricewaterhouseCoopers

The Quarterly Journal of Economics

Quantitative Solvency Test

Zeitschrift für ausländisches und internationales Privatrecht

Rechnungsabgrenzungsposten

Recht der internationalen Wirtschaft (Zeitschrift)

Rahmenkonzept

Rechtssache

Revue Suisse du droit des affaires

Rückstellungen

Seite

Securities Act

Small Cap Index

Societas Europaea

Securities Exchange Act

Securities and Exchange Commission

Societas Europea-Richtlinie

Southern Reporter, Second Series

Statement of Financial Accouting Concept

Statement of Financial Accounting Standard

Sammlung

Simpler Legislation for the Internal Market

Small and Medium-sized Entities

Spalte

Stanford Law Review

Strafgesetzbuch

Steuern und Bilanzen (Zeitschrift)

Gesetz über die Zulassung von Stückaktien

Steuern und Wirtschaft (Zeitschrift)

South Western Reporter, Second Series

Schweizerische Zeitschrift für Wirtschaftsrecht

Tabelle

Texas Law Review

Theoretical Inquiries in Law

Transparenz und Publizitätsgesetz

Tausend

Tochterunternehmen

Textziffer

unter anderem

University of California at Davis Law Review 


\author{
U. Chi. L. Rev. \\ UCLA L. Rev. \\ UFCA \\ UFTA \\ UK \\ UK-GAAP \\ UM \\ UMAG \\ U. Miami L. Rev. \\ U. Rich. L. Rev. \\ US \\ USA \\ US-GAAP \\ UV
}

Va.

Va. L. Rev.

Verb.

Vgl.

Vol.

Vor, Vorb.

VorstOG

Wash. L. Rev.

WiSt

WISU

WL

WM

WpDRiLi

WPg

WpHG

WPO

WpPG

WpÜG

Yale L.J.

z.B.

ZBB

ZEW

ZfB

$\mathrm{ZfbF}$

$\mathrm{ZfhF}$

ZfRV

ZGR

ZHR

$\mathrm{ZInsO}$

ZIP

ZPO

ZVglRWiss
University of Chicago Law Review

University of California at Los Angeles Law Review

Uniform Fraudulent Conveyance Act

Uniform Fraudulent Transfer Act

United Kingdom

UK-Generally Accepted Accounting Principles

Unternehmensbewertung \& Management

Gesetz zur Unternehmensintegrität und Modernisierung des Anfechtungsrechts

University of Miami Law Review

University of Richmond Law Review

United States (of America)

United States of America

US-Generally Accepted Accounting Principles

Umlaufvermögen

Virginia

Virginia Law Review

Verbindlichkeiten

Vergleiche

Volume

Vorbemerkung

Vorstandsvergütungs-Offenlegungsgesetz

Washington Law Review

Wirtschaftswissenschaftliches Studium (Zeitschrift)

Das Wirtschaftsstudium (Zeitschrift)

Westlaw

Wertpapier-Mitteilungen (Zeitschrift)

Wertpapier-Dienstleistungsrichtlinie

Die Wirtschaftsprüfung (Zeitschrift)

Wertpapierhandelsgesetz

Wirtschaftsprüferordnung

Wertpapierprospektgesetz

Wertpapiererwerbs- und Übernahmegesetz

Yale Law Journal

zum Beispiel

Zeitschrift für Bankrecht und Bankwirtschaft

Zentrum für Europäisches Wirtschaftsrecht

Zeitschrift für Betriebswirtschaft

Zeitschrift für betriebswirtschaftliche Forschung

Zeitschrift für handelswissenschaftliche Forschung

Zeitschrift für Rechtsvergleichung

Zeitschrift für Unternehmens- und Gesellschaftsrecht

Zeitschrift für das gesamte Handels- und Wirtschaftsrecht

Zeitschrift für das gesamte Insolvenzrecht

Zeitschrift für Wirtschaftsrecht

Zivilprozessordnung

Zeitschrift für vergleichende Rechtswissenschaft 


\section{Abbildungsverzeichnis}

Abb. 1: Lösungsvorschläge zur Konzernproblematik von $§ 58 \mathrm{AktG}$.

Abb. 2: Ausschüttungsregeln gemäß $\S 6.40 \mathrm{MBCA}$

100

\section{Tabellenverzeichnis}

Tab. 1: Aufteilung der Rechtsformen in den USA

Tab. 2: Reformvorschläge der SLIM-Arbeitsgruppe (1999) zur Kapitalrichtlinie

Tab. 3: Kurzfristige Reformvorschläge der High Level Group (2002) zur Kapitalrichtlinie („SLIM-Plus“)

Tab. 4 Richtlinienvorschlag zur Änderung der Kapitalrichtlinie vom 29.09.2004 156

Tab. 5: Maximalausschüttung der DAX-30-Unternehmen auf Basis des California Corporations Code im Vergleich zur Kapitalrichtlinie 
„Die Gewöhnung an eine Regulierung stellt noch keine Bewährung dar."

Dieter Schneider (1987), S. 106.

\section{Kapitel I: Einführung}

\section{Problemstellung und Ziel der Untersuchung}

„Dem tradierten deutschen Kapital- und Gläubigerschutz bläst derzeit auf europäischer wie internationaler Ebene ein eisiger Wind ins Gesicht." "Auslöser für diese bedrohlich anmutende Wetterlage sind insbesondere die grundlegenden Veränderungen auf dem Gebiet des europäischen Bilanzrechts und aktuelle Vorschläge zur Reform des Gesellschaftsrechts in Europa. Die seit vielen Jahrzehnten in Deutschland und zahlreichen weiteren Mitgliedstaaten der Europäischen Union (EU) angewandten Kapitalerhaltungsregeln, die auf vom Vorsichtsprinzip geprägte Rechnungslegungsdaten zugreifen, drohen zukünftig durch die zunehmende Internationalisierung der Rechnungslegung an Wirksamkeit einzubüßen. Zudem ist das hergebrachte europäische Kapitalschutzkonzept, das aus einem Mindestkapital sowie zahlreichen detaillierten Regeln zur Kapitalaufbringung und Kapitalerhaltung besteht, insgesamt unter Rechtfertigungsdruck geraten.

War bisher die Rechnungslegung für alle Kapitalgesellschaften innerhalb der EU durch die Vierte EU-Richtlinie (Bilanzrichtlinie) ${ }^{2}$ und die Siebente EU-Richtlinie (Konzernabschlussrichtlinie $)^{3}$ geregelt, ist ein tiefgreifender Wandel auf dem Gebiet des europäischen Bilanzrechts mit der Verordnung der EU vom 19.07.2002 betreffend die Anwendung internationaler Rechnungslegungsstandards (IAS-Verordnung, IAS-VO) vollzogen worden ${ }^{4}$. Danach müssen

Merkt (2004b), S. 6.

Vgl. Vierte Richtlinie des Rates vom 25.07.1978 (78/660/EWG), ABl. EG Nr. L 222/11 vom 14.08.1978.

Vgl. Siebente Richtlinie des Rates vom 13.06.1983 (83/349/EWG), ABl. EG Nr. L 193/1 vom 18.07.1983.

4 Vgl. Verordnung (EG) Nr. 1606/2002 des europåischen Parlaments und des Rates vom 19.07.2002, ABI. EG L 243/1 vom 11.09.2002. Vgl. dazu z.B. Busse von Colbe (2002d); Buchheim/Gröner (2003); Kirsch (2003); Prinz (2003); C. Ernst (2004). 
alle kapitalmarktorientierten Mutterunternehmen ${ }^{5}$ in der EU seit 2005 (bzw. spätestens ab 2007) ${ }^{6}$ ihren Konzernabschluss zwingend nach den International Financial Reporting Standards (IFRS) ${ }^{7}$ aufstellen und veröffentlichen. Darüber hinaus können die nationalen Gesetzgeber nach Art. 5 IAS-VO die Rechnungslegung nach IFRS verpflichtend oder wahlweise auf den Konzernabschluss nicht kapitalmarktorientierter Konzerne sowie den Einzelabschluss kapitalmarkt- und nicht kapitalmarktorientierter Unternehmen ausweiten.

Der deutsche Gesetzgeber hat hierauf mit dem Bilanzrechtsreformgesetz (BilReG) vom 04.12.2004 reagiert $^{8}$. Durch das BilReG ist das Handelsgesetzbuch (HGB) unter anderem um $\S 315 \mathrm{a}$ ergänzt worden, der die von der IAS-VO betroffenen Unternehmen zur Anwendung der IFRS-Rechnungslegungsstandards verpflichtet und von den handelsrechtlichen Vorschriften zur Konzernrechnungslegung weitgehend befreit (§ 315a Abs. 1-2 HGB). Der deutsche Gesetzgeber hat darüber hinaus die Mitgliedstaatenwahlrechte in Art. 5 IAS-VO umgesetzt. Gemäß § 315a Abs. 3 HGB dürfen alle konzernrechnungslegungspflichtigen Unternehmen ihren Konzernabschluss nach IFRS aufstellen, auch wenn sie nicht kapitalmarktorientiert sind $^{9}$. Nach $\S 325$ Abs. 2a HGB haben die Unternehmen weiterhin die Möglichkeit, anstelle eines handelsrechtlichen Einzelabschlusses einen Einzelabschluss nach IFRS zu veröffentli-

5 Als kapitalmarktorientiert gelten gemäß Art. 4 IAS-VO alle Unternehmen, deren Eigenkapital- und/oder Schuldtitel in einem beliebigen EU-Mitgliedstaat zum Handel in einem geregelten Markt zugelassen sind. Als geregelter Markt gilt gemäß Art. 4 Abs. 1 Nr. 14 der Richtlinie 2004/39/EG vom 21.04.2004 (ABl. EG L 145/1) ein von einem Marktbetreiber betriebenes und/oder verwaltetes multilaterales System, das die Interessen einer Vielzahl Dritter am Kauf und Verkauf von Finanzinstrumenten innerhalb des Systems und nach seinen nichtdiskretionären Regeln in einer Weise zusammenführt oder das Zusammenführen fordert, die zu einem Vertrag in Bezug auf Finanzinstrumente fuhrt, die gemäß den Regeln und/oder den Systemen des Marktes zum Handel zugelassen wurden, sowie eine Zulassung erhalten hat und ordnungsgemă $ß$ und gemäß den Bestimmungen des Titels III funktioniert. Diese Bestimmungen finden sich in Art. 36-47 der Richtlinie 2004/39/EG.

6 Nach Art. 9 IAS-VO können die EU-Mitgliedstaaten eine Übergangsfrist bis 2007 für Unternehmen vorsehen, von denen lediglich Schuldtitel zum Handel in einem geregelten Markt eines Mitgliedstaates zugelassen sind. Gleiches gilt fur Unternehmen, deren Wertpapiere sowohl in der EU als auch in einem Drittland gehandelt werden und die ihren Konzernabschluss bereits zum Zeitpunkt der Verabschiedung der IAS-VO nach anderen international anerkannten Rechnungslegungsgrundsätzen aufstellen. Diese Regelung, die bereits durch das Bilanzrechtsreformgesetz in deutsches Recht umgesetzt wurde, ist insbesondere fur die in den USA gelisteten Unternehmen relevant, die von der US-amerikanischen Börsenaufsicht, der Securities and Exchange Commission (SEC), (noch) zur Bilanzierung nach US-amerikanischen Rechnungslegungsnormen (US-GAAP) verpflichtet werden.

7 Die IFRS umfassen gemăß IAS 1.11 auch die International Accounting Standards (IAS). Von den ursprünglich verabschiedeten 41 IAS sind noch 31 Standards in Kraft. Zusammen mit den bislang veroffentlichten 7 IFRS umfasst die IFRS-Rechnungslegung somit 38 Standards, die von der IAS-VO betroffene Unternehmen anwenden müssen (Stand: 01.06.2006).

8 Vgl. Gesetz zur Einführung internationaler Rechnungslegungsstandards und zur Sicherung der Qualität der Abschlussprüfung (Bilanzrechtsreformgesetz - BilReG) vom 04.12.2004, BGBl. I 2004, Nr. 65, S. 3166-3182. Vgl. zu diesem Gesetz ausführlich Gabriel/Ernst (2004); Hoffmann/Lüdenbach (2004); Pfitzer/Oser/Orth (2004); Jessen/Weller (2005); Wendlandt/Knorr (2005).

9 Dieses Wahlrecht kann nicht nur von Kapitalgesellschaften, sondern auch von bestimmten Personengesellschaften und Einzelkaufleuten genutzt werden. Voraussetzung ist, dass diese gemäß $\S 264$ a HGB oder $\S 11$ PublG als Mutterunternehmen zur Konzernrechnungslegung verpflichtet sind. Gleiches gilt fur Kreditinstitute und Versicherungsunternehmen unabhängig von ihrer Größe und Rechtsform ( $\S \S 340 \mathrm{i}, 341 \mathrm{i}$ HGB). Vgl. auch Pellens/Fülbier/Gassen (2006), S. 49-51. 
chen $^{10}$, wenn die in $\S 325$ Abs. $2 b$ HGB genannten Voraussetzungen erfüllt sind. Die befreiende Wirkung des IFRS-Abschlusses gilt allerdings ausschließlich für die Offenlegung. Zur Ausschüttungsbemessung und als Grundlage für die Besteuerung haben die Unternehmen unverändert einen traditionellen HGB-Einzelabschluss aufzustellen ${ }^{11}$.

Der Einfluss der ausschließlich auf die Informationsfunktion ausgerichteten IFRS-Rechnungslegung auf den Einzelabschluss nimmt durch die IAS-VO europaweit deutlich zu und ist keineswegs nur auf große kapitalmarktorientierte Unternehmen beschränkt. Das liegt z.B. daran, dass alle in IFRS-Konzernabschlüsse einbezogenen Tochterunternehmen ihre Rechnungslegung zur Erstellung der Handelsbilanz II an die IFRS anpassen müssen, wovon auch viele nicht börsennotierte kleine und mittelgroße Unternehmen betroffen sind. Darüber hinaus erstellen bereits zahlreiche mittelständische Unternehmen auf freiwilliger Basis IFRS-Abschlüsse oder denken über eine baldige IFRS-Anwendung nach ${ }^{12}$. An das erhöhte Transparenzniveau ihrer Rechnungslegung knüpfen sie unter anderem die Hoffnung, ihre Verhandlungsposition gegenüber Kreditinstituten zu verbessern und auch für potentielle Investoren attraktiver $z u$ werden ${ }^{13}$. Die IFRS-Bilanzierung mag weiterhin für diejenigen Unternehmen von Vorteil sein, die Zahlen des externen Rechnungswesens auch für die Unternehmenssteuerung nutzen möchten, um ein separates internes Rechnungswesen zu vermeiden ${ }^{14}$.

Es wird prognostiziert, dass sich der Trend zur IFRS-Bilanzierung durch die neuen Vorschriften der internationalen Bankenregulierung noch weiter verfestigen wird. Die so genannten Baseler Eigenkapitalrichtlinien (Basel II) sehen vor, dass sich die Eigenkapitalunterlegung von Banken bei der Kreditvergabe an der Bonität ihrer Schuldner orientieren muss ${ }^{15}$. Die Kreditinstitute werden die Bonität ihrer Kunden auf Basis von internen oder externen Ratings beurteilen müssen, die sich insbesondere auf Zahlen der Rechnungslegung beziehen. Obwohl das Basel-II-Regelwerk keine IFRS-Abschlüsse fordert, erscheint es plausibel, dass Banken und Ratingagenturen verbreitet angewandte, möglichst vergleichbare und wahlrechtsfreie Rechnungslegungsdaten präferieren ${ }^{16}$.

Die Verbreitung der IFRS wird zukünftig auch durch aktuelle Bestrebungen des International Accounting Standards Board (IASB) begünstigt. Im Rahmen des Projekts „Accounting Standards for Non-Publicly Accountable Entities (NPAEs)“ - bis zur Umbenennung im Januar 2005 unter dem Namen „Accounting Standards for Small and Medium-sized Entities (SMEs)“ bekannt - arbeitet das IASB an einem IFRS-Regelwerk für nicht kapitalmarktorientierte Unternehmen ${ }^{17}$, das den Rechnungslegungsaufwand für die vielfach kleinen und mittel-

10 Davon betroffen sind neben Kapitalgesellschaften auch Nicht-Kapitalgesellschaften, die unter $\S \S 264 \mathrm{a}$, 3401, 3411 HGB oder § 9 PublG fallen.

11 Zur Begründung vgl. $B M J$ (2003), S. 6-9.

$12 \mathrm{Vgl}$. zu diesem Ergebnis einer Befragung mittelständischer Unternehmen in Nordrhein-Westfalen $v$. Keitz/ Stibi (2004), S. 424; und ausfürlich KPMG/Fachhochschule Münster (Hrsg.) (2004).

13 Vgl. v. Keitz/Stibi (2004), S. 428.

14 Vgl. zu den Möglichkeiten und Grenzen einer Konvergenz von internem und externem Rechnungswesen ausfuhrlich Dirrigl (1998).

is Die Vorschriften von Basel II werden voraussichtlich Anfang 2007 in Kraft treten. Vgl. zu den geplanten Details Paul/Stein (2002); Kümpel (2004), S. 2506-2518; Paul (2004).

16 Merkt (2004a), S. 308, Fn. 15, weist auf Berichte aus der Praxis hin, nach denen Kreditinstitute ihre Mitarbeiter nur noch nach IFRS schulen. Vgl. auch Ballwieser (2001e), S. 160-162.

17 Vgl. zu den Beweggründen und vorläufigen Ansichten IASB (2004). Zu den Gründen der Umbenennung vgl. $I A S B$ (2005). 
großen Gesellschaften reduzieren und den Bedürfnissen der Adressaten dieser Abschlüsse gerecht werden soll ${ }^{18}$.

Es erscheint wahrscheinlich, dass mit steigender Anzahl der Unternehmen, die freiwillig einen zusätzlichen Einzelabschluss nach IFRS publizieren, mittelfristig die befreiende Wirkung eines solchen Abschlusses gefordert werden wird ${ }^{19}$. Einer solchen Forderung werden sich wohl insbesondere auch die kapitalmarktorientierten Konzerne in Deutschland anschließen, die zurzeit aufgrund der bestehenden Gesetzeslage mehrere Abschlüsse nach unterschiedlichen Rechnungslegungsnormen aufstellen müssen: einen Konzernabschluss nach IFRS, einen Einzelabschluss nach HGB und aus diesem - über die Maßgeblichkeit abgeleitet - eine Steuerbilanz. Darüber hinaus müssen diejenigen Unternehmen, die auch in den USA gelistet sind, zusätzlich eine Überleitungsrechung von IFRS auf US-GAAP erstellen ${ }^{20}$.

Diese Bilanzierungsvielfalt führt bei den betroffenen Unternehmen aus ökonomischer Sicht zu kaum mehr zu rechtfertigenden finanziellen und zeitlichen Belastungen. Auch die für die Fortentwicklung der Rechnungslegung zuständigen Institutionen, die Rechtsprechung und die für die Rechnungslegungsausbildung Verantwortlichen werden in unverhältnismäßiger Weise in Anspruch genommen. Darüber hinaus kommt es durch die unterschiedlichen Rechnungslegungsnormen zu Einbußen bei der Vergleichbarkeit von Abschlüssen, und zwar nicht nur bei Gesellschaften innerhalb der EU insgesamt, sondern auch innerhalb der jeweiligen Mitgliedstaaten $^{21}$. Vor diesem Hintergrund plädieren zahlreiche Autoren für die (wahlweise) Einführung der IFRS auch im Einzelabschluss ${ }^{22}$. Insbesondere mit dem Hinweis, das tradierte Gläubigerschutzkonzept durch bilanzielle Kapitalerhaltung sei mit einem befreienden IFRS-

18 Vgl. dazu ausführlich Böcking/Herold/Müßig (2004b); Dallmann/Ull (2004); Haller/Eierle (2004); Knorr/ Zeimes (2005); Zabel/Cairns (2005).

19 Vgl. zu dieser Einschätzung auch Merkt (2004a), S. 309.

20 Die EU-Kommission und die SEC haben sich am 22.04.2005 für ihre weiteren Konvergenzbemühungen auf eine „Roadmap“ mit dem Ziel geeinigt, dass Unternehmen, die einen IFRS-Konzernabschluss vorlegen, frühestens ab 2007 und spätestens ab 2009 keine Überleitungsrechnung mehr vorweisen müssen. Vgl. EUKommission (2005b). Vgl. zu den SEC-Anforderungen fur eine Börsennotierung deutscher Unternehmen in den USA ausführlich Harrer/Fisher/Evans (2003); Nahr (2003); Pellens/Fülbier/Gassen (2006), S. 882-897.

21 Das „Bilanzierungswirrwarr“ von HGB-, IFRS- und US-GAAP-Abschlüssen führt auch zu Schwierigkeiten bei der externen Bilanzanalyse. Vgl. Pellens/Gassen (2001), S. 137.

22 Für eine Pflicht sind Budde (1997), S. 121; AKEU (2001), S. 161 (allerdings Befreiungsmöglichkeit für nicht kapitalmarktorientierte kleine und mittelgroße Unternehmen); Böcking (2001), S. 1439; Niehues (2001), S. 1221-1222 (mit Ausnahme kleiner Unternehmen); Böcking (2002), S. 439; IDW (2002b), S. 985-986 (langfristig für alle in den Anwendungsbereich der Bilanzrichtlinie fallende Unternehmen); AKEU (2003), S. 1585-1587 (mit Ausnahme von Unternehmen ohne besondere wirtschaftliche Bedeutung); Böcking/Busam/Dietz (2003), S. 476; Kübler (2003b), S. 362; Böcking (2004), S. 178; Böcking/Herold/ Müßig (2004a); Grundmann (2004), S. 288. Für ein Wahlrecht plädieren Niehus (2001), S. 741-742; Pellens/Gassen (2001), S. 142; Buchholz (2002), S. 1282, 1284; Busse von Colbe (2002a), S. 169; Niehus (2002), S. 1390. 
Einzelabschluss nicht zu vereinbaren, wird dieser Vorschlag von einer ebenfalls großen Gruppe von Autoren abgelehnt ${ }^{23}$.

Zumindet bezogen auf Scheinauslandsgesellschaften, d.h. Gesellschaften mit ausländischer Rechtsform und Verwaltungssitz in Deuschland, steht allerdings bereits fest, dass das „deutsche Kapitalschutzrecht (...) seine große Zukunft schon hinter sich“24 hat. Der Grund dafür ist in der jüngeren Rechtsprechung des Europäischen Gerichtshofes (EuGH) zu sehen. In seinen Urteilen Centros $^{25}$, Überseering ${ }^{26}$ und Inspire Art $^{27}$ hat sich der EuGH mit der Niederlassungsfreiheit von wirksam im Gründungsstaat gegründeten Gesellschaften in anderen EUMitgliedstaaten auseinander gesetzt ${ }^{28}$. Maßnahmen der Mitgliedstaaten, die darauf abzielen, Zweigniederlassungen ausländischer Gesellschaften den inländischen Kapitalschutzregeln zu unterwerfen, verstoßen nach dieser Rechtsprechung wohl gegen die Niederlassungsfreiheit. Unter dem Gesichtspunkt des Gläubigerschutzes stellt der EuGH klar, dass potentielle Gläubiger durch das Auftreten solcher Auslandsgründungen als Gesellschaften ausländischen Rechts in ausreichender Weise darüber informiert seien, dass andere Regeln als die des inländischen Gesellschaftsrechts anwendbar seien. Dazu zählten auch die Vorschriften zur Aufbringung und Erhaltung des Gesellschaftskapitals sowie der Haftung der Geschäftsführer. Weiterhin vertritt der EuGH die Ansicht, dass die Mindestkapitalregeln zum Schutz von Vertragsgläubigern überflüssig seien und ein Gläubigerschutzkonzept durch Publizität vorzuziehen sei.

Das europäische Kapitalschutzsystem, das vom deutschen Gesellschaftsrecht stark geprägt ist, wird auch im deutschen Schrifttum in zunehmender Weise kritisiert und seine Zweckmäßigkeit und Nützlichkeit in Frage gestellt ${ }^{29}$. Es wird bezweifelt, dass das gesetzliche Mindestnennkapital und die umfangreichen materiellrechtlichen Bestimmungen über die Kapitalaufbringung und -erhaltung in Verbindung mit dem vom Vorsichtsprinzip geprägten Bilanzrecht in der Lage sind, den angestrebten Gläubigerschutz zu erfüllen. Aus empirischen Untersu-

23 Vgl. Baetge/Thiele (1997), S. 22-24; Schön (1997b), S. 157; Hommelhoff (2000), S. 144-145; Schön (2000), S. 738-739; Ekkenga (2001), S. 2363; Moxter (2001), S. 606; Watrin (2001 a), S. 234, 255; Watrin (2001b), S. 936-938; Arbeitskreis Bilanzrecht der Hochschullehrer Rechtswissenschaft (2002), S. 2373-2374; Deutsche Bundesbank (2002), S. 51; Euler (2002), S. 880; Kahle (2002b), S. 246-247; Kirsch (2002), S. 753-754; Schildbach (2002), S. 271-273; Zabel (2002), S. 919; DAV (2003a), S. 460; Habersack (2003), S. 239; Kahle (2003), S. 274; Kirsch (2003), S. 276-277; Schulze-Osterloh (2003a), S. 99; Schulze-Osterloh (2003b), S. 351; Zeitler (2003), S. 1529; Arbeitskreis Bilanzrecht der Hochschullehrer Rechtswissenschaft (2004), S. 546-547; Hennrichs (2004), S. 138; Küting (2004a), S. 686; Küting (2004b); Moxter (2004), S. 280; Schulze-Osterloh (2004b), S. 176-177; Merschmeyer (2005), S. 269; Ekkenga (2006), S. 397.

$24 \quad$ Mülbert (2004), S. 151.

25 Vgl. EuGH, Urteil vom 09.03.1999 - Rs. C-212/97, Slg. 1999, I-1459 - Centros.

26 Vgl. EuGH, Urteil vom 05.11.2002 - Rs. C-208/00, Slg. 2002, I-09919 - Überseering.

27 Vgl. EuGH, Urteil vom 30.09.2003 - Rs. C-167/01, Slg. 2003, I-10155 - Inspire Art.

28 Vgl. zu dieser Entscheidungskette ausführlich z.B. Kern (2004); SandrockWetzler (Hrsg.) (2004). Vgl. zu einem prägnanten Überblick Merkt (2004b), S. 6. Zu umfangreichen weiteren Nachweisen vgl. auch Merkt (2004a), S. 309, Fn. 18-20.

29 Vgl. Kübler (1989), S. 29-35, 59-65; Kübler (1990); Mertens (1994), S. 432, 441; Bauer (1995), S. 118-128, 331-340; Kübler (1995b), S. 558-561; Kübler (1995c), S. 362-373; Klose-Mokroß (1997), S. 59-186; Walter (1998); Bachmann (2001), S. 365-368; Escher-Weingart (2001), S. 119-137, 235-254; Grundmann (2001), S. 816-820; Halbhuber (2001), S. 1417-1419; Hopt (2002a), S. 1018-1020; Mülbert/ Birke (2002), S. 715-732; Kübler (2003c), S. 100-114; Meilicke (2003), S. 808; Roth/Altmeppen (2003), Einl., Tz. 24-32; Grundmann (2004), S. 143-145; Micheler (2004), S. 330-347; Mülbert (2004), S. 154-162; Sandrock (2004b), S. 64-71; Grunewald/Noack (2005). 
chungen zur Gewinnverwendung von Konzernunternehmen in Deutschland wird in diesem Zusammenhang weiterhin dringender Reformbedarf der aktienrechtlichen Kompetenzverteilung gemäß $§ 58$ Abs. 2 AktG abgeleitet ${ }^{30}$.

Gleichwohl werden auch zahlreiche Stimmen laut, welche die Stärken des bestehenden Kapitalschutzkonzepts betonen und sich gegen grundlegende Eingriffe aussprechen ${ }^{31}$. International hingegen sind die angeführten Vorteile des Systems immer schwieriger vermittelbar. Dies belegen Abhandlungen und Reformdiskussionen in der ausländischen Literatur der jüngeren Vergangenheit ${ }^{32}$. Zudem ist festzustellen, dass eine Reihe von EU-Mitgliedstaaten das Mindestkapitalerfordernis in ihren - nicht durch europäisches Gesellschaftsrecht harmonisierten $\mathrm{GmbH}-G e s e t z e n$ erheblich gelockert oder ganz abgeschafft haben ${ }^{33}$. Bemerkenswert ist auch, dass der deutsche Gesetzgeber die Absenkung der Kapitalziffer für die $\mathrm{GmbH}$ von $25.000 €$ auf $10.000 €$ seit kurzem ebenfalls ins Auge fasst ${ }^{34}$.

Eine Reihe von Vereinfachungen der Kapitalaufbringungs- und -erhaltungsregeln, die seit 1976 durch die Zweite EU-Richtlinie (Kapitalrichtlinie) für die Aktiengesellschaft und ihr entsprechende Rechtsformen europaweit kodifiziert sind ${ }^{35}$, hat eine Arbeitsgruppe im Rahmen der so genannten SLIM-Initiative ${ }^{36}$ der EU-Kommission bereits 1999 vorgeschlagen ${ }^{37}$. Die Reformvorschläge wurden von der im Herbst 2001 durch die EU-Kommission eingesetzten High Level Group of Company Law Experts wieder aufgegriffen und leicht modifiziert

30 Vgl. Linnhoff/Pellens (1987), S. 994-1004; Pellens (1994), S. 119-136; Pellens (1996), S. 167-174; Kühnberger/Schmidt (1999), S. 1275-1282.

31 Vgl. Hommelhoff (1998), S. 399; Lutter (1998b); Niederleithinger (1998), S. 378; Schön (2001), S. 78; Watrin (2001a), S. 229; Arbeitsgruppe Europäisches Gesellschaftsrecht (2002), S. 1316-1317; Baldamus (2002), S. 85-89; Schön (2002), S. 3-5; Arbeitsgruppe Europäisches Gesellschaftsrecht (2003), S. 872, 874; DAV (2003b), S. 1013; Bayer (2004a), S. 8-9; Hennrichs (2004), S. 126-128; Rammert (2004), S. 591-592; Schön (2004a), S. 166-170; Schön (2004b), S. 438-448; Bezzenberger (2005), S. 184-199; Hennrichs (2005), S. 261-262; Kuhner (2005), S. 776-777, 787; Moxter (2006).

32 Vgl. Cheffins (1997), S. 524-534; Davies (1998); Armour (2000a); Armour (2000b); Enriques/Macey (2001), S. 1184-1204; Wymeersch (2001), S. 30-33; Ferran (2003); Rickford (2004).

33 So beträgt das Mindestkapital nach spanischem Recht nur noch $3.012 €$, und nach französischem Recht ist gar keine` mehr vorgeschrieben. Vgl. jeweils m.w.N. Mülbert (2004), S. 152; Merkt (2004a), S. 317.

$34 \mathrm{Vgl}$. zum Referentenentwurf eines Gesetzes zur Neuregelung des Mindestkapitals im GmbH-Recht (MindestkapG) vom 29.04.2005 BMJ (2005b). Die ursprünglichen Planungen zur Einführung der Ein-Euro$\mathrm{GmbH}$ bei gleichzeitigen Haftungsverschärfungen wurden nicht umgesetzt. Vgl. Seibert (2005). Vgl. zu einer kritischen Würdigung Barta (2005); Eilmann/Seulen (2005); Hirte (2005); Ihrig (2005); K. Schmidt (2005). Vgl. auch Priester (2005), S. 921: „Wer eine 1-€-GmbH mit dem Argument verlangt, $25.000 €$ bewirkten auch keinen Gläubigerschutz, erinnert an jemanden, der einem bei Eis und Schnee in der Badehose frierend herumlaufenden Manne rät, er solle diese auch noch ausziehen, sie wärme ohnehin nicht.“ Zum Referentenentwurf des Gesetzes zur Modernisierung des GmbH-Rechts und zur Bekămpfung von Missbräuchen (MoMiG) vom 29.05.2006, das Unternehmensgründungen erleichtern und beschleunigen soll, vgl. $B M J$ (2006). Vgl. dazu auch o.V. (2006).

$35 \mathrm{Vgl}$. Zweite Richtlinie des Rates vom 13.12.1976 (77/91/EWG), ABl. EG Nr. L 26/1 vom 31.01.1977.

36 Zur Erläuterung des Begriffs vgl. Kapitel IV.2.1.

37 Vgl. SLIM (1999a). Die Vorschläge sehen unter anderem Erleichterungen bei der Wertprüfung von Sacheinlagen, erweiterte Möglichkeiten zum Rückkauf eigener Aktien sowie zum Bezugsrechtsausschluss bei börsennotierten Gesellschaften vor. Vgl. dazu ausführlich Kapitel IV.2.2. 
$\left(\right.$,SLIM-Plus“) ${ }^{38}$. Bereits am 21.09.2004 hat die EU-Kommission diese Empfehlungen in einem Richtlinienvorschlag zur Änderung der Kapitalrichtlinie umgesetzt ${ }^{39}$.

Die High Level Group hat es aber nicht bei Vorschlägen zur behutsamen Weiterentwicklung des Kapitalsystems auf Basis der modifizierten SLIM-Vorschläge bewenden lassen. Die europäischen Gesellschaftsrechtsexperten plädieren vielmehr dafür, ein vollständig neues Kapitalschutzkonzept zu entwickeln und den Mitgliedstaaten zu erlauben, das herkömmliche System durch das Alternativsystem zu ersetzen. Wenngleich nach Ansicht der Expertengruppe noch weitere Untersuchungen für die genaue Ausgestaltung notwendig sind, werden die Hauptmerkmale bereits kurz skizziert und erläutert ${ }^{40}$. Neben der Abschaffung des festen Mindestkapitals soll ein wesentliches Kernelement des vorgeschlagenen Kapitalsystems eine Solvenzprüfung sein, die aus einem Bilanztest und einer Liquiditätsprüfung bestehen soll. Die beschriebenen Testverfahren orientieren sich größtenteils an US-amerikanischen Ausschüttungsregulierungen. In zahlreichen Bundesstaaten der USA, welche die Ausschüttungsrestriktionen des Model Business Corporation Act (MBCA) in ihr Kapitalgesellschaftsrecht übernommen haben, existieren ähnliche Vorschriften ${ }^{41}$. Zum Teil erinnern die Ausschüttungsrestriktionen auch an das kalifornische Recht ${ }^{42}$. Weitere Charakteristika des Alternativsystems sind eine Solvenzbescheinigung, mit der die Unternehmensleitung die Zulässigkeit der Ausschüttung im Sinne der Testverfahren schriftlich zu bestätigen hat, sowie die Einführung einer Insolvenzverschleppungshaftung.

Die EU-Kommission hat auf den Abschlussbericht der High Level Group am 21.05.2003 mit dem Aktionsplan „Modernisierung des Gesellschaftsrechts und Verbesserung der Corporate Governance in der Europäischen Union" ${ }^{\text {43 }}$ reagiert und - bezogen auf das europäische Kapitalsystem - „sich in weiser Voraussicht des Widerstands aus Deutschland auf ein vorsichtiges Dreistufenprogramm beschränkt ${ }^{* 44}$. Danach soll die Kapitalrichtlinie kurzfristig durch die nunmehr bereits vorliegende Änderungsrichtlinie auf Grundlage von „SLIM-Plus“ vereinfacht werden. Mittelfristig, d.h. in den Jahren 2006 bis 2009, soll mit Hilfe einer Durchführbarkeitsstudie die Alternative zum Kapitalerhaltungskonzept geprüft werden, die je nach Ergebnis der Studie langfristig (ab 2009) umgesetzt werden könnte.

In der deutschen Literatur ist der Reformvorschlag der High Level Group nicht nur auf $\mathrm{Zu}$ stimmung ${ }^{45}$, größtenteils sogar auf erbitterten Widerstand gestoßen. Insbesondere eine mit prominenten Gesellschaftsrechtlern besetzte Arbeitsgruppe lehnt ein Alternativkonzept kate-

38 Vgl. High Level Group (2002c), S. 13-16, 88-93. Vgl. auch Kapitel IV.3.2.2.

39 Vgl. EU-Kommission (2004). Vgl. dazu im Einzelnen Kapitel IV.5.

$40 \quad$ Vgl. High Level Group (2002c), S. 94-97.

41 Vgl. Ralston (1983), S. 1030-1043; Kummert (1984), S. 242-256; Manning (1985), S. 1529-1535; Keustermans (1986), S. 276-283; McGough (1987); Manning/Hanks (1991), S. 177-193; Dooley/Goldman (2001); MBCA Ann. (2002), § 6.40; Black (2004), § 3.1-3.8. Vgl. dazu ausführlich Kapitel III.2.2.1.

42 Vgl. Barton (1975), S. 212-220; Ackerman/Sterrett (1976); Anderson (1976); Dreyfuss (1976); Ben-Dror (1983), S. 375-389; Kummert (1984), S. 226-242; Ballantine/Sterling (2004), Ch. 8; Black (2004), $\S 3.9-3.15$; Deering's (2004), Ch. 5; Marsh/Finkle/Sonsini (2005), Ch. 14. Vgl. dazu ausführlich Kapitel III.2.3.2.

43 Vgl. EU-Kommission (2003a).

44 Hopt (2005), S. 464.

45 Vgl. Sandrock (2003), S. 472-473, 476-477; Mülbert (2004), S. 160; Sandrock (2004b), S. 68-72, 99. Vgl. die Vor- und Nachteile abwägend Maul/Lanfermann/Eggenhofer (2003), S. 1294. 
gorisch $\mathrm{ab}^{46}$. In Großbritannien hingegen hat sich eine international besetzte Gruppe von Gesellschafts- und Bilanzrechtsexperten bereits im Jahr 2004 klar für einen Systemwechsel entschieden und einen eigenen detaillierten Vorschlag unterbreitet (Rickford-Bericht) ${ }^{47}$. Aber auch in Deutschland verspricht die Zukunft eine noch weiter andauernde kontroverse Diskussion über die Zukunft des europäischen Kapitalschutzes ${ }^{48}$.

Vor dem Hintergrund der aufgezeigten Problematik einer abweichenden Beurteilung der sich abzeichnenden gesellschaftsrechtlichen Veränderungen auf europäischer Ebene stellt sich die Frage, ob die - zumindest von Teilen der Fachwelt präferierten - US-amerikanischen Kapitalschutzregeln in europäisches Recht übernommen werden sollen. Ziel dieser Arbeit ist es, einen Beitrag zur Beantwortung dieser Frage zu leisten. Dazu sollen zum einen die in den USA seit Jahrzehnten bestehenden Regulierungen ausführlich und rechtsvergleichend analysiert werden. Die verschiedenen Vorschriften sollen zum anderen aus ökonomischer Sicht kritisch beurteilt werden. Bei dieser Beurteilung des Kapitalsystems spielt das interne CorporateGovernance-System der Gesellschaft, z.B. die Machtverhältnisse ihrer Organe, die Gewinnverwendungskompetenz, Klagemöglichkeiten und Haftungsregeln, eine besondere Rolle. Da die innere Struktur der Aktiengesellschaft im europäischen Recht bisher nicht harmonisiert worden ist, wird für Europa ausschließlich auf die deutschen Regelungen abgestellt.

Eine dezidierte Darstellung der US-amerikanischen Regeln steht allerdings vor dem Problem, dass das Kapitalsystem als Bestandteil des Gesellschaftsrechts in den USA nicht in die Gesetzgebungskompetenz des Bundes, sondern in die der Einzelstaaten fällt ${ }^{49}$. Mithin müssten 50 verschiedene Rechtssysteme erörtert werden, um einen Vollständigkeitsanspruch erheben zu können. Dies kann im Rahmen dieser Arbeit nicht geleistet werden.

Allerdings gilt in den USA die so genannte Gründungstheorie. Danach haben die Unternehmen die gesellschaftsrechtlichen Vorschriften des Einzelstaates zu beachten, in dem sie gegründet worden sind. Im Hinblick auf die Problemstellung dieser Arbeit besteht ein großer Vorteil darin, dass die Einzelstaatenrechte von unterschiedlicher Bedeutung sind. So ist das Gesellschaftsrecht des zweitkleinsten Bundesstaates - Delaware - das mit Abstand wichtigs$\mathrm{te}^{50}$. Auch in Kalifornien sind überdurchschnittlich viele Gesellschaften inkorporiert. Darüber hinaus folgen ca. 40 Staaten größtenteils den Vorschriften des $\mathrm{MBCA}^{51}$, der von der American Bar Association zur Harmonisierung des US-amerikanischen Gesellschaftsrechts entwickelt worden ist und in regelmäßigen Abständen überarbeitet wird.

Die rechtsvergleichende Analyse konzentriert sich daher erstens auf die Kapitalschutzregeln des Delaware General Corporation Law und zweitens auf die des MBCA in seiner derzeit gültigen Fassung ${ }^{52}$. Drittens und schwerpunktmäßig werden die Bestimmungen des California Corporations Code beleuchtet. Der Grund dafür ist nicht nur darin zu sehen, dass Kalifornien

46 Vgl. Arbeitsgruppe Europäisches Gesellschaftsrecht (2003), S. 874. Vgl. zu ihrem Vorgehen kritisch Hopt (2005), S. 471-472.

47 Vgl. Rickford (2004). Vgl. dazu Kapitel IV.6.

48 Davon zeugt auch die Tatsache, dass fur das Thema beim Deutschen Juristentag im September 2006 eine eigene Abteilung vorgesehen ist. Darüber hinaus hat jünst der Arbeitskreis „Kapital in Europa“ seine Ergebnisse veröffentlicht. Vgl. Lutter (Hrsg.) (2006).

49 Vgl. Bainbridge (2002), S. 14; Merkt/Göthel (2006), S. 153, Fn. 1.

so Vgl. zur Bedeutung mit empirischen Nachweisen z.B. Bebchuk/Cohen (2003).

51 Black (2004), §1.13, Fn. 16, listet 37 Staaten auf.

52 Es handelt sich dabei um den Model Business Corporation Act 2000/01/02 Supplement, 3rd Edition, welcher der Kommentierung des MBCA Ann. (2002) zugrunde liegt. 
ebenfalls ein wichtiger Gründungsstaat ist. Ausschlaggebend ist vielmehr der in den USA einzigartige und innovative Ansatz seiner seit 1977 bestehenden Ausschüttungsrestriktionen. Aufgrund der Tatsache, dass die im kalifornischen Kapitalgesellschaftsrecht kodifizierten Testverfahren auf US-GAAP-Konzernabschlüssen basieren, ist die kalifornische Regulierung für die europäische Reformdebatte so interessant.

Da die Kapitalrichtlinie europaweit nur von Aktiengesellschaften und ihnen entsprechenden Rechtsformen anzuwenden ist und sich daran offensichtlich auch in Zukunft nichts ändern soll, wird im Folgenden ausschließlich diese Rechtsform betrachtet. Aus den Rechtsformen des US-amerikanischen Rechts wird zum Vergleich die corporation herangezogen. Diese Rechtsform ist am ehesten mit der Aktiengesellschaft vergleichbar und kann wie diese börsennotiert sein.

\section{Gang der Untersuchung}

Im folgenden zweiten Kapitel werden zunächst die rechtlichen Grundlagen der Aktiengesellschaft in Deutschland und der corporation in den USA dargestellt. Infolge des Rechtsvergleichs weist das Kapitel deshalb zwei identisch aufgebaute Teile auf. Eingangs wird die Aktiengesellschaft bzw. die corporation kurz in die möglichen Rechtsformen unternehmerischer Tätigkeit eingeordnet, um einen Eindruck von der zahlenmäßigen Verbreitung und der wirtschaftlichen Bedeutung zu vermitteln. Es schließen sich Betrachtungen zu den gesellschaftsund kapitalmarktrechtlichen Regulierungsgrundlagen der betrachteten Rechtsformen an. Dabei wird deutlich, dass die jeweilige Schwerpunktsetzung in Deutschland und in den USA grundsätzlich unterschiedlich ist; jedoch ist insbesondere durch europäische Reformmaßnahmen der letzten Jahre eine Annäherung der beiden Systeme festzustellen. Daran anschließend werden die Rechte und Pflichten der Gesellschaftsorgane und ihre Machtverteilung untereinander diskutiert. Bevor im weiteren Verlauf der Arbeit das Dividendenrecht der Aktionäre im Mittelpunkt steht, werden die sonstigen Herrschafts-, Informations- und Vermögensrechte kurz skizziert.

In Kapitel III werden die jeweiligen Bestandteile des Kapitalschutzsystems deutscher bzw. europäischer und US-amerikanischer Prägung im Einzelnen herausgearbeitet. Zunächst werden die aktuellen Kapitalaufbringungs- und Kapitalerhaltungsregeln der Aktiengesellschaft, wie sie in Deutschland seit dem Aktiengesetz von 1965 nahezu unverändert gelten, erläutert. Hier liegt der Fokus insbesondere auf dem zentralen Zusammenhang von Gewinnermittlungsund Gewinnverwendungsregeln. Die Darstellung der Entwicklungen seit 1965 durch Einflüsse auf europäischer Ebene schließt den ersten Teil des dritten Kapitels ab. Zwar ist die Kapitalrichtlinie von 1976 stark vom deutschen Recht geprägt worden, dennoch unterscheiden sich manche Regelungen, insbesondere hinsichtlich des Zusammenhangs von Kapitalrichtlinie und den den bilanziellen Ausschüttungsrestriktionen zugrunde liegenden Rechnungslegungsregeln, die europaweit in der Bilanzrichtlinie mit zahlreichen Wahlrechten kodifiziert sind. Diese Ausführungen sind auch deshalb von Relevanz, weil sie in Kapitel V im Rahmen der kritischen Würdigung des bestehenden europäischen Kapitalregimes wieder aufgegriffen werden. Daneben wird kurz auf die seit dem 08.10.2004 rechtlich zulässige Europäische Aktiengesellschaft eingegangen.

Der zweite Teil des dritten Kapitels widmet sich den US-amerikanischen Kapitalschutzregeln. Da die Vorschriften in den USA früher nicht gesetzlich geregelt waren, werden zunächst von der Rechtsprechung entwickelte Theorien sowie darauf aufbauende bedeutsame Urteile erläu- 
tert. Den Schwerpunkt des Kapitels bilden dann die Kapitalschutzregeln des MBCA und der Kapitalgesellschaftsrechte Delawares und Kaliforniens. Im Einzelnen werden die Kapitalaufbringungs- und -erhaltungsregeln, der Zusammenhang der Ausschüttungsrestriktionen mit den Rechnungslegungsregeln, auf die sich die Testverfahren beziehen, die Sorgfaltspflichten, Haftungsregeln und Klagemöglichkeiten herausgearbeitet.

Kapitel IV wendet sich detailliert den Reformvorschlägen des europäischen Kapitalsystems zu. Einleitend wird die Notwendigkeit einer solchen Reform durch die Internationalisierung der Rechnungslegung thematisiert. Die aus der IAS-VO und dem BilReG resultierende aktuelle Bilanzierungsvielfalt im Einzel- und Konzernabschluss deutscher bzw. europäischer Unternehmen und die damit verbundenen Schwierigkeiten auf Seiten der Bilanzersteller sowie der Rechnungslegungsadressaten werden erörtert. Es wird ebenfalls aufgezeigt, welche Kapitalschutzprobleme mit der zunehmenden IFRS-Bilanzierung der letzten Jahre verbunden sind. Im Anschluss daran werden die Reformvorschläge auf europäischer Ebene in chronologischer Abfolge systematisiert und erläutert. Zusätzlich zu den Arbeiten der SLIM-Arbeitsgruppe (1999) und der High Level Group (2002) werden der Aktionsplan der EU-Kommission (2003), die Inhalte der vorgelegten Änderungsrichtlinie (2004) sowie interessante Reformvorschläge aus Großbritannien (2004) und Deutschland (2006) thematisiert. Dabei wird auch jeweils ein kurzer Überblick über die Zusammensetzung, die Aufgabenstellung und die zentralen Ergebnisse der verschiedenen Expertengruppen gegeben, bevor dann schwerpunktmäßig die auf die Kapitalrichtlinie bezogenen Reformvorschläge beleuchtet werden. Einen besonderen Stellenwert nehmen in diesem Kapitel die Vorschläge der High Level Group ein. Neben den kurzfristig zu realisierenden Maßnahmen („SLIM-Plus“) werden insbesondere die Vorschläge zur langfristigen Entwicklung eines alternativen europäischen Kapitalsystems, die stark an US-amerikanische Vorschriften angelehnt sind, beleuchtet. Es werden die Ausschüttungsrestriktionen des vorgesehenen Bilanz- und Liquiditätstests und darüber hinaus die weiteren Bestandteile des Alternativkonzepts - Solvenzbescheinigung, Haftungsregeln und Aktionärsrechte - erläutert.

Im fünften Kapitel werden ausgewählte Reformmöglichkeiten aus ökonomischer Sicht analysiert. Zunächst wird der Frage nachgegangen, ob ein Eingriff des Staates in das Marktgeschehen und damit in das individuelle Entscheidungsverhalten der Wirtschaftssubjekte durch die gesetzliche Vorgabe von Kapitalschutzregeln überhaupt notwendig ist. In einem ersten Schritt werden dafür die wesentlichen potentiellen Interessenkonflikte in Unternehmen zwischen Managern, Anteilseignern und Gläubigern sowie besondere Konfliktsituationen im Konzern kurz skizziert. Aus dem umfangreichen Instrumentenkasten an wirtschaftstheoretischen Ansätzen zur Regulierungsrechtfertigung wird im zweiten Schritt das Vorgehen der Neuen Institutionenökonomik und der Marktprozesstheorie ausgewählt und auf die Kapitalschutzregeln angewandt. Im Anschluss an die theoretischen Betrachtungen werden die Ziele des europäischen Gesetzgebers auf dem Gebiet des aktienrechtlichen Kapitalschutzes sowie seine Zielvorstellungen bei der anstehenden Reform herausgearbeitet, die im weiteren Verlauf der Arbeit als Messlatte zur Beurteilung fungieren. Die in der Literatur zugunsten des bestehenden Kapitalschutzregimes vorgebrachten Argumente werden dargestellt und daraufhin geprüft, ob sie die angestrebten Ziele des EU-Gesetzgebers erreichen. Sodann werden grundlegende Mängel des europäischen Kapitalsystems aufgezeigt, wobei ein Schwerpunkt auf das problembehaftete Zusammenspiel von Ausschüttungsregeln und europäischem Bilanzrecht gelegt wird. Eine Analyse von Selbstschutzmöglichkeiten verschiedener Gläubigergruppen und eine Einschätzung der mit einem Systemwechsel verbundenen Kosten und Nutzen runden diesen Teil des Kapitels ab. Schließlich werden ausgewählte Reformmöglichkeiten für ein alternati- 
ves europäisches Kapitalsystem kritisch gewürdigt, wobei erneut die selbst gesteckten Ziele und Vorgaben des europäischen Gesetzgebers als Beurteilungsmaßstab herangezogen werden. Solvenztests ${ }^{53}$, die in allen Bundesstaaten der USA aufgrund von gesellschafts- oder insolvenzrechtlichen Bestimmungen zu beachten sind und den Kern des Rickford-Reformvorschlags bilden, werden zunächst analysiert. Sodann werden die sonstigen Kapitalschutzregeln von Delaware, dem MBCA und von Kalifornien kritisch gewürdigt. Dabei stehen jeweils die Ausschüttungsrestriktionen der Bilanztestverfahren und die ihnen zugrunde liegenden Rechnungslegungsnormen im Mittelpunkt der Betrachtungen. Die kritische Würdigung des kalifornischen Kapitalgesellschaftsrechts umfasst auch Ergebnisse einer empirischen Untersuchung zum Gläubigerschutz sowie die beispielhafte Anwendung der kalifornischen Bilanztests auf die Unternehmen des DAX-30.

Kapitel VI schließt die Arbeit mit einer Zusammenfassung der wesentlichen Erkenntnisse und einem Ausblick auf weiteren Forschungsbedarf ab.

53 In der aktuellen Reformdebatte ist der Begriff „Solvenztest“ weit verbreitet. In den USA werden diese Testverfahren überwiegend als equity insolvency test bezeichnet und in der deutschsprachigen Literatur daher teilweise mit „Insolvenztest“ übersetzt. In dieser Arbeit werden die Begriffe synonym verwendet. 


\section{Kapitel II: \\ Rechtliche Ausgestaltung der Aktiengesellschaft in Deutschland und der Corporation in den USA}

\section{Aktiengesellschaft in Deutschland}

\subsection{Einordnung der Aktiengesellschaft in die Rechtsformen unternehmerischer Tätig- keit}

Zur Ausübung der unternehmerischen Tätigkeit steht im deutschen Gesellschaftsrecht eine Vielzahl von Rechtsformen zur Verfügung ${ }^{54}$. Die Aktiengesellschaft ist gemäß $\S 1$ Abs. 1 AktG eine Gesellschaft mit eigener Rechtspersönlichkeit (juristische Person), für deren Verbindlichkeiten den Gläubigern nur das Gesellschaftsvermögen haftet. Sie gilt als Handelsgesellschaft ( $\S 3 \mathrm{AktG}$ ) und ist damit gemäß $\S 6$ Abs. 1 HGB Formkaufmann. Von der gesetzlichen Struktur her ist die Aktiengesellschaft als Publikumsgesellschaft ausgestaltet, die als Sammelbecken größerer Kapitalmengen von zahlreichen anonymen Geldgebern besonders geeignet ist ${ }^{55}$ und somit insbesondere von Großunternehmen als Rechtsform bevorzugt wird ${ }^{56}$.

Im Vergleich zu anderen Rechtsformen ist die Aktiengesellschaft in Deutschland zahlenmäßig gering $^{57}$. Nach der Kapitalmarktstatistik der Deutschen Bundesbank gab es im August 2005 lediglich 16.114 Aktiengesellschaften ${ }^{58}$. Im Hinblick auf das bei ihr insgesamt konzentrierte Kapital nimmt die Aktiengesellschaft aber die führende Stellung ein. Im August 2005 belief sich das Grundkapital dieser Gesellschaften auf ca. $165 \mathrm{Mrd} . €^{59}$. Auch ein Blick in die Umsatzsteuerstatistik 2001 des Statistischen Bundesamtes zeigt die überragende wirtschaftliche Bedeutung der Aktiengesellschaft. Mit einem Anteil von gerade einmal 0,2\% der knapp 3

$54 \quad$ Vgl. zu den Rechtsformen im Überblick Süchting (1995), S. 34-47.

55 Vgl. Kübler (1999b), S. 7, 158. Schmalenbach (1950), S. 12, nennt die Aktiengesellschaft ein „Pumpwerk, das die Kapitalien aus aller Welt zu sammeln weiß“.

56 Um die Rechtsform der Aktiengesellschaft auch für mittelständische Unternehmen attraktiver zu machen, wurde das AktG 1994 durch das „Gesetz über kleine Aktiengesellschaften und zur Deregulierung des Aktienrechts“ geändert. Dieses Gesetz ermöglicht die Gründung der Einmann-AG und erleichtert die Einberufung und Durchführung der Hauptversammlung. Vgl. dazu ausführlich Lutter (1994a); Claussen (1996); Priester (1996). Vgl. zu den Besonderheiten der kleinen Aktiengesellschaft ausführlich Seibert/Kiem (Hrsg.) (2000). Der starke Anstieg von ca. 4.000 Aktiengesellschaften im Jahre 1995 auf ca. 15.000 im Jahre 2002 ist nicht nur auf dieses Gesetz, sondern insbesondere auf die positive Entwicklung der Börsen zurückzuführen. Vgl. Leven (2003), S. R192. Zu den Motiven mittelständischer Unternehmen bei der Rechtsformentscheidung für die Aktiengesellschaft vgl. Helm (2004b); Helm (2004c); ausführlich Helm (2004a), S. 56-77.

57 Vgl. zu einem Überblick über die Entwicklung der Anzahl der Aktiengesellschaften in Deutschland seit 1886 Leven (2003), S. R189-192.

58 Vgl. Deutsches Aktieninstitut (2005), S. 01-1-a (inklusive KGaA).

59 Vgl. Deutsches Aktieninstitut (2005), S. 01-1 (inklusive KGaA). 
Mio. in die Auswertung einbezogenen Unternehmen erreicht sie 19,5\% der gesamten Umsätze (Durchschnittsumsatz: 121 Mio. $€)^{60}$.

Die Aktiengesellschaft ${ }^{61}$ ist in Deutschland die einzige Rechtsform, die von den Vorschriften der Kapitalrichtlinie und somit von den möglichen Auswirkungen der aktuell diskutierten europäischen Gesellschaftsrechtsreform direkt betroffen ist. Vor dem Hintergrund der Tatsache, dass die $\mathrm{GmbH}$ in Deutschland stark verbreitet ist und im GmbH-Recht der Grundsatz der Aufbringung und Erhaltung eines Stammkapitals von mindestens $25.000 €$ zu beachten ist ( $\S 5,7,29-31 \mathrm{GmbHG})$, der in den Grundzügen dem aktienrechtlichen Pendant entspricht, sind Reformüberlegungen für die $\mathrm{GmbH}$ ebenfalls von großer Relevanz ${ }^{62}$.

\subsection{Rechtliche Ausgestaltung der Aktiengesellschaft}

\subsubsection{Gesellschafts- und Kapitalmarktrecht als Regulierungsgrundlage}

Das im ausgehenden 19. Jahrhundert in Deutschland erstmals kodifizierte Gesellschaftsrecht ${ }^{63}$ war zunächst primär als dispositives Recht ausgestaltet. Durch Verträge oder Satzungsbestimmungen konnten die Unternehmensbeteiligten auf vielfältige Weise von den gesetzlichen Vorschriften abweichen. Das Gesellschaftsrecht hatte die Aufgabe, verschiedene Gesellschaftsformen (z.B. OHG, KG, AG) zur Verfügung zu stellen und Konflikte, für die die Satzung keine Lösung vorsah, zu schlichten ${ }^{64}$.

Dieses auf dem Prinzip der Privatautonomie und dem Vertrauen auf Marktmechanismen basierende Gesellschaftsrecht hat sich im Laufe des 20. Jahrhunderts dahingehend gewandelt, dass es zunehmend auch wirtschafts- und verteilungspolitische Zwecke erfüllen sollte ${ }^{65}$. Im Bereich der Aktiengesellschaft ist diese Tendenz besonders deutlich in der durchgreifenden Reform des Aktienrechts von 1965 erkennbar ${ }^{66}$. Eine Vielzahl von Vorschriften im Aktiengesetz 1965 dient dem Schutz der Aktionäre, wobei der Schutz von Klein- und Minderheitsakti-

60 Vgl. H. Hansen (2004), S. 40-41. Von den zum Jahresende 2001 existierenden insgesamt 13.598 Aktiengesellschaften sind in der Umsatzsteuerstatistik nur 6.856 (50\%) erfasst. Eine im Jahre 2003 bundesweit durchgeführte Handels- und Vereinsregisteruntersuchung ergibt folgende Zahlen, die zum Teil aber auf Schätzungen beruhen: 172.000 Einzelunternehmen, 28.000 OHGs, $211.000 \mathrm{KGs}, 950.000 \mathrm{GmbHs}, 16.600$ Aktiengesellschaften (davon $40 \mathrm{KGaA}$ ). Vgl. Kornblum (2004). Vgl. ausfuhrlich Kornblum (2003a); Kornblum (2003b).

61 Die Besonderheiten der $\mathrm{KGaA}$, die auf europäischer Ebene von der Bilanzrichtlinie, nicht hingegen von der Kapitalrichtlinie reguliert ist, werden in dieser Arbeit nicht behandelt. Vgl. zur KGaA etwa K. Schmidt (2002), S. 971-981; Hueck/Windbichler (2003), S. 446-450.

62 Vgl. zur aktuellen Diskussion des Kapitalsystems der GmbH z.B. Eidenmüller/Engert (2005); Grunewald Noack (2005).

63 Vgl. Kübler (1995a), S. 223; zu den Ursprüngen des Gesellschaftsrechts vgl. Kübler (1999b), S. 5-6 m.w.N.

64 Vgl. Kübler (1999b), S. 7-9 und S. 280-283.

6s Vgl. Kübler (1999b), S. 9-17.

66 In der Begründung zum Regierungsentwurf des Aktiengesetzes 1965 heißt es: „Es ist daher ein Anliegen von hervorragender volkswirtschaftlicher und gesellschaftspolitischer Wichtigkeit, das Aktiengesetz, das die rechtliche Organisation der Aktiengesellschaft regelt, so zu gestalten, daß es mit den Grundsätzen unserer Wirtschaftsverfassung im Einklang steht." Vgl. Kropff(1965), S. 14. 
onären im Vordergrund steht ${ }^{67}$. Der Kleinaktionär, der regelmäßig nur geringe Einflussmöglichkeiten auf die Geschäftspolitik der Gesellschaft hat, soll durch ein breites aktienrechtliches Instrumentarium sowie durch Vorschriften im Bilanzrecht vor der Willkür des Managements geschützt werden ${ }^{68}$. Durch das AktG 1965 ist erstmals ein eigenständiges Konzernrecht gesetzlich kodifiziert worden, das den speziellen Gefahren, denen die Minderheitsgesellschafter im Konzern ausgesetzt sind, Rechnung trägt ${ }^{69}$.

Das deutsche Gesellschaftsrecht versucht damit, der in Deutschland vorherrschenden Eigentümerstruktur und Unternehmensorganisation gerecht zu werden. Insbesondere im Gegensatz zu den USA und Großbritannien befindet sich der größte Teil des Aktienkapitals in den Händen von anderen Unternehmen sowie Versicherungen und Banken ${ }^{70}$. Großaktionären kommt in Deutschland traditionell eine hohe Bedeutung zu, während die Anzahl der Aktiengesellschaften mit hohem Streubesitzanteil gering ist ${ }^{71}$. Der Konzernverbund stellt die dominierende Organisationsform dar ${ }^{72}$, wobei der hohe Verflechtungsgrad der großen Konzerne untereinander (wechselseitige Beteiligungen, Überkreuzbeteiligungen, Pyramidenstrukturen) ein Charakteristikum der Beteiligungsstruktur in Deutschland darstellt. Diese Strukturen werden regelmäßig mit dem Schlagwort der „Deutschland $\mathrm{AG}^{“}$ belegt ${ }^{73}$.

Weiterhin spielt traditionell die Fremdkapitalfinanzierung über Banken eine maßgebliche Rolle bei der Unternehmensfinanzierung ${ }^{74}$, was zu einer starken Ausprägung des Gläubigerschutzes im deutschen Recht geführt hat. Des Weiteren sind durch die enge Verzahnung von Aktien- und Mitbestimmungsrecht die Interessen der Arbeitnehmer unmittelbar in den Unternehmensorganen vertreten, was eine Erweiterung der gesellschaftlichen Organisationsregelung darstellt ${ }^{75}$. Schließlich kommt in dem stetig gewachsenen Einfluss des Steuerrechts auf das Gesellschaftsrecht das zu schützende Interesse des Staates an Steuereinnahmen zum Ausdruck $^{76}$.

67 In der Begründung zum Regierungsentwurf des Aktiengesetzes 1965 heißt es: „Besonderes Augenmerk schenkt der Entwurf entsprechend den oben dargelegten Grundgedanken der Reform auch der Rechtsstellung der einzelnen Aktionäre und der Aktionärsminderheiten." Vgl. Kropff (1965), S. 15. Vgl. auch Hopt (2002a), S. 1015; Merkt (2003), S. 127; Coenenberg (2005), S. 11.

68 Vgl. Kübler (1999b), S. 12; Raiser (2001), S. 65.

69 Vgl. Großfeld (1968), S. 42-43; Richardt (1974), S. 21; Mülbert (1996), S. 259; Emmerich/Habersack (2005), S. 5.

70 Vgl. Pellens (2001a), S. 26-27; Hopt (2002a), S. 1015; Rudolph (2003), S. 2054; F. Ruhwedel (2003), S. 43-47 m.w. N. zu zahlreichen empirischen Untersuchungen. Vgl. zur Bedeutung der verschiedenen Aktionärstypen in Deutschland, Frankreich, Japan, Großbritannien und den USA Deutsches Aktieninstitut (2005), S. 08.6-4. Zu empirischen Daten speziell für Deutschland vgl. F. Ruhwedel (2003), S. 201-222.

71 Vgl. F. Ruhwedel (2003), S. 43.

72 Nahezu alle Großunternehmen in Deutschland sind konzernverbunden. Bei den börsennotierten Unternehmen sind zahlenmäßig über $95 \%$ und hinsichtlich der Marktkapitalisierung fast $100 \%$ der Gesellschaften als Konzerne organisiert. Vgl. dazu Busse von Colbe (2002b), S. 358.

73 Vgl. grundlegend Adams (1994). Zu den erhofften Auswirkungen des Steuersenkungsgesetzes im Jahre 2000 auf die Beteiligungsstrukturen vgl. Hillebrandt (2001).

74 Vgl. Rudolph (2003), S. 2056; Steiner/Mader/Starbatty (2003), S. 524.

75 Die unternehmerische Mitbestimmung ergibt sich aus folgenden Gesetzen: MontanMitbestG vom 21.05.1951 (BGBl. I, 347); MontanMitbestErgG vom 07.08.1956 (BGBl. I, 707); MitbestG vom 04.05.1976 (BGBI. I, 1153); DrittelbG vom 18.05.2004 (BGBI. I, 974).

76 Vgl. Kübler (1999b), S. 269-271. 
Die geschilderten Entwicklungen haben dazu geführt, dass das heutige Gesellschaftsrecht grundsätzlich als zwingendes Recht ausgestaltet ist. Dies soll verhindern, dass die verschiedenen gesetzlichen Ziele durch private Verträge konterkariert werden ${ }^{77}$. Klare gesetzliche Strukturen sollen zudem die unterschiedlichen Zielvorstellungen der Anspruchsgruppen schützen und zu einem Ausgleich bringen ${ }^{78}$. Besonders deutlich wird die aktienrechtliche Gesetzesstrenge in $\S 23$ Abs. 5 AktG. Danach darf die Satzung von den Vorschriften des AktG nur abweichen, wenn es das Gesetz ausdrücklich zulässt. Ergänzende Satzungsbestimmungen sind nur zulässig, wenn das AktG keine abschließende Regelung enthält, wenn es also einen Sachverhalt unvollständig oder gar nicht geregelt hat ${ }^{79}$. Die Konzeption der gesetzlichen Normierung soll die aktuellen und potentiellen Aktionäre dadurch schützen, dass sie bei ihren Kapitalanlageentscheidungen auf vergleichbare, gesicherte Strukturen und Verfahrensweisen der Aktiengesellschaften vertrauen können. Die Rechtssicherheit und die Standardisierung sollen auch die Attraktivität des Aktienhandels und die Transparenz des Kapitalmarkts erhöhen $^{80}$.

Es kann also festgehalten werden, dass die Aktiengesellschaft in ein Gesellschaftsrecht eingebettet ist, das durch zwingende Regeln die vielfach unterschiedlichen Interessen der Unternehmensbeteiligten (so genannte Stakeholder) ${ }^{81}$ schützen will. Dieser mehrdimensionale Ansatz ist das konstitutive Merkmal des in Deutschland und Kontinentaleuropa vorherrschenden Corporate-Governance-Modells ${ }^{82}$. Auch wenn seit Ende der 1980er Jahre Deregulierungstendenzen festzustellen sind ${ }^{83}$, hat sich an dem zwingenden Gefüge des Aktienrechts grundlegend nichts geändert ${ }^{84}$.

Es ist allerdings zu beobachten, dass der Einfluss des Kapitalmarktrechts ${ }^{85}$ in Deutschland und Europa seit den 1990er Jahren immer mehr zunimmt ${ }^{86}$. Die kapitalmarktrechtlichen Regelungen verfolgen das Ziel, den Individualschutz des einzelnen Anlegers und insbesondere

77 Vgl. Kübler (1999b), S. 16.

78 Vgl. Merkt (2003), S. 127-128.

79 Zu Beispielen für Abweichungen und Ergänzungen der Satzung vgl. Hüffer (2006), § 23, Tz. 35-38.

80 Vgl. Grunewald (2005), S. 234-235. Zur Kritik, dass $§ 23$ Abs. 5 AktG die Satzungsautonomie von nicht börsennotierten Gesellschaften zu stark einschränke und der gesellschaftsrechtliche Aktionärsschutz bei börsennotierten Gesellschaften nicht ausreiche, vgl. Raiser (2001), S. 66-67. Mertens (1994), S. 427, 431-432, 440-441, geht sogar davon aus, dass Wirtschaftshistoriker künftiger Generationen rätseln werden, ob es sich bei der Norm um ein „Produkt der BRD oder der DDR“ handele, und fordert eine erweiterte Organisationsautonomie.

81 Vgl. zur Bedeutung und Abgrenzung von Shareholder- und Stakeholder-Interessen Ballwieser (1994), S. 1389-1390; Busse von Colbe (1997), S. 271-274; Mülbert (1997), S. 131-135; R. Schmidt/Spindler (1997), S. 517-540; Speckbacher (1997), S. 631-635; Kübler (1998a), S. 323-326.

82 Vgl. Merkt (2001a), S. 145-146; Assmann (2003), S. 2-5; Merkt (2003), S. 127.

83 Vgl. z.B. Gesetz für kleine Aktiengesellschaften und zur Deregulierung des Aktienrechts vom 02.08.1994 (BGBI. I 1994, 1961), das die Einmanngründung, einen erleichterten Bezugsrechtsausschluss und den Wegfall der Mitbestimmung nach $\S 76$ ff. BetrVG 1952 für kleine Aktiengesellschaften mit weniger als 500 Arbeitnehmern ermöglicht; Gesetz über die Zulassung von Stückaktien (StückAG) vom 25.03.1998 (BGBl. I, 590), wonach so genannte unechte nennwertlose Aktien zugelassen werden; Gesetz zur Verbesserung von Kontrolle und Transparenz im Unternehmensbereich (KonTraG) vom 27.04.1998 (BGBI. I, 786), das das Verbot des Erwerbs eigener Aktien durch die Aktiengesellschaft lockert.

$84 \quad$ Vgl. Spindler (1998), S. 55; Assmann (2003), S. 4.

85 Vgl. zum Begriff und Gegenstand des Kapitalmarktrechts Hopt (1977), S. 431; U. Schneider (2001), S. 270-272; Kümpel (2004), S. 2.

86 Vgl. Assmann (2003), S. 4-5. 
die Funktionsfähigkeit des Kapitalmarktes (Funktionenschutz) zu gewährleisten ${ }^{87}$. In vielfacher Hinsicht ergänzen sie nicht nur den traditionell im Gesellschaftsrecht geregelten Schutz von Gläubigern und Gesellschaftern ${ }^{88}$; es kann vielmehr ,eine schleichende Verdrängung zwingenden Gesellschaftsrechts durch zwingendes Kapitalmarktrecht diagnostiziert ${ }^{\text {" } 89}$ werden. In der Absicht, den deutschen Kapitalmarkt in Zeiten hohen internationalen Wettbewerbsdrucks attraktiver zu machen, hat der deutsche Gesetzgeber mit einer Reihe von Regulierungen auf dem Gebiet des Kapitalmarktrechts reagiert ${ }^{90}$. Weitere Reformen sind geplant ${ }^{91}$.

Die Akzentverschiebung vom Gesellschafts- zum Kapitalmarktrecht ist auch bei den gesetzlichen Publizitätspflichten zu erkennen. Orientierten sich diese Publizitätsvorschriften in Deutschland lange Zeit in erster Linie an Rechtsform, Größe und Branche der Unternehmen ${ }^{92}$, so gewinnen in jüngerer Vergangenheit die Kapitalmarkt- und/oder Börsenorientierung als Publizitätskriterien immer mehr an Bedeutung ${ }^{93}$.

Vor dem Hintergrund der zunehmenden kapitalmarktrechtlichen Regelungen für Aktiengesellschaften mit Kapitalmarktzugang nehmen die Unterschiede im Regelungsregime zwischen der kapitalmarktorientierten und der nicht kapitalmarktorientierten Aktiengesellschaft zu, so dass die börsennotierte Aktiengesellschaft sogar als eigener Typus qualifiziert wird ${ }^{94}$.

Das für Aktiengesellschaften relevante Gesellschafts- und Kapitalmarktrecht unterliegt - wie bereits angedeutet - nicht nur Einflüssen des deutschen Gesetzgebers. Es wird seit Jahren zunehmend durch die Harmonisierung der nationalen Rechtssysteme innerhalb der EU bestimmt $^{95}$. Die Rechtsangleichung vollzieht sich vornehmlich durch Richtlinien ${ }^{96}$, seltener

87 Vgl. Hopt (1977), S. 431; Schwark (1979), S. 6; Kiel (1994), S. 7-9; Fülbier (1998), S. 159-162; EscherWeingart (2001), S. 180-186; Pellens (2001a), S. 61.

88 Vgl. Grunewald(2005), S. 230-231.

89 Merkt (2003), S. 128. Assmann (2003), S. 5, sieht in diesem Prozess keine Annäherung der beiden Systeme, sondern die Erosion bzw. den Verfall des kontinentaleuropäisch-deutschen Corporate-Governance-Modells. Bereits Kübler (1995a), S. 227, merkt an, „,daß sich das Kapitalmarktrecht als hinreichend profilierter newcomer neben dem älteren Gesellschaftsrecht erfolgreich etabliert hat.“

90 Vgl. z.B. Wertpapierhandelsgesetz (WpHG) vom 26.07.1994 (BGBl. I 1994, S. 1749); Wertpapiererwerbsund Übernahmegesetz (WpÜG) vom 20.12.2001 (BGBI. I 2001, S. 3822). Vgl. auch Erstes Finanzmarktförderungsgesetz vom 11.07.1989 (BGBI. I 1989, S. 1412); Zweites Finanzmarktförderungsgesetz vom 26.07.1994 (BGBI. I 1994, S. 1749); Drittes Finanzmarktförderungsgesetz vom 24.03.1998 (BGBl. I 1998, S. 529); Viertes Finanzmarktförderungsgesetz vom 21.06.2002 (BGBl. I 2002, S. 2010). Vgl. dazu im Überblick Schwark (2004) m.w.N.

91 Vgl. zum 10-Punkte-Programm der Bundesregierung zur Stärkung der Unternehmensintegrität und des Anlegerschutzes vom 25.02.2003 Bundesregierung (2003); dazu Seibert (2003a). Vgl. zu den Auswirkungen auf das Bilanzrecht C. Ernst (2003). Zum Stand der Reformgesetze in Deutschland vgl. Hopt (2005), S. 469-471.

92 Vgl. Pellens (2001b), Sp. 1744-1749.

93 Vgl. z.B. Pellens/Crasselt (2004), Sp. 1462.

94 Vgl. Nobel (1998), S. 309; Assmann (2003), S. 6. Vgl. auch Merkt (2003), S. 128 m.w.N., der darauf hinweist, dass der „tiefe Graben (...) demnach nicht zwischen AG und GmbH, sondern zwischen kapitalmarktorientierter Gesellschaft und Privatgesellschaft" verläuft. Zur Forderung nach Differenzierung der Rechnungslegungs- und Publizitätspflichten nach Börsennotierung vgl. bereits Pellens/Fülbier (2000).

95 Vgl. Kübler (1999b), S. 446-459; Grundmann (2004), S. 68-78. 
durch Verordnungen ${ }^{97}$. Umfangreiche Reformen in diesen Rechtsgebieten sieht der Aktionsplan der Europäischen Kommission vom 21.05.2003 für die nächsten Jahre vor ${ }^{98}$. Dieser basiert auf einer Fülle von Vorschlägen, die eine hochrangige Expertengruppe auf dem Gebiet des Gesellschaftsrechts erarbeitet hat ${ }^{99}$. Darüber hinaus nimmt der EuGH zunehmend die Rolle des „Motors der europäischen Gesellschaftsrechtsangleichung “100 ein. Als eindruckvolle Beispiele können die Entscheidungen Centros, Überseering und Inspire Art angeführt werden, in denen sich der EuGH mit der Niederlassungsfreiheit in Europa befasst und „der deutschen Sitztheorie jedenfalls innerhalb der Europäischen Union den Garaus gemacht" "101 hat.

Es erscheint wahrscheinlich, dass sich der europäische Gesetzgeber in der Zukunft bei einer Reihe von gesetzlichen Maßnahmen am US-amerikanischen Corporate-Governance-System orientieren wird. Damit wird das deutsche System der Unternehmensleitung und -kontrolle weiter unter Druck geraten. Darüber hinaus wirken sich schon aktuell Regelungen des USamerikanischen Gesetzgebers direkt auf die interne Corporate Governance deutscher Unternehmen aus. So gelten viele Vorschriften des Sarbanes-Oxley Act, mit dem der US-amerikanische Gesetzgeber im Juli 2002 neben weiteren Regulierungen auf die Finanzskandale in den USA reagiert hat ${ }^{102}$, auch für deutsche Gesellschaften, die in den USA gelistet sind, sowie deren Tochterunternehmen ${ }^{103}$. Sie stehen teilweise in Widerspruch zum deutschen Gesellschaftsrecht ${ }^{104}$. Vor diesem Hintergrund werden Forderungen nach harmonisierten Spielregeln für die weltweit zunehmend zusammenwachsenden Kapitalmärkte laut ${ }^{105}$.

Die zahlreichen nationalen und internationalen, sich teilweise überlappenden Initiativen im Aktien- und Kapitalmarktrecht führen dazu, dass sich deutsche Aktiengesellschaften aktuell und zukünftig mit erheblichen Änderungen der Unternehmensverfassung auseinandersetzen

96 Vgl. zu den wesentlichen Richtlinieninhalten im Überblick Kübler (1999b), S. 450-457; Habersack (2003), S. 41-60; Grundmann (2004), S. 48-60. Richtlinien der jüngeren Vergangenheit sind z.B. die Marktmissbrauchsrichtlinie vom 28.01.2003 (ABI. EU L 96/16), die Modernisierungsrichtlinie vom 16.06.2003 (ABI. EU L 178/16), die Prospektrichtlinie vom 04.11.2003 (ABI. EU L 345/64), die Übernahmerichtlinie vom 21.04.2004 (ABl. EU L 142/12) und die Transparenzrichtlinie vom 15.12.2004 (ABl. EU L 390/38).

97 Eine Verordnung der jüngeren Vergangenheit ist - neben der IAS-VO - z.B. die Verordnung über das Statut der Europäischen Gesellschaft (SE) vom 08.10.2001 (ABl. EG L 294/1).

98 Vgl. EU-Kommission (2003a). Vgl. dazu auch Kapitel IV.4.

99 Vgl. High Level Group (2002c). Vgl. dazu auch Kapitel IV.3.

100 Merkt (2004b), S. 4.

101 Hopt (2005), S. 468. Zu den Konsequenzen dieser Rechtsprechung für das deutsche Steuerrecht vgl. etwa Micker (2003).

102 Vgl. Sarbanes-Oxley Act (2002)

103 Vgl. zu einer Übersicht der 19 deutschen Unternehmen, die an der NYSE und der NASDAQ gelistet sind, Pellens/Fülbier/Gassen (2006), S. 894 (Stand: September 2005).

104 Vgl. die Anforderungen des Sarbanes-Oxley Act für europäische Unternehmen als überzogen kritisierend Merkt (2004b), S. 2. Vgl. zu den Auswirkungen des Gesetzes auf deutsche Unternehmen ausfuhrlich Menzies (Hrsg.) (2004). Für einen komprimierten Überblick vgl. z.B. Pfitzer/Oser/Orth (2005), S. 3-16; Waldersee/Richardt (2005), S. 469-486.

105 Vgl. Pellens (2003), S. 476. 
müssen ${ }^{106}$. In den folgenden Kapiteln wird der vorstehend geschilderten Entwicklung Rechnung getragen. Ausführungen zum Kompetenzgefüge der Aktiengesellschaft aus der Perspektive des Aktienrechts werden um Ausführungen zu den kapitalmarktrechtlichen Vorschriften für die börsennotierte bzw. kapitalmarktorientierte Aktiengesellschaft ergänzt.

\subsubsection{Zuständigkeiten der Organe}

Die Struktur der Aktiengesellschaft zeichnet sich durch ein komplexes System von Rechtsbeziehungen der Unternehmensbeteiligten untereinander und vielfältige Interessengegensätze aus ${ }^{107}$. Die ausführlichen Vorschriften des Aktiengesetzes verfolgen das Ziel, diese Interessengegensätze $\mathrm{zu}$ einem Ausgleich $\mathrm{zu}$ bringen ${ }^{108}$. Die für die Aktiengesellschaft typische dreigliedrige Führungsorganisation (Vorstand, Aufsichtsrat, Hauptversammlung) ist dabei von herausragender Bedeutung.

\subsubsection{Vorstand}

Die Vorstandsmitglieder erhalten ihre Rechtsstellung im Vorstand als Organ der Aktiengesellschaft, indem sie nach $\S 84$ Abs. $1 \mathrm{~S} .1 \mathrm{AktG}$ durch den Aufsichtsrat für maximal fünf Jahre bestellt werden. Von dem körperschaftlichen Akt der Bestellung zu unterscheiden ist der schuldrechtliche Anstellungsvertrag zwischen den Vorstandsmitgliedern und der Aktiengesellschaft, vertreten durch den Aufsichtsrat $(\S 112 \mathrm{AktG})^{109}$. Der Anstellungsvertrag überträgt den Vorständen einen Anspruch auf Vergütung und verpflichtet sie zur Geschäftsführung. Darüber hinaus leiten sich aus dem Vertrag besondere Treuepflichten der Vorstandsmitglieder gegenüber der Aktiengesellschaft ab, die sich insbesondere in der Verschwiegenheitspflicht ( $\$ 93$ Abs. 1 S. 2 AktG) und im Wettbewerbsverbot ( $\$ 88 \mathrm{AktG}$ ) konkretisieren und das Management insgesamt zur Wahrnehmung der Interessen der Gesellschaft verpflichten ${ }^{110}$.

$106 \mathrm{Zu}$ den diesbezüglichen deutschen Unternehmensreformgesetzen zählen in chonologischer Abfolge insbesondere das Anlegerschutzverbesserungsgesetz (AnSVG) vom 28.10.2004 (BGBI. I 2004, 2630), das bereits erwähnte Bilanzrechtsreformgesetz (BilReG) vom 04.12.2004 (BGBI. I 2004, S. 3166), das Bilanzkontrollgesetz (BilKoG) vom 15.12.2004 (BGBl. I 2004, 3408), das Abschlussprüferaufsichtsgesetz (APAG) vom 27.12.2004 (BGBI. I 2004, 3846); das Kapitalanleger-Musterverfahrensgesetz (KapMuG) vom 16.09.2005 (BGBI. I 2005, 2437, das Gesetz zur Unternehmensintegrităt und Modernisierung des Anfechtungsrechts (UMAG) vom 22.09.2005 (BGBl. I 2005, 2802). Im Entwurfsstadium befinden sich das Wertpapierprospektgesetz (WpPG), das Kapitalmarktinformationshaftungsgesetz (KapInHaG), das Bilanzrechtsmodernisierungsgesetz (BilMoG). Vgl. dazu im Überblick Hopt (2005), S. 469-471; Pfitzer/Oser/ Orth (2005), S. 43-107, jeweils m.w.N. Speziell zu den kapitalmarktrechtlichen Entwicklungen vgl. M. Weber (2004).

Vgl. Raiser (2001), S. 126-127.

$108 \mathrm{Vgl}$ Kraft/Kreutz (2000), S. 316.

109 Vgl. zur Bestellung und Anstellung ausführlich Raiser (2001), S. 148-155; G. Henn (2002), S. 276-299; Lutter/Krieger (2002), S. 131-166; K. Schmidt (2002), S. 416-418; Hueck/Windbichler (2003), S. 280-286; Fonk (2004), S. 491-501, 512-578.

110 Vgl. Mertens (1988c), §93, Tz. 57-86; HueckWindbichler (2003), S. 285-286; Fonk (2004), S. 518-525; Hüffer (2006), §84, Tz. 8-9. Zu einer Analyse der Treuepflichten der Vorstandsmitglieder vgl. Schmitt (2003), S. 27-120. 
Dem Vorstand der Aktiengesellschaft ist die Vertretung ( $\$ 78 \mathrm{AktG})$ und die Geschäftsführung ( $§ 77 \mathrm{AktG}$ ) übertragen ${ }^{111}$. Gemäß $§ 76$ Abs. $1 \mathrm{AktG}$ leitet der Vorstand die Gesellschaft eigenverantwortlich (weisungsfrei). Dies unterscheidet ihn von den Geschäftsführern einer $\mathrm{GmbH}$, die den Weisungen der Gesellschafterversammlung unterliegen. Im Aktienrecht findet sich keine Legaldefinition der „Leitung“. Es werden aber eine Reihe von Aufgaben besonders hervorgehoben (z.B. in $\S \S 83,90-92,170 \mathrm{AktG}$ ). Nach herrschender Meinung ist unter Leitung die Ausübung der Unternehmerfunktionen zu verstehen ${ }^{112}$. Der Vorstand bestimmt die Unternehmenspolitik, ergreift geschäftliche Initiativen und übernimmt die Führung der Gesellschaft.

Geschäftsführungsaufgaben können grundsätzlich nicht auf Dritte oder ein anderes Organ übertragen werden. In einer weniger restriktiven Interpretation des $\S 76 \mathrm{Abs} .1 \mathrm{AktG}$ wird es allerdings als ausreichend erachtet, wenn der Vorstand bei einer Aufgabendelegation die Möglichkeit behält, die Entscheidungsbefugnis jederzeit zurückzuerlangen ${ }^{113}$. Das Ausmaß der Leitungsbefugnis findet seine Grenzen in der Satzung ${ }^{114}$, in der Geschäftsordnung sowie in den Kompetenzen der anderen Organe ${ }^{115}$. Losgelöst von diesen rechtlichen Vorschriften wird der Umfang der Leitungsbefugnis in der Praxis maßgeblich von der Eigentümer- und Stimmrechtsstruktur der Gesellschaft bestimmt. Während der Einfluss des Vorstands bei einer Aktiengesellschaft mit hohem Streubesitzanteil vergleichsweise hoch sein wird, werden seine Entscheidungen bei Existenz eines Großaktionärs unter Umständen weitestgehend von der Hauptversammlung beeinflusst $\operatorname{sein}^{116}$.

Diesen weitreichenden Befugnissen der Unternehmensleitung steht gemäß $\$ 93 \mathrm{AktG}$ eine zivilrechtliche Haftung gegenüber, die „nach dem Wortlaut des Gesetzes von außerordentlicher Strenge ist, sich aber seit längerem als für die Praxis wenig bedeutsam erwiesen hat ${ }^{\star 117}$. Der Vorstand ist nach $\S 93$ Abs. 1 AktG bei der Geschäftsführung zur ,Sorgfalt eines ordent-

111 Besteht der Vorstand aus mehr als einer Person, gelten die Grundsätze der Gesamtvertretung ( $\$ 78$ Abs. 2 AktG) und Gesamtgeschäftsführung ( $§ 77$ Abs. 1 AktG), wobei insbesondere in der Satzung abweichende Regelungen getroffen werden können. Unter Vertretungsbefugnis ist die Durchführung von Prozesshandlungen sowie jedes nach außen gerichtete rechtsgeschäftliche Auftreten des Vorstands für die Gesellschaft zu verstehen. Vgl. Hüffer (2006), § 78, Tz. 3. Im Gegensatz zur Geschäftsführungsbefugnis kann die Vertretungsbefugnis des Vorstands (im Außenverhältnis) grundsätzlich nicht beschränkt werden ( $\$ 82$ Abs. 1 AktG).

112 Vgl. Mertens (1988a), § 76, Tz. 4. Zur Lehre der Unternehmerfunktionen aus betriebswirtschaftlicher Sicht vgl. D. Schneider (1995), S. 30-41; D. Schneider (1997b). Vgl. dazu im Überblick Paul (2005b).

113 Vgl. Grunewald (2005), S. 249.

114 Anders als nach der früher verbreiteten US-amerikanischen Ultra-Vires-Lehre kann die Vertretungsmacht allerdings nicht durch den Zweck der Gesellschaft beschränkt werden. Vgl. Kropff(1965), S. 103; Mertens (1988b), § 82, Tz. 2.

115 Die Mitwirkungsbefugnisse der anderen Organe sind allerdings eng umrissen. Zum einen sind bestimmte Geschäfte gemåß $§ 111$ Abs. 4 S. 2 AktG nur mit Zustimmung des Aufsichtsrats durchzufuhren. Zum anderen kann der Vorstand verlangen, dass die Hauptversammlung über Fragen der Geschäftsführung entschei$\operatorname{det}(\S 119$ Abs. 2 AktG).

116 Vgl. Hueck/Windbichler (2003), S. 277-279; F. Ruhwedel (2003), S. 39-43.

117 Kübler (1999b), S. 187. Zu einer umfassenden Darstellung der Haftungssituation von Vorstandsmitgliedern vgl. Thümmel (2003). 
lichen und gewissenhaften Geschäftsleiters" verpflichtet ${ }^{118}$. Bei Pflichtverletzungen muss der Vorstand gemäß $\S 93$ Abs. 2 AktG den entstandenen Schaden der Gesellschaft ersetzen, wenn er nicht nachweisen kann, dass er seinen Sorgfaltspflichten nachgekommen ist (Beweislastumkehr). Neben den im Gesetz formulierten Pflichten des Vorstands (z.B. $\S \S 93$ Abs. 1 S. 2 und Abs. 3 Nr. 1-9 AktG) sind in der Literatur weitere Gruppen von haftungsauslösenden Pflichten herausgearbeitet worden ${ }^{119}$. Dazu zählen auch die aus dem US-amerikanischen Recht stammenden Sorgfalts- (duty of care) und Loyalitätspflichten (duty of loyalty) gegenüber der Gesellschaft.

Trotz dieser Pflichten wird dem Vorstand durch die Rechtsprechung insgesamt ein weiter Ermessensspielraum bei der Ausführung seiner Geschäftspolitik gewährt. In der ARAG/Garmenbeck-Entscheidung ${ }^{120}$ hat der Bundesgerichtshof (BGH) Sorgfaltspflichtverletzungen von Fehleinschätzungen abgegrenzt und damit dem Vorstand die Möglichkeit gegeben, auch unternehmerische Risiken einzugehen ${ }^{121}$. Dies ist an die in den USA entwickelte business judgment rule angelehnt, nach der Ex-post-Beurteilungen von unternehmerischen Entscheidungen durch Gerichte ausgeschlossen sind, wenn die Unternehmensleitung bestimmte Mindestanforderungen eingehalten hat ${ }^{122}$.

Die Ersatzpflicht besteht grundsätzlich gegenüber der Aktiengesellschaft, wobei sie entfällt, wenn die Handlung der Unternehmensleitung auf einem gesetzmäßigen Beschluss der Hauptversammlung beruht ( $§ 93$ Abs. 4 AktG). Der Anspruch muss vom Aufsichtsrat ( $1112 \mathrm{AktG})$ oder unter bestimmten Voraussetzungen im so genannten Klagezulassungsverfahren von einer qualifizierten Aktionärsminderheit im eigenen Namen $(\S \S 148,149 \mathrm{AktG})$ geltend gemacht werden $^{123}$. Bei grober Pflichtverletzung eines Vorstandsmitglieds kann ausnahmsweise nach $\S 93 \mathrm{Abs} .5 \mathrm{AktG}$ der Ersatzanspruch der Gesellschaft auch von den Gläubigern geltend gemacht werden, wenn sie von der Aktiengesellschaft keine Befriedigung erlangen können. Aktionäre können hingegen aus $\S 93$ AktG keine Ansprüche herleiten ${ }^{124}$.

Auch wenn die Zahl der Schadensersatzprozesse gegen Vorstandsmitglieder in letzter Zeit zunimmt, sind sie noch immer vergleichsweise selten ${ }^{125}$. Dies mag daran liegen, dass der Aufsichtsrat aus unternehmenspolitischen Gründen von Klagen gegen den Vorstand nach Mög-

118 Vgl. zu den Pflichten der Vorstandsmitglieder in Deutschland ausführlich Ihlas (1997), S. 74-84. Zur Verantwortlichkeit von Vorstandsmitgliedern bei Fehlverhalten von nachgeordneten Unternehmensangehörigen vgl. Fleischer (2003). Neben dem Vorstand können auch andere Personen der Aktiengesellschaft gegenüber schadensersatzpflichtig werden ( $\$ 117 \mathrm{AktG})$. Vgl. zu dieser so genannten aktienrechtlichen Haftungsklausel Würdinger (1981), S. 155-157; Kübler (1999b), S. 188-189; Hueck/Windbichler (2003), S. 299-300.

119 Vgl. dazu ausführlich Raiser (2001), S. 158-168 m.w.N.

120 Vgl. BGH-Urteil vom 21.04.1997 - II ZR 175/95.

121 Vgl. zur Rechtslage in Deutschland den Überblick bei Thümmel (2004b), S. 471-472 m.w.N. und Verweis auf jüngere Gerichtsurteile.

122 Vgl. zu unternehmerischen Ermessensentscheidungen im deutschen Recht ausführlich Paefgen (2002), S. 171-256. Zu einer ökonomischen Einschätzung vgl. Fleischer (2001), S. 24-25. Vgl. zur business judgment rule im US-amerikanischen Recht Clark (1986), S. 123-125; Gevurtz (2000), S. 278-301. Vgl. auch Kapitel II.2.2.2.1.

123 Vgl. Hüffer (2006), §§ 148, 149. Vgl. zur Kritik an den erschwerten Klagevoraussetzungen gegen die Unternehmensleitung Adams (1994), S. 155; Wenger (1996), S. 442-445.

gl. Hüffer (2006), § 93, Tz. 19.

Vgl. Ihlas (1997), S. 310-325; Hopt (2002a), S. 1028. 
lichkeit absieht. Wenn der Aufsichtsrat offensichtliche Pflichtverletzungen des Vorstands nicht verfolgt, macht er sich allerdings grundsätzlich selbst schadensersatzpflichtig ${ }^{126}$.

Reformmaßnahmen des deutschen Gesetzgebers in der jüngeren Vergangenheit haben zu Erleichterungen von Schadensersatzklagen gegen Vorstandsmitglieder geführt ${ }^{127}$. Seit dem Gesetz zur Unternehmensintegrität und Modernisierung des Anfechtungsrechts (UMAG) ${ }^{128}$ gilt das Minderheitenrecht bereits für Aktionäre, deren Anteilsbesitz $1 \%$ des Grundkapitals oder einen Nennbetrag von $100.000 €$ umfasst $(\S 148 \mathrm{Abs} .1 \mathrm{AktG})^{129}$. Den Haftungsmaßstab stellt die oben bereits angesprochene business judgment rule dar, die in $\S 93$ Abs. $1 \mathrm{~S} .2 \mathrm{AktG}$ kodifiziert ist ${ }^{130}$. Hat eine Klage Erfolg, so muss das beklagte Vorstandsmitglied der geschädigten Aktiengesellschaft gemäß $§ 93$ Abs. 2-3 AktG Schadensersatz zahlen (Innenhaftung). Werden Pläne zur Einführung der persönlichen Haftung von Vorstandsmitgliedern umgesetzt, könnten die Aktionäre zukünftig von den Managern Ansprüche auch für sich selbst geltend machen (Außenhaftung) $)^{131}$.

\subsubsection{Aufsichtsrat}

Der Aufsichtsrat ( $\S 95-116 \mathrm{AktG}$ ) besteht gemäß $\S 95 \mathrm{AktG}$ aus mindestens drei und in $\mathrm{Ab}$ hängigkeit von der Höhe des Grundkapitals und Bestimmungen in der Satzung maximal 21 Mitgliedern. In Unternehmen mit weniger als 500 Arbeitnehmern setzt sich der Aufsichtrat ausschließlich aus Anteilseignervertretern zusammen ${ }^{132}$, die von der Hauptversammlung mit einfacher Mehrheit gewählt werden ( $\S 101$ Abs. 1, 119 Abs. 1 Nr. 1, 124 Abs. 3 S. 3, 133 Abs. $1 \mathrm{AktG})^{133}$.

In Unternehmen mit mehr als 500 Beschäftigten ist der alleinige Einfluss der Aktionäre auf die Besetzung des Aufsichtsrats nicht mehr gegeben, so dass von einer Funktionserweiterung

126 Vgl. dazu Raiser (2001), S. 170 m.w.N.

$127 \mathrm{Zu}$ diesbezüglichen Vorschlägen vgl. bereits Ulmer (1999); Baums (Hrsg.) (2001); Bundesregierung (2003), Maßnahme 1.

128 Vgl. Gesetz zur Unternehmensintegrität und Modernisierung des Anfechtungsrechts (UMAG) vom 22.09.2005 (BGBI. I 2005, 2802). Vgl. dazu ausführlich Fleischer (2004a); Kuthe (2004); Meilicke/Heidel (2004); Paefgen (2004); Seibert/Schütz (2004); Schütz (2004); Thümmel (2004b).

129 Weitere Kernelemente des Gesetzes bilden die Schaffung eines Aktionärsforums im elektronischen Bundesanzeiger ( $\S 127 \mathrm{a} \mathrm{AktG})$, das bereits angesprochene Klagezulassungsverfahrens ( $\S 148,149 \mathrm{AktG})$ und die Ausdehnung des Freigabeverfahrens ( $\$ 246 a$ AktG).

130 Kritisiert wird unter anderem, dass der Haftungsfreiraum bei unternehmerischen Entscheidungen nicht explizit an die vorherige sorgfältige Ermittlung der Entscheidungsgrundlagen anknüpft und die Unternehmensvertreter erst bei grob fahrlässigem Verhalten haften. Vgl. z.B. Meilicke/Heidel (2004), S. 1481-1482; Ulmer (2004), S. 861-863.

131 Vgl. Bundesregierung (2003), Maßnahme 2.

132 Mitbestimmungsfrei sind zudem Familiengesellschaften, so genannte Tendenzunternehmen und Unternehmen der Religionsgemeinschaften ( $§ 1$ Abs. 2 DrittelbG). Aktiengesellschaften, die vor dem 10.08.1994 eingetragen worden sind, sind nur dann mitbestimmungsfrei, wenn sie Familiengesellschaften sind $(\S 1$ Abs. 1 S. 1 DrittelbG). Vgl. dazu Wellkamp (2000), S. 42; Semler (2004), S. 77; Hüffer (2006), §96, Tz. 10, 12.

133 Davon abweichend kann die Satzung gemäß $\S 101$ Abs. 2 AktG bestimmten Aktionären oder Inhabern vinkulierter Namensaktien ein Entsendungsrecht fur maximal ein Drittel der Aufsichtsratssitze einräumen. Vgl. dazu kritisch Sandrock (2004a), S. 61. Zu einem Überblick uber Rechtsprechung und Literaturmeinung hinsichtlich der Listenwahl von Aufsichtsräten vgl. Mutter (2004). 
des Aufsichtsrats gesprochen wird ${ }^{134}$. Diese Unternehmen unterliegen den Regeln der unternehmerischen Mitbestimmung, die den Arbeitnehmern und ihren Vertretern Einfluss auf die Geschäftspolitik verschaffen. Je nach Größe und Branche des Unternehmens kommen die Mitbestimmungsregeln des Drittelbeteiligungsgesetzes (DrittelbG) von $2004^{135}$, des Mitbestimmungsgesetzes (MitbestG) 1976 oder des Montan-Mitbestimmungsgesetzes (MontanMitbestG) 1951 bzw. bei Montan-Konzernen die des Mitbestimmungsergänzungsgesetzes (MitbestErgG) 1988 zur Anwendung ${ }^{136}$. Während den Arbeitnehmern gemäß $\S 4$ Abs. 1 DrittelbG ein Drittel der Aufsichtsratssitze zustehen, greift nach dem MitbestG und dem MontanMitbestG die paritätische Mitbestimmung ${ }^{137}$, wobei zwei bis drei Sitze den Gewerkschaftsvertretern vorbehalten sind ${ }^{138}$. Anteilseigner- und Arbeitnehmervertreter müssen gleichbehandelt werden; die Anteilseignerseite hat aber zumindest in Konfliktsituationen ein Übergewicht $^{139}$.

Der Aufsichtsrat überwacht den Vorstand ( $\$ 111$ Abs. $1 \mathrm{AktG})$ und vertritt die Aktiengesellschaft gegenüber den Vorstandsmitgliedern ( $\S 112 \mathrm{AktG})$, die er bestellt und abberuft ( $\S 84$ $\mathrm{AktG})$. Für diese Tätigkeiten kann ihm eine Vergütung gewährt werden $(\S 113 \mathrm{AktG}){ }^{140}$. Innerhalb dieser Hauptaufgaben dominiert die Überwachungsfunktion ${ }^{141}$. Der Aufsichtsrat kontrolliert die formalen Pflichten des Vorstands sowie seine abgeschlossenen und geplanten unternehmerischen Entscheidungen. Die Intensität der Kontrolle ist abhängig von der wirtschaftlichen Lage des Unternehmens. Während sich seine Tätigkeit bei normalem Geschäftsverlauf durch kooperative Beratung und Diskussionen mit dem Vorstand auszeichnet, kann in Krisensituationen ein aktives Eingreifen nötig $\operatorname{sein}^{142}$. Die alleinige Geschäftsführungsbefugnis des Vorstands darf dadurch aber nicht angetastet werden ( $\$ 111 \mathrm{Abs} .4 \mathrm{~S} .1 \mathrm{AktG})$. Wie im vorherigen Kapitel bereits kurz skizziert, können bestimmte Geschäfte allerdings nur mit Zustimmung des Aufsichtsrats durchgeführt werden. Gemäß $\S 111$ Abs. 4 S. 2 AktG müssen Satzung

134 Vgl. Kübler (1999b), S. 190.

135 Am 01.07.2004 ist das Gesetz über die Drittelbeteiligung der Arbeitnehmer im Aufsichtsrat (DrittelbG) in Kraft getreten, das die $\S \S 76$ bis 87a Betriebsverfassungsgesetz (BetrVG) 1952 abgelöst hat. Zu den geringen materiell-rechtlichen Änderungen der bisherigen Rechtslage durch das DrittelbG vgl. Huke/Prinz (2004); Melot de Beauregard (2004); Seibt (2004).

136 Vgl. Raiser (2001), S. 182-184; P. Ruhwedel (2002), S. 46-48; Hueck/Windbichler (2003), S. 311-320. Von der unternehmerischen Mitbestimmung ist die betriebliche Mitbestimmung zu unterscheiden, die im DrittelbG geregelt ist. Vgl. Niedenhoff(2002), S. 28-34; Richardi (2002), § 1, Tz. 6-7; Mag (2003), S. 85-87.

Im Gegensatz zu dem bereits erwähnten Wahlverfahren der Anteilseignervertreter sind die Wahlvorschriften fur die Arbeitnehmervertreter kompliziert. Vgl. dazu überblicksartig Raiser (2001), S. 188-189; Lutter/ Krieger (2002), S. 6-8. Vgl. dazu ausführlich Wienke (1992).

Nach Adams (2004) handelt es sich um ,ein lukratives Aufsichtsratpostenbeschaffungsprogramm für Gewerkschaftsfunktionäre."

139 Vgl. Raiser (2001), S. 195; K. Schmidt (2002), S. 835. Aufgrund dieser uneinheitlichen Regeln ist die Zusammensetzung des Aufsichtsrats in der Unternehmenspraxis vielfach zweifelhaft bzw. Veränderungen ausgesetzt. In solchen Fällen sind die $§ \S 97-99$ AktG (Statusverfahren) zu beachten. Vgl. dazu Göz (1998); Raiser (2001), S. 184-185.

140 Die Vergütung kann in der Satzung festgelegt oder von der Hauptversammlung bewilligt werden. Zur Höhe der Aufsichtsratsvergütung vgl. Helm (2003); Freudenberg (2004). Zu einer kritischen Analyse einer variablen Vergütung vgl. Fallgatter (2003). Die Ausgabe von Aktienoptionen an Mitglieder des Aufsichtsrats ist nach der jüngsten BGH-Rechtsprechung mit dem Aktiengesetz nicht vereinbar. Vgl. BGH-Urteil vom 16.02.2004 - II ZR 316/02. Vgl. dazu Paefgen (2004a). Diesbezügliche Vorschläge in der Literatur schon früher kritisierend vgl. Theisen (1999), S. 1665.

141 Vgl. Lutter/Krieger (2002), S. 23; K. Schmidt (2002), S. 820-822.

142 Vgl. Raiser (2001), S. 178; Lutter/Krieger (2002), S. 33-35. 
oder der Aufsichtsrat dafür einen Katalog zustimmungspflichtiger Geschäfte aufstellen ${ }^{143}$. Kann ein gesetzeswidriges Verhalten des Vorstands nicht anders verhindert werden, hat der Aufsichtsrat im Extremfall sogar das Recht, die Vornahme eines bestimmten Rechtsgeschäfts ad hoc an seine Zustimmung zu binden ${ }^{144}$. Hat der Vorstand gegen seine Pflichten verstoßen und sich gegenüber der Gesellschaft schadensersatzpflichtig gemacht, muss der Aufsichtsrat darüber hinaus den Schaden geltend machen ${ }^{145}$.

Um seiner Überwachungsfunktion nachkommen zu können, stehen dem Aufsichtsrat umfangreiche Einsichts-, Prüfungs- und Informationsrechte zu. Ein Einsichts- und Prüfungsrecht besteht nach $\S 111$ Abs. 2 AktG in Bezug auf die Bücher, Schriften und Vermögensgegenstände der Gesellschaft. Für bestimmte Bereiche darf der Aufsichtsrat Sachverständige (z.B. Wirtschaftsprüfer) heranziehen, z.B. zur Bilanzanalyse bei der Vorbereitung auf die Aufsichtsratssitzung $^{146}$. In der Praxis ist es zudem üblich, dass für eine Reihe von Aufgaben aus den eigenen Reihen heraus Ausschüsse gemäß $\S 107$ Abs. 3 AktG gebildet werden, die Verhandlungen und Beschlüsse des Gesamtaufsichtsrats vorbereiten oder selbst Beschlüsse fassen. Von einer Beschlussfassung ausgenommen sind die in $\S 107$ Abs. 3 S. 2 AktG genannten Fälle, z.B. die Billigung des Jahresabschlusses. Auch die Überwachungsfunktion kann nicht delegiert werden $(\S 111 \mathrm{Abs} .5 \mathrm{AktG})^{147}$. Seit einigen Jahren steigt die Verbreitung von Prüfungsausschüssen, die sich an dem Vorbild der US-amerikanischen audit committees orientieren ${ }^{148}$.

Zusätzlich zu den dargestellten Hauptaufgaben des Aufsichtsrats existiert eine Reihe weiterer Aufgaben, beispielsweise die Festsetzung der Bezüge der Vorstandsmitglieder, die in einem angemessenen Verhältnis zu deren Aufgaben und zur wirtschaftlichen Lage der Aktiengesellschaft stehen müssen $(\S 87 \mathrm{AktG})^{149}$. Im Rahmen dieser Arbeit sind insbesondere die in den $\S \S 171-172,58$ AktG genannten Aufgaben von Interesse. Der vom Vorstand aufgestellte und von einem Abschlussprüfer geprüfte Jahresabschluss ist dem Aufsichtsrat inklusive Lage- und Prüfungsbericht vorzulegen. Der Aufsichtsrat hat diese Unterlagen und den Vorschlag des Vorstands zur Verwendung des Bilanzgewinns zu prüfen und darüber der Hauptversammlung

143 Vgl. zu dieser durch das TransPuG (2002) eingeführten obligatorischen Regelung Dietrich (2003); O. Lange (2003); Lieder (2004).

144 Vgl. Mertens (1995), § 111, Tz. 65; Grunewald (2005), S. 260.

145 Vgl. dazu Raiser (2001), S. 214-215 m.w.N.

146 Vgl. Raiser (2001), S. 217.

147 Vgl. zu den Rechten und Pflichten von Aufsichtsratsauschüssen ausführlich Lutter/Krieger (2002), S. 242-261; Siebel (2004).

148 Vgl. Kirsten (2004), S. 173; Kropff (2004), S. 436-437. Die Einrichtung eines solchen Ausschusses wird in Ziffer 5.3.2 des Deutschen Corporate Governance Kodex (DCGK) explizit empfohlen. Vgl. dazu Theisen (2003), S. 501-502. Einer empirischen Untersuchung zur Folge haben im Geschäftsjahr 1999 ca. $40 \%$ der DAX-30-Unternehmen und ca. $20 \%$ der MDAX-Unternehmen einen Prüfungsausschuss. Vgl. Fischbach (2003), S. 43-54; Veit (2003). Zu den rechtlichen Unterschieden zwischen dem deutschen und dem angelsächsischen audit committee vgl. Scheffler (2003); Schmitz (2003), S. 182-183.

149 Vgl. zu Schwierigkeiten bei der Konkretisierung des angemessenen Verhältnisses Spindler (2004); Hüffer (2006), § 87, Tz. 2-3. Die mit $§ 87$ AktG verbundenen Probleme haben durch den Mannesmann-Prozess im Jahre 2004 besondere Aktualität erlangt. Die Zahlungen an die ausgeschiedenen Vorstandsmitglieder als angemessen bezeichnend vgl. Hüffer (2003), S. 27, 38; Hüffer (2004); gleicher Ansicht ist Baums, vgl. dazu o.V. (2004), S. 13. A.A. Bayer (2004b); Binz/Sorg (2004); Lutter/Zöllner (2004). Nach dem Vorstandsvergütungs-Offenlegungsgesetzes (VorstOG) vom 03.09.2005 (BGBI. I 2005, 2267) sind ab dem Geschäftsjahr 2006 die Bezüge für jedes einzelne Vorstandsmitglied von börsennotierten Gesellschaften im Anhang zum Jahres- bzw. Konzernabschluss offen zu legen. Die Angaben können nur dann unterbleiben, wenn die Hauptversammlung dies mit Dreiviertelmehrheit beschlossen hat. Vgl. dazu Spindler (2005). 
zu berichten ( $\S 171$ Abs. 1 und 2 AktG). Billigt der Aufsichtsrat den Jahresabschluss, dann ist dieser festgestellt ( $\$ 172 \mathrm{AktG}$ ). Diese Kompetenz ist von hoher Bedeutung, da die Hauptversammlung an den festgestellten Jahresabschluss gebunden ist und diesen in der Regel nicht mehr beeinflussen kann. Zudem können Vorstand und Aufsichtsrat das der Hauptversammlung zur Verwendung vorgeschlagene Ergebnis durch Thesaurierung gemäß den Bestimmungen in $\S 58$ Abs. 2 AktG weiter mindern und damit dem Einfluss der Hauptversammlung entziehen.

Neben den geschilderten Einsichts- und Prüfungsrechten sind für eine effektive Überwachung die Informationsrechte von entscheidender Bedeutung. Nach $\S 90 \mathrm{AktG}$ hat der Vorstand den Aufsichtsrat in umfassender Weise mit Informationen zur aktuellen Lage der Gesellschaft und zur beabsichtigten Geschäftspolitik zu versorgen ${ }^{150}$. Die Berichtspflicht besteht nicht nur auf Verlangen des Aufsichtsrats ( $\$ 90$ Abs. $3 \mathrm{AktG}$ ). Der Vorstand muss vielmehr von sich aus tätig werden ${ }^{151}$. Es wird in diesem Zusammenhang die Einschätzung vertreten, dass die Berichtspflicht trotz des Prinzips der Gewaltenteilung innerhalb der Verwaltung dazu führe, dass insbesondere der Aufsichtsratsvorsitzende in die Leitung des Unternehmens in vielen Fällen eng eingebunden $\operatorname{sei}^{152}$.

Die Aufsichtsratsmitglieder haben gemäß $\S 116$ i.V.m. $\S 93$ AktG grundsätzlich dieselbe Sorgfaltspflicht zu beachten wie die Mitglieder des Vorstands. Die Rechtsprechung hat Mindestanforderungen herausgearbeitet, die an alle Aufsichtsratsmitglieder zu stellen sind ${ }^{153}$. Sie müssen z.B. über ausreichenden Sachverstand verfügen, um die Berichte des Vorstands und die Prüfungsberichte des Abschlussprüfers beurteilen zu können. Über die Mindestfähigkeiten hinaus wird hinsichtlich ihrer beruflichen Qualifikation und ihrer Funktion im Aufsichtsrat differenziert $^{154}$. Bei Verletzung ihrer Sorgfaltspflicht haften sie auf Schadensersatz ${ }^{155}$. Schadensersatzprozesse sind aber selten, da der Schadensnachweis schwierig zu erbringen ist und der Vorstand tendenziell wenig Interesse hat, Ansprüche im Namen der Aktiengesellschaft geltend zu machen und damit indirekt eigenes Fehlverhalten einzugestehen ${ }^{156}$.

Aufsichtsratsmitglieder unterliegen auch der Treue- bzw. Loyalitätspflicht und müssen daher private Interessen und die einzelner Gruppen (z.B. Anteilseigner, Arbeitnehmer, öffentliche Hand, Unternehmen, in deren Aufsichtsrat sie ebenfalls tätig sind) hinter das eher nebulöse Unternehmensinteresse $^{157}$ zurückstellen. Es wird einschränkend darauf hingewiesen, dass

$150 \S 90 \mathrm{AktG}$ ist durch das KonTraG und das TransPuG präzisiert worden. Vgl. dazu C. Ernst/Seibert/Stuckert (1998), S. 51-52; Baums/Stöcker (2003), S. 8-10; Seibert (2003b), S. 53-54; Strunk/Kolaschnik (2003), S. 31-35.

151 Vgl. zu einer Systematisierung der verschiedenen Berichte Lutter/Krieger (2002), S. 78-91, 94-98.

152 Vgl. Semler (2000), S. 730; Raiser (2001), S. 196; K. Schmidt (2002), S. 869.

153 Vgl. zu zentralen Gerichtsurteilen Theisen (2003), S. 453-455.

154 Vgl. Raiser (2001), S. 216-218; Doralt (2004), S. 794-800; Hüffer (2006), § 116, Tz. 2-3.

155 Vgl. zur Haftungssituation von Aufsichtsratsmitgliedern umfassend Thümmel (2003).

156 Nach Lutter (1995c), S. 1134, zielt das Gesetz ab ,auf den Vatermord und der ist - Gott sei Dank - höchst selten“. Vgl. auch Thümmel (1999), S. 887; Raiser (2001), S. 216 mit Verweis auf Gerichtsurteile; Grunewald (2005), S. 265-266.

157 Vgl. zur Diskussion dieses Begriffs und was sich dahinter verbergen soll Flume (1983), S. 56-63; Raiser (2001), S. 218-222; Marsch-Barner (2004), S. 734-735; v. Schenck (2004), S. 339, 341-342; Grunewald (2005), S. 266-267, jeweils m.w.N. 
Aufsichtsratsmitglieder vielfältigen, gesetzlich bedingten Interessenkonflikten ausgesetzt sind und sie im Gegensatz zu den Vorstandsmitgliedern nur ein Nebenamt innehaben ${ }^{158}$.

Die Treuepflicht ist verletzt, wenn ein Aufsichtsratsmitglied den Vorstand aus Eigennutz zum Abschluss eines für die Aktiengesellschaft schädlichen Rechtsgeschäfts zwingt oder selbst unzulässigem Druck nachgibt ${ }^{159}$. Eine Pflichtverletzung liegt weiterhin vor, wenn ein Aufsichtsratsmitglied in den Kompetenzbereich des Vorstands eingreift bzw. Kompetenzübergriffe des Vorstands toleriert ${ }^{160}$. Nicht mit dem Unternehmensinteresse vereinbar ist es ferner, durch zu hohe Dividendenzahlungen die Investitionsfähigkeit und damit die wirtschaftliche Stabilität des Unternehmens zu gefährden ${ }^{161}$. Trotz der strengen gesetzlichen Ausgestaltung der Haftung sind Haftungsklagen gegen den Aufsichtsrat (noch) selten ${ }^{162}$.

Die Wirksamkeit der Aufsichtsratstätigkeit sowie die Besonderheiten des deutschen Aufsichtsratsmodells (dualistisches System) ${ }^{163}$ werden in der Literatur seit über 100 Jahren kritisch und kontrovers diskutiert ${ }^{164}$. Spätestens seit einer Reihe von Unternehmenskrisen und Fehlinvestitionen in den 1990er Jahren wird die Kontrolleffizienz der Aufsichtsräte erneut verstärkt angezweifelt. Kritisiert werden unter anderem die mangelnde Sachkenntnis und Professionalität sowie die unzureichende Informationsversorgung vieler Aufsichtsratsmitglieder, die geringe Tagungshäufigkeit und die zu hohe Anzahl der Mitglieder ${ }^{165}$. Des Weiteren wird es als problematisch angesehen, dass der Umfang der Überwachungsfunktion im Gesetz nur unzureichend dargestellt wird und in der Betriebswirtschaftslehre entwickelte Vorschläge von Führungs- und Überwachungsgrundsätzen ${ }^{166}$ in der Praxis und Rechtsprechung bisher kaum aufgegriffen worden sind ${ }^{167}$. Andere Autoren hingegen beurteilen die Qualität der Aufsichtsratstätigkeit positiver ${ }^{168}$.

158 Vgl. Kübler (1999b), S. 192 m.w.N.; Raiser (2001), S. 218-222

159 Vgl. dazu mit Nachweisen zur Rechtsprechung Raiser (2001), S. 212, 220; K. Schmidt (2002), S. 827-828.

160 Vgl. Raiser (2001), S. 212.

161 Vgl. Raiser (2001), S. 221.

162 Vgl. Theisen (2003), S. 519-520. Vgl. zu den steigenden Haftungsrisiken der Aufsichtsratsmitglieder Buchta/van Kann (2003), S. 1668, mit Verweis auf Gerichtsurteile; Thümmel (2004a). Zum erhöhten Schadensersatzrisiko bei Nichtbeachtung von $§ 170$ Abs. 3 S. 2 AktG vgl. Bormann/Gucht (2003), S. 1893.

163 Vgl. zur Entstehung des Aufsichtsrats in Deutschland Passow (1909). Zu einem historischen Abriss von 1861 bis 1994 vgl. Lutter (1995a), S. 7-10.

164 Vgl. bereits Stier-Somlo (1903), S. 31-74, zu Reformvorschlägen hinsichtlich der Zusammensetzung des Aufsichtsrats, der fachlichen Qualifikation seiner Mitglieder, der Begrenzung der Anzahl der Aufsichtsratsmandate, des Umfangs der Überwachungspflicht, der Haftpflicht und der Vergütung. Vgl. kritisch auch Schmalenbach (1910/11).

165 Vgl. Lutter (1994b); Lutter (1995b), S. 295; Lutter (1995c); Kübler (1999b), S. 194. Die Zweifel an der Funktionsfähigkeit deutscher Aufsichtsräte wird durch empirische Befunde gestützt. Vgl. P. Ruhwedel/Epstein (2003).

166 Vgl. insbesondere Potthoff (1961); Theisen (1987), S. 250-438; v. Werder (1996), S. 5-21; P. Ruhwedel (2002), S. 98-196.

167 Vgl. Theisen (2003), S. 520-521.

168 So weist z.B. Raiser (2001), S. 220, auf die gesamtwirtschaftlichen Vorteile des komplexen Beziehungsgeflechts im Aufsichtsrat hin. Vgl. auch Bea/Scheurer (1994), S. 2152; Escher-Weingart (2000), S. 400. Zu einem positiven Gesamturteil der Aufsichtsratstätigkeit vgl. bereits Rießer (1903), S. 299; Stier-Somlo (1903), S. 31. 
In jüngerer Vergangenheit ist schließlich der Einfluss der Arbeitnehmer und der Gewerkschaftsvertreter im Aufsichtsrat erneut massiver Kritik ausgesetzt ${ }^{169}$. Namhafte Vertreter aus Theorie und Praxis sprechen sich sogar für die Substitution der unternehmerischen Mitbestimmung im Aufsichtsrat durch ein separates Organ (Konsultationsrat) aus ${ }^{170}$. Auch im Ausland stößt die Mitbestimmung in Deutschland auf Unverständnis und wird als Standortproblem angesehen ${ }^{171}$.

Die bisherigen Bemühungen des deutschen Gesetzgebers, die Funktionsfähigkeit des Aufsichtsrats zu erhöhen, haben nur zu geringen Verbesserungen geführt ${ }^{172}$. Die Auswirkungen des Deutschen Corporate Governance Kodex (DCGK) ${ }^{173}$ sowie weitere Reformvorhaben der Bundesregierung und der EU-Kommission ${ }^{174}$ bleiben abzuwarten.

\subsubsection{Hauptversammlung}

Die Hauptversammlung ist die Versammlung aller Aktionäre der Gesellschaft, in der diese ihre Rechte ausüben ( $\$ 118 \mathrm{AktG})$. Mindestens einmal im Jahr hat der Vorstand eine ordentliche Hauptversammlung einzuberufen ( $\S 121$ Abs. 1-2, 175 Abs. 1 S. 2 AktG). Außerordentliche Hauptversammlungen müssen stattfinden, wenn ein Verlust in Höhe der Hälfte des Grundkapitals auftritt ( $\$ 92$ Abs. 1 AktG) oder wenn es das Wohl der Gesellschaft erfordert; in letzterem Fall hat auch der Aufsichtsrat eine Einberufungspflicht ( $§ 111$ Abs. 3 AktG). Schließlich können Minderheitsaktionäre, deren Anteile $5 \%$ oder einen in der Satzung festgelegten geringeren Prozentsatz am Grundkapital ausmachen, die Einberufung verlangen $(\S 122$ Abs. 1 AktG).

Die Hauptversammlung ist mit einer Reihe von Befugnissen ausgestattet, die insbesondere in $\S 119$ Abs. 1 Nr. 1-8 AktG sowie einigen weiteren Normen des AktG und des Umwandlungsgesetzes geregelt sind. Nur in engen Grenzen kann die Satzung der Hauptversammlung darüber hinausgehende Kompetenzen zuweisen. In der Literatur findet zumeist eine Einteilung der Zuständigkeiten in laufende Angelegenheiten und Grundlagenentscheidungen statt ${ }^{175}$.

169 Vgl. z.B. Kübler (1999a), S. 419-421; Hopt (2002d), S. 42-46; Schiessl (2002), S. 595-597; Schwark (2002), S. 84-86; Ulmer (2002); Wiesner (2003), S. 217. Eine komprimierte Darstellung der zahlreichen Kritikpunkte an den mitbestimmungsrechtlichen Regelungen findet sich bei Sandrock (2004a), S. 60-62. Vgl. v. Werder (2004). Vgl. ebenfalls Schiessl (2003), S. 255-256. Zu Gegenargumenten zu den wichtigsten Kritikpunkten vgl. Hans Böckler Stiftung (2004).

171 Vgl. K. Schmidt (2002), S. 479; Bohl (2003), S. 14; Adams (2004).

172 Vgl. zu den Reformansätzen hinsichtlich des Aufsichtsrats durch das KonTraG und das TransPuG ausführlich Theisen (2003), S. 437-491. Die durch das KonTraG in $\S 100$ Abs. 2 AktG erneut reduzierte Höchstzahl an Aufsichtsratssitzen verhindert frühere Fälle von uber 100 Posten einer Person. Vgl. dazu Hueck (1991), S. 219.

173 Dieser sieht gemäß Ziffer 5.6 DCGK Effizienzprüfungen des Aufsichtsrats vor. Vgl. dazu Theisen (2002), S. 74-75; Seibt (2003); Schilling (2004).

174 Diese Reformbestrebungen in Deutschland und in der EU sehen z.B. eine persönliche Außenhaftung von Aufsichtsräten bei Sorgfaltspflichtverletzungen, d.h. eine Schadensersatzpflicht nicht nur gegenüber der Gesellschaft, sondern unmittelbar gegenüber den Aktionären, vor. Vgl. Bundesregierung (2003), Maßnahme 2; EU-Kommission (2003a), S. 17-19.

175 Vgl. z.B. Zöllner (1973), §119, Tz. 14-19; Raiser (2001), S. 225-227; HueckWindbichler (2003), S. 328-330; Hüffer (2006), § 119, Tz. 5-10. 
$\mathrm{Zu}$ den laufenden Angelegenheiten gehört erstens die Wahl der Aufsichtsratsmitglieder, soweit diese nicht von der Arbeitnehmerseite gewählt bzw. entsendet werden. Die Hauptversammlung beeinflusst somit mittelbar die Besetzung des Vorstands. Sie entscheidet zweitens über die Verwendung des Bilanzgewinns. Diese Entscheidungskompetenz ist allerdings materiell stark eingeschränkt, da sie dabei im Regelfall an den durch den Vorstand aufgestellten und vom Aufsichtsrat gebilligten und damit festgestellten Jahresabschluss gebunden ist. Nur in den Ausnahmefällen, in denen der Aufsichtsrat den Jahresabschluss nicht billigt oder die Verwaltung die Feststellung des Jahresabschlusses der Hauptversammlung überlässt $(\S 173$ $\mathrm{AktG}$ ), ist dieses Recht von Bedeutung.

Von größerer Tragweite ist hingegen drittens die Entlastung der Mitglieder des Vorstands und des Aufsichtsrats. Mit diesem gesellschaftsrechtlichen Institut billigt die Hauptversammlung die Verwaltung der Aktiengesellschaft für das abgelaufene Geschäftsjahr und spricht der zukünftigen Verwaltung ihr Vertrauen aus ${ }^{176}$. Fälle, in denen die Entlastung verweigert wird, finden in der Öffentlichkeit große Beachtung und führen meist zu einem erheblichen Imageverlust des betreffenden Verwaltungsmitglieds. Bei einem Vorstandsmitglied kann die Verweigerung die vorzeitige Abberufung aus wichtigem Grund gemäß $\S 84$ Abs. 3 AktG rechtfertigen. Im Allgemeinen bestellt die Hauptversammlung viertens den Abschlussprüfer ${ }^{177}$.

$\mathrm{Zu}$ den Grundlagenentscheidungen zählen z.B. Satzungsänderungen, Maßnahmen der Kapitalerhöhung und -herabsetzung, Abschluss und Änderungen von Unternehmensverträgen sowie weitere Eingriffe in die Struktur der Gesellschaft wie Eingliederung, Verschmelzung, Umwandlung, Ausschluss von Minderheitsaktionären (Squeeze-out) und Auflösung ${ }^{178}$.

Soweit das Gesetz oder die Satzung nichts anderes vorschreiben, kommen Hauptversammlungsbeschlüsse gemäß $\S 133$ Abs. 1 AktG mit einfacher Mehrheit der abgegebenen Stimmen zustande. Für Grundlagenbeschlüsse ist die qualifizierte Mehrheit von drei Viertel des bei der Abstimmung vertretenen Grundkapitals notwendig ${ }^{179}$.

Neben den gesetzlich geregelten Befugnissen sind im Schriftum und in der Rechtsprechung ungeschriebene Hauptversammlungszuständigkeiten entwickelt worden, die verhindern sollen, dass das auf Machtbalance gerichtete aktienrechtliche Kompetenzgefüge ${ }^{180}$ gestört und Aktionärsrechte ausgehöhlt werden ${ }^{181}$. In seinem viel beachteten Holzmüller-Urteil ${ }^{182}$ vom 25.02.1982 hat der BGH entschieden, dass der Vorstand verpflichtet ist, grundlegende Entscheidungen, die „tief in die Mitgliedsrechte der Aktionäre und deren im Anteilseigentum

176 Vgl. Hüffer (2006), § 120, Tz. 2.

$177 \mathrm{Vgl}$. zu den Ausnahmen $\S 318$ Abs. 3-4 HGB.

178 Daneben findet sich im Gesetz eine Reihe weiterer Zuständigkeiten, beispielsweise die Abberufung von Anteilseignervertretern im Aufsichtsrat ( $\$ 103 \mathrm{AktG})$, die Festsetzung der Vergütung von Aufsichtsratsmitgliedern ( $\$ 113 \mathrm{Abs} .1-2 \mathrm{AktG}$ ) und die Bestellung von Sonderprüfern ( $\S 142 \mathrm{AktG}$ ).

179 Bei Eingliederungen und bestimmten Umwandlungsfällen sind noch höhere Mehrheiten erforderlich. Vgl. zu einer detaillierten Übersicht über die jeweiligen Stimmquoten Klunzinger (2004), S. 177-178.

180 Vgl. Hüffer (2006), § 118, Tz. 4.

181 Vgl. dazu bereits Lutter (1974a), S. 208-217. Vgl. auch Raiser (2001), S. 227-231 m.w.N. Zu einer ausführlichen Analyse und Kritik der ungeschriebenen Hauptversammlungskompetenzen vgl. z.B. Warschkow (1991), S. 19-156.

182 Vgl. BGH-Urteil vom 25.02.1982 - II ZR 174/80. In der Literatur ist die Holzmüller-Entscheidung auf ein breites Echo gestoßen. Zu einem komprimierten Überblick über die verschiedenen Meinungen vgl. Hüffer (2006), § 119, Tz. 16-17. Für Nachweise zur liberaus umfangreichen Literatur vgl. auch Koppensteiner (2004a), Vorb. § 29l, Tz. 43. Aus der jungeren Vergangenheit vgl. insbesondere Henze (2003). 
verkörpertes Vermögensinteresse eingreifen " ${ }^{\text {183 }}$, der Hauptversammlung vorzulegen; anderenfalls verletzte der Vorstand seine Sorgfaltspflicht ${ }^{184}$.

Aufgrund der aufgezeigten Kompetenzen wird die Hauptversammlung auch als „das ,Parlament“ der Gesellschaft“"185, der „Sitz der Aktionärsdemokratie“"186 oder das „,oberste Organ“"187 bezeichnet. Dies darf allerdings nicht darüber hinwegtäuschen, dass die Einflussmöglichkeiten der Hauptversammlung auf die Unternehmensführung nur begrenzt sind. Auch kommt es in der Praxis nur selten vor, dass der Vorstand die Hauptversammlung gemäß $§ 119$ Abs. 2 AktG explizit über Fragen der Geschäftsführung entscheiden lässt ${ }^{188}$.

\subsubsection{Rechte und Pflichten der Aktionäre}

Die bisherigen Ausführungen haben die Kompetenzen der Organe der Aktiengesellschaft sowie ihr Verhältnis untereinander beleuchtet. Die Rechte und Pflichten des einzelnen Aktionärs standen dabei nicht im Mittelpunkt; lediglich die Hauptversammlung als Willensbildungsorgan der Aktionäre wurde betrachtet.

Die Rechte und Pflichten ergeben sich aus der Mitgliedschaft, die die Aktionäre durch Übernahme von Aktien bei der Gründung ( $\S 2,29 \mathrm{AktG}$ ), durch Zeichnung von Aktien im Zuge einer Kapitalerhöhung ( $\$ 185 \mathrm{AktG})$ oder im Wege der Gesamtrechtsnachfolge (z.B. Erbschaft) bzw. Einzelnachfolge (z.B. Börsenhandel) erwerben ${ }^{189}$. Für die Mitgliedschaftsrechte und -pflichten gilt der im Aktienrecht seit langem anerkannte ${ }^{190}$ und seit 1979 in $\S 53$ a AktG verankerte Gleichbehandlungsgrundsatz, nach dem die Aktionäre unter gleichen Voraussetzungen gleich zu behandeln und willkürliche Differenzierungen unzulässig sind ${ }^{191}$. Hauptver-

BGHZ 83, 131.

Mit zwei grundlegenden Urteilen hat der BGH im April 2004 seine 22 Jahre alten Aussagen präzisiert und einige Unsicherheiten in der Praxis beseitigt. Vgl. BGH-Urteile vom 26.04.2004 - II ZR 154/02 und II ZR 155/02 („Gelatine“). Eine ungeschriebene Zuständigkeit der Hauptversammlung bestehe nur bei strukturverändernden Maßnahmen im Kernbereich der Unternehmenstätigkeit, die in ihrer Bedeutung dem Schwellenwert von $80 \%$ im Holzmüller-Fall nahe komme. Der BGH legt weiterhin fest, dass der Hauptversammlungsbeschluss mit Dreiviertelmehrheit des vertretenen Grundkapitals gefasst werden müsse. Vgl. ausfuhrlich Bungert (2004); Fleischer (2004b); Fuhrmann (2004); Götze (2004); Koppensteiner (2004c).

G. Henn (2002), S. 380.

K. Schmidt (2002), S. 837.

Klunzinger (2004), S. 173. Für v. Rechenberg (1986), S. 162-163, ist die Hauptversammlung zwar nicht das oberste Organ im Sinne einer weisungsabhängigen Hierarchie. Die Hauptversammlung sei aber im Hinblick auf die innere Verfassung der Aktiengesellschaft das wichtigste Organ. Wiethölter (1961), S. 92-93, weist hingegen darauf hin, dass es in der aktienrechtlichen Praxis vielmehr um „die Wirkung und die Struktur des in der AG maßgebenden Einflusses“ gehe und es das oberste Organ somit nicht gebe.

Vgl. Raiser (2001), S. 129.

Vgl. Kraft/Kreutz (2000), S. 348; Staake (2004), S. 248.

Vgl. Hueck (1958), S. 35, 44-58.

Vgl. Hüffer (2006), §53a, Tz. 1-12. Im Aktiengesetz kommt dieser Grundsatz an vielen Stellen zum Ausdruck, so z.B. bei der Verteilung der Dividende ( $\$ \S 58 \mathrm{Abs} .4,60 \mathrm{AktG})$, bei der Auskunftserteilung ( $\$ 131$ AktG), beim Stimmrecht ( $\S \S 12,134$ Abs. 1 und 2 AktG), beim Bezugsrecht ( $\S 186 \mathrm{AktG})$, bei der Kapitalerhöhung aus Gesellschaftsmitteln ( $\$ 212$ AktG), bei der Anfechtungsbefugnis ( $(245 \mathrm{AktG}$ ) und bei der Verteilung des Restvermøgens ( $\$ 271$ AktG). Die Satzung kann allerdings die Aktien mit unterschiedlichen Rechten ( $\S 11,12,60$ Abs. 3 AktG) und Pflichten ( 55 AktG) ausstatten. 
sammlungsbeschlüsse, die gegen das Gleichheitsgebot verstoßen, sind nach $\S 243$ Abs. 1 AktG anfechtbar.

\subsubsection{Aktionärspflichten}

Bevor sich die weiteren Ausführungen auf die Aktionärsrechte konzentrieren, sollen zunächst die Pflichten der Anteilseigner kurz skizziert werden. Diese lassen sich in Haupt-, Neben- und Treuepflichten unterteilen ${ }^{192}$.

Die primäre und in vielen Fällen einzige Pflicht besteht in der Leistung der Einlage, die durch den Ausgabebetrag der Aktie begrenzt ist ( $\$ 54$ Abs. 1 AktG). Um die Kapitalaufbringung und -erhaltung sicherzustellen, sieht das Gesetz strenge Regelungen zur Durchsetzung des Anspruchs der Gesellschaft vor, die im Extremfall zum Ausschluss des säumigen Aktionärs durch das so genannte Kaduzierungsverfahren ( $\$ 64 \mathrm{AktG}$ ) führen können ${ }^{193}$. Die unter bestimmten Voraussetzungen bestehenden Nebenleistungspflichten gemäß $\S 55 \mathrm{AktG}$ haben kaum praktische Bedeutung ${ }^{194}$. Schließlich trifft den Aktionär aufgrund der Rechtsbeziehung zu seiner Aktiengesellschaft eine Treuepflicht, die weit über den in $\S 242$ BGB kodifizierten Grundsatz von „Treu und Glauben“ hinausgeht ${ }^{195}$. Die Intensität der Treuepflicht ist abhängig von der Struktur der Aktiengesellschaft und der Stellung des Aktionärs in ihr. Ein Kleinaktionär, der insgesamt nur in sehr eingeschränktem Umfang einer Treuepflicht unterliegt, handelt beispielsweise treuwidrig, wenn er mit einer für das Unternehmen besonders nachteiligen Anfechtungsklage Zahlungen von der Aktiengesellschaft für die Rücknahme der Klage erpressen will.

Obwohl zwischen den Aktionären kein rechtsgeschäftliches Verhältnis besteht, sind sie nach aktueller Rechtsprechung und nach herrschender Meinung auch untereinander durch eine Treuepflicht verbunden. Großaktionäre dürfen danach ihren Einfluss nicht ohne Rücksicht auf die Interessen der Minderheitsaktionäre ausüben. Die Treuepflicht dient aber nicht nur dem Minderheitenschutz ${ }^{196}$; einzelne Aktionäre oder eine Aktionärsgruppe dürfen ihre Herrschaftsrechte ebenfalls nicht grob eigennützig ausüben (z.B. Verhinderung einer Sanierung durch eine Sperrminorität). Die Treuepflicht stellt somit eine rechtliche Generalklausel dar, nach der jeder Aktionär seine Rechte unter angemessener Berücksichtigung der gesellschaftsbezogenen Interessen der anderen Aktionäre auszuüben hat.

Während die Haupt- und Nebenpflichten, die sich auf die Gründungsphase der Aktiengesellschaft konzentrieren, für den weiteren Gang der Untersuchung von untergeordneter Bedeutung sind, ist die Treuepflicht von besonderer Relevanz. Sie beeinflusst die Ausübung der Aktionärsrechte, indem sie z.B. die Ausübung des Stimmrechts und die Möglichkeit von Anfechtungsklagen beschränkt ${ }^{197}$. Die Treuepflicht hat zudem eine Schrankenfunktion hinsicht-

192

193

194

195

196

197

Vgl. z.B. Hueck/Windbichler (2003), S. 365-369.

Vgl. zur Einlagepflicht ausfuhrlich Grunewald (2005), S. 235-242.

Vgl. Lutter (1988a), § 55, Tz. 2.

Vgl. zur Treuepflicht und ihrer Entwicklung in der Rechtsprechung und im Schrifttum ausfuhrlich Wilhelm (1998), S. 217-229; Wellkamp (2000), S. 82-115; Escher-Weingart (2001), S. 206-227; Raiser (2001), S. 109-116; K. Schmidt (2002), S. 799-803; Eisenhardt (2003), S. 364-367; Hueck/Windbichler (2003), S. 365-367; Grunewald (2005), S. 245-248 Hüffer (2006), § 53a, Tz. 13-22.

Vgl. Wiedemann (1980), S. 431-437, der diesen Aspekt betont.

Vgl. Wellkamp (2000), S. 82. 
lich der eigennützigen Mitgliedschaftsrechte und verbietet beispielsweise die unverhältnismäBige, die Interessen anderer Anteilseigner nicht berücksichtigende Ausübung des Dividendenrechts $^{198}$.

\subsubsection{Aktionärsrechte}

Die einzelnen Rechte des Aktionärs lassen sich nach verschiedenen Kriterien klassifizieren. Wird danach differenziert, welchen Aktionären die Rechte zustehen, existieren Rechte, die grundsätzlich allen gleichermaßen (allgemeine Mitgliedschaftsrechte, z.B. Auskunftsrecht), einer Gruppe (Gattungsvorrechte, z.B. Dividendenvorrecht gemäß §§ 139-141 AktG) oder nur einzelnen Aktionären (Sonderrechte, z.B. Entsendungsrecht gemäß $§ 101 \mathrm{Abs} .2 \mathrm{AktG}$ ) zustehen $^{199}$. Aus verbandsrechtlicher Sichtweise werden diese Aktionärsrechte aus der Mitgliedschaft an der Gesellschaft abgeleitet. Dahingegen werden aus kapitalmarktrechtlicher Perspektive Rechte für aktuelle (und potentielle) Aktionäre in ihrer Eigenschaft als Anleger formuliert. Im Weiteren sollen beide Sichtweisen berücksichtigt werden. Nach dem Inhalt der Rechte werden Herrschafts-, Informations- und Vermögensrechte unterschieden ${ }^{200}$.

\subsection{Herrschaftsrechte}

Die Herrschaftsrechte werden von den Aktionären grundsätzlich in der Hauptversammlung ausgeübt und dienen der Durchsetzung ihrer Vermögensrechte. Das Teilnahmerecht an der Hauptversammlung steht jedem Aktionär zu ( $\$ 118$ Abs. 1 AktG), unabhängig davon, ob er stimmberechtigt ist. Der Aktionär muss nicht persönlich anwesend sein, um sein Teilnahmerecht auszuüben, sondern kann sich z.B. durch einen Bevollmächtigten vertreten lassen ${ }^{201}$. Bestandteil des Teilnahmerechts ist auch das Recht, sich zu Gegenständen der Tagesordnung sachdienlich zu äußern sowie Anträge und Gegenanträge ( $§ 126 \mathrm{AktG}$ ) zu stellen ${ }^{202}$.

Das Stimmrecht als das wichtigste Herrschaftsrecht verleiht dem Aktionär ,die Möglichkeit, [sich] im Rahmen der Zuständigkeiten der HV [Hauptversammlung] an der Verwaltung der Verwaltungsrechten einerseits und Vermögensrechten andererseits differenziert, wobei das Auskunftsrecht S. 181; Raiser (2001), S. 99; G. Henn (2002), S. 16; K. Schmidt (2002), S. 797; Hüffer (2006), § 11, Tz. 3. Wird die Hauptversammlung audiovisuell übertragen (§ 118 Abs. 3 AktG), gilt das Verfolgen der Hauptversammlung über das Internet nach herrschender Meinung allerdings nicht als Teilnahme. Vgl. Hueck Windbichler (2003), S. 336. Vgl. zur Zulässigkeit von Internet-Hauptversammlungen Hirte (2000b).

Vgl. Hüffer (2006), § 118, Tz. 9. Vgl. zu möglichen Einschränkungen des Teilnahme- und Rederechts, die einen geordneten Ablauf der Hauptversammlung gewährleisten sollen, Wellkamp (1998), S. 33-43; K. Schmidt (2002), S. 840-841. Zum Ablauf der Hauptversammlung ausführlich vgl. Obermüller/Werner/ Winden (2001), S. 117-160; Martens (2003). Der Versammlungsleiter kann ermächtigt werden, das Frageund Rederecht angemessen zu begrenzen (§131 Abs. 2 S. 2 AktG). Vgl. dazu auch Seibert/Schütz (2004), S. 255-256. 
Gesellschaft (...) zu beteiligen und mitbestimmend auf ihr Schicksal einzuwirken “203. Im Grundsatz steht das Stimmrecht nach $\S 12 \mathrm{AktG}$ jedem Aktionär entsprechend seiner Beteiligung zu und bestimmt sich bei Nennbetragsaktien nach ihrem Nennbetrag, bei Stückaktien nach deren Anzahl ${ }^{204}$. Eine Ausnahme des Grundsatzes „Eine Aktie - eine Stimme“ stellen Vorzugsaktien ohne Stimmrecht ( $\S 12$ Abs. 1 S. 2, 139-141 AktG) dar ${ }^{205}$. Inhaber dieser Aktiengattung erhalten nur dann ein Stimmrecht, wenn und solange die Vorzugsdividende zwei Jahre im Rückstand ist. „Mehrstimmrechtsaktien, die in den Wirtschaftskrisen nach dem Ersten Weltkrieg eine beträchtliche, aber nicht segensreiche Rolle spielten“ ${ }^{\text {¿206, }}$, sind seit dem KonTraG von 1998 verboten ( $\$ 12$ Abs. 2 AktG). Dahingegen sind Beschränkungen des Stimmrechts durch Höchststimmrechte gemäß $\S 134$ Abs. 1 AktG erlaubt, seit dem KonTraG allerdings nur bei nicht börsennotierten Gesellschaften.

Da die Beteiligung an der Hauptversammlung zeitintensiv ist und in keinem Verhältnis zu den daraus resultierenden Vorteilen steht ${ }^{207}$, nehmen viele Kleinaktionäre nicht an der Hauptversammlung teil. Nach einer Erhebung der Deutschen Schutzvereinigung für Wertpapierbesitz (DSW) lag die Hauptversammlungspräsenz im Jahr 2005 bei den DAX-30-Unternehmen im Durchschnitt nur bei 45,87\% $(1998: 60,95 \%)^{208}$.

Hauptversammlungsbeschlüsse, die gegen Gesetz oder Satzung verstoßen und damit mangelhaft sind, können zur Nichtigkeit oder Anfechtbarkeit führen ${ }^{209}$. Ein nichtiger und nicht nach $\S 242 \mathrm{AktG} \mathrm{zu}$ heilender Beschluss führt dazu, dass die beabsichtigte Rechtswirkung nicht eintritt. Zur Wahrung der Rechtssicherheit im Interesse der Gesellschaft, ihrer Aktionäre und Gläubiger zählt das Gesetz in $\S 241 \mathrm{AktG}$ und in den Sondervorschriften der $\S \S 250,253,256$ AktG die Nichtigkeitsgründe abschließend auf. Es soll vermieden werden, dass aufgrund eines geringfügigen Verstoßes gegen eine aktienrechtliche Vorschrift unter Umständen noch

203 Würdinger (1981), S. 71. Vgl. zu den Problemen und Reformüberlegungen der grenzüberschreitenden Stimmrechtsausübung (cross-border voting) Noack (2002).

204 Der Aktionär kann sein Stimmrecht auch durch Dritte ausüben lassen. In Deutschland weit verbreitet ist die Bevollmächtigung von Kreditinstituten durch das so genannte Banken- oder Depotstimmrecht, das in $\S \S 125-128,135$ AktG geregelt und in der Literatur nicht unumstritten ist. Vgl. z.B. Wiethölter (1961), S. 322-336; Süchting/Paul (1998), S. 124-134; Grunewald (2005), S. 277 m.w.N. Vgl. zur Regulierungsbegründung Kropff(1965), S. 194-195.

Zur Kritik an Vorzugsaktien vgl. z.B. Pellens/Hillebrandt (2001). Stimmrechtsverbote bestehen unter anderem für eigene Aktien der Gesellschaft ( $\S 56$ Abs. 3, 71b, 71d AktG) und bei Interessenkollision ( 136 AktG). Vgl. dazu Raiser (2001), S. 252-255.

206 K. Schmidt (2002), S. 849.

207 Vgl. Kübler (1999b), S. 171. Vgl. bereits ausfuhrlich zu den Gründen der Passivität Wiethölter (1961), S. 316-319; Pross (1965), S. 126-150; Großfeld (1968), S. 16-21. Diese aus ökonomischer Sicht sinnvolle Passivität wird vielfach mit dem Begriff ,rationale Apathie“ beschrieben. Vgl. z.B. Picot/Michaelis (1984), S. 256; Bott (2002), S. 22-23 m.w.N; Palmiter (2003), S. 107.

208 Bei der Continental AG lag die Prăsenz 2005 sogar nur bei 23,55\%. Vgl. DSW (2005). Zu einem Überblick über weitere Erhebungen der letzen Jahre für deutsche Unternehmen vgl. Bott (2002), S. 411 . Zu Vorschlägen zur Steigerung der Hauptversammlungspräsenz vgl. Pellens/Gassen/Neuhaus/Schmidt (2006), S. 29-34: Klühs (2006).

209 Zudem können Beschlüsse auch schwebend unwirksam sein, z.B. wenn sie noch der Zustimmung bestimmter Aktionäre bedürfen. Vgl. dazu und zu den Klagemöglichkeiten der Aktionäre ausführlich z.B. Wilhelm (1998), S. 237-262; Raiser (2001), S. 265-290; G. Henn (2002), S. 504-542; K. Schmidt (2002), S. 855-866. 
nach Jahren ein weitreichender Beschluss (z.B. Kapitalerhöhung, Satzungsänderung, Aufsichtsratswahl) für nichtig erklärt und damit rückgängig gemacht werden muss ${ }^{210}$.

Im Rahmen dieser Arbeit ist die Nichtigkeit gemäß $§ 256$ AktG von Bedeutung. Danach ist der festgestellte Jahresabschluss nichtig, wenn z.B. die Bestimmungen im Gesetz oder in der Satzung zur Einstellung in oder zur Entnahme aus den Kapital- und Gewinnrücklagen verletzt worden sind ( $\$ 256 \mathrm{Abs} .1 \mathrm{Nr} .4 \mathrm{AktG}$ ). Gleiches gilt, wenn eine nach den Vorschriften des HGB unzulässige Über- oder Unterbewertung von Bilanzpositionen stattgefunden hat und damit die Vermögens- und Ertragslage der Gesellschaft vorsätzlich unrichtig dargestellt wird (§ 256 Abs. 5 AktG).

Wenn Anlass zu der Annahme besteht, dass bestimmte Positionen des festgestellten Jahresabschlusses unangemessen hohe stille Reserven beinhalten, kommt eine Sonderprüfung wegen unzulässiger Unterbewertung durch gerichtlich bestellte Wirtschaftsprüfer gemäß $\S \S 258-261$ $\mathrm{AktG}$ in Betracht ${ }^{211}$. Einen solchen Antrag können Aktionäre, die zusammen über $1 \%$ des Grundkapitals oder den anteiligen Betrag von $100.000 €$ verfügen, innerhalb eines Monats nach der Hauptversammlung stellen ( $\S 258$ Abs. 2 i.V.m. $\S 142$ Abs. 2 AktG). Haben die Sonderprüfer unangemessen hohe stille Reserven ermittelt, so bleibt der festgestellte Jahresabschluss dennoch wirksam. Es sind aber bei den einzelnen Bilanzpositionen Unterschiedsbeträge zu vermerken, um die die Aktiva zu niedrig bzw. die Passiva zu hoch angesetzt worden sind ( $§ 261$ Abs. 1 S. 5 AktG). Die Summe der Unterschiedsbeträge ist als „Ertrag aufgrund höherer Bewertung gemäß dem Ergebnis der Sonderprüfung" sowohl in der Gewinn- und Verlustrechnung als auch auf der Passivseite der Bilanz gesondert auszuweisen ( $\$ 261$ Abs. 1 S. 6 AktG). Nach $\S 261$ Abs. 3 AktG zählt dieser Ertrag nicht zum Jahresüberschuss, der durch Vorstand und Aufsichtsrat in die Gewinnrücklagen eingestellt werden könnte. Die Vorschrift verfolgt den Zweck, die Verfügungsmasse der Hauptversammlung und damit das mitgliedschaftliche Dividendenrecht zu schützen ${ }^{212}$.

Ein Gewinnverwendungsbeschluss ist ebenfalls nichtig, wenn der Jahresabschluss, auf dem er beruht, nichtig ist ( $§ 253 \mathrm{AktG}$ ). Als Rechtsbehelf kommt die Nichtigkeitsklage gemäß $\S 249$ $\mathrm{AktG}$ in Betracht ${ }^{213}$, wobei je nach Nichtigkeitsgrund unterschiedliche Fristen zwischen sechs Monaten und drei Jahren zu beachten sind ${ }^{214}$.

Alle anderen Verstöße gegen das Gesetz oder die Satzung machen einen Hauptversammlungsbeschluss lediglich unter einschränkenden Voraussetzungen anfechtbar ( $2243 \mathrm{AktG}$ ). Die Klage ist innerhalb eines Monats nach der Beschlussfassung gegen die Gesellschaft, vertreten durch Vorstand und Aufsichtsrat, zu erheben ( $\$ 246 \mathrm{AktG}$ ). Anfechtungsbefugt sind Aktionäre grundsätzlich nur dann, wenn sie auf der Hauptversammlung anwesend waren und gegen den Beschluss Widerspruch erklärt haben ( $\$ 245$ AktG). Die Anfechtung ist ausge-

210 Nichtigkeit tritt im Aktienrecht damit nur in besonders gravierenden Fällen ein, wohingegen nach den allgemeinen Grundsătzen des Privatrechts jedes Rechtsgeschăft nichtig ist, das gegen ein Gesetz oder die guten Sitten verstößt ( $\S 134,138$ BGB).

211 Vgl. Claussen (1974); Hueck/Windbichler (2003), S. 390-391; Hüffer (2006), §§ 258-261. Vgl. zu einer Fixierung dessen, was „nicht unwesentliche“ Unterbewertung gemäß $\S 258$ Abs. $1 \mathrm{Nr} .1$ AktG bedeutet, Frey (1966), S. 634.

212 Vgl. Claussen (1974), S. 320-322. Ein Ausschüttungszwang in Höhe des Ertrags ist vom Gesetzgeber diskutiert, aber nicht verwirklicht worden. Vgl. Kropff (1965), S. 342-343.

213 Wenn deren Voraussetzungen nicht erfullt sind, kommt die allgemeine Feststellungsklage nach § 256 ZPO in Betracht. Vgl. Raiser (2001), S. 285.

214 Vgl. zu den Fristen im Einzelnen Hüffer (2006), § 242, Tz. 3-5, § 256, Tz. 30. 
schlossen, wenn der Verstoß für den Aktionär kaum von Relevanz ist ${ }^{215}$ oder die Gesellschaft nachweisen kann, dass der Anfechtungsgrund auf das Zustandekommen des Beschlusses keinen Einfluss gehabt hat ${ }^{216}$. Die Anfechtungsgründe lassen sich danach unterscheiden, ob sie auf Verfahrensmängeln (z.B. Verstöße im Abstimmungsverfahren oder bei der Beschlussfeststellung, Fehler bei der Einberufung der Hauptversammlung) oder Inhaltsmängeln (Verletzung des Gleichbehandlungsgebotes oder der Treuepflicht) basieren ${ }^{217}$.

Neben den in $\S 243$ Abs. 1 AktG genannten Anfechtungsmöglichkeiten bestehen weitere gemäß $\S 243$ Abs. 2, 251, 254, 255 AktG. Im Rahmen dieser Arbeit ist insbesondere der Anfechtungsgrund nach $\S 254$ AktG von Interesse. Danach haben Aktionäre, die zusammen $5 \%$ des Grundkapitals oder den anteiligen Betrag von $500.000 €$ erreichen, ein besonderes Anfechtungsrecht, wenn die ausgeschüttete Dividende weniger als $4 \%$ des Grundkapitals beträgt. Voraussetzung dafür ist, dass die Hauptversammlung höhere Beträge in die Gewinnrücklagen einstellt oder als Gewinn vorträgt, obwohl sie dazu weder durch Gesetz oder Satzung noch aufgrund wirtschaftlicher Notwendigkeiten gezwungen ist. Diese Norm soll vor einer Aushungerungspolitik der Aktionärsminderheit durch die Mehrheit schützen; sie wird aufgrund der geringen Mindestdividendenhöhe aber als wenig effektiv kritisiert ${ }^{218}$.

Die Vorschriften zum Anfechtungsrecht sollen gewährleisten, dass sich die Verwaltung möglichst früh auf eine Anfechtungsklage einstellen kann und ansonsten Rechtssicherheit besteht. Eine Anfechtungsklage kann für die Aktiengesellschaft nämlich gravierende wirtschaftliche Risiken bergen, wenn sich beispielsweise der Anfechtungsprozess über Jahre hinzieht und dazu führt, dass eine beschlossene Kapitalerhöhung nicht durchgeführt werden kann. In diesem Fall sieht $\S 244$ AktG die Möglichkeit der nachträglichen Bestätigung des angefochtenen Beschlusses durch die Hauptversammlung vor. Das ist dann nicht möglich, wenn der Kläger ein rechtliches Interesse daran hat, dass der anfechtbare Beschluss bis zur Bestätigung für nichtig erklärt wird ( $\$ 244$ S. 2 AktG).

Aufgrund der hohen Tragweite der Anfechtungsklage für die Gesellschaft, ist es nicht weiter verwunderlich, dass das Klagerecht mitunter missbraucht und von der Aktiengesellschaft wie ein „Damoklesschwert“ gefürchtet wird ${ }^{219}$. In zahlreichen Fällen haben sich Aktionäre ihr Anfechtungsrecht abkaufen lassen oder eine Anfechtungsklage nur mit dem Ziel erhoben, von der Gesellschaft Leistungen für die Rücknahme der Klage zu erpressen ${ }^{220}$. Die Rechtsprechung hat daraufhin Missbrauchstatbestände entwickelt, bei deren Vorliegen Anfechtungsklagen als unbegründet abgewiesen werden ${ }^{221}$. Die missbräuchliche Ausnutzung des Anfech-

Vgl. Kübler (1999b), S. 203; HueckWindbichler (2003), S. 350. Seit Verabschiedung des UMAG kann gemäß § 243 Abs. 4 AktG wegen eines Verstoßes gegen das Auskunftsrecht nur angefochten werden, wenn ein ,objektiv urteilender Aktionär" sein Verhalten vom Inhalt dieser Informationen abhängig gemacht hätte. Vgl. Schütz (2004), S. 419-420; Seibert/Schütz (2004), S. 256.

217 Vgl. Raiser (2001), 277-282; HueckWindbichler (2003), S. 349-350; Grunewald (2005), S. 283-284.

218 Vgl. Raiser (2001), S. 280; Hueck/Windbichler (2003), S. 392.

219 Vgl. Paefgen (2002), S. 269-277.

220

Vutter (1988c), S. 194; Martens (1992), S. 1678; Volhard (1998), S. 398; Hüffer (2006), § 245, Tz 22. $\mathrm{Zu}$ den Auswirkungen des deutschen Anfechtungsrechts auf die Zusammenschlüsse von Krupp/Hoesch, Krupp/Thyssen und Daimler-Benz/Chrysler vgl. Paefgen (2002), S. 271.

221 stellt die Rechtsprechung allerdings kein ausreichendes Korrektiv dar. 
tungsrechts soll durch das so genannte Freigabeverfahren gemäß § 246a AktG, das durch das UMAG eingeführt wurde, weiter eingeschränkt werden ${ }^{222}$.

\subsection{Informationsrechte}

Damit die Aktionäre die bisher beschriebenen Herrschaftsrechte sinnvoll ausüben können, benötigen sie Informationen über die Aktiengesellschaft ${ }^{223}$. Auch den Stellenwert ihrer Vermögensrechte können sie nur beurteilen, wenn sie über die wirtschaftliche Lage der Gesellschaft informiert sind.

Jedem Aktionär steht gemäß $\S \S 131,132$ AktG ein Auskunftsrecht in der Hauptversammlung zu. Auf Verlangen hat der Vorstand die Aktionäre mit Informationen zur Geschäftspolitik des Unternehmens und seiner Tochterunternehmen zu versorgen, die sie zur sachgemäßen Ausübung ihres Stimmrechts benötigen. Das Auskunftsrecht soll dem Aktionär zudem eine Entscheidungsgrundlage dafür bieten, ob eine Anfechtungsklage gegen einen Hauptversammlungsbeschluss erhoben werden soll. Nur in den engen Grenzen des $\S 131$ Abs. 3 AktG kann der Vorstand die Auskunft verweigern, beispielsweise wenn sie zu einem nicht unerheblichen Nachteil für die Aktiengesellschaft oder einem verbundenen Unternehmen führen könnte (§ 131 Abs. 3 Nr. 1 AktG) ${ }^{224}$. Weiterhin braucht der Vorstand, wenn er zusammen mit dem Aufsichtsrat den Jahresabschluss feststellt, keine Angaben über die Höhe der stillen Reserven zu machen $(\S 131 \text { Abs. } 3 \text { Nr. } 3 \text { AktG) })^{225}$. Dahingegen kann der Vorstand die Auskunft nicht mit der Begründung verweigern, der Aktionär verfolge eigennützige Interessen, z.B. die Erhöhung der Dividende ${ }^{226}$. Die Verweigerung der Auskunft stellt in der Praxis den häufigsten Grund für Anfechtungsklagen gegen Hauptversammlungsbeschlüsse dar ${ }^{227}$.

Über das bloße Auskunftsrecht als Individualrecht in der Hauptversammlung hinaus stehen den Aktionären weitere Informationen zu. Im Rahmen der so genannten Unternehmenspublizität stellen Aktiengesellschaften - teils freiwillig, teils aufgrund gesetzlicher Verpflichtungen - Unternehmensinformationen bereit. Dazu gehören insbesondere Rechnungslegungsdaten, aber auch vielfältige weitere Unternehmensdaten, die z.B. über das Internet zur Verfügung gestellt werden ${ }^{228}$. Als vorrangiges Ziel der gesetzlich erzwungenen Publizität wird die Reduktion der asymmetrischen Informationsverteilung zwischen den besser informierten Managern und den schlechter informierten Unternehmensexternen (Aktionäre, Gläubiger, Lieferan-

222 Danach kann die Gesellschaft bei Anfechtungsklagen gegen weitreichende Hauptversammlungsbeschlüsse in einem Eilverfahren die „Freigabe“ des Beschlusses, d.h. die Eintragung ins Handelsregister, beantragen. Bekommt der Anfechtungskläger später Recht, erhălt er Schadensersatz. Vgl. dazu auch Seibert/Schütz (2004), S. 256-258.

223 Vgl. Kübler (1999b), S. 198; Raiser (2001), S. 240; K. Schmidt (2002), S. 842; Hueck/Windbichler (2003), S. 337; Hüffer (2006), § 131, Tz. 1. Zur diesbezüglichen Motivation des Gesetzgebers vgl. Kropff (1965), S. 184 .

224 Vgl. zu den Verweigerungsgründen ausführlich Obermüller/Werner/Winden (2001), S. 253-261; Hüffer (2006), § 131, Tz. 24-32. Wird die begehrte Auskunft verweigert, kann der Aktionär ein Auskunftserzwingungsverfahren nach $\S 132$ AktG einleiten.

225 Vgl. dazu kritisch Siegel/Bareis/Rückle/Schneider/Sigloch/Streim/Wagner (1999).

226 Vgl. Kübler (1999b), S. 198.

227 Vgl. Wiedemann/Frey (2002), S. 416.

228 Vgl. Fülbier (1998b), S. 22-23; Merkt (2001b), S. 22-26; Pellens (2001b), Sp. 1742; Pellens/Crasselt (2004), Sp. 1461-1466; Pellens/Fülbier/Gassen (2006), S. 840-845. 
ten, Kunden etc.) angesehen ${ }^{229}$. Aktionäre sollen auf der Basis von aktuellen Unternehmensinformationen ihre Chance/Risiko-Position besser abschätzen können. Da die Informationsmöglichkeiten nicht auf die aktuellen Aktionäre beschränkt sind, sondern auch den potentiellen Aktionären offen stehen, wird von einem Kollektivgut ${ }^{230}$ gesprochen, das Teil des Anlegerschutzes $^{231}$ ist. Auch Gläubiger profitieren von der Unternehmenspublizität, weil sie mit den umfangreichen Informationen das Ausfallrisiko ihres Engagements besser abschätzen kön$\operatorname{nen}^{232}$.

Wie bereits ausgeführt, sind Publizitätsvorschriften in Deutschland traditionell im Gesellschaftsrecht angesiedelt. Hinsichtlich des Umfangs der Publizität knüpfen gesellschaftsrechtliche Regelungen primär an die Rechtsform, Größe und Branchenzugehörigkeit an. Hinsichtlich Börsennotierung bzw. Kapitalmarktorientierung wird im Gesellschaftsrecht nur vereinzelt differenziert. Sämtliche Anteilseigner der Aktiengesellschaft haben gemäß $\S 175$ Abs. 2, 176 Abs. 1 AktG ein Recht auf Vorlage bzw. Abschrift von Jahresabschluss und Lagebericht (bzw. Konzernabschluss und Konzernlagebericht bei bestehender Konzernrechnungslegungspflicht gemäß $\S \S 290-293$ HGB $)^{233}$, Bericht des Aufsichtsrats und Vorschlag des Vorstands für die Verwendung des Bilanzgewinns. Eine jährliche Publizitätspflicht für diese Unterlagen besteht nach $\S 325$ HGB, wobei die $\S \S 326-327$ HGB größenabhängige Erleichterungen gewähren. Die Dokumente sind zum zuständigen Handelsregister einzureichen und im Bundesanzeiger bekannt zu machen, bei großen Aktiengesellschaften ist die Reihenfolge gemäß $\S 325$ Abs. 2 HGB umgekehrt. Dafür haben die gesetzlichen Vertreter zwölf Monate Zeit.

Zusätzlich zu den regelmäßigen Publizitätspflichten haben Aktiengesellschaften fallweise rechtlich bedeutende Tatsachen bekannt zu machen, wie z.B. Kapitalmaßnahmen ( $\$ \S 184$, 195, 201, 210, 223, 227, 239 AktG), Unternehmensverträge ( $\S 294,298$ AktG), Eingliederungen ( $\S 319$ Abs. 4, 327 Abs. 3 AktG), Ausschluss von Minderheitsaktionären ( $\$ 327 \mathrm{e}$ AktG), Auflösung ( $\S \S 263,398 \mathrm{AktG})$ und Insolvenzantrag ( $\$ 32 \mathrm{HGB}$ ).

Börsennotierte Unternehmen haben gemäß $\S 285$ Nr. 11 HGB erweiterte Anhangangaben zu machen und müssen gemäß $\S 161$ AktG eine Entsprechungserklärung zum Deutschen Corporate Governance Kodex abgeben. Börsennotierte Mutterunternehmen müssen schon seit längerem ihren Konzernabschluss um eine Kapitalflussrechnung, eine Segmentberichterstattung $^{234}$ und einen Eigenkapitalspiegel erweitern ${ }^{235}$. Für kapitalmarktorientierte Aktiengesell-

\footnotetext{
229 Vgl. Pellens/Fülbier/Gassen (2006), S. 841.

230 Vgl. Groß (1997), S. 100.

231 Vgl. Ewert (1998), S. 45. Vgl. zur historischen Entwicklung des Anlegerschutzes in Deutschland ausfuhrlich Pellens (1994), S. 18-46.

232 Vgl. insbesondere Kübler (1995b), S. 558-563.

233 Erhöhte Anforderungen an den Lagebericht bzw. den Konzernlagebericht stellen die Fair-Value- und die Modernisierungsrichtlinie, die in Deutschland durch das BilReG in $\S \S 289,315$ HGB umgesetzt worden sind. Vgl. zu den Änderungen ausführlich Kajüter (2004a); Kajüter (2004b); K. Lange (2004); Kaiser (2005). Zu den aus der Übernahmerichtlinie resultierenden zusătzlichen Angaben im Lagebericht vgl. Lanfermann/Maul (2004), S. 1518-1520.

234 Zur Praxis der Segmentberichterstattung von nach IFRS bilanzierenden Konzernen des Prime Standard vgl. Langguth/Engelmann (2005).

235 Seit dem BilReG sind die Kapitalflussrechnung und der Eigenkapitalspiegel Bestandteile des Konzernabschlusses aller Mutterunternehmen, der um eine Segmentberichterstattung erweitert werden kann (§ 297 Abs. 1 HGB). Kapitalmarktorientierte Mutterunternehmen sind durch die IAS-VO zur Segmentberichterstattung verpflichtet.
} 
schaften entfallen sämtliche größenabhängige Erleichterungen ( $\S 267$ Abs. 3 S. 2, 293 Abs. 5 HGB).

Während die genannten gesellschaftsrechtlichen Vorschriften primär dem Gläubigerschutzgedanken entspringen und das Korrelat für die Haftungsbeschränkung darstellen ${ }^{236}$, sollen die im Kapitalmarktrecht begründeten Publizitätsregeln für börsennotierte bzw. kapitalmarktorientierte Unternehmen vorrangig dem Anlegerschutz dienen. Wie in Kapitel II.1.2.1 bereits erläutert, hat sich das Kapitalmarktrecht auf der Ebene der EU und in Deutschland in den letzten Jahren erheblich weiterentwickelt.

Unternehmen werden als kapitalmarktorientiert bezeichnet, wenn ihre Eigen- und/oder Fremdkapitaltitel an einem organisierten Kapitalmarkt i.S.d. § 2 Abs. 5 WpHG zugelassen sind bzw. eine Zulassung hierzu beantragt is $\mathrm{t}^{237}$. Börsennotierte Gesellschaften stellen eine Teilmenge der kapitalmarktorientierten Unternehmen dar. Es handelt sich gemäß $\S 3$ Abs. 2 AktG um Gesellschaften, deren Aktien an einem Markt zugelassen sind, der von staatlich anerkannten Stellen geregelt und überwacht wird, regelmäßig stattfindet und für das Publikum zugänglich ist. Als solche Märkte gelten in Deutschland der amtliche Markt ( $\S 30 \mathrm{ff}$. BörsG) und der geregelte Markt ( $\S 49$ ff. BörsG), nicht jedoch der Freiverkehr ( $\$ 57$ BörsG) und andere außerbörsliche Handelsplätze.

Für kapitalmarktorientierte Gesellschaften bestehen umfangreichere regel- und unregelmäßige Publizitätsvorschriften ${ }^{238}$. Somit verfügen Aktionäre solcher Unternehmen über erweiterte Informationsrechte. Alle kapitalmarktorientierten Mutterunternehmen, für die bis zum 31.12.2004 das Wahlrecht gemäß $\S 292 \mathrm{a}$ HGB bestand, anstelle eines HGB-Konzernabschlusses einen Abschluss nach IFRS oder US-GAAP zu erstellen, müssen seit dem Jahre 2005 aufgrund der IAS-VO grundsätzlich ihren Konzernabschluss nach IFRS aufstellen.

Im Gegensatz zum Jahresabschluss ist die Zwischenberichterstattung in Deutschland ausschließlich kapitalmarktrechtlich reguliert ${ }^{239}$. § 44b BörsG i.V.m. $§ \S 53-62$ BörsZulV verpflichtet börsennotierte Aktiengesellschaften zur Veröffentlichung eines Halbjahresberichtes auf Basis des Einzel- oder Konzernabschlusses innerhalb einer Frist von zwei Monaten. Während dieser Halbjahresbericht ausreichend ist für Unternehmen, die zum Börsensegment des General Standard zugelassen sind, haben Unternehmen im Börsensegment des Prime Standard $^{240}$ eine Quartalsberichterstattung zu befolgen ( $\$ 63$ der Börsenordnung (BO) der Frankfurter Wertpapierbörse). Nach $\S 63$ Abs. 4 Nr. 1 BO ist auch über im Quartal gezahlte oder vorgeschlagene Dividendenzahlungen zu berichten.

gl. dazu ausführlich Kapitel V.5.1 und V.5.2.

Es handelt sich dabei um die Umsetzung von Art. 1 Nr. 13 WpDRiLi (Richtlinie 93/22/EWG des Rates vom 10.05.1993 über Wertpapierdienstleistungen, ABl. EG 1993 L 141/27), wobei der deutsche Gesetzgeber zur Vermeidung von Missverständnissen von der Übernahme des dort verwendeten Begriffs ,geregelter Markt" abgesehen hat. Vgl. dazu Beck (2004), § 2, Tz. 45-46. Wie bereits erwähnt, ist die WpDRiLi mittlerweile durch die Richtlinie 2004/39/EG vom 21.04.2004 (ABI. EG L 145/1) ersetzt worden. 
Kapitalmarktrechtlich fundiert ist zudem eine Reihe von unregelmäßigen Publizitätspflichten. Mit der Börsenzulassung muss gemäß $\S \S 30$ Abs. 3, 4 und 32 Abs. 1 Nr. 2 BörsG i.V.m. $\S \S 13-47$ BörsZulV je nach Börsensegment ein Börsenzulassungsprospekt, ein Unternehmensbericht oder ein Verkaufsprospekt veröffentlicht werden. Weiterhin besteht nach $\S 15$ WpHG die Pflicht zur Ad-hoc-Publizität ${ }^{241}$. Hiernach sind alle im Unternehmensbereich eingetretenen, den Anlegern nicht bekannten Tatsachen unverzüglich zu veröffentlichen, die wegen ihrer Auswirkungen auf die Vermögens-, Finanz- und Ertragslage oder den allgemeinen Geschäftsverlauf zu erheblichen Aktienkursänderungen führen bzw. im Fall von Schuldverschreibungen die Zahlungsfähigkeit des Emittenten beeinträchtigen können. Beispielhaft können hier Gewinnwarnungen genannt werden, die bekannt gegeben werden müssen, wenn die Unternehmensleitung der Ansicht ist, die Markterwartungen nicht mehr erfüllen zu können. Gemäß $§ 21-30$ WpHG sind weiterhin Änderungen der Anteilseignerstruktur unverzüglich zu veröffentlichen, wodurch die Aktionäre über die Eigentümer- und Stimmrechtstruktur ihrer Aktiengesellschaft und daraus resultierend über mögliche Interessenkonflikte informiert wer$\operatorname{den}^{242}$.

Nach der EU-Transparenzrichtlinie ${ }^{243}$ sollen zukünftig alle Kapitalmarktunternehmen den IFRS-Konzernabschluss oder, soweit ein Unternehmen über keine Tochterunternehmen verfügt, den nach nationalen Vorschriften aufgestellten Einzelabschluss als einen Bestandteil eines Jahresfinanzberichts veröffentlichen. Dieser beinhaltet darüber hinaus den Lagebericht und eine Erklärung der verantwortlichen Personen zur Richtigkeit und Vollständigkeit der Unterlagen. Zudem sieht die Richtlinie vor, dass kapitalmarktorientierte Unternehmen einen Halbjahresfinanzbericht publizieren, der einen konsolidierten Zwischenbericht nach IAS 34, eine Aktualisierung des Lageberichts und eine Erklärung zur Richtigkeit und Vollständigkeit der Unterlagen enthält. Börsennotierte Unternehmen sollen zusätzlich zur Veröffentlichung bestimmter Quartalsangaben verpflichtet werden ${ }^{244}$.

Als Fazit kann festgehalten werden, dass den Aktionären umfangreiche Informationsrechte zustehen. Dabei sind die kapitalmarktrechtlichen Publizitätspflichten im Vergleich zu den gesellschaftsrechtlichen umfangreicher und zeitnäher. Bei den kapitalmarktorientierten Unternehmen sind die Veröffentlichungspflichten mittlerweile sogar mit denen in den USA vergleichbar $^{245}$. Von der Informationsversorgung profitieren nicht nur die Aktionäre, sondern alle

241 Vgl. für einen komprimierten Überblick über die Ad-hoc-Publizität Fülbier (1998a); Fülbier (1999); Hirth/Neus (2001); Pellens/Fülbier/Gassen (2006), S. 877-879. Vgl. zu einer ökonomischen Analyse der Ad-hoc-Publizität ausfuhrlich Fülbier (1998b). Zur Kurserheblichkeit von Ad-hoc-Mitteilungen nach § 15 WpHG vgl. z.B. Nowak (2001). Vgl. zu den seit Oktober 2004 verschärften Ad-hoc-Pflichten durch das AnSVG z.B. S. Schneider (2005). Zur diesbezulglichen Verunsicherung in der Praxis vgl. auch o.V. (2005b); Simon/Leuering (2005).

242 Vgl. zu den Mitteilungs- und Veröffentlichungspflichten hinsichtlich der Aktionärsstruktur nach deutschem Recht sowie zum Publizitătsverhalten der DAX-100-Unternehmen ausführlich F. Ruhwedel (2003), S. 50-58.

243 Vgl. Buchheim (2003); Möllers (2003), S. 395-396; Buchheim/Burger/Ulbrich (2004).

244 Unternehmen, deren Wertpapiere an der Frankfurter Börse zum Börsensegment des Prime Standards zugelassen sind, haben schon seit Anfang 2003 Publizitătspflichten der öffentlich-rechtlichen Börsenordnung zu beachten, die der EU-Transparenzrichtlinie weitgehend entsprechen, zum Teil sogar über die Anforderungen der Richtlinie hinausgehen. Vgl. Pellens/Crasselt (2004), Sp. 1465.

Vgl. Pellens/Fülbier/Gassen (2006), S. 869. 
Unternehmensbeteiligten. Insbesondere aktuelle und potentielle Gläubiger können sich durch die Auswertung der Informationen möglicherweise wirksam schützen ${ }^{246}$.

\subsection{Vermögensrechte}

Durch seine Mitgliedschaft in der Aktiengesellschaft erwirbt der Aktionär eine Reihe vermögensbezogener Rechte. Dabei stellt das Dividendenrecht „das wichtigste mitgliedschaftliche Vermögensrecht des Aktionärs ${ }^{\text {‘247 }}$ dar. Im Allgemeinen besteht die Dividende in einer Geldzahlung. Seit dem TransPuG 2002 kann die Hauptversammlung gemäß $\S 58$ Abs. 5 AktG aber auch eine Sachausschüttung beschließen, wenn die Satzung eine entsprechende Ermächtigung vorsieht. Der Gesetzgeber lässt damit in Anlehnung an zahlreiche ausländische Rechtsordnungen und in Einklang mit der Kapitalrichtlinie die Sachdividende als Alternative zur Barausschüttung explizit $\mathrm{zu}^{248}$. Auch wenn die Bedeutung der Sachdividende in Deutschland zunimmt ${ }^{249}$, wird sie im weiteren Verlauf dieser Arbeit nicht mehr gesondert betrachtet, da die Sachausschüttungshöhe grundsätzlich denselben Gewinnermittlungs- und Gewinnverwendungsregeln wie die Barausschüttung unterliegt ${ }^{250}$.

Dividendenzahlungen oder sonstige Leistungen, die gegen die aktienrechtlichen Vorschriften verstoßen haben, sind von den Aktionären grundsätzlich gemäß $\S 62$ Abs. 1 AktG der Gesellschaft zurück zu gewähren. Rückerstattungsansprüche der Gesellschaft bestehen z.B. bei einem Verstoß gegen die Gewinnverteilungsregel des $\S 60 \mathrm{AktG}$ oder bei fehlendem Gewinnverwendungsbeschluss gemäß $\S 174 \mathrm{AktG}^{251}$. Gläubiger können gemäß $\S 62$ Abs. $2 \mathrm{~S} .1$ AktG den Anspruch der Gesellschaft geltend machen, soweit sie von ihr keine Befriedigung

246 Darauf wird in Kapitel V.5.4.1 ausführlich eingegangen.

247 Lutter (1988b), § 58, Tz. 79.

248 Nach Ansicht des Gesetzgebers kann eine Sachausschüttung in Form von börsengehandelten Werten eine mehrheitliche und sogar ausschließliche Sachdividende rechtfertigen. Nicht börsengehandelte Werte hingegen können nur dann die herkömmliche Bardividende ersetzen, wenn alle Aktionäre zustimmen. Vgl. BMJ (2002), S. 26-27.

249 Viele Satzungen sehen mittlerweile diese Möglichkeit vor. Vgl. z.B. die Nachweise bei Schnorbus (2003), S. 509, Fn. 7. In der Praxis dominiert die Ausgabe von Aktien, z.B. von Tochtergesellschaften oder Beteiligungsbesitz. Es finden sich aber auch Unternehmen, die Produkte der Gesellschaft ausschütten. So bietet die Königsegger WalderBräu AG ihren Aktionären fünf Kästen Bier pro Aktie an. Vgl. Königsegger WalderBräu AG (2003). Die Vorzugsaktionäre der Mosel Weinberg AG erhalten alle zwei Jahre als "flüssige“ Dividende 0,75 Liter Qualitätswein der Anbaugebiete, in denen die Gesellschaft Weinbergbesitz hat. Vgl. Mosel Weinberg AG (2003).

$250 \mathrm{Vgl}$. zu den verschiedenen Aspekten der Sachdividende, insbesondere den Problemen bei der handels- und steuerrechtlichen Bewertung Hasselbach/Wicke (2001); Lutter/Leinekugel/Rödder (2002); W. Müller (2002), S. 757-759; Schüppen (2002), S. 1276-1277; Holzborn/Bunnemann (2003); Menner/Broer (2003), S. 1077-1079; Prinz/Schürner (2003); Schnorbus (2003); Strunk (2003); Waclawik (2003); Orth (2004).

Vgl. Hüffer (2006), § 62, Tz. 7-8. 
erlangen können ${ }^{252}$. Von einer Rückzahlungspflicht ausgenommen sind aber Aktionäre, die Dividenden in gutem Glauben empfangen haben $(\S 62 \mathrm{Abs} .1 \mathrm{~S} .2 \mathrm{AktG})^{253}$.

Das Dividendenrecht ist in Deutschland geprägt vom Zusammenspiel von den aktienrechtlichen Kapitalaufbringungs- und Kapitalerhaltungsregeln einerseits und den handelsrechtlichen Gewinnermittlungsbestimmungen andererseits. Darüber hinaus ist es beeinflusst von der aktienrechtlichen Kompetenzverteilung zwischen der Verwaltung und der Hauptversammlung. Diese Zusammenhänge sowie Besonderheiten im Konzernverbund werden in Kapitel III.1.2 ausführlich beleuchtet.

Das Recht auf einen Anteil am Liquidationserlös ( $\$ 271$ Abs. 1 AktG) sichert dem Aktionär im Falle der Auflösung der Gesellschaft die Auszahlung des Restvermögens nach Befriedigung der anderen Kapitalgeber entsprechend seiner Anteilsquote. Im Rahmen der Zwangsliquidation ist dieser Zahlungsanspruch allerdings in der Regel wertlos ${ }^{254}$. Zu Auszahlungen von Teilen des Gesellschaftskapitals an die Aktionäre kommt es ebenfalls, wenn die Hauptversammlung mit Dreiviertelmehrheit eine ordentliche Kapitalherabsetzung gemäß $\S \S 222-228 \mathrm{AktG}$ beschlossen hat und die Gläubigerschutzmaßnahmen des $\S 225 \mathrm{AktG}$ beachtet worden sind.

Bei Kapitalerhöhungen gegen Einlagen ( $\S 182-191$ AktG) soll das Bezugsrecht gemäß $§ 186$ Abs. 2 AktG sicherstellen, dass die Beteiligungs- und Stimmrechtsquote der Altaktionäre nicht verwässert wird. Indem die jungen Aktien den Altaktionären zur Zeichnung angeboten werden, können diese durch Ausübung des Bezugsrechts ihre bisherige Quote am Grundkapital aufrechterhalten. Weiterhin stellt das Bezugsrecht einen Ausgleich für die Vermögensverwässerung dar, die sich regelmäßig dadurch ergibt, dass die neuen Aktien unter dem Kurs der alten Aktien emittiert werden und sich nach Durchführung der Kapitalerhöhung ein niedrigerer Mischkurs einstellt ${ }^{255}$. Im Rahmen einer genehmigten Kapitalerhöhung ( $\$ \S 202-206$ $\mathrm{AktG}$ ) kann die Satzung den Vorstand für maximal fünf Jahre dazu ermächtigen, das Grundkapital um höchstens $50 \%$ zu erhöhen. In diesen Fällen gelten gemäß $§ 203$ Abs. 1 AktG grundsätzlich dieselben Vorschriften hinsichtlich des Bezugsrechts wie bei der Kapitalerhöhung gegen Einlagen ( $\S 185-191$ AktG). Ist eine bedingte Kapitalerhöhung ( $\S \S 192-201)$ beschlossen worden, besteht das Bezugsrecht gemäß $\S 221$ Abs. 4 AktG ebenfalls analog $\S 186 \mathrm{AktG}$ für Inhaber von Wandelschuldverschreibungen ${ }^{256}$. Bei der Kapitalerhöhung aus Gesellschaftsmitteln ( $\S 207-220$ AktG) erfolgt lediglich ein Passivtausch innerhalb des Ei-

252 Im Insolvenzverfahren übt der Insolvenzverwalter oder Sachwalter das Recht der Gläubiger aus (§62 Abs. 2 S. 2 AktG).

253 Seit der Angleichung des AktG an die Kapitalrichtlinie liegt Bösgläubigkeit bereits bei einfacher Fahrlässigkeit vor, wobei die Gesellschaft für das Vorliegen der Kenntnis oder der fahrlässigen Unkenntnis die Beweislast trägt. Vgl. Nienhaus (2002), S. 5-6. An die Gutgläubigkeit werden in Abhängigkeit von den Lebens- und Berufskreisen unterschiedliche Anforderungen an die Aktionäre gestellt. Vgl. Hüffer (2006), $\S 62, \mathrm{Tz} .11$.

254 Vgl. Süchting (1995), S. 84. Strobl (1996), S. 408, weist darauf hin, dass in Deutschland die durchschnittliche Quote der nicht bevorrechtigten Forderungen in der Insolvenz bei lediglich $3 \%$ bis $4 \%$ liegt. Vgl. ebenso Merkt (2006b), S. 97.

255 Vgl. Süchting (1995), S. 89, 92; Perridon/Steiner (2004), S. 379.

256 Dahingegen ist das Bezugsrecht der Altaktionäre ausgeschlossen, wenn eine bedingte Kapitalerhöhung gemäß $\S 192$ Abs. 2 Nr. 3 AktG vorgenommen wird, um Arbeitnehmern und Vorstandsmitgliedern Aktienoptionen (Stock Options) zu gewähren. Verwässerungseffekte halten sich aber in Grenzen, da das bedingte Kapital in diesem Fall $10 \%$ des Grundkapitals nicht übersteigen darf und die Eckpunkte des Aktienoptionsplans von der Hauptversammlung mit Dreiviertelmehrheit beschlossen werden müssen. 
genkapitals, indem die Kapital- und Gewinnrücklagen zugunsten des Grundkapitals vermindert werden. Durch die Ausgabe von Zusatzaktien gemäß $\S 212$ AktG bleibt die Beteiligungsquote der Aktionäre unverändert.

Das Bezugsrecht kann gemäß § 186 Abs. 3-4 AktG ganz oder teilweise eingeschränkt werden. Dazu müssen aber eine Reihe von Voraussetzungen beachtet werden, die einerseits formeller Natur und im Gesetz geregelt und andererseits materieller Gestalt und von Rechtsprechung und Schrifttum entwickelt worden sind ${ }^{257}$. Mit dem „Gesetz für kleine Aktiengesellschaften und zur Deregulierung des Aktienrechts" von 1994 wurde für börsennotierte Aktiengesellschaften in $\S 186$ Abs. 3 S. 4 AktG eine Sonderregelung geschaffen ${ }^{258}$. Danach wird der Ausschluss des Bezugsrechts als verhältnismäßig erachtet, wenn die Kapitalerhöhung durch Bareinlagen $10 \%$ des Grundkapitals nicht überschreitet und der Ausgabepreis den Börsenkurs nicht wesentlich unterschreitet. Der erleichterte Bezugsrechtsausschluss soll bei den Gesellschaften zu niedrigeren Kapitalkosten infolge von geringerem Verwaltungsaufwand und höheren, kurzfristig erzielbaren Erlösen führen. Dadurch sollen Wettbewerbs- und Standortnachteile deutscher Gesellschaften im internationalen Vergleich vermieden werden, ohne die Vermögensrechte der Altaktionäre zu sehr zu beeinträchtigen ${ }^{259}$.

Eine Alternative zu Dividendenzahlungen können Aktienrückkäufe darstellen ${ }^{260}$. Für den Erwerb eigener Aktien hat der Gesetzgeber mit dem KonTraG in $\S 71$ Abs. 1 Nr. 8 AktG erweiterte Möglichkeiten geschaffen ${ }^{261}$. Voraussetzung für den Rückkauf ist ein mit einfacher Stimmenmehrheit ( $\$ 133$ Abs. 1 AktG) vorliegender Ermächtigungsbeschluss der Hauptversammlung. Dieser kann innerhalb von 18 Monaten vom Vorstand ausgeübt werden, um ma-

257 Vgl. dazu ausfuhrlich Lutter (1989), § 186, Tz. 50-88; Wellkamp (1998), S. 142-145; Hüffer (2006), § 186, Tz. 20-43.

258 Vgl. zur Neuregulierung der $\S \S 192-193$ AktG durch das KonTraG C. Ernst/Seibert/Stuckert (1998), S. 78-82; Seibert (1998), S. 40-48; Pellens/Bonse (1999), S. 861-862; Hüffer (2006), §192, Tz. 15-22, $\S 193$, Tz. 7-10.

259 Vgl. Nippel/Schweizer (1996), S. 531; Seibert/Köster/Kiem (1996), S. 108-110. Das Bezugsrecht im Allgemeinen und die Neuregelung im Jahre 1994 für börsennotierte Unternehmen im Besonderen werden im rechts- und wirtschaftswissenschaftlichen Schrifttum unterschiedlich beurteilt. Vgl. zu einem Überblick uber die Literaturmeinungen und zu den Schwierigkeiten einer ökonomischen Beurteilung des Bezugsrechtsausschlusses gemäß § 186 Abs. 3 S. 4 AktG Pellens/Bonse (1999), S. 854-857. Der Richtlinienvorschlag zur Änderung der Kapitalrichtlinie vom 21.09.2004 sieht auf europäischer Ebene Erleichterungen des Bezugsrechtsauschlusses für börsennotierte Gesellschaften vor. Vgl. dazu Kapitel IV.5.

260 Empirische Untersuchungen in Deutschland năhren bislang allerdings Zweifel daran, dass Dividenden in Deutschland ähnlich häufig wie in den USA durch Aktienrückkäufe substituiert werden. Einer Ende 1998 bis Anfang 1999 durchgefuhrten Befragungsstudie von Aktiengesellschaften, deren Hauptversammlungen im Jahre 1998 einen Ermächtigungsbeschluss nach § 71 Abs. 1 Nr. 8 AktG erteilten, zufolge stellt dieses Instrumentarium keine echte Alternative zu Dividendenzahlungen dar. Vgl. Pellens/Schremper (2000), S. 142, 153. Auch die Vorstände der DAX-100-, NEMAX-50- und SDAX-Gesellschaften, die im Frühjahr 2002 zur Ausschüttungspolitik befragt wurden, messen dem Aktienrückkauf nur eine untergeordnete Bedeutung bei und planen, auch in der Zukunft Aktienrückkăufe nur vergleichsweise selten durchzuführen. Manche Unternehmensvertreter sprechen dem Ruckkauf gänzlich die Qualität eines Ausschüttungsinstruments ab. Vgl. dazu Pellens/Gassen/Richard (2003), S. 317. Zu einer Übersicht angezeigter Ermächtigungsbeschlusse vgl. BaFin (2006).

261 Vgl. dazu im Einzelnen Pellens/Schremper (2000), S. 134-135, 137-140; Schremper (2002), S. 16-52; Hüffer (2006), § 71, Tz. 19c-19p. Die geplante Änderungsrichtlinie sieht die Abschaffung der 10\%-Regel und eine Verlängerung des Zeitraums vor. Vgl. dazu ebenfalls Kapitel IV.5. 
ximal $10 \%$ des Grundkapitals zurückzukaufen ${ }^{262}$. Das Management hat damit die Möglichkeit, in den gesetzlichen Grenzen Kurspflege zu betreiben, indem die Nachfrage nach eigenen Aktien erhöht und der Aktienkurs daraus resultierend gesteigert wird ${ }^{263}$. Soll bei einer späteren Veräußerung der eigenen Aktien das Bezugsrecht der Aktionäre ausgeschlossen werden, bedarf es einer Dreiviertelmehrheit der Hauptversammlung entsprechend $\S 186$ Abs. 3 AktG.

Bei Strukturänderungen (z.B. Verschmelzung, Spaltung, Formwechsel) und in verschiedenen konzernrechtlichen Konstellationen (Abschluss von Beherrschungs- und Gewinnabführungsverträgen, Eingliederung, Squeeze-out) haben die Aktionäre weiterhin zahlreiche Ausgleichs-, Umtausch- und Abfindungsansprüche ${ }^{264}$. Es ist festzustellen, dass die konzernspezifischen Vorschriften der $\S \S 291-328$ AktG den Schutz der Vermögensrechte der Aktionäre in den Vordergrund stellen, während der Schutz der Herrschaftsrechte weniger stark ausgeprägt ist $^{265}$.

\subsection{Zwischenergebnis}

Als Ergebnis der Ausführungen kann festgehalten werden, dass in Deutschland die Struktur der Aktiengesellschaft durch zwingende Regelungen im Aktiengesetz vorgegeben ist. Die Aktiengesellschaft hat mit dem Vorstand, dem Aufsichtsrat und der Hauptversammlung drei Organe, deren aktienrechtlich kodifizierten Kompetenzen eine Machtbalance untereinander sicherstellen sollen. Dem Vorstand obliegt die eigenverantwortliche und weisungsungebunde Geschäftsführung und Vertretung der Gesellschaft. Der Aufsichtsrat bestellt die Vorstandsmitglieder und überwacht die Geschäftsführung. Dazu stehen ihm verschiedene Einsichtsund Prüfungsrechte zu. Außerdem dürfen bestimmte Geschäftsführungsmaßnahmen nur mit der Zustimmung des Aufsichtsrats durchgeführt werden. Eine nicht unumstrittene Besonderheit des deutschen Aufsichtsrats besteht in der Mitbestimmung durch Arbeitnehmer- und Gewerkschaftsvertreter bei Aktiengesellschaften bestimmter Größe.

Der Hauptversammlung als Versammlung aller Aktionäre sind Fragen der Geschäftsführung grundsätzlich entzogen. Ihr stehen aber grundlegende Entscheidungen zu, so z.B. die Wahl und Abberufung der Aktionärsvertreter im Aufsichtsrat, die Entlastung der Mitglieder der Verwaltung, Satzungsänderungen und Maßnahmen der Kapitalbeschaffung. Die Machtverteilung zwischen den Organen kann in der Unternehmenspraxis allerdings vom aktienrechtlichen Ideal der Machtbalance abweichen. Dies zeigt sich z.B. dann, wenn eine vom Großaktionär dominierte Hauptversammlung dem Vorstand das Misstrauen ausspricht und der Aufsichtsrat daraufhin den Vorstand abberuft.

262 Mit § 71b AktG wird sichergestellt, dass der Gesellschaft aus den eigenen Aktien keine Mitgliedschaftsrechte zustehen. $\S 71$ Abs. 2 S. 2 bestimmt aus Gläubigerschutzgesichtspunkten, dass nur solche Mittel für den Erwerbsvorgang genutzt werden, die auch in Form von Dividenden an die Aktionäre ausgezahlt werden könnten.

263 Zur Kapitalmarktrelevanz von Aktienrückkäufen deutscher Unternehmen vgl. Schremper (2003).

264 Vgl. Raiser (2001), S. 100; Hirte (2003), S. 182. Vgl. zu den jeweiligen Schutzmaßnahmen der Vermogensposition der Aktionäre ausfuhrlich Mülbert (1996), S. 193-200, 259-303, 338-359, 406-513.

265 Vgl. Mülbert (1996), S. 99. Vgl. zu demselben Ergebnis bezogen auf das AktG 1937 Mestmäcker (1958), S. 346. Bereits v. Gierke (1887), S. 240, weist - bezogen auf das Aktienrecht des HGB 1884 - darauf hin, dass das Mitgliedschaftsrecht im engeren Sinne „,nur die Rolle eines unselbständigen Annexes spielt.“ 
Den Aktionären stehen nach dem Aktiengesetz zahlreiche Herrschafts-, Informations- und Vermögensrechte zu. Folglich ist auch das Dividendenrecht im Aktienrecht dezidiert geregelt. Die Aktionäre beschließen demnach auf der Hauptversammlung über die Verwendung des Bilanzgewinns. Dabei sind sie allerdings an den vom Vorstand aufgestellten, von Abschlussprüfer und Aufsichtsrat geprüften und im Regelfall von Vorstand und Aufsichtsrat festgestellten Jahresabschluss gebunden. Zur Beurteilung der Angemessenheit des Gewinnverwendungsvorschlags können die Aktionäre umfangreiche Informationen nutzen, die ihnen durch die gesetzlichen Publizitätspflichten der Aktiengesellschaft zur Verfügung stehen. Davon profitieren gleichzeitig andere Unternehmensbeteiligte, z.B. Gläubiger. Schließlich können die Aktionäre unter bestimmten Voraussetzungen die Verwendung des Bilanzgewinns anfechten bzw. eine Klage auf Feststellung der Nichtigkeit des festgestellten Jahresabschlusses erheben.

Als Ergebnis der bisherigen Ausführungen bleibt weiterhin festzuhalten, dass die Ausgestaltung des in- und externen Corporate-Governance-Systems der Aktiengesellschaft in zunehmender Weise durch das Kapitalmarktrecht, den europäischen Gesetzgeber und die Rechtsprechung des EuGH beeinflusst wird. Auch das Tempo der Reformmaßnahmen im Gesellschafts- und Kapitalmarktrecht hat in den letzten Jahren stark zugenommen ${ }^{266}$. Durch den Aktionsplan der EU-Kommission vom 21.05.2003 und zusätzliche Initiativen des deutschen Gesetzgebers wird das Reformtempo in den nächsten Jahren wohl auch beibehalten. Aktiengesellschaften müssen sich daher auf weitere erhebliche Änderungen und Mehraufwand einstellen.

Im folgenden Kapitel II.2 werden die rechtlichen Grundlagen der US-amerikanischen corporation dargestellt. Im Vergleich zum deutschen Recht, das den Aufbau und die Struktur der Aktiengesellschaft einheitlich im Aktiengesetz regelt, fällt das Gesellschaftsrecht in den USA in die Gesetzgebungskompetenz der Einzelstaaten mit der Folge, dass das Recht der corporation von Staat zu Staat teilweise beachtliche Unterschiede aufweist. Die Ausführungen werden sich daher zunächst auf die Grundzüge, wie sie in den meisten Staaten der USA vorzufinden sind, beschränkten. Erst in Kapitel III.2 werden wesentliche gesellschaftsrechtliche Aspekte, die im Zusammenhang mit Dividendenentscheidungen stehen, wie z.B. Sorgfaltspflichten des Managements und Haftungsvorschriften, für ausgewählte Einzelstaatenrechte detailliert analysiert.

\section{Corporation in den USA}

\subsection{Einordnung der Corporation in die Rechtsformen unternehmerischer Tätigkeit}

Zur Ausübung der unternehmerischen Tätigkeit stehen im US-amerikanischen Recht zahlreiche Rechtsformen zur Verfügung ${ }^{267}$. Bevor im Weiteren ausschließlich die corporation analysiert wird, sollen die wesentlichen Merkmale der anderen Organisationsformen kurz skizziert werden.

\footnotetext{
266 Vgl. dazu auch die amúsanten Ausführungen von M. Weber (2004), S. 3674: „Mitterweile ist selbst neuesten Texten ihre Verfallszeit geradezu mit eingebaut, und zuweilen könnten sie zuverlässiger noch angeben, wann sie (alsbald wieder) außer Kraft treten als (wenn davor überhaupt noch) ,in Kraft'.“

Vgl. im Überblick Gevurtz (2000), S. 2-5; Merkt/Göthel (2006), S. 128-151.
} 
Die einfachste Form stellt die sole proprietorship ${ }^{268}$ dar, die keine eigene Rechtspersönlichkeit besitzt, sondern einer einzelnen Person gehört, die unbeschränkt haftet und anfallende Gewinne auch selbst versteuert. Die sole proprietorship ist mit dem Einzelunternehmen in Deutschland vergleichbar, und auch die gesetzlichen Regelungen sind weitgehend deckungsgleich $^{269}$.

Die general partnership und die limited partnership ${ }^{270}$ sind die Hauptformen der USamerikanischen Personengesellschaften. Die general partnership ist ein mit Gewinnerzielungsabsicht gemeinschaftlich geführter Zusammenschluss von zwei oder mehr Personen. Gesellschafter können natürliche oder juristische Personen sein, welche die partnership vertreten und jeweils persönlich und unbeschränkt für Gesellschaftsschulden haften. Besteht keine abweichende gesellschaftsvertragliche Regelung, haben alle Gesellschafter einen Anspruch auf gleiche Gewinnverteilung. Im Vergleich zum deutschen Gesellschaftsrecht weist die general partnership Ähnlichkeiten mit der OHG und der GbR auf.

Bei der limited partnership haften eine oder mehrere Personen unbeschränkt (general partner) und eine oder mehrere Personen beschränkt auf ihre Einlagen (limited partner). Die Geschäftsführung obliegt grundsätzlich den general partners, während die limited partners die Rolle stiller Teilhaber einnehmen. Die Gewinnverteilung ist im Gründungszertifikat (certificate) zu regeln bzw. wird in Abhängigkeit vom jeweiligen Anteil an der Gesellschaft vorgenommen. Die limited partnership ähnelt der deutschen KG bzw. der GmbH \& Co. KG in den Fällen, in denen eine Kapitalgesellschaft Komplementär ist.

Neben diesen Hauptformen der partnership kommen mit der limited liability company (LLC), der limited liability partnership (LLP) und der mining partnership verschiedene Variationen vor $^{271}$. Zudem existieren Mischformen aus Kapital- und Personengesellschaft, wie z.B. der business trust, die professional corporation und die joint stock company ${ }^{272}$.

Die corporation tritt in der Form der public corporation und der close corporation auf ${ }^{273}$. Eine allgemein gültige Definition der close corporation existiert nicht. Sie zeichnet sich typischerweise durch einen kleinen Kreis von Anteilseignern, fehlende Marktgängigkeit der Anteile und wesentliche Beteiligung der (Mehrheits-) Anteilseigner an der Unternehmensleitung aus $^{274}$. Gesetzliche Regelungen stellen häufig auf eine bestimmte geringe Anzahl von Anteilseignern und in der Satzung festgelegte Anteilsübertragungsverbote bzw. -beschränkungen

Vgl. zu den partnerships ausführlich Klein/Coffee (2002), S. 52-105. Eine Besonderheit ist darin zu sehen, dass nahezu alle Bundesstaaten die von der National Conference of Commissioners on Uniform State Laws herausgegebenen Uniform Acts vollständig oder nur mit geringen Abweichungen angenommen haben, so dass bei dieser Rechtsform eine vergleichsweise hohe Rechtsvereinheitlichung besteht. Vgl. Bungert (2003), S. 2.

271 Vgl. Klein/Coffee (2002), S. 101-105. Die LLP ist insbesondere bei großen Rechtsanwaltskanzleien und Wirtschaftsprüfungsgesellschaften als Rechtsform weit verbreitet.

272 Vgl. Hay (2002), S. 234-235; Merkt/Göthel (2006), S. 140-143, 150-151.

273 Ebenfalls gebräuchlich sind die Beichnungen publicly held und closely held corporation.

274 Vgl. zu dieser Beschreibung die einschlägige Gerichtsentscheidung in Donahue v. Rodd Electrotype Co. of New England, Inc., 367 Mass. 578, 328 N.E.2d 505 (Mass.1975). 
$\mathrm{ab}^{275}$. In der close corporation kann somit das Pendant zur deutschen $\mathrm{GmbH}$ gesehen wer$\operatorname{den}^{276}$.

Die public corporation ist eine gewerblich tätige juristische Person, die im eigenen Namen Rechte und Pflichten hat und unter eigenem Namen klagen und verklagt werden kann. Ihre Anteile sind in der Regel weit gestreut und frei übertragbar. Für ihre Verbindlichkeiten haftet grundsätzlich nur das Gesellschaftsvermögen, die Gesellschafter sind haftungsbeschränkt. In bestimmten Ausnahmesituationen kann von diesem Haftungskonzept durch die von der Rechtsprechung entwickelte Durchgriffshaftung (piercing the corporate veil) abgewichen werden $^{277}$. Ein Durchgriff kann z.B. zugelassen werden, wenn das Gesellschaftsvermögen zum Schaden der Gläubiger an die Gesellschafter oder Dritte verteilt oder die juristische Person missbraucht wurde, um eine Täuschung oder ein Delikt zu begehen. Da allerdings mehrere Voraussetzungen erfüllt sein müssen, wird vor dem Fehlschluss gewarnt, „USamerikanische Richter seien besonders schnell mit dem Dolch bei der Hand, um den ,Schleier' zwischen Gesellschaft und Gesellschaftern zu zerschneiden. “' ${ }^{\text {'78 }}$ Darüber hinaus ist festzustellen, dass bisher noch kein Gericht den Haftungsdurchgriff auf die Aktionäre einer public corporation zugelassen hat $^{279}$.

Da die corporation das US-amerikanische Äquivalent zur Aktiengesellschaft darstellt ${ }^{280}$, wird sie im Folgenden ausschließlich behandelt ${ }^{281}$. Tab. 1 vermittelt abschließend einen Eindruck von der zahlenmäßigen und insbesondere wirtschaftlichen Bedeutung der corporation in den $\mathrm{USA}^{282}$.

\begin{tabular}{|l|r|r|r|r|}
\hline Rechtsform & \multicolumn{1}{|c|}{ Anzahl } & \multicolumn{1}{|c|}{$\begin{array}{c}\text { Anteil } \\
\text { (in \%) }\end{array}$} & \multicolumn{1}{c|}{$\begin{array}{c}\text { Umsatz } \\
\text { (in Mrd. US-\$) }\end{array}$} & \multicolumn{1}{|c|}{ Beschäftigte } \\
\hline Corporation & 4.369 .903 & 21,0 & 16.869 & 92.428 .028 \\
\hline Sole proprietorship & 15.122 .882 & 72,6 & 871 & 5.698 .881 \\
\hline Partnership & 1.226 .455 & 5,9 & 621 & 3.917 .924 \\
\hline Sonstige & 102.694 & 0,5 & 190 & 1.314 .982 \\
\hline Summe & $\mathbf{2 0 . 8 2 1 . 9 3 4}$ & $\mathbf{1 0 0 , 0}$ & $\mathbf{1 8 . 5 5 1}$ & $\mathbf{1 0 3 . 3 5 9 . 8 5 1}$ \\
\hline
\end{tabular}

Tab. 1: Aufteilung der Rechtsformen in den USA

Quelle: Pellens (2001a), S. 40.

275 Vgl. Bungert (2003), S. 56. Nach § 342(a)(1) Delaware General Corporation Law darf eine close corporation nicht mehr als 30 , nach $\S 158$ (a) California Corporations Code nicht mehr als 35 Anteilseigner aufweisen. Nach dem bundesstaatlichen Kapitalmarktrecht darf eine close corporation nicht mehr als 500 registrierte Aktionäre und ein Gesellschaftsvermögen von mehr als 10 Mio. US- $\$$ haben $(\S 12(\mathrm{~g})$ SEA i.V.m. SEC Rule 12g-1).

Vgl. Bungert (2003), S. 57; Merkt/Göthel (2006), S. 144

Merkt/Göthel (2006), S. 237.

Vgl. Palmiter (2003), S. 540. Auch die Tatsache, dass die Durchgriffshaftung in Delaware vergleichsweise unterentwickelt ist, wird damit begründet, dass dort börsennotierte Gesellschaften vorherrschen. Vgl. Bainbridge (2002), S. 164. Zu einer Darstellung und Analyse der Durchgriffshaftung in Delaware vgl. auch Fleischer (2005), S. 95-97 m.w.N.

Vgl. Bungert (2003), S. 3, 31.

In Anlehnung an die US-amerikanische Literatur wird diese Gesellschaftsform in dieser Arbeit nur noch als corporation bezeichnet, der Zusatz „public“ wird weggelassen.

Vgl. dazu auch Merkt/Göthel (2006), S. 128 m.w.N. 


\subsection{Rechtliche Ausgestaltung der Corporation}

\subsubsection{Gesellschafts- und Kapitalmarktrecht als Regulierungsgrundlage}

Das US-amerikanische Rechtssystem hat seine historischen Wurzeln im englischen Recht ${ }^{283}$. Es ist maßgeblich geprägt vom common law-System, das von den ersten englischen Siedlern eingeführt wurde. Als common law wird das ursprüngliche Richterrecht der common law courts in England bezeichnet. Für die Fälle, in denen common law-Rechtsbehelfe unzureichend waren, entstand zusätzlich zur Rechtsprechung durch die common law-Gerichte ein System von equity-Rechtsprechung und -Rechtsmitteln ${ }^{284}$. Wenngleich die beiden Normenkomplexe später verschmolzen, existiert in Delaware mit dem bedeutenden Chancery Court noch heute ein equity court ${ }^{285}$.

Seit dem Ende des 19. Jahrhunderts nimmt in den USA die Bedeutung des bundes- und einzelstaatlichen Gesetzesrechts (statutory law) zu. Dennoch ist das US-amerikanische Rechtsystem primär durch Richterrecht geprägt, und selbst Gesetze unterliegen der bindenden Auslegung durch die Rechtsprechung ${ }^{286}$. Rechtssicherheit wird dadurch erreicht, dass die Richter frühere Entscheidungen übergeordneter Gerichte zu identischen oder vergleichbaren Sachverhalten (precedents) $\mathrm{zu}$ berücksichtigen haben ${ }^{287}$. Neues Recht entsteht in der Regel dann, wenn das jeweils höchste Gericht von seinem Präjudiz abweicht oder es aufhebt. Nur in Ausnahmefällen werden untere Gerichtsinstanzen absichtlich von einem bestehenden Präjudiz in der Überzeugung abweichen, dass auch das ranghöhere Gericht es als veraltet betrachtet. In dieses System der richterlichen Rechtsfortbildung kann der Gesetzgeber eingreifen, indem er Gesetze verabschiedet. Die Auslegung der Gesetze erfolgt dann aber erneut durch die Gerichte, und die erlassene Rechtsprechung bindet wiederum die rangniederen Gerichte ${ }^{288}$.

Ein weiteres grundlegendes Charakteristikum des US-amerikanischen Rechts stellt die weitgehende Rechtsetzungskompetenz der Einzelstaaten dar. In der Verfassung der USA (US Constitution) ist geregelt, dass die 50 Bundesstaaten grundsätzlich souverän sind und sämtliche Hoheitsrechte besitzen, sofern die Verfassung die Gesetzgebungskompetenz nicht dem Bund zuschreibt. Nach Art. I $§ 8$ US Constitution fällt z.B. der Wirtschaftsverkehr mit dem Ausland (foreign commerce) und zwischen den Einzelstaaten (interstate commerce) in den

283 Das englische und US-amerikanische Recht bilden eine Rechtsfamilie. Vgl. Rheinstein (1987), S. 88, 92; David/Grasmann (1988), S. 59-62, 508; Zweigert/Kötz (1996), S. 177, 233.

284 Die Ursprünge der equity gehen zurück auf das Billigkeitsrecht der englischen Krone. Wer sich aufgrund der Formstrenge der Klagearten des common law im Stich gelassen fühlte, konnte sich an den Konig als „Quelle aller Gerechtigkeit und Gnade“ wenden (equity leitet sich von lat. „aequitas“ ab). Später wurde diese Funktion vom König delegiert, und es entstanden die so genannten equity courts. Vgl. ausfuhrlich Fulda (1966), S. 31-35; David/Grasmann (1988), S. 448-553; Blumenwitz (2003), S. 14-18.

Vgl. Blumenwitz (2003), S. 33. Common law und equity zusammen werden als case law bezeichnet. Dieses Fall- bzw. Richterrecht wird dem gesetzten Recht (statutory law) gegenüber gestellt. Die synonyme Verwendung von common und case law ist daher ungenau. Vgl. Hay (2002), S. 6. Vgl. dazu auch Rheinstein (1987), S. 89; Zweigert/Kötz (1996), S. 185.

286 Vgl. Hay (2002), S. 6, 8; Blumenwitz (2003), S. 5.

287 Vgl. Pellens (2001a), S. 37.

288 Vgl. zum Ganzen Hay (2002), S. 8-11; Blumenwitz (2003), S. 38-40, 63. 
Hoheitsbereich des Bundes ${ }^{289}$. Vorschläge, nach denen die Gesetzgebungskompetenz für die Inkorporation von Gesellschaften ebenfalls dem Bund zustehen sollte, konnten sich bei den Beratungen zur Verfassung im Jahre 1787 nicht durchsetzen ${ }^{290}$. Das Gesellschaftsrecht ist damit Sache der Einzelstaaten, so dass eine „Einführung in das US-amerikanische business corporation law (...) steng genommen - je nachdem, wie man es sieht - eine Einführung ins Nichts oder eine fünfzigfache Einführung “291 ist.

Nach der Gründungstheorie unterliegen die corporations dem Kapitalgesellschaftsrecht des Gründungsstaates $^{292}$. Die Gründer können sich daher einen Bundesstaat als Inkorporationsstaat aussuchen, dessen Gesellschaftsrecht ihnen am vorteilhaftesten erscheint. Dieses System hat zu einem Wettbewerb der Einzelstaaten um die meisten Gesellschaftsgründungen geführt, den mittlerweile Delaware für sich entschieden hat ${ }^{293}$. Eine möglichst hohe Anzahl von Unternehmensgründungen aufzuweisen, ist für die Bundesstaaten deshalb attraktiv, weil die Gesellschaften eine Gründungsgebühr (incorporation oder filing fees) und eine periodische Konzessionssteuer (franchise tax) ) $^{294}$ an den Gründungsstaat zu zahlen haben ${ }^{295}$. Darüber hinaus ziehen die bedeutendsten Inkorporationsstaaten Rechtsanwaltskanzleien und Rechtsberatungsunternehmen an, wodurch Arbeitsplätze entstehen und Steuereinnahmen erhöht werden können ${ }^{296}$. Vor diesem Hintergrund erscheint es aus Sicht der Bundesstaaten ökonomisch rational zu sein, ein Gesellschaftsrecht zu entwickeln, das viele Gesellschaften anlockt.

In der Literatur wird der Wettbewerb zwischen den Bundesstaaten unterschiedlich beurteilt. Es wird die Meinung vertreten, er verleite die Bundesstaaten zur Schaffung eines Gesellschaftsrechts, das vorrangig den Interessen der Unternehmensvertreter entspreche. Die Entwicklung von besonders liberalen, unternehmensfreundlichen Gesellschaftsrechten, z.B. indem Mindestkapitalvorschriften abgeschafft, Unternehmensübernahmen erschwert und weit-

Durch zwei Generalklauseln - interstate commerce clause und necessary and proper clause - werden die Befugnisse des Bundes teilweise sehr weit ausgelegt. Daraus resultiert in vielen Bereichen ein Nebeneinander von bundes- und einzelstaatlichen Normen, die von den Unternehmen parallel zu befolgen sind. Vgl. dazu Pellens (2001a), S. 38.

Vgl. H. Henn/Alexander (1983), S. 25; Merkt (1996), S. 3. Merkt (2001), S. 143, weist darauf hin, dass der historische Verfassungsgeber die „weitreichenden und überaus segensreichen Folgen dieser Aufgabenteilung (...) im Jahre 1787 überhaupt nicht absehen (konnte). Aber wahre gesetzgeberische Größe manifestiert sich nicht zuletzt in intuitiv-prognostischen Fähigkeiten."

291 Merkt/Göthel (2006), S. 153. Vgl. auch Bungert (2003), S. 1: „Streng genommen gibt es kein US-amerikanisches Gesellschaftsrecht.“

Vgl. Pellens (2001a), S. 40; Merkt/Göthel (2006), S. 154.

Über $50 \%$ der an der NYSE gelisteten corporations und knapp $60 \%$ der Fortune 500-corporations sind in Delaware gegründet. Vgl. Bainbridge (2002), S. 16; Choper/Coffee/Gilson (2004), S. 238; Pinto/Branson (2004), S. 15. Der Wettbewerb der Einzelstaaten wird in der deutschen Literatur als „Delaware-Effekt“ bezeichnet. Vgl. dazu insbesondere Merkt (1995), S. 549-554; Merkt (1996), S. 11; Merkt (2001), S. 143-144. Vgl. auch Zimmer (1996), S. 187; Hay (2002), S. 235. Vgl. dazu Romano (1993), S. 6-8; Merkt (1995), S. 553

In Delaware machen die Einnahmen, die aus Unternehmensgründungen resultieren, ca. $30 \%$ der Steuereinnahmen aus. Vgl. zur Bedeutung dieser Einnahmen im Zeitablauf Cary (1974), S. 668-669; Romano (1993), S. 6-12; Bebchuk/Hamdani (2002), S. 556, 583.

Vgl. Bebchuk/Hamdani (2002), S. 583. Zur Höhe dieser indirekten Auswirkungen aufgrund von Unternehmensgründungen in Delaware vgl. Kahan/Kamar (2002). 
reichende Haftungsausschlussklauseln für das Management zugelassen werden, wird schlagwortartig als "race to the bottom“ bezeichnet ${ }^{297}$.

Die Gegenmeinung lehnt diese negative Sichtweise ab. Der Wettbewerb der Bundesstaaten führe im Gegenteil zu gesellschaftsrechtlichen Rahmenbedingungen, die sich positiv auf den Unternehmenswert der Gesellschaften auswirken würden ${ }^{298}$. Dementsprechend wird die Entwicklung als „race to the top“ interpretiert ${ }^{299}$. Diese positive Interpretation kann in der USamerikanischen Literatur aktuell als die herrschende Meinung bezeichnet werden ${ }^{300}$.

Bebchuk/Cohen untersuchen empirisch, wodurch die Gründungsentscheidung von Unternehmen beeinflusst wird und welche Eigenschaften eines Gesellschaftsrechtssystems es mehr oder weniger attraktiv für Unternehmensgründungen machen ${ }^{301}$. In ihre Analyse gehen alle 6.530 börsennotierten Unternehmen des Nichtfinanzsektors ein, die Ende 1999 sowohl in den USA gegründet waren als auch dort ihren Hauptsitz hatten. Die Autoren finden heraus, dass der Hauptsitz der Gesellschaften einen entscheidenden Einfluss auf die Wahl des Inkorporationsstaates hat. Die Bundesstaaten weisen einen signifikanten „Heimvorteil“ auf, d.h. viele Unternehmen bevorzugen die Gründung im Staat des Unternehmenssitzes. Selbst Bundesstaaten, die kaum Unternehmen von außerhalb anlocken, haben einen hohen Anteil an den Gründungen ihrer innerstaatlichen Gesellschaften. Während beispielsweise Oregon von $72,22 \%$ der Gesellschaften, die dort ihren Sitz haben, als Gründungsstaat gewählt wird, unterwerfen sich diesem Gesellschaftsrecht lediglich $0,11 \%$ der Gesellschaften von außerhalb. Dieser Befund steht im Gegensatz zu der herkömmlichen Sicht in der Literatur, nach der alle Gesellschaftsrechtssysteme im Wettbewerb zueinander stehen und derjenige Gründungsstaat gewählt wird, dessen Gesellschaftsrecht für das jeweilige Unternehmen am vorteilhaftesten ist.

Bebchuk/Cohen identifizieren mehrere Faktoren, die dazu führen, dass Unternehmen sich im Staat ihres Hauptsitzes gründen. Insbesondere kleinere Gesellschaften wollen zusätzliche Kosten, die mit der Gründung außerhalb des Sitzstaates verbunden sein können, vermeiden. Die Gründungsgebühren und Konzessionssteuern unterscheiden sich lediglich in ihrer Höhe, da sie in allen Bundesstaaten erhoben werden. Zusätzliche Transaktionskosten entstehen hingegen, wenn überregional arbeitende Rechtsanwaltskanzleien gebraucht werden ${ }^{302}$.

Für große Gesellschaften, bei denen diese Kosten von untergeordneter Bedeutung sind ${ }^{303}$ und die sich vielfach ohnehin von überregionalen Rechtsanwaltskanzleien beraten lassen, gilt dieser Zusammenhang nicht. Große Unternehmen gründen sich insbesondere dann in ihrem Sitzstaat, wenn dieser klein ist und sie aufgrund ihrer wirtschaftlichen Bedeutung mit wohlwollender Behandlung der öffentlichen Institutionen rechnen können ${ }^{304}$. Ohnehin schon beste-

Vgl. Cary (1974), S. 666; Bebchuk (1992), S. 1444-1445; Bebchuk/Ferell (1999), S. 1170; Bebchuk/Cohen (2003), S. 384.

Vgl. zu neueren empirischen Untersuchungen, die den Wettbewerb positiv bewerten, Daines (2001); Romano (2001); Bhagat/Romano (2002). Vgl. dazu kritisch Bebchuk/Cohen/Ferrell (2002). Vgl. Winter (1977); Fischel (1982); Winter (1989); Easterbrook/Fischel (1991); Romano (1993). Bebchuk/Cohen (2003), S. 384.

Vgl. hier und im Folgenden Bebchuk/Cohen (2003).

Diese Hypothese wird - bezogen auf kanadische Unternehmen - auch von Cumming/MacIntosh (2002), S. 287-296, bestätigt.

303 Im Jahre 1999 zahlten die an der NYSE gelisteten Unternehmen durchschnittlich 134.000 US- $\$$ an franchise tax. Vgl. Bebchuk/Hamdani (2002), S. 590.

304 Bebchuk/Cohen (2003), S. 399, bezeichnen diesen Sachverhalt treffend als ,the big fish in a small pond phenomenon". Vgl. auch Sitkoff (2002), S. 1109-1113. 
hende Vorteile, die kleine Bundesstaaten aus wirtschaftspolitischen Gründen diesen Gesellschaften als Anreiz gewähren - z.B. Zuschüsse und Subventionen, Kreditvergabe in Krisensituationen - können durch die dortige Gründung auch auf gesellschaftsrechtliche Angelegenheiten ausgedehnt werden. Darüber hinaus haben nicht überregional arbeitende Anwaltskanzleien einen Anreiz, dass die von ihnen betreuten Unternehmen im Sitzstaat gegründet sind ${ }^{305}$. Allerdings wählen Unternehmen, die in jüngerer Zeit an die Börse gegangen sind, eher Gründungsstaaten außerhalb ihres Unternehmenssitzes.

Der Markt für Unternehmensgründungen außerhalb des Sitzstaates wird mit weitem Abstand von Delaware dominiert ${ }^{306}$. Von den insgesamt 4.393 Unternehmen des Untersuchungssamples, die außerhalb ihres Sitzstaates gegründet sind, haben $3.744(85,23 \%)$ Delaware als Inkorporationsstaat gewählt. Nevada und Colorado folgen weit abgeschlagen mit $172(3,92 \%)$ bzw. 58 (1,32\%) Gesellschaften auf den Plätzen zwei und drei. Mit Ausnahme von Unternehmen mit Sitz in Montana zieht Delaware Gesellschaften aus allen Bundesstaaten an. Selbst in Kalifornien haben 898 (71,61 \%) der insgesamt 1.254 Gesellschaften Delaware als Gründungsstaat gewählt. Es stellt sich also heraus, dass die überwältigende Mehrheit der corporations entweder in ihrem Heimatstaat oder in Delaware gegründet wird ${ }^{307}$.

Als ein weiteres interessantes Ergebnis der Untersuchung von Bebchuk/Cohen kann festgehalten werden, dass solche Bundesstaaten als Gründungsstaaten beliebt sind, die einen hohen Schutz vor Unternehmensübernahmen bieten. Aufgrund dieses Befunds wird der Wettbewerb zwischen den Bundesstaaten auch als „race to protect managers from takeovers“ bezeichnet $^{308}$. Zu diesen Staaten gehört auch Delaware, wenngleich die dortigen Anti-Übernahmegesetze weniger restriktiv sind als die in Massachusetts, Ohio und Pennsylvania, die extreme Hürden für Übernahmen aufgebaut haben. Dafür weist Delaware eine umfangreiche Fallrechtssammlung zu Übernahmen auf, nach der z.B. der Einsatz von so genannten poison pills zulässig ist ${ }^{309}$. Unter poison pills sind solche Maßnahmen zu subsumieren, die in Kraft treten, wenn der Bieter eine bestimmte Mehrheit an der Zielgesellschaft erlangt, und die Übernahme wirtschaftlich unattraktiv machen ${ }^{310}$. Somit weist auch Delaware einen wirkungsvollen Schutz vor Übernahmen auf, der zur Beliebtheit dieses Staates für Unternehmensgründungen beiträgt. Umgekehrt wird die Tatsache, dass Kalifornien keine Anti-Übernahmegesetze aufweist, als Grund dafür gesehen, dass dort nur knapp $22 \%$ der Heimatgesellschaften gegründet sind. Es zeigt sich, dass viele Bundesstaaten auf einfache Weise die Zahl der Unternehmensgründungen steigern könnten, wenn sie restriktivere Gesetze zur Abwehr von Übernahmen verabschieden würden. Somit scheinen nicht alle Bundesstaaten das Ziel zu verfolgen, die Anzahl der Gründungen zu maximieren.

Eine Reihe von Einflussfaktoren führt dazu, dass die dominierende Stellung Delawares wenig gefährdet ist ${ }^{311}$. Durch die große Anzahl an Gründungen bestehen in Delaware Netzwerkef-

Vgl. dazu auch Carney (1998), S. 720-728; Coates (2001), S. 1308-1311.

Vgl. Bebchuk/Cohen (2003), 394-396 (Tab. 5 auf S. 395 weist Rechenfehler bei den Prozentangaben auf).

So auch Epstein/Freer/Roberts (2002), S. 151.

Vgl. bereits Bebchuk/Ferrell (1999), S. 1168

Vgl. insbesondere die Entscheidung des Delaware Supreme Court in Moran v. Household International, Inc., 500 A.2d 1348 (S.Ct.Del. 1985).

Vgl. Merkt/Göthel (2006), S. 629, 657-664.

Vgl. zur folgenden Argumentation ausführlich Bebchuk/Hamdani (2002), S. 585-595; Kahan/Kamar (2002), S. 724-735. 
fekte $^{312}$. Einerseits hat eine Vielzahl von Gerichtsentscheidungen zu einem detaillierten und verlässlichen case law-System geführt. Andererseits herrscht in Delaware eine hohe Konzentration an Rechtsexperten auf dem Gebiet des dortigen Gesellschaftsrechts. Beide Vorteile vergrößern sich mit der Zunahme an Unternehmensgründungen, wodurch hohe Eintrittsbarrieren für die anderen Bundesstaaten auf dem Markt für Unternehmensgründungen entstehen. Weiterhin bietet Delaware eine ausgeprägte institutionelle Infrastruktur mit spezialisierten Gerichten, Sachverständigen, Rechtsdiensten und Gesellschaftsrechtsexperten, deren Aufbau durch einen Wettbewerber mit hohen Kosten einhergehen würde ${ }^{313}$. Die vorteilhaften Eigenschaften Delawares führen auch dazu, dass selbst deutlich niedrigere Gebühren nicht ausreichen würden, Unternehmen von Delaware abzuwerben. Insgesamt scheint der Wettbewerbsdruck auf Delaware somit erheblich schwächer ausgeprägt als vielfach behauptet wird ${ }^{314}$.

Neben den erwähnten gesellschaftsrechtlichen Vorschriften und Grundsätzen des common law sind seit den frühen 1930er Jahren kapitalmarktrechtliche Regulierungen von besonderer Bedeutung. Durch den Börsenzusammenbruch von 1929 und die dadurch resultierende Weltwirtschaftskrise geriet die weitgehende Deregulierung im Gesellschaftsrecht der Einzelstaaten in die Kritik. Das Vertrauen der Anleger war infolge von gewaltigen Aktienkursverlusten und zahlreichen Bankzusammenbrüchen nachhaltig erschüttert. In den liberalen Wertpapiergesetzen der Einzelstaaten, den so genannten blue sky laws ${ }^{315}$, sah der Bundesgesetzgeber nur einen unzureichenden Schutz der Anleger vor Manipulationen des Börsenhandels. Um die Vertrauenskrise zu überwinden, verabschiedete der Bund 1933 den Securities Act (SA) und 1934 den Securities Exchange Act (SEA) ${ }^{316}$. Diese zentralen Kapitalmarktgesetze sind der Roosevelt'schen Gesetzgebung des New Deal zur Bekämpfung der Großen Depression entsprungen und werden als Geburtstunde des Kapitalmarktrechts gesehen ${ }^{317}$.

Während der SA den Primärmarkt reguliert, d.h. die Erstausgabe öffentlich gehandelter Wertpapiere, bezieht sich der SEA auf den Sekundärmarkt, also den Handel von bereits emittierten Wertpapieren. Beide Regulierungen zielen darauf ab, die Funktionsfähigkeit des öffentlichen Kapitalmarkts zu schützen, indem den Wertpapieremittenten weitgehende Registrierungs-, Offenlegungs- und Verhaltenspflichten auferlegt werden, die bei einem Verstoß zivil- und strafrechtliche Sanktionen nach sich ziehen. Den Schwerpunkt bildet die Unternehmenspublizität. Durch die umfangreichen Informationen sollen sich die aktuellen und potentiellen Kapitalanleger ein Bild von der wirtschaftlichen Lage und Entwicklung des Unternehmens machen und anschließend ihre (Des-)Investitionsentscheidung treffen können. Die beiden Kapitalmarktgesetze enthalten darüber hinaus Regelungen zum Insiderhandel, zur Prospekt- und Insiderhaftung, Erteilung von Stimmrechtsvollmachten (proxies) und zu Übernahmeangebo-

312 Vgl. zu einer Analyse von Netzwerkeffekten auf dem Markt für Unternehmensgründungen grundlegend Klausner (1995), S. 841-847.

313 Vgl. dazu ausfuhrlich Bebchuk/Ferrell (2001), S. 135-140; Bebchuk/Hamdani (2002), S. 580-589.

314 Vgl. Bebchuk/Cohen (2003), S. 420. Bebchuk/Hamdani (2002), S. 586, sprechen daher anstelle von „race“ treffend von ,leisurely walk“.

315 Die Bezeichnung spielt auf die Zielsetzung der Gesetze an zu verhindern, dass Aktien für Gegenleistungen von zweifelhaftem Wert, wie z.B. den blauen Himmel, ausgegeben werden. Vgl. Bauer (1995), S. 300, Fn. 4; Gassen (2000), S. 62.

316 Vgl. hier und im Folgenden zum SA und SEA ausfuhrlich Pellens (2001a), S. 64-69. Neben diesen grundlegenden Primary Acts existieren auf Bundesebene weitere Secondary Acts, die spezielle Problembereiche des Wertpapierrechts regeln. Zu einer Übersicht uber die Secondary Acts vgl. Pellens (2001a), S. 62.

317 So Kübler (1995a), S. 224. Vgl. auch Pellens/Fülbier/Gassen (2006), S. 844. 
$\operatorname{ten}^{318}$. Zusätzlich zu den kapitalmarktrechtlichen Vorschriften des Bundes- und Einzelstaatenrechts sind insbesondere die Börsenordnungen ${ }^{319}$ und die kapitalmarktrelevante Rechtsprechung von großer praktischer Bedeutung ${ }^{320}$.

Mit dem SEA wurde 1934 auch die Securities and Exchange Commission (SEC) als unabhängige Börsenaufsichtsbehörde geschaffen. Diese mächtige und einflussreiche Behörde ist lediglich dem Kongress unterstellt und ist mit weitreichenden und gewaltenübergreifenden Kompetenzen ausgestattet ${ }^{321}$. Die Hauptaufgabe der SEC besteht darin, die bundesgesetzlichen Regelungen des US-amerikanischen Kapitalmarktrechts auszulegen und durchzusetzen. Die Behörde verpflichtet alle registrierten Unternehmen zu einer detaillierten und standardisierten Berichterstattung. Die der SEC bereit zu stellenden Informationen umfassen insbesondere testierte Jahres- bzw. Konzernabschlüsse mit Angaben der Werte für die letzten zwei bzw. drei Jahre, zahlreiche Daten zur Kapital-, Liquiditäts- und Ertragssituation der letzen fünf Geschäftsjahre, Markt-, Kurs- und Dividendeninformationen, bestimmte Quartalsdaten und Segmentinformationen, qualitative und quantitative Angaben über Marktrisiken sowie den Management's Discussion and Analysis of Financial Condition and Results of Operations (MD\&A), der dem Lagebericht gemäß $\S \S 289,315$ HGB ähnelt. Dieses so genannte BasisInformations-Paket ist die Grundlage der Emissionspublizität und der jährlichen Berichtspflichten, das je nach Anlass noch erweitert und den Aktionären und der interessierten Öffentlichkeit zeitnah ${ }^{322}$ zur Verfügung gestellt wird. Darüber hinaus besteht eine Pflicht zur Quartalsberichterstattung und Ad-hoc-Publizität ${ }^{323}$.

Im Rahmen ihrer legislativen Kompetenz ist die SEC ermächtigt, Rechnungslegungsvorschriften für kapitalmarktorientierte Unternehmen zu entwickeln und zu erlassen. Die Regulierungskompetenz für die Rechnungslegung hat die SEC bereits früh - zunächst an den Berufsstand der Wirtschaftsprüfer und seit 1973 an das zur Unabhängigkeit und Neutralität verpflichtete Financial Accounting Standards Board (FASB) ${ }^{324}$ - delegiert. Bei der Entwicklung von Rechnungslegungsstandards hat das FASB grundsätzlich die verschiedenen Interessen aller durch die Rechnungslegung berührten Personengruppen zu berücksichtigen. Die SEC nimmt allerdings großen Einfluss auf die Arbeit des FASB, indem sie die FASBVerlautbarungen nur dann den kapitalmarktorientierten Unternehmen vorschreibt, wenn sie mit dem substantial authoritative support der SEC ausgestattet sind. Die vom FASB verabschiedeten Statements of Financial Accounting Standards (SFAS) und Interpretationen bilden zusammen mit den noch gültigen Verlautbarungen der Vorgängerorganisationen die USGAAP im engeren Sinne ${ }^{325}$. Die US-GAAP haben für sämtliche kapitalmarktorientierten Gesellschaften Verpflichtungscharakter, da die SEC grundsätzlich nur US-GAAP-konforme Ab-

318 Vgl. im Überblick Merkt/Göthel (2006), S. 178.

319 Vgl. zum Company Manual der NYSE z.B. Merkt/Göthel (2006), S. 181-182.

320 Vgl. Pellens (2001a), S. 63.

321 Vgl. dazu Pellens/Fülbier/Gassen (2006), S. 58-60.

322 Der Jahresbericht ist bei der SEC bereits 90 Tage nach Ende des Geschäftsjahrs einzureichen. Für Unternehmen mit einem Streubesitz von mehr als 75 Mio. US-\$ gilt sogar eine Frist von 60 Tagen. Vgl. Pellens/Fülbier/Gassen (2006), S. 857.

323 Vgl. zu der Fülle an Detailinformationen im Rahmen der SEC-Publizitätspflichten ausfuhrlich Pellens/Fülbier/Gassen (2006), S. 850-867.

324 Zu Organisation, Arbeitsweise und Standardsetzungsprozess des FASB vgl. Pellens/Fülbier/Gassen (2006), S. 60-66.

325 Vgl. zu einer Systematisierung der US-GAAP insbesondere Rubin (1984). Vgl. auch Pellens/Fülbier/Gas$\operatorname{sen}(2006)$, S. 68-71. 
schlüsse mit uneingeschänktem Bestätigungsvermerk akzeptiert. Wirtschaftsprüfer wiederum sind verpflichtet, ein uneingeschränktes Testat nur bei Einhaltung der US-GAAP zu ertei$\operatorname{len}^{326}$.

Um zu vermeiden, dass die SEC eigene Vorschriften erlässt, orientiert sich das FASB bei der Erstellung von Rechnungslegungsnormen insbesondere an den Informationsinteressen der Kapitalmarktteilnehmer. Diese Fokussierung findet sich auch im Rahmenkonzept (Conceptual Framework) des FASB. In SFAC 1.24 (Statement of Financial Accounting Concept) werden eine Reihe von Abschlussadressaten und ihre jeweiligen Informationsbedürfnisse aufgelistet. $\mathrm{Da}$ die zum Teil divergierenden Informationsbedürfnisse nicht vollständig zu befriedigen seien, erfolgt nach SFAC 1.30 eine primäre Orientierung der Rechnungslegung an den Informationsbedürfnissen der Investoren. Dieses Vorgehen wird damit begründet, dass die Informationen für Investoren auch die Informationsbedürfnisse der anderen Adressaten weitgehend befriedigen dürften.

Ein Beispiel dafür, dass sich der US-Gesetzgeber nicht nur unmittelbar im Anschluss an die Weltwirtschaftskrise, sondern auch in der jüngeren Vergangenheit durch Krisen zur Regulierung gezwungen sieht ${ }^{327}$, stellt der Sarbanes-Oxley Act aus dem Jahre 2002 dar $^{328}$. Damit reagierte der Gesetzgeber auf den Enron-Skandal und weitere Bilanzfälschungen der vorangegangenen $\mathrm{Zeit}^{329}$. Um dem Vertrauensschwund der Anleger entgegenzuwirken und die Rechnungslegung börsennotierter Unternehmen zu verbessern, wurden die Pflichten der für die Rechnungslegung und Prüfung verantwortlichen Personen deutlich ausgeweitet ${ }^{330}$. Zudem wurden die Wirtschaftsprüfer der neu gegründeten staatlichen Berufsaufsichtsbehörde, dem Public Company Accounting Oversight Board (PCAOB), unterstellt.

Die bereits in den 1930er Jahren entstandenen und seitdem weiterentwickelten Kapitalmarktregulierungen weisen auch eine sozialpolitische Komponente auf ${ }^{331}$. Anders als in Deutschland nach dem Ersten Weltkrieg wurde der Kapitalmarkt in den USA früh von großen Bevölkerungsgruppen über Pensionsfonds als ein bedeutender Baustein der privaten Altersversorge genutzt. Das Kapitalmarkt- und Wertpapierrecht soll daher auch das Vertrauen der Bevölkerungsteile sicherstellen, die den Kapitalmarkt nicht zu Spekulationszwecken, sondern aufgrund der nur schwach ausgeprägten staatlichen Sozialgesetzgebung primär zur Vorsorge in Anspruch nehmen.

Im Gegensatz zum deutschen Corporate-Governance-Modell, das sich um die Berücksichtigung der unterschiedlichen Interessen aller Unternehmensbeteiligten bemüht, stellt das kapitalmarktrechtliche Modell der USA allein auf den Schutz der Anlegerinteressen $a b^{332}$. Die Leitung und Kontrolle von Unternehmen hat sich primär an den Interessen der Eigenkapital-

Vgl. Rule 203 des Code of Professional Ethics des AICPA.

Vgl. zum krisentheoretischen Erklärungsansatz für Regulierungen im Rahmen der positiven Regulierungstheorie Fülbier (1998), S. 222 m.w.N.

Vgl. Sarbanes-Oxley Act (2002).

Vgl. zu den Bilanzskandalen in den USA und Deutschland im Überblick Ballwieser (2003).

Der Sarbanes-Oxley Act ist von allen bei der SEC registrierten Unternehmen zu beachten, also auch von deutschen Unternehmen, die den US-amerikanischen Kapitalmarkt in Anspruch nehmen. Auch deutsche Tochterunternehmen von SEC-registrierten Gesellschaften sind von den zusätzlichen Anforderungen teilweise betroffen. $\mathrm{Zu}$ den Auswirkungen auf die Rechnungslegung und Abschlussprufung deutscher Unternehmen vgl. z.B. Lanfermann/Maul (2003).

Vgl. Kübler (1995a), S. 224.

Vgl. Merkt (2001a), S. 145; Assmann (2003), S. 3-4; Merkt (2003), S. 127. 
geber zu orientieren. Dieser eindimensionale Ansatz ist auch auf die dominierende Rolle der öffentlichen Kapitalmärkte bei der Eigen- und Fremdkapitalbeschaffung US-amerikanischer Unternehmen zurückzuführen ${ }^{333}$.

Zusammenfassend kann das Verhältnis von gesellschafts- und kapitalmarktrechtlichen Regulierungen in den USA wie folgt charakterisiert werden ${ }^{334}$ : Das in die Gesetzgebungskompetenz der Einzelstaaten fallende Gesellschaftsrecht ist im Vergleich zu Deutschland weitgehend dereguliert. Die privatvertragliche Gestaltungsfreiheit für die Corporate Governance der Unternehmen wird kaum durch zwingende gesellschaftsrechtliche Vorschriften eingeschränkt. Das Kapitalmarktrecht auf Bundesebene gibt einen zwingenden Rahmen nicht verhandelbarer Vorschriften vor und sorgt insofern für einen Ausgleich zur einzelstaatlichen Deregulierung. Der kapitalmarktrechtliche Regulierungsansatz rückt die Interessen der Anleger in den Mittelpunkt, die durch zwingende und mit Sanktionen bewehrte Offenlegungspflichten der Unternehmen mit den erforderlichen Informationen versorgt werden sollen, um ihre (Des-)Investitionsentscheidungen treffen zu können. Kennzeichnend für das Rechtssystem der USA ist zudem die hohe Bedeutung des Richterrechts als Rechtsquelle. Aufgrund der gesellschaftsrechtlichen Gesetzgebungskompetenz der Einzelstaaten weichen die gesellschaftsrechtlichen Vorschriften der Bundesstaaten teilweise erheblich voneinander ab. Um der Rechtszersplitterung entgegenzuwirken, haben sowohl die National Conference of Commissioners on Uniform State Laws als auch das Committee on Corporate Laws der American Bar Association (Amerikanischer Bundesverband der Anwaltschaft) Mustergesetzentwürfe (Uniform Laws, Model Acts) erarbeitet und den Parlamenten der Einzelstaaten zur Übernahme in ihr Recht empfohlen $^{335}$, worauf im weiteren Verlauf dieser Arbeit noch genauer eingegangen wird. Wenngleich einige dieser Mustergesetze von zahlreichen Bundesstaaten übernommen worden sind, darf jedoch das Ausmaß an Rechtsvereinheitlichung nicht überbewertet werden. Denn einerseits haben viele Gesetzgeber bestimmte Änderungen gegenüber den Entwürfen vorgenommen, und andererseits werden die Modellgesetze von der einzelstaatlichen Rechtsprechung zum Teil unterschiedlich ausgelegt ${ }^{336}$.

\subsubsection{Zuständigkeiten der Organe}

Wie die vorstehenden Ausführungen gezeigt haben ist das Gesellschaftsrecht in den USA weitgehend dispositives Recht ${ }^{337}$. Im Gegensatz zur deutschen Aktiengesellschaft, deren Struktur durch zwingende Vorschriften im Aktiengesetz überwiegend starr und einheitlich vorgegeben ist, besteht bei der Ausgestaltung der corporation in den USA ein großer Gestaltungsspielraum für privatautonome Regelungen. Trotz der unterschiedlichen Gesetzgebungskompetenz ist das Grundmuster der Zuständigkeitsverteilung zwischen den Organen, d.h. dem

\footnotetext{
333 Vgl. F. Ruhwedel (2003), S. 44-47; Heintges (2005), S. 67-71.

334 Vgl. Assmann (2003), S. 3-4; Merkt (2003), S. 127.

335 Vgl. Pellens (2001 a), S. 41; Hay (2002), S. 8; Blumenwitz (2003), S. 70-71.

336 Vgl. auch Zweigert/Kötz (1996), S. 245.

337 Vgl. auch Kübler (1995a), S. 226.
} 
board of directors, den leitenden Angestellten (officers) und den Anteilseignern (shareholders) in etwa gleich ausgestaltet ${ }^{338}$.

Das Ziel der folgenden Ausführungen ist es, die Kompetenzverteilung der Organe in den Grundzügen darzustellen. Diejenigen Rechte und Pflichten, die in dieser Arbeit von zentraler Bedeutung sind - so z.B. Sorgfaltspflichten, die directors bei der Dividendenentscheidung zu beachten haben, Dividendenrecht der Aktionäre, Haftungsvorschriften bei unzulässigen Dividendenzahlungen, Klagemöglichkeiten -, werden schwerpunktmäßig in Kapitel III unter expliziter Berücksichtigung der Kapitalgesellschaftsrechte Delawares, Kaliforniens und der Bestimmungen des MBCA erörtert.

\subsubsection{Board of Directors}

Dem board of directors ist die Geschäftsführung, Überwachung und Vertretung der corporation anvertraut. Es handelt sich demnach um ein aktives Gesellschaftsorgan, das die Funktionen von Aufsichtsrat und Vorstand einer deutschen Aktiengesellschaft in sich vereinigt ${ }^{339}$. Die directors werden direkt von den Aktionären auf der Gesellschafterversammlung in der Regel für ein Jahr gewählt. Sie können sich unbegrenzt oft zur Wiederwahl stellen. Eine Mindestanzahl an board-Mitgliedern ist in den meisten Einzelstaatenrechten nicht mehr vorgegeben, sie kann von den Anteilseignern in den articles of incorporation oder in den bylaws festgelegt werden $^{340}$. Empirischen Studien zufolge beträgt die durchschnittliche Anzahl 13 bis 14 Perso$\operatorname{nen}^{341}$.

Die directors treten nur wenige Male im Geschäftsjahr zusammen ${ }^{342}$ und legen im Wesentlichen die elementaren Leitlinien der Unternehmenspolitik fest ${ }^{343}$. Auch geht die Initiative zu grundlegenden strukturellen und organisatorischen Veränderungen der corporation häufig vom board of directors aus, zu deren Durchsetzung aber die Zustimmung der Anteilseigner

338 Vgl. Escher-Weingart (2000), S. 394-395. In Abhängigkeit von der Größe der corporation kommt es in der Praxis allerdings häufig zu Abweichungen von diesem so genannten statutory scheme. Vgl. Hamilton (2000), S. 228-240; Merkt/Göthel (2006), S. 311-314.

339 Vgl. Hay (2002), S. 230. Aufgrund der Mischung von Kontroll- und Managementfunktionen wird auch von one tier-system gesprochen.

340 Die articles of incorporation, die der Satzung einer Aktiengesellschaft entsprechen, werden von den Unternehmensgründern entworfen, von einem Notar beglaubigt und beim Secretary of State des Gründungsstaates eingereicht (filing). Der Secretary of State ist in etwa mit dem Handelsregister vergleichbar und darf nicht mit dem synonymen Außenminister der USA verwechselt werden. Vgl. dazu Kübler (1989), S. 23. Nach der Überprüfung des notwendigen Inhalts (z.B. Firma, Gesellschaftszweck, Sitz, Anzahl der von ihr auszugebenden Aktien) und nach Begleichung der Gründungsgebühren (filing fees) wird eine Gründungsurkunde (certificate of incorporation) ausgestellt als Beweis ihrer Eigenschaft als juristische Person. In der formellen Gründungsversammlung werden die officers ernannt und die bylaws erlassen. Die bylaws ähneln der Geschäftsordnung einer Aktiengesellschaft und regeln in ausführlicher Weise das Innenverhältnis der corporation. Sie sind im Vergleich zu den articles of incorporation einfacher zu ändern, Letztere gehen im Konfliktfall aber vor. Vgl. Bungert (2003), S. 32-33.

341 Vgl. Pellens (2001a), S. 51 m.w.N.

342 In vielen Staaten sind auch Entscheidungen im schriftlichen Verfahren unter Verwendung von elektronischen Medien und in Gestalt von Telefon- bzw. Videokonferenzen erlaubt. Vgl. Hamilton (2000), S. 315; Bainbridge (2002), S. 215.

343 Vgl. hier und im Folgenden Gevurtz (2000), S. 190-195; Hamilton (2000), S. 304-321; Bainbridge (2002), S. 208-231; Emanuel (2005), S. 59-73. 
notwendig ist. $\mathrm{Zu}$ den Hauptaufgaben der directors gehören die Bestellung, Kontrolle und Abberufung der officers, die Zustimmung zum Abschluss bedeutender Verträge der Gesellschaft mit Dritten und die Entscheidung über Dividendenausschüttungen. Zur Beschlussfassung reicht grundsätzlich die einfache Mehrheit der Mitglieder des board of directors aus. In vielen Bundesstaaten darf eine Zahl unterhalb der Mehrheit in der Satzung oder in den bylaws, eine qualifizierte Mehrheit ausschließlich in der Satzung festgelegt werden. Das board of directors handelt eigenverantwortlich und ist nicht an Weisungen der Anteilseignerversammlung gebunden. Sind die Aktionäre mit der Arbeit des board nicht einverstanden, können sie dies primär durch die Wahl eines anderen board auf der nächsten Gesellschafterversammlung zum Ausdruck bringen. Darüber hinaus ist in vielen Bundesstaaten die Abberufung von directors durch die Gesellschafter ohne besonderen Grund möglich.

Zur Erledigung der Aufgaben des board of directors können verschiedene board committees eingesetzt werden, die mit einzelnen board-Mitgliedern besetzt und insbesondere bei größeren corporations üblich sind. Diese auf Beschluss der Mehrheit der board-Mitglieder eingerichteten Ausschüsse übernehmen einen speziellen Aufgabenbereich des board of directors und sind mit eigener Entscheidungsbefugnis ausgestattet. Eine Reihe von Aufgaben können allerdings nicht delegiert werden, so beispielsweise Änderungen der Satzung oder der bylaws und die Ausgabe oder der Rückerwerb von Aktien.

In der Unternehmenspraxis verbreitet sind Ausschüsse, die potentielle Kandidaten für das board und das leitende Management auswählen (nominating committees), Gehaltsausschüsse (compensation committees), die die Vergütung des Spitzenmanagements festlegen, executive committees, die für die Unternehmensleitung zwischen den board-Sitzungen zuständig sind und Prüfungsausschüsse (audit committees), die mit der Prüfung und Kontrolle der Geschäftsführung durch die officers betraut werden, die Funktionsfähigkeit des internen Überwachungssystem sowie des Rechnungswesens gewährleisten sollen und den Abschlussprüfer vorschlagen. Audit committees sind gesellschaftsrechtlich nur von wenigen Bundesstaaten vorgeschrieben. Für kapitalmarktorientierte Unternehmen hat die SEC audit committees als kapitalmarktrechtlich vorgeschriebenes Kontrollsystem $(\S 13(\mathrm{~b})(2)(B)$ SEA) anerkannt. Zudem ist die Einrichtung eines Prüfungsausschusses eine Voraussetzung für die Börsenzulassung an der NYSE ${ }^{344}$.

Im Gegensatz zu anderen Ausschüssen sind audit committees mehrheitlich oder sogar ausschließlich mit outside directors besetzt, d.h. mit board-Mitgliedern, die weder Geschäftsführungsaufgaben innerhalb der corporation wahrnehmen noch Angestellte der Gesellschaft sind. Da ein gutgläubiges Mitglied des board of directors nicht für die Fahrlässigkeit der sorgfältig ausgewählten Mitglieder des Prüfungsausschusses haftet, geht die Einrichtung eines solchen Ausschusses mit einer Verminderung der Haftung der übrigen board-Mitglieder einher.

Für ihre Tätigkeit als director sehen viele corporations in den bylaws oder in der Satzung eine Vergütung sowie Aufwandsentschädigungen für die Teilnahme an board-Sitzungen oder die Mitgliedschaft in Ausschüssen vor ${ }^{345}$. Nach dem Gesellschaftsrecht zahlreicher Bundesstaaten kann das board die Vergütung der directors sogar selbst festlegen.

344

345

gl. Emanuel (2005), S. 72.

Vgl. Merkt/Göthel (2006), S. 332. Nach common law steht den directors hingegen keine Vergütung zu mit der Begründung, sie seien zugleich Gesellschafter, so dass sich ihr Entgelt aus der Kursentwicklung ergäbe. 
Bei der Erfüllung ihrer Aufgaben haben die directors eine Sorgfalts- (duty of care) und eine Treuepflicht (duty of loyalty bzw. fiduciary duty) gegenüber der Gesellschaft zu beachten ${ }^{346}$. Die Sorgfaltspflicht erfordert, dass sie ihre Aufgaben in der Weise erfüllen, wie dies von einer vernünftigen Person in entsprechender Lage jeweils zu erwarten wäre. Ein Verstoß gegen die Sorgfaltspflicht liegt beispielsweise vor, wenn der director eine nicht nachvollziehbare, extrem risikoreiche Maßnahme beschließt oder er sich vor einer Entscheidung nicht hinreichend informiert.

Die Sorgfaltspflicht wird jedoch durch den großzügigen gerichtlichen Kontrollmaßstab der so genannten business judgment rule abgeschwächt ${ }^{347}$. Danach sehen Gerichte von einer materiellen Überprüfung von Entscheidungen des board of directors ab, wenn die directors ohne Eigeninteresse und auf Grundlage eines angemessenen Maßes an Informationen eine Entscheidung getroffen haben, die nach ihrer Überzeugung und gemessen an einem Vernünftigkeitsmaßstab im Interesse der Gesellschaft liegt.

Die Treuepflicht erfordert von den directors Entscheidungen in gutem Glauben und ein faires Handeln. Die Treuepflicht, die ursprünglich von der Rechtsprechung entwickelt worden und heute in einigen Einzelstaaten gesetzlich kodifiziert ist, konkretisiert sich in verschiedenen Fallkonstellationen. Aus den Treuepflichten folgt z.B., dass der director grundsätzlich nicht mit der Gesellschaft in Wettbewerb treten darf, wenn ein Schaden für die Gesellschaft wahrscheinlich ist. Allerdings kann sich der director vor einer Anfechtung schützen, indem er eine formgültige Genehmigung durch das board oder die Aktionärsversammlung einholt. Ebenfalls nicht mit der Treuepflicht zu vereinbaren ist es, die der Gesellschaft zustehende Gelegenheit zum Geschäftsabschluss auszunutzen, es sei denn, ein neutrales board beschließt nach vollständiger Offenlegung, die Gelegenheit der Gesellschaft nicht zu nutzen. Treuepflichten sind weiterhin bei Insichgeschäften zu beachten. Hierbei handelt es sich um Geschäfte, bei denen sich der director und die Gesellschaft (vertreten durch den director) gegenüberstehen, und fraglich ist, ob der director im Interesse der Gesellschaft gehandelt hat. Ein Spezialproblem im Zusammenhang mit den Treuepflichten der directors ergibt sich beim insider trading, d.h. beim Kaufen und Verkaufen von Aktien der corporation aufgrund von wesentlichen, der Öffentlichkeit nicht zugänglichen Informationen über diese Gesellschaft. Beschränkungen ergeben sich insbesondere aus den insider trading-Vorschriften des bundesstaatlichen Kapitalmarktrechts ${ }^{348}$.

Im Rahmen dieser Arbeit sind die Pflichten der directors bei der Ausschüttungsentscheidung von besonderem Interesse. Im Gegensatz zum Vorstand einer deutschen Aktiengesellschaft entscheidet das board of directors allein darüber, ob und gegebenenfalls in welcher Höhe eine Dividende gezahlt wird ${ }^{349}$. Die board-Mitglieder müssen allerdings eine Reihe von Beschränkungen beachten ${ }^{350}$. Zum einen sind die gesetzlichen Restriktionen im Gesellschaftsrecht des Gründungsstaates sowie die diesbezügliche Rechtsprechung zu berücksichtigen. Einschränkungen können sich zum anderen aus der Satzung oder den bylaws ergeben. In der Satzung kann beispielsweise geregelt sein, dass eine Aktiengattung mit einem Dividendenvorrecht

346 Vgl. im Überblick Bungert (2003), S. 41, 43-44.

347 Vgl. dazu ausführlich z.B. Eisenberg (2000), S. 536-568; Gevurtz (2000), S. 278-320; Bainbridge (2002), S. 251-304. Vgl. im Überblick Palmiter (2003), S. 197-208; Emanuel (2005), S. 185-193; Merkt/Göthel (2006), S. 426-428.

348 Wichtige Verbotsnormen sind $\S \S 10(\mathrm{~b}), 16(\mathrm{~b})$ SEA.

349 Vgl. Gevurtz (2000), S. 153; Bainbridge (2002), S. 793; Emanuel (2005), S. 537.

350 Vgl. Gevurtz (2000), S. 153-154. 
ausgestattet ist oder einer bestimmten Aktiengattung in regelmäßigen Abständen eine Dividende zu zahlen ist, wenn als Nebenbedingung die gesetzlichen Ausschüttungsvorschriften eingehalten werden ${ }^{351}$. Außerdem können sich direkte oder indirekte Ausschüttungsbeschränkungen aus den Kreditverträgen der corporation ergeben ${ }^{352}$. Schließlich können insolvenzrechtliche Vorschriften und weitere gesetzliche Regelungen Einfluss auf die Dividendenhöhe haben. Die vorstehend nur überblicksartig genannten Restriktionen werden in Kapitel III.2 ausführlich beleuchtet.

Anders als nach $\S 92$ Abs. 2 AktG besteht in den USA keine gesetzlich geregelte Insolvenzantragspflicht. Von der Rechtsprechung in Delaware sind allerdings Geschäftsleiterpflichten in Insolvenznähe entwickelt worden, nach denen die board-Mitglieder in einer solchen Situation nicht nur den Aktionären, sondern auch den Gläubigern gegenüber verpflichtet sind ${ }^{353}$.

Bei einem Verstoß gegen die der Gesellschaft gegenüber obliegenden Sorgfalts- und Treuepflichten greifen umfangreiche Haftungsvorschriften, wobei sowohl das board of directors als Organ als auch die directors persönlich haftbar gemacht werden können ${ }^{354}$. In den Fällen der gesetzlichen Haftung, haften die Mitglieder des board gesamtschuldnerisch. Wird ein director in Anspruch genommen, findet im Innenverhältnis ein Ausgleich statt. Als Haftungsgrund explizit verankert ist in vielen Einzelstaatenrechten darüber hinaus der gesetzes- bzw. satzungswidrige Verstoß gegen die Ausschüttungsrestriktionen, worauf in Kapitel III.2 ebenfalls noch ausführlich eingegangen wird.

Ist ein director der Ansicht, dass eine Entscheidung des board unzulässig ist, kann er unter bestimmten Voraussetzungen einer Haftung dadurch entgehen, dass er einen schriftlichen Widerspruch einlegt. Der Widerspruch wird grundsätzlich nur dann wirksam, wenn er im Sitzungsprotokoll festgehalten wird; anderenfalls wird vermutet, dass das board-Mitglied zugestimmt hat ${ }^{355}$. Ist der Widerspruch nicht protokolliert worden, kann der director aber in der Regel die Haftung vermeiden, indem er dem Protokollführer den Widerspruch zuschickt. In Delaware kann eine Haftung für Verletzungen der Sorgfaltspflicht sogar in der Satzung ausgeschlossen werden. In einigen anderen Einzelstaaten werden directors von der Haftung befreit, wenn sie nachweisen können, dass sie sich bei ihrer Entscheidung gutgläubig auf das Urteil anderer vertraut haben ${ }^{356}$.

Wird ein director von einem Aktionär oder Dritten erfolglos gerichtlich in Anspruch genommen, steht ihm nach den Kapitalgesellschaftsrechten eine Entschädigung (indemnification) für die Kosten einer Prozessverteidigung zu. Darüber hinaus kann die Gesellschaft den director entschädigen, wenn er gutgläubig im Interesse der Gesellschaft zu handeln glaubte. Die meisten Einzelstaatenrechte gestatten es der corporation, eine Versicherung zur Entschädigung der Manager, die so genannte director and officer liability insurance (D\&O insurance) abzu-

Vgl. Gevurtz (2000), S. 153, Fn. 5.

Vgl. zu den Ergebnissen empirischer Untersuchungen von Vereinbarungen in Kreditverträgen Kapitel V.5.4.1.

Vgl. dazu die Leitentscheidung in Credit Lyonnais Bank Nederland N.V. v. Pathe Communications Corp., WL 277613 (Del.Ch.1991). Vgl. dazu z.B. Eisenberg (2000), S. 150-151, 933; Choper/Coffee/Gilson (2004), S. 47-49, 233-235. Vgl. auch Fleischer (2005), S. 95 m.w.N.

Vgl. Gevurtz (2000), S. 288-304; Palmiter (2003), S. 208-209.

Vgl. Hamilton (2000), S. 316-317.

Vgl. Merkt/Göthel (2006), S. 321 m.w.N. 
schließen. Sie bietet einen Versicherungsschutz gegen Haftung für Fahrlässigkeit, nicht betrügerisches Fehlverhalten und Verletzungen gegen Offenlegungsvorschriften ${ }^{359}$.

\subsubsection{Officers}

Die officers werden vom board of directors bestellt. Sie tätigen als die leitenden Angestellten - allerdings unter Aufsicht des board - die operativen Tagesgeschäfte der corporation ${ }^{358}$. In der Regel werden bei den officers verschiedene Ämter unterschieden, deren Kompetenzen üblicherweise in den bylaws geregelt sind. Bei größeren Unternehmen gibt es meist einen chief executive officer (CEO), teilweise auch als president bezeichnet, einen oder mehrere vice presidents, einen secretary und einen treasurer. Der CEO ist unter anderem zuständig für die Unterzeichnung von Verträgen und sonstigen zeichnungsbedürftigen Dokumenten der corporation sowie für die Einstellung und Kündigung von Angestellten unterhalb der Ebene der officers. Häufig hat der Vorsitzende des board of directors, der chairman, gleichzeitig das Amt des CEO inne. Die Hauptaufgabe des secretary besteht darin, wichtige Dokumente gegenzuzeichnen, Sitzungs- und Versammlungsprotokolle anzufertigen, board-Beschlüsse zu beglaubigen und für die rechtzeitige Benachrichtigung von Mitgliedern des board und der Anteilseigner vor Sitzungen und Versammlungen zu sorgen. Der treasurer bekleidet das Finanzressort, verwaltet also sämtliche Konten und Guthaben und hat die Erfüllung von Zahlungsverpflichtungen sowie das Eintreiben der Forderungen sicherzustellen.

Von besonderer Bedeutung in der Praxis sind Fragen der Vertretungsmacht der officers ${ }^{359}$. Probleme resultieren daraus, dass die directors die eigentlichen Entscheidungsträger der corporation sind und den officers folglich nur eine begrenzte Vertretungsmacht zusteht. Allerdings findet insbesondere bei großen Gesellschaften eine immer stärkere Verlagerung der Geschäftsführungsaufgaben auf die officers statt. Um ihr operatives Tagesgeschäft sinnvoll erledigen zu können, ist die Vertretung der Gesellschaft in vielen Fällen notwendig. In den bylaws werden gewöhnlich die Möglichkeiten zur Vertretung grob umrissen. Danach sind die officers spezieller Ressorts zur Vertretung der Gesellschaft gegenüber Dritten kraft ihres Amtes befugt, soweit sie im Rahmen ihrer Ressortzuständigkeiten tätig werden. Einer ausdrücklich eingeräumten Vertretungsmacht bedarf es insofern nicht.

Officers haben nach common law-Grundsätzen einen Anspruch auf Vergütung in Höhe des Wertes der von ihnen erbrachten Dienste ${ }^{360}$. In der Praxis besteht die Vergütung in der Regel neben dem vertraglich vereinbarten Grundgehalt überwiegend aus variablen Bestandteilen, die sich am bilanziellen Jahresergebnis oder anderen Erfolgsgrößen orientieren. Hinzu kommen häufig zusätzliche Vergütungen, wie z.B. Lebens-, Unfall- und Krankenversicherungen,

357 In der US-amerikanischen Praxis machen Spitzenmanager den Abschluss einer solchen Versicherung zur Bedingung für die Übernahme einer Spitzenposition. Die D\&O-Versicherung beinhaltet aber eine Eigenbeteiligung und umfasst z.B. keine vorsätzlichen Pflichtverletzungen oder wissentliche Verstőße gegen die insider trading-Vorschriften. Vgl. dazu ausfuhrlich z.B. Gevurtz (2000), S. 447-448; Palmiter (2003), S. 256-263; Emanuel (2005), S. 382-384.

358 Vgl. hier und im Folgenden Eisenberg (2000), S. 210-214; Gevurtz (2000), S. 180-186; Hamilton (2000), S. 322-342; Bainbridge (2002), S. 231-240; Emanuel (2005), S. 77-84.

359 Vgl. dazu Merkt/Göthel (2006), S. 327-331.

360 Vgl. Eisenberg (2000), S. 664-670; Gevurtz (2000), S. 357-362; Palmiter (2003), S. 241-246. 
Erwerbsunfähigkeitsrenten, betriebliche Altersversorgung und sonstige Sozialleistungen. Weit verbreitet sind in den USA auch aktienkursbasierte Entlohnungsformen.

Officers haben bei der Erfüllung ihrer Aufgaben der Gesellschaft gegenüber Sorgfalts- und Treuepflichten zu beachten ${ }^{361}$. Sie ergeben sich einerseits aus ihrem Anstellungsverhältnis und andererseits aufgrund ihrer Eigenschaft als Vertreter der Gesellschaft und entsprechen in etwa den oben bereits erläuterten Pflichten der board-Mitglieder. Unterschiede ergeben sich in Abhängigkeit von den jeweiligen Hierarchieebenen der officers. Eine Minderung der Sorgfalts- und Treuepflichten kann sich für Teilzeit-officers ergeben. Hinsichtlich der Treuepflichten ist ferner zu beachten, dass officers im Vergleich zu den directors geringere Entscheidungsfreiheiten haben. Kommen officers ihren Pflichten nach, gilt die bereits angesprochene business judgment rule für sie analog. Gleiches gilt für mögliche Entschädigungen durch die Gesellschaft und den Schutz durch die D\&O-Versicherung.

Eine persönliche Haftung im Zusammenhang mit Geschäften der Gesellschaft scheidet für officers grundsätzlich aus, wenn sie die Grenzen ihres Verantwortungs- und Tätigkeitsbereichs beachtet haben ${ }^{362}$. Etwas anderes gilt ausnahmsweise in den Fällen, in denen der officer eine Garantie abgibt, dass er für die Erfüllung einer Verbindlichkeit persönlich einsteht. Eine persönliche Haftung ist weiterhin dann möglich, wenn er gegenüber einem Dritten den Eindruck erweckt, er handele im eigenen und nicht im Namen der corporation. Schließlich kann sich aus Gesetzen eine Haftung ergeben, wenn der zuständige officer beispielsweise die Lohnsteuer nicht abführt, die franchise tax nicht bezahlt oder gegen kapitalmarktrechtliche Vorschriften verstößt.

\subsubsection{Shareholders' Meeting}

Die gesetzlichen Regelungen zur Gesellschafterversammlung sind in allen Einzelstaaten nahezu identisch ${ }^{363}$. Mindestens einmal jährlich hat eine Versammlung der Gesellschafter (annual shareholders' meeting) stattzufinden. Sonstige Anteilseignerversammlungen (special shareholders' meeting) können auf Antrag des board of directors, in machen Bundesstaaten auch vom chief executive officer oder von den Gesellschaftern mit einer bestimmten Mindestbeteiligung (zumeist $10 \%$ ) einberufen werden.

Auf der Gesellschafterversammlung wird das alte board of directors abberufen und ein neues gewählt. Die Gesellschafterversammlung ist darüber hinaus mit einer Reihe von weiteren grundlegenden Rechten ausgestattet ${ }^{364}$. Sie kann Änderungen und Ergänzungen der Satzung und der bylaws beschließen und somit die innere Struktur der corporation bestimmen. Ihr steht die Entscheidungsbefugnis bei Angelegenheiten außerhalb der gewöhnlichen Geschäftstätigkeit zu, z.B. bei Veräußerung wesentlicher Teile des Geschäftsvermögens, bei einem Zusammenschluss mit einer anderen Gesellschaft oder bei Auflösung der Gesellschaft. Die Aktionäre können auf der Gesellschafterversammlung ferner bestimmte Entscheidungen der directors und der officers durch einen Ratifikationsbeschluss vor der Nichtigkeit oder Anfechtbarkeit bewahren.

Vgl. Hamilton (2000), S. 334; Bainbridge (2002), S. 285-286; Emanuel (2005), S. 177.

Vgl. hier und im Folgenden Merkt/Göthel (2006), S. 339-343.

Vgl. Merkt/Göthel (2006), S. 351-356.

Vgl. dazu Gevurtz (2000), S. 195-198, 210-219; Hamilton (2000), S. 254-258.
} 
Auf der Gesellschafterversammlung sind Aktionäre stimmberechtigt, die bis zu einem bestimmten Zeitpunkt (record date) vor der Versammlung als Aktionäre registriert waren ${ }^{365}$. Die Gesellschafterversammlung ist nur dann beschlussfähig, wenn das erforderliche quorum, d.h. der erforderliche Anteil ausstehender Anteile, anwesend ist. In vielen Einzelstaaten ist die Versammlung beschlussfähig, wenn die Inhaber einer einfachen Mehrheit der ausgegebenen und stimmberechtigten Anteile anwesend sind. Manche Staaten erlauben, dass in der Satzung oder in den bylaws ein niedrigeres quorum festgelegt wird ${ }^{366}$. Bei Anwesenheit der vorgeschriebenen Mindestzahl kann in der Regel deren einfache Mehrheit wirksame Beschlüsse fassen. In der Satzung oder in den bylaws kann allerdings grundsätzlich oder für bestimmte Entscheidungen eine qualifizierte Mehrheit vorgesehen werden.

Um dem Problem einer Beschlussunfähigkeit aufgrund mangelnder Teilnehmer entgegenzuwirken, besteht für die Aktionäre die Möglichkeit der Erteilung von Stimmrechtsvollmachten (proxies) ${ }^{367}$. Dadurch können (Klein-)Aktionäre ihr Stimmrecht von den Mitgliedern des Managements ausüben lassen. Dazu verschickt das Management proxy-Vordrucke, die Einzelheiten der Bevollmächtigung (z.B. Namen der Kandidaten, für die das Management stimmen wird, Wirtschaftsprüfungsgesellschaft, die den Prüfungsauftrag erhalten soll) beinhalten, und bittet um Unterzeichnung und Rücksendung. Die Aktionäre können auch von einzelnen Gesellschaftern um die Erteilung der Stimmrechtsvollmacht gebeten werden ${ }^{368}$. Unter bestimmten Voraussetzungen unterliegen die proxy-Aufforderungen den kapitalmarktrechtlichen Vorschriften der SEC, die verschiedene Registrierungs- und Offenlegungspflichten beinhalten und bei Verstößen eine von der Rechtsprechung entwickelte proxy-Haftung nach sich ziehen.

\subsubsection{Rechte und Pflichten der Aktionäre}

\subsubsection{Aktionärspflichten}

Neben den Mitgliedern des board of directors und den officers haben auch die Aktionäre bestimmte Pflichten zu beachten. Da allerdings die Aktionäre weder eine Geschäftsführungsbefugnis besitzen noch Dienste für die corporation erbringen, unterscheiden sich ihre Pflichten von denen der board-Mitglieder und officers grundlegend. Nach der herrschenden Meinung unterliegen die Mehrheitsgesellschafter einer Treuepflicht gegenüber den Minderheitsgesellschaftern, den Vorzugsaktionären und den Gesellschaftsgläubigern ${ }^{369}$. Begründet werden diese Pflichten in der Rechtsprechung zum einen mit der überlegenden Stellung des Mehrheitsaktionärs. Zum anderen wird angeführt, eine Treuepflicht müsse auch denjenigen treffen, der aufgrund seiner Stimmenmehrheit Einfluss auf das Management nehmen kann.

Die Treuepflicht der Minderheitsgesellschafter besteht insbesondere darin, dass sie ihr Stimmrecht nicht missbrauchen dürfen. Treuwidrig ist beispielsweise der Verkauf des Stimmrechts.

Vgl. Hamilton (2000), S. 258-262.

Teilweise werden aber auch besonders hohe quorum-Erfordernisse festgeschrieben, mit denen Minderheitsgesellschaftern Vetorechte gewährt werden. Vgl. Bungert (2003), S. 46-47.

Vgl. zum proxy-System etwa Hamilton (2000), S. 273-277, 418-437; Bainbridge (2002), S. 472-495; Palmiter (2003), S. 145-171; Emanuel (2005), S. 125-129; Merkt/Göthel (2006), S. 398-415.

Vgl. Emanuel (2005), S. 126.

Vgl. H. Henn/Alexander (1983), S. 654-656. 
Diesen Aktionärspflichten steht eine Reihe von Rechten gegenüber, die im Folgenden im Überblick dargestellt werden. Dabei wird insbesondere auf die wesentlichen Gemeinsamkeiten und Unterschiede im Vergleich zu den Aktionären einer deutschen Aktiengesellschaft hingewiesen. Analog zu Kapitel II.1.2.3.2 wird nach Herrschafts-, Informations- und Vermögensrechten differenziert.

\subsubsection{Aktionärsrechte}

\subsection{Herrschaftsrechte}

Mit dem Teilnahme-, Rede- und Stimmrecht im Rahmen der Gesellschafterversammlung und dem Klagerecht stehen den Aktionären Herrschaftsrechte zu, mit denen sie ihre Vermögensrechte absichern können.

Wie bereits erwähnt, können Aktionäre ihr Stimmrecht auf der Gesellschafterversammlung selbst ausüben oder eine Stimmrechtsvollmacht (proxy) ausstellen. Inwieweit einem Aktionär ein Stimmrecht zusteht, hängt von der von ihm gehaltenen Aktie ab, wobei die Einzelstaatengesetze im Gegensatz zum deutschen Aktienrecht sehr weitgehende Freiheiten bei der Ausgestaltung der Aktien vorsehen. Von dem Prinzip des one share-one vote kann in vielfältiger Weise abgewichen werden. Viele Einzelstaatengesetze erlauben die Ausgabe von stimmrechtslosen Aktien (non voting stock) ${ }^{370}$, Mehrstimmrechtsaktien und Höchststimmrechtsaktien, die nur mit einem Bruchteil einer Stimme ausgestattet sind ${ }^{371}$. Mindestens eine Aktiengattung muss allerdings mit einem uneingeschränkten Stimmrecht ausgestaltet sein. Weit verbreitet sind verschiedene Formen von Vorzugsaktien (preferred shares), die z.B. mit einem Vorrecht auf Dividendenzahlungen oder auf den Liquidationserlös ausgestattet sind ${ }^{372}$.

Um den Minderheitsgesellschaftern eine gewisse Repräsentation zu sichern, sehen manche Einzelstaaten das so genannte cumulative voting als Abstimmungsverfahren bei der Wahl des board of directors vor, in anderen Staaten muss es in der Satzung verankert werden. Im Gegensatz zum straight voting, bei dem jeder stimmberechtigte Anteil je Kandidat einmal gezählt wird und die einfache Mehrheit entscheidet, können die Anteilseigner beim cumulative voting ihre Stimmen kumulieren ${ }^{373}$.

370 Soweit es aber um grundlegende Änderungen der Gesellschaftsstruktur geht, sind stimmrechtslose Aktien nach den meisten Einzelstaatenrechten stimmberechtigt. Vgl. Merkt/Göthel (2006), S. 275.

371 Stammaktien werden folglich häufig in verschiedene Gattungen (classes of common stock) unterteilt, die dann üblicherweise als class A stock, class B stock usw. bezeichnet werden.

372 Satzungsbestimmungen sehen bei Vorzugsaktien häufig ein Einziehungsrecht (redemption right) der Gesellschaft vor. Danach kann die corporation die Vorzugsaktien einziehen, wofür die betreffenden Aktionäre einen festgelegten redemption price erhalten. Nach vielen Einzelstaatenrechten können Gesellschaften im Rahmen einer so genannten recapitalization kumulierte Dividendenrückstände durch Einziehung der alten Vorzugsaktien und Ausgabe neuer Vorzugsaktien beseitigen. Dazu muss allerdings die Mehrheit der auf die betreffenden Vorzugsaktien entfallenden Stimmen zustimmen, wobei den uberstimmten Aktionăren eine angemessene Abfindung zusteht. Vgl. Merkt/Göthel (2006), S. 605-607.

373 Vgl. dazu ausfuhrlich Merkt/Gothel (2006), S. 314-317. Zu einem anschaulichen Beispiel vgl. auch Pellens (2001a), S. 54; Ross/Westerfield/Jaffe (2005), S. 387. 
Darüber hinaus können die Aktionäre untereinander Stimmbindungsvereinbarungen eingehen, wobei zwischen voting agreements und voting trusts unterschieden wird $^{374}$. Voting agreements stellen formlose Absprachen unter zwei oder mehreren Aktionären dar, in denen sie sich z.B. verpflichten, ihre Stimmrechte bei bestimmten Tagesordnungspunkten in einer festgelegten Weise auszuüben. Bei einem voting trust wird der Eigentumstitel bezüglich der Anteile vom Treuhänder (trustee) gehalten, der das Stimmrecht in Übereinstimmung mit den Vereinbarungen ausübt, während den Aktionären als beneficial owners die Dividende sowie sonstige Vermögensrechte zustehen.

Den Aktionären stehen verschiedene Klageformen zur Verfügung, von denen im Folgenden die direct suit, die derivative suit und die class action kurz erläutert werden ${ }^{375}$. Die direct suit stellt eine Klage des Aktionärs aus eigenem Recht dar, mit der er gegen gesetzes- und satzungswidrige Beschlüsse und Maßnahmen der Verwaltungsorgane vorgehen kann, durch die er sich z.B. in seinen Vorzugs-, Bezugs-, Stimm- oder Minderheitsrechten verletzt sieht. Eine direct suit ist weiterhin die richtige Klageart, wenn er Einsichtsrechte wahrnehmen oder Verstöße gegen einen voting trust geltend machen will. Im Wege einer direct suit kann er auch seinen Anspruch auf eine vom board bereits beschlossene Dividende geltend machen. Einzelne Aktionäre können ferner auf Auflösung der Gesellschaft klagen (involuntary dissolution), wenn das Management oder der Mehrheitsaktionär ihre Machtstellung zu betrügerischen Zwecken missbraucht haben, das Gesellschaftsvermögen zweckwidrig verwendet wurde oder im board of directors eine Pattsituation mit der Folge entstanden ist, dass die Gesellschaft nicht mehr entscheidungsfähig ist ${ }^{376}$.

Die derivative suit stellt eine Klage aus abgeleitetem Recht dar, mit der ein Aktionär im eigenen Namen Ansprüche der Gesellschaft geltend machen kann, die aus unterschiedlichen Gründen nicht von der corporation bzw. von dem dafür zuständigen Organ selbst eingeklagt werden $^{377}$. In der Regel handelt es sich bei dem Schädiger um ein Mitglied des board oder einen officer. In solchen Fällen kann nicht davon ausgegangen werden, dass diejenige Person, die selbst eine Pflichtverletzung (z.B. Verstoß gegen die Sorgfalts- und Treuepflichten oder gegen das Verbot des self-dealing) begangen hat oder dem Ersatzpflichtigen kollegial verbunden ist, die gerichtliche Verfolgung von Ansprüchen der Gesellschaft anstrengen wird. Im Konzern existiert zudem die double bzw. multiple derivative suit, bei der ein Aktionär des Mutterunternehmens aus abgeleitetem Recht des Tochterunternehmens klagt.

Um den Missbrauch des Instruments der Klage zu verhindern, sehen die meisten Einzelstaatenrechte verschiedene Klagevoraussetzungen vor. Danach muss der Kläger bereits zum Zeitpunkt der Schädigung Aktionär gewesen sein und während des gesamten Verfahrens Aktionär bleiben. Vor Erhebung der Klage muss das board of directors erfolglos aufgefordert worden sein, die Klage selbst zu erheben. Schließlich hat der Kläger eine Sicherheit für die Prozesskosten der corporation zu hinterlegen. Hat eine derivative suit Erfolg, fließt der zugesprochene Schadensersatz ins Gesellschaftsvermögen und kommt dem klagenden Aktionär wie allen übrigen Aktionären nur indirekt über Kurssteigerungen oder Gewinnausschüttungen zugute. Gestützt auf empirische Untersuchungen wird die derivative suit als Instrument zur Kontrolle

374 Vgl. Merkt/Göthel (2006), S. 356-360.

375 Vgl. dazu ausführlich Merkt/Göthel (2006), S. 506-557.

376 Vgl. Bungert (2003), S. 53; Merkt/Göthel (2006), S. 706-709.

377 Vgl. hierzu ausführlich Eisenberg (2000), S. 928-994; Gevurtz (2000), S. 386-425; Hamilton (2000), S. 535-555; Emanuel (2005), S. 347-374; Merkt/Göthel (2006), S. 506-557. 
der Unternehmensleitung in großen Teilen der Literatur für ungeeignet und unwirtschaftlich gehalten $^{378}$.

Die class suit ist in den USA aus praktischen Notwendigkeiten heraus für die Fälle entwickelt worden, in denen die Zahl der möglichen Kläger so groß ist, dass eine Beteiligung aller Kläger unverhältnismäßig aufwendig oder sogar unmöglich wäre ${ }^{379}$. Anstelle dessen erhebt ein Aktionär aus eigenem Recht eine Klage, die stellvertretend auch für alle anderen möglichen Kläger gilt.

\subsection{Informationsrechte}

Um ihre vorstehend beschriebenen Herrschaftsrechte zielgerichtet ausüben zu können, sind die Aktionäre auf Informationsrechte angewiesen. Nach den common law-Grundsätzen hat jeder ordnungsgemäß eingetragene Aktionär das Recht auf Einsichtnahme in sämtliche Geschäftsbücher und -unterlagen ${ }^{300}$. Dafür muss der Aktionär allerdings einen hinreichenden Grund (proper purpose) anführen können, wie z.B. Einsichtnahme in das Aktienbuch zur Kontaktaufnahme mit anderen Gesellschaftern in der Absicht, eine derivative suit vorzubereiten, zur Erteilung von proxy-Stimmrechten aufzufordern oder Informationen hinsichtlich einer geplanten Fusion zu verbreiten. Viele corporations wiesen lange Zeit Gesellschafter, die ihr Einsichtnahmerecht geltend machen wollten, ab, von denen auch nur wenige den Aufwand einer Klage auf sich nahmen ${ }^{381}$.

Mittlerweile haben zahlreiche Einzelstaaten das Einsichtnahmerecht gesetzlich kodifiziert, das weder in der Satzung noch in den bylaws eingeschränkt werden kann ${ }^{382}$. Darüber hinaus sehen viele Einzelstaatengesetze vor, dass den Anteilseignern ein Jahresabschluss der Gesellschaft vorzulegen ist, der aus Gewinn- und Verlustrechnung, Bilanz und Eigenkapitalveränderungsrechnung bestehen muss. Wird der Jahresabschluss von einem Wirtschaftsprüfer testiert, muss dieser auch den Bestätigungsvermerk enthalten. Ist dies nicht der Fall, muss im Jahresabschluss darüber berichtet werden, ob die US-GAAP angewandt bzw. welche anderen Rechnungslegungsmethoden herangezogen wurden und inwiefern es $\mathrm{zu}$ Abweichungen bei der Vorgehensweise im Vergleich zum Vorjahr gekommen ist. Im Gegensatz zum deutschen Aktiengesetz existiert im US-amerikanischen Recht kein gesetzlich kodifiziertes Auskunftsrecht der Anteilseigner mit der Möglichkeit eines Auskunftserzwingungsverfahrens ${ }^{383}$.

Während die gesellschaftsrechtlich kodifizierte Rechnungslegungspflicht - mit Ausnahme des kalifornischen Rechts - weder formal noch materiell besonderen Vorschriften unterliegt, ergeben sich aus dem bundesstaatlichen Kapitalmarktrecht detaillierte und zwingend zu beachtende Rechnungslegungs- und Offenlegungspflichten. Wie in Kapitel II.2.2.1 bereits im Einzelnen erläutert, werden Anteilseigner von kapitalmarktorientierten und bei der SEC regist-

\footnotetext{
378 Vgl. Merkt/Göthel (2006), S. 552-557 m.w.N.

379 Vgl. zur class suit z.B. Hamilton (2000), S. 556-574; Palmiter (2003), S. 303-304.

380 Vgl. zu den Einsichtnahmerechten ausführlich Hamilton (2000), S. 599-608; Merkt/Göthel (2006), S. 367-371. Vgl. auch Bungert (2003), S. 47.

381 Vgl. Merkt/Göthel (2006), S. 369.

382 Vgl. Hamilton (2000), S. 602-603; Palmiter (2003), S. 112-113.

383 Vgl. Bungert (2003), S. 47.
} 
rierten corporations mit umfassenden, regelmäßigen und zeitnah veröffentlichen Informationen versorgt.

\subsection{Vermögensrechte}

Die Vermögensrechte von Aktionären einer corporation umfassen im Wesentlichen das Recht auf anteilige Beteiligung an Gewinnausschüttungen, das Recht auf anteilige Berücksichtigung bei der Verteilung des Liquidationserlöses im Falle der Auflösung der Gesellschaft und - abhängig von den Vorschriften in der Satzung - gegebenenfalls das Bezugsrecht.

Im Gegensatz zu Deutschland leitet sich der Anspruch der Aktionäre auf Dividendenzahlungen bei einer corporation nicht aus dem verteilungsfähigen Jahresüberschuss im festgestellten Jahresabschluss $\mathrm{ab}^{384}$. Ob und gegebenenfalls in welcher Höhe eine Dividende gezahlt wird, ergibt sich aus dem Ausschüttungsbeschluss des board of directors. Bei seiner Entscheidung wird das board von der business judgment rule geschützt, d.h. sein Beschluss wird keiner gerichtlichen Kontrolle unterzogen, wenn die board-Mitglieder bestimmte Sorgfalts- und Treuepflichten beachtet haben. Zusätzlich zu etwaigen Ausschüttungsbeschränkungen, die sich aus Kreditvereinbarungen und sonstigen vertraglichen Abreden ergeben können, muss das board of directors verschiedene gesetzliche Restriktionen beachten, die die zulässige Höchstausschüttung determinieren ${ }^{385}$. Verbotswidrig gezahlte Dividenden können dazu führen, dass die Mitglieder des board zum Schadensersatz verpflichtet werden. Auch Aktionäre können sich haftbar machen, wenn sie unzulässige Dividenden erhalten haben ${ }^{386}$. Gesetzliche Mindestausschüttungsregeln existieren hingegen nicht. Die Aktionäre einer corporation haben somit grundsätzlich keinen Anspruch auf Dividendenausschüttungen ${ }^{387}$. Gleichwohl weisen empirische Untersuchungen zur Ausschüttungspolitik börsennotierter Gesellschaften auf deutlich höhere Ausschüttungsquoten in den USA im Vergleich zu Deutschland hin ${ }^{388}$. Hat das board of directors die Ausschüttung einer Dividende beschlossen, erwerben die Aktionäre einen Anspruch auf Auszahlung der Dividende ${ }^{389}$.

Vgl. Pellens (2001a), S. 55.

Hierauf ist in Kapitel II.2.2.2.1 bereits überblicksartig hingewiesen worden. Die Einzelheiten werden in Kapitel III.2 detailliert dargestellt.

Vgl. dazu im Überblick Merkt/Göthel (2006), S. 302-303. Vgl. zu den Haftungsregeln ausführlich die Kapitel III.2.2.1.4 (MBCA), III.2.3.1.3 (Delaware), III.2.3.2.4 (Kalifornien).

Vgl. Bainbridge (2002), S. 793; Black (2004), §1.2, S. 9 jeweils mit zahlreichen Rechtsprechungsnachweisen. Etwas anderes gilt allenfalls dann, wenn den Aktionären im Rahmen einer Garantieerklärung Dividendenausschüttungen versprochen worden sind. Vgl. Merkt/Göthel (2006), S. 298, Fn. 250 m.w.N. Ausnahmen gelten darüber hinaus fur closely held corporations, bei denen Gerichte teilweise die Zahlung von Dividenden angeordnet haben, insbesondere dann, wenn sie vom Management aus unredlichen Motiven (z.B. unangemessen hohe Vergütungen für board-Mitglieder und officers) versagt wurden. Teilweise wird den Gesellschaftern von closely held corporations ein Dividendenanspruch selbst dann zugesprochen, wenn die Geschäftslage für eine Rücklagenbildung spricht. Begründet wird dieses Vorgehen damit, dass Anteile an einer closely held corporation nur eingeschränkt handelbar sind und Anteilseigner solcher Gesellschaften in besonderer Weise auf ein Einkommen in Form von Dividenden angewiesen sind.

Vgl. Kronstein/Claussen (1960), S. 135; Ziemann (1993), S. 138-139, 144-146; Augustin (1994), S. 661-662.

Vgl. z.B. McLaren v. Crescent Planing Mill Co., 117 Mo. App. 40, 93 S.W. 819 (1906); Caleb \& Co. v. Dupont de Nemours \& Co., 615 F.Supp. 96 (S.D. N.Y. 1985). 
In den meisten Einzelstaatengesetzen ist ein weit gefasster Ausschüttungsbegriff kodifiziert, der nicht nur Dividenden, sondern jede Form der direkten oder indirekten Übertragung von Vermögenswerten an die Aktionäre umfasst. Den gesellschaftsrechtlichen Ausschüttungsregeln unterliegen damit auch Aktienrückkäufe, die in den USA neben Dividendenzahlungen seit langem ein verbreitetes Ausschüttungsinstrument darstellen ${ }^{390}$.

Führt die corporation eine Kapitalerhöhung durch, werden die derzeitigen Aktionäre nach den Grundsätzen des common law durch ein Bezugsrecht (preemptive right) geschützt ${ }^{391}$. Dadurch soll es den Altaktionären ermöglicht werden, bei der Ausgabe neuer Aktien keine Kapital- und Stimmrechtsverwässerung zu erleiden. Das Bezugsrecht unterliegt allerdings in vielen Bundesstaaten wesentlichen Beschränkungen. In manchen Einzelstaatengesetzen ist ein Bezugsrecht zwar vorgesehen, kann aber in der Satzung abbedungen werden. Andere Staaten schreiben ein Bezugsrecht gesetzlich nicht vor, gewähren den Unternehmen aber die Möglichkeit, es in der Satzung zu verankern. In der Praxis ist die Gewährung von Bezugsrechten bei public corporations unüblich ${ }^{392}$, da in der kostspieligen und zeitraubenden Abwicklung des Bezugsrechts eine Beeinträchtigung der flexiblen Eigenkapitalbeschaffung gesehen wird. Die Altaktionäre werden nach der Rechtsprechung durch die Verpflichtung des board, die neuen Aktien nicht unter ihrem Marktwert auszugeben, geschützt. Eine Treuepflicht gegenüber den Minderheitsgesellschaftern haben auch die Mehrheitsaktionäre zu beachten ${ }^{393}$.

Bei der Liquidation einer corporation steht den Aktionären ein Anteil am verbleibenden Gesellschaftsvermögen zu. Vorher sind allerdings die Ansprüche Dritter sowie etwaige in der Satzung vorgesehene Liquidationsvorrechte bestimmter Aktiengattungen zu befriedigen ${ }^{394}$.

\subsection{Zwischenergebnis}

Als Ergebnis der Ausführungen zur corporation ist festzuhalten, dass sie in allen Bundestaaten der USA nach einem ähnlichen Grundmuster aufgebaut ist. Danach legen die Mitglieder des board of directors die wesentlichen Leitlinien der Geschäfts- und Unternehmenspolitik fest. Die officers werden vom board bestellt und führen als leitende Angestellte - unter der Aufsicht des board - die operativen Tagesgeschäfte der Gesellschaft. Der Gesellschafterversammlung (shareholders' meeting) obliegt die Bestellung und Abberufung des board of directors und Entscheidungen in grundlegenden oder außergewöhnlichen Angelegenheiten.

Den Aktionären steht eine Reihe von mitgliedschaftlichen Rechten zu. Im Rahmen ihrer Herrschaftsrechte stellt die Möglichkeit der (multiple) derivative suit eine Besonderheit des USamerikanischen Rechts dar. Im Gegensatz zu den Aktionären einer deutschen Aktiengesellschaft haben die Gesellschafter einer corporation grundsätzlich keinen Anspruch auf die $\mathrm{Zu}-$ teilung einer Dividende. Die Ausschüttungsentscheidung fällt in die alleinige Kompetenz des board of directors, das dabei allerdings bestimmte Sorgfalts- und Treuepflichten sowie gesetzliche, satzungsmäßige und vertragliche Ausschüttungsrestriktionen zu beachten hat. Zur ziel-

Vgl. Schremper (2002), S. 2; Jaeger (2004), S. 32-33, jeweils m.w.N. Vgl. zur ungebremsten Popularität von Aktienrückkäufen in den USA in der jüngeren Vergangenheit $o . V$. (2005a).

Vgl. Gevurtz (2000), S. 134-139; Bainbridge (2002), S. 79-80; Emanuel (2005), S. 571-574; Merkt/Göthel (2006), S. 279-281.

Vgl. Kübler (1989), S. 50 m.w.N; Gevurtz (2000), S. 136; Hamilton (2000), S. 200-201.

Vgl. Gevurtz (2000), S. 137-139; Merkt/Göthel (2006), S. 281, jeweils m.w.N.

Vgl. Gevurtz (2000), S. 118; Merkt/Göthel (2006), S. 713. 
gerichteten Ausübung der Herrschaftsrechte und zur Beurteilung der Dividendenpolitik des Managements können die Aktionäre insbesondere von kapitalmarktorientierten corporations die umfangreichen und zeitnah bereitgestellten Informationen nutzen, die ihnen aufgrund der Publizitätspflichten von SEC-registrierten Unternehmen zur Verfügung gestellt werden müssen.

Im Vergleich zum Corporate-Governance-System in Deutschland fällt die unterschiedliche Schwerpunktsetzung von Regulierungen im Kapital- und Gesellschaftsrecht der USA auf. Im Gegensatz zu Deutschland ist das Gesellschaftsrecht weitgehend dereguliert und lässt den Gesellschaftern große Spielräume bei der Ausgestaltung der Unternehmensverfassung. Da das Gesellschaftsrecht in den Kompetenzbereich der Einzelstaaten fällt, weichen die gesellschaftsrechtlichen Vorschriften von Staat zu Staat teilweise erheblich voneinander ab, was durch die Auslegung des Rechts durch einzelstaatliche Gerichte noch verstärkt wird. Zwingend zu beachtende Vorschriften ergeben sich für die kapitalmarktorientierte corporation aus dem Kapitalmarktrecht, wobei sich diese insbesondere in umfangreichen Publizitätspflichten konkretisieren.

Aufbauend auf den rechtlichen Grundlagen der Aktiengesellschaft und der corporation wird im nachfolgenden Kapitel III das Kapitalsystem dieser Gesellschaften im Detail herausgearbeitet. Vor dem Hintergrund der aufgezeigten Besonderheiten des US-amerikanischen Rechtssystems wird hinsichtlich des Einzelstaatenrechts mit Delaware und Kalifornien eine Auswahl getroffen. Darüber hinaus werden die Regeln des MBCA, dessen Ausschüttungsregeln von vielen Staaten der USA übernommen worden sind, sowie die wesentlichen Kapitalschutzregeln weiterer Gesetze dargestellt. 


\title{
Kapitel III: \\ Kapitalschutzsysteme in Deutschland und in den USA
}

\author{
1 Kapitalschutzsystem in Deutschland
}

\subsection{Aktien- und handelsrechtliche Regelungen}

\subsubsection{Einleitung}

Das deutsche Kapitalschutzsystem der Aktiengesellschaft ist durch ein Zusammenspiel von Kapitalaufbringungs- und Kapitalerhaltungsregeln sowie handelsrechtlicher Bilanzierung gekennzeichnet. Dieses Konzept stellt ein Beispiel für den mehrdimensionalen Ansatz gesellschaftsrechtlicher Regulierung in Deutschland dar, der die Interessen verschiedener Gruppen zu berücksichtigen versucht ${ }^{395}$. Dem Interesse der Anteilseigner an angemessenen Dividendenzahlungen stehen die Interessen anderer Unternehmensbeteiligter - insbesondere der Gläubiger - an Gewinnthesaurierung zur Erhöhung der Haftungsmasse entgegen.

Die handelsrechtlichen Rechnungslegungsregeln versuchen, einen Ausgleich dieser beiden Interessenlagen herbeizuführen. Zum einen werden die Interessen der Aktionäre berücksichtigt, indem Bilanzansatzpflichten für bestimmte Aktiva und Bilanzansatzverbote für bestimmte Passiva sowie Bewertungsuntergrenzen für Aktiva und Bewertungsobergrenzen für Passiva zu beachten sind. Damit wird der Gewinn zum Zwecke des Anlegerschutzes nach unten hin begrenzt (Mindestausschüttung). Zum anderen werden die Interessen der Gläubiger durch Bilanzansatzverbote für bestimmte Aktiva und Bilanzansatzpflichten für bestimmte Passiva sowie Bewertungsobergrenzen für Vermögensgegenstände und Bewertungsuntergrenzen für Schulden geschützt, wodurch der Gewinn nach oben hin begrenzt wird (Höchstausschüttung). Wie die weiteren Ausführungen zeigen werden, stellen die Gewinnermittlungsregeln in Deutschland das Gläubigerschutzprinzip in den Vordergrund ${ }^{396}$. Auch der Grundsatz der Aufbringung und Erhaltung des Grundkapitals soll primär dem Gläubigerschutz dienen ${ }^{397}$.

\subsubsection{Kapitalaufbringung}

Aktiengesellschaften müssen ein gesetzliches Mindestkapital in Höhe von $50.000 €(\S 7$ $\mathrm{AktG})^{398}$ aufweisen, das traditionell als Korrelat zum Privileg der Haftungsbeschränkung der

\footnotetext{
395 Vgl. Merkt (2001a), S. 145; Merkt (2003), S. 127.

Vgl. Moxter (1986), S. 67; Adler/Düring/Schmaltz (1997b), § 264, Tz. 88; Beater (2001), § 264, Tz. 23; Winkeljohann/Schellhorn (2006), § 264, Tz. 35. Vgl. ausführlich Kapitel III.1.1.3.2.

Vgl. Kübler (1999b), S. 153-154; Hueck/Windbichler (2003), S. 252.

Ein höheres Eigenkapital müssen Kreditinstitute aufweisen, die Unternehmen als Emissionsbegleiter bei der Börsenzulassung beraten. Ihre Mindestkapitalausstattung muss gemäß $\S 30$ BörsG $730.000 €$ betragen. Die Emittenten selbst erhalten gemäß § 2 BörsZulV eine Börsenzulassung nur unter der Voraussetzung, dass der voraussichtliche Kurswert ihrer Aktien mindestens 1,25 Mio. $€$ betragen wird. Ist eine Schătzung nicht möglich, muss die Gesellschaft ein bilanzielles Eigenkapital in dieser Höhe aufweisen. Für die Zulassung anderer Wertpapiere gilt ein Mindestnennbetrag von $250.000 €$ (§ 2 Abs. 2 BörsZulV).
} 
Aktionäre gesehen wird ${ }^{399}$. Die Gläubiger sollen dadurch geschützt werden, dass ihnen die auf der Aktivseite der Bilanz ausgewiesenen Vermögensgegenstände in wirtschaftlichen Krisenzeiten zur Erfüllung ihrer Ansprüche zur Verfügung stehen und zwar mindestens in der Höhe, in der Eigenkapital, wie es auf der Passivseite ausgewiesen wird, zwingend vorzuhalten ist.

Zum Schutz des Grundkapitals sieht das Aktienrecht vielfältige Vorschriften vor, von denen die wichtigsten im Folgenden der Vollständigkeit halber kurz genannt werden sollen, im weiteren Verlauf der Arbeit aber nicht weiter vertieft werden ${ }^{400}$. Das Verbot der Unterpariemission stellt sicher, dass Aktien nicht unter ihrem Nennbetrag bzw. rechnerischen Wert ausgegeben werden ( $\$ 9$ Abs. 1 AktG). Die Gründer der Aktiengesellschaft müssen sich zur Übernahme aller Aktien verpflichtet haben, damit die Gesellschaft rechtsfähig wird ( $\S 2,29$ AktG). Von der Verpflichtung, ihre Einlage zu leisten, dürfen die Aktionäre nicht befreit werden ( $§ 66 \mathrm{AktG})$, und die Einlagenrückgewähr ist verboten ( $\$ 57 \mathrm{AktG})$. Der Erwerb eigener Aktien durch die Aktiengesellschaft ist nur unter sehr restriktiven Voraussetzungen erlaubt (§§71-71e AktG), weil auch dadurch Vermögen der Gesellschaft an die Aktionäre zurückfließt, was wirtschaftlich gesehen einer Einlagenrückgewähr entspricht ${ }^{401}$. Bareinlagen müssen bei der Gründung grundsätzlich zu mindestens $25 \%$ des Nennbetrags bzw. des rechnerischen Wertes geleistet werden ( $\S \S 36$ Abs. 2, 36a Abs. 1 AktG). Bei Sachgründungen ist der Gründungsbericht gemäß $\S 33 \mathrm{AktG}$ nicht nur durch Vorstand und Aufsichtsrat, sondern auch durch vom Gericht bestellte unabhängige Sachverständige (in der Regel Wirtschaftsprüfer) zu begutachten. Sacheinlagen müssen innerhalb von fünf Jahren erbracht sein ( $\$ 36 \mathrm{a} \mathrm{Abs} .2$ $\mathrm{AktG})$. Eine deutsche Besonderheit zur Sicherung der Kapitalaufbringung stellt ferner die Lehre von der verdeckten Sacheinlage dar ${ }^{402}$.

\subsubsection{Kapitalerhaltung}

\subsubsection{Gewinnverwendungsregeln}

Die Rechte der Aktionäre auf Dividendenzahlungen und der Schutz der Gläubiger vor zu hohen Ausschüttungen sind in den letzten 150 Jahren starken Wandlungen unterlegen ${ }^{403}$. Sie sehen heute bei der Aktiengesellschaft wie folgt aus: Zunächst ist der über die handelsrechtlichen Grundsätze ordnungsmäßiger Buchführung (GoB) ermittelte und in der Gewinn- und Verlustrechnung ausgewiesene Jahresüberschuss gegebenenfalls um Einstellungen in die gesetzliche Rücklage zu kürzen ( 150 Abs. 1 AktG). Gemäß $§ 150$ Abs. 2 AktG sind solange $5 \%$ des um einen Verlustvortrag geminderten Jahresüberschusses in die gesetzliche Rücklage

399 Vgl. Lutter (1964), S. 41; Wiedemann (1980), S. 557-558. Zu weiteren Funktionen des Kapitalsystems vgl. z.B. Lutter (1998); dazu kritisch etwa Grundmann (2004), S. 142-145. Vgl. dazu ausführlich Kapitel V.5.1-V.5.3.

400 Vgl. zu diesen Vorschriften ausführlich Grunewald (2005), S. 235-245, 290-293. Vgl. überblicksartig auch Hueck/Windbichler (2003), S. 252-254; Klunzinger (2004), S. 154-156.

401 Vgl. Kübler (1999b), S. 154; HueckWindbichler (2003), S. 253, 356.

402 Vgl. dazu umfassend Klose-Mokroß (1997); Hüffer (2006), § 27, Tz. 9-19 m.w.N. Zur strittigen Europarechtskonformität vgl. ausführlich z.B. Schwarz (2000), S. 375-378 m.w.N. Zur Kritik vgl. auch Kapitel V.5.3.2

403 Vgl. dazu insbesondere Kohl (1991), S. 90-149. Zu einem Überblick vgl. auch Frodermann (1994), S. 29-31. Vgl. zu einem geschichlichen Überblick speziell zum Konzernrecht Pellens (1994), S. 18-37. 
einzustellen, bis diese zusammen mit der Kapitalrücklage $10 \%$ oder einen in der Satzung festgelegten höheren Anteil am gezeichneten Kapital erreicht ${ }^{404}$.

Im Regelfall der Feststellung des Jahresabschlusses durch Vorstand und Aufsichtsrat ( $\$ 172$ AktG) darf die Verwaltung anschließend höchstens die Hälfte des verbleibenden Jahresüberschusses den Gewinnrücklagen zuweisen ( $\$ 58$ Abs. 2 S. 1 AktG). Die Satzung kann die Verwaltung allerdings dazu ermächtigen, einen größeren oder kleineren Teil ${ }^{405} \mathrm{zu}$ thesaurieren, solange die anderen Rücklagen die Hälfte des Grundkapitals nicht übersteigen ( $\$ 58$ Abs. $2 \mathrm{~S}$. 2 und $3 \mathrm{AktG})^{406}$. Die aus früheren Jahresüberschüssen gebildeten Gewinnrücklagen können - mit Ausnahme der Beträge zur Bildung der gesetzlichen und satzungsmäßigen Rücklage, die den Bindungen gemäß $\S 150 \mathrm{Abs}$. 3 AktG unterliegen - aufgelöst und zur Gewinnausschüttung verwandt werden.

Die Hauptversammlung entscheidet demnach über die Verwendung des um Einstellungen und Auflösungen von Gewinnrücklagen modifizierten Jahresüberschusses, den Bilanzgewinn ( 58 Abs. 4 AktG). Lediglich im Ausnahmefall, dass die Feststellung des Jahresabschlusses nicht durch Vorstand und Aufsichtsrat erfolgt, erlangt die Hauptversammlung eine größere Gewinnverwendungskompetenz. In diesem Fall obliegt der Hauptversammlung die Feststellung des Jahresabschlusses ( $§ 173 \mathrm{AktG})$ und somit die vollständige Gewinnverwendung. In der Satzung kann aber vereinbart werden, dass bis zu $50 \%$ des Jahresüberschusses in die anderen Gewinnrücklagen einzustellen sind ( $§ 58 \mathrm{Abs} .1 \mathrm{AktG})$.

Das deutsche Aktiengesetz reguliert folglich zum einen eine Mindestausschüttung an die Aktionäre in Höhe des halben Jahresüberschusses. Die von den Aktionären in der Hauptversammlung mit qualifizierter Mehrheit beschlossene Satzung kann diesen Betrag nach herrschender Meinung allerdings so lange bis auf Null reduzieren ${ }^{407}$, wie die anderen Gewinnrücklagen die Hälfte des Grundkapitals nicht übersteigen. Die Hauptversammlung hat bei ihrem Beschluss über die Verwendung des Bilanzgewinns zu beachten, dass in Jahren, in denen eine Thesaurierung oder ein Gewinnvortrag bei vernünftiger kaufmännischer Beurteilung zum Schutz der Gesellschaft nicht erforderlich erscheinen, die Aktionäre eine Dividende von mindestens $4 \%$ des durch Einlagen belegten Grundkapitals erhalten müssen. Anderenfalls kann der Beschluss über die Verwendung des Bilanzgewinns gemäß $\S 254 \mathrm{Abs} .1 \mathrm{AktG}$ angefochten werden ${ }^{408}$.

Zum anderen wird die Höchstausschüttung an die Aktionäre durch das Zusammenspiel der GoB und gesellschaftsrechtlicher Vorschriften begrenzt. So knüpfen die strengen Kapitalerhaltungsregeln der $\S \S 150,174 \mathrm{AktG}$ sowie die Ergebnisverwendung nach $\S 58 \mathrm{AktG}$ an ein Jahresergebnis an, das nach den vom Gläubigerschutzgedanken geprägten HGB-Regelungen ermittelt wird und somit von den angewandten Bilanzansatz- und -bewertungsregeln abhängig ist. Auf diese Rechnungslegungsregeln wird im Folgenden ausführlich eingegangen.

404 Vgl. hier und im Folgenden z.B. auch Dirrigl/Wagner (1993), S. 263-266; Hueck/Windbichler (2003), S. 362-364, 379-380, 387-388.

405 Die bisherige Einschränkung, dass die Satzung von börsennotierten Gesellschaften Vorstand und Aufsichtsrat nur zur Einstellung eines grőßeren Teils ermächtigen darf, ist durch das TransPuG abgeschafft worden.

406 Diese Grenze gilt allerdings nur fur den Thesaurierungsbetrag, der die 50\%-Grenze des $§ 58$ Abs. 2 S. 1 AktG übersteigt. Vorstand und Aufsichtsrat können also unabhängig von der Höhe der Gewinnrucklagen und des gezeichneten Kapitals jedes Jahr $50 \%$ des korrigierten Jahresuberschusses den Rücklagen zufuhren. Vgl. dazu Adler/Düring/Schmaltz (1997a), § 58, Tz. 60, 67.

Vgl. z.B. Hüffer (2006), § 58, Tz. 12.

Vgl. dazu bereits Kapitel II.1.2.3.2.1. 


\subsubsection{Gewinnermittlungsregeln}

Die soeben erläuterten aktienrechtlichen Gewinnverwendungsregeln greifen auf ein Geschäftsjahresergebnis zurück, das sich unter Befolgung der Rechnungslegungsvorschriften des HGB als Differenz zwischen Erträgen und Aufwendungen ergibt. Bei der Erstellung des Jahresabschlusses müssen gemäß $\S 243$ Abs. 1 HGB die GoB beachtet werden. Die GoB stellen einen „Normbehelf in der Form eines unbestimmten Rechtsbegriffes“409 dar, der durch die (Steuer-)Rechtsprechung, das Fachschrifttum und Praktiker ausgefüllt wird und die Weiterentwicklung der Rechnungslegungsregeln und deren Anpassung an sich verändernde Bedingungen ermöglicht. ${ }^{410}$. Zur Gewinnung der GoB werden zwei Methoden diskutiert ${ }^{411}$. Nach der induktiven Methode werden die GoB aus den in der Praxis zu beobachtenden Bilanzierungsweisen ordentlicher und ehrbarer Kaufleute abgeleitet ${ }^{412}$. Bei der deduktiven Methode werden die $\mathrm{GoB}$ aus den Jahresabschlusszwecken hergeleitet ${ }^{413}$. Die herrschende Meinung plädiert für die deduktive Ermittlung ${ }^{414}$.

Die Basis für die Gewinnung der handelsrechtlichen GoB bilden danach die Zwecke, die mit der gesetzlichen Rechnungslegung verfolgt werden. Diese Zwecke müssen selbst wiederum aus der Entstehungsgeschichte des Gesetzes, den Absichten des Gesetzgebers, den Ansichten der Anwender und Adressaten, Entscheidungen der Rechtsprechung sowie betriebswirtschaftlichen Überlegungen hergeleitet werden ${ }^{415}$.

\subsection{Zwecke des handelsrechtlichen Jahresabschlusses}

In der Literatur werden überwiegend drei Zwecke bzw. Funktionen des handelsrechtlichen Jahresabschlusses unterschieden ${ }^{416}$. Dem Jahresabschluss wird erstens eine Dokumentationsfunktion zugeschrieben ${ }^{417}$. Die zahlenmäßige Abbildung der Geschäftsvorfälle während der Berichtsperiode sowie der Stand von Vermögen und Schulden am Ende der Periode sollen

409

410

411

$\mathrm{Zu}$ einem Überlick vgl. Leffson $(1$ (2005), S. 106-107.

412 Vgl. Schmalenbach (1933), S. 231-233; Trumpler (1950), S. 80.

413 Vgl. Döllerer (1959), S. 1218-1221. Je nach dem, ob als Deduktionsbasis betriebswirtschaftlich abgeleitete oder gesetzlich festgelegte Jahresabschlusszwecke herangezogen werden, wird weiter zwischen betriebswirtschaftlich deduktiver und handelsrechtlich deduktiver Methode unterschieden. Vgl. zu dieser Unterscheidung D. Schneider (1983), S. 158; Baetge/Kirsch (1995), S. 138-140. Schließlich wird zur Auslegung gesetzlicher GoB die hermeneutische Methode bemüh. Zur hermeneutischen Methode vgl. Baetge/Kirsch (1995), S. 140-145; Ballwieser (1995), S. 46; Baetge/Kirsch/Thiele (2005), S. 107-113.

414 Vgl. Leffson (1987), S. 29; Adler/Düring/Schmaltz (1998), § 243, Tz. 14; Förschle (2006), § 243, Tz. 14.

415 Vgl. Baetge (2002), Sp. 637-638.

416 Vgl. ausführlich Leffson (1987), S. 28-63; Baetge/Kirsch/Thiele (2005), S. 94-104; Coenenberg (2005), S. 12-16; Pellens/Fülbier/Gassen (2006), S. 10-13. Für einen prägnanten Überblick vgl. Pellens (1998); Bonse/Linnhoff/Pellens (2002a), S. 316-317; Busse von Colbe (2002c); Wöhe (2005), S. 836-838. Zu den Zielkonflikten vgl. z.B. Busse von Colbe (1994), S. 44-49. Stützel (1967), S. 322-332, identifiziert zehn Zwecke. Zur Kritik daran, dass der Gesetzgeber den Zweck des gesetzlichen Rechnungswesens nicht explizit vorgibt, vgl. Streim (1986), S. 12-14.

417 Diese Ansicht kann insofern kritisiert werden, als durch die Erstellung des Jahresabschlusses zwangsläufig eine Dokumentation von Geschäftsvorfällen erfolgt. 
vollständig und nachprüfbar dokumentiert werden. Damit kann der Jahresabschluss in Insolvenz- oder Vergleichsfällen sowie in möglichen Rechtstreitigkeiten als Beweisinstrument herangezogen werden. Die Dokumentation des Unternehmensgeschehens dient zudem der Rechenschaft der Unternehmensvertreter gegenüber ihnen selbst und insbesondere gegenüber den außenstehenden Unternehmensbeteiligten.

Der Jahresabschluss hat zweitens eine Informationsfunktion. Die Jahresabschlussdaten sollen für einen großen Kreis von Nutzern (z.B. Eigen- und Fremdkapitalgeber, Lieferanten, Kunden, Arbeitnehmer) eine Entscheidungshilfe für ihre weiteren oder potentiellen Geschäftsbeziehungen mit dem Unternehmen bieten. In der Literatur wird die Informationsfunktion aber primär dem Konzernabschluss zugeschrieben ${ }^{418}$.

Nach verbreiteter Ansicht dient der Jahresabschluss in Deutschland drittens und in erster Linie der Einkommensbemessungsfunktion ${ }^{419}$. Durch die Vorschriften zur Ermittlung des Gewinns einer Kapitalgesellschaft sollen zum einen die Kapitalgeber, d.h. die Gläubiger und die Gesellschafter, geschützt werden ${ }^{420}$. Dabei wird der Gläubigerschutz in den Vordergrund gestellt ${ }^{421}$. Der im Jahresabschluss ermittelte Gewinn ist zum anderen Basis für Steuerzahlungen an den Fiskus.

Während die Ansprüche der meisten anderen Unternehmensbeteiligten vertraglich abgesichert sind (z.B. Zinszahlungen an die Fremdkapitalgeber gemäß Kreditvertrag, Lohn- und Gehaltszahlungen an die Arbeitnehmer gemäß Arbeitsvertrag, Zahlung des Kaufpreises an die Lieferanten gemäß Kaufvertrag), haben die Anteilseigner des Unternehmens keinen vertraglich festgelegten Anspruch als Gegenleistung für ihr Eigenkapital, das sie dem Unternehmen überlassen haben. Sie sind so genannte Residualanspruchsberechtigte ${ }^{422}$, die nur befriedigt werden können, wenn nach Erfüllung aller vertraglichen Verpflichtungen ein Restbetrag übrig bleibt. Im Jahresabschluss wird dieses Residualeinkommen nach festgelegten Regeln ermittelt, das dann für Ausschüttungen an die Aktionäre zur Verfügung steht.

418 Vgl. zu den grundsătzlichen Mängeln des handelsrechtlichen Einzelabschlusses als Informationsinstrument z.B. D. Schneider (1963), S. 467; Busse von Colbe (1966b), S. 88-96; Moxter (1986), S. 64-68; Ballwieser (1987), S. 57; Clemm (1987), S. 100-106; Pellens (1989), S. 33-40; D. Schneider (1997a), S. 10-11, 200-207; Schildbach (2004), S. 27-31. Zur Abkopplungsthese, nach der Informationsverzerrungen in Bilanz und Gewinn- und Verlustrechnung durch Zusatzinformationen im Anhang zu beseitigen sind, vgl. Moxter (1979), S. 141-142; Beisse (1989), S. 22-23; diese These ablehnend vgl. z.B. Merkt (2006a), § 264, Tz. 9 m.w.N.

Vgl. Busse von Colbe (2002c), Sp. 892. Zu dem Begriff „Einkommensbemessungsfunktion“ sowie der Kritik an den in der Literatur gebräuchlichen Begriffen Ausschüttungs- oder Zahlungsbemessungsfunktion vgl. D. Schneider (1997a), S. 8-9 und 84-86. In dieser Arbeit werden die drei Begriffe synonym verwendet. Vgl. zur Notwendigkeit des Kapitalgeberschutzes Streim (1988), S. 23-25.

421 Vgl. Streim (1988), S. 20-21.

422 In Anlehnung an den englischen Sprachgebrauch vgl. z.B. Fama/Jensen (1983), S. 302; Klein/Coffee (2002), S. 120. Stützel (1981), S. 208-209, spricht von Restbetragsbeteiligten und grenzt diese von Festbetragsbeteiligten ab. Vgl. auch D. Schneider (1992), S. 620-624, 631-632. 


\subsection{Auswirkungen der Grundsätze ordnungsmäßiger Buchführung auf den aus- schüttungsfähigen Gewinn}

Im Folgenden werden einige $\mathrm{GoB}^{423}$, die auf die Höhe des zu ermittelnden Gewinns einen zentralen Einfluss haben, kurz erläutert.

Gemäß § 246 Abs. 1 HGB hat der Jahresabschluss grundsätzlich sämtliche Vermögensgegenstände, Schulden, Rechnungsabgrenzungsposten, Aufwendungen und Erträge zu enthalten (Vollständigkeitsgebot) ${ }^{424}$. Die Begriffe des Vermögensgegenstandes und der Schulden sind gesetzlich nicht definiert, sondern werden durch die GoB bestimmt. Der Begriff des Vermögensgegenstandes umfasst nach herrschender Meinung wirtschaftliche Werte, die selbständig bewertbar und selbständig verkehrsfähig, d.h. einzeln veräußerbar sind ${ }^{425}$. Hinsichtlich der Zuordnung von Vermögensgegenständen zum Unternehmen kommt es nicht auf das zivilrechtliche, sondern das wirtschaftliche Eigentum $\mathrm{an}^{426}$. Unter die Schulden werden Verbindlichkeiten und Rückstellungen subsumiert. Voraussetzungen für den Ansatz einer Schuld in der Bilanz sind, dass eine rechtliche oder wirtschaftliche Verpflichtung zu einer Leistung besteht, diese am Bilanzstichtag eine wirtschaftliche Belastung begründet und quantifizierbar ist $^{427}$. Unabhängig von der Qualifizierung eines Sachverhalts als Vermögensgegenstand oder Schuld und des damit infolge des Vollständigkeitsgrundsatzes einhergehenden Bilanzansatzes (abstrakte Aktivierungs- bzw. Passivierungsfähigkeit) existieren im HGB eine Reihe von Bilanzierungswahlrechten, z.B. die Aktivierungswahlrechte für den derivativen Geschäfts- oder Firmenwert gemäß $\S 255$ Abs. 4 HGB und für das Disagio gemäß $\S 250 \mathrm{Abs}$. $3 \mathrm{HGB}^{428}$. Eine Besonderheit des deutschen Bilanzrechts stellen die Aufwandsrückstellungen nach $\S \S 249$ Abs. 1 S. 3, 249 Abs. 2 HGB dar, die unter den Begriff der Schulden fallen und wahlweise passiviert werden dürfen. Ferner wird das Vollständigkeitsgebot durch explizite Bilanzierungsverbote durchbrochen, so z.B. im Falle von immateriellen Vermögensgegenständen des Anlagevermögens, die nicht entgeltlich erworben wurden ( $\$ 248$ Abs. 2 HGB). Die abstrakte und konkrete Aktivierungs- bzw. Passivierungsfähigkeit weichen damit teilweise voneinander $\mathrm{ab}$.

Neben den Regelungen zur Bilanzierung dem Grunde nach (Bilanzansatz) sind die Bestimmungen zur Bilanzierung der Höhe nach (Bilanzbewertung) zu beachten. Die Bewertungsvorschriften nach HGB verfolgen das Ziel der nominalen Kapitalerhaltung ${ }^{429}$. Sie ergeben sich für Aktiengesellschaften aus den $\S \S 240,252-256,279-283 \mathrm{HGB}$, wobei die allgemeinen Bewertungsgrundsätze in $\S 252$ HGB kodifiziert sind ${ }^{430}$. Für die Gewinnermittlung sind das

423 Vgl. zu einer Systematisierung der GoB ausführlich Leffson (1987), S. 157-492. Zu einem Überblick über die im HGB kodifizierten und die unkodifizierten GoB vgl. Ballwieser (2001b), § 243, Tz. 8-13 m.w.N. Zur Unterscheidung formeller und materieller GoB vgl. D. Schneider (1997a), S. 88.

424 Vgl. dazu und zu weiteren Grundsätzen z.B. Streim (1988), S.31-35.

425 Vgl. Coenenberg (2005), S. 76. Vgl. zu den Kriterien ausfuhrlich Adler/Düring/Schmaltz (1998), § 246, Tz. 15-30; Ballwieser (2001c), §246, Tz. 11-59; Baetge/Kirsch/Thiele (2005), S. 156-1167.

426 Vgl. Förschle/Kroner (2006), § 246, Tz. 5.

427 Vgl. ausfuhrlich Adler/Düring/Schmaltz (1998), § 246, Tz. 102-109.

428 Vgl. zur Wahlrechtsproblematik kritisch Streim (1998), S. 330-333, 340.

429 Vgl. Wenger (1981), S. 75-76, 204-223; Baetge/Kirsch/Thiele (2005), S. 99-102.

430 Im Folgenden steht insbesondere das Vorsichtsprinzip im Vordergrund. Zudem sind in $\S 252$ HGB die Prinzipien der Bilanzkontinuität, der Unternehmensfortführung (going concern), der Einzelbewertung, des Stichtags, der Periodisierung und der Stetigkeit geregelt. 
Realisationsprinzip, das Prinzip der Abgrenzung der Sache und der Zeit nach sowie das Imparitätsprinzip von herausragender Bedeutung. Diese Prinzipien zusammen bilden die Grundsätze periodengerechter Erfolgsermittlung ${ }^{431}$.

Das Realisationsprinzip gemäß $\S 252$ Abs. 1 Nr. 4 HGB besagt, dass Erträge in der Gewinnund Verlustrechnung erst dann zu erfassen sind, wenn sie realisiert sind, d.h. der Umsatzakt auf dem Absatzmarkt erfolgt ist ${ }^{432}$. Rechtlich gilt eine Leistung im Zeitpunkt des Gefahrenübergangs als erbracht ${ }^{433}$. Bis dahin sind die Leistungen unter Beachtung des Anschaffungskostenprinzips in der Bilanz höchstens zu ihren historischen Anschaffungs- oder Herstellungskosten anzusetzen ( $§ 253$ i.V.m. $§ 255$ HGB). Bei strenger Befolgung des Realisationsprinzips ist eine vorzeitige Teilgewinnrealisierung auch im Rahmen langfristiger Auftragsfertigung nicht möglich ${ }^{434}$.

Den realisierten Erträgen sind die ihnen zurechenbaren Aufwendungen gegenüberzustellen (Abgrenzung der Sache nach). Ist eine sachliche Zuordnung nicht möglich, greift der Grundsatz der Abgrenzung der Zeit nach. Danach sind zeitraumbezogene Aufwendungen zeitproportional auf die Perioden zu verteilen. Nicht zeitraumbezogene Aufwendungen sind der Periode zuzurechnen, in der sie anfallen ${ }^{435}$.

Während Gewinne erst berücksichtigt werden, wenn sie realisiert sind, müssen $\S 252$ Abs. 1 Nr. 4 1. Halbs. HGB entsprechend antizipierbare Risiken und Verluste bereits vor dem Realisationszeitpunkt ergebniswirksam erfasst werden (Imparitätsprinzip). Somit werden Gewinne und Verluste imparitätisch behandelt. Imparitätsprinzip und Realisationsprinzip stellen die beiden Ausprägungen des Vorsichtsprinzips ${ }^{436}$ (§ 252 Abs. 1 Nr. 4 HGB) dar, dem in Deutschland vielfach eine übergeordnete Stellung zugesprochen wird ${ }^{437}$. Daraus resultierend sind Vermögensgegenstände am Abschlussstichtag mit dem niedrigeren Betrag von Buchwert und tatsächlichem Wert anzusetzen (Niederstwertprinzip). Zudem sind drohende Verluste aus schwebenden Geschäften durch Bildung einer Rückstellung ergebnismindernd zu berücksichtigen ( $\$ 249$ Abs. 1 HGB). Nach dem Vorsichtsprinzip ist darüber hinaus bei Vorliegen einer Bandbreite mehrerer denkbarer Wertansätze ein eher pessimistischer Wert anzusetzen, wenngleich es nicht gestattet ist, unzulässige stille Reserven zu legen ${ }^{438}$.

Die Vermögensgegenstände sind gemäß $§ 253$ HGB höchstens mit ihren Anschaffungs- oder Herstellungskosten anzusetzen, die in $\S 255$ Abs. 1-3 HGB definiert sind. Bei der Ermittlung der Herstellungskosten steht dem Management der Aktiengesellschaft ein erheblicher bilanz-

431 Vgl. Coenenberg (2005), S. 41-44. Vgl. die amüsante Kritik des Begriffs ,periodengerechte Erfolgsermittlung“ von D. Schneider (1997a), S. 172-173, der ihn als „Lumpenjargon der Jetztzeit“ im Schopenhauer'schen Sinne bezeichnet.

${ }^{432}$ Vgl. D. Schneider (1997a), S. 37, 119. Vgl. zum Realisationsprinzip grundlegend Schmalenbach (1962), S. 76-78; Leffson (1987), S. 247-299.

433 Vgl. $\S \S 323,446,447,644$ BGB. Vgl. zu Einzelheiten auch Adler/Düring/Schmaltz (1995), §252, Tz. 82-85; Moxter (1999), S. 48-69.

434 Vgl. Baetge/Kirsch/Thiele (2005), S. 690; Pellens/Fülbier/Gassen (2006), S. 385.

435 Vgl. dazu ausführlich Leffson (1987), S. 299-331.

436 Vgl. Beisse (1999), S. 2182; Winkeljohann/Geißler (2006), § 252, Tz. 29.

437 Vgl. dazu kritisch z.B. Budde/Steuber (1996), S. 544-545; Weber-Grellet (1996), S. 2090; Kübler (2000), S. 556-557.

438 Vgl. Leffson (1987), S. 479; Adler/Düring/Schmaltz (1995), § 252, Tz. 68; Ballwieser (2001d), § 252, Tz. 57; Winkeljohann/Geißler (2006), § 252, Tz. 32-33. 
politischer Spielraum zur Verfügung ${ }^{439}$. Werden alle Wahlrechte ausgeübt, ist ein herstellungsbezogener Vollkostenansatz möglich. Werden allerdings nur die Einzelkosten als Pflichtbestandteil aktiviert, mindern bei Lagererhöhungen die dementsprechend höheren Aufwendungen das handelsrechtliche Ergebnis. Bei Vermögensgegenständen des Umlaufvermögens ist am Abschlussstichtag das strenge Niederstwertprinzip gemäß $§ 253$ Abs. 3 S. 1-2 HGB zu beachten, nach dem bei einer Wertminderung zwingend auf den niedrigeren Wert abzuschreiben ist. Bei Vermögensgegenständen des Anlagevermögens muss ebenfalls abgeschrieben werden, wenn die Wertminderung voraussichtlich dauerhaft ist; bei nur vorübergehender Wertminderung besteht lediglich für Finanzanlagen ein Wahlrecht $(\$ \S 253$ Abs. 2 S. 3 i.V.m. 279 Abs. 1 S. 2 HGB). Die Bewertung der Schulden ist in $\S 253$ Abs. 1 S. 2 HGB geregelt. Verbindlichkeiten werden danach mit ihrem Rückzahlungsbetrag und Rentenverpflichtungen, für die eine Gegenleistung nicht mehr zu erwarten ist, mit ihrem Barwert angesetzt. Rückstellungen werden mit dem Betrag nach vernünftiger kaufmännischer Beurteilung angesetzt, wobei eine Abzinsung nur dann zulässig ist, wenn die ihnen zugrunde liegenden Verbindlichkeiten einen Zinsanteil enthalten.

Charakteristisch für die HGB-Bilanzierung sind des Weiteren die zahlreichen expliziten $\mathrm{Be}-$ wertungswahlrechte ${ }^{440}$. Das handelsrechtliche Ergebnis kann beispielsweise durch Aufwandsvorverlagerungen stark gemindert werden, indem die degressive Abschreibungsmethode angewandt wird (Wahlrecht gemäß $\S 253$ Abs. 2 S. 1-2 HGB), Abschreibungen auf den niedrigeren Zukunftswert im Umlaufvermögen vorgenommen werden (Wahlrecht gemäß $§ 253$ Abs. 3 S. 3 HGB) und der derivative Geschäfts- oder Firmenwert trotz längerer Nutzungsdauer frühzeitig abgeschrieben wird (Wahlrecht gemäß $\S 255$ Abs. 4 S. 2-3 HGB). Es zeigt sich also, dass die handelsrechtlichen Ansatz- und Bewertungsvorschriften dem bilanzierenden Unternehmen zahlreiche Möglichkeiten bieten, das Jahresergebnis zu beeinflussen. Darüber hinaus verfügt das bilanzierende Unternehmen über vielfältige bilanzielle Ermessenspielräu$\mathrm{me}^{441}$, da z.B. die Nutzungsdauer von Vermögensgegenständen oder die Rückstellungshöhe bei Prozesskostenrisiken geschätzt werden müssen. Diese Ermessensspielräume können ergebnismindernd zur Legung stiller Reserven genutzt werden ${ }^{442}$. Eingeschränkt werden die Instrumente der Bilanzpolitik lediglich durch den Grundsatz der Bewertungsstetigkeit gemäß $\S 252$ Abs. 1 Nr. 6 HGB, nach dem einmal ausgeübte Bewertungswahlrechte grundsätzlich beizubehalten sind ${ }^{443}$. Zudem müssen Aktiengesellschaften Durchbrechungen des Stetigkeitsprinzips gemäß $\S 284$ Abs. 2 Nr. 3 HGB im Anhang angeben und begründen sowie die Auswirkungen auf die Vermögens-, Finanz- und Ertragslage gesondert darstellen. Neben Angaben zu Abweichungen von Bewertungsmethoden muss auch über Abweichungen von den Bilanzierungsgrundsätzen im Rahmen der Ansatzwahlrechte berichtet werden.

$\mathrm{Zu}$ berücksichtigen ist, dass der handelsrechtliche Jahresabschluss gemäß $§ 264$ Abs. 2 HGB unter Beachtung der GoB ein den tatsächlichen Verhältnissen entsprechendes Bild der Vermögens-, Finanz- und Ertragslage der Gesellschaft zu vermitteln hat ${ }^{44}$. Diese Vorschrift stellt allerdings keine übergeordnete Generalnorm dar, sondern ist lediglich bei gesetzlichen Lü-

439 Vgl. Pellens (2001a), S. 168; Coenenberg (2005), S. 101

440 Vgl. zu den Bewertungswahlrechten des HGB, die zur Gewinnreduzierung genutzt werden können, Pellens/Bonse (1998), S. 388; Streim (1998), S. 332.

441 Vgl. z.B. D. Schneider (1997a), S. 194-195; Coenenberg (2005), S. 321-323.

442 Vgl. z.B. Pellens/Bonse (1998), S. 388-389. Vgl. zur Kritik der stillen Reserven Kapitel V.2.

$443 \mathrm{Zu}$ den Ausnahmefallen vgl. Winkeljohann/Geißler (2006), § 252, Tz. 59-64.

444 Gleiches gilt bezogen auf den Konzernabschluss gemäß $§ 297$ Abs. 2 HGB 
cken und Zweifelsfragen heranzuziehen ${ }^{445}$. Im Konfliktfall gehen daher die gesetzlichen Einzelvorschriften vor. Die Norm schränkt zudem die Ausübung der handelsrechtlichen Wahlrechte nicht ein $^{446}$. Aktiengesellschaften sind somit nicht gezwungen, von den zur Wahl stehenden Bilanzierungsmöglichkeiten diejenige auszuwählen, welche die tatsächlichen Verhältnisse am besten widerspiegelt. Schließlich scheidet für die Auslegung der Norm ein Rückgriff auf das true-and-fair-view-Prinzip des englischen Rechts aus, obwohl § 264 Abs. 2 HGB entstehungsgeschichtlich auf die Verankerung der englischen Wünsche in der Bilanzrichtlinie zurückgeht $^{447}$.

\subsection{Auswirkungen der Verknüpfung von handels- und steuerrechtlicher Bilanzie- rung}

Eine deutsche Besonderheit - zumindest im Vergleich zum anglo-amerikanischen Rechtsraum $^{448}$ - stellt die Verknüpfung von handels- und steuerrechtlicher Bilanzierung dar ${ }^{449}$. Nach $\S 5$ Abs. $1 \mathrm{EStG}$ sind die handelsrechtlichen Rechnungslegungsvorschriften einschließlich der nicht kodifizierten $\mathrm{GoB}$ grundsätzlich maßgeblich für die steuerliche Gewinnermittlung ${ }^{450}$. Danach führen in der Regel Aktivierungs- und Passivierungsge- und -verbote im Handelsrecht zu entsprechenden Ge- bzw. Verboten in der Steuerbilanz. Der Grundsatz der Maßgeblichkeit wird allerdings in vielfältiger Hinsicht eingeschränkt ${ }^{451}$. Zum einen gehen gemäß $\S 5$ Abs. 6 EStG abweichende Bestimmungen des Steuerrechts den Vorschriften des HGB und den GoB vor (steuerlicher Bewertungsvorbehalt). Zum anderen werden nicht alle handelsrechtlichen Wahlrechte steuerlich anerkannt. Nach der Rechtsprechung des Bundesfinanzhofes (BFH) werden handelsrechtliche Wahlrechte prinzipiell zu steuerrechtlichen Geboten auf der Aktivseite und zu Verboten auf der Passivseite ${ }^{452}$.

Von „umgekehrter Maßgeblichkeit“ wird gesprochen ${ }^{453}$, wenn das bilanzierende Unternehmen aus wirtschaftspolitischen Gründen gewährte steuerliche Bilanzierungsvergünstigungen nur dann nutzen kann, wenn sie in gleicher Weise auch in der Handelsbilanz ausgeübt werden

Vgl. z.B. Busse von Colbe (1987b), S. 120.

Vgl. Streim (1994), S. 396-398.

Vgl. Winkeljohann/Schellhorn (2006), § 264, Tz. 21, 24. Zur unterschiedlichen Ausprägung des Grundsatzes des true and fair view nach HGB, IFRS und US-GAAP vgl. ausfuhrlich Bonse (2004), S. 25-31.

In mehreren kontinentaleuropäischen Ländern bestehen ähnliche Verknüpfungen von handels- und steuerrechtlicher Bilanzierung. Vgl. zu einem Rechtsvergleich von Frankreich, der Schweiz, Großbritannien, den Niederlanden und den USA ausführlich Broer (2001), S. 125-173.

Vgl. zum Maßgeblichkeitsprinzip ausführlich Brönner/Bareis (1991); Stobbe (1991); Vogt (1991); L. Schmidt (1994); Pannen (2000).

Das Maßgeblichkeitsprinzip geht in Deutschland auf Steuergesetze in Sachsen und Bremen im Jahre 1874 zurück, die aus Vereinfachungsgründen die Aufstellung nur einer Bilanz fur handels- und steuerrechtliche Zwecke vorsahen. Für das gesamte Reichsgebiet fand das Maßgeblichkeitsprinzip seinen Niederschlag in $\S 33$ Abs. 2 EStG 1920 bzw. in $\S 13$ EStG 1925. Vgl. zu den historischen Ursprüngen Pohl (1983), S. 11-127; D. Schneider (1991), S. 185-190. Vgl. überblicksartig auch Dziadkowski/Henselmann (2004), S. 3-5 m.w.N.

451 Vgl. Hennrichs (1999a), S. 141-148; D. Schneider (1999), S. 107-110. Vgl. zu den Durchbrechungen der Maßgeblichkeit detailliert Pannen (2000), S. 34-44; Dziadkowski/Henselmann (2004), S. 10-18.

452 Vgl. BFH-Beschluss vom 03.02.1969, BStBI. II, 291, hier S. 293.

453 Vgl. Knobbe-Keuk (1993), S. 28. 
(§ 5 Abs. 1 S. 2 EStG). Damit die Unternehmen die steuerlichen Vergünstigungen auch dann in Anspruch nehmen können, wenn die HGB-Vorschriften entsprechende Wahlrechte nicht enthalten, erlauben die $\S \S 247$ Abs. 3, 254, 273, 279 Abs. 2, 280 Abs. 2 HGB ein Abweichen von den handelsrechtlichen Bilanzierungsvorschriften.

Das Maßgeblichkeitsprinzip sowie die umgekehrte Maßgeblichkeit werden seit langem stark kritisiert ${ }^{44}$. Vermehrt wird die vollständige Abkopplung von Handels- und Steuerbilanz gefordert $^{455}$. Um einen Steuerstundungseffekt zu realisieren, haben Unternehmen einen Anreiz, durch geschickte Nutzung der Bilanzierungswahlrechte einen möglichst niedrigen Gewinnausweis zu erzielen. Eine so motivierte Bilanzierungsweise steht aber einer zutreffenden Darstellung der tatsächlichen wirtschaftlichen Lage des Unternehmens entgegen. Insbesondere durch die umgekehrte Maßgeblichkeit beeinflussen Vorschriften des Steuerrechts die Handelsbilanz, so dass zu Recht von einer „Deformierung der handelsrechtlichen Rechnungslegung ${ }^{\text {“456 }}$ gesprochen wird.

\subsubsection{Besonderheiten im Konzern}

Wie eingangs bereits erwähnt, sollen die Kapitalschutzregeln in Deutschland sowohl die Interessen der Aktionäre an angemessenen Dividendenzahlungen berücksichtigen als auch dem Schutz der Gläubiger vor zu hohen Ausschüttungen und einer willkürlichen Schmälerung des Gesellschaftsvermögens dienen. Das Ziel der folgenden Ausführungen ist es, auf die Besonderheiten im Konzern hinzuweisen, die dazu führen können, dass das Kapitalschutzsystem auf legale Weise ausgehöhlt wird. Weiterhin werden Lösungsmöglichkeiten, die in der Literatur entwickelt worden sind, kurz skizziert. Die Konzernproblematik ist insofern von herausragender praktischer Relevanz, als die überwiegende Mehrzahl der Aktiengesellschaften in Deutschland konzernverbunden ist ${ }^{457}$.

$\S 58 \mathrm{AktG}$ bezieht sich auf den Einzelabschluss der Gesellschaft ${ }^{458}$. Die isolierte Anwendung dieser Norm auf den Einzelabschluss eines Konzern-Mutterunternehmens und auf die Jahresabschlüsse der in den Konzernabschluss einbezogenen Konzernunternehmen kann aber der Fiktion der rechtlichen Einheit des Konzerns nicht gerecht werden.

454 Vgl. Karsten (1967), S. 428: ,gesetzgeberische(...) Schizophrenie“; Flämig (1968); Knobbe-Keuk (1993), S. 30-33; Küting (1997), S. 84; Weber-Grellet (1999); Schildbach (2004), S. 178-181, 407-410.

455 Vgl. insbesondere D. Schneider (1997a), S. 90-91; Weber-Grellet (1999), S. 2666; Wagner (2000), S. 200; Herzig (2001), S. 155-159. Streim (1990), S. 527-545, hingegen plädiert für die Einheitsbilanz; ähnlich AKEU (2003); Küting (2004b): „Angestrebt wird somit eine im Mittelstand durchgehend praktizierte steuerlich geprägte Einheitsbilanz“; und Schulze-Osterloh (2004c), S. 1137: „Die inzwischen nicht mehr realisierbare Einheitsbilanz könnte zum Segen der Praxis wiederbelebt werden.“. Vgl. zu einer ausfuhrlichen Abwägung der Vor- und Nachteile Söffing (1995), S. 650-673. Zu einer pragmatischen Sicht vgl. Ballwie$\operatorname{ser}(1990)$, S. 489-495.

456 Karsten (1967), S. 425. Vgl. ebenfalls Streim (1988), S. 163; Knobbe-Keuk (1993), S. 31 m.w.N.; Herzig (2001), S. 158; Schulze-Osterloh (2004c), S. 1134-1135; Coenenberg (2005), S. 113. Auch D. Schneider (1997a), S. 90, sieht die Informationsfunktion des Jahresabschlusses beeinträchtigt, „denn wer liest schon den Anhang, in dem das Ausmaß solcher Wahlrechte anzugeben ist ( $285 \mathrm{Nr} .5 \mathrm{HGB}$ )?“. Empirische Hinweise, dass diese etwas provokante These zumindest aus Sicht von Kleinaktionären zuzutreffen scheint, liefern E. Ernst/Gassen/Pellens (2005), S. 22-23. Schildbach (1999a), S. 424, hingegen relativiert die steuerrechtlichen Verzerrungen der Handelsbilanz.

457 Vgl. Busse von Colbe (2000), S. 501 m.w.N.; Busse von Colbe (2002b), S. 358.

458

Vgl. Adler/Düring/Schmaltz (1997a), § 58, Tz. 85. 
Ökonomisch besteht das Problem einerseits darin, dass das Management einer KonzernObergesellschaft im Vergleich zu dem eines Einzelunternehmens über erleichterte Innenfinanzierungsmöglichkeiten verfügt ${ }^{459}$. Es kann gewinnbringende unternehmerische Aktivitäten in Tochterunternehmen verlagern und die dort anfallenden Gewinne - durch Ausübung seines Stimmrechts auf den Hauptversammlungen der Tochterunternehmen - mit dem Ergebnis thesaurieren, dass die Gewinnverwendungskompetenz der Hauptversammlung des Mutterunternehmens erheblich oder sogar vollständig beschnitten wird. Das Management eines KonzernMutterunternehmens kann andererseits durch konzerninterne Erfolgsverlagerungen im Einzelabschluss des Mutterunternehmens noch ausschüttbare Gewinne generieren, obwohl der Konzern bereits hohe Verluste aufweist ${ }^{460}$.

Die Gefahr, dass im Konzernverbund das Dividendenrecht der Aktionäre des Mutterunternehmens ausgehöhlt werden kann, ist ein im Schrifttum seit langem bekanntes Problem ${ }^{461}$. Im Anschluss an die grundlegenden Arbeiten von Lutter ${ }^{462}$ ist diese Beeinträchtigung der Aktionärsrechte in der Literatur intensiv beleuchtet worden. Durch die bereits erwähnte Holzmüller-Entscheidung ${ }^{463}$ des BGH aus dem Jahre 1982 wurde das Interesse an dieser Problematik noch verstärkt. Nach Auffassung des BGH haben die Aktionäre des Mutterunternehmens das Recht, bei ,grundlegenden, für ihre Rechtsstellung bedeutsamen Entscheidungen in der Tochtergesellschaft über ihre Hauptversammlung so beteiligt $\mathrm{zu}$ werden wie wenn es sich um eine Angelegenheit der Obergesellschaft selbst handelte ${ }^{6464}$.

Seit mittlerweile mehr als drei Jahrzehnten wird die Rücklagenbildung im Konzern in den Rechts- und Wirtschaftswissenschaften kontrovers diskutiert. Die in der Literatur entwickelten Vorschläge und Auffassungen lassen sich in vier Gruppen einteilen ${ }^{465}$, die in Abb. 1 im Überblick dargestellt werden.

Vgl. zur Innenfinanzierung im Konzern Pellens/Bonse (1998).

Vgl. Busse von Colbe (1993), S. 25.

Vgl. Netter (1928), S. 31; Quassowski (1931), S. 2919; Hannemann (1934), S. 27; Mestmäcker (1958), S. 272; Busse von Colbe (1960), S. 146; H. Weber (1972), S. 487.

Vgl. insbesondere Lutter (1974b), S. 361-364; Lutter (1974a), S. 210-214. Zur späteren Weiterentwicklung vgl. Lutter (1987), S. 331-348; Lutter (1988b), § 58, Tz. 38-60; Lutter (1998a), S. 411-415.

Vgl. BGH-Urteil vom 25.02.1982 - II ZR 174/80, BGHZ 83, 122.

BGHZ 83, 140. Auch wenn der Holzmüller-Entscheidung eine andere Fallkonstellation (Ausgliederung des wertvollsten Betriebsteils auf ein dafür gegründetes Tochterunternehmen ohne Zustimmung der Hauptversammlung und anschließende Kapitalerhöhung) zugrunde lag, wird sie zur Beurteilung der Rücklagenbildung und Gewinnverwendung im Konzern herangezogen.

Vgl. zur Darstellung des Meinungsstandes z.B. Linnhoff/Pellens (1987), S. 992-993; Busse von Colbe (1987a), S. 65-69; Pellens (1994), S. 95-105; Hoffmann-Becking (1999), S. 613-614; Theisen (2000), S. 480-485; Hinz (2002), S. 268-285. In der juristischen Literatur werden die in der Betriebswirtschaftslehre entwickelten Vorschläge regelmäßig nicht erwähnt. Vgl. z.B. Bayer (2003), § 58, Tz.63-65; Hüffer (2006), § 58, Tz. 16. Vgl. anders aber Lutter (1988b), § 58, Tz. 55; Großfeld (1998), S. 162. 


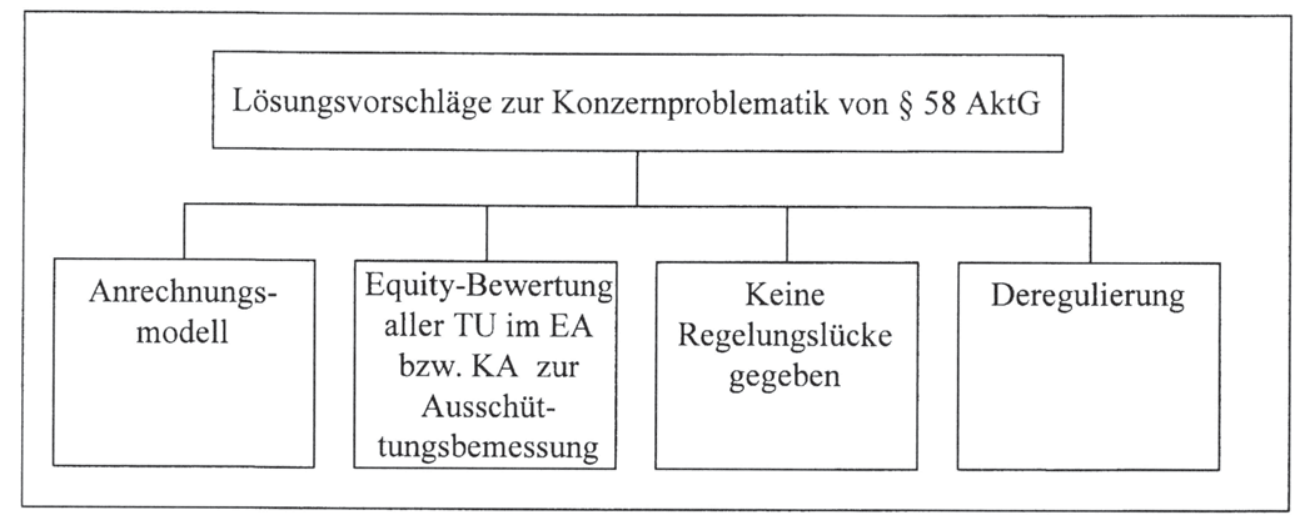

Abb. 1: Lösungsvorschläge zur Konzernproblematik von § $58 \mathrm{AktG}$

Die erste Gruppe von Autoren identifiziert in der Regelung des $\S 58 \mathrm{AktG}$ eine verdeckte Regelungslücke ${ }^{466}$, die über eine Rechtsfortbildung zu schließen $\mathrm{sei}^{467} . \S 58 \mathrm{AktG}$ müsse konsequent auf den Konzernverbund angewandt werden, indem die bereits bei den Untergesellschaften gebildeten Rücklagen bei der Rücklagenbildung auf der Ebene der Muttergesellschaft angerechnet würden (Anrechnungsmodell) ${ }^{468}$. Maßgeblich für die Gewinnverwendung wäre danach zwar weiterhin der Einzelabschluss des Mutterunternehmens. Die Unternehmensvertreter der Konzernmutter dürften aber ,nicht mehr an Gewinnrücklagen bilden, als sie hätten bilden können, wären ihre Konzerngesellschaften in Wirklichkeit ein unausgegliederter Teil von ihnen selbst gewesen (Fiktion der Einheit) ${ }^{، 469}$.

Unterschiedliche Meinungen bestehen hinsichtlich der Frage, welche Rechtsfolgen an ein Nichtbefolgen dieser Obergrenze zu knüpfen sind. Einerseits wird vertreten, ein Verstoß gegen das Anrechnungsmodell führe zur Nichtigkeit des Jahresabschlusses gemäß $§ 256$ Abs. 1 Nr. $4 \mathrm{AktG}^{470}$. Eine vermittelnde Auffassung andererseits sieht von der strikten Durchrechnung der Rücklagenbildung in untergeordneten Konzernebenen auf die der Verwaltung zur Disposition stehende Gesamtquote $a b$ und plädiert lediglich für eine Pflicht zur angemessenen Berücksichtigung der im Konzern gebildeten Rücklagen. Eine Verletzung dieser Pflicht führe nicht zur Nichtigkeit, sondern biete nur die Grundlage einer Sonderprüfung analog $§ 258$ $\mathrm{AktG}^{471}$.

466 Vgl. zum Begriff der Regelungslucke grundlegend Sauer (1940), S. 280-286; Larenz (1991), S. 370-381. Vgl. insbesondere den Literaturuberblick und die ausfuhrliche Analyse von Frodermann (1994), S. 54-79, der zu dem Ergebnis kommt, dass § 58 AktG hinsichtlich der Rucklagenbildung im Konzern eine verdeckte Regelungslücke enthălt.

Vgl. Lutter (1974b), S. 362; Timm (1980), S. 90, 160; Hefermehl/Bungeroth (1983), § 58, Tz. 8; Götz (1984), S. 93 ; Geßler (1985a), S. 25-29; Geßler (1985b), S. 259; Hübner (1985), S. 798-799; Lee (1987), S. 136-137; Lutter (1987), S. 334-348; Lutter (1988b), § 58, Tz. 38-60; Gollnick (1991), S. 171-200; Kohl (1991), S. 195-254; Gollnick (1992), S. 23-25; Götz (1994), S. 587-599; Lutter (1998a), 411-416; Schön (2000), S. 740; Bayer (2003), § 58, Tz. 69-70; Koppensteiner (2004a), Vorb. § 291, Tz. 33.

468 Dieser Begriff geht auf Götz (1984), S. 93, und Lutter (1988b), § 58, Tz. 50, zurück.

469 Lutter (1987), S. 340.

470 Vgl. Götz (1984), S. 93-94; Geßler (1985b), S. 258-259.

471 Vgl. Lutter (1987), S. 338; Lutter (1988b), § 58, Tz. 41; Bayer (2003), § 58, Tz. 69. 
Die zweite Gruppe von Autoren fordert Gesetzesänderungen ${ }^{472}$. Danach soll die Norm des $\S 58 \mathrm{AktG}$ zwar beibehalten werden. Als Ermittlungsgrundlage soll aber entweder ein um die Equity-Bewertung aller Tochterunternehmen verändertes Einzelabschlussergebnis des Mutterunternehmens ${ }^{473}$ oder direkt das Ergebnis des (gegebenenfalls modifizierten) Konzernabschlusses ${ }^{474}$ verwandt werden ${ }^{475}$.

Die dritte Gruppe von Autoren lehnt die Anwendung des $\S 58 \mathrm{AktG}$ auf den Konzernsachverhalt $\mathrm{ab}^{476}$. Die Existenz einer Regelungslücke wird bestritten, und eine Rechtsfortbildung wird als nicht gangbar abgelehnt. Teilweise wird argumentiert, dass die Anwendung der Norm auf den Konzernverbund nicht im Sinne des historischen Gesetzgebers sei ${ }^{477}$. Vereinzelt wird sogar behauptet, eine Anwendung sei mangels eines beobachtbaren Missbrauchs in der Geschäftspraxis nicht notwendig ${ }^{478}$. Die Auffassung dieser dritten Gruppe stellt die herrschende (juristische) Meinung des Schrifttums dar. Vor dem Hintergrund der vorherrschenden Organisationsform des Konzerns als wirtschaftlicher Einheit mehrerer rechtlich selbständiger Unternehmen können die vorgetragenen Argumente aus ökonomischer Sicht allerdings nicht überzeugen. Zudem bestätigen empirische Studien keinesfalls die Vermutung, dass „nichts darauf hin(deutet), daß durch Thesaurierungsmaßnahmen bei den Tochtergesellschaften den Aktionären der Obergesellschaft erhebliche Teile des Konzernjahresüberschusses entzogen werden. “479

Die bisher für Deutschland durchgeführten empirischen Untersuchungen ${ }^{480}$ über die Gewinnverwendungspolitik im Konzern kommen im Gegenteil zu dem Ergebnis, dass eine Novellie-

472 Vgl. Böhm (1979), S. 102-185; U. Schneider (1984), S. 519-521; Kirchner (1985), S. 233; Pick (1985), S. 255-275; Busse von Colbe (1986), S. 367; Lehertshuber (1986a), S. 151-205; Lehertshuber (1986b), S. 337-340; Ordelheide (1986), S. 309; Pausenberger (1986), S. 368; U. Schneider (1986), S. 1997; Busse von Colbe (1987a), S. 72-77; Ordelheide (1987), S. 985-986; Lehertshuber (1989), S. 1535; Warschkow (1991), S. 89-118; Kretschik (1992), S. 64-66, 86-87; Theisen (1992), S. 182-184; Busse von Colbe (1993), S. 24-27; Frodermann (1994), S. 127-152; Pellens (1994), S. 231-258; Prantl (1994), S. 285-338; Ordelheide (1998), S. 557-558; Hinz (2002), S. 285-313; Busse von Colbe/Ordelheide/Gebhardt/Pellens (2003), S. $31-32$.

473 Vgl. dazu insbesondere Pick (1985), S. 255-275.

474 Vgl. zu den Modifikationen im Einzelnen Busse von Colbe (1987a), S. 72-76.

475 Zu Zweifeln an der Eignung des Konzernabschlusses zur Ausschüttungsbemessung aus ökonomischer Sicht vgl. Faß (1992), S. 114-184; Schildbach (1993), S. 57-63, 94-98. A.A. Busse von Colbe (1994), S. 56-57.

476 Vgl. Thomas (1985), S. 369-385; Werner (1985), S. 940-953; Goerdeler (1986), S. 231-237; Westermann (1986), S. 437-443; Beusch (1987), S. 31-44; Ebenroth (1987), S. 42-46; Ebenroth (1988), S. 4; Piltz (1988), S. 650-651; Beckmann (1989), S. 941-943; Werner (1990), S. 10-12; H.-P. Müller (1991), S. 346; Eichholz (1993), S. 182-183; Adler/Düring/Schmaltz (1997a), § 58, Tz. 85-88; Krieger (1999), S. 977-978; Hüffer (2006), §58, Tz. 17.

477 Vgl. Werner (1985), S. 945; Westermann (1986), S. 441-442. Vgl. auch Kropff(1991), S. 32, nach dem die Rücklagenbildung im Konzern „ein vom Aktiengesetz nicht gelöstes und wohl nicht einmal gesehenes Problem“ darstellt. In der Begründung zum AktG 1965 heißt es allerdings, dass zur Beurteilung ,der Angemessenheit einer Gewinnausschüttung[,] aus dem Konzernabschluß gewonnene Erkenntnisse mit zu berücksichtigen sind", so Kropff (1965), S. 437. Vgl. auch den Bericht der Unternehmensrechtskommission (1980), S. 661-665, in dem Lösungsmöglichkeiten der Gewinnverwendungsproblematik diskutiert werden. Vgl. Thomas (1985), S. 383; Werner (1985), S. 946; und Beusch (1987), S. 36-37, die ihre Behauptungen aber nicht belegen. Piltz (1988), S. 651, wiederum zieht falsche Schlüsse aus der empirischen Untersuchung von Linnhoff/Pellens (1987). Beusch (1987), S. 36-37. Vgl. Linnhoff/Pellens (1987), S. 994-1004; Pellens (1994), S. 119-136; Pellens (1996), S. 167-174; Kühnberger/Schmidt (1999), S. 1275-1282. 
rung des $\S 58 \mathrm{AktG}$, nach der das vom Konzern erwirtschaftete Ergebnis die Grundlage für die Ausschüttung an die Anteilseigner des Konzernmutterunternehmens bildet, für einige Unternehmen zu signifikant höheren Ausschüttungsbeträgen führen würde, die gleiche Ausschüttungsquote vorausgesetzt ${ }^{481}$. Dies würde zu einer entsprechenden Reduktion des Innenfinanzierungspotentials führen. Der in der Literatur beschriebene Tresoreffekt ${ }^{482}$, der darin besteht, dass Tochterunternehmen „zu ,Spardosen' des Konzerns gemacht werden “483, indem bei ihnen anfallende Gewinne thesauriert werden und somit den Aktionären des Mutterunternehmens verschlossen bleiben, wird also empirisch bestätigt.

Die empirischen Ergebnisse bilden den Ausgangspunkt für eine vierte Auffassung. Danach könnte die Regulierung des $\S 58 \mathrm{AktG}$ - zumindest für börsennotierte Aktiengesellschaften im Vertrauen auf eine Marktlösung abgeschafft werden ${ }^{484}$. Eine aktionärsschädigende Dividendenpolitik im Sinne zu hoher Thesaurierungen könnte durch Marktkräfte (z.B. Aktienverkäufe der Anteilseigner, sinkende Aktienkurse, steigende Übernahmegefahr, möglicher Reputations- und Arbeitsplatzverlust der Manager) bestraft und letztlich verhindert werden. Weiterhin deuten Ergebnisse einer Befragung von Unternehmensvorständen börsennotierter Unternehmen in Deutschland darauf hin, dass $\S 58 \mathrm{AktG}$ lediglich der Charakter einer Nebenbedingung zukommt. Im rechtlich zulässigen Rahmen orientieren sich die Manager bei ihrer Dividendenpolitik insbesondere an der Konzernertragslage und stellen dann - z.B. durch konzerninterne Gewinnverlagerungen - sicher, dass das Jahresergebnis im Einzelabschluss des Mutterunternehmens mit $§ 58 \mathrm{AktG}$ im Einklang steht ${ }^{485}$.

Die vorstehend aufgezeigten Probleme und Lösungsmöglichkeiten von Kapitalschutzregeln im Konzern werden bei der Darstellung und Beurteilung des kalifornischen Rechts erneut aufgegriffen. Wie noch zu zeigen ist, hat der kalifornische Gesetzgeber Regelungen getroffen, mit denen sowohl die Aktionäre und Gläubiger des Mutterunternehmens als auch diejenigen der Tochterunternehmen geschützt werden sollen ${ }^{486}$.

\footnotetext{
481 Das Ausmaß der Einbußen in der Gewinnverwendungskompetenz der Anteilseigner der Mutterunternehmen lăsst sich auch quantifizieren. Vgl. dazu Pellens (1994), S. 136.

482 Vgl. U. Schneider (1984), S. 501-502.

483 Ordelheide (1986), S. 308. Busse von Colbe (1993), S. 24-25, spricht von Sparschweinen des Mutterunternehmens, die in schlechten Zeiten geplündert werden können.

484 Vgl. Pellens/Bonse (1998), S. 398; Pellens/Gassen (2001), S. 140; Pellens/Gassen/Richard (2003), S. 328; Pellens/Fülbier/Gassen (2006), S. 916. Vgl. zu diesen Überlegungen bereits früher Busse von Colbe (1987a), S. 64; ferner Schildbach (1986), S. 75. Vgl. auch Albach/Corte/Friedewald/Lutter/Richter (1988), S. 126-127, die vorschlagen, die gesetzliche Regelung durch Satzungsautonomie zu ersetzen.

485 Vgl. Pellens/Gassen/Richard (2003), S. 326.

486 Vgl. zum kalifornischen Kapitalschutzsystem Kapitel III.2.3.2. Zu einer kritischen Würdigung sowie einer Anwendung der kalifornischen Ausschüttungsregeln auf die DAX-30-Unternehmen vgl. Kapitel V.6.5.
} 


\subsection{Europarechtliche Entwicklungen}

\subsubsection{Europäisches Kapitalschutzsystem von 1976}

\subsubsection{Aufbau und Anwendungsbereich der Kapitalrichtlinie}

Wie bereits in Kapitel II.1.2.1 erläutert, hat die EU zur Harmonisierung des Gesellschaftsrechts unter anderem eine Reihe von Richtlinien erlassen. Detaillierte Vorschriften zur Kapitalaufbringung, -erhaltung und -änderung für Aktiengesellschaften und die ihnen entsprechenden Gesellschaftsformen der anderen Rechtsordnungen enthält die im Jahre 1976 erlassene Zweite EU-Richtlinie, die aus diesem Grund auch als Kapitalrichtlinie bezeichnet wird $^{487}$. Sie wurde 1978 in deutsches Recht transformiert ${ }^{488}$ und ,zementiert für das Aktienrecht das überlieferte System des Nennkapitals“489. Da die Enstehung der Kapitalrichtlinie weitgehend vom deutschen Recht geprägt wurde, sind die Auswirkungen auf das deutsche Aktienrecht überschaubar geblieben ${ }^{490}$. Die Normen des Aktiengesetzes sind allerdings richtlinienkonform auszulegen ${ }^{491}$.

Entgegen den ursprünglichen Überlegungen, den Anwendungsbereich der Richtlinie auf alle Kapitalgesellschaften auszudehnen ${ }^{492}$, werden die $\mathrm{GmbH}$ und ähnliche Rechtsformen nicht erfasst. Trotz des rechtsformübergreifenden Charakters ihres Inhalts betrifft die Umsetzung der Kapitalrichtlinie daher in den Staaten der EU eine unterschiedliche Anzahl von Gesellschaften. Während in Deutschland nur ca. 16.000 existierende Aktiengesellschaften betroffen sind und die zahlenmäßig stark dominierenden $\mathrm{GmbH}$ von der Transformation der Kapitalrichtlinie unberührt bleiben, wird in Frankreich die von der Kapitalrichtlinie erfasste Rechtsform der "Societé anonyme“ von ca. 150.000 Unternehmen unterschiedlicher Größe genutzt $^{493}$. Insofern verwundert es, dass in der Kapitalrichtlinie die Harmonisierungsnotwendigkeit insbesondere damit begründet wird, dass ,,in der Wirtschaft der Mitgliedstaaten die Tä-

487 Vgl. Zweite Richtlinie des Rates vom 13.12.1976 (77/91/EWG), ABI. EG Nr. L 26/1 vom 31.01.1977. Nach Art. 1 Abs. 2 Kapitalrichtlinie (KapRL) brauchen die Mitgliedstaaten diese Richtlinie auf bestimmte Investmentgesellschaften und Genossenschaften nicht anzuwenden. $\mathrm{Zu}$ den diesbezulglichen Sonderregeln vgl. Mülbert (2000), S. 547-549.

488 Vgl. Gesetz zur Durchfuhrung der Zweiten Richtlinie des Rates der Europäischen Gemeinschaften zur Koordinierung des Gesellschaftsrechts vom 13.12.1978, BGBl. I 1595. Es ist am 01.07.1979 in Kraft getreten. Ein Durchführungsgesetz zur Richtlinie 92/101/EWG des Rates vom 23.11.1992 zur Änderung der Richtlinie 77/91/EWG, ABl. EG Nr. L $347 / 64$ vom 28.11.1992, war nicht erforderlich, da der deutsche Gesetzgeber mit § 71d AktG bereits eine Art. 24a KapRL entsprechende Vorschrift zum Erwerb eigener Aktien durch Tochterunternehmen erlassen hatte. 
tigkeit dieser Gesellschaften vorherrscht“494. Obwohl beispielsweise in der deutschen Literatur selbst in der jüngeren Vergangenheit noch immer die Ausdehnung auf das GmbH-Recht gefordert wird ${ }^{495}$ und die Problematik auch der EU-Kommission bewusst ist, gibt es keine Anzeichen für eine solche Regulierung in naher $\mathrm{Zukunft}^{496}$.

Die Kapitalrichtlinie verankert das Prinzip des Mindestkapitals in der EU. Den Erwägungsgründen der Kapitalrichtlinie zur Folge sollen die Vorschriften ein Mindestmaß an Gleichwertigkeit beim Schutz der Aktionäre ${ }^{497}$ und der Gläubiger gewährleisten ${ }^{498}$. Durch strenge Vorschriften zur Leistung von Bar- und Sacheinlagen, zur Kapitalerhaltung sowie zum erschwerten Erwerb eigener Aktien wird dem Gläubigerschutz allerdings besondere Bedeutung beigemessen $^{499}$.

\subsubsection{Kapitalaufbringung}

Art. 6 Abs. $1 \mathrm{KapRL}$ schreibt ein Grundkapital von mindestens $25.000 €$ vor. Die Höhe dieses Betrages soll auf Vorschlag der EU-Kommission durch den Ministerrat alle fünf Jahre überprüft und gegebenenfalls angepasst werden (Art. 6 Abs. 3 KapRL). Eine Anpassung ist bisher allerdings ausgeblieben, obwohl allein zum Ausgleich der Inflation mittlerweile ein Mindestkapital in mehr als doppelter Höhe angemessen wäre ${ }^{500}$. Neben dem Verbot der Unterpariemission gemäß Art. $8 \mathrm{KapRL}$ enthält die Richtlinie strenge Vorgaben hinsichtlich der Leistung von Bar- und Sacheinlagen. Nach Art. 9 KapRL müssen die Aktionäre bei Bareinlagen im Zeitpunkt der Gründung mindestens $25 \%$ des Nennbetrags bzw. des rechnerischen Werts der Aktien geleistet haben. Sacheinlagen müssen ferner spätestens fünf Jahre nach der Gründung vollständig erbracht worden sein. Art. $7 \mathrm{KapRL}$ sieht vor, dass es sich bei Sacheinlagen um Vermögensgegenstände handeln muss, deren wirtschaftlicher Wert feststellbar ist, mit der bedeutenden Einschränkung, dass es sich nicht um „Verpflichtungen zu Arbeits- oder Dienst-

494 Vgl. KapRL, Präambel, erster Erwägungsgrund.

495 Vgl. z.B. Ulmer (1999), S. 664; Lutter (2000a), S. 9-10; Lutter (2000b), S. 137; Schön (2000), S. 728. Vgl. abwägend Fleischer (2000), S. 1020-1021. Vgl. zu dieser Forderung bereits Lutter (1964), S. 502 m.w.N. Zu einer strikt ablehnenden Sichtweise vgl. hingegen Enriques/Macey (2001), S. 1168; und bezogen auf die private limited company in Großbritannien ebenfalls ablehnend Davies (1998).

496 Vgl. Schwarz (2000), S. 364; Habersack (2003), S. 44; Grundmann (2004), S. 142.

497 Dies kommt in der Kapitalrichtlinie insbesondere in den Informationspflichten bei schweren Verlusten (Art. 17), der Beteiligung der Hauptversammlung bei Kapitalmaßnahmen (Art. 25, 30), dem eingefuhrten Bezugsrecht der Aktionäre bei Kapitalerhöhungen (Art. 29) und der Verankerung des Gleichbehandlungsgrundsatzes der Aktionäre (Art. 42) zum Ausdruck.

KapRL, Prăambel, zweiter und fünfter Erwăgungsgrund. Zu den unterschiedlichen Schwerpunkten des Gesellschafter- und Gläubigerschutzes vgl. Arbeitsgruppe Europäisches Gesellschaftsrecht (2002), S. 1316-1317.

499 Vgl. Ganske (1978), S. 2461; Gansen (1992), S. 6; Kübler (1999b), S. 450; Schön (2000), S. 709; Niehues (2001), S. 1214; Wymeersch (2001), S. 30; Habersack (2003), S. 114.

500 Wird eine durchschnittliche Inflationsrate im Zeitraum von 1977 bis 2006 in Höhe von $5 \%$ unterstellt, ergibt sich ein Wert von 102.903,39 $€$. Bei einer Inflationsrate von $3 \%$ ergeben sich $58.914,14 €$. Vgl. dazu auch Baldamus (2002), S. 88. Drinkuth (1998), S. 137, sieht hingegen in einem deutlich uber $25.000 €$ hinausgehenden Betrag einen Verstoß gegen die Niederlassungsfreiheit. Vgl. dazu kritisch Grundmann (2004), S. 147, Fn. 39. Vgl. anschaulich bezogen auf das Mindestkapital der GmbH Priester (1992), S. 161: „Für die 20000,- Goldmark des Jahres 1892 konnte man sich eine relativ noble Villa kaufen, für die 50000,DM des Jahres 1980 dagegen allenfalls eine kleine Eigentumswohnung.“ 
leistungen" handeln darf. Als Sacheinlagen in Betracht kommen z.B. Patente, Urheber- und Nutzungsrechte, Forderungen, Grundstücke, Maschinen, Beteiligungen und ganze Unternehmen $^{501}$.

Gemäß Art. 3h KapRL müssen die Gegenstände, ihr Wert und der Name des Einlegers in der - gemäß Art. 3 Publizitätsrichtlinie offenzulegenden - Satzung angegeben werden. Vor der Gründung der Aktiengesellschaft sind die Sacheinlagen nach Art. $10 \mathrm{KapRL}$ Gegenstand eines besonderen Berichts, der von einem oder mehreren öffentlich bestellten und von der Gesellschaft unabhängigen Sachverständigen erstellt wird und der ebenfalls offenzulegen ist. Der Sachverständigenbericht muss jede Einlage beschreiben, die herangezogenen Bewertungsmethoden nennen und angeben, ob die ermittelten Werte mindestens dem Nennwert bzw. dem rechnerischen Wert der ausgegebenen Aktien entsprechen ${ }^{502}$.

\subsubsection{Kapitalerhaltung}

\subsection{Auschüttungsrestriktionen}

Um zu verhindern, dass das von den Aktionären aufgebrachte Kapital an diese zurückfließt, beinhaltet Art. 15 KapRL Ausschüttungsrestriktionen ${ }^{503}$. Der Ausschüttungsbegriff wird nicht ausführlich definiert. In Art. 15 Abs. 1d KapRL wird lediglich darauf hingewiesen, dass er Dividendenzahlungen und Zinsen für Aktien umfasst ${ }^{504}$. Ausschüttungen dürfen gemäß Art. 15 Abs. 1a KapRL nur erfolgen, solange das „Nettoaktivvermögen“ - so die wenig glückliche Übersetzung von net assets (also Aktiva abzüglich Schulden ${ }^{505}$ ) - die Summe aus gezeichnetem Kapital und Rücklagen, deren Ausschüttung durch Gesetz ${ }^{506}$ oder Satzung $^{507}$ unzulässig ist, vor und nach der Ausschüttung zumindest deckt. In der englischsprachigen Literatur wird dieser Bilanztest als net asset test bezeichnet ${ }^{508}$.

Zusätzlich zur Ermittlung der Höchstausschüttung über Bilanzpositionen kann der maximale Ausschüttungsbetrag auch über die Gewinn- und Verlustrechnung hergeleitet werden. Nach Art. 15 Abs. 1c KapRL darf die Ausschüttung nicht höher sein als der Jahresüberschuss des abgelaufenen Geschäftsjahrs zuzüglich eines Gewinnvortrags und Entnahmen aus dafür ver-

S01

Vgl. Hueck/Windbichler (2003), S. 270. Zu weiteren Details vgl. insbesondere K. Schmidt (2002), S. 573-577 m.w.N.

502

$\mathrm{Vgl}$. zu den strengeren Vorgaben des deutschen Aktienrechts, insbesondere hinsichtlich verdeckter Sacheinlagen, Schwarz (2000), S. 375-378; Habersack (2003), S. 118-121; Hueck/Windbichler (2003), S. 269-273, jeweils m.w.N. Zu einer kritischen Analyse der Gründungsmodalităten vgl. Kapitel V.5.3.2.

Davon ausgenommen sind Kapitalherabsetzungen (Art. 15 Abs. 1a KapRL).

Unter den Auschüttungsbegriff fallen auch Sachdividenden. Vgl. Leinekugel (2001), S. 23-31. Der Aktienrückkauf ist hingegen in Art. 19-24a KapRL gesondert geregelt.

So auch Rickford (2004), S. 963. In der Kapitalrichtlinie findet sich keine Definition des Nettoaktivvermögens. Vgl. zur Kritik des Begriffs bereits Lutter (1975), S. 57.

Z.B. durch Art. 37 Abs. 2 KapRL (Rücklage bei Kapitalherabsetzungen durch Einziehung von Aktien), Art. 33 Abs. 2 BilRL (Bildung einer Neubewertungsrücklage), $\S 150$ Abs. 2 AktG (Einstellung in die gesetzliche Rücklage nach deutschem Recht). Vgl. zu weiteren Beispielen Leinekugel (2001), S. 20-21.

507 Z.B. durch $\S 58$ Abs. 1 AktG (Verwendung des Jahresüberschusses, wenn die Hauptversammlung den Jahresabschluss feststellt). Vgl. zur Kritik an der Berucksichtigung von satzungsmäßigen Rücklagen Lutter (1975), S. 57.

Vgl. Rickford(2004), S. 938. 
fügbaren Rücklagen, abzüglich von Verlusten aus früheren Geschäftsjahren und Beträgen, die gemäß Satzung oder Gesetz in die Rücklagen eingestellt werden. Es dürfen also das aktuelle Periodenergebnis und die in vorherigen Geschäftsjahren thesaurierten, frei verfügbaren $\mathrm{Ge}$ winne ausgeschüttet werden. Demzufolge wird diese Voraussetzung auch treffend als earned surplus test bezeichnet ${ }^{509}$. Eine Ausschüttungsbegrenzung auf den Gewinn des letzten Geschäftsjahrs, wie sie in Teilen der Literatur gesehen wird ${ }^{510}$, ist mit dem Wortlaut der Kapitalrichtlinie nicht vereinbar ${ }^{511}$.

Ist gegen die Ausschüttungsrestriktionen verstoßen worden, sind die Aktionäre gemäß Art. 16 KapRL zur Rückzahlung der unzulässigen Ausschüttung verpflichtet. Voraussetzung dafür ist jedoch, dass die Gesellschaft nachweisen kann, dass die Aktionäre von dem Verstoß gegen Art. $15 \mathrm{KapRL}$ wussten oder ,sie darüber nach den Umständen nicht in Unkenntnis sein konnten“. Des Weiteren besteht nach Art. 17 KapRL bei „schweren Verlusten des gezeichneten Kapitals" die Pflicht, die Hauptversammlung einzuberufen, damit die Aktionäre über das weitere Schicksal der Gesellschaft entscheiden können. Diese Norm ist aber lückenhaft ${ }^{512}$. So müssen die Mitgliedstaaten die Einberufungsfrist festlegen und die Höhe des als schwer zu erachtenden Verlustes bestimmen, der allerdings unter Beachtung von Art. 17 Abs. 2 KapRL nicht auf mehr als $50 \%$ des gezeichneten Kapitals festgesetzt werden darf. Problematisch ist, dass die Kapitalrichtlinie hinsichtlich der Ermittlung des Verlustes keine genaueren Vorgaben macht und zudem keine Sanktionen für die Fälle vorsieht, in denen die Geschäftsleitung der Einberufungs- und Anzeigepflicht nicht nachkommt ${ }^{513}$.

Eine Auslegung des Art. 17 KapRL unter expliziter Berücksichtigung der Grundsätze in Art. $15 \mathrm{KapRL}$ legt nahe, dass der „Verlust“ mit dem Jahresfehlbetrag gleichzusetzen und dieser dem gezeichneten Kapital gegenüberzustellen ist ${ }^{514}$. Die herrschende Meinung hingegen stellt darauf ab, dass das Vermögen nur noch die Hälfte des gezeichneten Kapitals deckt und somit eine Unterbilanz eingetreten ist ${ }^{515}$. Kommt die Geschäftsleitung ihrer Einberufungs- und Anzeigepflicht nicht nach, macht sie sich nach $\S 93 \mathrm{Abs} .2 \mathrm{AktG}$ der Gesellschaft gegenüber schadensersatzpflichtig ${ }^{516}$.

\subsection{Rechnungslegungsregeln}

In materieller Hinsicht sind die Rechnungslegungsregeln von entscheidender Bedeutung für die Ausschüttungsrestriktionen der Kapitalrichtlinie. Die Ansatz- und Bewertungsvorschriften determinieren die Höhe von „Nettoaktivvermögen“" und Jahresergebnis und somit den maxi-

Vgl. Rickford (2004), S. 938.

Vgl. so Schwarz (2000), S. 379; missverständlich auch Ankele (1970), S. 990; Nienhaus (2002), S. 111; Habersack (2003), S. 121-122.

Vgl. dies klarstellend Grundmann (2004), S. 153. Vgl. auch Schön (1997a), S. 291; Drinkuth (1998), S. 183; Fankhauser (2001), S. 171-172; Leinekugel (2001), S. 13-23; Niehues (2001), S. 1212; Baldamus (2002), S. 16.

Vgl. zur Kritik des Art. 17 KapRL Habersack (2003), S. 127.

Vgl. zu Letzterem Lutter (1975), S. 57-59.

So Habersack (2003), S. 128.

Vgl. Schwarz (2000), S. 381; Hüffer (2006), § 92, Tz. 2.

Vgl. Hüffer (2006), §92, Tz. 15. Für eine Schadensersatzpflicht der Vorstandsmitglieder auch gegenüber den Aktionären plädiert Habersack (2003), S. 128-129. 
mal zulässigen Ausschüttungsbetrag. Da die Kapitalrichtlinie selbst keine Bilanzierungsvorschriften enthält, sind die in der Bilanzrichtlinie ${ }^{517}$ kodifizierten Ansatz- und Bewertungsregeln zu beachten ${ }^{518}$. Wie im Folgenden näher dargelegt wird, bilden die Kapital- und die Bilanzrichtlinie zusammen „ein einheitliches kapitalschützendes Richtlinienkonzept ${ }^{\text {“519 }}$ im Aktienrecht der EU-Mitgliedstaaten ${ }^{520}$.

Als zentralen Rechnungslegungsgrundsatz haben die Unternehmen das Vorsichtsprinzip gemäß Art. 31 Abs. 1c Bilanzrichtlinie (BilRL) zu beachten. Gewinne sind danach erst dann auszuweisen, wenn sie realisiert sind. Neben dem Realisationsprinzip ist als weitere Ausprägung des Vorsichtsprinzips das Imparitätsprinzip zu befolgen, nach dem ein Verlust oder eine Verbindlichkeit bereits bei Wahrscheinlichkeit des Bestehens auszuweisen ist (Art. 20 Abs. 1 BilRL). Alle Bilanzpositionen sind gemäß Art. 32 BilRL grundsätzlich mit den Anschaffungs- und Herstellungskosten zu bewerten, die in Art. 35 Abs. 2 bis 4 BilRL definiert werden. Hinsichtlich der Folgebewertung ist zu beachten, dass Gegenstände des Anlagevermögens mit begrenzter Nutzungsdauer planmäßig über die Nutzungsdauer abzuschreiben sind (Art. 35 Abs. 1b BilRL). Darüber hinaus ist das Anlagevermögen gemäß Art. 35 Abs. 1c(bb) BilRL außerplanmäßig auf den niedrigeren beizulegenden Wert abzuschreiben, wenn es sich voraussichtlich um eine dauerhafte Wertminderung handelt (gemildertes Niederstwertprinzip). Im Gegensatz dazu ist das Umlaufvermögen gemäß Art. 39 Abs. 1b BilRL bei einer Wertminderung immer auf den niedrigeren Marktpreis bzw. ,in Sonderfällen“ auf einen ,anderen niedrigeren Wert" abzuschreiben (strenges Niederstwertprinzip).

Art. 33 BilRL eröffnet als ein an die Unternehmen übertragbares Mitgliedstaatenwahlrecht ${ }^{521}$ die Möglichkeit, von den Anschaffungs- und Herstellungskosten als Bewertungsobergrenze abzuweichen. Die Mitgliedstaaten können danach ihren Gesellschaften gestatten oder vorschreiben,

- Sachanlagen mit zeitlich begrenzter Nutzungsdauer und Vorräte mit Wiederbeschaffungswerten zu bewerten (Art. 33 Abs. 1a BilRL),

- alle Bilanzpositionen, inklusive des Eigenkapitals, mit einer Methode zum Ausgleich der Inflation zu bewerten (Art. 33 Abs. 1b BilRL),

- für das gesamte Anlagevermögen eine Neubewertung ${ }^{522}$ durchzuführen (Art. 33 Abs. lc BilRL).

517 Vgl. Vierte Richtlinie des Rates vom 25.07.1978 (78/660/EWG), ABI. EG Nr. L 222/11 vom 14.08.1978 Im Unterschied zur Kapitalrichtlinie gilt die Bilanzrichtlinie nicht nur für die Aktiengesellschaft, sondern auch für die $\mathrm{KGaA}$ und die $\mathrm{GmbH}$

518 Vgl. Hennrichs (1999b), S. 95-96; Fédération des Experts Comptables Européens (2001), S. 9; Niehues (2001), S. 1212-1213

519 Schön (2001), S. 77

520 Die Ausführungen beschränken sich auf die besonderen Charakteristika der Bilanzrichtlinie. Zu einer ausführlichen Analyse der Rechnungslegungsgrundsătze nach $\mathrm{HGB}$, die EU-richtlinienkonform sein müssen, vgl. bereits Kapitel III.1.1.3.2.

521 Der deutsche Gesetzgeber hat von dieser Möglichkeit keinen Gebrauch gemacht. Zur Systematisierung der Wahlrechte in Mitgliedstaatenwahlrechte, ubertragbare Mitgliedstaatenwahlrechte, weitergeleitete und originäre Unternehmenswahlrechte vgl. Schwarz (2000), S. 281-283.

522 Vor Inkrafttreten der Anpassungsrichtlinie 2003/51/EG (Modernisierungsrichtlinie) war die Neubewertung nur von Sach- und Finanzanlagen, nicht hingegen von immateriellen Vermögenswerten möglich. Vgl. Bieker/Schmidt (2002), S. 211; Busse von Colbe (2002d), S. 1533; Niehus (2002), S. 1387; Böcking/Herold/ Wiederhold (2003), S. 399-400. 
Wird von diesen Methoden Gebrauch gemacht, muss einerseits darüber im Anhang berichtet werden. Andererseits ist der Unterschiedsbetrag, der sich im Vergleich zur Bewertung mit Anschaffungs- und Herstellungskosten ergibt, in der Position „Neubewertungsrücklage" auf der Passivseite im Eigenkapital gesondert auszuweisen (Art. 33 Abs. 2a BilRL). Die Neubewertungsrücklage kann gemäß Art. 33 Abs. 2b BilRL jederzeit ganz oder teilweise in gezeichnetes Kapital umgewandelt werden; sie ist aufzulösen, wenn sie ganz oder teilweise nicht mehr erforderlich ist (Art. 33 Abs. 2c BilRL). Die Neubewertungsrücklage ist gemäß Art. 33 Abs. 2c BilRL ausschüttungsgesperrt: „Die Neubewertungsrücklage darf, außer wenn sie einen realisierten Gewinn darstellt, weder unmittelbar noch mittelbar auch nicht zum Teil ausgeschüttet werden." Die Ausschüttungssperre verhindert somit, dass der mit der Kapitalrichtlinie bezweckte Gläubigerschutz durch eine fair value-Bewertung nach Art. 33 BilRL ausgehöhlt wird, indem unrealisierte Gewinne an die Aktionäre ausgeschüttet werden.

Die Bilanzrichtlinie enthält darüber hinaus drei weitere Ausschüttungssperren. Werden Aufwendungen zur Errichtung und Erweiterung des Unternehmens aktiviert, dürfen gemäß Art. 34 Abs. 1b BilRL Gewinne nur bis zur Höhe des noch aktivierten Teils ausgeschüttet werden, wenn die ausschüttungsfähigen Rücklagen und der Gewinnvortrag mindestens so hoch wie der noch nicht abgeschriebene Teil des aktivierten Betrages sind. Gleiches gilt grundsätzlich für aktivierte Forschungs- und Entwicklungskosten nach Art. 37 Abs. 1 BilRL, wobei Mitgliedstaaten in Ausnahmefällen davon abweichen dürfen. Schließlich dürfen bei der Equity-Bewertung von Beteiligungen die übersteigenden Beträge, die noch nicht als Dividenden eingegangen sind oder auf deren Zahlung noch kein Anspruch besteht, nicht an die Aktionäre ausgeschüttet werden (Art. 59f BilRL).

Bemerkenswert ist, dass der europäische Gesetzgeber durch Reformen auf dem Gebiet des Bilanzrechts in jüngerer Vergangenheit das Kapitalerhaltungskonzept aufgeweicht hat ${ }^{523}$. Durch die Fair-Value-Richtlinie ${ }^{524}$ im Jahre 2001 wurde die Bilanzrichtlinie um Art. 42a bis $42 \mathrm{~d}$ ergänzt. Mitgliedstaaten können seitdem ihren Gesellschaften gestatten oder vorschreiben, bestimmte Finanzinstrumente einschließlich derivativer Finanzinstrumente zum beizulegenden Zeitwert zu bewerten (Art. 42a Abs. 1 BilRL) ${ }^{525}$. Als Zeitwert kommt der Marktwert oder, wenn sich ein verlässlicher Markt für die Finanzinstrumente nicht ermitteln lässt, ein Wert unter Verwendung allgemein anerkannter Bewertungsmodelle und -methoden in $\mathrm{Be}-$ tracht (Art. 42b BilRL). Gemäß Art. 42c BilRL sind Wertänderungen von zum Zeitwert bewerteten Finanzinstrumenten unter Missachtung des Vorsichtsprinzips ergebniswirksam zu behandeln. Lediglich bei Sicherungsinstrumenten, die im Rahmen einer Bilanzierung von Sicherungsgeschäften erfasst werden, bei der Wertänderungen nicht oder nur teilweise ergebniswirksam behandelt werden, und bei Wechselkursdifferenzen von Auslandsbeteiligungen sind die Wertänderungen in einer so genannten Zeitwert-Rücklage zu erfassen (Art. 42c Abs. 1a und b BilRL). Bei sonstigen Finanzinstrumenten können die Mitgliedstaaten die Bildung der Zeitwert-Rücklage gemäß Art. 42c Abs. 2 BilRL vorschreiben oder zulassen. Eine Ausschüttungssperre der in der Zeitwert-Rücklage erfassten Wertänderungen findet sich in

\footnotetext{
523 Vgl. dazu Gelter (2004), S. 185.

524 Vgl. Richtlinie 2001/65/EG vom 27.09.2001, ABl. EG Nr. L 283/28 vom 27.10.2001. Vgl. dazu Kirsch (2005), S. 13-21.

525 Ausnahmen sind in Art. 42a Abs. 2 bis 4 BilRL geregelt. Z.B. ist die Zeitwertbilanzierung fur bis zur Fälligkeit gehaltene nicht derivative Finanzinstrumente und Anteile an Tochtergesellschaften ausgeschlossen.
} 
der Richtlinie nicht ${ }^{526}$. Es liegt damit weitgehend im Belieben der EU-Mitgliedstaaten, wie weit der Kapitalschutz im Hinblick auf die Bewertung von Finanzinstrumenten geht.

Darüber hinaus können die Mitgliedstaaten seit der Modernisierungsrichtlinie ${ }^{527}$ aus dem Jahr 2003 nach Art. 42e BilRL allen oder bestimmten Gruppen von Gesellschaften gestatten oder vorschreiben, bestimmte Arten von Vermögensgegenständen mit Ausnahme von Finanzinstrumenten zum fair value zu bewerten. Nach Art. $42 \mathrm{f}$ BilRL dürfen die Differenzbeträge ergebniswirksam behandelt werden.

Hintergrund dieser Maßnahmen ist die Angleichung der Bilanzrichtlinie an die IFRS ${ }^{528}$ mit dem Ziel, potentielle Konflikte im Rahmen des Anerkennungsverfahrens (so genannter Endorsement Mechanism) nach Art. 3 IAS-VO vorzubeugen. Ob nämlich ein neuer oder überarbeiteter IFRS in europäisches Recht umgesetzt wird, ist davon abhängig, dass die EUKommission die Übereinstimmung mit den EU-Richtlinien und den europäischen Interessen gewahrt sieht und ihn dem EU-Parlament zur Anerkennung in einem Verordnungsentwurf vorschlägt $^{529}$.

\subsubsection{Gewinnverwendungskompetenz}

Die Gewinnverwendungskompetenz ist im EU-Gesellschaftsrecht nicht geregelt. Gemäß Art. 2d KapRL wird lediglich vorgeschrieben, dass die Satzung der Gesellschaft die Anzahl und die Bestellung der Mitglieder von Geschäftsführungs- und Aufsichtsorgan sowie die Kompetenzverteilung zwischen den Organen regeln muss. Überlegungen zur Ausstattung der Hauptversammlung mit weitgehenden Kompetenzen zur Feststellung des Jahresabschlusses und zur Gewinnverwendung, wie sie im Vorschlag einer Fünften Richtlinie (Strukturrichtlinie $)^{530}$ zum Ausdruck kommen ${ }^{531}$, haben sich nicht durchsetzen können und werden wohl in dieser Form auch nicht mehr weiter verfolgt ${ }^{532}$.

526 Darauf weist auch Niehues (2001), S. 1217, hin. A.A. wohl Grundmann (2004), S. 249: „keineswegs auch für eine Ausschüttung derselben."

527 Vgl. Richtlinie 2003/51/EG vom 18.06.2003, ABl. EU L 178/16 vom 17.07.2003.

528 Vgl. dazu kritisch Hennrichs (2004), S. 122: „Es besteht die Gefahr, dass das Europäische Bilanzrecht zu einem unstimmigen Prinzipiendurcheinander verkommt und damit seine Ordnungskraft verliert."

529 Vgl. zum Anerkennungsverfahren (Komitologieverfahren) der IFRS ausführlich und kritisch Buchheim/ Gröner/Kühne (2004); Pellens/Fülbier/Gassen (2006), S. 90-93.

530 Zum ursprünglichen Vorschlag einer Fünften Richtlinie vgl. ABl. EG Nr. C 131 vom 13.12.1972; zum geänderten Vorschlag vgl. ABl. EG Nr. C 240 vom 09.09.1983; zur dritten Änderung des Vorschlags vgl. ABl. EG Nr. C 321 vom 12.12.1991.

531 Vgl. hiezu im Einzelnen Kaminski (1972), S. 636-637; Sonnenberger/Coester (1974), S. 184-185; H.P. Müller (1977), S. 1886-1888; Kolvenbach (1983), S. 2240-2241; Chmielewicz (1984), S. 404-408; Niedernhuber (1985); Niedernhuber (1988), S. 228-230; Kostrzewa (1995), S. 13-21, 68-69, 104-105, 130; Lutter (1996), S. 171-195. Vgl. zu einer ökonomischen Analyse der Ausschüttungsregeln des Entwurfs der Strukturrichtlinie im Vergleich zum Aktiengesetz Wagner (1988).

532 Vgl. van Hulle (2000), S. 522; Wagenhofer/Ewert (2003), S. 188. Die Gewinnverwendungskompetenz liegt damit weiterhin in den Händen der Nationalstaaten. Vgl. zur Situation in Deutschland Kapitel III.1.1.3.1. Vgl. zu einem ausführlichen europäischen Rechtsvergleich Grundmann (2004), S. 163-224. 


\subsubsection{Europäische Aktiengesellschaft}

Nach jahrzehntelangen Verhandlungen ${ }^{533}$ sind am 08.10.2001 die Verordnung über das Statut der Europäischen Gesellschaft (Societas Europaea, SE) ${ }^{534}$ und die sie ergänzende Richtlinie ${ }^{535}$ verabschiedet worden. Seit dem 08.10.2004 steht damit den Unternehmen die supranationaleuropäische Rechtsform der Europäischen Aktiengesellschaft zur Verfügung ${ }^{536}$. Während ursprünglich über 400 Vorschriften vorgesehen waren, wird die neue Rechtsform nunmehr in lediglich 70 Artikeln geregelt, wobei vielfach auf die Bestimmungen nationalen Sitzrechts verwiesen wird $^{537}$.

Im Gegensatz zur deutschen Aktiengesellschaft kann eine Europäische Aktiengesellschaft nicht von natürlichen Personen gegründet werden. Es werden vielmehr mit der Verschmelzung, der Gründung einer Holding-Gesellschaft und einer Tochtergesellschaft sowie der Umwandlung vier detailliert geregelte Gründungsarten unterschieden ${ }^{538}$. Hinsichtlich der Struktur der Rechtsform besteht die Besonderheit darin, dass die Unternehmen das Wahlrecht haben, ob die Europäische Aktiengesellschaft nur einen Vorstand (monistisches System) oder Vorstand und Aufsichtsrat (dualistisches System) haben soll. In beiden Systemen führt das Leitungsorgan die Geschäfte in eigener Verantwortung. Überwachungsaufgaben übernehmen der Aufsichtsrat bzw. die nicht geschäftsführenden Vorstände im monistischen System. Die Hauptversammlung bestellt den Vorstand im monistischen und den Aufsichtsrat im dualistischen System ${ }^{539}$. In welchem Umfang die Gesellschaft der Mitbestimmung unterliegt, kann grundsätzlich im Wege der Verhandlung von Unternehmensleitung und Arbeitnehmervertretung festgelegt werden (Art. 3-6 SE-RL). Dafür wird ein besonderes Verhandlungsgremium geschaffen, „dessen Zusammensetzung und Beschlussmodalitäten mit einer die Grenzen der Skurrilität streifenden Akribie festgelegt worden sind“"540. Es kann mit absoluter Mehrheit bestimmen, dass das bisher höchste Mitbestimmungsniveau in den beteiligten Unternehmen erhalten oder ausgebaut wird. Mit Zweidrittelmehrheit kann es das Mitbestimmungsniveau mindern. Wird keine Einigung erzielt, greift nach Ablauf der Verhandlungsfrist die Auffanglösung gemäß Art. 7 SE-RL, nach welcher der höchste Standard in den beteiligten Gesell-

533 Vgl. zur Entstehungsgeschichte Theisen/Wenz (2005), S. 27-36.

534 Vgl. Verordnung (EG) Nr. 2157/2001 des Rates vom 08.10.2001 über das Statut der Europäischen Gesellschaft (SE), ABI. EG, L 294/1 vom 10.11.2001. Angelehnt an den lateinischen Begriff wurde die Rechtsform in der verabschiedeten Fassung nur noch als Europäische Gesellschaft bezeichnet. Vgl. Grundmann (2004), S. 481.

535 Vgl. Richtlinie 2001/86/EG des Rates vom 08.10.2001 zur Ergănzung des Statuts der Europäischen Gesellschaft hinsichtlich der Beteiligung der Arbeitnehmer, ABl. EG, L 294/22 vom 10.11.2001.

536 Vgl. zur Europäischen Aktiengesellschaft im Überblick etwa Hommelhoff (2001); Hirte (2002); Grundmann (2004), S. 480-502. Vgl. umfassend Theisen/Wenz (Hrsg.) (2005). Vgl. zu Nachweisen zur überaus umfangreichen Literatur Grundmann (2004), S. 478-479.

537 Vgl. Grundmann (2004), S. 483. Zur so genannten Rechtsquellenpyramide vgl. Theisen/Wenz (2005), S. 50-52 m.w.N.

538 Vgl. dazu ausfuhrlich Neun (2005).

539 Vgl. zu den Organen der Europäischen Aktiengesellschaft ausfuhrlich Theisen/Hölzl (2005), S. 278-312.

540 Kübler (2003a), S. 224. 
schaften zur Anwendung kommt. In dem Grundsatz der mitbestimmungsrechtlichen Besitzstandswahrung wird ein Wettbewerbsnachteil für deutsche Unternehmen gesehen ${ }^{541}$.

Zu Fragen der Finanzverfassung finden sich kaum eigenständige Vorschriften. Das Mindestkapital muss gemäß Art. 4 Abs. 2 SE-VO mindestens $120.000 €$ betragen $^{542}$. Hinsichtlich der sonstigen Kapitalaufbringungs- und -erhaltungsregeln wird in Art. 5 SE-VO auf die im jeweiligen Sitzland umgesetzten Regeln der Kapitalrichtlinie verwiesen.

\subsection{Zwischenergebnis}

Als Ergebnis der bisherigen Analyse ist festzuhalten, dass das deutsche bzw. europäische Kapitalschutzsystem danach trachtet, die divergierenden Interessen von Aktionären und Gläubigern zu einem Ausgleich zu bringen. Das Interesse der Aktionäre an angemessenen Dividendenzahlungen wird zum einen dadurch berücksichtigt, dass das Management gesetzlich kodifizierte Rechnungslegungsregeln zu beachten hat und den Gewinn insofern nicht willkürlich schmälern kann. Zum anderen gewährt der deutsche Gesetzgeber der Hauptversammlung als Organ aller Aktionäre die Kompetenz zur Verwendung des Bilanzgewinns.

Das primäre Ziel der detaillierten und gesetzlich verankerten Kapitalaufbringungs- und -erhaltungsregeln besteht im Schutz der Gläubiger. Vor dem Hintergrund der Haftungsbeschränkung der Gesellschafter von Aktiengesellschaften sollen diese Vorschriften sicherstellen, dass die Gesellschaft möglichst über ein bestimmtes Mindestvermögen dauerhaft verfügt, das zur Erfüllung der Ansprüche der Gläubiger zur Verfügung steht.

Die Ziele des Gesetzgebers werden allerdings dadurch eingeschränkt, dass die Rechnungslegungsregeln zahlreiche explizite Bilanzierungswahlrechte und Ermessensspielräume enthalten, die der Unternehmensleitung bei der Gewinnermittlung weitreichende Einflussmöglichkeiten gewähren. Darüber hinaus ist deutlich geworden, dass die Kapitalschutzregeln im Konzern durch das Management des Konzern-Mutterunternehmens sowohl zum Nachteil der Aktionäre als auch der Gläubiger auf legale Weise umgangen werden können.

Diese und weitere Kritikpunkte an den bestehenden deutschen bzw. europäischen Kapitalschutzregeln haben insbesondere auf europäischer Ebene zu Reformvorschlägen geführt. Dabei ist verschiedentlich auf US-amerikanische Vorschriften verwiesen worden, die im nachfolgenden Kapitel III.2 detailliert dargestellt werden. Im späteren Verlauf der Arbeit werden diese einer kritischen Würdigung unterzogen und daraufhin überprüft, ob sie bei der anstehenden europäischen Gesellschaftsrechtsreform als Vorbild dienen sollten.

Den Besonderheiten des US-amerikanischen Rechtssystems wird im Folgenden dadurch Rechnung getragen, dass mit dem Delaware General Corporation Law und dem California

${ }^{541}$ Vgl. Hirte (2002), S. 6. Kübler (2003a), S. 228, weist allerdings darauf hin, dass sich ein Unternehmen der Mitbestimmung dadurch entziehen kann, dass es beispielweise nach Großbritannien fusioniert und sich nach zwei Jahren von der Rechtsform der Europäischen Aktiengesellschaft in eine Gesellschaft britischen Rechts umwandelt. Als erstes deutsches Großunternehmen hat im September 2005 die Allianz AG den Wechsel der Rechtsform in die Europäische Aktiengesellschaft angekündigt. Vgl. o.V. (2005c); o.V. (2005d).

542 Nach Art. 4 Abs. 3 SE-VO sind nationale Rechtsvorschriften, die ein höheres Mindestkapital von Gesellschaften bestimmter Branchen vorschreiben, auch auf die Europăische Aktiengesellschaft anzuwenden. Zu den diesbezüglichen Regeln in Deutschland und ausgewăhlten EU-Staaten vgl. Mayer (2005), Art. 4, Tz. 17-20. 
Corporations Code die Kapitalschutznormen von zwei bedeutenden Einzelstaatengesetzen dargestellt werden. Darüber hinaus werden die Vorschriften des MBCA beleuchtet, dessen Vorschriften von vielen Bundesstaaten der USA in das Gesellschaftsrecht übernommen worden sind. Dabei wird jeweils auch auf Gerichtsurteile hingewiesen, die im Hinblick auf Dividendenausschüttungen zu beachten sind und gesetzliche Vorschriften konkretisieren. Auf Kapitalschutzregeln, die sich aus anderen Rechtsgebieten, wie z.B. dem Insolvenzrecht und dem Steuerrecht, ergeben können, wird ebenfalls kurz eingegangen.

\section{Kapitalschutzsysteme in den USA}

Vorschriften zur Kapitalaufbringung und -erhaltung der corporation sind im Wesentlichen in zwei Regelwerken kodifiziert ${ }^{53}$. Sie ergeben sich zum einen aus den Einzelstaatengesetzen bzw. den zur Rechtsvereinheitlichung entwickelten Modellgesetzen. Zum anderen sind die Gläubigerschutzregeln des creditors' rights oder fraudulent conveyance law zu berücksichtigen. Die Dividendenentscheidung des board of directors wird darüber hinaus auch von anderen Gesetzen indirekt beeinflusst. Schließlich wirken sich Gerichtsentscheidungen und von der Rechtsprechung entwickelte Doktrinen auf den Kapitalschutz der corporation aus. Diese vielfältigen, unterschiedlichen und sich teilweise überlappenden Regelungen und Einflussfaktoren werden im Folgenden systematisiert und detailliert herausgearbeitet.

\subsection{Common Law und Rechtsprechung}

In den USA sind von der Rechtsprechung früh Grundsätze entwickelt worden, die bei der Aufbringung und Erhaltung des Kapitals der corporation zu beachten sind. Obwohl in der Folgezeit gesetzliche Regelungen entstanden sind, haben viele common law-Grundsätze nicht an Relevanz verloren, weil sie zur Auslegung der Gesetze heranzuziehen sind ${ }^{544}$.

Im Gegensatz zu Deutschland wurde in den USA nie ein Mindestkapital in nennenswerter Höhe vorgeschrieben. Ende des 19. Jahrhunders führten einige Bundesstaaten zum Schutz der Gläubiger ein Mindestkapital zwischen 200 US-\$ und 1.000 US- $\$$ ein $^{545}$. Die Aufbringung des entsprechenden Vermögens war aber keine Voraussetzung für die Eintragung der Gesellschaft, sondern je nach Bundesstaat in unterschiedlicher Weise mit Sanktionen bewehrt. Nach common law hafteten die Gesellschafter für die Verbindlichkeiten der corporation unbeschränkt, wenn das Mindestkapital nicht in voller Höhe erbracht worden war ${ }^{546}$. Aufgrund dieser als unverhältnismäßig erachteten Rechtsprechung schafften in der Folgezeit die meisten Einzelstaaten das Mindestkapitalerfordernis ab.

Im US-amerikanischen common law entwickelten sich ebenfalls Kapitalaufbringungsregeln, die sicherstellen sollen, dass die corporation im Zeitpunkt der Gründung oder der Kapitalerhöhung über Vermögenswerte in Höhe des Aktiennennwerts verfügt. Es soll verhindert werden, dass Aktien unter Nennwert bzw. gegen überbewertete Sacheinlagen ausgegeben werden.

\footnotetext{
543 Vgl. Eisenberg (2000), S. 1244-1245.

544 Vgl. bezogen auf die Ausschüttungsrestriktionen Bauer (1995), S. 215-216.

545 Vgl. Drobnig (1959), S. 11, Fn. 1; H. Henn/Alexander (1983), S. 295; Gevurtz (2000), S. 129.

546 Vgl. Bauer (1995), S. 133 mit Rechtsprechungsnachweisen.
} 
$\mathrm{Zu}$ diesem Zweck wurde das Verbot des so genannten stock watering ${ }^{547}$ entwickelt, das auch heute noch zu beachten ist ${ }^{548}$. Den Schwierigkeiten bei der Bewertung von Sacheinlagen versuchten einige Gerichte zunächst dadurch zu begegnen, dass sie lediglich Bargeld für einlagefähig erachteten ${ }^{549}$. Es wurde aber bald der Grundsatz entwickelt, nach dem Bargeld, bereits erbrachte Dienstleistungen und tatsächlich erhaltene Vermögenswerte einlagefähig sind. Hinsichtlich der Einlagefähigkeit von Vermögenswerten verfolgen die Gerichte zumeist einen sehr liberalen Ansatz und stellen lediglich darauf ab, dass die Vermögenswerte einen wirtschaftlichen Wert haben ${ }^{550}$.

Im Gegensatz zu Deutschland unterliegen Sacheinlagen keiner Bewertungskontrolle durch unabhängige Sachverständige im Gründungszeitpunkt. Die Wertansätze der directors werden in den USA erst dann durch Gerichte überprüft, wenn die Gesellschaft insolvent ist und der Insolvenzverwalter oder Gläubiger Ansprüche aufgrund von überbewerteten Sacheinlagen geltend machen. Von der Rechtsprechung sind allerdings keine allgemeingültigen Bewertungskriterien entwickelt worden, es wird vielmehr in Einzelfallentscheidungen auf den konkreten Nutzen der Einlage für die jeweilige Gesellschaft abgestellt ${ }^{551}$. Nach der im common law entwickelten good faith rule haften die directors bei einer Überbewertung nur dann, wenn die Gläubiger das Verschulden der directors nachweisen können ${ }^{552}$.

Lange Zeit bevor die Einzelstaaten gesetzliche Regelungen schufen, entwickelten sich in der Rechtsprechung verschiedene Theorien zur Kapitalerhaltung ${ }^{553}$. Die trust fund theory wurde im Jahre 1824 vom Bundesberufungsrichter Story in der Sache Wood v. Dummer ${ }^{554}$ begrün$\operatorname{det}^{555}$. In diesem Fall schütteten die directors einer Bank trotz ausstehender Schuldverschreibungen und absehbarer Zahlungsschwierigkeiten der Gesellschaft $75 \%$ des Gesellschaftsvemögens als Dividenden aus. Da die Gesellschaft bei Fälligkeit der Schuldverschreibungen insolvent war, verklagten die Gläubiger die Aktionäre aufgrund unzulässiger Ausschüttung von Gesellschaftsvermögen. Das Gericht verurteilte die Beklagten zur Zahlung an die Kläger mit der Begründung, das Nennkapital stelle einen trust fund dar. Das dem Nennkapital entsprechende Vermögen sei treuhänderisch zugunsten der Gläubiger gebunden und trete an die

${ }^{547}$ Der Begriff spielt auf unlautere Praktiken im Viehhandel an, nach denen die Tiere vor dem Verkauf getränkt wurden, um das Gewicht zu erhöhen. Unter dem Oberbegriff watered stock werden erstens Aktien, die unentgeltlich ausgegeben werden (bonus stock), zweitens Aktien, die unter pari emittiert werden (discount stock), und drittens Aktien, die gegen überbewertete Sacheinlagen verkauft werden (watered stock), gefasst. Vgl. dazu Bauer (1995), S. 140.

Vgl. etwa Bainbridge (2002), S. 771.

Vgl. Bauer (1995), S. 140 mit Rechtsprechungsnachweisen.

Vgl. Bauer (1995), S. 142, der zu dem Ergebnis kommt, dass Fălle, in denen Gerichte die Einlagefähigkeit ablehnen, selten sind und „, in den Bereich der Kuriosităten“ fallen, wie z.B. eine nicht erprobte Geheimformel zur Verminderung der Explosionsgefahr von Benzin.

Vgl. Bauer (1995), S. 166.

Die von der Rechtsprechung nur selten angewandte true value rule stellt hingegen allein auf die objektive Überbewertung ab. Vgl. Bauer (1995), S. 168-170. Vgl. zum good faith-Prinzip im US-amerikanischen Recht ausführlich Rezori (2004), S. 42-64 m.w.N.

Diese Theorien sind später in unterschiedlichem Umfang in den einzelstaatlichen Gesellschaftsrechten kodifiziert worden. Vgl. H. Henn/Alexander (1983), S. 431, 433.

Vgl. Wood v. Dummer, 30 F.Cas. 435, No. 17944 (C.C.D.Me.1824).

Vgl. zur trust fund theory Kehl (1941), S. 8, 15-16, 23-25; Ballantine (1946), S. 803-806; H. Henn/Alexander (1983), S. 431-432; Friedman (1985), S. 199, 516-517; Maier (1986), S. 133-134; Kübler (1989), S. 18-19; Manning/Hanks (1990), S. 50-51; Bauer (1995), S. 185-190, 214 m.w.N.; Gevurtz (2000), S. 130-131; Bainbridge (2002), S. 769-770; Klein/Coffee (2002), S. 215. 
Stelle der persönlichen Haftung der Aktionäre ${ }^{556}$. Ihren Höhepunkt erreichte die trust fund theory durch die ca. 50 Jahre später ergangene Entscheidung im Fall Sawyer v. Hoag ${ }^{557}$.

Gegen Ende des 19. Jahrhunderts nahm die Bedeutung der Theorie ab. So führte der Supreme Court der USA in der Sache Handley v. Stutz ${ }^{558}$ aus, dass nur Gläubiger, die nach einer Aktienemission der Gesellschaft Kredit gewähren, durch die trust fund theory geschützt werden. Darüber hinaus hielt das Gericht die Ausgabe von Aktien unter dem Nennwert bei einer schlechten wirtschaftlichen Lage der Gesellschaft zum Zwecke der Sanierung für zulässig. Im Jahre 1892 verwarf der Minnesota Supreme Court in der Sache Hospes v. Northwestern Manufacturing and Car Corporation ${ }^{559}$ als erstes Gericht die trust fund theory. Die Haftung der Aktionäre bei der Ausgabe von watered stock wurde nicht mehr mit Grundsätzen des Trustrechts, sondern mit Hilfe des Deliktsrechts begründet. Ersatzansprüche der Gläubiger gegenüber den Aktionären im Fall der Insolvenz der Gesellschaft werden damit gerechtfertigt, dass sie durch die nicht voll eingezahlten Aktien über die Höhe des Nennkapitals getäuscht werden. Die Gerichtsentscheidung markiert somit den Beginn der holding out theory ${ }^{560}$. Wenngleich die holding out theory dogmatische Schwächen der trust fund theory löst, ist sie selbst nicht unproblematisch. Sie fußt einerseits auf der unrealistischen Annahme, dass das Nennkapital die Grundlage für die Kreditentscheidung darstellt. Andererseits ist sie mit praktischen Schwierigkeiten bei einer größeren Anzahl von Gläubigern und Aktionären verbunden, da es sich um individuelle, deliktische Ansprüche der Gläubiger gegenüber individuellen Aktionären handelt, die nicht vom Insolvenzverwalter geltend gemacht werden können.

$\mathrm{Zu}$ Beginn des 20. Jahrhunderts griffen Gerichte die gesellschaftsrechtlichen Anspruchsgrundlagen, die in einigen Bundesstaaten geschaffen worden waren, auf und entwickelten die statutory obligation theory ${ }^{561}$, nach der die Gläubiger einen Anspruch gegen die Aktionäre auf vollständige Einzahlung des Aktiennennbetrags haben.

Die materielle Bedeutung der aufgezeigten Kapitalaufbringungs- und Kapitalerhaltungsregeln des common law nahm zu Beginn des 20. Jahrhunderts insofern ab, als Gesellschaften begannen, Aktien mit sehr niedrigen Nennwerten (low par stock) auszugeben ${ }^{562}$. New York ging

s56 Vgl. dazu die Kritik von Bauer (1995), S. 186, der darauf hinweist, dass das Gesellschaftsvermögen keinen trust darstellt, da es nicht der Zweck einer Gesellschaft sei, ihr Vermögen treuhänderisch im alleinigen Interesse der Gläubiger zu halten. Vgl. auch Maier (1986), S. 134 m.w.N.; Böckmann (2005), S. 39. Im Ergebnis ist die trust fund theory mit dem Verbot der Einlagenruckgewähr gemäß $§ 57$ Abs. 1 AktG vergleichbar. Vgl. Wüstemann (1999), S. 54, Fn. 216.

557 Vgl. Sawyer v. Hoag, 84 U.S. 610 (1873). Vgl. dazu Kübler (1989), S. 19.

558 Vgl. Handley v. Stutz, 139 U.S. 417 (1891). Vgl. dazu Ballantine (1946), S. 470, 804-805; Kübler (1989), S. 19-20; Manning/Hanks (1990), S. 27-28; Bauer (1995), S. 198-199; Böckmann (2005), S. 41-43.

559 Vgl. Hospes v. Northwestern Manufacturing \& Car Co., 48 Minn. 174, 50 N.W. 1117 (1892). Vgl. dazu Kübler (1989), S. 20-21; Manning/Hanks (1990), S. 51; Bauer (1995), S. 190.

$560 \mathrm{Vgl}$. zur holding out theory, die auch als fraud oder misrepresentation theory bezeichnet wird, Ballantine (1946), S. 806-808; H. Henn/Alexander (1983), S. 432; Kübler (1989), S. 21-22; Manning/Hanks (1990), S. 51-52; Bauer (1995), S. 190-193; Gevurtz (2000), S. 131; Böckmann (2005), S. 39-40.

561 Vgl. zur statutory obligation theory, die auch als statutory liability theory bezeichnet wird, mit Rechtsprechungsnachweisen Ballantine (1946), S. 810-812; Kübler (1989), S. 22-23; Manning/Hanks (1990), S. 52; Bauer (1995), S. 194-196.

562 Wăhrend im 19. Jahrhundert ein Aktiennennwert von 100 US-\$ als Zeichen der Solidität der Gesellschaft ublich war, wurden nun Aktien mit einem Nennwert von 1 US-\$ oder sogar nur 1 Cent ausgegeben. Vgl. Manning/Hanks (1990), S. 28-29; Bauer (1995), S. 294-295; Marsh/Finkle/Sonsini (2005), § 5.13[A], S. 49. 
bereits 1912 einen Schritt weiter und ließ die Ausgabe von nennwertlosen Aktien (no par stock) $\mathrm{zu}^{563}$, dem sich in der Folgezeit nahezu alle Bundesstaaten anschlossen ${ }^{564}$.

Im Hinblick auf Dividendenausschüttungen bildete sich in den USA bereits im 17. Jahrhundert der Grundsatz heraus, nach dem nur Gewinne (profits) der Gesellschaft und nicht die Einlagen (capital) an die Aktionäre ausgeschüttet werden dürfen ${ }^{565}$. Dieser Grundsatz wurde im 19. Jahrhundert vom common law übernommen, wie die oben bereits angesprochene Entscheidung Wood v. Dummer zeigt. Die darin entwickelte trust fund theory bildete auch die Grundlage für die ersten gesetzlichen Ausschüttungsregulierungen ${ }^{566}$. Die alleinige Unterscheidung von profits und capital und die Beschränkung der Ausschüttungen auf die profits der Gesellschaft wurde durch die Verbreitung von low par und no par stock weitgehend unbrauchbar $^{567}$. In den Einzelstaatengesetzen entstanden daraufhin Definitionsversuche verschiedener Eigenkapitalkonten ${ }^{568}$, die allerdings von der Rechtsprechung nicht einheitlich ausgelegt wurden. Weitere Rechtsunsicherheit bestand hinsichtlich der anzuwendenden Rechnungslegungsregeln und der etwaigen Berücksichtigung von Wertsteigerungen der Vermögenswerte, der zu beachtenden Gläubigerschutzmechanismen bei Kapitalherabsetzungen sowie der Ansprüche der Gläubiger bei unrechtmäßigen Dividendenzahlungen ${ }^{569}$.

Wie bereits erwähnt ${ }^{570}$, haben die Aktionäre einer corporation grundsätzlich keinen gesetzlichen Anspruch auf Dividendenausschüttungen. Die Kompetenz zur Festlegung einer Dividende liegt beim board of directors, der bestimmte Sorgfalts- und Treuepflichten zu beachten hat, ansonsten aber durch die business judgment rule vor einer gerichtlichen Überprüfung seiner Dividendenentscheidung geschützt ist. Die Chancen für die Aktionäre einer börsennotierten corporation, auf dem Klageweg eine Dividende durchzusetzen, sind somit eher gering $^{571}$. Anders sieht die Situation von (Minderheits-)Aktionären von closely held corporations aus. Gerichte sind bei closely held corporations traditionell eher geneigt, in die Dividendenpolitik einzugreifen ${ }^{572}$. Gerichte berücksichtigen bei ihren Entscheidungen, dass Aktionäre solcher Gesellschaften, die nicht gleichzeitig Angestellte sind, auf Dividendenzahlungen zur

Nach anfänglichen kontroversen Diskussionen in der US-amerikanischen Literatur zu den resultierenden Auswirkungen auf den Gläubigerschutz zeigte sich in der Praxis, dass „,weder die Befurchtungen der Gläubiger, nun betrugerischen Gesellschaftsgründern hilflos ausgeliefert zu sein, noch die Hoffnung der Gesellschafter auf völlige Narrenfreiheit bei der Gesellschaftsfinanzierung in dem erwarteten Ausmaß zutrafen." So Bauer (1995), S. 296.

Lediglich Nebraska und North Dakota sehen keine nennwertlosen Aktien vor. Vgl. MBCA Ann. (2002), $\S 6.21$, S. 80B.

565 Vgl. Bauer (1995), S. 213-214 m.w.N. Vgl. zu den historischen Ursprüngen ausfuhrlich Kehl (1941), S. 3-13. (2005), S. 552.

Vgl. insofern missverständlich Wüstemann (1999), S. 51, der den Eindruck vermittelt, auch Aktionäre einer public corporation hătten ,einen durch case law erhärteten Anspruch auf eine Mindestausschüttung“. Vgl. hingegen Eisenberg (2000), S. 1242: „It is hard to imagine a real-life scenario, today, in which the courts would order a publicly held corporation to pay a dividend." Vgl. auch Warrikoff (1963), S. 62-65, der 13 Fälle identifiziert, in denen Dividendenzahlungen durch die Gerichte angeordnet wurden, die ausschließlich closely held corporations betrafen. 
Einkommenssicherung angewiesen $\operatorname{sind}^{573}$. In seltenen Fällen sind closely held corporations selbst dann zur Verteilung einer Dividende verpflichtet worden, wenn plausible wirtschaftliche Gründe (z.B. Erweiterungsinvestitionen) dagegen sprechen ${ }^{574}$. Im Allgemeinen muss der Aktionär aber nachweisen, dass eine Ausschüttung aus unredlichen Motiven ${ }^{575}$ heraus unterblieben und der Dividendenverzicht nicht durch einen plausiblen betriebswirtschaftlichen Grund zu rechtfertigen ist ${ }^{576}$.

Die wohl berühmteste Gerichtsentscheidung auf dem Gebiet der Ausschüttungspolitik ist bereits im Jahre 1919 durch den Michigan Supreme Court im Fall Dodge v. Ford Motor Co. ${ }^{577}$ ergangen. Nachdem die closely held corporation im Zeitraum von 1911 bis 1915 zusätzlich zur jährlichen Dividende in Höhe von 1,2 Mio. US-\$ Sonderdividenden von insgesamt 41 Mio. US-\$ ausgeschüttet hatte, kündigte Henry Ford an, die Gesellschaft werde in der Zukunft keine Sonderdividenden mehr zahlen. Die Gewinne sollten vielmehr verwandt werden, um noch mehr Arbeiter einzustellen und die Preise der Autos bei gleich bleibender oder steigender Qualität zu senken. Zu diesem Zeitpunkt wies die Gesellschaft ein surplus von ca. 112 Mio. US-\$ und flüssige Mittel von über 50 Mio. US-\$ auf. Die Gebrüder Dodge klagten auf Dividendenzahlung in Höhe von $75 \%$ der liquiden Mittel der Gesellschaft ${ }^{578}$. Ein aus der Sicht der beiden Minderheitsaktionäre positives Urteil war insofern wahrscheinlich, als Ford keinen unternehmerischen Grund für die veränderte Dividendenpolitik vorbrachte, sondern sich sogar öffentlich zu seinen altruistischen Zielen bekannt hatte. Das Gericht führte aus, dass in einer corporation nicht soziale Motive, sondern primär die Interessen der Aktionäre zu

573 Vgl. Gevurtz (2000), S. 155; Bauman/Weiss/Palmiter (2003), S. 283; Black (2004), §4.13, S. 39; Merkt/Göthel (2006), S. 298.

574 Vgl. Miller v. Magline, Inc., 76 Mich.App. 284, 256 N.W.2d 761 (1977). Das Gericht ordnete eine Dividende in Höhe von 75 US-\$ pro Aktie für den Zeitraum von 1963 bis 1968 mit der Begründung an, die Verweigerung von Dividendenzahlungen stehe im Widerspruch zu einem der wesentlichen Ziele einer auf Gewinn angelegten Gesellschaft, Gewinne zu erwirtschaften und diese unter allen Anteilseignern zu verteilen. Der Dividendenverzicht könne nicht gerechtfertigt werden, wenn die Gesellschaft andererseits große Teile der Gewinne in Form von Gehăltern an einige der Aktionäre zahle. Vgl, auch das ähnlich gelagerte Gerichtsurteil in Patton v. Nicholas, 154 Tex. 385, 279 S.W.2d 848 (1955), das ebenfalls eine jăhrliche Dividendenzahlung anordnete. Gerichte können in solchen Situationen alternativ auch die Auflösung der Gesellschaft oder eine zwingende Abfindung anordnen. Vgl. dazu Eisenberg (2000), S. 1244 und ausführlich S. 444-477 m.w.N.

575 Ein Katalog von Faktoren, die auf bad faith hinweisen, ist in Gottfried v. Gottfried, 73 N.Y.S.2d 692 (N.Y.Sup.Ct.1947), S. 695, entwickelt worden. Dazu gehören große Feindseligkeiten zwischen Mehrheitsund Minderheitsaktionären, Ausschluss der Minderheitsaktionäre von einer Beschäftigung innerhalb der Gesellschaft, hohe Gehälter und sonstige Vergütungen an die officers, hohe persönliche Einkommensteuerzahlungen der Mehrheitsaktionäre im Falle von Dividendenzahlungen und der Wunsch der Mehrheitsaktionäre, die Anteile der Minderheiten so billig wie möglich zu erwerben. Vgl. auch Black (2004), §4.13, S. 39-40.

576 Vgl. Ballantine (1946), S. 554; Warrikoff (1963), S. 64; Clark (1986), S. 602; Hamilton (2000), S. 593; Cox/Hazen (2003), S. 1205-1206; Black (2004), § 4.12 mit umfassenden Rechtsprechungsnachweisen; Choper/Coffee/Gilson (2004), S. 212; Emanuel (2005), S. 551.

577 Vgl. Dodge v. Ford Motor Co., 204 Mich. 459, 170 N.W. 668 (1919). Nach Clark (1986), S. 602, handelt es sich um den „classic American case in which a court did order the payment of dividends.“ Eisenberg (2000), S. 139, bezeichnet den Fall als „One of the most famous of all corporation-law cases“. Zu einer sehr lesenswerten Zusammenfassung der Gerichtsentscheidung vgl. Clark (1986), S. 602-604.

578 Vor dem Hintergrund, dass die Bruder die Dividendenzahlungen fur die Erweiterung ihres eigenen Automobilunternehmens einsetzen wollten, spekuliert Clark (1986), S. 604, dass Henry Ford nicht primär altruistische Motive verfolgt hat, sondern vielmehr einen Wettbewerber vermeiden wollte. Vgl. ähnlich Palmiter (2003), S. 188. Vgl. dazu bereits Kronstein/Claussen (1960), S. 119. 
verfolgen seien ${ }^{579}$. Die Gesellschaft wurde daraufhin verpflichtet, eine Dividende in Höhe von 19,3 Mio. US-\$ zu zahlen.

\subsection{Harmonisierungstendenzen durch Model Acts und Bundesgesetze}

\subsubsection{Model Business Corporation Act}

\subsubsection{Ursprünge und ältere Model Business Corporation Acts}

Bestrebungen, die gesellschaftsrechtlichen Vorschriften für corporations in den USA bundesstaatenübergreifend zu vereinheitlichen, reichen bis in die $1920 \mathrm{er} \mathrm{Jahre} \mathrm{zurück}{ }^{580}$. Die National Conference of Commissioners on Uniform State Laws veröffentlichte nach mehrjährigen Vorarbeiten im Jahre 1928 den Uniform Business Corporation Act, der als Einheitsgesetz konzipiert war und von den Einzelstaaten möglichst ohne Veränderungen in ihr jeweiliges einzelstaatliches Recht übernommen werden sollte. In den folgenden Jahren wurde er von Louisiana, Washington und Kentucky vollständig und von Idaho teilweise übernommen. Andere Staaten, die gleichzeitig an der Modernisierung ihres Gesellschaftsrechts arbeiteten, schlossen sich nicht an, so dass sich bereits in den 1930er Jahren abzeichnete, dass eine vollständige Vereinheitlichung nicht zu erreichen war ${ }^{581}$.

In den frühen 1940er Jahren unternahm die American Bar Association - der US-amerikanische Bundesverband der Anwaltschaft - einen weiteren Versuch zur Vereinheitlichung des Gesellschaftsrechts und legte 1946 den ersten Entwurf eines Model Business Corporation Act (MBCA) vor. Eine endgültige Version des MBCA wurde 1950 veröffentlicht. Seitdem ist der MBCA in regelmäßigen Abständen ergänzt oder überarbeitet worden, wobei größere Veränderungen insbesondere in den Jahren 1953, 1959, 1969 und 1984 vorgenommen wurden. Im Gegensatz zum Uniform Business Corporation Act hat der MBCA seit seiner Veröffentlichung die gesellschaftsrechtliche Gesetzgebung der Einzelstaaten stark beeinflusst und wurde von einer Vielzahl von Bundesstaaten ganz oder zumindest teilweise übernommen. Dabei ist allerdings zu berücksichtigen, dass die Einzelstaaten teilweise mit erheblicher zeitlicher Verzögerung Änderungen des MBCA umgesetzt haben ${ }^{582}$.

Bevor im weiteren Verlauf dieser Arbeit ausschließlich die Vorschriften des MBCA in der aktuellen Fassung behandelt werden, soll im Folgenden ein kurzer Überblick zu den Kapitalschutzregeln des MBCA (1969) gegeben werden, die zahlreiche einzelstaatliche Gesellschaftsrechte über lange Zeit stark beeinflusst haben. Auch wenn sie in der Folgezeit erheblicher Kritik ausgesetzt waren und durch den grundlegend überarbeiteten und im Jahre 1984

Vgl. dazu auch Ballantine (1946), S. 228, 552-553.

Vgl. hier und im Folgenden Eisenberg (1974); Booth (2000); MBCA Ann. (2002), Introduction, S. 27-30; Merkt/Göthel (2006), S. 144, 170-174.

Der Uniform Business Corporation Act wurde daraufhin 1943 von der National Conference of Commissioners on Uniform State Laws in Model Business Corporation Act umbenannt und 1958 zurückgezogen. Vgl. Booth (2000), S. 63-64. Nicht zu verwechseln ist dieser Model Act mit dem MBCA der American Bar Association.

Die Ausschüttungsregulierung von South Dakota folgt z.B. noch heute dem MBCA von 1969. Vgl. Black (2004), § 1.3, Fn. 12. 
veröffentlichten MBCA abgeschafft wurden, existieren sie in ähnlicher Weise in Delaware noch heute ${ }^{583}$.

Der MBCA 1969 in der Fassung von verfolgt das Konzept des legal capital. Danach werden drei Eigenkapitalkonten unterschieden ${ }^{584}$.

- Stated capital: In das stated capital (auch legal capital oder paid-in capital bezeichnet) wird das Kapital zum Zeitpunkt der Gründung eingestellt. Die Höhe dieses Grundkapitals ergibt sich, indem die ausgegebenen Aktien mit ihrem Nennwert (par value) multipliziert werden (§ 2(j) MBCA (1969)). Ein Mindestnennkapital ist im Modellgesetz seit 1960 nicht mehr vorgeschrieben ${ }^{585}$. Sind nennwertlose Aktien ausgegeben worden, können die directors die Höhe des stated capital festlegen ${ }^{586}$.

- Earned surplus: Die Eigenkapitalposition earned surplus umfasst die akkumulierten Gewinne seit der Gründung der Gesellschaft abzüglich angefallener Verluste und gezahlter Dividenden sowie sonstiger Ausschüttungen.

- Capital surplus: Als capital surplus wird schließlich das Eigenkapital bezeichnet, das weder stated capital noch earned surplus ist. Es wird auch als unearned surplus bezeichnet und kann in drei Kategorien unterteilt werden ${ }^{587}$.

(1) Paid-in surplus: Hat die Gesellschaft Aktien über Nennwert ausgegeben, stellt der den Nennwert übersteigende Betrag (Agio) multipliziert mit der Aktienanzahl paidin surplus dar. Im nennwertlosen System ergibt sich das paid-in capital, indem von dem bei der Gründung eingezahlten Kapital das von der Geschäftsleitung festgelegte stated capital abgezogen wird.

(2) Revaluation surplus: Soweit Vorschriften in den Kapitalgesellschaftsrechten oder einschlägige Gerichtsentscheidungen die Bewertung der Vermögenswerte über ihre historischen Anschaffungs- oder Herstellungskosten hinaus zulassen, ist der höhere Betrag auf der Passivseite als revaluation surplus auszuweisen ${ }^{588}$.

(3) Reduction surplus: Hat das Management im Falle von nennwertlosen Aktien eine Kapitalherabsetzung gemäß $\S 69$ MBCA (1969) beschlossen, der die Aktionäre mit einfacher Mehrheit zugestimmt haben, wird das stated capital um einen bestimmten Betrag reduziert und das capital surplus um denselben Betrag erhöh ${ }^{589}$. Bei Aktien mit Nennwert kann ein reduction surplus ebenfalls kreiert werden. Um den Nennwert der Aktien zu vermindern, muss allerdings die Satzung geändert werden, worüber die Aktionäre in der Hauptversammlung abzustimmen haben.

Vgl. Bainbridge (2002), S. 776.

Vgl. im Folgenden Palmiter (2003), S. 523-524; Emanuel (2005), S. 539-540, 542-543.

$\S 51$ MBCA (1950) sah noch ein Mindestkapital von 1.000 US-\$ vor. Vgl. dazu auch MBCA Ann. (2002), $\S 6.21$, S. 77-78.

Vgl. Palmiter (2003), S. 523 ; Emanuel (2005), S. 539.

Vgl. Emanuel (2005), S. 542-543.

Vgl. Palmiter (2003), S. 527.

$\S 70$ MBCA (1969) weist diesen Betrag also nicht in einem separaten Eigenkapitalkonto aus. Nach manchen Einzelstaatenrechten wird jedoch in solchen Fällen ein separates Konto mit der Bezeichnung ,reduction surplus" explizit gefordert. Vgl. Palmiter (2003), S. 528. 
Unter der Nebenbedingung, dass die corporation durch die Ausschüttung nicht insolvent im Sinne von $\S 2(n)$ MBCA (1969) ${ }^{590}$ wird, ist zur Bestimmung der maximal zulässigen Ausschüttungshöhe gemäß $§ 45(a)$ MBCA (1969) ein earned surplus test durchzuführen. Danach dürfen Dividenden grundsätzlich nur aus dem earned surplus ausgeschüttet werden ${ }^{591}$. Auf den ersten Blick scheint der MBCA (1969) also das von den Anteilseignern eingezahlte Kapital vor Ausschüttungen zu schützen. Weitere Bestimmungen des MBCA (1969) verwässern diesen Schutz jedoch. Nach $\S 45$ [Alternative](a) (1969) können beispielsweise Dividenden aus dem Gewinn des aktuellen Geschäftsjahres gezahlt werden, selbst wenn kein earned surplus existiert. Darüber hinaus kann ein Defizit im earned surplus-Konto ausgeglichen werden, indem Teile des capital surplus dorthin transferiert werden (§ 70 MBCA (1969)).

Unzulässig ist eine Dividendenzahlung grundsätzlich aus dem capital surplus. Aber auch diese Ausschüttungsrestriktion kann auf legale Weise einfach umgangen werden. $§ 46 \mathrm{MBCA}$ (1969) eröffnet nämlich dem board of directors unter bestimmten Voraussetzungen ${ }^{592}$ die Möglichkeit, auch aus dem capital surplus auszuschütten, wenn dies in der Satzung ausdrücklich vorgesehen ist oder die Aktionäre mehrheitlich zustimmen. Eine solche Ausschüttung wird lediglich nicht als Dividende, sondern als capital distribution bezeichnet ${ }^{593}$.

Es bleibt daher festzuhalten, dass die Vorschriften des MBCA (1969) insgesamt nicht verhindern können, dass das von den Aktionären investierte Kapital in Form von Dividenden an sie zurückfließt ${ }^{594}$.

Die Neufassung der Ausschüttungsregeln des im Jahre 1984 in Kraft getretenen MBCA war in den Augen ihrer Verfasser notwendig, da die vorstehend erläuterten Ausschüttungsrestriktionen seines Vorgängers als zu kompliziert und manipulationsanfällig und folglich als Schutzinstrument ungeeignet angesehen wurden ${ }^{595}$. Die als überflüssig und unzweckmäßig erachtete Unterscheidung verschiedener surplus-Konten und die daran geknüpften unterschiedlichen Ausschüttungsrestriktionen, das Mindestkapital und die Pflicht zur Ausgabe von Nennwertaktien wurden abgeschafft. Lediglich der Solvenztest wurde als zweckmäßig erach-

§ 2(n) MBCA (1969): „Insolvent means inability of a corporation to pay its debts as they become due in the usual course of its business."

591 Solomon/Schwartz/Baumann/Weiss (1994), S. 258, beschreiben die Logik dieses Testverfahrens einprăgsam wie folgt: „Dividends are supposed to be the fruit of the tree, and unless fruit has been borne, nothing can be picked." Siehe auch Emanuel (2005), S. 541.

$592 \mathrm{Zu}$ beachten sind insbesondere die Ansprüche etwaiger Vorzugsaktionäre gemaß $\S 46(\mathrm{c})$, (d) MBCA (1969).

593 Vgl. auch Bainbridge (2002), S. 776.

594 Vgl. Gevurtz (2000), S. 162.

595 „It has long been recognized that the traditional ,par value' and ,stated capital' statutes do not provide significant protection against distributions of capital to shareholders." So MBCA Ann. (2002), § 6.40, S. 197. $\mathrm{Zu}$ einem komprimierten Überblick über die Ausschulttungsegeln des MBCA (1969) vgl. MBCA Ann. (2002), §6.40, S. 209-211. 
tet und ins neue Recht übernommen ${ }^{596}$. Mittlerweile haben 37 Staaten der USA den MBCA in der aktuellen Fassung in ihr Gesellschaftsrecht übernommen ${ }^{597}$.

\subsubsection{Kapitalaufbringung}

Im Gegensatz zu den früheren Regelungen lässt der MBCA die Kapitalaufbringung und damit die Bildung des Gesellschaftsvermögens weitgehend außer Acht. Es ist weder ein Mindestkapital noch ein Mindestausgabepreis für die Aktien vorgesehen. Die Gesellschafter müssen lediglich die vertraglich vereinbarte Einlage erbringen, wobei die directors aufgrund ihrer Treuepflicht für einen angemessenen Ausgabepreis sorgen müssen ${ }^{598}$. Auch die Beschränkungen der Sacheinlagefähigkeit wurden aufgehoben. Nach $\S 6.21(\mathrm{~b}) \mathrm{MBCA}$ sind materielle und immaterielle Vermögenswerte sowie alle vermögenswerten Vorteile für die Gesellschaft (benefit to the corporation) einlagefähig. Explizit genannt werden z.B. Bargeld, verbriefte Geldforderungen (promissory notes), erbrachte Dienstleistungen sowie vertragliche Verpflichtungen zu zukünftigen Dienstleistungen. Es wird betont, dass der Begriff des benefit to the corporation weit auszulegen ist ${ }^{599}$. Darüber hinaus sei es - unter Berücksichtigung der Sorgfaltspflichten gemäß $\S 8.30 \mathrm{MBCA}$ - die Sache der directors, den Wert der Gegenleistung festzulegen ${ }^{600}$.

\subsubsection{Kapitalerhaltung}

\subsection{Ausschüttungsrestriktionen}

Die Ausschüttungsregeln sind in $\S 6.40 \mathrm{MBCA}$ („Distributions to Shareholders“) kodifiziert. Im Gegensatz zu seinen Vorgängern sind die Bestimmungen des aktuellen MBCA auf jede Form von distribution anzuwenden ${ }^{601}$. Dazu gehören gemäß $\S 1.40(6)$ MBCA direkte oder indirekte ${ }^{602}$ Vermögensübertragungen von der Gesellschaft auf ihre Aktionäre in bar oder in Form von anderen Vermögenswerten. Im Einzelnen werden genannt: Dividenden, Aktienrückkäufe im Wege des repurchase, der redemption oder einer anderen Art von Kauf, Aus-

596 Vgl. MBCA Ann. (2002), §6.40, S. 198, 208.

597 Nach Black (2004), § 1.3, Fn. 16, sind es die folgenden Bundesstaaten: Alabama, Arizona, Arkansas, Colorado, Connecticut, Florida, Georgia, Hawaii, Idaho, Illinois, Indiana, Iowa, Kentucky, Maine, Maryland, Michigan, Minnesota, Mississippi, Montana, Nebraska, Nevada, New Hampshire, New Jersey, New Mexico, North Carolina, Oregon, Pennsylvania, Rhode Island, South Carolina, Tennessee, Utah, Vermont, Virginia, Washington, West Virginia, Wisconsin und Wyoming. Vgl. auch den Überblick zu den Ausschüttungsregeln der Bundesstaaten der USA in MBCA Ann. (2002), § 6.40, S. 212-216. shares, John Rockefeller's promissory note and Barbra Streisand's contract for a future concert performance are now recognized as the valuable economic assets that everyone but lawyers always knew they were."

Vgl. MBCA Ann. (2002), §6.21, S. 66-68

Vgl. Hamilton (2000), S. 589.

Damit ist beispielsweise der Rückkauf von Aktien des Mutterunternehmens durch ein Tochterunternehmen, das unter der Kontrolle des Mutterunternehmens steht, gemeint. Vgl. MBCA Ann. (2002), §1.40, S. 84C. 
schüttungen in Form von Zahlungszusagen an die Anteilseigner (indebtedness) ${ }^{603}$ und auf sonstige Weise. Stock dividends, d.h. Dividenden in der Form von Gratisaktien, fallen hingegen nicht mehr unter den Ausschüttungsbegriff des Modellgesetzes.

An die Stelle der zahlreichen Ausschüttungsrestriktionen in den früheren Versionen des MBCA, die sich in Abhängigkeit von den verschiedenen Eigenkapitalkonten unterschieden, sind zwei Testverfahren getreten ${ }^{604}$ : der traditionelle equity insolvency test $(\S 6.40(\mathrm{c})(1)$ $\mathrm{MBCA}$ ) und ein balance sheet test $(\S 6.40(\mathrm{c})(2) \mathrm{MBCA})$. Darüber hinaus müssen etwaig bestehende zusätzliche Ausschüttungsrestriktionen, die in der Satzung der Gesellschaft festgelegt sind, beachtet werden ( $\$ 6.40(a)$ MBCA).

\subsection{Equity Insolvency Test}

Die Grundvoraussetzung für eine Ausschüttung besteht darin, dass die Gesellschaft den so genannten equity insolvency test ${ }^{605}$ erfüllt, der in $\S 6.40(\mathrm{c})(1)$ MBCA kodifiziert ist: „No distribution may be made if, after giving it effect, the corporation would not be able to pay its debts as they become due in the usual course of business". Eine Dividendenausschüttung ist demnach nur dann erlaubt, wenn die Gesellschaft anschließend ihre im gewöhnlichen Geschäftsverlauf fällig werdenden Verbindlichkeiten zurückzahlen kann ${ }^{606}$.

Der Test versucht, das zentrale Interesse der Fremdkapitalgeber zu berücksichtigen. Fremdkapitalgeber sind daran interessiert, dass die Gesellschaft über ausreichend liquide Mittel verfügt, damit sie ihre Kredite inklusive Zinsen entsprechend der Tilgungs- und Zinszahlungsmodalitäten zurückzahlen kann ${ }^{607}$. Fraglich ist aber, unter welchen Umständen von der Solvenz des Unternehmens im Sinne des $\S 6.40(\mathrm{c})(1)$ MBCA auszugehen ist. Ein erster Anhaltspunkt für die Solvenz wird darin gesehen, dass die liquiden Mittel die kurzfristigen Verbindlichkeiten übersteigen ${ }^{608}$. Eine rein stichtagsbezogene Betrachtung auf Basis von Bilanzdaten

Unter ,indebtedness issued as a distribution“ fallen z.B. Schuldverschreibungen und verbriefte Geldforderungen (promissory notes). Beispiel: Eine Gesellschaft verfügt über einen ausschüttungsfähigen Gewinn von 1.000 US-\$, den sie an die Aktionäre in der Folgezeit ausschüten möchte. Die Gesellschaft gibt ein schriftliches Zahlungsversprechen (note) an die Aktionäre, in dem es die Zahlung von 200 US-\$ uber die nächsten fünf Jahre zusichert. Die Aktionäre erhalten dadurch die Stellung von Gläubigern.

Vgl. MBCA Ann. (2002), §6.40, S. 197.

Vgl. z.B. Palmiter (2003), S. 521. Ben-Dror (1983), S. 376, bezeichnet ihn als equitable insolvency test. Vgl. zu einer Erlăuterung des Begriffs und den historischen Ursprüngen des Testverfahrens ausfuhrlich Kapitel III.2.2.2.1. Der Insolvenztest des MBCA ähnelt dem des Uniform Fraudulent Transfer Act (UFTA), ist aber nicht mit ihm identisch. Darauf wird insbesondere in $M B C A A n n$. (2002), $\S 6.40$, S. 199, hingewiesen. Vgl. zum UFTA ausführlich ebenfalls Kapitel III.2.2.2.1.

Weder im Gesetz noch in der offiziellen Kommentierung findet sich ein Hinweis auf die genaue Länge des Zeitraums. Vgl. MBCA Ann. (2002), § 6.40, S. 199 („sufficient period of time“). Vgl. dazu kritisch Murphy (1981), S. 870-871.

Vgl. etwa Baetge/Kirsch/Thiele (2004a), S. 16. Vgl. auch Manning/Hanks (1990), S. 67.

Vgl. Emanuel (2005), S. 559. 
reicht gleichwohl nicht aus ${ }^{609}$. Wenn das Management z.B. weiß, dass ein Lieferant für eine umfangreiche Rohstofflieferung in Kürze eine hohe Rechnung ausstellen wird, zu deren fristgerechter Begleichung dem Unternehmen nach Ausschüttung der geplanten Dividende nicht genügend liquide Mittel verbleiben, gilt die Gesellschaft als insolvent im Sinne des Testverfahrens, selbst wenn aktuell der Kassenbestand die kurzfristigen Verbindlichkeiten übersteigt. Im umgekehrten Fall ist es denkbar, dass die Gesellschaft trotz aktuell zu geringer Kassenbestände die Voraussetzung für Dividendenzahlungen erfüllt, weil kurzfristig von hohen Einzahlungen aus dem operativen Geschäft hinreichend sicher ausgegangen werden kann.

Nach Ansicht der offiziellen Kommentierung des Modellgesetzes kann in den meisten Fällen von der Solvenz im Sinne des $\S 6.40$ (c)(1) MBCA ausgegangen werden, wenn das Unternehmen in regelmäßigen Abständen von Abschlussprüfern geprüfte Bilanzen vorlegt, der jüngste Bestätigungsvermerk die Annahme der Unternehmensfortführung nicht einschränkt und es seitdem zu keinen wirtschaftlich ungünstigen Ereignissen gekommen ist ${ }^{610}$.

Liegen hingegen Hinweise vor, die auf wirtschaftliche Schwierigkeiten oder Liquiditätsengpässe des Unternehmens hindeuten, müssen die Mitglieder des board of directors weitergehende Untersuchungen zur Beurteilung der Solvenz durchführen. Indikatoren für mögliche zukünftige Liquiditätsprobleme könnten z.B. Einbrüche der Konjunktur, starke Umsatzrückgänge oder eingeleitete Klagen mit existenzbedrohendem Streitwert darstellen ${ }^{611}$. In solchen Situationen muss das Management zur Klärung der Frage, ob der equity insolvency test eingehalten ist, die zukünftige finanzielle Lage der Gesellschaft genauer analysieren ${ }^{612}$. Die Unternehmensleitung muss beurteilen, ob durch die bestehende und zukünftig erwartete Nachfrage nach Produkten und Dienstleistungen des Unternehmens in ausreichender Höhe Einzahlungen erwirtschaftet werden, um die aktuell und in der Zukunft bestehenden Verpflichtungen bei Fälligkeit erfüllen zu können. Weiterhin muss abgeschätzt werden, ob von einer Refinanzierung kurzfristig auslaufender Kredite vernünftigerweise ausgegangen werden kann. Bei diesen Prognosen sind auch Eventualschulden explizit zu berücksichtigt.

Schließlich wird darauf hingewiesen, dass es in manchen Situationen nützlich sein könne, für Zwecke des Solvenztests eine detaillierte Cashflow-Rechnung auf Basis eines Businessplans

Vgl. aber Brownstein v. Fiberonics Industries, Inc., 110 N.J. Super. 43, 264 A.2d 262, 7 U.C.C. Rep. Serv. 866 (Ch. Div. 1970). Das Gericht diagnostiziert die Insolvenz der Gesellschaft, indem sie die kurzfristigen Schulden mit dem Umlaufvermögen vergleicht und feststellt, dass die Gesellschaft die kurzfristigen Schulden nur durch den Verkauf von betriebsnotwendigen Maschinen tilgen könnte. Vgl. dazu kritisch Black (2004), § 3.7, S. 9. In dem Fall In re R.M.L., Inc., 92 F3d 139 (3d Cir. 1996) hat das Gericht ein negatives Eigenkapital in beträchtlicher Höhe als Indiz für die Insolvenz der Gesellschaft gewertet.

Vgl. MBCA Ann. (2002), §6.40, S. 198. Vgl. zu dieser Einschătzung auch In re Omni Mechanical Contractors, Inc., 114 B.R. 518 (Bankr. E.D. Tenn. 1990), S. 530-531. Das Kapitalgesellschaftsrecht von North Dakota sieht einen safe harbor vor, wenn die directors sich bei der Ausschüttungsentscheidung auf testierte Abschlüsse verlassen. Vgl. § 10-19.1-92(2) North Dakota Century Code.

611 Nach Ansicht des Gerichts in F.T.C. v. Med Resorts Intern., Inc., 2000 WL 1889635 (N.D. IIl. 2000) sind solche Faktoren bei der Beurteilung der Solvenz zwingend zu berücksichtigen.

612 Vgl. MBCA Ann. (2002), § 6.40, S. 198-199. 
für einen angemessenen Zeitraum durchzuführen ${ }^{613}$. Dadurch soll sichergestellt werden, dass auch langfristige Verbindlichkeiten in die Betrachtung einbezogen werden.

\subsection{Balance Sheet Test}

Hat die Gesellschaft den Solvenztest erfüllt, muss als zweite Voraussetzung für eine Ausschüttung der balance sheet test nach $\S 6.40$ (c)(2) MBCA durchgeführt werden ${ }^{614}$. Während der equity insolvency test die Liquiditätssituation des Unternehmens analysiert, berücksichtigt der balance sheet test die zweite in den USA weit verbreitete Definition der Insolvenz, die Insolvenz aufgrund von Überschuldung (bankruptcy meaning). Aus diesem Grund wird dieser Bilanztest auch als bankruptcy insolvency test bezeichnet ${ }^{615}$.

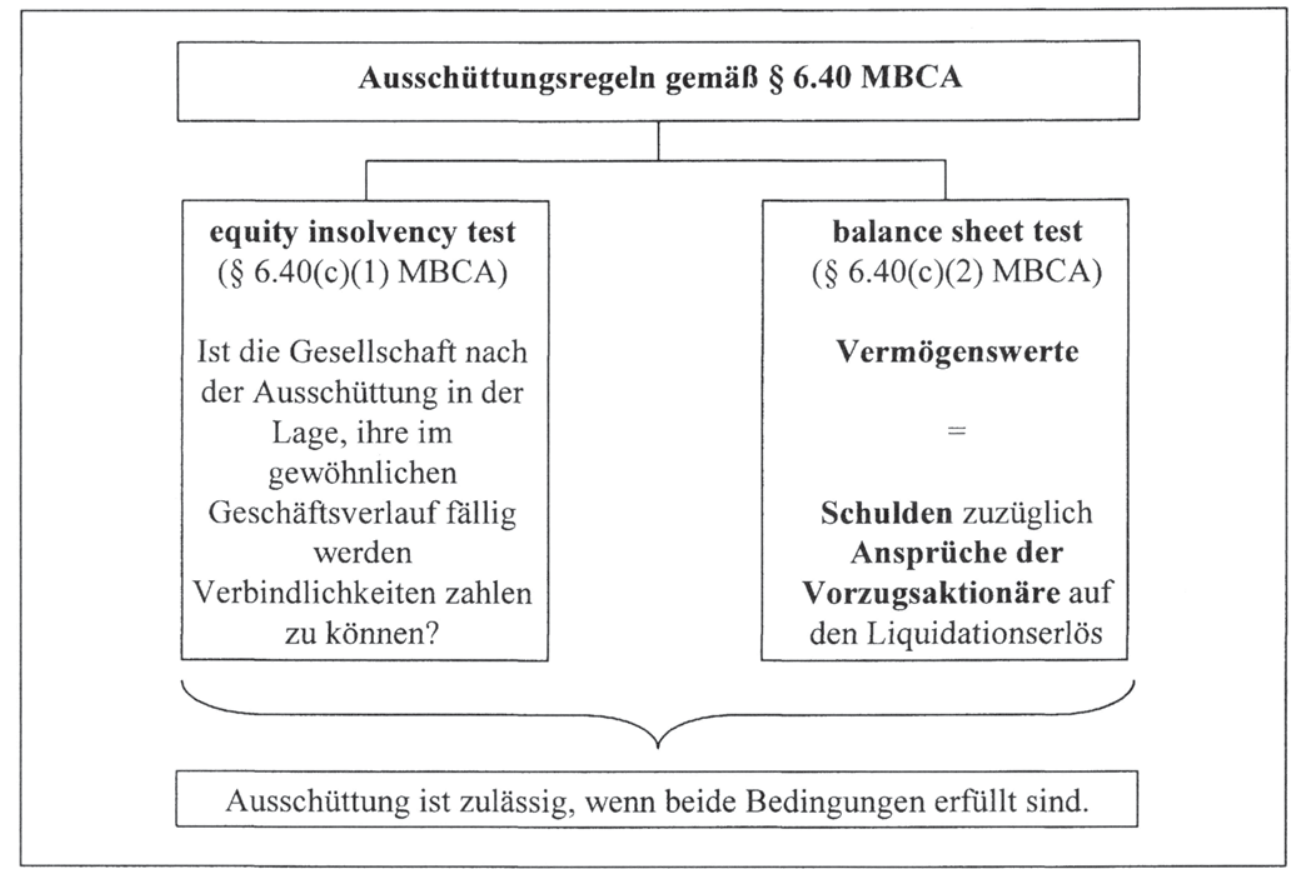

Abb. 2: Ausschüttungsregeln gemäß $§ 6.40 \mathrm{MBCA}$

613 Vgl. MBCA Ann. (2002), §6.40, S. 199. Eine detaillierte Cashflow-Analyse wird allerdings von kleinen closely held corporations nicht notwendigerweise gefordert. Vgl. Black (2004), § 3.3, S. 4. Es existieren zahlreiche insolvenzrechtliche Fälle, in denen Gerichte Cashflow-Rechnungen zur Bestimmung der equity insolvency bei der Urteilsfindung herangezogen haben. Vgl. z.B. U.S. v. Gleneagles Inv. Co., Inc., 565 F.Supp.556 (MD Pa 1983); Telefest, Inc. v. VU-TV, Inc., 591 F. Supp. 1368 (D.C.N.J. 1984); Credit Managers Ass'n of Southern California v. Federal Company, 629 F. Supp. 175 (C.D. Cal. 1985). Vgl. Palmiter (2003), S. 525.

615 Vgl. z.B. Ben-Dror (1983), S. 380; Palmiter (2003), S. 525. Zu einer Erläuterung des Begriffs und den historischen Ursprüngen des Testverfahrens vgl. Kapitel III.2.2.2.1. Die beiden Testverfahren des $\S 6.40$ (c) MBCA zusammen werden unter dem Begriff des dual (insolvency) test subsumiert. Vgl. Hamilton (2000), S. 589. 
Wie in Abb. 2 verdeutlicht, bestimmt der balance sheet test, dass nach der Ausschüttung die Vermögenswerte (total assets) sowohl die Schulden (total liabilities) als auch die Ansprüche der Vorzugsaktionäre auf den Liquidationserlös (preferential rights upon dissolution) übersteigen müssen. Zur Bestimmung der maximalen Ausschüttungshöhe werden derartige Vorrechte somit wie Schulden behandelt ${ }^{616}$.

Wenn die Satzung nichts anderes bestimmt, stellen die Ansprüche der Vorzugsaktionäre denjenigen Betrag dar, der im fiktiven Falle einer Liquidation der Gesellschaft zum Zeitpunkt der Ausschüttung gebraucht würde, um die Vorzugsrechte auf den Liquidationserlös zu befriedigen. Mit anderen Worten darf die Ausschüttung nicht größer als das Eigenkapital abzüglich der Ansprüche der Vorzugsaktionäre auf den Liquidationserlös sein. Bei einem solventen Unternehmen, das keine Vorzugsaktien ausgegeben hat, darf demzufolge die Dividendenzahlung maximal das komplette Eigenkapital aufzehren ${ }^{617}$.

Beschließt die Gesellschaft Ausschüttungen in Form von Zahlungszusagen an die Aktionäre (indebtedness), gelten diese gemäß $\S 6.40(\mathrm{~g}) \mathrm{MBCA}$ bei Durchführung des balance sheet test nicht als Schulden. Dafür muss allerdings vertraglich festgelegt sein, dass die Zahlungen nur zu einem Zeitpunkt geleistet werden können, in dem die Ausschüttungsrestriktionen des $\S 6.40$ (c) MBCA erfüllt sind ${ }^{618}$.

\subsection{Rechnungslegungsregeln}

Die Ausschüttungsrestriktion des balance sheet test steht und fällt mit dem ihm zugrunde liegenden Rechnungslegungssystem ${ }^{619}$. Nach $\S 6.40(\mathrm{~d})$ MBCA stehen den Unternehmen hinsichtlich der Rechnungslegung drei Vorgehensweisen zur Verfügung. Die Testverfahren können erstens auf Grundlage von Jahresabschlüssen durchgeführt werden, die auf der Basis vernünftiger Rechnungslegungspraktiken (financial statements prepared on the basis of accounting practices and principles that are reasonable in the circumstances) erstellt worden sind. Die Tests können sich zweitens auf Jahresabschlüsse beziehen, die auf der Grundlage einer Bewertung zum aktuellen Marktwert (on a fair valuation (...) method) ergeben. Die Jahresabschlüsse können drittens nach einer anderen Bilanzierungsmethode erstellt werden, wenn diese unter den Umständen vernünftig ist (other method that is reasonable in the circumstances).

Somit ist eine Bewertung der Vermögenswerte über die historischen Anschaffungs- bzw. Herstellungskosten hinaus zu aktuellen Marktwerten möglich, wenn die Unternehmensleitung dabei gutgläubig handelt ${ }^{620}$ und von der Unternehmensfortführung ausgegangen werden

\footnotetext{
616 Dies ist allerdings in der Satzung abdingbar $(\S 6.40(\mathrm{c})(2) \mathrm{MBCA})$. Vgl. auch MBCA Ann. (2002), 6.40 , S. 202-2003.

617 Vgl. Gevurtz (2000), S. 162.

618 Vgl. zur indebtedness ausführlich MBCA Ann. (2002), §6.40, S. 205.

619 Dies betonen auch Manning/Hanks (1990), S. 65. Wăhrend $90 \%$ der Tătigkeiten eines Anwalts für Gesellschaftsrecht nicht sonderlich kreativ seien, betont Bainbridge (2002), S. 778, dass „Figuring out ways for a company to pay a dividend despite the literal terms of the statute and the present state of the firm's balance sheet, however, is one item that falls within the 10 percent or so where creativity is desirable. And lawyers have gotten quite good at what accountants would see as juggling the books."

Vgl. Palmiter (2003), S. 527.
} 
kann $^{621}$. Entscheidet sich das Management der Gesellschaft für eine Bilanzierung zu aktuellen Marktwerten, sollte dies grundsätzlich für alle Vermögenswerte und Schulden gelten ${ }^{622}$.

Die Verfasser des MBCA wollten den Unternehmen keine zwingenden Bilanzierungsregeln vorgeben, sondern Ansatz und Bewertung der Vermögenswerte und Schulden in das Ermessen des board of directors stellen ${ }^{623}$. Zudem müssen die Testverfahren im Konzern nicht zwingend auf Basis des Konzernabschlusses durchgeführt werden ${ }^{624}$. Die US-GAAP sind explizit mit der Begründung nicht vorgeschrieben, die Ausschüttungsregulierung solle ein hohes $\mathrm{Ma} ß$ an Flexibilität für die betroffenen Unternehmen bieten ${ }^{625}$. Es wird somit der Tatsache Rechnung getragen, dass die Ausschüttungsrestriktionen des MBCA für jede corporation gelten, also nicht nur für börsennotierte Gesellschaften, die aufgrund des SEA (1934) zur Bilanzierung nach US-GAAP verpflichtet sind, sondern auch für kleine closely held corporations. Bei einer US-GAAP-Rechnungslegungspflicht wären diese Gesellschaften vielfach auf die Mitwirkung eines Wirtschaftsprüfers angewiesen ${ }^{626}$. Die US-GAAP gelten aber immer als „reasonable in the circumstances“ im Sinne von $\S 6.40(\mathrm{~d}) \mathrm{MBCA}^{627}$.

Es ist davon auszugehen, dass auch Abschlüsse, die nach den verschiedenen Varianten des so genannten ,other comprehensive basis of accounting“ (OCBOA) $)^{628}$ aufgestellt werden, in den Anwendungsbereich von $\S 6.40$ (d) MBCA fallen. Insbesondere kleinere Unternehmen in den USA erstellen Abschlüsse nach OCBOA anstelle von US-GAAP, um Zeit und Kosten zu sparen $^{629}$. Die Vorschriften nach OCBOA können z.B. den steuerrechtlichen Bilanzierungsvorschriften $^{630}$ ähneln oder eine Rechnungslegung vorsehen, die weitgehend auf Ein- und Auszahlungen basiert. Vereinfachungen gegenüber den US-GAAP werden insbesondere im Rahmen der Bewertung und weniger in den Offenlegungspflichten gesehen ${ }^{631}$.

\subsection{Zeitpunkt der Durchführung der Testverfahren}

Eine Dividende wird an diejenigen Aktionäre ausgeschüttet, die zu einem bestimmten Stichtag (record date) Aktien der Gesellschaft halten ${ }^{632}$. Der record date wird in der Regel gemäß

621 Vgl. MBCA Ann. (2002), §6.40, S. 202.

622 Ausnahmen von diesem Grundsatz scheinen nach Auffassung von MBCA Ann. (2002), § 6.40, S. 202, zulässig zu sein: „Ordinarily a corporation should not selectively revalue assets.“

623 Vgl. MBCA Ann. (2002), §6.40, S. 200.

624 Vgl. MBCA Ann. (2002), §6.40, S. 200.

625 Vgl. hier und im Folgenden MBCA Ann. (2002), § 6.40, S. 201-202.

626 Vgl. Hamilton (2000), S. 590.

627 Vgl. MBCA Ann. (2002), §6.40, S. 201.

$628 \mathrm{Vgl}$. zu den verschiedenen Ausprägungen von OCBOA (cash basis, modified cash basis, tax basis) ausfuhrlich Grice (2003); Ratcliffe (2003).

629 Ratcliffe (2003), S. 72, schätzt die Einsparungen auf $20 \%$ bis $30 \%$ und weist zudem darauf hin, dass OCBOA-Abschlüsse für viele Bilanzersteller und ihre Bilanzadressaten verständlicher als US-GAAPAbschlüsse sind und viele Banken und Versicherungen diese Abschlüsse bereits akzeptieren.

Im Gegensatz zu Deutschland ist die gesellschaftsrechtliche Rechnungslegung in den USA nicht uber ein Maßgeblichkeitsprinzip mit der steuerrechtlichen Rechnungslegung verknüpft. Vgl. zum Verhältnis der US-GAAP zu steuerrechtlichen Vorschriften in den USA Haller (1994), S. 246-254; Schreiber (2000), S. 61-88.

631 Vgl. Grice (2003), S. 17.

632 Vgl. Hamilton (2000), S. 583; MBCA Ann. (2002), § 6.40, S. 203. 
$\S 7.07$ (a) MBCA in den bylaws oder vom board of directors bestimmt ${ }^{633}$. Ist kein record date festgelegt worden, ist gemäß $\S 6.40$ (b) MBCA der Tag der Beschlussfassung (date of authorization) maßgeblich. $\S 6.40$ (e) MBCA sieht vor, dass die Legalität der Ausschüttung im Zeitpunkt der Beschlussfassung zu prüfen ist, wenn die Auszahlung innerhalb von 120 Tagen nach diesem Stichtag erfolgen soll. Vergehen mehr als 120 Tage, müssen die Voraussetzungen für eine rechtmäßige Ausschüttung am Tag der Auszahlung gegeben sein. Bei einer Ausschüttung in Form von Zahlungszusagen an die Aktionäre müssen die Testverfahren am jeweiligen Auszahlungstag eingehalten werden ( $\S 6.40(\mathrm{~g}) \mathrm{MBCA})$.

Ist die Dividende vom board of directors beschlossen worden, stellt sie eine Verbindlichkeit der Gesellschaft gegenüber den Aktionären dar ${ }^{634}$. Eine beschlossene Dividendenzahlung kann grundsätzlich nicht rückgängig gemacht werden, wenn sich beispielsweise noch vor dem vereinbarten Tag der Ausschüttung herausstellt, dass das Eigenkapital niedriger als ursprünglich angenommen ist. Es ist allerdings möglich, dass ein Gericht die Rücknahme der Dividendenzahlung akzeptiert, wenn zwingende wirtschaftliche Gründe vorliegen ${ }^{635}$. Soll die beschlossene Dividende ratenweise gezahlt werden, wird gemäß $\S 6.40(\mathrm{f}) \mathrm{MBCA}$ ebenfalls auf das Datum des Beschlusses abgestellt. Sollte die Gesellschaft zwischenzeitlich insolvent werden, haben die Aktionäre genauso wie die Gläubiger einen Anspruch gegenüber der Gesellschaft.

\subsubsection{Haftungsregeln bei unzulässigen Dividendenzahlungen}

\subsection{Haftungsregeln für Directors}

Der MBCA enthält ausführliche Vorschriften, unter welchen Voraussetzungen die directors aufgrund von unzulässigen Ausschüttungen haften. Sie sind im Wesentlichen in $\S 8.33$ MBCA („Directors' Liability for Unlawful Distributions“) kodifiziert, der den allgemeinen Haftungsvoraussetzungen in $\S 8.31$ MBCA ähnelt. Die Haftungsbestimmungen in $\S 8.33$ MBCA können gemäß $§ 2.02(b)(4)(C)$ MBCA in der Satzung der Gesellschaft nicht abgemildert werden.

Nach § 8.33(a) MBCA haftet ein director persönlich gegenüber der Gesellschaft in Höhe der unzulässigen Dividendenzahlung ${ }^{636}$, wenn er einer Ausschüttung zugestimmt hat, die gegen die Ausschüttungsrestriktionen des MBCA verstö $\beta t^{637}$. Seine Zustimmung zur illegalen Dividendenzahlung wird gemäß $§ 8.24$ (d) MBCA unterstellt, wenn er nicht zu Beginn der betreffenden board-Sitzung gegen sie Widerspruch eingelegt hat und seine Ablehnung oder Stimmenenthaltung im Sitzungsprotokoll festgehalten wird oder er dem Protokollführer der betreffenden Sitzung einen schriftlichen Widerspruch zuschickt. Die directors haften in Höhe des

\footnotetext{
633 Vgl. dazu mit ausfuhrlichen Rechtsprechungsnachweisen MBCA Ann. (2002), § 7.07.

634 Vgl. Hamilton (2000), S. 583.

635 Vgl. Palmiter (2003), S. 532.

636 Vgl. hierzu Bainbridge (2002), S. 777.

637 Gleiches gilt, wenn er gegen $§ 14.09$ (a) MBCA verstoßen hat, er also bei Auflösung der Gesellschaft Ausschüttungen an die Aktionäre veranlasst hat, bevor die sonstigen Ansprüche bedient worden sind. Vgl. auch Com. Transp. Com'r v. Matyiko, 253 Va. 1, 481 S.E.2d 468 (1997); F.T.C. v. Med Resorts Intern., Inc., 2000 WL 1889635 (N.D. Ill. 2000).
} 
Betrags, der über die maximal zulässige Ausschüttung gemäß §6.40(a) MBCA hinausgeht, also in Höhe des rechtswidrig ausgeschütteten Betrags.

Das Modellgesetz lässt allerdings offen, wer unter welchen Umständen klagebefugt ist ${ }^{638}$. Anders als beispielsweise nach dem Recht Delawares (§ 174(a) Del.GCL) haftet der director nach dem MBCA nicht zusätzlich gegenüber den Gläubigern. Gläubiger sind somit auf den Insolvenzverwalter im Falle der Insolvenz der Gesellschaft angewiesen ${ }^{639}$. Der Kläger (party asserting liability) ${ }^{640}$ muss weiterhin innerhalb von zwei Jahren ( $\$ 8.33(\mathrm{c}) \mathrm{MBCA}$ ) nachweisen, dass der director zum Zeitpunkt des Dividendenbeschlusses gegen die Verhaltensanforderungen in $\S 8.30 \mathrm{MBCA}$ („Standards of Conduct for Directors“) ${ }^{641}$ verstoßen hat.

Nach $\S 8.30(a),(b)$ MBCA muss jedes Mitglied des board of directors seine Pflichten als director

- gutgläubig,

- in einer Art und Weise, die nach seiner Ansicht im besten Interesse der Gesellschaft ist, und

- mit einer Sorgfalt, die eine Person in ähnlicher Position und unter vergleichbaren Umständen vernünftigerweise für angemessen halten würde, erfüllen ${ }^{642}$.

Darüber hinaus ist jeder director ausdrücklich verpflichtet, sich zur Vorbereitung von Entscheidungen $\mathrm{zu}$ informieren und sachkundig $\mathrm{zu}$ machen ${ }^{643}$. Insgesamt gesehen formuliert $\S 8.30 \mathrm{MBCA}$ den Anspruch, der an das Verhalten der Verwaltungsmitglieder zu stellen ist, die in ihrer Eigenschaft als Mitglied des board of directors Führungsverantwortung übernehmen. In $\S 8.30 \mathrm{MBCA}$ ist hingegen nicht die business judgment rule gesetzlich kodifiziert, deren Inhalt und Anwendung weiterhin von der Rechtsprechung bestimmt und weiter entwickelt wird $^{644}$.

Unter Beachtung seiner oben beschriebenen Verhaltenspflichten kann der Geschäftsführer nach $\S 8.30(\mathrm{c}) \mathrm{MBCA}$ einzelne Aufgaben an einen bestimmten Personenkreis delegieren und auf ihre Erfüllung vertrauen. Dies gilt allerdings nur so lange, wie er keine Hinweise hat, die ein solches Vertrauen ungerechtfertigt erscheinen lassen ${ }^{645}$. Das Recht, Aufgaben zu delegieren, ist bis auf die im Modellgesetz oder sonstigen Rechtsvorschriften explizit vorgesehenen Ausnahmen nicht beschränkt. $\S 8.30(\mathrm{e}) \mathrm{MBCA}$ zählt drei Personenkreise auf, die für eine

Vgl. mit ausführlichen Rechtsprechungsnachweisen Black (2004), § 4.10, S. 29-30.

Vgl. Gevurtz (2000), S. 166.

„Party“ ist in $\S 8.50(7) \mathrm{MBCA}$ als natürliche Person definiert.

$\S 8.30 \mathrm{MBCA}$ ist 1998 stark überarbeitet worden. Vgl. dazu MBCA Ann. (2002), § 8.30, S. 175-176. Derzeit wird § $8.30 \mathrm{MBCA}$ erneut ubberarbeitet. Die ursprünglich für Mitte 2004 geplanten Änderungen sind bisher noch nicht verabschiedet worden. Zu der wahrscheinlich zukünftigen Fassung vgl. Eisenberg (2004), S. 387-389.

In $\S 8.33(\mathrm{~b}) \mathrm{MBCA}$ ist somit die so genannte duty of care normiert. Vgl. dazu und zu einer detaillierten Kommentierung der zentralen Begrifflichkeiten MBCA Ann. (2002), § 8.30, S. 162-163, 166-170.

Vgl. dazu im Einzelnen MBCA Ann. (2002), § 8.30, S. 168-169.

So MBCA Ann. (2002), § 8.30, S. 163. Vgl. auch Black (2004), §4.1, S. 6, Fn. 12.

MBCA Ann. (2002), §8.30, S. 164, kommentiert dies wie folgt: „Section 8.30 expressly prevents a director from ,hiding his or her head in the sand'...". Vgl. auch Commonwealth Transportation Commissioner v. Matyiko, 253 Va. 1, 481 S.E.2d 468 (1997). 
Aufgabendelegation grundsätzlich in Frage kommen, wenn der director sie berechtigterweise als vertrauenswürdig und sachkundig auf dem betreffenden Gebiet einschätzt ${ }^{646}$ :

(1) Officers und sonstige Angestellte des Unternehmens.

(2) Unternehmensexterne Berater und Experten, wie z.B. Rechtsanwälte und Wirtschaftsprüfer.

(3) Ein Ausschuss (committee) des board of directors, dem der director selbst nicht angehört $^{647}$. Gemäß $§ 8.25(\mathrm{e})(1) \mathrm{MBCA}$ darf die Ausschüttungsentscheidung selbst nicht an einen Ausschuss delegiert werden. Das board of directors kann aber z.B. eine Bandbreite hinsichtlich der Höhe und des Zeitpunkts der Dividendenzahlung vorgeben und dem Ausschuss die Entscheidung innerhalb des vorgegebenen Rahmens überlassen ${ }^{648}$.

Der director kann sich schließlich gemäß $§ 8.30(d)$ MBCA auf Informationen, die von den oben genannten Personen zusammengestellt oder vorgetragen werden, verlassen. Explizit einbezogen sind davon Jahresabschlüsse und andere Finanzdaten. Letzteres wird bezogen auf die Ausschüttungsentscheidung - wie in Kapitel III.2.2.1.4.2 ausführlich dargelegt - in $\S 6.40(\mathrm{~d})$ MBCA präzisiert. Es ist allerdings notwendig, dass sich der Geschäftsführer mit den Inhalten der präsentierten Informationen vertraut macht ${ }^{649}$.

Bezogen auf die Gefahr eines director, eine unzulässige Dividendenzahlung an die Gesellschaft zurückzahlen zu müssen, kann also festgehalten werden, dass ihm eine Reihe von Verteidigungsmöglichkeiten zur Verfügung steht ${ }^{650}$. Er kann einen Regressanspruch abwehren, indem er erstens bei seinen Tätigkeiten eine angemessene Sorgfalt beachtet und zweitens bei der Delegation von Aufgaben ein berechtigtes Vertrauen in die beauftragten Personen setzen kann. Schließlich wird er durch die business judgment rule nach common law geschützt. Auf den letzteren Schutz braucht in den meisten Fällen aber dann nicht zurückgegriffen werden, wenn die Vorschriften des $\S 8.30 \mathrm{MBCA}$ eingehalten worden $\operatorname{sind}^{651}$.

Ist ein director auf Zurückzahlung der unzulässigen Dividende an die Gesellschaft verurteilt worden, hat er gegenüber allen anderen directors, die ebenfalls nach $\S 8.30$ (a) MBCA haftbar gemacht werden könnten, Ausgleichsansprüche (contribution) gemäß $\S 8.30(\mathrm{~b})(1) \mathrm{MBCA}$. Zudem kann er von denjenigen Aktionären, die wussten, dass die Ausschüttung gegen $\S 6.40$ (a) MBCA verstoßen hat, eine anteilige Entschädigung (recoupment) verlangen $(\S 8.30(\mathrm{~b})(2) \mathrm{MBCA})^{652}$. Das Modellgesetz nimmt dabei keine Aufteilung der Rückzahlungsverpflichtung auf Aktionäre und directors vor, sondern überlässt dieses Problem der Recht-

\footnotetext{
646 Vgl. dazu ausführlich MBCA Ann. (2002), § 8.33, S. 172-175.

647 Vgl. dazu auch Dellastatious v. Williams, 242 F.3d 191 (4th Cir. 2001).

648 Vgl. MBCA Ann. (2002), § 8.25, S. 140-141.

649 Vgl. MBCA Ann. (2002), § 8.30, S. 172. Vgl. auch Baker v. Mutual Loan \& Investment Co., 213 S.C. 558, 50 S.E.2d 692 (1948). In diesem Fall begründet das Gericht die Haftung der directors aufgrund einer unzulässigen Dividendenzahlung damit, dass sie sich nicht in ausreichender Weise mit der finanziellen Lage die Bilanz wies einen Verlust aus - auseinandergesetzt hätten. Vgl. auch Cornell v. Seddinger, $237 \mathrm{~Pa} .389$, 85 A. 446 (1912).

650 Vgl. im Folgenden MBCA Ann. (2002), § 8.33, S. 216QQ-216RR.

651 Vgl. Black (2004), § 4.1, S. 8.

652 Beide Ansprüche sind innerhalb eines Jahres nach Urteilsverkündung geltend zu machen $(\S 8.33(\mathrm{c})(2)$ MBCA).
} 
sprechung ${ }^{653}$. Hat der Aktionär von der Unzulässigkeit der erhaltenen Dividende nicht gewusst, ist eine Rückzahlung ausgeschlossen ${ }^{654}$.

\subsection{Haftungsregeln für Aktionäre}

Im Gegensatz zum kalifornischen Corporations Code, in dem die Voraussetzungen einer Haftung der Aktionäre detailliert geregelt sind ${ }^{655}$, findet sich im MBCA keine vergleichbare eigenständige Norm. Wie im letzten Abschnitt erörtert, können die Aktionäre zur Rückzahlung indirekt verpflichtet werden, wenn ein director aufgrund einer illegalen Dividendenzahlung in Anspruch genommen worden ist und von den Aktionären fristgerecht eine Entschädigung verlangt ${ }^{656} . \S 8.33(\mathrm{~b})(2) \mathrm{MBCA}$ setzt dafür allerdings voraus, dass die Aktionäre von dem Verstoß gegen die Ausschüttungsregeln tatsächlich gewusst haben ${ }^{657}$. Die Voraussetzung ist somit noch restriktiver als es beispielsweise in Delaware oder Kalifornien der Fall ist ${ }^{658}$.

Trotz der fehlenden gesetzlichen Norm existieren Gerichtsentscheidungen, die einen Anspruch der Gläubiger gegen die Ausschüttungsempfänger für zulässig gehalten haben ${ }^{659}$. Die Gerichte wenden dabei zumeist im common law entwickelte Grundsätze an. Aktionäre, die in gutgläubiger Weise von der Rechtmäßigkeit der Ausschüttung ausgingen, haften danach nicht. Es existieren weiterhin Urteile von Insolvenzgerichten (bankruptcy courts), nach denen Insolvenzverwalter im Namen von Gläubigern illegale Dividenden von den Aktionären zurückverlangen konnten ${ }^{660}$. Der MBCA enthält keine Hinweise, ob eine Haftung der Aktionäre bei rechtswidrig erhaltenen Dividendenzahlungen zusätzlich nach anderen Gesetzen in Frage kommt.

\subsubsection{Kapitalschutzregeln anderer Model Acts und Gesetze}

\subsubsection{Creditors' Rights Laws}

Die Dividendenpolitik der corporation kann auch durch insolvenzrechtliche Vorschriften, die zum Schutz der Gläubiger die Handlungsspielräume der Schuldner unabhängig von gesellschaftsrechtlichen Regelungen und vertraglichen Vereinbarungen einschränken, beeinflusst werden. Regelungen, die Schuldner daran hindern sollen, ihre Vermögenswerte zu transferieren und somit vor dem Zugriff der Gläubiger zu bewahren, sind in England bereits $1571 \mathrm{im}$ Statute of Elizabeth festgeschrieben worden, das von vielen Staaten der USA übernommen

Vgl. MBCA Ann. (2002), § 8.33, S. 216RR; Black (2004), §4.35.

Vgl. MBCA Ann. (2002), § 8.33, S. 216RR.

Vgl. § 506 Cal.Corp.Code. Vgl. dazu ausführlich Kapitel III.2.3.2.4.2.

Es handelt sich also um eine sekundäre gesetzliche Aktionärshaftung. Vgl. Merkt/Göthel (2006), S. 303.

Zum knowledge-Begriff vgl. auch Resolution Trust Corp. v. Dean, 854 F. Supp. 626, (D. Ariz. 1994), hier S. 652 .

Vgl. Black (2004), § 4.35 .

Vgl. dazu mit Rechtsprechungsnachweisen Black (2004), §4.35. Vgl. aus der jüngeren Rechtsprechung z.B. In re Lake Country Investments, 255 B.R. 588 (Bankr. D. Idaho 2000).

Vgl. z.B. In re Hoffman Associates, Inc., 194 B.R. 943 (Bankr. D. S.C. 1995). 
wurde $^{661}$. Das englische Recht war auch Vorbild für den im Jahre 1918 von der National Conference of Commissioners on Uniform State Laws (NCCUSL) verkündeten Uniform Fraudulent Conveyance Act (UFCA). Der überarbeitete und in Uniform Fraudulent Transfer Act (UFTA) umbenannte Nachfolger wurde 1984 zur Übernahme in alle Bundesstaaten empfohlen. Mittlerweile haben 42 Staaten der USA den UFTA in ihr Recht transformiert; der UFCA gilt noch in drei Staaten ${ }^{662}$.

Die $§ \S 7-8$ UFTA räumen den Gläubigern das Recht ein, auf dem Klageweg gegen bestimmte im UFTA als betrügerisch (fraudulent) klassifizierte Transaktionen mit dem Ziel vorzugehen, solche Transaktionen zu vermeiden oder die transferierten Vermögenswerte beschlagnahmen zu lassen. Gemäß $\S \S 4-5$ UFTA werden Vermögensverschiebungen oder eingegangene Verpflichtungen des Schuldners als betrügerisch angesehen, wenn:

- sie mit der Absicht durchgeführt wurden, die Gläubiger zu behindern (hinder), aufzuhalten oder zu betrügen $(\S 4(\mathrm{a})(1) \mathrm{UFTA})^{663}$, oder

- der Schuldner im Gegenzug dafür keinen angemessenen Wert erhält und

(1) ihm für seine aktuelle oder geplante Geschäftstätigkeit unverhältnismäßig wenig Vermögen verbleibt $(\S 4(\mathrm{a})(2)(\mathrm{i}) \mathrm{UFTA})^{664}$, oder

(2) er seine Verbindlichkeiten bei Fälligkeit nicht mehr erfüllen kann (§4(a)(2)(ii) UFTA), oder

(3) er zu diesem Zeitpunkt insolvent ist oder durch die Übertragung bzw. durch die eingegangene Verpflichtung insolvent wird ( $\$$ 5(a) UFTA).

Nach § 2(a) UFTA liegt Insolvenz dann vor, wenn die Schulden die Vermögenswerte auf fair value-Basis übersteigen. Es handelt sich also um den bankruptcy insolvency test. Da der Insolvenztatbestand in $\S 2$ (a) UFTA regelmäßig nur schwierig nachzuweisen sei, wird die Insolvenz darüber hinaus widerlegbar vermutet, wenn der Schuldner seine Verbindlichkeiten bei Fälligkeit im Allgemeinen nicht zahlt (§2(b) UFTA ${ }^{665}$ und er mithin den equity insolvency test nicht erfüllt ${ }^{666}$. Bemerkenswert ist, dass nach $\S 4$ UFTA nicht nur aktuelle, sondern auch zukünftige Gläubiger anspruchsberechtigt sind. Bei Sachverhalten, die unter $\S 5$ UFTA fallen, müssen die aktuellen Gläubiger die betrügerische Absicht des Schuldners nicht nachweisen.

Vgl. NCCUSL (1984), S. 1-5; Palmiter (2003), S. 551-552.

So Black (2004), § 4.37 .

Eine nicht abschließende Auflistung von elf Konstellationen, die auf ,actual intent“ hinweisen, findet sich in $\S 4$ (b) UFTA.

Zur Auslegung der Norm durch die Rechtsprechung vgl. ausführlich Black (2004), § 4.40. „Unreasonably small“ wird im deutschen Schriftum teilweise auch mit ,unvernünftig gering“ übersetzt. Vgl. Mülbert (2004), S. 160; Fleischer (2005), S. 94.

Vgl. zur Begründung dieser Norm NCCUSL (1984), S. 13-14. Nichtzahlung liegt beispielsweise vor, wenn Zahlungen in signifikanter Höhe ausbleiben oder 30 Tage nach Fälligkeit nicht gezahlt wurden.

Die Bezeichnungen der beiden Testverfahren deuten auf ihre historischen Wurzeln im Richterrecht Englands hin. Die englischen law courts wandten in Insolvenzverfahren den so genannten bankruptcy insolvency test an. Danach ist eine Gesellschaft insolvent, wenn ihre Schulden die Vermögenswerte übersteigen. Die englischen equity courts hingegen gingen von der Insolvenz des Unternehmens aus, wenn es nicht in der Lage war, seine Verbindlichkeiten bei Fälligkeit zu tilgen. In Anspielung auf diese Gerichte wird das Testverfahren als equity insolvency test bezeichnet. Vgl. dazu Manning/Hanks (1991), S. 63-65. Zum Begriff „equity“ vgl. bereits Kapitel II.2.2. 
Die beiden Insolvenzdefinitionen des UFTA unterscheiden sich grundlegend. Der bankrupty insolvency test untersucht, ob die Gesellschaft überschuldet ist und stellt dafür auf Bilanzdaten ab. Im Gegensatz dazu geht der equity insolvency test der Frage nach, ob das Unternehmen insolvent aufgrund von Illiquidität ist und zieht dafür Plan-Gewinn- und Verlustrechnungen bzw. Plan-Kapitalflussrechnungen heran. Aufgrund der unterschiedlichen Herangehensweisen kommen die beiden Testverfahren nicht notwendigerweise zum selben Ergebnis ${ }^{667}$. Verfügt beispielsweise ein Unternehmen über wertvolle, aber wenig liquide Vermögenswerte und einen nur geringen Kassenbestand, kann Insolvenz wegen Illiquidität eintreten, obwohl das Unternehmen noch Eigenkapital aufweist und somit keine Insolvenz aufgrund von Überschuldung vorliegt.

Nach der herrschenden Meinung sind die Vorschriften des UFTA bzw. seines Vorgängers auch auf Dividendenzahlungen anwendbar und stellen somit neben den gesellschaftsrechtlichen Ausschüttungsrestriktionen einen zusätzlichen Schutz für die Gläubiger dar ${ }^{668}$. Die Auffassung wird unter anderem damit begründet, dass die Unternehmen für ihre Dividendenausschüttung keine Gegenleistung erhalten ${ }^{669}$. Weiterhin wird angeführt, dass gemäß $\S 1(12)$ UFTA die Auszahlung von Geld explizit zu den Vermögensübertragungen gezählt wird.

Dividendenzahlungen, die nach dem Gesellschaftsrecht des betreffenden Einzelstaates zulässig sind, können durch die im Einzelfall strengeren Vorschriften des UFTA verhindert werden, wenn im Anschluss an die Ausschüttung der Gesellschaft nur noch unverhältnismäßig wenig Vermögenswerte verbleiben würden ${ }^{670}$. Die herrschende Ansicht ist von zahlreichen Gerichtsentscheidungen bestätigt worden, in denen die Unrechtmäßigkeit von Dividendenzahlungen mit Verstößen gegen die Bestimmungen des UFTA bzw. des UFCA begründet worden

Vgl. Manning/Hanks (1990), S. 64; Marsh/Finkle/Sonsini (2005), Ch. 14, S. 43. Vgl. dazu auch Süchting (1995), S. 459.

668 Vgl. grundlegend Clark (1977), S. 554-560; Clark (1986), S. 86-90, 624-625. Vgl. auch H. Henn/Alexander (1983), S. 890; McDaniel (1986), S. 432; Manning/Hanks (1990), S. 64-65; Eisenberg (2000), S. 1246; Kahan (2003), S. 146-147; Black (2004), § 4.55; Choper/Coffee/Gilson (2004), S. 228; Emanuel (2005), S. 544; Marsh/Finkle/Sonsini (2005), Ch. 14, S. 68-70. Die Anwendbarkeit der fraudulent conveyanceRegeln auf Dividendenausschüttungen ist im Schriftum bereits früh erörtert worden. Vgl. Kehl (1941), S. 35-37.

„The specific restraints on corporate distributions simply remove all doubts as to whether a dividend to shareholders is a ,transfer without fair consideration' within the meaning of general fraudulent conveyance law." So Clark (1977), S. 555. „Fair consideration“ ist in §4(a)(2) UFTA mittlerweile durch „reasonably equivalent value" ersetzt worden. Zur Begründung vgl. NCCUSL (1984), S. 19. Streng genommen könnte argumentiert werden, dass die zeitlich vorgelagerte Überlassung von Kapital die Gegenleistung der Aktionäre darstellt.

670 Vgl. die Regelungen des UFTA als ineffektiv kritisierend Kummert (1984), S. 281-282; Bauer (1995), S. 253; Böckmann (2005), S. 83. 
$\operatorname{sind}^{671}$. Lediglich eine Mindermeinung lehnt die Anwendung der fraudulent conveyance laws auf Dividendenausschüttungen $a b^{672}$.

Eine Dividendenausschüttung, die gegen den bankruptcy insolvency test verstößt, kann weiterhin auch von den bundesrechtlich kodifizierten Bestimmungen des Bankruptcy Reform Act of $1978^{673}$ betroffen sein ${ }^{674}$. Der Insolvenzverwalter kann alle betrügerischen Vermögensverschiebungen eines Unternehmens in seiner Eigenschaft als Schuldner, die innerhalb des letzten Jahres vor dem Tag des Insolvenzantrags stattgefunden haben, für ungültig erklären. Die in $\S 548$ Bankruptcy Code kodifizierten Voraussetzungen dafür stimmen im Wesentlichen mit denen des UFTA überein ${ }^{675}$. Die Transaktionen werden zum einen als betrügerisch eingestuft, wenn der Schuldner sie mit Absicht durchgeführt hat. Gleiches gilt zum anderen, wenn die Gesellschaft keine angemessene Gegenleistung erhalten hat oder sie insolvent ist bzw. es durch die Transaktion wird, ihr unangemessen wenig Vermögenswerte verbleiben oder sie ihre Verbindlichkeiten bei Fälligkeit nicht mehr tilgen kann. Das Insolvenzgericht kann ferner gemäß $\S 510$ (c)(1) Bankruptcy Code bestimmen, dass die Ansprüche der Gesellschafter gegenüber dem Unternehmen im Rang hinter die Forderungen anderer Gesellschaftsgläubiger zurücktreten $^{676}$.

Die insolvenzrechtlichen Regelungen unterscheiden sich in mehrerer Hinsicht von den gesellschaftsrechtlichen Ausschüttungsregulierungen ${ }^{677}$. Nach dem UFTA bzw. UFCA können Gläubiger in eigenem Namen gegen betrügerische Dividendenzahlungen vorgehen. Nach dem Gesellschaftsrecht der Einzelstaaten hingegen haften die Geschäftsführer und die Aktionäre in der Regel gegenüber der Gesellschaft und nur in seltenen Fällen gegenüber den Gläubigern ${ }^{678}$. Die Dividendengesetze sehen eine gesamtschuldnerische Haftung der Geschäftsführer vor. Aktionäre können nur dann verpflichtet werden, die erhaltene Dividende zurückzuzahlen, wenn sie von der Unrechtmäßigkeit wussten. Nach den Uniform Acts können auch Aktionäre, die von der Gesetzwidrigkeit nichts gewusst haben, zur Rückzahlung verpflichtet werden. Da der UFTA die Rückabwicklung unzulässiger Rechtsgeschäfte regelt, ist selbst der gutgläubige Empfänger einer „betrügerischen“ Dividende zur Rückgabe verpflichtet.

Die fraudulent conveyance laws führen weiterhin in bestimmten Konstellationen zu strengeren Ausschüttungsrestriktionen. Eine Dividendenausschüttung, durch die das Unternehmen im Anschluss nur noch ein unangemessen niedriges Vermögen aufweist, kann im Einklang mit

671 Vgl. z.B. Powers v. Heggie, 268 Mass. 233, 167 N.E. 314, 317 (1929); In re Kettle Fried Chicken of America, Inc., 513 F.2d 807 (6th Cir. 1975); U.S. v. Gleneagles Investment Co., Inc., 565 F.Supp.556 (MD Pa 1983). Vgl. zur diesbezüglichen Rechtsprechung umfassend Black (2004), § 4.56-58.

672 Vgl. Kehl (1941), S. 36; Kummert (1984), S. 281. Es wird einerseits argumentiert, dass es sich bei den gesellschaftsrechtlichen Ausschüttungsregeln um abschließende Spezialnormen handele. Die insolvenzrechtlichen Vorschriften werden andererseits nur auf Schenkungen für anwendbar gehalten. Vgl. auch Committee on Corporate Laws (1979), S. 1882-1883. §152 MBCA (1979) wies dementsprechend noch explizit darauf hin, dass die Bestimmungen des MBCA andere Einzelstaatengesetze in Bezug auf die Rechtmäßigkeit von Ausschüttungen ersetzen. In MBCA Ann. (2002), §6.40, S. 199, wird hingegen die unterschiedliche Zielsetzung der jeweiligen Insolvenztests betont.

Vgl. dazu den aktuellen Überblick von Meyer-Löwy/Poertzgen/Eckhoff (2005).

Vgl. Hamilton (2000), S. 585. Insolvenz liegt nach § 101(32) Bankruptcy Code vor, wenn ,the sum of such entity's debts is greater than all of such entity's property, at a fair valuation".

Vgl. Black (2004), § 4.43-48; Mülbert (2004), S. 160.

Vgl. dazu auch Fleischer (2005), S. 94.

Vgl. Black (2004), § 4.36, 4.50-54.

Vgl. Bauer (1995), S. 252. 
den Ausschüttungsgesetzen stehen. Nach dem UFTA hingegen ist eine solche Ausschüttung als betrügerisch anzusehen. Somit bietet erst diese allgemeine Vorschrift den Schutz, den viele einzelstaatliche Ausschüttungsrestriktionen seit der Einfuihrung von Aktien ohne oder lediglich mit niedrigem Nennwert nicht mehr bieten.

Schließlich ist es für Gläubiger einfacher, bei unrechtmäßigen Dividenden ihre Ansprüche nach den Vorschriften des UFTA durchzusetzen ${ }^{679}$. Während nämlich im Kapitalgesellschaftsrecht die Kläger die Beweislast trifft, kehrt sich die Beweislast nach dem UFTA zumindest dann um, wenn der Gläubiger eine Vermögensübertragung der Gesellschaft ohne Gegenleistung nachweisen kann. Anfechtungsberechtigt sind in dem Fall, in dem der Schuldner zum Zeitpunkt der Vermögensübertragung insolvent ist oder es durch die Transaktion wird, die Gläubiger, die bereits vorher einen Anspruch hatten. In den anderen Fällen sind alle Gläubiger anfechtungsberechtigt, unabhängig davon, wann ihr Anspruch entstanden ist.

\subsubsection{Accumulated Earnings Tax des Internal Revenue Code}

Seit 1936 existiert in den USA mit der accumulated earnings tax eine Strafsteuer für corporations, die Gewinnthesaurierungen vornehmen, um der Besteuerung von Dividenden mit Einkommensteuer auf der Ebene der Aktionäre zu entgehen ${ }^{680}$. Ist die US-amerikanische Finanzverwaltung, der Internal Revenue Service (IRS), der Ansicht, die Gesellschaft verfüge über unangemessen hohe Gewinnrücklagen, wird gemäß §§ 531-537 Internal Revenue Code (IRC) eine Zusatzsteuer in Höhe von aktuell $15 \%$ des akkumulierten steuerpflichtigen Jahreseinkommens (accumulated taxable income) bei einem Freibetrag von 250.000 US-\$ erhoben ${ }^{681}$.

Die Unternehmen haben zwar vielfältige Möglichkeiten, der Strafsteuer zu entgehen, indem sie den IRS überzeugen, dass sie die einbehaltenen Gewinne für Investitionszwecke benötigen $^{682}$. Dennoch existieren Fälle, in denen Unternehmen zur Zahlung dieser Steuer verpflichtet worden sind ${ }^{683}$. Einen Beleg dafür ergibt sich beispielsweise aus der im gesellschaftsrechtlichen Fachschrifttum viel beachteten Gerichtsentscheidung in der Sache Smith v. Atlantic Properties, Inc. ${ }^{684}$. In dem Fall ging es um die Frage, ob ein Minderheitsaktionär einer closely held corporation seine Treuepflicht verletzt, wenn er sein Vetorecht dazu nutzt, um Dividendenausschüttungen zu verhindern. Die 1951 gegründete Immobiliengesellschaft Atlantic Properties, Inc., war zu jeweils $25 \%$ im Besitz von vier Aktionären. In der Satzung war festgelegt, dass für alle Unternehmensentscheidungen des board of directors eine Zustimmung von $80 \%$ des Aktienkapitals notwendig war. Jeder Aktionär hatte folglich ein Vetorecht.

Die Gesellschaft wirtschaftete sehr profitabel und wies bereits im Jahre 1961 Gewinnrücklagen in Höhe von 172.000 US-\$ auf. Während sich die anderen Anteilseigner für Dividendenzahlungen aussprachen, nutzte ein Aktionär sein Vetorecht, um diese mit dem Argument zu verhindern, die einbehaltenen Gewinne seien für Instandhaltungs- und Erweiterungsmaßnah-

Vgl. dazu Black (2004), § 4.55, S. 99.

Vgl. H. Henn/Alexander (1983), S. 948-949 m.w.N.

Vgl. Pellens (2001a), S. 75 m.w.N. Vor Verabschiedung des „Jobs and Growth Tax Relief Act of 2003“ betrug der Steuersatz 39,6\%.

Vgl. Kroschel (2000), S. 317-318, 408-419; o.V. (2001).

Vgl. Cox/Hazen (2003), S. 1202 m.w.N.

Vgl. Smith v. Atlantic Properties, Inc., 12 Mass.App.Ct. 201, 422 N.E.2d 798 (1981). Vgl. dazu z.B. Clark (1986), S. 604-605; Eisenberg (2000), S. 395-400; Gevurtz (2000), S. 462; Bauman/Weiss/Palmiter (2003), S. 1228-1231; Blatt (Hrsg.) (2003), S. 87-88; Emanuel (2005), S. 167-168. 
men an Gebäuden und Einrichtungen der Gesellschaft zu verwenden. Auch in den folgenden Jahren stimmte er gegen Dividendenzahlungen. Gleichzeitig unternahm er keinen ernsthaften Versuch, den IRS von der wirtschaftlichen Notwendigkeit der Gewinnthesaurierungen zu überzeugen. Folglich musste die Gesellschaft in den Jahren 1962 bis 1968 accumulated earnings taxes wegen unangemessen hoher Gewinnrücklagen zahlen.

Schließlich reichten die übrigen drei Aktionäre eine Klage in dem Bestreben ein, den die Dividendenzahlung verweigernden Aktionär aus dem board auszuschließen, die Ausschüttung von Dividenden durchzusetzen und die von der Gesellschaft geleisteten Strafsteuern durch ihn erstattet zu bekommen. Das Gericht entschied, der Beklagte habe seine Treuepflicht gegenüber den anderen Aktionären verletzt und müsse die Strafsteuern inklusive Zinsen an die Gesellschaft zurückzahlen ${ }^{685}$. Darüber hinaus wurden die directors der Gesellschaft angewiesen, eine angemessene jährliche Dividende festzulegen.

Nachdem sich die bisherigen Ausführungen zum US-amerikanischen Kapitalschutzsystem auf die Grundsätze des common law sowie die Vorschriften des MBCA und ausgewählter weiterer Model Acts bzw. Gesetze konzentriert haben, werden im Folgenden abschließend die Kapitalschutzregeln der gesellschaftsrechtlichen Einzelstaatengesetze von Delaware und Kalifornien beleuchtet.

\subsection{Kapitalschutzsysteme bedeutender Inkorporationsstaaten}

\subsubsection{Delaware}

\subsubsection{Kapitalaufbringung}

Das Gesellschaftsrecht Delawares schreibt seit 1967 kein Mindestkapital mehr vor ${ }^{686}$. Bei der Ausgabe von Aktien kann grundsätzlich das board of directors nach $§ 154$ Del.GCL festlegen, dass nur ein Teil des Verkaufserlöses als capital und der Rest als surplus ausgewiesen wird. Handelt es sich ausschließlich um Nennwertaktien, darf das capital aber nicht niedriger als die Summe der Nennwerte sein. Sind sowohl Nennwertaktien als auch nennwertlose Aktien ausgegeben worden, muss das capital die Summe der Nennwerte übersteigen. Hat die Gesellschaft beispielsweise 1 Mio. Aktien mit einem Nennwert von 1 US- $\$$ zu einem Emissionspreis von 10 US-\$ je Aktie verkauft, kann das Management als capital einen Betrag zwischen 1 Mio. US-\$ und 10 Mio. US-\$ frei wählen. Bei einer Emission von ausschließlich nennwertlosen Aktien kann sogar ein capital von Null ausgewiesen werden ${ }^{687}$. Ein ähnliches Ergebnis lässt sich auch bei Aktien mit Nennwert erzielen, wenn dieser sehr niedrig festgesetzt wird (z.B. 1 Cent).

\footnotetext{
685 Das Gericht kam zu der Einschätzung, dass der Aktionär durch sein Vetorecht Dividendenzahlungen verhindert hatte, weil er zum einen die anderen Aktionäre nicht mochte und zum anderen hohe persönliche Steuerzahlungen auf Dividenden vermeiden wollte. Vgl. auch Bainbridge (2002), S. 821; Black (2004), $\S 4.13$, Fn. 9.

686 Vgl. Folk/Ward/Welch (1988), § 102.5, S. 13.

687 Vgl. Gevurtz (2000), S. 158.
} 
Nimmt die Unternehmensleitung eine Aufteilung des von den Aktionären einzuzahlenden Kapitals in capital und surplus nicht bereits bei der Aktienausgabe ${ }^{688}$ vor, sind im capital die Summe der Nennbeträge aller Nennwertaktien sowie der komplette Verkaufserlös für die nennwertlosen Aktien auszuweisen ${ }^{689}$. Das Kapital kann gemäß $\S 152$ Del.GCL sowohl in Form von Bareinlagen als auch durch Sacheinlagen erbracht werden. Als Sacheinlagen kommen bereits erbrachte Dienstleistungen, bewegliche und unbewegliche Sachen sowie Nutzungsrechte an Grundstücken in Betracht. Im Gegensatz zu §6.21(b) MBCA sind zukünftige Dienstleistungen jedoch nicht einlagefähig. Bei der Bewertung haben die directors die good faith rule in $\S 152$ Del.GCL zu beachten. Sie allein entscheiden danach über den Wert der eingebrachten Vermögenswerte ${ }^{690}$. Die Einlagebewertung ist für die Gesellschaft, ihre Aktionäre und Gläubiger bindend, es sei denn, es liegt ein tatsächlicher Betrug (actual fraud) oder ein gerichtlich festgestellter so genannter constructive fraud vor ${ }^{691}$

In der Folgezeit kann die Unternehmensleitung Beträge vom surplus ins capital transferieren (§ 154 Del.GCL).

\subsubsection{Kapitalerhaltung}

\subsection{Ausschüttungsrestriktionen}

Als Ausschüttungsrestriktionen sieht das Gesellschaftsrecht Delawares zwei alternative Testverfahren vor: den surplus test und den net profits test. Weitere Beschränkungen können sich aus der Satzung ergeben $(\S 170(a) \text { Del.GCL })^{692}$. Im Gegensatz zu den meisten anderen Einzelstaaten und dem MBCA ist in Delaware ein Solvenztest nicht explizit vorgeschrieben ${ }^{693}$. Allerdings verstoßen die directors gegen ihre Treuepflicht gegenüber den Gläubigern, wenn sie die Ausschüttung einer Dividende veranlassen, obwohl die Gesellschaft insolvent ist ${ }^{694}$.

\subsection{Surplus Test}

Der surplus test ${ }^{695}$ gemäß $§ 170($ a) Del.GCL soll sicherstellen, dass eine Dividendenausschüttung das capital der Gesellschaft nicht vermindert, und wird daher auch als capital impairment

Bei Sacheinlagen verlängert sich die Frist für die Aufteilung um 60 Tage ( $\$ 154$ Del.GCL).

Vgl. dazu auch Bainbridge (2002), S. 774.

Vgl. Bainbridge (2002), S. 772. Vgl. zu dieser Regelung kritisch auch Fleischer (2005), S. 93.

Vgl. zur Unterscheidung von actual und constructive fraud mit zahlreichen Rechtsprechungsnachweisen Bainbridge (2002), S. 772.

Formulierungen in der Satzung können dazu führen, dass eine Dividende ausschließlich aus dem surplus ausgeschüttet werden darf und der net profits test nicht zur Anwendung kommt. Vgl. z.B. Jones v. First Nat. Bldg. Corp., 155 F.2d 815 (C.C.A. 10th Cir. 1946); Weinberg v. Baltimore Brick Co., 35 Del. Ch. 225, 114 A.2d 812 (1955).

Vgl. Kreidmann (1957), S. 374; Black (2004), § 1.3, S. 13, Fn. 3.

Vgl. LaSalle Nat. Bank v. Perelman, 82 F. Supp. 2d 279 (D. Del. 2000); Pereira v. Cogan, 294 B.R. 449 (S.D. N.Y. 2003).

Vgl. zu diesem Begriff z.B. Hamilton (2000), S. 585; Black (2004), §2.23. Der surplus test stellt eine Ausprägung des balance sheet test dar. Vgl. Palmiter (2003), S. 524. 
test ${ }^{696}$ bezeichnet. Folglich sind Dividendenzahlungen grundsätzlich nur aus dem surplus zulässig. Surplus ist nach $\S 154$ Del.GCL definiert als der Überschuss der Netto-Vermögenswerte (Vermögenswerte abzüglich Schulden) über das capital ${ }^{697}$. Da das Gesellschaftsrecht Delawares keine Ansatz- und Bewertungsregeln für die Vermögenswerte und Schulden vorschreibt, sind Entscheidungen der Rechtsprechung bei der Ermittlung des surplus von besonderer Bedeutung. Ältere Gerichtsentscheidungen propagieren eine konservative Bilanzierung, nach der unrealisierte Gewinne nicht ausgewiesen werden dürfen und Vermögenswerte bei eingetretenen Wertminderungen auf ihren niedrigeren aktuellen Wert abgeschrieben werden müssen ${ }^{698}$.

$\mathrm{Zu}$ einem grundlegenden Wandel der Rechtsprechung in Delaware kam es durch die viel beachtete Entscheidung des Delaware Supreme Court in der Sache Klang v. Smith's Food \& Drug Centers, Inc. ${ }^{699}$, aus dem Jahre 1997. Das Gericht musste entscheiden, ob ein Aktienrückkauf, der zu einem negativen Eigenkapital von mehr als 100 Mio. US-\$ geführt hatte, gegen den surplus test gemäß $\S 160$ Del.GCL verstieß. Da die Vorschrift im Wesentlichen derjenigen entspricht, die auf Dividendenausschüttungen anzuwenden ist ( $\$ 170$ Del.GCL), ist die Gerichtsentscheidung auf Dividendenzahlungen nach dem Recht Delawares analog anwendbar $^{700}$.

Nach Auffassung des Gerichts ist die Gesellschaft bei der Durchführung des surplus test nicht an die Bilanz gebunden, da sie nicht notwendigerweise den aktuellen Wert der Vermögenswerte und Schulden widerspiegele ${ }^{701}$. Es sei der Zweck von $\S 160$ Del.GCL, das Management daran zu hindern, durch zu hohe Ausschüttungen von Vermögenswerten die Gläubiger zu schädigen und die wirtschaftliche Überlebensfähigkeit der Gesellschaft zu gefährden. Dass die aktuellen Marktwerte der Vermögenswerte noch nicht realisiert seien oder sich in der Bilanz noch nicht niedergeschlagen hätten, sei in diesem Zusammenhang irrelevant. Entscheidend sei vielmehr der tatsächliche ökonomische Wert der Gesellschaft, der sich in der Neubewertung zeige. Die Unternehmensleitung darf daher für Ausschüttungszwecke die Bilanzpositionen zum aktuellen Marktwert neu bewerten, wenn sie dabei in gutem Glauben vorgeht

ggl. Klang v. Smith's Food \& Drug Centers, Inc., 702 A.2d 150 (Del. 1997). In jüngeren Gerichtsentscheidungen wird die Bewertung zum aktuellen Marktwert ebenfalls furr zulässig erklärt. Vgl. Angelo, Gordon \& Co. v. Allied Riser Communications Corp., 805 A.2d 221 (Del. Ch. 2002); Pereira v. Cogan, 294 B.R. 449 (S.D. N.Y. 2003). Zu weiteren wichtigen Gerichtsentscheidungen vgl. Balotti/Finkelstein (2004), §170, S. 166-167.

700 So Eisenberg (2000), S. 1255.

701 Vgl. Klang v. Smith's Food \& Drug Centers, Inc., 702 A.2d 150 (Del.Supr.1997), hier S. 154 
und nachvollziehbare Bewertungsmethoden heranzieht ${ }^{702}$. Ein auf der Passivseite der Bilanz resultierender surplus steht dann für Ausschüttungen zur Verfügung ${ }^{703}$.

Bei der Festlegung der Dividende darf sich die Unternehmensleitung gemäß $§ 172$ Del.GCL in gutem Glauben auf Berichte und Informationen von Unternehmensangehörigen und externen Experten stützen. Die Unternehmensleitung braucht keine Haftung zu befürchten, wenn sie berechtigterweise davon ausgehen kann, dass diese Personen über das nötige Fachwissen verfügen und sie mit angemessener Sorgfalt ausgewählt wurden. Somit kann sich der director bei der Dividendenentscheidung z.B. auf einen surplus verlassen, der in einer von einem Wirtschaftsprüfer geprüften Bilanz ausgewiesen wird ${ }^{704}$. Er kann sich ebenfalls auf ein surplus beziehen, das sich aufgrund einer Bewertung zum aktuellen Marktwert ergibt, wenn die Bewertung z.B. von einer Investmentbank oder einem Gutachter durchgeführt wurde ${ }^{705}$.

\subsection{Kapitalherabsetzung}

Die Unternehmensleitung kann mit einfacher Mehrheit weitere ausschüttungsfähige Beträge kreieren, indem sie eine Kapitalherabsetzung gemäß $§ 244$ Del.GCL beschlie $\mathrm{t}^{706}$. Dazu ist in den meisten Fällen weder die Zustimmung der Aktionäre erforderlich ${ }^{707}$ noch muss sie öffentlich bekannt gegeben werden ${ }^{708}$. Die einzige Zulässigkeitsbeschränkung besteht darin, dass die Vermögenswerte im Anschluss an die Kapitalherabsetzung zur Tilgung der Schulden ausreichen müssen ( $§ 244$ (b) Del.GCL). Diese Restriktion ist aber nur von eingeschränkter praktischer Bedeutung, da eine solche Form der Kapitalherabsetzung lediglich einen Passivtausch darstellt und die Vermögenswerte nicht berührt ${ }^{709}$. Ist das capital im Extremfall auf Null redu-

702 Vgl. Klang v. Smith's Food \& Drug Centers, Inc., 702 A.2d 150 (Del.Supr.1997), hier S. 152. Dieser Grundsatz findet sich bereits in Morris v. Standard Gas \& Electric Co., 31 Del.Ch. 20, 63 A.2d 577 (1949). Das Fallrecht Delawares führt daher hinsichtlich der Rechnungslegung zu demselben Ergebnis wie $\S 6.40($ d) MBCA. Vgl. so auch Bainbridge (2002), S. 779.

Der Delaware Supreme Court kommt zu demselben Ergebnis wie der Supreme Court von New York in der bereits in den 1940er Jahren ergangenen, in der Fachwelt stark beachteten Entscheidung Randall v. Bailey, 23 N.Y.S.2d 173 (N.Y.Sup.1940), aff'd, 288 N.Y. 280, 43 N.E.2d 43 (1942). Eine in New York gegründete Gesellschaft hatte eine Immobilie mit einem Buchwert von 1,5 Mio. US-\$ auf einen Wert von 8,7 Mio. US$\$$ zugeschrieben und aus dem resultierenden revaluation surplus eine Dividende in Höhe von 3,7 Mio. US-\$ ausgeschüttet. Das Gericht hielt Zuschreibungen zu diesem Zweck für zulässig und stützte seine Ansicht zum Teil auf die Formulierung im damals gültigen Kapitalgesellschaftsrecht von New York, nach dem Dividenden lediglich das Grundkapital nicht vermindern durften. Vgl. dazu auch Clark (1986), S. 618-619; Bauer (1995), S. 220; Eisenberg (2000), S. 1255-1256; Hamilton (2000), S. 586.

Vgl. Kahn v. United States Sugar Corp., No. 7313 (Del. Ch. Dec. 10, 1985); Black \& Decker Corp. v. American Standard, Inc., 682 F. Supp. 772, 778 (D. Del. 1988); Southdown, Inc. v. Moore McCormack Resources, Inc., 686 F. Supp. 595, 599 (S.D. Tex. 1988). In Farland v. Wills, 1 Del. J. Corp. L. 467, 1975 WL 1960 (Del. Ch. 1975), S. 476, vertritt das Gericht die Auffassung, dass die Unternehmensleitung die Vermögenswerte zum aktuellen Marktwert anzusetzen hat.

Vgl. auch Bauer (1995), S. 224, der darauf hinweist, dass „das Nennkapital oft ohnehin so niedrig (ist), daß es nicht mehr viel herabzusetzen gibt." 
ziert worden, kann die Gesellschaft so lange Dividenden zahlen, wie die Vermögenswerte die Schulden zumindest decken.

Durch die Kapitalherabsetzung vermindert sich das capital um einen bestimmten Betrag. Gleichzeitig erhöht sich das surplus um denselben Betrag. Nach $\S 244(a)(1)$ bis (4) Del.GCL werden verschiedene Fallkonstellationen unterschieden ${ }^{710}$. So kann das capital z.B. dadurch verringert werden, dass ausgegebene Aktien eingezogen werden ( $\$ 244(\mathrm{a})(1)$ Del.GCL). Weiterhin können Aktien mit hohem Nennwert in solche mit niedrigem oder ohne Nennwert umgewandelt werden, sofern noch nicht ausgegebene Aktien vorhanden sind und zusätzlich ein Ermächtigungsbeschluss der Hauptversammlung zur Umwandlung der Aktien vorliegt $(\S 244(a)(3)$ Del.GCL). Darüber hinaus können gemäß $\S 244(a)(4)$ Del.GCL Beträge vom capital zum surplus transferiert werden. Dazu gehören beispielsweise der Teil des capital, der die Summe der Aktiennennwerte übersteigt, sowie der komplette im capital ausgewiesene Anteil des Verkaufserlöses der nennwertlosen Aktien.

Eine weitere Möglichkeit, das capital zu verringern, eröffnet $\S 242(a)(3)$ Del.GCL. Durch eine Satzungsänderung können die Nennwerte der Aktien herabgesetzt und Nennwertaktien in nennwertlose Aktien umgewandelt werden. Einem entsprechenden Beschluss des board of directors müssen aber die Aktionäre entweder auf einer außerordentlichen oder auf der nächsten regulären Hauptversammlung mehrheitlich zustimmen (§ 242(b)(1) Del.GCL). Ebenfalls im Wege einer Satzungsänderung kann die Zahlung von in Rückstand geratenen Vorzugsdividenden vermieden werden, indem das in der Satzung verankerte Recht der Vorzugsaktionäre auf Vorzugsdividende eliminiert wird $(\$ 242(\mathrm{a})(4) \text { Del.GCL })^{711}$.

\subsection{Net Profits Test (Nimble Dividends)}

Die bisherigen Ausführungen haben gezeigt, dass die gesellschaftsrechtliche Ausschüttungsregulierung Delawares dem Management vielfältige Möglichkeiten bietet, ein surplus zu kreieren, aus dem Dividenden gezahlt werden können. Darüber hinaus kann die bei der Aktienausgabe von den Aktionären gezahlte Gegenleistung im Extremfall in voller Höhe als surplus ausgewiesen werden, so dass das investierte Kapital durch Dividendenausschüttungen an die Aktionäre auf legale Weise zurückfließen kann. Dennoch existiert in Delaware neben dem surplus test noch ein weiteres alternatives Testverfahren. Nach $\S 170(a)(2)$ Del.GCL können Gewinne (net profits) des aktuellen und vorhergehenden Geschäftsjahrs als Dividende ausgeschüttet werden, selbst wenn kein surplus besteht ${ }^{712}$. Delaware war 1927 der erste Bundes-

\footnotetext{
710 Vgl. dazu Black (2004), § 2.26-30.

711 Vgl. dazu sowie zur alternativ zulässigen Vermeidungsstrategie durch Unternehmenszusammenschluss und anschließender Umwandlung von Vorzugs- in Stammaktien ausfürlich Black (2004), § 5.6-8.

712 „The directors (...) may declare and pay dividends (...) in case there shall be no such surplus, out of its net profits for the fiscal year in which the dividend is declared and/or the preceding fiscal year."Zur Kritik an dem mangelhaften Sprachstil und den zahlreichen unpräzisen Formulierungen in $\S 170$ (a) Del.GCL vgl. Manning/Hanks (1990), S. 83-84; Black (2004), § 2.46. Im Gesellschaftsrecht Delawares werden „,net profits" nicht năher definiert. Zur diesbezüglichen Rechtsprechung vgl. Black (2004), § 2.33.
} 
staat, der solche Dividenden gesetzlich ermöglichte ${ }^{713}$. Sie werden als nimble dividends ${ }^{714}$ (,schnelle, flinke Dividenden") bezeichnet, da das Management die Ausschüttung der in der jüngeren Vergangenheit angefallenen Gewinne ${ }^{715}$ schnell beschließen muss. Anderenfalls verfällt dieses Privileg und die Gewinne müssen dazu genutzt werden, das bestehende Defizit im surplus-Konto auszugleichen oder zu reduzieren. Darüber hinaus wird es als zulässig erachtet, dass eine Gesellschaft mit positivem surplus eine Dividende ausschüttet, die über den Betrag des surplus hinaus auch die Gewinne der jüngeren Vergangenheit umfasst ${ }^{716}$.

Nach $\S 170$ (a) Del.GCL wird die Zahlung von nimble dividends allerdings durch eine Schutzvorschrift für Vorzugsaktionäre eingeschränkt. Danach dürfen nimble dividends nicht ausgeschüttet werden, wenn die Netto-Vermögenswerte niedriger sind als die Summe der Nennwerte der Vorzugsaktien bzw. das vom board bestimmte stated capital im Falle von nennwertlosen Vorzugsaktien. Sobald das Verhältnis ausgeglichen ist, sind nimble dividends wieder zulässig ${ }^{717}$. Erstaunlicherweise wird demnach als Ausschüttungsrestriktion nicht die Höhe der vorrangigen Liquidationsansprüche herangezogen ${ }^{718}$. Vorzugsaktionäre werden folglich unzureichend geschützt, wenn ihr Liquidationsanspruch größer ist als der Nennwert oder der vom Management festgelegte Wert (stated value) ihrer Aktien ${ }^{719}$.

\subsection{Sonderregeln für Wasting Asset Corporations}

Die Ausschüttungsregulierung in Delaware weist in $\S 170(\mathrm{~b})$ Del.GCL eine Besonderheit für so genannte wasting assets corporations auf ${ }^{720}$. Als wasting asset corporation werden Gesellschaften bezeichnet, deren Unternehmenszweck in dem Abbau nicht erneuerbarer Vermögenswerte (wasting assets) besteht ${ }^{721}$. Darunter fallen z.B. Unternehmen, die Kohle-, Erdöloder Erdgasvorkommen ausbeuten, sowie Kupfer- oder Goldminen. Diese auf den ersten Blick exotisch anmutende Regelung erlangt insofern große praktische Bedeutung, als nach dem Recht Delawares auch Patente zu den wasting assets zählen (§ 170(b) Del.GCL). Somit ist es zulässig, dass ein Unternehmen aufgrund von Patenten die wasting asset-Regel anwen-

713 Vgl. Weiner (1929b), S. 909; Baker/Cary (1959), S. 1229; Manning/Hanks (1990), S. 83. Nach anderen Quellen ist New Jersey 1904 der erste Staat mit einer entsprechenden gesetzlichen Vorschrift gewesen. Vgl. Kehl (1941), S. 31; Black (2004), §2.42, S. 43. Bereits davor gab es diese Möglichkeit allerdings in manchen Bundesstaaten gemäß common law. Vgl. z.B. Goodnow v. American Writing Paper, 73 N.J.Eq. 692, 69 A. 1014 (N.J.1908). Vgl. dazu ausführlich $\operatorname{Kehl}(1941)$, S. 59-64.

Dieser Begriff wird dem Harvard-Professor Ralph J. Baker zugeschrieben. Vgl. o.V. (1948), S. 130; McCormick (1949), S. 196; Baker/Cary (1959), S. 1228; Kreidmann (1957), S. 374; Zeff(1961), S. 754, Fn. 7.

715 Die Vorschrift wird daher auch als current earnings test bezeichnet. Vgl. Eisenberg (2000), S. 1257.

716 Vgl. Bainbridge (2002), S. 775, Fn. 1.

717 Black (2004), § 2.46, weist darauf hin, dass diese Bedingung unverständlicherweise nicht nach, sondern lediglich vor der Dividendenausschüttung erfullt sein muss.

718 Darauf weisen Manning/Hanks (1990), S. 83, Fn. 32; und Black (2004), § 2.46, hin. Dies ist umso verwunderlicher, als es im Gesetz von 1927 noch anders war.

719 Vgl. Black (2004), § 2.46.

720 Eine ăhnliche Regelung enthält $\S 510$ (b) N.Y.BCL. In Kalifornien wurde eine entsprechende Vorschrift ( 1503 Cal.Corp.Code) durch die Gesellschaftsrechtsreform 1977 abgeschafft.

${ }^{221}$ Vgl. Kehl (1941), S. 125; Eisenberg (2000), S. 1258; Cox/Hazen (2003), S. 1237; Black (2004), § 2.48. Zum Teil wird auch von consuming-asset corporations gesprochen. Vgl. Zeff (1961), S. 741; H. Henn/Alexander (1983), S. 897. 
det, obwohl sich seine wirtschaftlichen Tätigkeiten auch auf andere, nicht erschöpfliche Vermögenswerte erstrecken ${ }^{722}$.

Solche Gesellschaften brauchen bei der Ermittlung der net profits keine Abschreibungen aufgrund der kontinuierlichen Wertminderung ihrer Vermögenswerte (depletion) zu berücksichtigen, es sei denn, die Satzung bestimmt etwas anderes. Folglich stehen die kumulierten Abschreibungen ${ }^{723}$ für Dividendenzahlungen zur Verfügung.

Die wasting asset-Doktrin wurde Ende des 19. Jahrhunderts von Morawetz entwickelt und von englischen Gerichten angewandt ${ }^{724}$. Eine Reihe von Gerichten in den USA hielt diese Regel auch ohne gesetzliche Verankerung im Gesellschaftsrecht für anwendbar ${ }^{725}$. Der Delaware Supreme Court hingegen entschied, dass sie mit den gesetzlichen Ausschüttungsrestriktionen in Delaware nicht zu vereinbaren sei, da diese keine Ausnahmen für bestimmte Gesellschaftstypen vorsähen. Auch die bereits ergangene common law-Rechtsprechung sei nicht anwendbar. Das Gericht wies aber darauf hin, dass eine gesetzliche Regelung geschaffen werden könne ${ }^{726}$. Der Gesetzgeber reagierte auf diese Entscheidung umgehend, so dass Delaware 1927 der erste Staat war, der die wasting assets-Vorschrift ins Gesetz aufnahm ${ }^{727}$. Im US-amerikanischen Schriftum wird betont, dass die Norm ausschließlich bei der Ermittlung der net profits, nicht hingegen im Rahmen des surplus-Tests zulässig sei ${ }^{728}$.

Die Möglichkeit, das von den Aktionären eingezahlte Kapital in der Form von Dividenden ausschütten und somit vom Kapitalerhaltungsgrundsatz abweichen zu können, wird mit den besonderen Merkmalen von wasting asset-Unternehmen begründet. Ihr Gesellschaftszweck sei es, ihre Aktiva in einem definitionsgemäß begrenzten Zeitraum auszubeuten und dabei anfallende Gewinne auszuschütten. Aufgrund der begrenzten Lebensdauer solcher Gesellschaften gingen die Unternehmensbeteiligten auch nicht von der Erhaltung des capital aus ${ }^{729}$.

722 Vgl. Eisenberg (2000), S. 1258; Marsh/Finkle/Sonsini (2005), § 14.03, S. 10.

723 „Depletion“ ist gleichbedeutend mit „depreciation“. Vgl. H. Henn/Alexander (1983), S. 898, Fn. 63. In der juristischen Literatur ist der Ausdruck „depletion reserve“ weit verbreitet. Vgl. z.B. Kehl (1941), S. 128; Cox/Hazen (2003), S. 1237. Dieser Begriff wird von Maier (1986), S. 146, und Bauer (1995), S. 232, mit „Substanzverringerungsreserve“ übersetzt. Im Sprachgebrauch der Rechnungslegung ist hingegen die Bezeichnung ,accumulated depletion“ gebräuchlich. Vgl. Carpenter (1970), S. 1733, Fn. 1.

Vgl. Morawetz (1886), S. 415-417; Lee v. Neuchatel Asphalte Co., 41 Ch.Div. 1 (C.A.1889). „The origin is no doubt in the confused ideas of the English judges as to corporate capital". So Ballantine (1946), S. 586, Fn. 14; wortwörtlich auch Cox/Hazen (2003), S. 1238, Fn. 11. Vgl. zu Rechtsprechungsnachweisen Maier (1986), S. 147, Fn. 78.

726 Vgl. Wittenberg v. Federal Mining \& Smelting Co., 15 Del.Ch. 147, 133 A. 48 (1926).

727 Vgl. Kehl (1941), S. 127; Ballantine (1946), S. 585; Carpenter (1970), S. 1737; Black (2004), § 2.50.

728 Vgl. Kehl (1941), S. 128-129; Ballantine (1946), S. 586, Fn. 12: „It is absurd to speak of ,surplus' when capital is impaired“. Vgl. auch das Urteil in Petroleum Rights Corporation v. Midland Royalty Corporation, 167 Atl. 835 (1933), nach dem ein surplus nur vorliegt, wenn Abschreibungen berücksichtigt wurden. Vgl. insofern unzutreffend Bauer (1995), S. 232.

729 Morawetz (1886), S. 415-416, fuhrt zur Begründung der von ihm entwickelten Doktrin Folgendes aus: "The capital of a mining company is not designed to be used, like that of a banking or manufacturing company, in carrying on business permanently. The working of a mine necessarily causes it to become exhausted and to depreciate in value, and this depreciation cannot be repaired. There would be no object in accumulating the money obtained by the company through working the mine, so as to keep up the original amount of capital. It is implied from the character of the speculation of a mining company, that the income derived from working the mine shall be distributed among the shareholders as dividends, after deducting the expenses, and making reasonable provisions for contingencies". 
Der Grundgedanke und die Funktionsweise dieser Sonderregel sollen abschließend an einem Beispiel verdeutlicht werden ${ }^{730}$ : Ein Unternehmen gibt Aktien im Wert von $1 \mathrm{Mrd}$. US-\$ aus und erwibt mit diesem Kapital eine Diamantmine. Die Mine hat eine Nutzungsdauer von zehn Jahren. Über diesen Zeitraum wird in jedem Jahr ein Zehntel des Diamantvorkommens abgebaut. Der Restwert betrage 0 . Es werden in jeder Periode Erträge in Höhe von 180 Mio. US- $\$$ erwirtschaftet, und es fallen zahlungswirksame Aufwendungen von jeweils 30 Mio. US-\$ an. Aufgrund der linearen Abschreibung der Mine von jährlich 100 Mio. US-\$ wird in der Gewinn- und Verlustrechnung jedes Jahr ein Gewinn von 50 Mio. US-\$ ausgewiesen. Da es sich um eine wasting asset corporation handelt, braucht sie die Abschreibung in Höhe von 100 Mio. US- $\$$ bei der Ermittlung der net profits nach $\S 170(\mathrm{~b})$ Del.GCL nicht vorzunehmen; sie kann somit jedes Jahr 150 Mio. US-\$ an die Aktionäre ausschütten. Das Prinzip der Nominalkapitalerhaltung wird also durchbrochen. Gäbe es diese Regel nicht, könnte die Gesellschaft unter Beachtung des surplus test in $\S 170$ (a) Del.GCL lediglich 50 Mio. US-\$ ausschütten. Am Ende der Nutzungsdauer wäre das eingezahlte Kapital in Höhe von 1 Mrd. US-\$ erhalten, das definitionsgemäß nicht für weitere Investitionsprojekte gebraucht würde und nur durch Auflösung der Gesellschaft an die Aktionäre fließen könnte.

\subsubsection{Haftungsregeln bei unzulässigen Dividendenzahlungen}

Gemäß $§ 174(a)$ Del.GCL haften die Mitglieder des board of directors persönlich und gesamtschuldnerisch bei einem vorsätzlichen oder fahrlässigen Verstoß gegen die gesetzlichen Ausschüttungsrestriktionen ( $§ 173$ Del.GCL). Die Haftung kann in der Satzung nicht abgemildert oder ausgeschlossen werden, worauf in $\S 102($ b)(7)(iii) Del.GCL explizit hingewiesen wird, und sie verjährt erst nach sechs Jahren. Die directors haften in Höhe der unrechtmäßig gezahlten Dividende inklusive Zinsen seit dem Entstehungszeitpunkt der Verpflichtung sowohl gegenüber der Gesellschaft als auch gegenüber den Gläubigern im Falle der Unternehmensauflösung oder Insolvenz (§ 174(a) Del.GCL) ${ }^{731}$.

Ein Mitglied der Unternehmensleitung haftet dann nicht, wenn es der rechtswidrigen Dividendenzahlung nicht zugestimmt hat. § 174(a) Del.DCL schreibt vor, dass der director seine Ablehnung gegen die Dividendenentscheidung im Sitzungsprotokoll schriftlich festhalten lassen muss. Ist er auf der entsprechenden Sitzung nicht anwesend, muss er dies unmittelbar nach Kenntnisnahme des dort gefassten Dividendenbeschlusses nachholen. Eine Haftung kann ferner unter bestimmten Voraussetzungen auch dann vermieden werden, wenn das board-Mitglied einer Dividende zugestimmt hat, die sich im Nachhinein als unrechtmäßig herausstellt. Für einen Haftungsausschluss müssen zwei Bedingungen erfüllt sein $(\S 172$ Del.GCL):

- Zum einen muss sich das board-Mitglied bei seiner Dividendenentscheidung in gutgläubiger Weise auf die Jahresabschlusszahlen und sonstigen Unternehmensinformationen gestützt haben.

- Zum anderen müssen diese Unternehmensdaten von Fachleuten zusammengestellt worden sein, vorausgesetzt, die Fachleute sind mit angemessener Sorgfalt von dem Unternehmen

730 Ein ähnliches Beispiel findet sich auch bei Marsh/Finkle/Sonsini (2005), § 14.03.

731 Vgl. z.B. Pereira v. Cogan, 294 B.R. 449 (S.D. N.Y. 2003). Anspruchsberechtigt sind in Delaware nur die Gläubiger, die der corporation bereits vor der unrechtmäßigen Ausschüttung einen Kredit gewăhrt haben (prior creditors). Vgl. z.B. Johnston v. Wolf, 487 A.2d 1132 (Del. 1985). 
ausgewählt worden. Dazu zählen officers, sonstige Angestellte des Unternehmens, committees aus den Reihen des board of directors sowie sonstige Experten.

Ein director, der erfolgreich verklagt worden ist ${ }^{732}$ und der der Gesellschaft den Schaden zurückgezahlt hat, kann gegenüber den anderen board-Mitgliedern, die der unzulässigen Dividendenzahlung ebenfalls zugestimmt haben, Ausgleichsansprüche (contribution) geltend machen (§ 174(b) Del.GCL). Zudem hat er das in § 174(c) Del.GCL normierte Recht, sich gegebenenfalls bestehende Ansprüche der Gesellschaft abtreten zu lassen ${ }^{733}$. Die Gesellschaft hat einen Anspruch gegen die Aktionäre auf Rückzahlung der Dividende, wenn diese von Tatsachen wussten, die auf die Unzulässigkeit der Dividende nach den gesetzlichen Vorschriften Delawares hindeuteten. Somit können nach dem Recht Delawares auch Aktionäre haftbar gemacht werden.

Wie oben bereits erwähnt, sieht $\S 174$ Del.GCL nicht ausdrücklich vor, dass außer den directors weitere Personengruppen die Ansprüche der Gesellschaft geltend machen können ${ }^{734}$. Nach einer jüngeren Gerichtsentscheidung kann aber ein Insolvenzverwalter gegen Aktionäre einer public corporation vorgehen, die wissentlich eine unerlaubte Dividendenzahlung erhalten haben ${ }^{735}$.

\subsubsection{Kalifornien}

\subsubsection{Einleitung und Überblick}

Die kalifornischen Kapitalschutzregeln in der heutigen Form sind im Zuge einer Reform des California Corporations Code Mitte der 1970er Jahre entwickelt worden und am 01.01.1977 in Kraft getreten ${ }^{736}$. Ausgangspunkt für die Reform der Kapitalaufbringungs- und -erhaltungsregeln war die Einschätzung, dass sowohl die Gläubiger als auch die (Vorzugs-)Aktionäre durch die vorherigen Regeln nur unzureichend geschützt wurden ${ }^{737}$. Die Reformmaßnah-

732 Vgl. zu den wenigen erfolgreichen Klagen Kummert (1980), S. 394.

$733 \S 174(c)$ Del.GCL „(...) shall be entitled (...) to be subrogated to the rights of the corporation against stockholders who received the dividend on (...) their stock with knowledge of facts indicating that such dividend (...) was unlawful under this chapter (...)."

Vgl. Bainbridge (2002), S. 775-776; Black (2004), § 4.33, S. 83.

735 Vgl. In re Integra Realty Resources, Inc., 198 B.R. 352 (Bankr. D. Colo. 1996). Zu einem ăhnlichen Ergebnis kommen altere Urteile, die vor der Verabschiedung von $§ 174$ Del.GCL ergangen sind. Vgl. Wood v. National City Bank, 24 F.2d 661 (C.C.A. 2d Cir. 1928); Fried v. Cano, 167 F. Supp. 625 (S.D. N.Y. 1958). Siehe dazu auch Black (2004), § 4.33 . Die Reform wurde aber bereits am 12.09.1975 verabschiedet. Vgl. Barton (1975), S. 210.

737 Vgl. Report of Assembly Select Committee (1975), §500, abgedruckt bei Marsh/Finkle/Sonsini (2005), App. A-1 18. Zur Darstellung und Kritik der in Kalifornien bis zum 01.01.1977 gültigen Kapitalschutzregeln vgl. Dreyfuss (1976), S. 840-844. Zu den Ursprüngen der gesetzlichen Kapitalaufbringungs- und -erhaltungsregeln in Kalifornien vgl. Marsh/Finkle/Sonsini (2005), § 14.01. 
men verfolgten primär das Ziel, die Gläubiger besser zu schützen ${ }^{738}$. Es sollten Vorschriften entwickelt werden, die sicherstellen, dass die Gesellschaft auch nach einer Ausschüttung die Ansprüche der Kreditgeber erfüllen kann.

Im Rahmen der Ausschüttungsregulierung wurden die traditionellen Testverfahren ersetzt durch einen innovativen und eigenständigen $A n s a t z^{739}$, der sich in vielen Details stark von den Vorschriften des $\mathrm{MBCA}^{740}$ oder denen anderer Bundesstaaten, die dem MBCA nicht folgen $^{741}$, unterscheidet. Das kalifornische Kapitalsystem zeichnet sich durch die folgenden Hauptmerkmale aus, die im weiteren Verlauf ausführlich dargestellt werden:

- Es besteht kein Mindestkapitalerfordernis und keine Pflicht zur Ausgabe von Nennwertaktien.

- Die Anwendung der US-GAAP zur Ermittlung des Ausschüttungsbetrags ist mit wenigen Ausnahmen zwingend vorgeschrieben.

- Bei konzernverbundenen Unternehmen beziehen sich die Ausschüttungsrestriktionen auf den US-GAAP-Konzernabschluss.

- Die Ausschüttungsregeln beziehen sich mit Ausnahme von Gratisaktien auf alle Ausschüttungsvarianten (Bar- und Sachdividenden, Aktienrückkauf).

- Es ist ein equity insolvency test zu beachten, der sich durch eine Besonderheit von den herkömmlichen Insolvenztests unterscheidet.

- Es sind weitere Ausschüttungsbeschränkungen kodifiziert, welche die finanzielle Gesamtsituation des Unternehmens berücksichtigen und vergleichsweise starr ausgestaltet sind, so dass dem Management relativ geringe Ermessensspielräume und wenig Möglichkeiten für Ausweichhandlungen verbleiben.

- Ausschüttungen, die über die in vergangenen Perioden einbehaltenen Gewinne der Gesellschaft hinausgehen, sind nur möglich, wenn bestimmte Bilanzkennzahlen eingehalten werden, für die feste Grenzwerte vorgegeben sind. Die kalifornischen Ausschüttungsregeln ähneln insoweit dem Vorgehen der Insolvenzprognose ${ }^{742}$.

Die Ausschüttungsrestriktionen, die Sorgfaltspflichten der directors und die Haftungsregeln für directors und Aktionäre bei unzulässigen Dividendenzahlungen ( $\S \S 309,316,500-506)$ sind gemäß $\S 2115$ (b) Cal.Corp.Code auch von so genannten foreign corporations anzuwenden. Als foreign corporation gilt nach $\S 2115$ Cal.Corp.Code eine Gesellschaft, wenn sie erstens mehr als die Hälfte ihrer Geschăftstătigkeit in Kalifornien tătigt und zweitens mehr als die Hălfte ihrer stimmberechtigten, ausgegebenen Aktien von Einwohnern Kaliforniens gehalten werden. Von dieser Regel ausgenommen sind gemäß §2115(c) Cal.Corp.Code Gesellschaften, deren Aktien an einer nationalen Börse gehandelt werden. Vgl. dazu auch Barton (1975), S. 219-220; Marsh/Finkle/Sonsini (2005), § 26.04.

739 Ackerman/Sterrett (1976), S. 1052, sehen in der neuen Ausschüttungsregulierung „One of the most revolutionary aspects of the new California General Corporation Law“. Dreyfuss (1976), S. 863, bezeichnet sie als „substantial innovation“. Das kalifornische Recht „,became the leader of the ,new wave' of corporate dividend provisions." So Black (2004), § 3.9.

So auch die Einschătzung in MBCA Ann. (2002), § 6.40, S. 214. Unzutreffend ist die Behauptung von Wüstemann (1996), S. 424, Kalifornien habe den MBCA in den Grundzügen übernommen.

741 Soweit ersichtlich, hat bisher lediglich Alaska die kalifornischen Regeln weitgehend ubernommen. Vgl. AS 10.06.358-10.06.390. Der entscheidende Unterschied zum kalifornischen Recht besteht allerdings darin, dass in Alaska eine Bilanzierung nach US-GAAP nicht zwingend vorgeschrieben ist. Vgl. insofern ungenau Peterson/Hawker (1997), S. 195.

742 Dieser Aspekt wird insbesondere von Ben-Dror (1983), S. 376, betont. 
- Es finden sich im Kapitalgesellschaftsrecht explizite Haftungsregeln sowohl für die directors als auch für die Aktionäre.

\subsubsection{Kapitalaufbringung}

Im Rahmen der Reform des Kapitalsystems schaffte Kalifornien als erster Bundesstaat das legal capital-Konzept $\mathrm{ab}^{743}$. Zusätzlich zum gesetzlichen Mindestkapital wurde das Institut der Nennwertaktie mit der Folge aufgegeben, dass im California Corporations Code seit 1977 nicht mehr zwischen Nennwertaktien und nennwertlosen Aktien differenziert wird ${ }^{744}$. Die vor 1977 üblichen Bezeichnungen stated capital, paid-in surplus, earned surplus und reduction surplus existieren ebenfalls nicht mehr. Das Eigenkapital der Gesellschaft wird nunmehr gesellschaftsrechtlich nur noch in capital und retained earnings unterteilt. Das capital braucht nicht weiter aufgespalten zu werden ${ }^{745}$.

Den einzigen verbliebenen Hinweis auf das Nennwertsystem enthält $\S 205$ Cal.Corp.Code ${ }^{746}$. Danach gilt für alle zur Ausgabe zugelassenen Aktien (authorized shares) ein Nennwert von 1 US-\$, wenn ein Gesetz Steuerzahlungen oder Gebühren von der Kapitalausstattung der Gesellschaft abhängig macht. Kalifornien selbst legt die Anmeldegebühr für Satzungen seit 1974 unabhängig vom Nennwert fest ${ }^{747}$. Die Vorschrift trägt aber der Tatsache Rechnung, dass andere Bundesstaaten, z.B. Nevada und Virginia, Gebühren von foreign state corporations auf Basis ihres Nennwerts erheben.

Unterliegt die Gesellschaft einem speziellen Gesetz, das Aktien mit Nennwert vorschreibt, ist der Nennbetrag gemäß $\S 205$ Cal.Corp.Code vom board of directors festzulegen. So nehmen beispielsweise verschiedene Regulierungen von Versicherungsunternehmen auf Nennwertaktien Bezug. Ist in der Satzung kein Nennwert enthalten, erlaubt es diese Vorschrift den Verwaltungsmitgliedern, einen solchen ohne bürokratischen Aufwand oder Änderung der Satzung zu beschließen.

Die Gegenleistung für die Ausgabe der Aktien wird vom board of directors oder, wenn die Satzung dies vorsieht, von den Aktionären festgelegt. Einlagefähig sind gemäß $\S 409(a)(1)$ Cal.Corp.Code nicht nur Bargeld, sondern z.B. auch bereits erbrachte Dienstleistungen und immaterielle Vermögenswerte, welche die corporation oder ein 100\%iges Tochterunternehmen erhalten hat. Im Gegensatz zum MBCA sind verbriefte Geldforderungen (promissory notes) und zukünftige Dienstleistungen nicht einlagefähig.

$743 \mathrm{Vgl}$. Ackerman/Sterrett (1976), S. 1052.

744 In $\S 202$ Cal.Corp.Code, der bestimmte Angaben zu den ausgegebenen Aktien in der Satzung vorschreibt, findet sich weder ein Hinweis auf Nennwertaktien noch auf nennwertlose Aktien. Dem steht aber nicht entgegen, dass Gesellschaften freiwillig Aktien mit Nennwert ausgeben. Vgl. Marsh/Finkle/Sonsini (2005), Ch. 5, S. 48.

745 Vgl. Dreyfuss (1976), S. 846.

746 Vgl. dazu Marsh/Finkle/Sonsini (2005), Ch. 5, S. 50-51.

747 Bis 1974 wurden Aktien ohne Nennwert im Vergleich zu Aktien mit (geringem) Nennwert durch weitaus höhere Anmeldegebühren diskriminiert. Vgl. Marsh/Finkle/Sonsini (2005), Ch. 5, S. 47-48. 


\subsubsection{Kapitalerhaltung}

\subsection{Rechnungslegungsregeln}

Als einziger Bundesstaat macht Kalifornien eindeutige Vorgaben, auf welcher Basis die Testverfahren zur Festlegung der maximalen Ausschüttungshöhe durchzuführen sind ${ }^{748}$. Nach $\S 114$ Cal.Corp.Code müssen Jahresabschlüsse und alle Rechnungslegungselemente, auf die im California Corporations Code Bezug genommen wird, nach US-GAAP aufgestellt wer$\operatorname{den}^{749}$. Der Tatsache, dass sich die US-GAAP kontinuierlich fortentwickeln, wird dadurch Rechnung getragen, dass auf die jeweils gültige Fassung verwiesen wird. Daraus folgt unter anderem, dass frühere Entscheidungen übergeordneter Gerichte in identischen oder vergleichbaren Fällen nicht anwendbar sind, wenn die Gerichtsentscheidungen auf der Basis mittlerweile nicht mehr gültiger Rechnungslegungsvorschriften ergingen ${ }^{750}$.

Losgelöst von der Vorgehensweise nach US-GAAP ist aber ausnahmsweise die Bilanzierung von Tauschgeschäften in $\S 500(\mathrm{~b})(2)$ Cal.Corp.Code explizit vorgeschrieben ${ }^{751}$. Etwaige Gewinne, die beim Tausch der Vermögenswerte anfallen, dürfen nur dann den Wertansatz des erhaltenen Vermögenswerts erhöhen, wenn dieser kurzfristig liquidierbar ist. Tauscht beispielsweise ein Unternehmen eine Beteiligung an einem Softwareunternehmen mit einem Buchwert von 100.000 US-\$ und einem Marktwert von 1 Mio. US-\$ gegen eine Beteiligung an einem Automobilzulieferer, die ebenfalls einen Marktwert von 1 Mio. US- $\$$ hat, ist die neu erworbene Beteiligung nach US-GAAP mit einem Wert von 1 Mio. US- $\$$ in der Bilanz auszuweisen $^{752}$. In der Gewinn- und Verlustrechnung ist ein Ertrag von 900.000 US-\$ zu erfassen. Wird unterstellt, dass dieser eingetauschte Vermögenswert - beispielsweise mangels Börsennotierung - nicht als kurzfristig liquidierbar gilt, muss das Unternehmen die Beteili-

Vgl. Ballwieser (2001a), Vor $§ 238$, Tz. 4. Marsh/Finkle/Sonsini (2005), Ch. 14, S. 15, führen dazu aus: „However, the law has generally been unwilling to recognize that accountants are experts in accounting and lawyers and courts are not. Therefore, the statutes and the cases have created various inconsistencies between the manner in which the corporation was required to account for its business transactions by its auditors, and by the Securities and Exchange Commission with respect to all filings with it, and the determination of the same accounting items for the purpose of these restrictions on distributions."

Bereits vor der Gesellschaftsrechtsreform haben Gerichte zur Auslegung von Rechnungslegungsbegriffen im Gesetzestext die US-GAAP herangezogen. Siehe dazu z.B. UMF Systems, Inc. v. Eltra Corporation et al., 17 Cal.3d 753, 553 P.2d 225, 132 Cal.Rptr. 129 (1976). Die US-GAAP-Pflicht in Kalifornien ubersieht Schildbach (1999a), S. 424. Im Staat Alaska, in dem die kalifornischen Testverfahren weitgehend ubernommen worden sind, können gemäß AS 10.06.358(e) entweder die US-GAAP die Grundlage der Testverfahren darstellen oder andere Rechnungslegungsregeln, die „fair and reasonable in the circumstances" sind. Wendet das Unternehmen andere Rechnungslegungsregeln an, muss es gemäß AS 10.06.358(f) beweisen, dass diese Charakterisierung zutrifft, wohingegen sie für die US-GAAP unterstellt wird.

Darauf weisen Ackerman/Sterrett (1976), S. 1080, hin.

751 Darüber hinaus existiert ein Bewertungswahlrecht im Umlaufvermögen für Zwecke des liquidity test. Vgl. dazu Kapitel III.2.3.2.3.2.3.2.

752 Vgl. Accounting Principles Board Opinion No. 29 „Accounting for Nonmonetary Transactions“ (APB 29.18). Ausschlaggebend für eine Bewertung von Tauschgeschäften zum fair value nach US-GAAP ist, dass es sich um nicht gleichartige Vermögenswerte handelt. Vgl. dazu auch KPMG (2003), S. 29. 
gung für Ausschüttungszwecke auf 100.000 US-\$ abschreiben und insofern von den USGAAP abweichen ${ }^{753}$.

Der ursprüngliche Gesetzestext sah darüber hinaus noch vor, dass die Bewertung der Vermögenswerte grundsätzlich nicht zu einem Ausweis von unrealisierten Gewinnen führen dür$\mathrm{fe}^{754}$. Diese Vorschrift widersprach in Einzelfällen den US-GAAP und war im Gesetzgebungsverfahren heftig umstritten ${ }^{755}$. Eine Ausnahme war allerdings für verkehrsfähige Wertpapiere (readily marketable securities) vorgesehen, die zum aktuellen Marktwert bewertet werden konnten ${ }^{756}$. Die Passage wurde aus $\S 500($ b)(2) Cal.Corp.Code bereits im Jahre 1977 gestrichen $^{757}$. Seitdem kommt es zu einem Ausweis unrealisierter Gewinne unter den nach US-GAAP geregelten Voraussetzungen. In ihrer aktuellen Fassung können die US-amerikanischen Rechnungslegungsvorschriften z.B. bei der Bilanzierung von bestimmten Wertpapieren des Umlaufvermögens (SFAS 115), Fremdwährungsforderungen und -verbindlichkeiten (SFAS 52) und Derivaten (SFAS 133) zu einem Ansatz der Vermögenswerte über die historischen Anschaffungs- oder Herstellungskosten und damit zum Ausweis unrealisierter Gewinne führen $^{758}$.

Nicht zur Rechnungslegung nach US-GAAP verpflichtet sind gemäß $§ 1501$ i.V.m. $§ 605$ Cal.Corp.Code solche Gesellschaften, die weniger als 100 Aktionäre haben. Sie müssen lediglich die Vermögenswerte und Schulden, Gewinne und Verluste der Gesellschaft darstellen und die dazu benutzten Bilanzierungsvorschriften offen legen. Diejenigen, die sich im Gesetzgebungsverfahren für die generelle Freistellung der so genannten small corporations von der US-GAAP-Pflicht aussprachen, konnten sich hingegen nicht durchsetzen ${ }^{759}$.

Eine weitere zentrale Besonderheit des kalifornischen Rechts besteht darin, dass sich die Ausschüttungsrestriktionen bei Unternehmen, die Tochterunternehmen halten, auf den Konzernabschluss nach US-GAAP beziehen $(\S 114 \text { Cal.Corp.Code })^{760}$. Gemäß $§ 189(\mathrm{a})$ Cal.Corp.Code wird eine Gesellschaft als Tochtergesellschaft bezeichnet, wenn mehr als $50 \%$ ihrer Stimmrechte (voting power) von einer anderen Gesellschaft direkt oder indirekt

753 So auch Marsh/Finkle/Sonsini (2005), Ch. 14, S. 33-34, die darauf hinweisen, dass bislang keine Rechtsprechung zur Frage, welche Vermögenswerte unter „currently realizable in cash" zu subsumieren sind, existiert.

$\S 500(b)(2)$ Cal.Corp.Code beinhaltete folgenden Einschub:,(...) provided, however, that in determining the amount of the assets of the corporation no appreciation in value not yet realized shall in any event be included, except with respect to readily marketable securities, (...)“. Abgedruckt z.B. bei Dreyfuss (1976), S. 849, Fn. 54. Dies führte zu der wenig plausiblen Konstellation, dass angefallene Gewinne beim Barkauf von Anlagevermögen nicht ausgewiesen werden konnten, wohl aber Gewinne bei Tauschgeschäften unter der oben genannten Voraussetzung, vgl. Ackerman/Sterrett (1976), S. 1066.

Vgl. dazu Ackerman/Sterrett (1976), S. 1064-1065 m.w.N.

Dies wiederum widersprach den damals gültigen US-GAAP. Vgl. dazu und zur problematischen Abgrenzung dieser Wertpapiere Ackerman/Sterrett (1976), S. 1064-1065.

Vgl. Deering's (2004), Ch. 5, § 500; Marsh/Finkle/Sonsini (2005), App. A-119. Dies übersehen Roberts/ Samson/Dugan (1990), S. 43; Bauer (1995), S. 328; Leuz/Deller/Stubenrath (1998), S. 114.

758 Vgl. KPMG (2003), S. 27.

759 Vgl. Marsh/Finkle/Sonsini (2005), Ch. 14, S. 18.

760 Darin wird ein bedeutender Unterschied zur alten Rechtslage in Kalifornien gesehen. Vgl. Barton (1975), S. 213. Auf diesen zentralen Punkt geht Kahle (2002b), S. 155-157, bei seiner kurzen Darstellung der kalifornischen Ausschüttungsregulierung nicht ein. 
über eine oder mehrere Tochtergesellschaften gehalten werden. Voting power wiederum ist in $\S 194.5$ Cal.Corp.Code definiert als das Recht, die directors zu wählen ${ }^{761}$.

Ein Mutter-Tochter-Verhältnis im Sinne des kalifornischen Gesellschaftsrechts führt aber nicht notwendigerweise zur Konzernrechnungslegungspflicht nach US-GAAP. Ausnahmen von der Konsolidierungspflicht bestehen, wenn die tatsächliche Kontrolle nicht beim Mutterunternehmen liegt, weil das Unternehmen beispielsweise Zahlungsbeschränkungen oder sonstigen staatlichen Restriktionen unterliegt ${ }^{762}$. Die Vorschriften zum Konsolidierungskreis nach US-GAAP werden in solchen Zweifelsfällen als maßgeblich erachtet ${ }^{763}$. $\$ 166$ Cal.Corp.Code schreibt vor, dass die Ausschüttungsrestriktionen für jede einzelne Gesellschaft greifen ${ }^{764}$. Das bedeutet, dass in einem mehrstufigen Konzern die Ausschüttungsregeln bei der Konzernmutter auf den Konzernabschluss anzuwenden sind. Bei einem Mutterunternehmen eines Teilkonzerns beziehen sie sich auf den Teilkonzernabschluss. Auf der untersten Stufe der Konzernhierarchie stehende Tochterunternehmen schließlich wenden die Regeln auf Basis ihres Einzelabschlusses an. Erfüllen solche Tochterunternehmen die Voraussetzungen des Cal.Corp.Code, können sie demnach eine Dividende ausschütten, selbst wenn ihr Mutterunternehmen zahlungsunfähig ist ${ }^{765}$.

Die Bedeutung der Rechnungslegung nach US-GAAP kommt auch in der Wortwahl des California Corporations Code zum Ausdruck. Konsequent werden Fachbegriffe der US-Rechnungslegung verwendet, deren Bedeutungen vergleichsweise feststehen. Die verschiedenen, vor der Reform auch im kalifornischen Gesellschaftsrecht verwendeten surplus-Konten wurden abgeschafft ${ }^{766}$. Die Bezeichnung earned surplus wurde durch den nach US-GAAP festgelegten Begriff retained earnings ersetz ${ }^{767}$.

\subsection{Ausschüttungsrestriktionen}

Die Ausschüttungsregeln sind im fünften Kapitel des Cal.Corp.Code kodifiziert ( $\S \S 500-511$ Cal.Corp.Code). Im Gegensatz zum alten Recht sind diese Vorschriften gemäß $\S 500$ Cal.Corp.Code auf jede Ausschüttungsform anzuwenden ${ }^{768}$. Diese Aussage wird in $\S 166$

Vgl. dazu ausfuhrlich Marsh/Finkle/Sonsini (2005), Ch. 14, S. 41-42.

Vgl. zum Konsolidierungskreis nach US-GAAP ausfuhrlich Sürken (1999), S. 54-57; Niehus/Thyll (2000), S. 30-45.

Vgl. Dreyfuss (1976), S. 847.

Vgl. Ackerman/Sterrett (1976), S. 1082; Marsh/Finkle/Sonsini (2005), Ch. 14, S. 40.

Vgl. Ackerman/Sterrett (1976), S. 1082.

Vgl. Anderson (1976), S. 650.

Nach US-GAAP stellen die retained earnings einbehaltene Gewinne dar, die losgelöst von satzungsmäßigen, vertraglichen oder gesetzlichen Bestimmungen für Ausschüttungen an die Aktionäre zur Verfügung stehen. Im Gegensatz zum HGB geben die US-GAAP keine bestimmten Gliederungsvorschriften fur die retained earnings und die sonstigen Eigenkapitalpositionen vor. Börsennotierte Unternehmen haben bestimmte Mindestangaben nach SEC Regulation S-X Rule 5-02 zu beachten. Vgl. dazu z.B. Förschle/Holland/ Kroner (2001), S. 31-33; KPMG (2003), S. 130-132; Kieso/Weygandt/Warfield (2004), S. 144-145, 182, 747-748.

768 Die besonderen Ausnahmen von den Ausschüttungsregeln für regulated investment companies, real estate investment trusts und registered open-end investment companies gemäß $\S 504 \mathrm{Cal}$.Corp.Code werden nicht dargestellt. Vgl. dazu ausfuhrlich Marsh/Finkle/Sonsini (2005), §14.15. Nach § 508 Cal.Corp.Code sind die Vorschriften des funften Kapitels nicht auf Gesellschaften anzuwenden, die sich in Auflösung befinden. 
Cal.Corp.Code konkretisiert. Danach ist unter einer Ausschüttung die Übertragung von Geld oder von sonstigen Vermögenswerten von der Gesellschaft auf ihre Aktionäre in der Form von Dividenden oder Aktienrückkäufen zu verstehen. Unter diese Definition fallen auch Vermögensübertragungen und Aktienrückkäufe durch Tochtergesellschaften. Explizit ausgeschlossen sind hingegen Gratisaktien (dividend in shares) ${ }^{769}$.

Entscheidend für die Anwendung von $\S 166$ Cal.Corp.Code ist, dass es sich um eine Transaktion handelt, durch die das Unternehmen Vermögenswerte hergibt, ohne dafür eine äquivalente Gegenleistung zu erhalten. Gerichte werden daher anhand von wirtschaftlichen Kriterien prüfen, ob im Zweifelsfall eine Ausschüttung vorliegt oder nicht. Folglich können auch angebliche Gehaltszahlungen an einen Anteilseigner der Ausschüttungsregulierung unterliegen, wenn dieser keine Dienstleistungen für die Gesellschaft erbringt ${ }^{770}$.

Grob skizziert knüpft das kalifornische Recht folgende Bedingungen an eine legale Dividendenausschüttung:

- Grundvoraussetzung ist, dass die Gesellschaft sowohl zum Zeitpunkt der Ausschüttung als auch im Anschluss daran solvent sein muss ( $\$ 501$ Cal.Corp.Code).

- Eine Dividende kann dann einerseits aus den retained earnings gezahlt werden ( $\$ 500(\mathrm{a})$ Cal.Corp.Code).

- Sie ist andererseits auch über die retained earnings hinaus zulässig, wenn bestimmte Bilanztests kumulativ erfüllt werden $(\S 500(b)$ Cal.Corp.Code).

\subsection{Equity Insolvency Test}

Der equity insolvency test ${ }^{771}$ des kalifornischen Kapitalgesellschaftsrechts ist in $\S 501$ Cal.Corp.Code wie folgt geregelt: „Neither a corporation nor any of its subsidiaries shall make any distribution to the corporation's shareholders (...) if the corporation or the subsidiary making the distribution is, or as a result thereof would be, likely to be unable to meet its liabilities (except those whose payment is otherwise adequately provided for) as they mature."

Auch in Kalifornien ist demnach zwingende Voraussetzung für eine Ausschüttung, dass die Gesellschaft solvent ist und auch nach der geplanten Dividendenzahlung solvent bleibt ${ }^{772}$. Eine Besonderheit des $\S 501$ Cal.Corp.Code besteht darin, dass Konzernbeziehungen explizit geregelt werden: Auch Tochterunternehmen müssen die Solvenzprüfung bestehen und können

769 Marsh/Finkle/Sonsini (2005), Ch. 14, S. 13, weisen zutreffend darauf hin, dass genau genommen diese Einschränkung überflüssig ist, da eine Ausschuttung in Form von zusätzlichen Aktien keine Übertragung von Vermögenswerten darstellt, sondern lediglich das bestehende Eigenkapital auf eine größere Anzahl von Aktien verteilt.

770 Vgl. Marsh/Finkle/Sonsini (2005), Ch. 14, S. 12-13.

771 Vgl. zu dieser Bezeichnung z.B. Ackerman/Sterrett (1976), S. 1057; Black (2004), § 3.10. Gesellschaften, die überschuldet sind, dürfen ebenfalls keine Dividenden zahlen, da sie - wie noch gezeigt wird - die Voraussetzungen gemäß $\S 500$ Cal.Corp.Code nicht erfüllen. Vgl. dazu Dreyfuss (1976), S. 854-855; Ben-Dror (1983), S. 376. Die ubergeordnete Bedeutung dieses Testverfahrens betonen Ballantine/Sterling (2004), Ch. 8, § 141.03[3], und bezeichnen es als overriding solvency test.

772 Es kommt dabei auf die Solvenz der Gesellschaft unmittelbar nach der Ausschüttung an. In dem Fall In re Tufts Electronics, Inc., 746 F.2d 915 (1st Cir. 1984) entschied das Gericht, dass die Insolvenz $11 \frac{1}{2}$ Jahre nach der Ausschüttung keinen Verstoß gegen den Insolvenztest von Massachusetts darstellt. 
folglich keine Dividenden an ihr Mutterunternehmen ausschütten, wenn sie dadurch insolvent würden. Durch die Formulierung ,likely to be unable to meet its liabilities“ stellt die kalifornische Regelung im Vergleich zum Testverfahren des MBCA eine Verschärfung dar, indem Dividenden bereits dann ausgeschlossen sind, wenn die Gesellschaft dadurch wahrscheinlich nicht in der Lage wäre, ihre Verbindlichkeiten bei Fälligkeit zu begleichen ${ }^{773}$.

Der kalifornische Solvenztest unterscheidet sich von dem des Modellgesetzes weiterhin dadurch, dass Ausschüttungen ausnahmsweise auch dann zulässig sind, wenn die Gesellschaft zwar aus eigenen Mitteln ihre Zahlungsverpflichtungen bei Fälligkeit nicht begleichen kann, die Zahlung aber anderweitig hinreichend sichergestellt ist. Der Klammerausdruck in $\S 501$ Cal.Corp.Code stellt offensichtlich darauf ab, dass Gläubiger, deren Ansprüche gesichert sind, nicht gegen Ausschüttungen der Gesellschaft an die Aktionäre vorgehen können. Die Vorschrift wird allerdings dahingehend kritisiert, dass Ausschüttungen in den Fällen, in denen nicht alle Verbindlichkeiten gesichert sind, die Wahrscheinlichkeit der Erfüllung der ungesicherten Gläubigeransprüche senkt ${ }^{774}$.

$\S 501$ Cal.Corp.Code selbst enthält keine Hinweise, was unter ,adequately provided for" zu verstehen ist. Eine Erläuterung ergibt sich aber aus § 2005 Cal.Corp.Code, der zur Auslegung von $\S 501$ Cal.Corp.Code herangezogen werden kann $^{775}$. Im Kern besagt diese Vorschrift, dass die Zahlung in zwei Situationen als ,adequately provided for“ gilt. Dies ist einerseits der Fall, wenn die Zahlung von einer dafür verantwortlichen Gesellschaft bzw. Person oder von der US-amerikanischen Regierung garantiert worden ist und die Höhe der garantierten Verpflichtung vom board of directors in gutgläubiger Weise und mit angemessener Sorgfalt bestimmt worden ist. Die Vorschrift ist andererseits erfüllt, wenn diese Beträge beim California State Treasurer oder einem Kreditinstitut hinterlegt sind. In der Literatur wird zudem die Auffassung vertreten, dass Ausschüttungen nach $\S 501$ Cal.Corp.Code zulässig sind, wenn die Stellung der Gläubiger nicht beeinträchtigt wird ${ }^{776}$. Danach könnte ein Unternehmen z.B. eine Dividende ausschütten, wenn sein übergeordnetes Mutterunternehmen die Zahlung der Verbindlichkeiten garantiert hat. Nach Auffassung der Rechtsprechung fallen unter ,adequately provided for" nicht nur Garantien, sondern auch Verbindlichkeiten, die durch eine Hypothek oder eine Verpfändung gesichert sind ${ }^{777}$.

\subsection{Retained Earnings Test}

Erfüllt die Gesellschaft den Insolvenztest, kann sie Dividenden grundsätzlich immer dann zahlen, wenn unmittelbar vor der Ausschüttung die retained earnings dem Betrag der vorgeschlagenen Dividende entsprechen oder ihn überschreiten ( $\$ 500$ (a) Cal.Corp.Code). Diese Ausschüttungsrestriktion wird als retained earnings test bezeichnet ${ }^{778}$. Die retained earnings

Vgl. Black (2004), § 3.10, S. 15. Die Formulierung führt dazu, dass den directors bei der Durchführung des Testverfahrens ein Ermessensspielraum eingeräumt wird. Vgl. Anderson (1976), S. 658.

774 Vgl. Marsh/Finkle/Sonsini (2005), § 14.13, S. 44.

775 So Ballantine/Sterling (2004), § 141.03[3].

776 Vgl. Ackerman/Sterrett (1976), S. 1059.

777 Vgl. Flynn v. California Casket Co., 105 Cal.App.2d 196, 233 P.2d 131 (1951), hier S. 206

778 Vgl. Ackerman/Sterrett (1976), S. 1063; Ballantine/Sterling (2004), Ch. 8, § 141.03[2][b]; Black (2004), $\S 3.11$.
} 
umfassen die Summe der in der Vergangenheit einbehaltenen und zwischenzeitlich nicht ausgeschütteten Gewinne.

Die Ausschüttungsrestriktion ist im Vergleich zu Gesetzen, die anstelle dessen Dividendenzahlungen aus dem earned surplus zulassen, weitaus strenger ${ }^{779}$. Im Gegensatz zur alten Rechtslage können Gesellschaften keine Dividenden aus dem paid-in surplus oder reduction surplus $^{780}$ ausschütten. Zudem kann ein Defizit im earned surplus nicht durch Beträge im paid-in surplus oder reduction surplus ausgeglichen werden ${ }^{781}$. Bei isolierter Betrachtung des retained earnings test muss die Gesellschaft negative retained earnings zunächst durch operative Gewinne ausgleichen. Erst wenn die retained earnings wieder positiv sind, stehen sie für Dividendenzahlungen zur Verfügung. Die folgenden Ausführungen werden aber noch zeigen, dass unter bestimmten Voraussetzungen Beträge ausgeschüttet werden können, obwohl keine oder sogar negative retained earnings vorliegen ${ }^{782}$. Verboten sind hingegen nach aktuellem kalifornischen Recht nimble dividends, die vor der Reform in Kalifornien aus dem Gewinn des letzten Geschäftsjahrs bestritten werden konnten. Ebenso existieren die geringeren Ausschüttungsrestriktionen für so genannte wasting asset corporations nicht mehr $^{783}$. Schließlich stellt das von den Aktionären eingezahlte Kapital in voller Höhe capital dar, das nicht auf andere Konten transferiert und grundsätzlich auch nicht verringert werden kann.

Bei Sachausschüttungen bestimmt sich deren Höhe nach dem Wert der jeweiligen Vermögenswerte auf Basis der US-GAAP-Bilanz (§ 500(c) Cal.Corp.Code). Hat das Management beispielsweise beschlossen, Vermögenswerte mit einem aktuellen Marktwert von 1 Mio. US$\$$ und einem Buchwert von 200.000 US-\$ auszuschütten, brauchen die retained earnings folglich nur mindestens 200.000 US- $\$$ zu betragen ${ }^{784}$.

\subsection{Balance Sheet Tests}

Existieren keine retained earnings oder übersteigt die vorgeschlagene Dividende die retained earnings, kann eine Dividendenausschüttung nur durchgeführt werden, wenn die beiden in $\S 500(\mathrm{~b})(1)$ und (2) Cal.Corp.Code kodifizierten Bilanztests - quantitative solvency test und

779 Vgl. zu dieser Einschătzung auch Bauer (1995), S. 326. Die Unterschiede zwischen earned surplus und retained earnings sind daher gerade nicht nur terminologischer Natur, wie Ben-Dror (1983), S. 383, Fn. 47, behauptet. Vgl. im Folgenden zu den materiellen Unterschieden ausführlich Ackerman/Sterrett (1976), S. 1061-1063. Vgl. ferner Black (2004), § 3.11.

780 Zur Definition dieser Eigenkapitalpositionen vgl. Kapitel III.2.2.1.1.

781 Ackerman/Sterrett (1976), S. 1062, weisen darauf hin, dass der Cal.Corp.Code offen lässt, wie die Unternehmen beim Übergang auf das neue Recht diese Beträge zu behandeln haben. Sie plädieren dafür, dass die Gesellschaften ihre Jahresabschlüsse anpassen und diese Beträge als capital ausweisen müssen.

782 Auf den ersten Blick daher missverstăndlich Bauer (1995), S. 326. Vgl. hingegen die präzise Darstellung der Rechtslage bei Marsh/Finkle/Sonsini (2005), Ch. 14, S. 28.

783 „Because these doctrines relating to ,nimble dividends' and to ,wasting assets' were even more irrational than the basic prohibitions, they have been discarded in the 1977 Law along with these prohibitions." So Marsh/Finkle/Sonsini (2005), Ch. 14, S. 10.

784 Vgl. auch Dreyfuss (1976), S. 850; Black (2004), §3.13. 
liquidity test ${ }^{785}$ - kumulativ erfüllt werden. Zudem müssen die Aktionäre gemäß $§ 507$ Cal.Corp.Code darauf hingewiesen werden, wenn die Dividendenausschüttung aus einer anderen Quelle als den retained earnings bestritten wird. Die Mitteilung hat zusammen mit der Ausschüttung oder innerhalb von drei Monaten nach Ende des Geschäftsjahrs zu erfolgen und muss die bilanzielle Auswirkung erläutern ${ }^{786}$.

\subsection{1 Quantitative Solvency Test}

Der quantitative solvency test bestimmt, dass nach einer Ausschüttung die Summe der Vermögenswerte mindestens $125 \%$ der Schulden ausmachen muss ( $\$ 500(\mathrm{~b})(1)$ Cal.Corp.Code). Folglich muss die Gesellschaft nach der Ausschüttung eine Eigenkapitalquote von mindestens $20 \%$ aufweisen $^{787}$. Wie bereits erläutert, sind für die Ermittlung der Bilanzpositionen grundsätzlich die Ansatz-, Bewertungs- und (bei konzernverbundenen Unternehmen) Konsolidierungsregeln nach US-GAAP zu befolgen. Das kalifornische Gesellschaftsrecht sieht allerdings eine Reihe von zwingend zu beachtenden Ausnahmen von den US-GAAP vor.

Von der Summe der Vermögenswerte sind der goodwill, die capitalized research and development expenses und die deferred charges abzuziehen. Hinsichtlich der capitalized research and development expenses (Forschungs- und Entwicklungskosten) ist allerdings anzumerken, dass sie nach SFAS 2.12 grundsätzlich sowieso als Aufwand der laufenden Periode zu behandeln sind. Eine Ausnahme vom generellen Verbot der Aktivierung von selbsterstellten immateriellen Vermögenswerten besteht für Auszahlungen für Softwareprodukte ab dem Zeitpunkt ihrer so genannten technischen Ausführbarkeit (technical feasibility) nach SFAS $86^{788}$. Deferred charges sind Auszahlungen, die ihren Nutzen in Perioden nach dem Bilanzstichtag entfalten und keine Vorauszahlungen darstellen. Sie fallen unter die asset-Definition nach USGAAP und entsprechen im Wesentlichen den aktiven Rechnungsabgrenzungsposten nach $\mathrm{HGB}^{789}$.

Von den Schulden sind die deferred taxes, das deferred income und other deferred credits zum Abzug zu bringen. Deferred taxes sind passive latente Steuern, die aus Differenzen zwischen dem steuerlichen Wertansatz eines Vermögenswerts oder einer Schuld und den im Abschluss

785 Die Begriffe finden sich nicht im Gesetz, sondern gehen auf Barton (1975), S. 212, zurück. Vgl. auch Ackerman/Sterrett (1976), S. 1063; Ben-Dror (1983), S. 385. Ben-Dror (1983), S. 376, bezeichnet die Testverfahren auch als total und current ratio test und Black (2004), § 3.12, als asset/liabilities test. Marsh/ Finkle/Sonsini (2005), $§ 14.09$, fassen beide Verfahren unter dem Begriff asset-liability ratio tests zusammen. Ballantine/Sterling (2004), Ch. 8, § 141.03[2][c], sprechen von remaining assets test.

786 Vgl. Marsh/Finkle/Sonsini (2005), Ch. 14, S. 86.

787 Unzutreffend ist daher die Aussage von Lutter (1983), S. 174, das Eigenkapital müsse ,an der Bilanzsumme mehr als 1/4 betragen“. Vgl. ebenfalls unrichtig Bauer (1995), S. 329; Watrin (2001a), S. 189. Wie die Ausführungen zum retained earnings test gezeigt haben, kann die corporation vielmehr eine Ausschüttung in Höhe der retained earnings vornehmen, ohne eine bestimmte Eigenkapitalquote einhalten zu müssen. Eine Eigenkapitalquote von $20 \%$ ist nur dann vorgeschrieben, wenn die Gesellschaft mehr als die retained earnings ausschütten möchte.

Zur Bilanzierung selbsterstellter immaterieller Vermögenswerte nach US-GAAP vgl. Fülbier/Honold/Klar (2000), S. 835-836; Pellens (2001a), S. 178-182; Kieso/Weygandt/Warfield (2004), S. 584-590.

Vgl. Haller (1994), S. 291-292; KPMG (2003), S. 21, 35, 44. 
bilanzierten Werten resultieren und zu künftigen Steuermehrbelastungen führen ${ }^{790}$. Beim deferred income handelt es sich um Vorauszahlungen der Kunden vor Erbringung der Leistung des bilanzierenden Unternehmens ${ }^{791}$. Other deferred credits bezeichnen schließlich andere Abgrenzungsposten für Auszahlungen, die erst in späteren Perioden anfallen, wirtschaftlich aber dem aktuellen Geschäftsjahr zuzurechnen sind. Sie sind unter den liability-Begriff nach US-GAAP zu subsumieren und entsprechen weitestgehend den passiven Rechnungsabgrenzungsposten nach $\mathrm{HGB}^{792}$.

Die Abweichungen von US-GAAP auf der Aktivseite der Bilanz werden damit begründet ${ }^{793}$, dass sich der Bilanztest nur auf solche Vermögenswerte beziehen solle, mit denen die Gesellschaft im fiktiven Liquidationsfall am Tag der Ausschüttung mit hoher Wahrscheinlichkeit einen Liquidationserlös realisieren kann. Es wird argumentiert, dass die genannten immateriellen Vermögenswerte und Abgrenzungsposten im Zeitpunkt der Auflösung einer Gesellschaft keinen Wert darstellten und abgeschrieben werden müssten. Bei den Abweichungen auf der Passivseite der Bilanz wird angeführt, die Abgrenzungsposten stellten den Liquidationswert falsch dar. Auch diese Positionen erschienen in der Bilanz auschließlich aus Gründen der periodengerechten Erfolgsermittlung und nicht, weil sie eine unmittelbare zukünftige Zahlungsverpflichtung darstellten ${ }^{794}$.

\subsection{2 Liquidity Test}

Der liquidity test als zweiter Bilanztest schreibt vor, dass im Anschluss an die Dividendenausschüttung das Umlaufvermögen die kurzfristigen Verbindlichkeiten mindestens decken muss $(\S 500(\mathrm{~b})(2) \text { Cal.Corp.Code })^{795}$. Die Anforderungen an eine Dividendenausschüttung erhöhen sich, wenn die Gesellschaft im Durchschnitt der vorangegangenen beiden Geschäftsjahre operative Ergebnisse vor Zinsen und Steuern erwirtschaftet hat, die geringer als die durchschnittlichen Zinsaufwendungen des Betrachtungszeitraumes sind, d.h. der Zinsdeckungsgrad $<1$ ist $^{796}$. Dann muss das Umlaufvermögen mindestens $125 \%$ der kurzfristigen Verbindlichkeiten ausmachen ${ }^{797}$.

\footnotetext{
790 Vgl. zum Konzept der latenten Steuern und ihrer Bilanzierung nach SFAS 109 z.B. Pellens (2001a), S. $254-269$.

791 Vgl. KPMG (2003), S. 38

792 Vgl. Gräfer (1992), S. 46-47; KPMG (2003), S. 81.

793 Vgl. dazu Ben-Dror (1983), S. 384; Marsh/Finkle/Sonsini (2005), Ch. 14, S. 16, 29-30.

794 Vgl. Marsh/Finkle/Sonsini (2005), Ch. 14, S. 29.

795 Der liquidity test ist gemäß $\S 500$ (b)(2) Cal.Corp.Code von solchen Unternehmen nicht anzuwenden, die ihre Vermögenswerte gemäß US-GAAP nicht in Anlage- und Umlaufvermögen unterteilen. Dies trifft beispielsweise auf Banken zu. Vgl. Marsh/Finkle/Sonsini (2005), Ch. 14, S. 34.

796 Zum Zinsdeckungsgrad bzw. zur Interest-Coverage-Ratio vgl. Coenenberg (2005), S. 1077.

797 Unzutreffend ist in diesem Zusammenhang die Behauptung von Ben-Dror (1983), S. 384, Fn. 50, die Erfüllung der quantitativen Vorgaben des liquidity test fuhre dazu, dass die Gesellschaft auch den Solvenztest bestehe. Vgl. zur Begründung bereits Kapitel III.2.2.2.1.
} 
Im Gesetzgebungsverfahren wurde die strikte Befolgung von US-GAAP hinsichtlich des liquidity test als problematisch erachtet ${ }^{798}$. Zu den kurzfristigen Verbindlichkeiten zählt nämlich nach US-GAAP auch der Teil der langfristigen Verbindlichkeiten, die innerhalb eines Jahres fällig werden ${ }^{799}$. Wahrscheinliche Einzahlungen des Unternehmens innerhalb der folgenden zwölf Monate, die aus langfristigen Kundenbeziehungen resultieren und die zur Tilgung der kurzfristigen Verbindlichkeiten erwartungsgemäß genutzt werden könnten, stellen hingegeben kein Umlaufvermögen nach US-GAAP dar ${ }^{800}$.

Vor diesem Hintergrund sieht der Cal.Corp.Code eine Ausnahme von den US-GAAP vor. Für Zwecke des liquidity test darf das Umlaufvermögen gemäß $§ 500(b)(2)$ Cal.Corp.Code um Nettobeträge erhöht werden, die von Kunden auf vertraglicher Basis erwartungsgemäß gezahlt werden ${ }^{801}$. Die genaue Höhe der Einzahlungen aus bestehenden Schuldverhältnissen ist vom board of directors für den zwölfmonatigen Zeitraum, der bei der Berechnung der kurzfristigen Verbindlichkeiten zugrunde gelegt wird, gutgläubig zu bestimmen. Die Beträge müssen auf vertraglichen Vereinbarungen basieren, in denen sich die Kunden zu festen oder regelmäßig wiederkehrenden Zahlungen während dieses Zeitraums verpflichten. Dazu zählen z.B. vereinbarte Leasingratenzahlungen. Zukünftige Kosten, die der Gesellschaft bei der Erfüllung ihres Vertragsteils voraussichtlich noch entstehen werden, sind von diesen Beträgen abzuziehen. Die erwarteten Einzahlungen sind weiterhin in angemessener Höhe zu kürzen, um dem Ausfallrisiko der Kunden Rechnung zu tragen ${ }^{802}$. Öffentliche Versorgungsbetriebe dürfen Beträge, die sie aufgrund von Dienstleistungsbeziehungen mit ihren Kunden erhalten werden, als Umlaufvermögen einstufen ${ }^{803}$.

\subsection{Zeitpunkt der Durchführung der Testverfahren}

Wie bereits erwähnt, muss die Gesellschaft die Ausschüttungsanforderungen unmittelbar vor bzw. unmittelbar nach (§500(a) bzw. $§ 500(b)$ Cal.Corp.Code) der Ausschüttung erfüllen. Das bedeutet aber nicht, dass das Unternehmen den zugrunde liegenden US-GAAP-Abschluss genau zu diesem Zeitpunkt aufstellen muss ${ }^{804}$. 166 Cal.Corp.Code legt fest, dass annahme-

798 So Dreyfuss (1976), S. 853, der als Mitglied des Committee on Corporations of the State Bar of California an der Reform des Cal.Corp.Code mitgewirkt hat. Einige der Verfasser des Cal.Corp.Code (1977) waren der Ansicht, dass beispielsweise öfentliche Versorgungsbetriebe (public utilities) oder Immobilienunternehmen (real estate) vielfach nicht in der Lage wären, das geforderte Verhăltnis von Umlaufvermögen zu kurzfristigen Verbindlichkeiten von 1:1 zu erfülen, und folglich trotz ausreichender Liquidităt keine Dividende zahlen könnten. Die beiden Industriezweige zeichnen sich dadurch aus, dass sie einen Großteil ihrer Einzahlungen aufgrund von Dauerschuldverhältnissen erzielen.

799 Vgl. Accounting Research Bulletin (ARB) 43 Ch. 3A7. Vgl. dazu auch Kieso/Weygandt/Warfield (2004), S. 620 .

800 Vgl. zu den Bestandteilen des Umlaufvermögens nach US-GAAP ausführlich Kieso/Weygandt/Warfield (2004), S. 173-177.

801 Vgl. Ackerman/Sterrett (1976), S. 1066-1067; Dreyfuss (1976), S. 853-854; Marsh/Finkle/Sonsini (2005), Ch. 14, S. 34-35.

Vgl. Ackermann/Sterrett (1976), S. 1066.

Vgl. Dreyfuss (1976), S. 853.

"(...) since it is obviously impossible to have a balance sheet available to the directors which is prepared as of the very morning on which they are meeting to consider the declaration of a dividend(...)". So Marsh/Finkle/Sonsini (2005), Ch. 14, S. 60. 
gemäß der Tag des Dividendenbeschlusses als Zeitpunkt der Ausschüttung gilt ${ }^{805}$. Die Gesellschaft muss demnach die Ausschüttungsrestriktionen am Tag der Beschlussfassung einhalten, obwohl die Ausschüttung im Normalfall erst zu einem späteren Zeitpunkt stattfindet ${ }^{806}$. In der Regel folgen der record date und der payment date in einem Zeitraum von zwei bis drei Monaten nach dem Tag der Beschlussfassung ${ }^{807}$. Börsennotierte Unternehmen müssen den record date der Börse mitteilen, damit diese den so genannten ex-dividend date festlegen kann ${ }^{808}$.

Gesetzlich festgelegt ist, dass der payment date nicht später als 60 Tage nach dem record date liegen darf $(\$ 701 \text { Cal.Corp.Code })^{809}$. Zu dem maximal zulässigen Zeitraum zwischen dem Tag des Dividendenbeschlusses und dem record date existiert keine gesetzliche Vorschrift. Legt das board of directors den record date und damit auch den payment date auf einen Tag in ferner Zukunft (z.B. zwölf Monate nach der Beschlussfassung), kann darin unter Umständen ein Verstoß gegen die Treuepflicht gesehen werden, wenn die directors im Einzelfall nicht so weit im Voraus die wirtschaftliche Lage des Unternehmens und damit die Zulässigkeit der Dividendenzahlung seriös abschätzen können ${ }^{810}$. Weiterhin kann auch ein Verstoß gegen $\S 501$ Cal.Corp.Code in Betracht kommen, wenn die Geschäftsleitung in dem Zeitraum bis zum payment date mit Verlusten rechnet, die zur Illiquidität führen. Die directors müssen somit ihre Entscheidung auf Basis des letzten Jahresabschlusses und unter Berücksichtigung der wirtschaftlichen Entwicklung der Gesellschaft seit dem Bilanzstichtag treffen ${ }^{811}$.

Fraglich ist, ob eine vom board beschlossene Dividendenzahlung rückgängig gemacht werden kann. Während ältere Gerichtsurteile zu dem Ergebnis kamen, dass die Aktionäre bereits zum Zeitpunkt der Beschlussfassung einen Dividendenanspruch erhalten ${ }^{812}$, entsteht dieses Recht nach aktuell herrschender Meinung erst am record date ${ }^{813}$. Eine rechtmäßig beschlossene Di-

Gemäß §311(f) Cal.Corp.Code kann das board of directors die Beschlussfassung grundsätzlich nicht delegieren. Ist eine bestimmte Dividendenpolitik einmal festgelegt worden, muss das board aber nicht bei jeder Quartalsdividendenzahlung einen erneuten Entscheidungsprozess durchlaufen. Vgl. dazu auch Marsh/ Finkle/Sonsini (2005), Ch. 14, S. 78-79.

Vgl. Dreyfuss (1976), S. 848.

Der record date wird vom board festgelegt, um den Kreis der Aktionäre zu bestimmen, der dividendenberechtigt ist. Der payment date ist der Tag, an dem die Gesellschaft die Dividende überweist. Ab dem exdividend date werden die Aktien ohne Dividendenrecht gehandelt. Der ex-dividend date ist in der Regel fünf Tage vor dem record date. Vgl. dazu Marsh/Finkle/Sonsini (2005), Ch. 14, S. 79-81. Ein Kăufer von Aktien hat so lange keinen Anspruch auf die Dividende, wie die Aktien bei einem Treuhänder hinterlegt sind oder die Aktien erst nach dem record date transferiert werden, es sei denn, es ist vertraglich anders vereinbart. Vgl. Richards v. Pacific Southwest Discount Corporation, 44 Cal. App.2d 551, 112 P.2d 698 (1941); Cates v. Consolidated Realty Company, 25 Cal.App. 531, 144 P. 301 (1914); Smith v. Taecker, 133 Cal.App. 351, 24 P.2d 182 (1933); MacDermot v. Hayes, 175 Cal. 95, 170 P. 616 (1917).

Ist kein record date festgelegt worden, dann gilt als record date entweder der Tag der Beschlussfassung oder der 60. Tag vor dem payment date, je nachdem welcher später ist (§ 701(b)(3) Cal.Corp.Code).

$810 \mathrm{Vgl}$. Marsh/Finkle/Sonsini (2005), Ch. 14, S. 56.

811 Vgl. Marsh/Finkle/Sonsini (2005), Ch. 14, S. 60. Bei Aktienrückkäufen und redemptions liegen in der Regel lange Zeiträume zwischen Beschlussfassung und Durchführung des Rückkaufs. § 166 Cal.Corp.Code schreibt folgerichtig vor, dass die Testverfahren zum Zeitpunkt der Durchführung erfüllt sein müssen. Vgl. dazu ausfuhrlich Marsh/Finkle/Sonsini (2005), Ch. 14, S. 57-60. Zur besonderen Problematik bei Vorliegen von vertraglichen Vereinbarungen zum Rückkauf von Aktien vgl. mit Rechtsprechungsnachweisen Marsh/ Finkle/Sonsini (2005), § 14.19.

812 Vgl. z.B. Smith v. Taecker, 133 Cal.App. 351, 24 P.2d 182 (1933); Meyers v. El Tejon Oil and Refining Co., 29 Cal.2d 184, 174 P.2d 1 (1946).

813 Vgl. Marsh/Finkle/Sonsini (2005), Ch. 14, S. 84-85. 
vidende darf aber auch dann ausgeschüttet werden, wenn die Gesellschaft nach dem Tag des Beschlusses die Testverfahren nicht mehr erfüllt ${ }^{814}$.

\subsection{Besonderheiten bei Vorzugsaktien}

Die $\S \S 502-503$ Cal.Corp.Code enthalten zwei weitere Testverfahren mit strengeren Ausschüttungsrestriktionen zum Schutz der Vorzugsaktionäre ${ }^{815}$. Hat die Gesellschaft Vorzugsaktien ausgegeben, die einen bevorrechtigten Anspruch auf den Liquidationserlös verbriefen (senior shares), ist $\S 502$ Cal.Corp.Code zu beachten. Danach können Dividenden erst dann an andere Aktiengattungen (junior shares) gezahlt werden, wenn im Anschluss daran die Vermögenswerte (abzüglich Goodwill, aktivierter Forschungs- und Entwicklungskosten und aktiver Rechnungsabgrenzungsposten) ausreichen, um nicht nur $100 \%$ der Schulden (abzüglich passiver latenter Steuern, passiver Rechnungsabgrenzungsposten und anderer Abgrenzungsposten), sondern auch die Ansprüche der Vorzugsaktionäre auf den Liquidationserlös zu decken. Die Vorschrift kann dazu führen, dass bei Vorhandensein von Vorzugsaktien keine Dividenden gezahlt werden können, obwohl die Gesellschaft retained earnings aufweist und somit die Anforderung an Dividendenausschüttungen gemäß $\S 500$ (a) Cal.Corp.Code erfüllt. Ein solcher Fall tritt beispielsweise ein, wenn das Unternehmen in seiner US-GAAP-Bilanz einen hohen Goodwill ausweist, und die Vermögenswerte im Sinne von $\S 502$ Cal.Corp.Code - also nach Abzug des Goodwill - nicht mehr $100 \%$ der (korrigierten) Schulden decken ${ }^{816}$

Existieren Vorzugsaktien, die einen kumulativen Dividendenanspruch besitzen, müssen nicht gezahlte Mindestdividenden in den Folgeperioden an die Vorzugsaktionäre nachgezahlt werden. Dividenden an Aktiengattungen ohne Vorrecht (junior shares) dürfen in solchen Fällen gemäß $\S 503$ Cal.Corp.Code erst dann ausgeschüttet werden, wenn nach der Ausschüttung die retained earnings die Summe der in Rückstand geratenen Dividenden der Vorzugsaktien (senior shares) decken. Die Gesellschaft ist somit gezwungen, finanzielle Mittel anzusammeln, um in der Zukunft die Ansprüche der Aktionäre mit kumulativem Dividendenanspruch erfüllen zu können ${ }^{817}$.

Auch in Kalifornien können in Rückstand geratene Vorzugsdividenden durch eine Satzungsänderung eliminiert werden ( $\$ 900$ (a) Cal.Corp.Code). Einer solchen Änderung muss allerdings die Mehrheit der Aktionäre inklusive der betroffenen Vorzugsaktionäre zustimmen (§ 903(a)(7) Cal.Corp.Code). Darüber hinaus können akkumulierte Vorzugsdividenden durch einen Unternehmenszusammenschluss wegfallen, wenn die Aktionäre diesem mehrheitlich zustimmen (§1101 Cal.Corp.Code). Aktionäre, die dem Zusammenschluss nicht zustimmen,

\footnotetext{
814 Vgl. Ackerman/Sterrett (1976), S. 1087.

${ }^{815}$ Marsh/Finkle/Sonsini (2005), Ch. 14, S. 46, weisen darauf hin, dass in der Praxis zumeist beide Verfahren gleichzeitig zu beachten sind.

816 Vgl. Dreyfuss (1976), S. 855, der vermutet, dass diese Problematik im Gesetzgebungsverfahren wahrscheinlich nicht bedacht worden ist.

817 Vgl. Ackerman/Sterrett (1976), S. 1073.
} 
können von der Gesellschaft verlangen, dass sie ihre Aktien zum aktuellen Marktwert zurückkauft (§ 1300(a) Cal.Corp.Code $)^{818}$.

Es wird darauf hingewiesen, dass die gesellschaftsrechtlichen Vorschriften insgesamt nur einen Mindestschutz für Vorzugsaktionäre bieten und vertragliche Vereinbarungen im Regelfall strengere Ausschüttungsrestriktionen beinhalten ${ }^{819}$. Solche Verträge können beispielsweise vorsehen, dass Dividenden nur aus den retained earnings ab dem Zeitpunkt der Ausgabe der Vorzugsaktien gezahlt werden dürfen und vorher angesammelte Gewinnrücklagen als Verlustpuffer eingefroren werden. Weiterhin sind Dividenden vielfach ausgeschlossen, wenn die Gesellschaft mit der Zahlung von Vorzugsdividenden in Rückstand geraten ist. Vertraglich ausgehandelte zusätzliche Ausschüttungsbeschränkungen sind gemäß $\S 505$ Cal.Corp.Code explizit zulässig. Es kann daher festgehalten werden, dass die Gesellschaft bei ihrer Dividendenentscheidung neben den gesetzlichen Vorschriften auch die Satzung ( $\$ 204(d)$ Cal.Corp.Code), die Geschäftsordnung (§ 212(b)(1) Cal.Corp.Code) und die Kreditvereinbarungen auf zusätzlich einzuhaltene Ausschüttungsbegrenzungen prüfen muss.

\subsubsection{Haftungsregeln bei unzulässigen Dividendenzahlungen}

\subsection{Haftungsregeln für Directors}

Directors, die einer Dividende zugestimmt haben, welche gegen die Vorschriften der $\S \S 500-503$ Cal.Corp.Code verstößt, haften grundsätzlich gemäß § 316(a)(1) Cal.Corp.Code gesamtschuldnerisch gegenüber der Gesellschaft zum Nutzen der Gläubiger oder der Vorzugsaktionäre. Voraussetzung ist zum einen, dass diese Anspruchsberechtigten der Ausschüttung nicht zugestimmt haben. Bedingung ist zum anderen, dass sie klagebefugt sind. Dafür verweist $\S 316$ (c) Cal.Corp.Code auf $\S 506$ (b) Cal.Corp.Code, wonach es sich um Personen handeln muss, die zum Zeitpunkt der Ausschüttung Gläubiger oder Vorzugsaktionäre waren und dem Dividendenbeschluss nicht zugestimmt haben ${ }^{820}$. Es sollen also diejenigen klagen können, die durch die gesellschaftsrechtliche Ausschüttungsregulierung geschützt werden sollen ${ }^{821}$.

818 Der aktuelle Marktwert bezieht sich gemäß $§ 1300$ (a) Cal.Corp.Code auf den Tag vor der erstmaligen Bekanntgabe der Bedingungen des Zusammenschlusses. Die so genannten dissenters' rights stehen den Aktionăren nicht zu, deren Aktien an einer nationalen Börse oder der NASDAQ gehandelt werden (§ 1300(b)(1) Cal.Corp.Code). Vgl. dazu im Einzelnen Black (2004), § 5.13-14. Ist der Ruckkauf von Aktien solcher dissenting shareholders aufgrund der Ausschüttungsrestriktionen des California Corporations Code nicht möglich, werden diese Aktionäre gemåß $§ 1306$ Cal.Corp.Code wie Fremdkapitalgeber behandelt. Sie haben dann einen - im Vergleich zu anderen Fremdkapitalgebern nachrangigen - Anspruch auf den Zeitwert zuzüglich Zinsen. Vgl. dazu Marsh/Finkle/Sonsini (2005), § 14.20.

Vgl. Marsh/Finkle/Sonsini (2005), Ch. 14, S. 46, 48, 77-78.

Vgl. dazu auch Kapitel III.2.3.2.4.2.

Vgl. Marsh/Finkle/Sonsini (2005), Ch. 14, S. 74. Vgl. auch Fenolio v. McDonald, 171 Cal.App.2d 508, 340 P.2d 657 (1959). Ein ehemaliger Aktionär kann aber auf dem Klageweg eine Ausschüttung rückgängig machen lassen, wenn er im Nachhinein von der Unrechtmäßigkeit erfährt. Vgl. Tiedje v. Aluminum Taper Milling Co., Inc., 46 Cal.2d 450, 296 P.2d 554 (1956). Vgl. dazu auch Marsh/Finkle/Sonsini (2005), Ch. 14, S. 76-77. 
Eine Haftung scheidet gemäß $\S 309$ (c) Cal.Corp.Code aber aus, wenn die directors ihre in $\S 309$ (a) und (b) Cal.Corp.Code näher bestimmten Sorgfaltspflichten beachtet haben. Nach $\S 309$ (a) Cal.Corp.Code muss ein director seine Aufgaben

- gutgläubig,

- in einer Art und Weise, die nach seiner Ansicht im besten Interesse der Gesellschaft und ihrer Aktionäre ist, und

- mit einer Sorgfalt, die eine durchschnittlich begabte Person ${ }^{822}$ in ähnlicher Position und unter vergleichbaren Umständen angewandt hätte, erfüllen ${ }^{823}$.

Die directors schulden den Gläubigern in Kalifornien somit keine Treuepflicht, die sich allein aus dem common law ableiten lässt ${ }^{824}$.

$\S 309$ (b)(1) bis (3) Cal.Corp.Code listet Personen auf, auf deren Informationen ein director vertrauen darf:

- Officers und Angestellte, die der director in den vorliegenden Angelegenheiten für zuverlässig und kompetent hält,

- Rechtsanwälte, unabhängige Wirtschaftsprüfer und andere Sachverständige,

- Mitglieder eines Ausschusses des board, dem der director selbst nicht angehört, und die nach seiner Ansicht Vertrauen verdienen.

Erneut werden Sorgfaltsmaßstäbe formuliert, die ein director beachten muss, wenn er sich auf Informationen und Urteile dieser Personenkreise stützt. Er muss gutgläubig handeln, angemessene Erkundigungen durchführen, wenn die Umstände es erfordern, und er darf keine Kenntnisse haben, die ein solches Vertrauen ungerechtfertigt erscheinen ließen. In $§ 309$ Cal.Corp.Code ist folglich die business judgment rule gesetzlich kodifiziert ${ }^{825}$.

Um eine gesetzlich zulässige Dividende festlegen zu können, sind die directors in besonderer Weise auf Jahresabschlüsse angewiesen. Wie oben dargelegt, können sie sich nach kalifornischem Recht auf Jahresabschlussinformationen verlassen, die vom Management der Gesellschaft vorgelegt und von Wirtschaftsprüfern geprüft worden sind ${ }^{826}$. Um ihr Vertrauen in die Tätigkeiten dieser Personen rechtfertigen zu können, wird es als ratsam erachtet, die Qualität der erhaltenen Informationen zu überprüfen. Das gilt auch für die von unabhängigen Wirtschaftsprüfern erbrachen Leistungen ${ }^{82}$.

Kommt ein director seinen Pflichten gemäß § 309(a) und (b) Cal.Corp.Code nicht nach und stimmt einer unrechtmäßigen Dividendenzahlung zu, haftet er für den unzulässigen Ausschüt-

822 Zur Kritik an der Ungenauigkeit der Redewendung „ordinarily prudent person“ vgl. MBCA Ann. (2002), $\S 8.30$, S. $162-163,167$. In der aktuellen Version des MBCA ist sie deshalb in $\S 8.30$ (b) MBCA durch den Ausdruck ,person in a like position“ ersetzt worden. 
tungsbetrag ( $§ 316(\mathrm{~d})$ Cal.Corp.Code $)^{828}$. Um der Haftung zu entgehen, reicht es nicht aus, dass der director sich der Stimme enthält; er muss gemäß $§ 316$ (b) Cal.Corp.Code gegen den unrechtmäßigen Dividendenbeschluss stimmen. In ihrer Höhe ist die Haftung allerdings beschränkt auf die Summe der Verbindlichkeiten gegenüber den Gläubigern bzw. den erlittenen Schaden der Vorzugsaktionäre.

Ist ein director verklagt worden, kann er den übrigen directors, die der unrechtmäßigen Dividendenausschüttung ebenfalls zugestimmt haben, den Streit verkünden (implead) und Ausgleichsansprüche (contribution) geltend machen (§316(e) Cal.Corp.Code). Der director kann die übrigen directors in das laufende Verfahren einbeziehen oder sie in einem separaten Prozess verklagen. Darüber hinaus hat er nach $\S 316(f)$ Cal.Corp.Code. das Recht, sich die eventuell bestehenden Ansprüche der Gesellschaft gegenüber den Ausschüttungsempfängern abtreten zu lassen. Der director kann in diesem Fall gegen Personen, die aufgrund der Abtretung ihm gegenüber haften, in einem cross-complaint oder in einem davon unabhängigen Verfahren vorgehen. Da jedoch die Aktionäre nicht haftbar gemacht werden können, wenn sie von der Unzulässigkeit der Ausschüttung nichts gewusst haben, ist der Abtretungsanspruch nur von geringem Wert ${ }^{829}$.

\subsection{Haftungsregeln für Aktionäre}

Die Haftung der Aktionäre ist in $§ 506(a)$ Cal.Corp.Code geregelt. Danach haften sie bei Erhalt unzulässiger Dividenden gegenüber der Gesellschaft zum Nutzen aller klagebefugten Gläubiger oder Aktionäre, wenn sie von Tatsachen wussten, die auf die Unzulässigkeit hindeuteten (with knowledge of facts indicating the impropriety thereof) ${ }^{830}$. Infolgedessen ist eine Haftung von Kleinaktionären börsennotierter Unternehmen, die über keine Insiderinformationen verfügen, in der Regel unwahrscheinlich ${ }^{831}$.

Klageberechtigt sind gemäß $§ 506$ (b) Cal.Corp.Code zum einen Gläubiger. Ihre Ansprüche müssen bereits vor der unzulässigen Dividendenzahlung entstanden sein ${ }^{832}$, und ihre Klage muss auf einem Verstoß gegen die $\S \S 500-501$ Cal.Corp.Code basieren. Zum anderen können Vorzugsaktionäre klagen, um Ansprüche bei Verstößen gegen die $\S \S 502-503$ Cal.Corp.Code geltend zu machen. Eine Klage kommt nur in Betracht, wenn sie bereits zum Zeitpunkt des Dividendenbeschlusses Vorzugsaktien besaßen. Weitere Voraussetzung für Klagen von Gläubigern und Vorzugsaktionären ist, dass sie dem Dividendenbeschluss nicht zugestimmt haben (§ 506(b) Cal.Corp.Code). Mit anderen Worten kann die Haftung der Aktionäre reduziert oder

828 Bei Sachdividenden besteht eine Haftung in Höhe des aktuellen Marktwerts (,fair market value“) der Sachmittel im Zeitpunkt der Ausschüttung, § 316(d) Cal.Corp.Code.

829 Vgl. Dreyfuss (1976), S. 859.

830 Zur Auslegung von „,with knowledge of the facts“ und „impropriety“ vgl. ausführlich England v. Christensen, 243 Cal.App.2d 413, 52 Cal.Rptr. 402 (1966). Vgl. auch Federal Sav. and Loan Ins. Corp. v. Molinaro, 901 F.2d 1490 (9th Cir. 1990).

831 Vgl. Ackerman/Sterrett (1976), S. 1091; Marsh/Finkle/Sonsini (2005), Ch. 14, S. 72. Vgl. ferner Hanson v. Kake Tribal Corp., 939 P2d 1320 (Alaska 1997).

832 Selbst ein Bevollmåchtigter des Gläubigers kann keinen Anspruch im Namen des Gläubigers geltend machen. Vgl. dazu Credit Managers Ass'n of Southern California v. Federal Company, 629 F. Supp. 175 (C.D. Cal. 1985). 
ausgeschlossen werden, wenn die Gesellschaft die Zustimmung (nahezu) aller Gläubiger bzw. Vorzugsaktionäre eingeholt hat ${ }^{833}$.

Die Haftung der Aktionäre ist begrenzt auf den Betrag der unzulässigen Dividendenzahlung zuzüglich Zinsen ${ }^{834}$ und darf die Höhe der Verbindlichkeiten der Gesellschaft gegenüber den Gläubigern oder den tatsächlich erlittenen Schaden der Vorzugsaktionäre nicht übersteigen. $\S 506$ (d) Cal.Corp.Code weist zudem explizit darauf hin, dass die Vorschriften in $\S 506$ Cal.Corp.Code einer Haftung der Aktionäre für Ansprüche, die unter dem UFTA geltend gemacht werden, nicht entgegenstehen ${ }^{835}$. Eine Dividendenzahlung kann folglich sowohl gegen die $\S \S 500-503$ Cal.Corp.Code als auch gegen den UFTA verstoßen. Die jeweiligen Bestimmungen sind separat und unabhängig voneinander zu sehen, so dass ein Kläger zwei Anspruchsgrundlagen hat ${ }^{836}$. Dividenden, die von einer insolventen Gesellschaft gezahlt werden oder die zur Insolvenz führen, verstoßen gegen den UFTA mit der Folge, dass der Empfänger gegenüber den Gläubigern haftet. Obwohl Insolvenz nach dem UFTA grundsätzlich im Sinne von Überschuldung (bankruptcy meaning) definiert ist ( $\$ 3439.02$ California Civil Code), wird in solchen Fällen häufig auch ein Verstoß gegen $\S 501$ Cal.Corp.Code - Insolvenz aufgrund von Illiquidität - vorliegen. Darüber hinaus kommt eine Haftung der Aktionäre gemäß $\S 3439.04$ (b)(1) California Civil Code selbst bei Beachtung der gesellschaftsrechtlichen Bestimmungen in Betracht, wenn die der Gesellschaft nach der Ausschüttung verbleibenden Vermögenswerte im Hinblick auf die Geschäftstätigkeit als zu gering eingeschätzt werden. Schließlich kann sich aus $\S 3439.04$ (b)(2) California Civil Code ein Anspruch ergeben, wenn der Kreditnehmer sich so stark verschuldet, dass er seine Verbindlichkeiten nicht tilgen $\operatorname{kann}^{837}$.

Zu einer Rückzahlung der unrechtmäßig erlangten Dividendenausschüttung durch die Aktionäre kann es - wie oben bereits erwähnt - auch dadurch kommen, dass sich die verklagten directors die bestehenden Ansprüche der Gesellschaft gegenüber den Ausschüttungsempfängern abtreten lassen ( $\$ 316(f)$ Cal.Corp.Code). Die Aktionäre, die erfolgreich verklagt worden sind, haben ihrerseits gegen alle anderen Aktionäre, die unter die Haftungsbestimmungen von $\S 506$ Cal.Corp.Code fallen, einen Ausgleichsanspruch aus $\S 506(\mathrm{c})$ Cal.Corp.Code.

\subsection{Zwischenergebnis}

Im Gegensatz zum deutschen bzw. europäischen Recht sind die Kapitalaufbringungs- und -erhaltungsregeln in den USA nicht für alle corporations in einem Regelwerk einheitlich kodifiziert. Diesbezügliche Vorschriften finden sich vielmehr in den Kapitalgesellschaftsrechten der Einzelstaaten, den creditors' rights laws auf Ebene der Bundesstaaten bzw. des Bundes,

833 Vgl. Marsh/Finkle/Sonsini (2005), Ch. 14, S. 67.

834 Zur strittigen Frage, ab welchem Zeitpunkt die Zinsen zu berechnen sind, vgl. Dreyfuss (1976), S. 856, Fn. 86.

835 Der UFTA ist in Kalifornien in $§ \S 3439-3439.12$ California Civil Code umgesetzt worden. Vgl. zum UFTA ausführlich Kapitel III.2.2.2.1. Zu einem ausführlichen Vergleich der Haftungsregeln des California Civil Code mit denen des Cal.Corp.Code vgl. Marsh/Finkle/Sonsini (2005), Ch. 14, S. 68-70.

836 Vgl. Peters (2003), S. A-15.

837 „This section of the Uniform Fraudulent Transfer Act introduces the concept of equity insolvency, and a concept of future equity insolvency, as a basis for liability of the transferee receiving assets of a debtor without consideration." So Marsh/Finkle/Sonsini (2005), Ch. 14, S. 70. 
im Steuerrecht sowie im common law. Somit ist auch der Gläubigerschutz in den USA ,auf sehr viele Säulen gestellt" ${ }^{638}$.

Zusammenfassend ist festzuhalten, dass sich ca. drei Viertel der Bundesstaaten bei den gesellschaftsrechtlichen Kapitalschutzregeln in ihren Einzelstaatengesetzen an den Vorgaben des MBCA in der aktuellen Fassung orientieren. Danach wird weder ein bestimmtes Mindestkapital noch die Ausgabe von Nennwertaktien vorgeschrieben. Auch die Kapitalaufbringungsregeln sehen kaum Restriktionen vor, so dass unter anderem sogar vertragliche Verpflichtungen zu zukünftigen Dienstleistungen einlagefähig sind. Ein Charakteristikum der Kapitalerhaltungsregeln besteht in dem weit gefassten Ausschüttungsbegriff, der nicht nur Dividenden, sondern weitere Formen von direkten und indirekten Vermögensübertragungen und somit auch Aktienrückkäufe umfasst. Grundvoraussetzung für eine Ausschüttung ist, dass die corporation den equity insolvency test besteht. Danach ist eine Ausschüttung nur möglich, wenn die Gesellschaft anschließend in der Lage ist, ihre im gewöhnlichen Geschäftsverlauf fällig werdenden Verbindlichkeiten zu begleichen. Darüber hinaus ist als weitere Ausschüttungsrestriktion der balance sheet test zu beachten, nach dem die Vermögenswerte im Anschluss an die Ausschüttung die Schulden und die Ansprüche der Vorzugsaktionäre auf den Liquidationserlös decken müssen. Hat die Gesellschaft keine Vorzugsaktien ausgegeben, kann - unter Beachtung des equity insolvency test - das Eigenkapital mithin durch Ausschüttungen bis auf Null reduziert werden. Im Gegensatz zu dem in der Kapitalrichtlinie kodifizierten Bilanztest, der auf ein Zahlenmaterial zugreift, das im Einklang mit der Bilanzrichtlinie zu erstellen ist, schreibt der MBCA für den balance sheet test keine bestimmten Rechnungslegungsregeln vor.

Diesen flexiblen und liberalen Ausschüttungsrestriktionen stehen allerdings bestimmte Sorgfaltspflichten der Mitglieder des board of directors bei der Ausschüttungsentscheidung gegenüber. Verstoßen sie gegen diese Pflichten und stimmen einer unzulässigen Ausschüttung zu, machen sie sich der Gesellschaft gegenüber haftbar. In solchen Fällen können auch die Aktionäre zur Rückzahlung der erhaltenen Vermögenswerte verpflichtet werden, wenn sie von der Unzulässigkeit der Ausschüttung gewusst haben.

Aufgrund der vorherrschenden Gründungstheorie ist in den USA eine Reihe von Einzelstaatengesetzen, in denen die Bestimmungen des Modellgesetzes nicht bzw. nur eingeschränkt umgesetzt worden sind, von besonderer Bedeutung. Den Kern der Kapitalschutzregeln in Delaware bildet der surplus test, der grundsätzlich verhindern soll, dass das von den Aktionären einbezahlte Kapital durch Ausschüttungen an sie zurückfließt. Dieses Ziel kann allerdings auf legale Weise umgangen werden und zwar erstens durch unkompliziert durchführbare Kapitalherabsetzungen, zweitens durch die Zulässigkeit von Dividenden aus aktuellen Gewinnen selbst bei negativem Eigenkapital (nimble dividends) und drittens durch den weiten Anwendungsbereich der wasting assets-Regelung, nach der Abschreibungen von nicht erneuerbaren Vermögenswerten bei der Gewinnermittlung nicht zu berücksichtigen sind. Schließlich wird es nach der Leitentscheidung in Klang v. Smith's Food \& Drug Centers, Inc., aus dem Jahre 1997 für zulässig erachtet, für Zwecke des surplus test eine Bilanz auf fair value-Basis aufzustellen.

Die Besonderheit der kalifornischen Regulierung kann aus europäischer Sicht darin gesehen werden, dass die dortigen Testverfahren zwingend auf (Konzern-) Bilanzen zugreifen, die abgesehen von bestimmten Modifizierungen - nach US-GAAP aufzustellen sind, d.h. nach einem Rechnungslegungssystem, das wie die IFRS-Rechnungslegungsnormen ausschließlich

838

Merkt (2004a), S. 315. 
der Informationsfunktion dienen soll. Sofern eine in Kalifornien gegründete Gesellschaft den equity insolvency test erfüllt, kann sie eine Ausschüttung aus den retained earnings vornehmen. Über die retained earnings hinaus sind Ausschüttungen nur dann zulässig, wenn die corporation im Anschluss daran erstens eine Eigenkapitalquote von mindestens $20 \%$ aufweist und zweitens ihr Umlaufvermögen die kurzfristigen Verbindlichkeiten deckt bzw. - im Falle eines Zinsdeckungsgrads $<1$ - um $25 \%$ übersteigt. Die verbindlich vorgegebenen Rechnungslegungsregeln sowie die Verwendung von Bilanzkennzahlen weisen darauf hin, dass sich der kalifornische Gesetzgeber bei der Regulierung der Ausschüttungsregeln von privatvertraglichen Abreden in Kreditvereinbarungen (covenants) hat inspirieren lassen ${ }^{839}$.

Einen zusätzlichen Schutz für Gläubiger von US-amerikanischen corporations können insolvenzrechtliche Vorschriften bieten. Danach ist eine Ausschüttung schon dann unzulässig, wenn anschließend der Gesellschaft nur noch unverhältnismäßig geringe Vermögenswerte verblieben. Darüber hinaus können die Gläubiger ihre Ansprüche bei „betrügerischen“ Dividendenzahlungen leichter durchsetzen und zwar in eigenem Namen und nicht im Namen der Gesellschaft. Selbst Aktionäre, die von der Gesetzwidrigkeit der Ausschüttung nichts gewusst haben, können zur Rückzahlung verpflichtet werden.

Weiterhin ist festzustellen, dass die gesetzlichen Kapitalschutznormen durch die durchzuführenden Testverfahren bestimmte Höchstausschüttunggrenzen setzen, eine Mindestausschüttung hingegen nicht vorschreiben. Auch auf dem Klageweg bestehen für Aktionäre von public corporations kaum Chancen, Dividendenzahlungen durchzusetzen. Lediglich bei closely held corporations existieren Entscheidungen, in denen die Gerichte Gewinnausschüttungen angeordnet haben. Darüber hinaus existiert mit der accumulated earnings tax des IRC ein indirekter Anreiz, eine Mindestausschüttung vorzunehmen, da bei unangemessen hohen Gewinnthesaurierungen eine Strafsteuer erhoben wird.

In der Gesamtschau fällt ebenfalls auf, dass die dargesellten gesellschafts- und insolvenzrechtlichen Testverfahren zur Festlegung der Höchstausschüttung dem Management weitreichende Spielräume gewähren. Dies liegt - mit Ausnahme der kalifornischen Regulierung zum einen daran, dass die den Bilanztests zugrunde liegenden Rechnungslegungsregeln nicht vorgeschrieben sind. Zum anderen geben die Gesetze keine konkreten Handlungsempfehlungen für die Durchführung der equity insolvency tests ${ }^{840}$. Auch in der Rechtsprechung haben sich bislang keine allgemein gültigen Methoden entwickelt.

Im folgenden vierten Kapitel werden die auf europäischer Ebene diskutierten Vorschläge zur Reform des Kapitalschutzsystems in Europa detailliert dargestellt, die zum Teil eng an USamerikanische Regulierungen angelehnt sind.

\footnotetext{
${ }^{839} \mathrm{Vgl}$. zu den typischen Ausgestaltungsformen von covenants in den USA und den diesbezuglichen Veränderungen in den letzten Jahrzehnten bis in die jüngere Vergangenheit ausführlich Kapitel V.5.4.1.

${ }^{840} \mathrm{Vgl}$. zu einem Vorschlag dazu, wie ein Solvenztest zum Zwecke des Gläubigerschutzes ausgestaltet sein sollte, Pellens/Jödicke/Richard (2005), S. 1398, 1400-1401.
} 


\section{Kapitel IV: Reformvorschläge für das Kapitalsystem in Europa}

\section{Notwendigkeit einer Reform durch die Internationalisierung der Rechnungslegung}

In Europa besteht mit der IAS-VO und ihrer Umsetzung durch die nationalen Gesetzgeber zurzeit - darauf ist bereits zu Beginn der Arbeit hingewiesen worden - ein Nebeneinander mehrerer Rechnungslegungssysteme. Alle kapitalmarktorientierten Mutterunternehmen sind seit 2005 europaweit gezwungen, einen IFRS-Konzernabschluss aufzustellen ${ }^{841}$. Aufgrund des BilReG müssen diese Unternehmen in Deutschland weiterhin einen Einzelabschluss nach HGB und eine Steuerbilanz - die aufgrund der mittlerweile stark eingeschränkten Maßgeblichkeit de facto ein weitgehend eigenständiges Rechenwerk darstellt ${ }^{842}$ - aufstellen. Dabei dient der Einzelabschluss nach HGB von solchen Gesellschaften im Wesentlichen nur noch der Ausschüttungsbemessung. Unternehmen müssen den handelsrechtlichen Einzelabschluss aber nicht veröffentlichen, wenn sie von der Möglichkeit des $\S 325$ Abs. 2a HGB Gebrauch machen und unter Beachtung von $\S 325$ Abs. 2b HGB ihren IFRS-Einzelabschluss offen legen. Das Nebeneinander verschiedener und sich kontinuierlich fortentwickelnder Rechnungslegungssysteme geht nicht nur mit erheblichen unternehmensinternen ${ }^{843}$, sondern auch mit externen Kosten einher ${ }^{844}$. Letztere ergeben sich beispielsweise bei der Bilanzanalyse, die durch die eingeschränkte Harmonisierung der Rechnungslegung in Europa erschwert wird.

Der aus den vielfältigen Rechnungslegungspflichten resultierende Aufwand ließe sich reduzieren, wenn die IFRS von allen Unternehmen, die von der Kapitalrichtlinie betroffen sind, auch im Einzelabschluss verpflichtend anzuwenden wären ${ }^{845}$. Fraglich ist aber, ob und inwieweit die Vorschriften der Kapitalrichtlinie, die insbesondere den Gläubigerschutz gewährleisten sollen ${ }^{846}$, mit einer IFRS-Rechnungslegung kompatibel sind ${ }^{847}$. Um dies zu prüfen, werden im Folgenden die wesentlichen Charakteristika der IFRS sowie die Hauptunterschiede im Vergleich zur HGB-Rechnungslegung ${ }^{848}$ als deutsche Ausprägung der Bilanzrichtlinie kurz dargestellt, bevor im weiteren Verlauf des IV. Kapitels die bereits existierenden Vorschläge zur Reform des europäischen Kapitalschutzsystems beleuchtet werden.

Im Gegensatz zu einem Einzelabschluss nach HGB, der verschiedene Zwecke erfüllen soll, besteht die Zielsetzung der IFRS-Rechnungslegungsnormen gemäß dem Rahmenkonzept des

\footnotetext{
${ }^{841} \mathrm{Zu}$ den zeitlich befristeten Ausnahmen vgl. bereits Kapitel I.1.

842 Vgl. Dziadkowski/Henselmann (2004), S. 5.

843 Diese bestehen z.B. darin, dass kapitalmarktorientierte Aktiengesellschaften in Deutschland für Zwecke der Rechnungslegung IFRS-, Steuerrechts- und HGB-Experten beschäftigen müssen. Merkt (2004a), S. 308, Fn. 15, weist darauf hin, dass Mitarbeiter von Banken inzwischen nur noch nach IFRS geschult werden.

844 Vgl. aber Ekkenga (2006), S. 396-397, der das Kostenargument in Frage stellt.

845 In der Literatur mehren sich die Stimmen, die davon ausgehen, dass der IFRS-Einzelabschluss zukünftig den HGB-Abschluss ersetzen wird. Vgl. etwa AKEU (2001), S. 161; Streim/Bieker/Esser (2004), S. 229.

846 Vgl. z.B. Habersack (2003), S. 114.

${ }^{847}$ Im Gegensatz zu Deutschland haben sich andere EU-Mitgliedstaaten entschieden, ihren Unternehmen die IFRS im Einzelabschluss vorzuschreiben oder befreiend zu gestatten. Eine IFRS-Pflicht besteht in Dänemark (ab 2009), Estland, Griechenland, Italien, Litauen, Malta, der Slowakei, Slowenien und der Tschechischen Republik. Ein IFRS-Wahlrecht sehen Finnland, Großbritannien, Island, Liechtenstein, Luxemburg, die Niederlande, Norwegen und Polen vor. In vielen Lăndern dürfen auch nicht kapitalmarktorientierte Gesellschaften die IFRS im Einzel- und Konzernabschluss anwenden. Vgl. EU-Kommission (2005a).

848

Vgl. dazu Kapitel III.1.1.3.2.
} 
IASB (RK.12) und IAS 1.13 ausschließlich in der Vermittlung entscheidungsrelevanter Informationen $^{849}$. Unabhängig von der rechnungslegenden Einheit sollen die Unternehmensbzw. Konzernbeteiligten ein möglichst aktuelles und wahrheitsgetreues Bild der Vermögens-, Finanz- und Ertragslage sowie der Cashflows des (Konzern-)Unternehmens erhalten, das sie in die Lage versetzt, künftige Entwicklungen abzuschätzen. Das IASB listet in RK.9 eine Reihe von Abschlussadressaten und ihre jeweiligen Informationsbedürfnisse auf ${ }^{850}$. Da die zum Teil divergierenden Informationsbedürfnisse von Investoren, Fremdkapitalgebern, Arbeitnehmern, Lieferanten, Kunden, staatlichen Institutionen sowie von der allgemein interessierten Öffentlichkeit nicht vollständig zu befriedigen seien, orientiert sich die Rechnungslegung nach IFRS gemäß RK.10 primär an den Informationsbedürfnissen der Investoren. Diese benötigen nach Auffassung des IASB detaillierte Unternehmensinformationen, um die Rendite-Risiko-Struktur ihrer Investition abschätzen zu können. Die Fokussierung der Rechnungslegung auf die Belange der Investoren wird vom IASB damit begründet, dass dadurch auch die Informationsbedürfnisse der meisten anderen Abschlussadressaten befriedigt würden.

Zur Sicherstellung der Informationsorientierung sind bei der Erstellung des Jahresabschlus$\operatorname{ses}^{851}$ bestimmte Rechnungslegungsgrundsätze ${ }^{852}$ einzuhalten. Von herausragender Bedeutung im Hinblick auf die Zielsetzung der IFRS sind die Primärgrundsätze der Relevanz und der Verlässlichkeit ${ }^{853}$. Informationen gelten gemäß RK.26 dann als relevant, wenn sie bei der Beurteilung vergangener, aktueller oder künftiger Ereignisse helfen und somit die wirtschaftlichen Entscheidungen der Adressaten beeinflussen. Der Grundsatz der Relevanz wird in RK.29-30 und IAS 1.29 durch den Sekundärgrundsatz der Wesentlichkeit dahingehend konkretisiert, dass nur solche Informationen als relevant eingestuft werden, die sich auf zentrale Abschlusspositionen wesentlich auswirken. Nach RK.31 gilt eine Jahresabschlussinformation als verlässlich, wenn sie frei von materiellen Fehlern und bewusster Verzerrung ist. Das Kriterium der Verlässlichkeit wird gemäß RK.33-38 konkretisiert durch die Sekundärgrundsätze der glaubwürdigen Darstellung, der wirtschaftlichen Betrachtungsweise, der Neutralität, der Vorsicht und der Vollständigkeit ${ }^{854}$. Aus deutscher Sicht ist insbesondere das Vorsichtsprin-

849 Auch eine Verknüpfung der IFRS-Rechnungslegung mit der steuerlichen Gewinnermittlung im Sinne der Maßgeblichkeit und Umkehrmaßgeblichkeit existiert nach IFRS nicht. Die Fähigkeit der IFRS-Rechnungslegung, auch mittels Gewinn- und Verlustrechnung und Bilanz und nicht nur durch sonstige (Konzen-)Jahresabschlussbestandteile (z.B. Kapitalflussrechnung, Segmentberichterstattung) entscheidungsnützliche Informationen für die Investoren vermitteln zu können, wird in der Literatur teilweise bestritten. Vgl. dazu z.B. Streim (1998), S. 333-340; Streim (2000), S. 113-129; Streim/Esser (2003a).

850 Vgl. dazu im Überblick Streim/Bieker/Leippe (2001), S. 179-182; Pellens/Fülbier/Gassen (2006), S. 105-106. Zu einem ausführlichen Vergleich der Jahresabschlussadressaten nach HGB, IFRS und USGAAP vgl. Bonse (2004), S. 20-24.

851 Bestandteile des Jahresabschlusses sind nach RK.7 Bilanz, Gewinn- und Verlustrechnung, Kapitalflussrechnung, Eigenkapitalveränderungsrechnung nach IAS 1.86-89, Anhang (notes) sowie weitere Rechnungen und erläuternde Angaben, wie z.B. die Segmentberichterstattung nach IAS 14 von kapitalmarktorientierten Unternehmen.

852 Vgl. dazu ausführlich etwa Pellens/Fülbier/Gassen (2006), S. 107-113. Zu einem Vergleich der Grundsätze nach HGB, IFRS und US-GAAP vgl. im Überblick Hayn/Waldersee (2004), S. 58-63.

853 Weitere Primärgrundsätze sind der Grundsatz der Verständlichkeit (RK.25) und der Grundsatz der Vergleichbarkeit (RK.39-42).

854 Die Primärgrundsătze der Relevanz und Verlässlichkeit werden durch die Nebenbedingungen der Zeitnähe, der Abwägung von Kosten und Nutzen und der Abwägung der qualitativen Anforderungen an den Abschluss (RK.43-45) ergänzt. 
zip $^{855}$ von Interesse. Nach RK.37 soll es nicht zu einer Überbewertung von Vermögenswerten, einer Unterbewertung von Schulden oder zu einem zu hohen Ausweis des Periodenergebnisses kommen. Es wird explizit darauf hingewiesen, dass der Grundsatz der Vorsicht nicht zur bewussten Bildung stiller Reserven führen darf. Konkretisiert wird das Vorsichtsprinzip z.B. durch die in IAS 36 normierten Abschreibungsvorschriften bei Wertminderungen des Anlage- und Umlaufvermögens ${ }^{856}$ sowie die Bilanzierung von drohenden Verlusten aus schwebenden Geschäften gemäß IAS 10. Insgesamt ist das Vorsichtsprinzip im Vergleich zur HGB-Rechnungslegung eher schwach ausgeprägt ${ }^{857}$.

Während das IASB lange Zeit davon ausging, dass bei Beachtung der Rechnungslegungsstandards und der vorstehend skizzierten Rechnungslegungsgrundsätze automatisch ein den tatsächlichen Verhältnissen entsprechendes Bild der Vermögens-, Finanz- und Ertragslage gewährleistet ist, ist seit 1997 in IAS 1.13 die Generalnorm der fair presentation normiert. Gemäß IAS 1.17 ist allerdings nur in äußerst seltenen Ausnahmefällen ein Abweichen von einzelnen IFRS möglich, wobei dann umfangreiche Anhangangaben zu machen sind ${ }^{858}$.

Die verschiedenen Posten eines IFRS-Abschlusses werden ebenfalls im Rahmenkonzept definiert. Der Begriff des Vermögenswerts (asset) nach RK.49(a) stellt auf den künftigen ökonomischen Nutzen einer in der Verfügungsmacht des Unternehmens stehenden Ressource ab und ist daher weiter gefasst als der des Vermögensgegenstands nach $\mathrm{HGB}^{859}$. Ein Nutzen besteht in dem Potential eines Vermögenswerts, einen direkten oder indirekten zukünftigen $\mathrm{Zu}-$ fluss von liquiden oder zahlungsmitteläquivalenten Mitteln zu gewährleisten. Unter die Definition des Vermögenswerts fallen sowohl materielle als auch immaterielle Vermögenswerte. Die bilanzielle Abbildung eines Vermögenswerts bleibt allerdings aus, wenn z.B. der Nutzenzufluss nicht ausreichend wahrscheinlich ist oder ein bestimmter IFRS dies verbietet.

Eine Schuld ist nach RK.49(b) eine gegenwärtige Verpflichtung des Unternehmens, die zu einem voraussichtlichen Abfluss von Ressourcen mit wirtschaftlichem Nutzen führt. Unter dieser Definition werden sowohl Verbindlichkeiten als auch Rückstellungen subsumiert. Im Gegensatz zum deutschen Handelsrecht werden Aufwandsrückstellungen von der Definition nicht erfasst, da sie keine Verpflichtung gegenüber Dritten darstellen ${ }^{860}$.

Vermögenswerte und Schulden sind in der Bilanz anzusetzen, wenn sie erstens die angesprochenen Definitionen erfüllen, es zweitens wahrscheinlich ist, dass ein wirtschaftlicher Nutzen dem Unternehmen zufließt bzw. von ihm abfließt und der Sachverhalt drittens verlässlich bewertbar ist (RK.83). Mangels einer konkreten Angabe des IASB hinsichtlich der Wahrschein-

\footnotetext{
855 Vgl. zur unterschiedlichen Ausgestaltung des Vorsichtsprinzips nach HGB, IFRS und US-GAAP Bonse (2004), S. 36-40.

856 Nicht in den Anwendungsbereich von IAS 36 fallen unter anderem Vorräte und die meisten finanziellen Vermögenswerte (IAS 36.2). Vgl. dazu auch Pellens/Fülbier/Gassen (2006), S. 245.

857 Vgl. Bonse (2004), S. 39-40; Pellens/Fülbier/Gassen (2006), S. 110.

858 Vgl. Bonse (2004), S. 28-29; Pellens/Fülbier/Gassen (2006), S. 112-113.

859 Vgl. Schulze-Osterloh (2003a), S. 95; Baetge/Kirsch/Thiele (2005), S. 182.

860 Vgl. Pellens/Fülbier/Gassen (2006), S. 114.
} 
lichkeit des Nutzenzu- und -abflusses wird im Schrifttum von dem Erfordernis einer mehr als $50 \%$ igen Wahrscheinlichkeit ausgegangen ${ }^{861}$.

Im Rahmen der Bewertung der Abschlusspositionen führt das IASB in RK.100 vier verschiedene Bewertungsgrundlagen an, die zur Anwendung kommen können: die historischen Anschaffungs- oder Herstellungskosten (historical cost), die Wiederbeschaffungskosten (current cost), der Veräußerungswert/Erfüllungsbetrag (realisable/settlement value) und der Barwert (present value). Allerdings findet in RK.100 keine Zuordnung der Bewertungsmaßstäbe zu den Abschlusspositionen statt. Darüber hinaus finden sich mit dem beizulegenden Zeitwert (fair value), dem Marktwert (market value), dem Nutzungswert (value in use) und dem Nettoveräußerungspreis (net selling price) in einzelnen IFRS weitere Wertmaßstäbe ${ }^{862}$.

Im Hinblick auf die Gewinnermittlung besteht ein wesentlicher Unterschied zum HGB in der weiter gefassten Interpretation des Realisationsprinzips, nach dem nicht nur tatsächlich realisierte, sondern auch realisierbare Erträge in der Gewinn- und Verlustrechnung erfasst wer$\operatorname{den}^{863}$. Dadurch kann es zu einem Ausweis unrealisierter Gewinne kommen. Liegen beispielsweise die Voraussetzungen zur Bilanzierung langfristiger Fertigungsaufträge nach dem Leistungsfortschritt (percentage of completion-Methode) gemäß IAS 11.22-24 vor, kommt es regelmäßig zu einer Gewinnrealisierung bereits zu einem Zeitpunkt, zu dem der Gefahrenübergang der Leistung auf den Käufer noch nicht stattgefunden hat ${ }^{864}$. Diese Vorgehensweise ist Ausdruck der bereits angesprochenen Zielsetzung des IASB, die wirtschaftliche Lage zutreffend abzubilden. Eine solche Bilanzierung stellt die periodengerechte Erfolgsermittlung zu Lasten des Realisationsprinzips in den Vordergrund.

Auch bestimmte Finanzinstrumente können bzw. müssen nach IAS 39 zum beizulegenden Zeitwert bilanziert werden, wodurch gegebenenfalls unrealisierte Gewinne ausgewiesen werden. Zu einer Zeitwertbilanzierung und damit zu einem Abweichen vom Anschaffungs- bzw. Herstellungskostenprinzip kommt es z.B. ebenfalls bei Fremdwährungstransaktionen (IAS 21.23), im Rahmen der Equity-Bewertung von Beteiligungen nach IAS 28, bei Immobilien, die als Finanzinvestitionen gehalten werden (IAS 40.33) und bei biologischen Vermögenswerten und bestimmten landwirtschaftlichen Erzeugnissen (IAS 41.12-13) ${ }^{865}$.

${ }^{861}$ Vgl. z.B. Baetge/Kirsch/Thiele (2005), S. 184; Coenenberg (2005), S. 79; Wagenhofer (2005), S. 135; Pellens/Fülbier/Gassen (2006), S. 117. Nach IAS 37.23 wird bei der Bilanzierung von Schulden ,ein Abfluss von Ressourcen oder ein anderes Ereignis als wahrscheinlich angesehen, wenn mehr dafür als dagegen spricht; d.h. die Wahrscheinlichkeit, dass das Ereignis eintritt, ist größer als die Wahrscheinlichkeit, dass es nicht eintritt." Es wird dort allerdings darauf hingewiesen, dass der Wahrscheinlichkeitsbegriff von IAS 37.23 nicht zwingend auf andere IFRS übertragbar ist.

Vgl. Mujkanovic (2002), S. 108-136; Baetge/Kirsch/Thiele (2005), S. 260-264. Zu den verschiedenen Ausprägungen des fair value in den IFRS vgl. Streim/Bieker/Esser (2003), S. 459-469; Ballwieser/Küting/ Schildbach (2004), S. 532-534.

Vgl. Pellens/Fülbier/Gassen (2006), S. 115.

864 Vgl. Pellens/Fülbier/Gassen (2006), S. 371.

865 Die mögliche Bilanzierung von Sachanlagen (IAS 16.31), immateriellen Vermögenswerten (IAS 38.75) und von Vermögenswerten aus Exploration und Evaluierung von mineralischen Ressourcen (IFRS 6.12) zum Zeitwert über die Anschaffungs- oder Herstellungskosten hinaus ist hingegen ergebnisneutral zu behandeln. Vgl. IAS 16.39, IAS 38.85 und IFRS 6.12. 
Im Gegensatz zur HGB-Rechnungslegung existieren in den IFRS keine expliziten Ansatzwahlrechte ${ }^{866}$. Die IFRS enthalten aber eine Reihe von Bewertungswahlrechten, z.B. hinsichtlich der Bewertungsvereinfachungsverfahren des Vorratsvermögens gemäß IAS 2.25, der Fremdkapitalkosten gemäß IAS 23.11, der Verrechnung versicherungsmathematischer Gewinne und Verluste bei leistungsorientierten Versorgungsplänen gemäß IAS 19.92-95 und der Bewertung von Sachanlagen (IAS 16.29) und immateriellen Vermögenswerten (IAS $38.72)^{867}$. Insgesamt weisen die IFRS im Vergleich zum HGB deutlich weniger explizite Wahlrechte auf ${ }^{868}$.

Ermessensspielräume, die sich dem bilanzierenden Unternehmen dadurch eröffnen, dass das Management bei der Bilanzierung auf Schätzungen angewiesen ist (z.B. Festlegung der Abschreibungsmethode und -dauer), bestehen auch nach IFRS. Für die IFRS-Rechnungslegung typische Ermessensspielräume existieren z.B. bei den Ansatzkriterien von Vermögenswerten und Schulden, den unterschiedlichen nicht näher konkretisierten Wahrscheinlichkeitsbegriffen, der Schätzung von Auftragserlösen und -kosten von Fertigungsaufträgen nach IAS 11 und IAS 18, dem Ansatz aktiver latenter Steuern auf Verlustvorträge nach IAS 12.34, der Segmentabgrenzung nach IAS 14, der Abgrenzung von Finanzierungsleasing und Operating Leasing nach IAS 17, der versicherungsmathematischen Annahmen im Rahmen der Bewertung von Pensionsrückstellungen nach IAS 19 und der Festlegung der funktionalen Währung bei der Währungsumrechnung nach IAS $21^{869}$.

Die alleinige Ausrichtung auf die Informationsfunktion und damit einhergehend die stärkere Gewichtung der Relevanz gegenüber der Verlässlichkeit von Abschlussinformationen sowie die zunehmende Zeitbewertung führen zu weiteren Ermessensspielräumen nach IFRS. Beispielhaft können hier die Ansatzkriterien von Entwicklungskosten gemäß IAS 38.45, die Ermittlung des erzielbaren Betrags und der zahlungsmittelgenerierenden Einheiten beim Impairment-Test nach IAS 36.5-7 und die Ermittlung des beizulegenden Zeitwerts nach IAS 39, IAS 40, IAS 41, IFRS 2, IFRS 3 und IFRS 5 genannt werden. Diese Vorschriften sind in der Literatur zum Teil auf erhebliche Kritik gestoßen ${ }^{870}$. Bemängelt wird zum einen, dass die Unternehmensleitung durch geschickte Sachverhaltsgestaltungen die Erfüllung oder Nicht-Erfüllung der Kriterienkataloge, die nach vielen IFRS für den Ansatz von Abschlusspositionen kumulativ zu erfüllen sind, steuern kann. Kritisiert werden zum anderen weitere bilanzpolitische Möglichkeiten, die sich aus dem zunehmenden fair value-Konzept ergeben. Liegen zur Bestimmung des beizulegenden Zeitwerts keine objektivierbaren Marktpreise (z.B. Börsenkurse) oder den Marktpreisen vergleichbare Werte vor, sind Schätzungen z.B. auf Basis von

866 Vgl. Wagenhofer (2005), S. 554. Nach dieser Ansicht wird der wahlweise Einbezug der Fremdkapitalkosten in die Anschaffungs- oder Herstellungskosten gemäß IAS 2.17 i.V.m. IAS 23.11 als Bewertungswahlecht interpretiert.

867 Vgl. dazu umfassend Wagenhofer (2005), S. 555-556. Die Zahl der Wahlrechte ist durch das im Mai 2002 gestartete so genannte Improvements Project des IASB erheblich reduziert worden. Vgl. zu den durch das Improvements Project hervorgerufenen Änderungen ausführlich Zülch (2004). Zu einem Überblick zu den Wahlrechten vor Verabschiedung des Improvements Project vgl. Pellens/Sürken (1998), S. 203-209.

Vgl. Küting/Reuter (2005), S. 710-711; Wagenhofer (2005), S. 557-558

$869 \mathrm{Zu}$ einem ausfürlicheren Überblick zu den wesentlichen Ermessensspielräumen nach IFRS vgl. Wagenhofer (2005), S. 558-560.

870 Vgl. etwa Lüdenbach/Hoffmann (2002), S. 1172-1174; Mujkanovic (2002), S. 259-263; Baetge (2003), S. 481-482; Streim/Bieker/Esser (2003), S. 469-478; Ballwieser/Küting/Schildbach (2004), S. 534-548; Baetge (2005); Hitz (2005); Küting (2005). Zu den Schwierigkeiten bei der Prüfung von beizulegenden Zeitwerten vgl. z.B. Niehus (1998), S. 495-498; Ruhnke/Schmidt (2003), S. 1041-1051. 
Discounted-Cashflow-Verfahren durchzuführen ${ }^{871}$, die zahlreiche subjektive Annahmen erfordern.

Die Ermessensspielräume werden in den Folgeperioden allerdings insofern begrenzt, als auch nach IFRS das Stetigkeitsprinzip zu beachten ist (RK.39, IAS 1.27, IAS 8.41). Darüber hinaus werden die bilanzpolitischen Spielräume de facto dadurch eingeschränkt, dass nach IFRS umfangreiche und über die handelsrechtlichen Pflichten hinausgehende Anhangangaben zu den angewandten Bilanzierungsmethoden verlangt werden ${ }^{872}$. Schließlich wird bezweifelt, dass die IFRS-Rechnungslegung insgesamt mehr Ermessensspielräume als das HGB gewähr ${ }^{873}$.

Fraglich ist nun, inwiefern sich die vorstehend skizzierten Unterschiede zur HGB-Rechnungslegung in einem IFRS-Abschluss auswirken. Im juristischen Schriftum wird bisweilen der Eindruck vermittelt, die Bilanzierung nach IFRS führe im Vergleich zum HGB grundsätzlich zu einer Vorverlagerung des Gewinnausweises, einem höheren Ansatz der Vermögenswerte, einem niedrigeren Ansatz der Schulden und einem höheren Eigenkapital ${ }^{874}$. Allgemeingültige Aussagen zum Umstellungseffekt sind jedoch nur bedingt möglich. Auf der einen Seite führt die Umstellung der Rechnungslegung von HGB auf IFRS ${ }^{875}$ tendenziell zu höheren Ansätzen der Sachanlagen, der immateriellen Vermögenswerte, der aktiven latenten Steuern und der Finanzinstrumente, woraus auch ein höheres Eigenkapital resultiert. Auf der anderen Seite kommt es tendenziell zu einem höheren Ausweis der Pensionsrückstellungen und folglich einem niedrigeren Eigenkapital ${ }^{876}$. Ob und inwieweit es $\mathrm{zu}$ wesentlichen Unterschieden kommt, ist unternehmensindividuell verschieden und hängt insbesondere von der Branche und der Geschäftstätigkeit des Unternehmens sowie der bisherigen Ausnutzung von bilanzpolitischen Möglichkeiten nach HGB ab ${ }^{877}$.

Losgelöst von den Einmaleffekten bei der Umstellung kommt es bei Anwendung der IFRS zu laufenden Unterschieden. Sie resultieren im Wesentlichen aus der weniger strikten Ausgestaltung des Realisations- und Vorsichtsprinzips und führen in der Regel zu einem zeitlich früheren Gewinnausweis. Allerdings gibt es auch Beispiele für IFRS-Bilanzierungsregeln, die im Vergleich zum HGB als vorsichtiger einzustufen sind, wie z.B. die Bewertung von Pensionsrückstellungen nach IAS 19 und das Aktivierungsverbot von Ingangsetzungs- und Erweite-

871 Die IFRS beinhalten bislang keine allgemein gültige Ermittlung des beizulegenden Zeitwerts (fair value). Zur Ermittlung des beizulegenden Zeitwerts abzüglich der Verkaufskosten findet sich in IAS 36.25-27 eine Hierarchie möglicher Informationsquellen. Vgl. auch IAS 36.BCZ9-BCZ30. Zu einem in der Literatur vorgeschlagenen Stufenkonzept zur Ermittlung von fair values vgl. Baetge/Zülch (2001), S. 546-547, 554-558. Vgl. zur fair value-Hierarchie nach US-GAAP ausfuhrlich Sellhorn (2004), S. 177-186; Bieker (2006), S. 173-177. Vgl. Pellens/Sürken (1998), S. 224.

873 Vgl. Wagenhofer (2005), S. 561: „Gleichzeitig sollte man nicht aus den Augen verlieren, was das HGB in solchen Fällen vorsieht. Zwei Beispiele: Beim Ansatz von Rückstellungen schweigt es überhaupt, womit sich der Bilanzierende die Kommentarmeinung aussuchen kann, die er gerade benötigt. Und bei den latenten Steuern wird ein ,voraussichtlicher' künftiger Ausgleich gefordert. Die Spielräume, die dabei entstehen, sind noch einen Quantensprung höher als nach IFRS.“

874 Vgl. Arbeitskreis Bilanzrecht der Hochschullehrer Rechtswissenschaft (2002), S. 2373; Merkt (2003), S. 132; Schulze-Osterloh (2003a), S. 97; Merkt (2004a), S. 307-308.

$875 \mathrm{Zu}$ den Regeln nach IFRS 1, die bei der erstmaligen Umstellung zu beachten sind, vgl. etwa Pellens/Detert (2003), S. 370-375.

876 Vgl. Wagenhofer (2005), S. 510.

877 Vgl. Wagenhofer (2005), S. 514. Vgl. zu den bilanzpolitischen Möglichkeiten im Jahr der Umstellung der Rechnungslegung von HGB auf IFRS kritisch Hoffmann/Zeimes (2004), § 6, Tz. 135-149. 
rungsaufwendungen gemäß IAS $38.6(a)^{878}$. Der stärkere Einfluss von Zeitwerten in der IFRSRechnungslegung kann dazu führen, dass die Periodenergebnisse im Zeitablauf stärker schwanken als nach HGB. Allerdings führen die IFRS teilweise auch zu gegenläufigen Effekten. Glättungseffekte ergeben sich z.B. dadurch, dass die Gewinne aus Fertigungsaufträgen auf die Dauer des Fertigungsauftrags verteilt oder Entwicklungskosten aktiviert werden. Folglich lassen sich allgemeingültige Aussagen hinsichtlich der Volatilität der Periodenergebnisse ebenfalls nicht treffen ${ }^{879}$.

Zusammenfassend bleibt festzuhalten, dass ein mögliches Zusammenspiel der bisherigen Kapitalschutzregeln mit einer IFRS-Rechnungslegung im Einzelabschluss problematisch erscheint ${ }^{880}$. Aufgrund des weiter gefassten Realisationsprinzips und des geringeren Stellenwerts des Vorsichtsprinzips kann es nach IFRS zu einem Ausweis unrealisierter Gewinne kommen, die für Ausschüttungen zur Verfügung stünden. In der Literatur sind Lösungsmöglichkeiten für diese Problematik entwickelt worden. Vorgeschlagen werden beispielsweise Ausschüttungssperren, die sich entweder auf alle noch nicht realisierten Ergebnisse im Einzelnen $^{881}$ oder zumindest pauschal auf Vermögenswerte in Höhe eines bestimmten Prozentsatzes des Eigenkapitals nach IFRS beziehen ${ }^{882}$. Vorgeschlagen wird ferner, die Ausschüttungsbemessung an die Steuerbilanz zu koppeln ${ }^{883}$. Die Lösungsvorschläge sind allerdings auch mit Nachteilen verbunden. Fraglich ist beispielsweise, ob der Gesetzgeber angesichts der kontinuierlichen und schnellen Fortentwicklung der IFRS-Rechnungslegung in der Lage wäre, zeitnah mit neuen Ausschüttungssperren auf neue Bilanzierungsregeln zu reagieren. Darüber hinaus besteht die Gefahr, dass mit der zunehmenden Anzahl von Ausschüttungssperren de facto ein Ausschüttungsabschluss und mithin ein dreigleisiges Rechnungslegungssystem erforderlich wird ${ }^{884}$. Pauschale Ausschüttungssperren wiederum vermeiden zwar die Kosten der Erstellung eines zusätzlichen Ausschüttungsabschlusses, können aber den unternehmensindividuellen Gegebenheiten nicht Rechnung tragen ${ }^{885}$, so dass möglicherweise Dividendenzahlungen verhindert würden, obwohl keine unrealisierten Gewinne bestehen. Die Anbindung an das steuerrechtliche Ergebnis ist schließlich problematisch, weil Ausschüttungs- und Steuerbemessung unterschiedliche Zwecke verfolgen ${ }^{886}$.

\footnotetext{
878 Vgl. zu zahlreichen Beispielen für die unterschiedliche Ausprägung des Vorsichtsprinzips nach IFRS und HGB Wagenhofer (2005), S. 527.

879 Vgl. hierzu Wagenhofer (2005), S. 568-570.

880 Vgl. z.B. Schön (2001), S. 76; Hennrichs (2005), S. 258-259; Ekkenga (2006), S. 395. Vgl. hingegen Streim/Esser (2003b); Streim/Esser (2003c), welche die These der Unvereinbarkeit der IFRS-Rechnungslegung zum Zwecke der Zahlungsbemessung relativieren. Vgl. ähnlich Schreiber (1999), S. 890; Wagenhofer/Ewert (2003), S. 180. Vgl. auch Busse von Colbe (2002a), S. 170: „Die Behauptung, mit der Anwendung der IAS auf den Jahresabschluss werde das Gläubigerschutzprinzip aufgegeben, ist so nicht haltbar.“

881 Vgl. Krumnow (1994), S. 694; Böcking (2001), S. 1439; Buchholz (2002), S. 1283; Kahle (2002a), S. 703, 707; Peemöller/Spanier/Weller (2002), S. 1801.

882 Vgl. Schulze-Osterloh (1995), S. 137-138.

883 Vgl. dazu Pellens (2001a), S. 608, 610; Pellens/Gassen (2001), S. 140.

884 Vgl. Pellens (2001a), S. 609; Busse von Colbe (2002a), S. 170; Hennrichs (2004), S. 128.

885 Vgl. Strobl (1996), S. 409; Siegel (1997), S. 140.

886 Vgl. Moxter (2001), S. 606; Pellens (2001a), S. 609; Schön (2001), S. 79.
} 


\subsection{Aufgabe und Überblick zu den Ergebnissen}

Die SLIM-Initiative wurde von der EU-Kommission im Jahre 1996 ins Leben gerufen. Die Abkürzung steht für „Simpler Legislation for the Internal Market" und deutet auf das von der EU-Kommission verfolgte Ziel hin. Es besteht darin, die Rechtsvorschriften in der EU zu vereinfachen und die Effizienz des europäischen Binnenmarktes zu erhöhen. Die behandelten Themengebiete sind breit angelegt ${ }^{887}$. Gegenstand der vierten Phase der SLIM-Initiative war das Gesellschaftsrecht. Die SLIM-Arbeitsgruppe zum Gesellschaftsrecht bestand aus insgesamt elf Mitgliedern - fünf Ministerialbeamte und fünf Praxisvertreter unter dem Vorsitz von Prof. Wymeersch von der Universität Gent -, die von der EU-Kommission im Jahre 1999 bestellt wurden ${ }^{888}$.

Die Arbeitsgruppe sollte sich nicht als bloßes „Streichorchester“889 verstehen, das lediglich Vorschläge erarbeitet, wie die gesellschaftsrechtlichen Vorschriften verringert und die Formulierungen der Gesetzestexte gestrafft werden können. Das Ziel der „Schlankheitskur für das EU-Gesellschaftsrecht ${ }^{\star 890}$ sollte vielmehr darin bestehen, den bürokratischen Aufwand materiell zu verringern und die Flexibilität der Unternehmenspraxis zu erhöhen. Wie von der EUKommission vorgeschlagen, befasste sich die Arbeitsgruppe schwerpunktmäßig mit der Kapitalrichtlinie. Andere bearbeitete Themen betrafen die Erste EU-Richtlinie (Publizitätsrichtlinie) $)^{891}$ und die Elfte EU-Richtlinie (Zweigniederlassungsrichtlinie) ${ }^{892}$. Die 1999 im Abschlussbericht ${ }^{893}$ der Arbeitsgruppe unterbreiteten Empfehlungen zu diesen beiden Richtlinien wurden von den Mitgliedstaaten weitgehend befürwortet, so dass die EU-Kommission zügig einen Richtlinienvorschlag erarbeiten ${ }^{894}$ und die entsprechende Richtlinie bereits im Jahre 2003 in Kraft treten konnte ${ }^{895}$. Spätestens ab dem 01.01.2007 müssen danach gemeinschaftsweit zugängliche elektronische Handelsregister eingeführt worden sein, bei denen die betroffenen Kapitalgesellschaften ihre offen zu legenden Jahresabschlussdaten und Urkunden in elektronischer Form einzureichen haben, um eine schnelle und bequeme Abfrage über das Internet zu ermöglichen ${ }^{896}$. Darüber hinaus wird die zusätzliche freiwillige Offenlegung in anderen Sprachen ermöglicht. Zudem werden den Unternehmen Vorgaben zu Mindestinformationen auf ihren Internetseiten gemacht.

887

889

890

891

892

893

894

895

896

Die Themen reichen von Zierpflanzen und Kosmetika über Umsatzsteuer bis hin zu radioaktivem Mull. Vgl. dazu Baldamus (2002), S. 38, Fn. 6 m.w.N.

Aus Deutschland waren als Vertreter der Anwendungspraxis Kallmeyer und Rasner beteiligt. Zu genaueren Angaben vgl. Baldamus (2002), S. 41.

Kallmeyer (2001), S. 407.

Neye (1999), S. 1944, in Anspielung auf die deutsche Übersetzung von „slim“ (schlank).

Vgl. Erste Richtlinie des Rates vom 09.03.1968 (68/151/EWG), ABl. EG Nr. L 65 vom 14.03.1968.

Vgl. Elfte Richtlinie des Rates vom 22.12.1989 (89/666/EWG), ABI. EG Nr. L 395 vom 30.12.1989.

Zum Abschlussbericht siehe SLIM (1999a). Die deutsche Übersetzung des Berichts - SLIM (1999b) - wird als fehlerhaft kritisiert. Vgl. Kallmeyer (2001), S. 407; Baldamus (2002), S. 2, Fn. 3.

Vgl. Baldamus (2002), S. 43; Scholz (2004), S. 173.

Vgl. Richtlinie 2003/58/EG, ABl. EU Nr. L 221 vom 04.09.2003. Vgl. zu ihren Inhalten ausführlich Scholz (2004).

In Deutschland sind davon alle Aktiengesellschaften, $\mathrm{KGaA}$ und $\mathrm{GmbH}$ betroffen. Vgl. zum Referentenentwurf eines Gesetzes über elektonische Handels- und Unternehmensregister BMJ (2005a). Vgl. dazu Spindler (2006). 


\subsection{Vorschläge zur Reform der Kapitalrichtlinie}

Die SLIM-Arbeitsgruppe hat den Schwerpunkt ihrer Tätigkeit auf die Erarbeitung von Vereinfachungsmöglichkeiten der Kapitalrichtlinie gelegt. Wie der nachfolgenden Tab. 2 zu entnehmen ist, hat die Arbeitsgruppe sechs Vorschläge gemacht, die zu einer beachtlichen Deregulierung der Kapitalrichtlinie führen würden ${ }^{897}$.

\begin{tabular}{|c|c|c|}
\hline & Thema & Inhalt des Vorschlags \\
\hline 1 & Sacheinlagen & $\begin{array}{l}\text { - Ein bereits existierender Bericht eines unabhängigen Sachverständigen über } \\
\text { den Wert der Einlage hat befreiende Wirkung, wenn er hinreichend aktuell und } \\
\text { qualitativ vergleichbar ist. } \\
\text { - Eine Wertprüfung ist entbehrlich, wenn Anteile börsennotierter Gesellschaften } \\
\text { zu Börsenkursen eingebracht werden. }\end{array}$ \\
\hline 2 & Nennwert & - Die Einführung echter nennwertloser Aktien soll geprüft werden. \\
\hline 3 & Zwangseinziehung & $\begin{array}{l}\text { - Mehrheitsaktionäre, die mindestens } 90 \% \text { der Aktien halten, bekommen die } \\
\text { Möglichkeit, die Minderheitsaktionäre gegen Barabfindung auszuschließen } \\
\text { (Squeeze-out). }\end{array}$ \\
\hline 4 & $\begin{array}{l}\text { Rückkauf eigener } \\
\text { Aktien }\end{array}$ & $\begin{array}{l}\text { - Der Ermächtigungszeitraum des Vorstands zum Erwerb eigener Aktien durch } \\
\text { die Hauptversammlung wird von } 18 \text { Monaten auf fünf Jahre ausgeweitet. } \\
\text { - Der Erwerb eigener Aktien ist bis in Höhe der ausschüttungsfähigen Rücklagen } \\
\text { zulässig. }\end{array}$ \\
\hline 5 & $\begin{array}{l}\text { Finanzielle } \\
\text { Unterstützung }\end{array}$ & $\begin{array}{l}\text { - Die finanzielle Unterstützung des Aktienerwerbs durch Dritte in Form von } \\
\text { Vorschüssen, Darlehen oder Sicherheiten ist in Höhe der ausschüttungsfähigen } \\
\text { Rücklagen zulässig. } \\
\text { - Alternativ soll sich das Verbot der finanziellen Unterstützung auf die Zeich- } \\
\text { nung neuer Aktien beschränken. }\end{array}$ \\
\hline 6 & Bezugsrechte & $\begin{array}{l}\text { - Bei börsennotierten Gesellschaften kann die Hauptversammlung den Vorstand } \\
\text { für einen Zeitraum von maximal fün Jahren dazu ermächtigen, das Bezugs- } \\
\text { recht bei einer Barkapitalerhöhung auszuschließen. } \\
\text { - Voraussetzung dafür ist, dass die neuen Aktien zum Marktpreis oder leicht } \\
\text { darunter emittiert werden. }\end{array}$ \\
\hline
\end{tabular}

Tab. 2: Reformvorschläge der SLIM-Arbeitsgruppe (1999) zur Kapitalrichtlinie

Im Rahmen dieser Arbeit ist insbesondere der Reformvorschlag zum Aktienrückkauf interessant. Vergleichbar mit dem Recht Kaliforniens und den Vorschriften des MBCA würde danach der Aktienrückkauf denselben Ausschüttungsregeln unterliegen wie Dividendenzahlungen. Dies erscheint sinnvoll, da für die Gesellschaft beide Ausschüttungsvarianten aus ökonomischer Perspektive mit denselben Konsequenzen verbunden sind ${ }^{898}$. Der Reformvorschlag hätte zur Folge, dass der Aktienrückkauf als Ausschüttungsinstrument attraktiver und flexib-

897 Vgl. zur ausfuhrlichen Darstellung und Kritik der sechs Vorschläge insbesondere Baldamus (2002), S. 91-249. Vgl. ferner Drygala (2001), S. 292-298; Kallmeyer (2001), S. 407-409; Wymeersch (2001), S. 30-36; Stühmer (2003), S. 49-199.

898 Vgl. so auch Martens (1996), S. 341; Lutter (1997), S. 56; Escher-Weingart/Kübler (1998), S. 558; Mülbert/Birke (2002), S. 703; Choper/Coffee/Gilson (2004), S. 225, Fn. 83. 
ler würde, ohne den Gläubigerschutz zu beschneiden ${ }^{899}$. Auch die Anhebung der bestehenden wenig praktikablen Ermächtigungsfrist von 18 Monaten auf fünf Jahre ist zu begrüßen ${ }^{900}$. Da beispielsweise Aktienoptionsprogramme in der Regel für eine Dauer von fünf Jahren aufgelegt werden, muss bisher der Ermächtigungsbeschluss in jeder ordentlichen Hauptversammlung neu beschlossen werden.

Im Gegensatz zu den sonstigen Vorschlägen der Arbeitsgruppe sind die zur Kapitalrichtlinie auf ein unterschiedliches Echo gestoßen ${ }^{901}$. Die Anregungen haben sich daher auch nicht unmittelbar in einem Richtlinienvorschlag niedergeschlagen. Sie sind aber von der im September 2001 eingesetzten High Level Group wieder aufgenommen worden.

\section{Vorschläge der High Level Group von 2002}

\subsection{Zusammensetzung und Aufgabe}

Im September 2001 setzte die EU-Kommission die so genannte „High Level Group of Company Law Experts" mit dem Ziel ein, Vorschläge für eine weitere Modernisierung des Gesellschaftsrechts in der EU zu erarbeiten. Die Expertengruppe bestand aus sieben Juristen unter dem Vorsitz von Prof. Winter von der Universität Rotterdam ${ }^{902}$. Sie erhielt ein zweiteiliges Mandat. Die Experten sollten zum einen - im Rahmen dieser Arbeit nicht weiter beachtete Vorschläge für eine Dreizehnte Richtlinie zur Regelung von Übernahmeangeboten erarbeiten, nachdem der existierende Richtlinienvorschlag im Juli 2001 vom Europäischen Parlament abgelehnt worden war ${ }^{903}$. Zum anderen wurde die Gruppe beauftragt, Empfehlungen für moderne gesellschaftsrechtliche Rahmenbedingungen in Europa zu unterbreiten.

Im Rahmen des zweiten Teils ihres Mandats veröffentlichte die Gruppe im April 2002 ein umfangreiches Konsultationspapier ${ }^{904}$ und bat alle am Gesellschaftsrecht interessierten Kreise

Vgl. den Reformvorschlag dennoch kritisierend Drygala (2001), S. 297; Baldamus (2002), S. 180-187; Bayer (2004a), S. 8. Für eine Abschaffung der 10\%-Grenze pladieren Kübler (1989), S. 63; Escher-Weingart/Kübler (1998), S. 558-559; Escher-Weingart (2001), S. 285, 288; Schremper (2002), S. 20; Kübler (2003c), S. 102; Oechsler (2006), S. 77. A.A. Arbeitsgruppe Europäisches Gesellschaftsrecht (2003), S. 873.

Vgl. so auch Kallmeyer (2001), S. 407-408. Vgl. die 18-Monatsgrenze ebenfalls kritisierend Martens (1996), S. 339; Benckendorff (1998), S. 304; Hirte (2000a), S. 242; Oechsler (2006), S. 79-81. A.A. Baldamus (2002), S. 173-178.

Vgl. überblicksartig Baldamus (2002), S. 43-44 m.w.N.

Die weiteren Mitglieder waren Christensen, Garcia, Hopt, Rickford, Rossi und Simon. Zu genaueren Angaben vgl. High Level Group (2002c), S. 143. Aufgrund ihres Vorsitzenden wird die Extpertengruppe in der Literatur auch als „Winter-Gruppe“ bezeichnet. Die offizielle deutsche Übersetzung lautet „Hochrangige Gruppe von Experten auf dem Gebiet des Gesellschaftsrechts".

$903 \mathrm{Vgl}$. zu den bis in die 1970er Jahre zurückreichenden Bemühungen um eine Regulierung von Übernahmeangeboten in der EU bis zum vorläufigen Scheitern im Jahre 2001 Hopt (2001); Hopt (2002c), S. 1-10; Habersack (2003), S. 348-350; Grundmann (2004), S. 436-437. Im Januar 2002 legte die Winter-Gruppe ihren Bericht über den ersten Teil ihres Mandats vor. Vgl. High Level Group (2002a); dazu Hopt (2002b), S. 383; Hopt (2002c), S. 10-13; Wiesner (2002). Auf Basis eines Kompromisses wurde schließlich die Richtlinie 2004/25/EG des Europäischen Parlaments und des Rates vom 21.04.2004 betreffend Übernahmeangebote, ABl. EU 2004 L 142/12, verabschiedet. Vgl. zu ihren Inhalten Grundmann (2004), S. 438-459; Maul/Muffat-Jeandet (2004).

904 Vgl. High Level Group (2002b). 
um Stellungnahmen und Anregungen bis Ende Juni 2002. Der Abschlussbericht der High Level Group über „Moderne gesellschaftsrechtliche Rahmenbedingungen in Europa“ wurde der EU-Kommission am 04.11.2002 vorgelegt ${ }^{905}$. Er basiert auf den über 2.500 Seiten ${ }^{906}$ umfassenden ca. 170 Stellungnahmen und Kommentaren ${ }^{907}$, einer Anhörung von Vertretern europäischer Wirtschafts- und Berufsvereinigungen sowie insbesondere auf den eigenen Erörterungen der Expertengruppe.

Auf knapp 180 Seiten bietet der Abschlussbericht ein breit gefächertes Themenspektrum ${ }^{908}$. Neben allgemeinen Themen (z.B. Maßnahmen zur Förderung effizienter und wettbewerbsfähiger Unternehmen in Europa, Bevorzugung von Publizitätserfordernissen anstelle von weiteren Regulierungen, stärkere Differenzierung nach börsennotierten, offenen und geschlossenen Gesellschaften, Einsatz neuer Informationstechnologien) werden spezifische Corporate-Governance-Angelegenheiten $^{909}$ (unter anderem Corporate-Governance-Erklärung, virtuelle Hauptversammlungen, grenzüberschreitende Stimmrechtsausübung), Unternehmensgruppen und Unternehmenspyramiden, Unternehmensrestrukturierungen und Unternehmensmobilität, der mögliche Bedarf an neuen Rechtsformen (z.B. die Europäische Privatgesellschaft) sowie Genossenschaften und andere Unternehmensformen erörtert. Darüber hinaus besteht ein zentrales Thema des Abschlussberichts in der möglichen Vereinfachung des Gesellschaftsrechts vor dem Hintergrund des SLIM-Berichts zur Kapitalrichtlinie, worauf im Folgenden ausschließlich eingegangen wird.

\subsection{Vorschläge zur Reform der Kapitalrichtlinie}

\subsection{1 Überblick}

Überlegungen zum Reformbedarf der Kapitalaufbringungs- und Kapitalerhaltungsregeln enthält das vierte Kapitel des Abschlussberichts der High Level Group ${ }^{910}$. Die Expertengruppe stimmt mit der großen Mehrheit der eingegangenen Stellungnahmen darin überein, dass das bestehende Kapitalsystem nicht in der Lage ist, die ihm zugeschriebenen Aufgaben zu erfül-

\footnotetext{
905 Vgl. High Level Group (2002c).

906 So Wiesner (2003), S. 213.

907 Vgl. von deutscher Seite insbesondere Arbeitsgruppe Europäisches Gesellschaftsrecht (2002). Mitglieder dieser Arbeitsgruppe sind Bayer, Fleischer, Hoffmann-Becking, Lutter, Noack, Röhricht, K. Schmidt, Ulmer, Wiedemann, Winter und Zöllner. Vgl. auch Bundesregierung (2002); IDW (2002a). Zu einer statistischen Auswertung aller Stellungnahmen vgl. High Level Group (2002c), S. 145-175.

$908 \mathrm{Zu}$ einem Überblick uber die Inhalte des Abschlussberichts vgl. Haberer (2003); Maul (2003); Wiesner (2003). Zu einer ausfuhrlichen kritischen Stellungnahme vgl. Arbeitsgruppe Europäisches Gesellschaftsrecht (2003). Vgl. dazu kritisch Hopt (2005), S. 471-472: „Diese Letztere ist allerdings, nicht deutschen Stimmen zufolge, aus europäischer Sicht wenig geschickt, weil sie primär das deutsche Recht verteidigt. Ob im Einzelnen sachlich zu Recht oder Unrecht, droht - wenn sich erst ein solcher Eindruck breit gemacht hat -, dass sie nicht mehr zur Kenntnis genommen wird.“

909 Vgl. dazu ausführlich Baums (2002).

910 Vgl. High Level Group (2002c), S. 84-101.
} 
len, und sieht insofern Verbesserungspotential ${ }^{911}$. Für eine Reform zieht die Expertengruppe grundsätzlich drei Optionen in Erwägung ${ }^{912}$.

Nach dem ersten Vorschlag wird an dem bestehenden Kapitalsystem im Grundsatz festgehalten. Es wird aber auf Basis der SLIM-Vorschläge, die von der Expertengruppe durch weitere Empfehlungen ergänzt werden („SLIM-Plus“), vereinfacht und modernisiert. Im Gegensatz $\mathrm{zu}$ diesem vergleichsweise geringen Eingriff in das bestehende System führt der zweite Ansatz zu einer radikalen Abkehr vom bisherigen Konzept gestützt ,auf die Erfahrungen der USBundesstaaten, die Gesetze auf der Grundlage des Model Business Corporations Act angenommen haben. “913 Der dritte Vorschlag sieht ebenfalls die Abschaffung des Mindestkapitalsystems vor, erhebt aber den Anspruch, „ein neues System zu erarbeiten, das in den Aufbau des europäischen Gesellschaftsrechts passt" ${ }^{\text {“914 }}$.

Die große Mehrheit (ca. 90 \%) der Stellungnahmen zum Konsultationspapier der High Level Group spricht sich für eine grundsätzliche Reform der Kapitalrichtlinie aus ${ }^{915}$. Gefragt nach den drei Konzepten plädieren ca. $45 \%$ der Befragten für die Weiterentwicklung des bestehenden Systems auf Basis von „SLIM-Plus“. Ca. $26 \%$ befürworten die Entwicklung eines neuen Systems, das an das US-amerikanische Kapitalsystem angelehnt ist, aber auf europäische Verhältnisse angepasst wird. Ca. $9 \%$ sprechen sich für die komplette Übernahme des US-amerikanischen Systems aus ${ }^{916}$. Ca. $10 \%$ der Befragten sehen keinen Reformbedarf, weitere ca. $10 \%$ verweisen auf andere Ansätze bzw. äußern keine Präferenz.

\subsubsection{Kurzfristige Reformvorschläge („SLIM-Plus“)}

Vor dem Hintergrund dieser Ergebnisse empfiehlt die High Level Group die Reform der Kapitalrichtlinie in zwei Etappen ${ }^{917}$. In einem ersten Schritt sollen kurzfristig die modifizierten und ergänzten Vorschläge der SLIM-Arbeitsgruppe („SLIM-Plus“) umgesetzt werden. Die Einzelheiten der vorgeschlagenen Maßnahmen sind der folgenden Tabelle zu entnehmen ${ }^{918}$.

\begin{tabular}{|l|l|l|}
\hline & Thema & Inhalt des Vorschlags \\
\hline 1 & $\begin{array}{l}\text { Mindesteigen- } \\
\text { kapital }\end{array}$ & $\begin{array}{l}\text { - Das vorgeschriebene Mindesteigenkapital soll weder abgeschafft noch angehoben } \\
\text { werden. }\end{array}$ \\
\hline 2 & Nennwert & - Die Einführung echter nennwertloser Aktien soll geprüft werden. \\
\hline
\end{tabular}

Vgl. High Level Group (2002c), S. 84, 97, 161-162.

Vgl. High Level Group (2002c), S. 86, 94-96, 162. Zur Darstellung der drei Konzepte vgl. ferner bereits High Level Group (2002b), S. 28-29.

High Level Group (2002c), S. 86 (Hervorhebung im Original).

High Level Group (2002c), S. 94.

Vgl. zu diesen Angaben High Level Group (2002c), S. 162.

Erneut muss darauf hingewiesen werden, dass es strenggenommen das US-amerikanische Kapitalsystem nicht gibt.

Vgl. High Level Group (2002c), S. 14, 87.

Vgl. High Level Group (2002c), S. 13-16, 88-93. 


\begin{tabular}{|c|c|c|}
\hline & Thema & Inhalt des Vorschlags \\
\hline 3 & Sacheinlagen & $\begin{array}{l}\text { - Das Erfordernis der Bewertung durch Sachverständige soll für die Fälle entfallen, } \\
\text { in denen bereits ein Marktpreis vorhanden ist, eine noch aktuelle Bewertung vor- } \\
\text { liegt oder die Werte aus geprüften Abschlüssen stammen. } \\
\text { - Die EU-Kommission soll die Zulässigkeit der Erbringung von Dienstleistungen } \\
\text { als Sacheinlagen mit entsprechenden Sicherheiten (z.B. treuhänderische Hinterle- } \\
\text { gung der Aktien bis zur vollständigen Erbringung der Dienstleistung, Versiche- } \\
\text { rung) prüfen. }\end{array}$ \\
\hline 4 & Bezugsrechte & $\begin{array}{l}\text { - Bei börsennotierten Gesellschaften kann die Hauptversammlung den Vorstand } \\
\text { dazu ermächtigen, Bezugsrechte bei einer Barkapitalerhöhung einzuschränken } \\
\text { oder auszuschließen. } \\
\text { - Voraussetzung dafür ist, dass die neuen Aktien zum unmittelbar vor der Ausgabe } \\
\text { geltenden Börsenkurs oder leicht darunter emittiert werden. } \\
\text { - Bei einer Einführung echter nennwertloser Aktien (Thema 2) muss die Einschrän- } \\
\text { kung neu überdacht werden. }\end{array}$ \\
\hline 5 & $\begin{array}{l}\text { Kapitalherab- } \\
\text { setzung }\end{array}$ & $\begin{array}{l}\text { - Das bestehende Gläubigerschutzsystem bei Kapitalherabsetzungen (Recht auf ge- } \\
\text { richtliche Beantragung angemessener Sicherheiten) wird auf alle Formen der Um- } \\
\text { strukturierung angewandt. } \\
\text { - Die Beweislast soll bei den Gläubigern liegen. Sie müssen nachweisen, dass ihnen } \\
\text { eine Kapitalherabsetzung schadet. } \\
\text { - Die Notwendigkeit von Sicherheiten für die Gläubiger bei einer Kapitalherabset- } \\
\text { zung zur Anpassung des Mindestnennbetrags an Verluste soll überdacht werden. }\end{array}$ \\
\hline 6 & $\begin{array}{l}\text { Rückkauf } \\
\text { eigener Aktien }\end{array}$ & $\begin{array}{l}\text { - Der Erwerb eigener Aktien wird bis in Höhe der ausschüttungsfähigen Rücklagen } \\
\text { zugelassen. } \\
\text { - Gleiches soll für die Verwendung eigener Aktien als Sicherheiten gelten. }\end{array}$ \\
\hline 7 & $\begin{array}{l}\text { Finanzielle } \\
\text { Unterstützung }\end{array}$ & $\begin{array}{l}\text { - Die finanzielle Unterstützung des Aktienerwerbs durch Dritte in Form von Vor- } \\
\text { schüssen, Darlehen oder Sicherheiten soll in Höhe der ausschüttungsfähigen } \\
\text { Rücklagen zulässig sein. } \\
\text { - Voraussetzung sind ein Aktionärsbeschluss und die Offenlegung. Die Hauptver- } \\
\text { sammlung kann den Vorstand für einen Zeitraum von maximal fünf Jahren dazu } \\
\text { ermächtigen. }\end{array}$ \\
\hline 8 & $\begin{array}{l}\text { Zwangseinzie- } \\
\text { hung }\end{array}$ & $\begin{array}{l}\text { - Mehrheitsaktionäre, die mindestens } 90 \% \text { der Aktien halten, bekommen die Mög- } \\
\text { lichkeit, die Minderheitsaktionäre gegen Barabfindung auszuschließen (Squeeze- } \\
\text { out). }\end{array}$ \\
\hline 9 & $\begin{array}{l}\text { Insolvenzver- } \\
\text { schleppungs- } \\
\text { haftung }\end{array}$ & $\begin{array}{l}\text { - Die Verantwortung von Vorstandsmitgliedern bei einer drohenden Insolvenz wird } \\
\text { ausgeweitet. } \\
\text { - Eine europäische Rahmenbestimmung über die Insolvenzverschleppungshaftung } \\
\text { wird eingeführt. }\end{array}$ \\
\hline 10 & $\begin{array}{l}\text { Ansprüche von } \\
\text { Insidern }\end{array}$ & $\begin{array}{l}\text { - Die Ansprüche von Insidern (bestimmte Aktionäre, Vorstandsmitglieder) werden } \\
\text { nachrangig behandelt, wenn das Vermögen des Unternehmens für seine Aktivitä- } \\
\text { ten nicht ausreicht. }\end{array}$ \\
\hline
\end{tabular}

Tab. 3: Kurzfristige Reformvorschläge der High Level Group (2002) zur Kapitalrichtlinie (,SLIM-Plus“) 


\subsubsection{Langfristige Entwicklung eines alternativen Kapitalsystems}

In einem zweiten Schritt soll die EU-Kommission nach Ansicht der High Level Group prüfen, ob ein alternatives europäisches Kapitalsystem eingeführt werden sollte, das den EUMitgliedsstaaten als Option angeboten wird. Die Mitgliedstaaten könnten dann selbst entscheiden, ob sie den Unternehmen das Alternativmodell vorschreiben oder am bestehenden lediglich auf Basis von SLIM-Plus reformierten - Konzept festhalten. Aufgrund der in den Stellungnahmen zum Konsultationspapier geäußerten schwerwiegenden Kritik am bestehenden Kapitalsystem plädiert die Expertengruppe dafür, ein Alternativsystem für einen effizienten Gläubiger- und Aktionärsschutz zu schaffen ${ }^{919}$. Dazu seien aber noch weitere Untersuchungen und Konsultationen erforderlich. Die möglichen Kernelemente eines solchen neuen Kapitalsystems werden von der High Level Group in den Grundzügen dargestellt ${ }^{920}$.

Das Ziel des Alternativsystems soll darin bestehen, „moderne Lösungen für den Gläubigerschutz in Unternehmen europäischen Zuschnitts zu integrieren und die Befugnisse der Aktionäre beizubehalten“921. Weiterhin müsse das Niveau des Gläubiger- und Aktionärsschutzes mindestens gleich bleiben. Die Expertengruppe vertritt aber die Ansicht, dass Mechanismen existieren, die diese Ziele in effizienterer Weise erreichen können. Ein zweckmäßiger und überlegener Schutz der Gläubiger und Aktionäre wird in der vorgesehenen Solvenzprüfung gesehen, die vermeiden soll, dass ein zahlungsunfähiges Unternehmen Ausschüttungen vornimmt.

Die Solvenzprüfung soll aus einer Prüfung der Bilanz und einer Liquiditätsprüfung bestehen $^{922}$. Nach dem vorgeschlagenen Bilanztest kann eine Ausschüttung nur vorgenommen werden, wenn im Anschluss daran die Aktiva die Schulden vollständig decken. Alternativ wird vorgeschlagen, dass nach der Ausschüttung die Aktiva die Schulden um eine bestimmte Marge übersteigen müssen. Die High Level Group sieht darin „einen zweckmäßigen Mechanismus zum Einbau von gesetzlichen Rücklagen in ein System ohne Mindestnennbetrag “923. Auch wenn die Expertengruppe darauf nicht explizit hinweist, sind Paralellen zu bestimmten US-amerikanischen Ausschüttungsrestriktionen offensichtlich. Ein Bilanztest, der Vermögenswerte mindestens in Höhe der Schulden vorschreibt, entspricht dem balance sheet test gemäß $\S 6.40(c)(2)$ MBCA. Ein Bilanztest, der die Einhaltung einer bestimmten Marge vorsieht, erinnert an den quantitative solvency test nach $\S 500(\mathrm{~b})(1)$ Cal.Corp.Code.

Die Liquiditätsprüfung als zweiter Bestandteil der Solvenzprüfung besagt, dass das Umlaufvermögen des Unternehmens ausreichend sein muss, um die (kurzfristigen) Verbindlichkeiten bei Fälligkeit in einem Zeitraum von z.B. zwölf Monaten zu tilgen. Auch hier wird alternativ eine Liquiditätsmarge vorgeschlagen, nach der das Umlaufvermögen die kurzfristigen Verbindlichkeiten um einen bestimmten Prozentsatz übersteigen muss. Eine solche Liquiditätsprüfung ähnelt dem liquidity test nach $\S 500(\mathrm{~b})(2)$ Cal.Corp.Code.

Ein Unterschied zur weit verbreiteten Vorgehensweise in den USA ist darin zu sehen, dass dort die Bilanztests nicht unter den Oberbegriff der Solvenzprüfung subsumiert werden. Vielmehr sehen - mit Ausnahme Delawares - alle Bundesstaaten der USA neben bestimmten

Vgl. High Level Group (2002c), S. 87.

Vgl. High Level Group (2002c), S. 94-97.

High Level Group (2002c), S. 94.

Vgl. High Level Group (2002c), S. 95.

High Level Group (2002c), S. 95.
} 
Bilanztests einen separaten Insolvenztest vor, der nicht auf Bilanzdaten abstellt, so z.B. der equity insolvency test nach $\S 6.40$ (c)(1) MBCA bzw. nach $\S 501$ Cal.Corp.Code ${ }^{924}$.

Hinsichtlich der anzuwendenden Bilanzierungsregeln im Rahmen der Solvenzprüfung beinhalten die Ausführungen der Expertengruppe weder einen konkreten Vorschlag noch einen Hinweis, ob die Testverfahren auf der Basis von Einzel- oder Konzernabschlüssen durchzuführen sind. Die Gruppe verweist diesbezüglich auf weiteren Untersuchungsbedarf. Lediglich im Zusammenhang mit dem Bilanztest wird festgestellt, dass die angewandte Bewertungsmethode der jeweiligen Unternehmenssituation (Fortführung, Liqidation) angemessen sein muss. Übereinstimmend mit der Regulierung in Kalifornien und des MBCA sollen die vorgeschlagenen Testverfahren ausdrücklich „,ür jede Ausschüttung von Dividenden oder andere Zahlungen, einschließlich Aktienrückkäufe und Kapitalherabsetzungen mit Rückzahlung an die Aktionäre“" ${ }^{925}$ gelten.

Als weitere Neuerung wird für das Alternativsystem eine Solvenzbescheinigung vorgesehen $^{926}$. Eine Ausschüttung ist nur dann möglich, wenn die Unternehmensleitung schriftlich bestätigt, dass die beschlossene Ausschüttung die Solvenzprüfungen erfüllt. Die Unternehmensleitung ist verantwortlich dafür, dass die Solvenzbescheinigung richtig ist. Die EUMitgliedstaaten werden aufgefordert, für irreführende Solvenzbescheinigungen angemessene Sanktionen (z.B. persönliche Haftung, Verbot der Tätigkeit als Vorstand ${ }^{927}$ ) vorzusehen. Schließlich soll das neue System auch eine Insolvenzverschleppungshaftung (wrongful trading) beinhalten. Im Gegensatz zur Haftung bei Insolvenzverschleppung nach deutschem Recht, hat die wrongful trading rule nach britischem Recht ( $\$ 214$ Insolvency Act 1986) präventiven Charakter. Der director haftet danach gegenüber der Gesellschaft, wenn er von der drohenden Insolvenz der Gesellschaft wusste oder hätte wissen müssen und er nicht alles unternommen hat, um die Nachteile für die Gläubiger zu minimieren ${ }^{928}$. Die vorgeschlagene Insolvenzverschleppungshaftung geht daher über die Anforderungen in $\S 92 \mathrm{AktG}$ hinaus, wonach der Vorstand spätestens drei Wochen nach Eintritt der Zahlungsunfähigkeit bzw. der Überschuldung der Aktiengesellschaft einen Insolvenzantrag stellen muss.

In einem eigenen Abschnitt wendet sich die Expertengruppe abschließend den Aktionärsrechten im alternativen System zu, die nach ihrer Ansicht „ohne das Konzept des Mindestnennbetrags erheblich verbessert werden" ${ }^{\text {“929 }}$ kann. Zum einen soll das Bezugsrecht nur durch einen auf objektiven Kriterien beruhenden Aktionärsbeschluss ausgeschlossen oder beschränkt werden. Zum anderen dürfen neue Aktien nur zu einem „fairen Wert“ ausgegeben werden. Diesbezüglich schlägt die Expertengruppe eine Differenzierung von börsennotierten und nicht börsennotierten Gesellschaften vor. Bei Ersteren soll der faire Wert auf dem durchschnittlichen Aktienkurs in einer Zeitspanne unmittelbar vor der Emission basieren. Bei Letzteren soll der Wert der Aktien aus dem geprüften Jahresabschluss als Mindestkurs entnommen werden.

924 Massachusetts sieht ausschließlich einen Solvenztest vor. Vgl. MBCA Ann. (2002), §6.40, S. 214; Black (2004), § 1.3, S. 15, Fn. 11.

925 High Level Group (2002c), S. 95.

926 Vgl. High Level Group (2002c), S. 95-96.

927 Nach deutschem Strafrecht kann ein Berufsverbot gegen den Vorstand einer Aktiengesellschaft unter den Voraussetzungen von $\S 70$ StGB verhängt werden, wenn er sich im Zusammenhang mit seiner Tătigkeit strafbar gemacht hat (z.B. Insolvenzverschleppung nach $\S 92$ Abs. 2 AktG, Bankrott gemäß $\S 283,283 \mathrm{a}$ StGB, Verletzung der Buchfuhrungspflicht gemäß $§ 283 \mathrm{~b} \mathrm{StGB})$.

Vgl. Baums (2002), S. 9; Maul (2003), S. 29.

High Level Group (2002c), S. 96. 
Schließlich sollen für Sacheinlagen bestimmte Sicherheiten eingeführt werden. Die Gruppe schlägt vor, bei jeder Aktienemission, die zu Sacheinlagen führt, entweder einen Aktionärsbeschluss oder eine Bescheinigung von den Vorständen auf Angemessenheit der Einlage zu verlangen.

\section{Aktionsplan der Europäischen Kommission vom 21.05.2003}

Nach Veröffentlichung des Abschlussberichts der High Level Group wurde die EUKommission aufgefordert, möglichst schnell einen Aktionsplan auszuarbeiten ${ }^{930}$. Dieser Aufforderung ist die EU-Kommission am 21.05.2003 durch die Veröffentlichung ihres Aktionsplans „Modernisierung des Gesellschaftsrechts und Verbesserung der Corporate Governance in der Europäischen Union" nachgekommen ${ }^{931}$. Das erklärte Ziel der EU-Kommission ist es, ein ,gutes Gesellschaftsrecht und gute Corporate-Governance-Praktiken“932 zu schaffen, um die weltweite Leistungs- und Wettbewerbsfähigkeit der EU-Unternehmen zu steigern sowie die Aktionärsrechte zu stärken und den Schutz Dritter zu verbessern. Der Aktionsplan will darüber hinaus auch einen Beitrag leisten, das durch eine Reihe von spektakulären Bilanzskandalen und Unternehmenszusammenbrüchen verlorene Vertrauen der Anleger in den Kapitalmarkt wieder herzustellen. Die Ziele können nach Ansicht der EU-Kommission nur durch „ein voll integriertes Konzept" ${ }^{\star 933}$ erreicht werden. Bestandteile dieses Konzepts sind neben dem Aktionsplan selbst der Aktionsplan für Finanzdienstleistungen aus dem Jahr $1999^{934}$, die Rechnungslegungsstrategie aus dem Jahr 2000, die zur IAS-Verordnung von 2002 führte, die Mitteilungen über die soziale Verantwortung der Unternehmen und zur Industriepolitik in einem erweiterten Europa aus dem Jahr $2002^{935}$ sowie der ebenfalls am 21.05.2003 veröffentlichte Aktionsplan zur Stärkung der Abschlussprüfung ${ }^{936}$.

Der Aktionsplan umfasst insgesamt 24 Maßnahmen, die kurzfristig (2003 bis 2005), mittelfristig (2006 bis 2008) und langfristig (ab 2009) umgesetzt werden sollen. Den Kern des Aktionsplans stellen Maßnahmen zur Verbesserung der Corporate Governance (z.B. erhöhte Offenlegungspflichten in Bezug auf die Unternehmensleitung und -überwachung, der Bezüge der Organmitglieder sowie der Rolle von institutionellen Anlegern, Stärkung der Aktionärsrechte), dar ${ }^{937}$. Weiterhin werden Rahmenregelungen zu Konzernen, Vereinfachungen hinsichtlich grenzüberschreitender Unternehmensumstrukturierungen und Vorschläge zur Einführung neuer Rechtsformen behandelt. Einen Schwerpunkt bildet schließlich die Modernisie(2003a); Hopt (2003), S. 424-427; Maul/Lanfermann/Eggenhofer (2003); Bayer (2004a), S. 5-11; van Hulle/Maul (2004). Zu einer Zusammenfassung von 114 Stellungnahmen im Rahmen der öffentlichen Konsultation zu den Vorschlägen des Aktionsplans vgl. GD Binnenmarkt (2003). Vgl. ferner zu einem Vortrag von Hopt zum Aktionsplan im Rahmen eines Workshops an der Ruhr-Universităt Bochum Horsch/Richard (2003), S. 360-361.

Vgl. EU-Kommission (2003a), S. 4.

EU-Kommission (2003a), S. 3.

EU-Kommission (2003a), S. 3.

Vgl. EU-Kommission (1999).

Vgl. EU-Kommission (2002a); EU-Kommission (2002b).

Vgl. EU-Kommission (2003b). Vgl. dazu van Hulle/Lanfermann (2003); Lanfermann (2004).

Vgl. zu diesem Themenkreis ausführlich Habersack (2004). Vgl. als Überblick dazu auch Müller-Thiemens (2004). 
rung der Kapitalrichtlinie. Der Aktionsplan sieht diesbezüglich kurz-, mittel- und langfristige Maßnahmen vor.

Überaus positiv schätzt die EU-Kommission die von der High Level Group erweiterten SLIM-Empfehlungen („SLIM-Plus“) ein ${ }^{938}$. Die Vereinfachung der Kapitalrichtlinie könne einen wesentlichen Beitrag zur Steigerung der Effizienz und Wettbewerbsfähigkeit der Unternehmen leisten, ohne dass der Schutz von Gläubigern und Aktionären verringert würde. Daher sollen die Vorschläge der Experten kurzfristig in einer Änderungsrichtlinie münden. Ein Vorschlag für eine Änderungsrichtlinie ist bereits im Jahr 2004 vorgelegt worden, worauf im nächsten Gliederungspunkt eingegangen wird. Das von der High Level Group in den Grundzügen vorgestellte Alternativsystem soll intensiv geprüft werden. Mittelfirstig will die EUKommission eine Machbarkeitsstudie in Auftrag geben, in der einerseits die Details eines solchen Konzepts ausgearbeitet werden und andererseits geprüft wird, ob es Aktionäre und Dritte zuverlässig schützen und zusätzlichen Nutzen bieten kann. Je nach Ergebnis der Durchführbarkeitsstudie könnte das Alternativmodell ab 2009 in die Kapitalrichtlinie aufgenommen werden.

Der Aktionsplan sieht weiterhin Maßnahmen vor, die bei einer etwaigen Neugestaltung des Kapitalsystems von wesentlicher Bedeutung wären ${ }^{939}$. So soll kurzfristig die kollektive Verantwortung aller Organmitglieder auf EU-Ebene über eine Richtlinie bestätigt werden. Danach sollen die Mitglieder der Verwaltung kollektiv für die Richtigkeit des Jahresabschlusses, der Corporate-Governance-Erklärung sowie weiterer wesentlicher Erklärungen verantwortlich sein und bei Verstößen auch haften. Davon wäre auch die mögliche Solvenzbescheinigung betroffen. Zur Stärkung der Verantwortung der Mitglieder des Vorstands ist mittelfristig ein entsprechender Richtlinienvorschlag geplant. Es sollen Regelungen über die Insolvenzverschleppung erarbeitet werden, nach denen Vorstände für die Insolvenz persönlich haftbar gemacht werden können, wenn sie bei drohender Insolvenz weder Maßnahmen zur Rettung des Unternehmens und zur Zahlung der Verbindlichkeiten einleiten noch die Insolvenz anmelden. Auch ein EU-weites Verbot der Tätigkeit als Vorstand als Strafe für irreführende Unternehmensabschlüsse und andere Formen des Fehlverhaltens wird erwogen.

\section{Richtlinienvorschlag zur Änderung der Kapitalrichtlinie vom 21.09.2004}

Am 21.09.2004 hat die EU-Kommission einen Richtlinienvorschlag zur Änderung der Kapitalrichtlinie vorgelegt ${ }^{940}$, mit dem kapitalbezogene Maßnahmen von Aktiengesellschaften erleichtert werden sollen. Die Richtlinie soll 20 Tage nach ihrer Veröffentlichung in Kraft treten und von den EU-Mitgliedstaaten bis zum 31.12.2006 in nationales Recht umgesetzt werden. Erneut wird betont, dass die vorgeschlagene Modernisierung der Kapitalrichtlinie die Leistungs- und Wettbewerbsfähigkeit der EU-Unternehmen bei gleichzeitiger Aufrechterhaltung des Aktionärs- und Gläubigerschutzes stärken soll ${ }^{941}$. Tab. 4 gibt einen Überblick über die vorgeschlagenen Änderungen.

\footnotetext{
938 Vgl. EU-Kommission (2003a), S. 21.

939 Vgl. EU-Kommission (2003a), S. 19. Vgl. dazu Habersack (2004), S. 6; van Hulle/Maul (2004), S. 495-496.

940 Vgl. EU-Kommission (2004). Vgl. dazu Maul/Eggenhofer/Lanfermann (2004); IDW (2005); Oechsler (2006).

941 Vgl. EU-Kommission (2004), S. 2, 6, 8.
} 


\begin{tabular}{|c|c|c|}
\hline & Thema & Inhalt des Vorschlags \\
\hline 1 & Sacheinlagen & $\begin{array}{l}\text { - Mitgliedstaaten sollen ihren Aktiengesellschaften gestatten können, bei der Ein- } \\
\text { bringung von Sacheinlagen auf eine Bewertung durch Sachverständige zu ver- } \\
\text { zichten, wenn es für die Bewertung einen klaren Anhaltspunkt gibt. } \\
\text { - Ein klarer Anhaltspunkt liegt vor, wenn Wertpapiere eingebracht und diese zum } \\
\text { gewichteten Durchschnittspreis der letzten drei Monate bewertet werden. Glei- } \\
\text { ches gilt, wenn Vermögensgegenstände eingebracht werden, die nicht länger als } \\
\text { drei Monate vorher durch einen unabhängigen Sachverständigen zum fair value } \\
\text { bewertet wurden oder ihr Wert einem nach EU-Recht aufgestellten und geprüften } \\
\text { Abschluss zu entnehmen ist. } \\
\text { - Erfolgt eine Einbringung von Sacheinlagen ohne Sachverständigenbericht, muss } \\
\text { eine Erklärung mit verschiedenen Angaben zur Offenlegung beim Handelsregis- } \\
\text { ter eingereicht werden. } \\
\text { - Minderheitsaktionäre, die mindestens } 5 \% \text { am gezeichneten Kapital der Gesell- } \\
\text { schaft halten, können eine Neubewertung verlangen. }\end{array}$ \\
\hline 2 & $\begin{array}{l}\text { Rückkauf eigener } \\
\text { Aktien }\end{array}$ & $\begin{array}{l}\text { - Die Genehmigung über den Erwerb eigener Aktien muss von der Hauptver- } \\
\text { sammlung erteilt werden, welche unter anderem die Höchstzahl der zu erwer- } \\
\text { benden Aktien und die Geltungsdauer, die fünf Jahre nicht überschreiten darf, } \\
\text { festlegt. } \\
\text { - Die Mitgliedstaaten können den Erwerb eigener Aktien bis in Höhe der aus- } \\
\text { schüttungsfähigen Rücklagen zulassen. }\end{array}$ \\
\hline 3 & $\begin{array}{l}\text { Finanzielle } \\
\text { Unterstützung }\end{array}$ & $\begin{array}{l}\text { - Mitgliedstaaten sollen vorsehen können, dass die Gesellschaften bei einem Er- } \\
\text { werb ihrer Aktien durch einen Dritten Vorschüsse geben, Darlehen gewähren } \\
\text { oder Sicherheiten leisten dürfen, wenn diese Geschäfte zu marktüblichen Kondi- } \\
\text { tionen erfolgen. Die Kreditwürdigkeit des Dritten muss überprüft worden sein, } \\
\text { und die Gesellschaft muss ihre Solvenz für die nächsten fünf Jahre durch eine de- } \\
\text { taillierte Cash-flow-Rechnung nachgewiesen haben. } \\
\text { - Die Verwaltung muss der Hauptversammlung einen schriftlichen Bericht zur } \\
\text { Genehmigung vorlegen und ihn offen legen. } \\
\text { - Die finanzielle Unterstützung darf nicht dazu führen, dass das Nettoaktivvermö- } \\
\text { gen unter den Betrag aus gezeichnetem Kapital und nicht ausschüttungsfähigen } \\
\text { Rücklagen sinkt. } \\
\text { - Aktionäre haben das Recht, den Hauptversammlungsbeschluss anzufechten. }\end{array}$ \\
\hline 4 & Bezugsrechte & $\begin{array}{l}\text { - Die Verwaltung einer börsennotierten Gesellschaft kann bei Befugnis zur Be- } \\
\text { schränkung oder Ausschluss des Bezugsrechts bei Kapitalerhöhungen auf die } \\
\text { Vorlage des schriftlichen Berichts an die Hauptversammlung verzichten, wenn } \\
\text { die neuen Aktien zum Marktpreis ausgegeben werden. }\end{array}$ \\
\hline 5 & $\begin{array}{l}\text { Kapitalherab- } \\
\text { setzung }\end{array}$ & $\begin{array}{l}\text { - Gläubiger, deren Forderungen vor der Bekanntmachung der Entscheidung über } \\
\text { die Kapitalherabsetzung entstanden sind, haben das Recht, eine Sicherheit für die } \\
\text { im Zeitpunkt der Bekanntmachung fälligen Forderungen zu erhalten. } \\
\text { - Die Gläubiger trifft diesbezüglich die Nachweispflicht. }\end{array}$ \\
\hline 6 & Zwangseinziehung & $\begin{array}{l}\text { - Mehrheitsaktionäre, die mindestens } 90 \% \text { bzw. } 95 \% \text { (Mitgliedstaatenwahlrecht) } \\
\text { der Aktien halten, bekommen die Möglichkeit, die Minderheitsaktionäre gegen } \\
\text { angemessene Barabfindung auszuschließen (Squeeze-out). } \\
\text { - Die Minderheitsaktionäre können die Überprüfung der Angemessenheit des } \\
\text { Preises innerhalb von drei Monaten beantragen. } \\
\text { - Die Minderheitsaktionäre einer börsennotierten Gesellschaft können vom Mehr- } \\
\text { heitsaktionär verlangen, dass er ihre Aktien zu einem angemessenen Preis er- } \\
\text { wirbt (Sell-out). }\end{array}$ \\
\hline
\end{tabular}

Tab. 4: Richtlinienvorschlag zur Änderung der Kapitalrichtlinie vom 29.09.2004 
Die Maßnahmen des Richtlinienvorschlags fußen größtenteils auf den SLIM-Plus-Empfehlungen, bleiben zum Teil aber auch hinter ihnen zurück. So werden weder die Einbringung von Dienstleistungen noch die Ausgabe echter nennwertloser Aktien ermöglicht. Für Letztere bleibt daher abzuwarten, ob sie im Anschluss an die Machbarkeitsstudie ab 2009 in europäisches Recht aufgenommen werden.

\section{Rickford-Bericht „Reforming Capital“}

\subsection{Zusammensetzung und Aufgabe}

Bevor im übernächsten Kapitel die bestehende Ausschüttungsregulierung von Aktiengesellschaften in Europa und ausgewählte Alternativkonzepte ökonomisch analysiert werden, soll im Folgenden kurz auf zwei beachtenswerte aktuelle Beiträge zur Reformdiskussion in Europa aus Großbritannien und Deutschland eingegangen werden.

Im Mai 2003 wurde auf Initiative des Accounting Standards Board, dem privatrechtlichen britischen Standardsetter auf dem Gebiet der Rechnungslegung, und dem Company Law Centre at the British Institute of International and Comparative Law die "Interdisciplinary Group on Capital Maintenance“ gegründet, um die europäischen Kapitalaufbringungs- und -erhaltungsvorschriften zu überprüfen und - wie von der High Level Group angeregt - einen Reformvorschlag auf Basis einer eingehenderen Untersuchung ${ }^{942} \mathrm{zu}$ erarbeiten. Dieser international besetzten Gruppe gehören Rechnungslegungs- und Gesellschaftsrechtsexperten aus Wissenschaft und Praxis, Vertreter der Wirtschafts- und Rechtswissenschaft sowie Vertreter von Verbänden und Ministerien unter dem Vorsitz von Prof. Rickford $\mathrm{an}^{943}$.

Bereits im April 2004 hat die Expertengruppe ihren Abschlussbericht ${ }^{944}$ veröffentlicht und der EU-Kommision zugeleitet. Darin wird zunächst das bestehende Kapitalsystem ausführlich analysiert und seine Wirksamkeit grundsätzlich in Frage gestellt ${ }^{945}$. Die Gruppe weist auf Verzerrungen des europäischen Kapitalsystems hin, die darin bestünden, dass Ausschüttungsund Bilanzierungsregeln eng miteinander verknüpft seien, obwohl diese jeweils unterschiedliche Zwecke erfüllten. Ausschüttungsregeln sollten primär die Gläubiger schützen, wohingegen die Rechnungslegungsregeln der bestmöglichen Informationsvermittlung auf Basis weitgehend historischer Daten dienten ${ }^{946}$. Die Gruppe ist der Ansicht, dass Bilanzen und Gewinnund Verlustrechnungen eine unvollständige und unzuverlässliche Basis für Ausschüttungsentscheidungen darstellten. Es wird die These vertreten, dass der Trend zur fair value-

\footnotetext{
942 Vgl. High Level Group (2002c), S. 87.

${ }_{943}$ Mitgewirkt haben unter anderem Cheffins, Davies und Hanks. Letzterer ist Ko-Autor des US-amerikanischen Standardwerks zum „Legal Capital“" von Manning/Hanks (1990). Zu weiteren Angaben vgl. Rickford (2004), S. 996-997. Rickford war auch - wie bereits erwähnt - Mitglied der High Level Group.

944 Vgl. Rickford (2004). Vgl. dazu Pellens/Jödicke/Richard (2005), S. 1397-1398. Vgl. ferner Schön (2004b), S. 431, 444; Hopt (2005), S. 464; Merkt (2006b), S. 100. Die Ausführungen von Micheler (2004), S. 338-341, beziehen sich auf eine Vorversion aus dem Januar 2004, der danach noch wesentlich uberarbeitet worden ist. Vgl. Rickford (2004), S. 922.

945 Die Analyse umfasst auch einen knappen Überblick über die Ausschüttungsregulierung in Großbritannien, Deutschland, Frankreich, Italien, Spanien, den USA (MBCA, Delaware, Kalifornien), Kanada und Neuseeland. Vgl. Rickford (2004), S. 998-1027.

946 Vgl. Rickford (2004), S. 966.
} 
Bilanzierung und die daraus resultierenden zunehmenden Ergebnisschwankungen eine konstante Ausschüttungspolitik verhinderten ${ }^{947}$. Die Konsequenz seien höhere Kapitalkosten der Unternehmen und eine Schädigung von Investoren, Beschäftigten und anderen Unternehmensbeteiligten $^{948}$.

Um diese Probleme zu beseitigen, wird ein detaillierter Reformvorschlag unterbreitet, der bei einem Scheitern auf Ebene der EU zumindest für nicht von der Kapitalrichtlinie erfasste Rechtsformen (private companies) in Großbritannien Anwendung finden soll ${ }^{949}$. Der Rickford-Bericht ist damit der aktuelle Höhepunkt einer Reformdiskussion zum Gesellschaftsrecht in Großbritannien, die im Frühjahr 1998 vom dortigen Wirtschaftsministerium initiiert worden ist ${ }^{950}$. Es wurde unter anderem eine „Company Law Steering Group“ gegründet, die von Rickford geleitet wurde, und im Jahr 1999 einen Bericht zur Gesellschaftsgründung und Kapitalerhaltung vorlegte ${ }^{951}$, der im Jahr 2000 um einen zweiten Bericht zur Kapitalerhaltung ergänzt wurde ${ }^{952}$. Das Konsultationsverfahren wurde durch den Abschlussbericht im Jahr 2001 beendet $^{953}$. Daraufhin veröffentlichte die britische Regierung im Juli 2002 ihr „Modernising Company Law White Paper “954, das konkrete Vorschläge für einen neuen Companies Act enthält und zudem darauf abzielt, die Reform der Kapitalrichtlinie zu beeinflussen.

\subsection{Two Part Solvency Test}

Die Überprüfung der Solvenz der Gesellschaft stellt das Kernstück der von der RickfordGruppe vorgeschlagenen Ausschüttungsregulierung dar ${ }^{955}$. Nach dem two part solvency test muss die Gesellschaft nach Ansicht der directors erstens unmittelbar nach der Ausschüttung in der Lage bleiben, ihre Schulden zu tilgen. Sie muss zweitens unter der Prämisse der Unternehmensfortführung wirtschaftlich fähig sein, ihre im folgenden Geschäftsjahr fällig werdenden Zahlungsverpflichtungen erfüllen zu können.

Der zweistufige Solvenztest wird nicht auf Basis von Bilanzdaten durchgeführt, wie es beispielsweise beim bankruptcy insolvency test der Fall ist. Anders als nach den Vorschriften des MBCA oder nach dem Recht Kaliforniens ist auch kein zusätzlicher Bilanztest vorgesehen. Bilanzdaten sind aber gleichwohl nicht irrelevant. Die Ausschüttung ist nämlich nur dann zulässig, wenn die Unternehmensleitung der Meinung ist, dass der Solvenztest unter Berücksichtigung des letzten geprüften Jahresabschlusses erfüllt ist. In den Fällen, in denen der

Vgl. Rickford (2004), S. 921. Dies wird am Beispiel ausgewählter Bilanzierungsvorschriften verdeutlicht. Vgl. Rickford (2004), S. 948-965.

948 Vgl. Rickford (2004), S. 925.

949 Vgl. Rickford (2004), S. 922, 996.

950 Vgl. DTI (1998). Zu einem Überblick über die Entwicklung in Großbritannien vgl. auch Micheler (2004), S. 337-338; Schön (2004b), S. 430-431.

951 Vgl. DTI (1999).

$952 \mathrm{Vgl}$. DTI (2000).

953 Vgl. DTI (2001).

954 Vgl. DTI (2002). Vgl. dazu ausführlich Goddard (2003).

955

Vgl. dazu ausführlich Rickford (2004), S. 921-922, 968-988, insbesondere 979-981.
} 
surplus ${ }^{956}$, den die Bilanz ausweist, die Sichtweise des Vorstands nicht rechtfertigt, muss er auf diese Tatsache hinweisen und erläutern, warum er dennoch den Solvenztest für erfüllt hält. Eine Beweislastumkehr, nach der der Vorstand bei einem Rechtsstreit beweisen muss, dass ein Abweichen von der Bilanz gerechtfertigt war, soll nicht eingeführt werden ${ }^{957}$. Der Reformvorschlag enthält allerdings keine genauen Handlungsanweisungen zur Durchführung der Testverfahren für die directors und zwar mit der Begründung, zur Analyse der Solvenz könnten keine allgemeingültigen Regeln aufgestellt werden ${ }^{958}$. Aus demselben Grund sei es auch nicht möglich, einen safe harbor für die Geschäftsleitung im Gesetz zu installieren.

Bei jeder Ausschüttung soll die Geschäftsleitung verpflichtet werden, in einer Solvenzbescheinigung (solvency certification) schriftlich die Einhaltung des Solvenztests zu bestätigen und diese offen zu legen. Die Solvenzbescheinigung soll nach Ansicht der Rickford-Gruppe aber nicht obligatorisch von einem Wirtschaftsprüfer geprüft werden müssen; vielmehr sollen effiziente Sanktionen bei Verstößen gegen pflichtgemäßes Verhalten greifen ${ }^{959}$. Vorstände sollen zivilrechtlich und in besonders schweren Fällen strafrechtlich haften, wenn sie ihre Sorgfaltspflichten schuldhaft nicht eingehalten haben. Auch Aktionäre sollen bei Verschulden verpflichtet werden, unrechtmäßig erhaltene Ausschüttungen an die Gesellschaft zurückzuzahlen. Darüber hinaus sprechen sich die Experten für erhöhte Verantwortlichkeiten der Vorstände bei einer drohenden Insolvenz aus, wie sie auch von der High Level Group vorgeschlagen werden.

Die Reformvorschläge führen mithin auch zur Abschaffung des Mindestkapitals, der Bilanztests und der Pflicht zur Ausgabe von Nennwert- bzw. Stückaktien, wobei die Unternehmen auf vertraglicher Basis oder durch Bestimmungen in der Satzung entsprechende Regelungen freiwillig vereinbaren könnten. Die Ausschüttungsregeln wären auf alle Ausschüttungsvarianten inklusive Aktienrückkäufe und Kapitalherabsetzungen anzuwenden ${ }^{960}$. Während die Solvenzbescheinigung und Bestimmungen zur Insolvenzverschleppungshaftung nach Ansicht der Rickford-Gruppe EU-weit verpflichtend eingeführt werden sollten, könnten die EU-Mitgliedstaaten wahlweise am bestehenden Kapitalsystem festhalten dürfen ${ }^{961}$.

\section{Vorschläge des Arbeitskreises „Kapital in Europa“}

\subsection{Zusammensetzung und Aufgabe}

Ende des Jahres 2004 wurde in Deutschland der Arbeitskreis „Kapital in Europa“ gegründet. Mit dem Ziel, die anstehenden gesellschaftsrechtlichen Reformen auf Ebene der EU zu beeinflussen, untersuchte diese international besetzte Expertengruppe von Rechts- und Wirtschaftswissenschaftlern ${ }^{962}$ unter dem Vorsitz von Prof. Lutter zahlreiche Instrumente des tra-

956 In diesem Zusammenhang ist unter surplus offensichtlich der Überschuss der Netto-Vermögenswerte (Vermögenswerte abzüglich Schulden) uber das gezeichnete Kapital und die nicht ausschüttungsfahigen Rücklagen gemeint, mit anderen Worten: die Summe aus aktuellem Jahresüberschuss und ausschuttungsfähigen Rücklagen.

957 Vgl. Rickford (2004), S. 977.

958 Vgl. Rickford (2004), S. 981.

959 Vgl. Rickford (2004), S. 973-975.

960 Vgl. Rickford (2004), S. 986.

961 Vgl. Rickford (2004), S. 921. 
dierten europäischen Kapitalschutzsystems auf ihren Reformbedarf. Unter anderem beschäftigte sich der Arbeitskreis intensiv mit den Vorschriften des Mindestkapitals, der Kapitalaufbringung durch Bar- und Sacheinlagen, der Ausgestaltung von Ausschüttungssperren, der verdeckten Gewinnausschüttung, der Geschäftsleiter- und Gesellschafterpflichten bei Verlust des hälftigen Garantiekapitals, der Haftung bei Insolvenzverschleppung, der Durchgriffshaftung, der Insolvenzanfechtung, des vertraglichen Gläubigerschutzes sowie mit ausgewählten Kapitalschutzsystemen anderer europäischer Staaten und der USA ${ }^{963}$. Die folgenden Ausführungen konzentrieren sich auf die Kernergebnisse der Arbeitsgruppe „Rechnungslegung und Kapital", die insbesondere alternative Ausschüttungsregeln als Teil einer reformierten Kapitalrichtlinie vorschlägt ${ }^{964}$.

\subsection{Vorschläge zur Reform der Kapitalrichtlinie}

Den Ausgangspunkt der Reformüberlegungen des Arbeitskreises „Kapital in Europa“ bilden die umfangreichen Rechnungslegungspflichten kapitalmarktorientierter Mutterunternehmen in Deutschland ${ }^{965}$. Nach Ansicht des Arbeitskreises sollen diese Unternehmen im Hinblick auf die Rechnungslegung entlastet werden ${ }^{966}$.

Vor diesem Hintergrund schlägt der Arbeitskreis vor, dass alle Unternehmen, die aufgrund der „IAS-Verordnung“ oder auf freiwilliger Basis nach IFRS bilanzieren, anstelle des bisher zusätzlich zu erstellenden HGB-Einzelabschlusses wahlweise den IFRS-Einzelabschluss als Grundlage der durch die Kapitalrichtlinie vorgeschriebenen Ausschüttungsregeln heranziehen können. Darüber hinaus sollen sie jedoch zur Durchführung eines liquiditäts- und zukunftsorientierten Solvenztests verpflichtet werden. Nach diesem Test sollen Ausschüttungen nur dann zulässig sein, wenn sichergestellt ist, dass die Gesellschaft in einem Zeitraum von mindestens 24 Monaten nach der geplanten Ausschüttung in der Lage ist, ihre fälligen Verbindlichkeiten zu erfüllen ${ }^{967}$. Im Konzern wäre dabei die konzernweite Vermögens-, Finanz- und Ertragslage explizit zu berücksichtigen ${ }^{968}$. An den bestehenden Mindestkapitalvorschriften soll festgehlten werden. Die Prüfung des Solvenztests durch Wirtschaftsprüfer soll obligatorisch sein; von einer Veröffentlichung des dem Solvenztest zugrunde liegenden Finanzplans wird aber abgesehen. Der Vorstand soll für die Richtigkeit der Solvenzerklärung haften ${ }^{969}$.

Darüber hinaus würden die vorgeschlagenen Maßnahmen nach Ansicht des Arbeitskreises auch zu einer Verbesserung des Gläubigerschutzes führen, der in der Zukunft auf drei Säulen

Zu den Mitgliedern zăhlen Bachner, Bayer, Booth, Conac, Drygala, Eidenmüller, Ekkenga, Embid Irujo, Engert, Fleischer, Grunewald, Habersack, Hirte, Huber, Kalss, Kidyba, Kleindiek, de Kluiver, Kuhner, Lutter, Mankowski, Maul, Merkt, Micheler, Miola, Noack, Paulus, Pellens, Pentz, Priester, Rammeloo, Röhricht, K. Schmidt, Schwanna, Sellhorn, Soltysinski, Spindler, Szumánski, Urbain-Parleani, Veil. Zu weiteren Angaben vgl. auch ZEW (2006). 
stehen würde ${ }^{970}:$ Die Gläubiger würden erstens durch die bilanzielle Kapitalerhaltung auf Basis von IFRS-Abschlüssen geschützt, zweitens durch Solvenztests anhand von zukunftsorientierten Cashflow-Prognosen und drittens durch die Informationsfunktion der Jahres- bzw. Konzernabschlüsse, die nach verbreiteter Ansicht auf Basis von IFRS im Vergleich zu den Vorschriften der Bilanzrichtlinie verbessert wird ${ }^{971}$. Das vorgesehene Unternehmenswahlrecht ist allerdings kritisch zu sehen, da es dem Ziel, den Gläubiger- und Aktionärsschutz EU-weit stärker zu harmonisieren, entgegenläuft. Wird unterstellt, dass das alternative Kapitalsystem insbesondere aufgrund des enthaltenen Solvenztests einen effektiveren Schutzmechanismus darstellt ${ }^{972}$, könnten die europäischen Aktiengesellschaften auch zukünftig das Ausmaß des Kapitalschutzes zum Nachteil der Gläubiger und Aktionäre selbst festlegen.

\section{Zwischenergebnis}

Die Verpflichtung aller kapitalmarktorientierter Mutterunternehmen in Europa zur Konzernrechnungslegung nach IFRS führt bei diesen Unternehmen zu einem Nebeneinander mehrerer Rechnungslegungssysteme. Die dadurch verursachten externen und unternehmensinternen Kosten haben in Teilen der Literatur zu Überlegungen geführt, die IFRS auch im Einzelabschluss vorzuschreiben oder zu gestatten. Wie eingangs dieses Kapitels ausgeführt, erscheint eine Verknüpfung von aktienrechtlichen Kapitalschutzregeln mit einer Rechnungslegung nach IFRS anstelle des HGB problematisch. Eine Lösung dieser Problematik könnte sich in den nächsten Jahren dadurch ergeben, dass das in der Kapitalrichtlinie für Aktiengesellschaften kodifizierte System des Gläubigerschutzes durch bilanzielle Kapitalerhaltung grundlegend reformiert werden soll.

Zusammenfassend kann festgehalten werden, dass erste Reformvorhaben des europäischen Kapitalsystems bereits eingeleitet worden sind. Aufbauend auf Arbeiten der SLIM-Initiative aus dem Jahre 1999 und deren Fortentwicklung durch die High Level Group im Jahre 2002 („SLIM-Plus") hat die EU-Kommission am 21.09.2004 einen Vorschlag zur kurzfristigen Änderung der Kapitalrichtlinie unterbreitet. Die Änderungsrichtlinie sieht unter anderem vor, dass die Einbringung von Sacheinlagen erleichtert wird, die Gesellschaft durch die Hauptversammlung für bis zu fünf Jahre zum Rückkauf eigener Aktien ermächtigt werden kann und der Aktienrückkauf denselben Restriktionen wie Dividendenausschüttungen unterliegt.

Nach dem Aktionsplan der EU-Kommission vom Mai 2003 sind langfristig weitergehende Reformmaßnahmen der Kapitalrichtlinie geplant. Dazu sollen mittelfristig die Vorschläge der High Level Group im Rahmen einer Machbarkeitsstudie geprüft werden. Die Gesellschaftsrechtsexperten der High Level Group plädieren für ein neues Kapitalschutzkonzept und haben dafür bereits einige Kernelemente skizziert. Nach dem Alternativkonzept soll in Anlehnung an US-amerikanische Regulierungen eine Ausschüttung nur dann erlaubt sein, wenn im Anschluss daran die Solvenz der Gesellschaft für einen bestimmten Zeitraum sichergestellt ist. Zur Beurteilung der Solvenz soll das Management bestimmte Liquiditäts- bzw. Bilanztests durchführen und in einer Solvenzbescheinigung schriftlich bestätigen, dass die Ausschüttung nicht gegen die Testverfahren verstößt. Bei unzulässigen Ausschüttungen sollen die Mitglie-

\footnotetext{
970 Vgl. Pellens/Sellhorn (2006), S. 485.

971 Vgl. zu dieser Fragestellung umfassend Bonse (2004).

972 Vgl. High Level Group (2002c), S. 94; Pellens/Jödicke/Richard (2005), S. 1401.
} 
der der Unternehmensleitung haften. Zudem ist die Einführung einer Insolvenzverschleppungshaftung geplant.

Ein erster konkreter Vorschlag für ein zukünftiges europäisches Kapitalschutzsystem ist in der jüngeren Vergangenheit von britischen Gesellschaftsrechtsexperten unter dem Vorsitzenden Rickford unterbreitet worden. Der Rickford-Bericht sieht ausschließlich einen auf Zahlungsgrößen basierenden Solvenztest vor, der gewährleisten soll, dass die Gesellschaft auch nach der Ausschüttung ihre im folgenden Geschäftsjahr fällig werdenden Verbindlichkeiten zahlen kann. Auch nach diesem Vorschlag soll die Geschäftsleitung verpflichtet werden, die Rechtmäßigkeit der Ausschüttung in einer Solvenzbescheinigung zu bestätigen.

Von deutscher Seite hat jüngst der Arbeitskreis „Kapital in Europa“ einen Reformvorschlag erarbeitet. Im Gegensatz zum Rickford-Bericht können danach die von der Kapitalrichtlinie betroffenen und nach IFRS bilanzierenden Gesellschaften wahlweise am bestehenden System festhalten. Wenden sie zur Vermeidung einer eigenständigen Ausschüttungsbilanz die bisherigen Kapitalerhaltungsregeln auf einen IFRS-Abschluss an, sind sie zusätzlich zur Erstellung eines Solvenztests verpflichtet. Ausschüttungen wären nur dann möglich, wenn das Unternehmen sowohl die Vorschriften der bilanziellen Kapitalerhaltung als auch den Solvenztest erfüllt.

Das Hauptanliegen der Ausführungen des fünften Kapitels besteht nun insbesondere darin, aus ökonomischer Sicht zu prüfen, ob die im dritten Kapitel ausführlich dargestellten USamerikanischen Kapitalschutzsysteme bei der anstehenden, grundlegenden Reform der Kapitalrichtlinie als Vorbild dienen können. 


\section{Kapitel V: Ökonomische Analyse der Kapitalschutzregeln und Schlussfolgerungen für deren Reform}

\section{Einleitung und Überblick}

Im Folgenden wird zunächst untersucht, ob ein staatlicher Eingriff in das Marktgeschehen und damit in das individuelle Entscheidungsverhalten der Wirtschaftssubjekte durch gesetzlich regulierte Kapitalschutzregeln für Aktiengesellschaften notwendig ist. Dazu werden zum einen die wesentlichen Konfliktpotentiale zwischen Management, Anteilseignern und Gläubigern in (Konzern-)Unternehmen skizziert. Zum anderen werden ausgewählte wirtschaftstheoretische Ansätze zur Regulierungsrechtfertigung auf die Kapitalschutzregeln angewandt.

An die theoretischen Betrachtungen schließen sich Ausführungen zu den Zielen des europäischen Gesetzgebers auf dem Gebiet des aktienrechtlichen Kapitalschutzes an. Der Anspruch des europäischen Kapitalsystems wird herausgearbeitet und kritisch hinterfragt. Dabei werden die zuvor dargestellten Ziele des EU-Gesetzgebers als Beurteilungsmaßstab herangezogen. Weiterhin werden die grundlegenden Mängel des tradierten Konzepts erörtert. Selbstschutzmöglichkeiten verschiedener Gläubigergruppen sowie die mit einem Systemwechsel verbundenen Kosten und Nutzen werden zudem aufgezeigt.

Schwerpunktmäßig werden dann ausgewählte Reformmöglichkeiten für ein alternatives Kapitalsystem kritisch gewürdigt, wobei erneut die selbst gesteckten Ziele und Vorgaben des europäischen Gesetzgebers als Messlatte fungieren. Im Einzelnen werden Solvenztests, die in allen Bundesstaaten der USA aufgrund von gesellschafts- oder insolvenzrechtlichen Bestimmungen zu beachten sind und den Kernbestandteil des Rickford-Berichts bilden, sowie die sonstigen Kapitalschutzregeln von Delaware, dem MBCA und Kalifornien kritisch gewürdigt. Im Mittelpunkt stehen dabei die Ausschüttungsrestriktionen der Bilanztestverfahren und die ihnen zugrunde liegenden Rechnungslegungsnormen.

\section{Agency-Konflikte in Unternehmen}

Unternehmen stellen aus ökonomischer Sicht Vertragsgeflechte zwischen den auf unterschiedlichen Märkten agierenden Unternehmensbeteiligten, wie z.B. dem Management, den Eigen- und Fremdkapitalgebern, den Lieferanten und des Arbeitnehmern, dar ${ }^{973}$. Zwischen den Beteiligten kann es zu Interessenkonflikten kommen, wobei im Allgemeinen potentielle Eigner-Gläubiger-, Eigner-Manager- und Eigner-Eigner-Konflikte unterschieden werden ${ }^{974}$. Sie resultieren insbesondere daraus, dass die Beteiligten unterschiedliche Interessen verfolgen und die verfügbaren Informationen asymmetrisch verteilt sind ${ }^{975}$. Sie werden in der Literatur regelmäßig als Agency-Probleme analysiert ${ }^{976}$. Im Folgenden sollen diese Konflikte bei Unternehmen in der Rechtsform der Aktiengesellschaft skizziert werden.

\footnotetext{
973 Vgl. z.B. Jensen/Meckling (1976).

974 Vgl. z.B. Schildbach (1986), S. 59; Pfaff (1989), S. 40; Pellens (1994), S. 70-71; Wagenhofer/Ewert (2003), S. 143.

975 Vgl. z.B. Streim (1988), S. 11-12; Elschen (1998), S. 557.

976 Vgl. Pfaff (1989), S. 40-41 m.w.N.
} 
Die Ursache für Konflikte zwischen Eignern und Gläubigern kann darin gesehen werden, dass den Gläubigern von haftungsbeschränkten Aktiengesellschaften nur das Unternehmensvermögen haftet. Ausschüttungen an die Aktionäre reduzieren diese Haftungsmasse und erhöhen daher unter Umständen das Risiko der Gläubiger, die vereinbarten Zins- und Tilgungsleistungen nicht $\mathrm{zu}$ erhalten ${ }^{977}$. Wird vereinfachend unterstellt, dass die von den Eignern beauftragte Unternehmensleitung im Interesse der Eigner handelt, ergeben sich für die Gläubiger unter anderem die folgenden Risiken ${ }^{978}$ :

- Stellt das Management fest, dass die Ausschüttung des Liquidationserlöses des Unternehmens an die Anteilseigner höher ist als die nach Berücksichtigung der Gläubigeransprüche anfallenden Einzahlungsüberschüsse bei Unternehmensfortführung, könnte es das Unternehmen liquidieren, wodurch die Ansprüche der Gläubiger wertlos würden.

- Die Unternehmensleitung könnte weiteres Fremdkapital aufnehmen und es in Form von Dividenden an die Eigner ausschütten. Dadurch würde sich die Position der Altgläubiger verschlechtern und eine Vermögensverlagerung zu den Anteilseignern stattfinden.

- Die Unternehmensleitung könnte unmittelbar im Anschluss an die Fremdkapitalaufnahme das Investitionsprogramm ändern und die Mittel in ein risikoreicheres Projekt investieren. Dadurch erhielten die Gläubiger keine risikoadäquate Verzinsung.

- Die Unternehmensleitung könnte Investitionsprojekte mit positivem Kapitalwert nicht durchführen, weil die daraus resultierenden Vorteile teilweise den Gläubigern zugute kämen.

Eigner-Manager-Konflikte entstehen aus der Trennung von Eigentum und Geschäftsführung $^{979}$. Während die Eigner primär an den finanziellen Vorteilen aus ihrem Investment in der Form von Kurssteigerungen und Dividendenzahlungen interessiert sind, spielen für das Management neben finanziellen Anreizen (Entlohnung) auch nicht finanzielle Anreize (z.B. Prestige, Macht) eine Rolle ${ }^{980}$. Die oben getroffene Annahme, die Manager agierten im Interesse der Eigner, wird dadurch aufgehoben. Ausschüttungen an die Anteilseigner sind in dieser Konfliktsituation insofern von Bedeutung, als sie die frei verfügbaren liquiden Mittel, die dem Management zur Verfügung stehen, verringern. Für die Eigner ergeben sich beispielsweise die folgenden Risiken ${ }^{981}$ :

- Wenn die Manager aus ihrer Tätigkeit für die Gesellschaft nicht finanzielle Vorteile ziehen können, die mit einem Verbrauch von Unternehmensressourcen einhergehen (z.B. teure Bürogebäude und Dienstwagen), mindert sich der Unternehmenswert zum Nachteil der Aktionäre.

Vgl. Wagenhofer/Ewert (2003), S. 144.

Vgl. zum Folgenden ausfuhrlich Ewert (1986), S. 10-20 m.w.N.; Schildbach (1986), S. 62-64; Streim (1988), S. 12-14; R. Schmidt/Terberger (1997), S. 415-421; Franken (2001), S. 43-57; Leippe (2002), S. 39-45; Wagenhofer/Ewert (2003), S. 153-158. Vgl. zu den speziellen Risiken für die Gläubiger von Konzernunternehmen Pellens (1994), S. 77-79; Theisen (2000), S. 620-622, jeweils m.w.N.

Vgl. etwa Wagenhofer/Ewert (2003), S. 183.

Vgl. Wagenhofer/Ewert (2003), S. 146 m.w.N.

Vgl. zum Folgenden ausführlich Schildbach (1986), S. 72-74; Streim (1988), S. 14-15; Pfaff(1989), S. 5-6, 41-44 m.w.N.; Faß (1992), S. 63-66; D. Schneider (1992), S. 630; Leippe (2002), S. 46-50; Wagenhofer/ Ewert (2003), S. 182-185. 
- Um die Periodenergebnisse zu steigern, könnte die Unternehmensleitung auch Investitionen mit negativem Kapitalwert durchführen. Dadurch würden finanzielle Mittel im Unternehmen gebunden, für welche die Aktionäre außerhalb des Unternehmens möglicherweise eine höhere Alternativrendite erwirtschaften könnten (Überinvestition).

- Manager könnten aus Sicht der Aktionäre zu einer zu risikoscheuen Investitionspolitik neigen, weil sie das Unternehmensrisiko im Gegensatz zu den Aktionären in der Regel nicht durch Diversifizierung ihres Portfolios eliminieren können (Unterinvestition).

- Aufgrund von Informationsvorsprüngen der Manager gegenüber den Aktionären könnten die aktuellen und potentiellen Aktionäre über die wirtschaftliche Lage des Unternehmens mit der Folge getäuscht werden, dass sie Unternehmensanteile zu teuer erwerben bzw. zu billig veräußern.

Die soeben skizzierten Eigenkapitalgeberrisiken erhöhen sich für Aktionäre von Konzernunternehmen, da Konzernleitungen noch größere Möglichkeiten haben, die Gesellschafter durch eigennütziges Handeln zu schädigen ${ }^{982}$. Zudem führt die Konzernbildung dazu, dass die Herrschafts-, Informations- und Vermögensrechte der Aktionäre des Mutterunternehmens weitgehend ausgehöhlt werden können ${ }^{983}$, worauf am Beispiel von $\S 58 \mathrm{AktG}$ bereits ausführlich hingewiesen worden ist ${ }^{984}$.

Eigner-Eigner-Konflikte ${ }^{985}$ werden im Folgenden nicht weiter analysiert. Sie können dadurch verursacht werden, dass die verschiedenen Eigentümergruppen z.B. unterschiedliche Konsumpräferenzen, Anlagestrategien und Einkommensteuerlasten aufweisen. Interessenkonflikte sind insbesondere zwischen Mehrheits- und Minderheitsaktionären ${ }^{986}$ sowie Alt- und Neuaktionären ${ }^{987}$ denkbar.

Weder die Gläubiger noch die Aktionäre stehen den Kapitalgeberrisiken völlig schutzlos gegenüber. Rational handelnde Fremdkapitalgeber werden die potentiellen Vermögensverlagerungen antizipieren und ihre Kreditkonditionen dementsprechend anpassen ${ }^{988}$. In Abhängigkeit von ihrer jeweiligen Verhandlungsmacht stehen den Gläubigern zahlreiche Selbstschutzmöglichkeiten zur Verfügung ${ }^{989}$. Im Gegenzug besteht für die Unternehmenseigner bzw. die Unternehmensleitung ein Anreiz, das Misstrauen bedeutender Gläubiger zu reduzieren, um die Fremdkapitalkosten zu mindern ${ }^{990}$. Ähnliches gilt für den Manager-Eigner-Konflikt. Potentielle Anteilseigner werden rationale Erwartungen über das Verhalten der Manager bilden, wodurch diese in ihrem eigenen Interesse Maßnahmen zur Verminderung des Konfliktpotentials ergreifen werden ${ }^{991}$. Dazu stehen zahlreiche unternehmensinterne Instrumente zur Verfü-

982 Vgl. dazu ausführlich Pellens (1994), S. 70-77. Zu zahlreichen Beispielen für gewinnverändernde und gewinnverlagernde Transaktionen vgl. auch Lehertshuber (1986a), S. 100-110. Vgl. dazu ausfuhrlich Pellens (1994), S. 52-69.

Vgl. Kapitel III.1.1.3.3.

Vgl. Schildbach (1986), S. 74-75; Pfaff(1989), S. 40-41. Vgl. ferner F. Ruhwedel (2003), S. 85-86.

Vgl. z.B. Dirrigl/Wagner (1993), S. 264.

Vgl. dazu z.B. Schildbach (1986), S. 75, 79-80; Faß (1992), S. 65-66.

Vgl. zum Gläubigerschutz durch rationale Erwartungen der Gläubiger ausführlich Wagenhofer/Ewert (2003), S. 158-160, 190

Vgl. dazu etwa Streim (1988), S. 16-18; R. Schmidt/Terberger (1997), S. 427-432. Vgl. zu den Selbstschutzmöglichkeiten verschiedener Gläubigergruppen ausführlich Kapitel V.5.4. 
gung, wie z.B. Risikomanagementsysteme, erfolgsabhängige Entlohnungssysteme und wertorientierte Managementsysteme ${ }^{992}$. Darüber hinaus hat der Gesetzgeber verschiedene Regelungen getroffen, mit denen die aufgezeigten Konflikte reduziert werden sollen ${ }^{993}$.

Im Folgenden wird der gesetzliche Kapitalschutz von Aktiengesellschaften als ein Beispiel für Eingriffe des Gesetzgebers in das Marktgeschehen näher betrachtet. Der deutsche bzw. europäische Gesetzgeber greift dabei in zweierlei Weise regulierend ein. Zum einen werden Kapitalaufbringungs- und Ausschüttungsregeln vorgegeben, die auf Rechnungslegungsdaten im Einzelabschluss zugreifen, die zwingend nach den Vorschriften des HGB bzw. der Bilanzrichtlinie $\mathrm{zu}$ erstellen sind ${ }^{994}$. Zum anderen legen die deutschen aktienrechtlichen Bestimmungen die Gewinnverwendungskompetenz fest ${ }^{995}$. Danach wird für den Regelfall der Feststellung des Jahresabschlusses durch Vorstand und Aufsichtsrat ( $\$ 172 \mathrm{AktG}$ ) die Kompetenz zur Verwendung des Jahresüberschusses je zur Hälfte in die Hände von Verwaltung und Hauptversammlung gelegt ${ }^{996}$. Ohne gesellschaftsrechtliche Vorgaben würden die Unternehmensbeteiligten über die Kompetenz der Verwendung des erwirtschafteten Periodenerfolgs des Unternehmens frei entscheiden. Wird hingegen die aktienrechtlich festgelegte Aufgabenverteilung zwischen den Organen von Aktiengesellschaften in Betracht gezogen, stünde ohne $\S 58$ AktG die Gewinnverwendungskompetenz zweifellos ausschließlich der Verwaltung $\mathrm{zu}^{997}$. Der Vorstand könnte somit auf Basis seiner weitgehenden Geschäftsführungsbefugnis aus $\S \S 76$ Abs. 1, 77 AktG unter Einbeziehung des Aufsichtsrats den Jahresüberschuss allein nach Vorteilhaftigkeitserwägungen verwenden. Dafür spricht auch die Tatsache, dass in der Bildung von Gewinnrücklagen eine Geschäftsführungsmaßnahme gesehen wird ${ }^{998}$. Insgesamt kann festgehalten werden, dass die individuelle Handlungs- und Vertragsfreiheit eingeschränkt wird; dies ist in einer marktwirtschaftlichen Ordnung kritisch zu hinterfragen und bedarf einer besonderen Rechtfertigung ${ }^{999}$.

Das Ziel der folgenden Ausführungen ist es, mit Hilfe einer regulierungstheoretischen Vorgehensweise zu überprüfen, ob eine staatliche Regulierungsnotwendigkeit für Kapitalschutzregeln abgeleitet werden kann, wobei die gesetzlichen Ausschüttungsregeln im Mittelpunkt stehen. Aus dem umfangreichen Instrumentenkasten von wirtschaftstheoretischen Ansätzen werden mit der Principal-Agent-Theorie und dem Transaktionskostenansatz zwei Ausprägun-

992 Vgl. zu möglichen unternehmensinternen und marktbezogenen Instrumenten im Überblick $F$. Ruhwedel (2003), S. 75-80 m.w.N. Vgl. auch Fülbier (1998b), S. 187-192; Franken (2001), S. 58-76.

993 Dazu zăhlen beispielsweise die umfangreichen Publizitătspflichten von Aktiengesellschaften sowie die in Kapitel II.1.2 behandelten Rechte und Pflichten der Organe von Aktiengesellschaften. Zu den aktienrechtlichen Schutzvorkehrungen im Konzern vgl. ausführlich Emmerich/Habersack (2005), S. 131-452. Vgl. zu einer ökonomischen Analyse der Schutzwirkung der aktienrechtlichen Bestimmungen der $\S \S 311-318$ AktG für Minderheitsaktionäre im faktischen Konzern ausführlich Richardt (1974). 
gen der Neuen Institutionenökonomie ${ }^{1000}$ herangezogen. Darüber hinaus werden marktprozesstheoretische Überlegungen angestellt.

\section{Analyse von Kapitalschutzregeln auf Basis ausgewählter Theorieansätze}

\subsection{Principal-Agent-Theorie}

Wie im vorherigen Kapitel bereits angedeutet, analysiert die Principal-Agent-Theorie vertragliche Auftragsbeziehungen zweier Personen, in der sich der Beauftragte (Agent) gegen eine Entlohnung zur Erbringung bestimmter Leistungen für den Auftraggeber (Principal) verpflichtet $^{1001}$. Die Problematik dieser Beziehung besteht darin, dass die Interessen der Beteiligten asymmetrisch verteilt sind und der Beauftragte einen Wissensvorsprung hat, den er zu Ungunsten des Auftraggebers nutzen kann $^{1002}$. Die in solchen Konstellationen anfallenden Vertretungskosten (agency costs) setzen sich aus den Überwachungskosten (monitoring costs) des Auftraggebers, den Rechenschafts- und Bindungskosten (bonding costs) des Beauftragten und dem verbleibenden Wohlfahrtsverlust trotz Überwachung und Rechenschaftslegung (residual loss) zusammen ${ }^{1003}$.

In der Beziehung zwischen Aktionären (Principal) und Management (Agent) bzw. zwischen Gläubigern (Principal) und Management (Agent) kann eine für diese Theorierichtung typische Auftragsbeziehung gesehen werden ${ }^{1004}$. Fraglich ist, ob die im vorstehenden Kapitel erörterten Konflikte durch Kapitalschutzregulierungen gelöst bzw. zumindest vermindert werden können. Die gesetzlichen Vorschriften bezwecken, dass der aus Sicht der Unternehmensleitung frei verfügbare Cashflow und damit das Potential, liquide Mittel zu verschwenden, reduziert werden ${ }^{1005}$. Dies ergibt sich daraus, dass den Aktionären nach $\S 58 \mathrm{AktG}$ auf der Hauptversammlung die Entscheidung über die Verwendung von in der Regel $50 \%$ des Jahresüberschusses zusteht ${ }^{1006}$. Darüber hinaus kann in der Anfechtungsmöglichkeit gemäß $\S 254 \mathrm{AktG}$ ein Instrument zur Minderung der Eigner-Eigner-Konflikte gesehen werden ${ }^{1007}$. Danach kann eine qualifizierte Minderheit von Aktionären den Beschluss über die Verwendung des Bilanzgewinns anfechten, wenn die Hauptversammlung Beträge in die Gewinnrücklagen einstellt oder als Gewinn vorträgt, obwohl die Thesaurierung wirtschaftlich nicht notwendig ist und nicht einmal eine Dividende in Höhe von 4 \% des Grundkapitals (abzüglich nicht eingeforderter Einlagen) ausgeschüttet wird.

1000 Vgl. zu den verschiedenen Teilgebieten der Neuen Institutionenökonomie Erlei/Leschke/Sauerland (1999), S. 42-44; Richter/Furubotn (2003), S. 39-45; Wolf (2005), S. 259-280.

1001 Vgl. Jensen/Meckling (1976), S. 308. Vgl. zu Vorläufern, Entstehung und Modellrichtungen der PrincipalAgent-Theorie z.B. D. Schneider (1995), S. 42-52; Meinhövel (2005).

1002 Vgl. D. Schneider (1992), S. 618. Vgl. dazu ausfuhrlich auch Crasselt (2003), S. 78-82.

1003 Vgl. grundlegend Jensen/Meckling (1976), S. 308. Vgl. dazu auch Bieker (2006), S.43.

1004 Vgl. D. Schneider (1992), S. 619.

$1005 \mathrm{Vgl}$. so auch Gassen (2000), S. 99.

1006 Wie an anderer Stelle bereits erläutert, kann die Satzung allerdings die Verwaltung dazu ermächtigen, mehr als $50 \%$ des Jahresüberschusses in die anderen Gewinnrücklagen einzustellen, solange die anderen Gewinnrücklagen die Hälfte des Grundkapitals nicht übersteigen (§ 58 Abs. 2 S. 2-3 AktG).

1007 Vgl. so auch Wagenhofer/Ewert (2003), S. 147. 
Aus Sicht der Gläubiger bieten die gesetzlichen Bestimmungen insofern einen Schutz, als sie den ausschüttungsfähigen Gewinn auf die Höhe des nach handelsrechtlichen Bilanzierungsnormen errechneten Bilanzgewinns beschränken. Zudem wird dem Management die Einstellung von Teilen des Jahresüberschusses in die Gewinnrücklagen ermöglicht, wodurch finanzielle Mittel für Investitionszwecke im Unternehmen gebunden und Haftungsfondsmittel erhöht werden. Darüber hinaus erscheint die gläubigerschützende Wirkung der durch das Vorsichtsprinzip geprägten HGB-Rechnungslegung unmittelbar einsichtig. Aktiva werden tendenziell niedriger und Passiva tendenziell höher als der Erwartungswert angesetzt, und erkennbare Verluste werden bereits am Bilanzstichtag berücksichtigt. Die enge Auslegung des Realisationsprinzips nach HGB verhindert die Ausschüttung unrealisierter Gewinne. Das Imparitätsprinzip führt in den Fällen, in denen ursprünglich antizipierte Verluste nicht eintreten, dazu, dass potentielle Ausschüttungen in die Zukunft verlagert werden, was im Hinblick auf die Interessen der Aktionäre als vertretbar angesehen wird ${ }^{1008}$.

Die aufgezeigten Argumentationslinien stellen aber keine hinreichende Regulierungsrechtfertigung dar. In der Literatur ist gezeigt worden, dass die zunehmende Verlagerung der Gewinnverwendungskompetenz von der Verwaltung auf die Aktionäre bei risikoscheuen Managern zu einer abnehmenden Investition in risikobehaftete Projekte mit entsprechend höherer Verzinsung führen kann (managementbedingtes Unterinvestitionsproblem) ${ }^{1009}$. Zudem existieren z.B. mit anreiz- und wertorientierten Entlohnungsverträgen zur Regulierung alternative Marktmechanismen, mit denen das eigennutzorientierte Handeln der Unternehmensleitung mit den Interessen der Anteilseigner in Einklang gebracht werden kann ${ }^{1010}$. Darüber hinaus besteht die Hoffnung, dass möglicherweise durch die zunehmende Entflechtung deutscher börsennotierter Gesellschaften die Funktionsfähigkeit der „Kontrollmärkte“ mit der Folge erhöht wird, dass sich die Principal-Agent-Konflikte zwischen Unternehmensleitung und Aktionären mildern ${ }^{1011}$. Bei funktionierenden Kontrollmärkten werden die Aktionäre auf eine aktionärsfeindliche Unternehmenspolitik mit dem Verkauf ihrer Aktien reagieren, wodurch der Aktienkurs des Unternehmens sinken wird. Mit sinkendem Aktienkurs steigt die Übernahmegefahr und aus Sicht des Managements das Risiko des Arbeitsplatzverlustes. Schließlich nimmt auch die Reputation der Manager Schaden. Insgesamt ergeben sich aus diesen Zusammenhängen für die Unternehmensleitung Anreize, eine aktionärsfreundliche Unternehmenspoltik zu verfolgen. Um potentielle Aktionäre zum Kauf der Aktien zu bewegen und durch Informationsasymmetrien möglicherweise verursachte negative Ausleseprozesse (adverse selection) ${ }^{1012}$ zu vermeiden, wird die Unternehmensleitung im eigenen Interesse versuchen, die asymmetrische Information abzubauen (signaling) ${ }^{1013}$. Auch der Dividendenpolitik kann in diesem Zusammenhang ein Signal-Charakter zukommen; mit ihr kann das Management einen Beitrag zur Reduzierung der Informationsasymmetrie leisten. Eine gesetzliche Regulierung, z.B. in der Form einer (teilweisen) Verwendungsgarantie des Jahresüber-

\footnotetext{
1008 Vgl. Schildbach (2004), S. 43.

1009 Vgl. dazu Pfaff (1989), S. 150-167. Vgl. auch Wagenhofer/Ewert (2003), S. 162. Vgl. zu den ublichen Annahmen, die diesen Modellen zugrunde liegen, ausfürlich Pfaff (1989), S. 64-66, 150-155; Wagenhofer/Ewert (2003), S. 151-158.

1010 Vgl. Pellens/Crasselt/Rockholtz (1998), S. 7-19 m.w.N.

1011 Unterschieden werden der Aktienmarkt als Kontollmarkt, der Markt für Unternehmenskontrolle und der Markt fur Manager. Vgl. grundlegend Jensen/Ruback (1983). Vgl. dazu auch Fülbier (1998b), S. 189-192; Pellens (2001a), S. 136 jeweils m.w.N.

1012 Vgl. hierzu grundlegend Akerlof (1970).

1013 Vgl. Richter/Furubotn (2003), S. 260-262, 294-299 m.w.N.
} 
schusses für die Aktionäre, ist mithin kontraproduktiv. Kann die Unternehmensleitung die Ausschüttungshöhe nicht mehr frei wählen, büßen die Ausschüttungen ihren Signal-Charakter ein.

Aus der Perspektive der Gläubiger ist die Verwendungskompetenz der Hauptversammlung über einen Teil des Gewinns eher kritisch zu sehen. Modelltheoretisch ist aufgezeigt worden, dass eingeschränkte Thesaurierungsmöglichkeiten der Unternehmensleitung $\mathrm{zu}$ reduzierten Kreditspielräumen führen können, die aus einem verschuldungsbedingten Unterinvestitionseffekt resultieren ${ }^{1014}$. Aber auch aus diesem Befund ist keine Regulierungsnotwendigkeit ableitbar, da sich mit den Über- und Unterinvestitionsproblemen gegenläufige Effekte gegenüberstehen, die selbst unter Modellbedingungen keine eindeutigen Handlungsempfehlungen ermöglichen ${ }^{1015}$.

Ähnliches gilt für die Beurteilung der vermeintlich gläubigerschützenden HGB-Rechnungslegungsnormen. Ausführliche ökonomische Wirkungsanalysen ${ }^{1016}$ kommen zu dem Ergebnis, dass sich Ausschüttungsrestriktionen unternehmenswertmindernd auswirken können. Die vorsichtige Bilanzierung kann sich auch auf die Position der Gläubiger ungünstig auswirken und die diesbezüglichen Agency-Probleme verstärken. Aus den Analysen kann gefolgert werden, dass eine allgemeine Vorziehenswürdigkeit des Vorsichtsprinzips in Bezug auf den Gläubigerschutz nicht abzuleiten ist und effiziente Ausschüttungsbeschränkungen nur unternehmensindividuell unter Berücksichtigung sonstiger Restriktionen (z.B. Vereinbarungen in den Kreditverträgen) zu bestimmen sind ${ }^{1017}$.

Zusammenfassend bleibt festzuhalten, dass sich aus den agencytheoretischen Überlegungen keine eindeutige Regulierungsrechtfertigung für die deutschen bzw. europäischen gesetzlichen Kapitalschutznormen ableiten lässt.

\subsection{Transaktionskostentheorie}

Aufgrund der Tatsache, dass die Informationen zwischen den Unternehmensbeteiligten unvollständig und ungleich verteilt sind, müssen die Individuen ökonomische Ressourcen zur Informationsgewinnung, -überprüfung und -verarbeitung einsetzen, um ihren Wissensstand und die Möglichkeiten, untereinander Transaktionen abzuwickeln, zu verbessern ${ }^{1018}$. Die bei der Anbahnung, Durchführung und Überprüfung von Transaktionen anfallenden Such-, Verhandlungs-, Durchsetzungs- und Überwachungskosten werden unter dem Begriff der Transaktionskosten zusammengefasst ${ }^{1019}$. Mit Hilfe der Transaktionskostentheorie ${ }^{1020}$ können ökonomische Organisationen und Aktivitäten daraufhin analysiert werden, inwiefern sie Transaktionskosten verursachen. Durch eine vergleichende Betrachtung kann dann eine Aus-

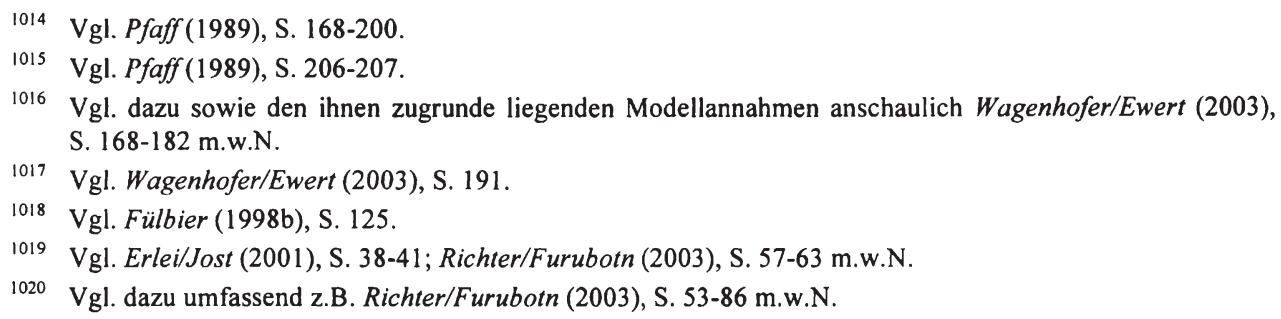


sage getroffen werden, welche Transaktion effizienter als eine andere in dem Sinne ist, dass sie ökonomische Ressourcen weniger stark beansprucht bzw. verschwendet.

Mit transaktionskostentheoretischen Überlegungen eng verbunden ist die Theorie der Eigentums- bzw. Verfügungsrechte (property rights theory), welche die Beziehungen zwischen Individuen und Ressourcen erforscht ${ }^{1021}$. $\mathrm{Zu}$ den Verfügungsrechten der Individuen an einem ökonomischen Gut zählen Nutzungsrechte (usus), Gestaltungs- und Veränderungsrechte (abusus), Nutznießungsrechte (usus fructus) und Veräußerungsrechte ${ }^{1022}$. Mit der Theorie der Eigentumsrechte kann die Vorteilhaftigkeit alternativer Verteilungen von Verfügungsrechten an Unternehmensressourcen hinsichtlich ihrer ökonomischen Effizienz beurteilt werden ${ }^{1023}$.

In einer auf Privateigentum aufbauenden marktwirtschaftlichen Ordnung ist es ein verfassungsrechtlich abgesichertes Prinzip, dass die Anteilseigner die Eigentumsrechte am Gewinn des Unternehmens halten ${ }^{1024}$. Somit stünde den Aktionären die Verwendungskompetenz über den Jahresüberschuss und etwaige Gewinnrücklagen $\mathrm{zu}^{1025}$. Da eine Eigentumsordnung nur dann als effizient zu bezeichnen ist, wenn Transaktionskosten minimiert werden, ist zu klären, ob die alleinige Gewinnverwendungskompetenz der Aktionäre Transaktionskosten verursacht. Transaktionskosten fallen bei einer solchen Kompetenzverteilung beispielsweise dadurch an, dass die Unternehmensleitung am Tag des Hauptversammlungsbeschlusses liquide Mittel in voller Höhe des im vorherigen Geschäftsjahr erwirtschafteten Jahresüberschusses für Ausschüttungszwecke vorhalten müsste. Mithin wüsste die Unternehmensleitung erst mehrere Monate nach dem Bilanzstichtag, ob sie Teile des Jahresüberschusses für Investitionen verwenden kann. Transaktionskosten sind in den resultierenden Opportunitätskosten der entgangenen bzw. verzögerten Investitionsprojekte zu sehen.

Die alleinige Gewinnverwendungskompetenz der Aktionäre könnte Transaktionskosten weiterhin dadurch verursachen, dass sie zu Unsicherheiten bei den übrigen Unternehmensbeteiligten (z.B. Gläubiger, Arbeitnehmer) im Hinblick auf die Erfüllung ihrer Ansprüche führt. Von der Regulierung des $\S 58$ AktG geht insofern eine transaktionskostensenkende Wirkung aus, als sie die Unsicherheit der übrigen Akteure bezüglich der Gewinnverwendung und des maximal an die Anteilseigner ausschüttungsfähigen Betrags reduziert. Allerdings ist darin keine ausreichende Begründung für einen staatlichen Eingriff zu sehen. Die transaktionskostenmindernde Wirkung stellt nämlich für die Beteiligten einen Anreiz dar, die Gewinnverwendungskompetenz der Anteilseigner auf privatvertraglichem Wege, z.B. in der Satzung, zu vereinbaren. Es könnte aber argumentiert werden, dass eine gesetzliche Regelung mit einer höheren Stabilität und folglich auch mit einer höheren Sicherheit für die übrigen Beteiligten einhergeht ${ }^{1026}$. Die in der 50\%-Regel des $\S 58 \mathrm{AktG}$ zum Ausdruck kommende Kompetenzverteilung könnte als ein effizientes Arrangement der Eigentumsrechte angesehen werden, die den Interessen der Unternehmensbeteiligten gleichermaßen Rechnung trägt.

\footnotetext{
1021 Vgl. Richter/Furubotn (2003), S. 87-144 m.w.N.

1022 Vgl. z.B. Picot/Schuller (2001), S. 83; Richter/Furubotn (2003), S. 23.

1023 Vgl. Pellens (1994), S. 190.

1024 Vgl. ähnlich Gassen (2001), S. 405.

1025 Vgl. Gassen (2001), S. 406.

1026 Vgl. Gassen (2001), S. 406, der in einer Satzungsautonomie Unsicherheiten für die Unternehmensbeteiligten sieht, da sich die Mehrheitsverhältnisse innerhalb des Gesellschafterkreises ändern und Satzungsänderungen folglich nicht ausgeschlossen werden können.
} 
Durch die bereits mehrmals angesprochene Öffnungsklausel des $\S 58 \mathrm{AktG}$, durch welche die Thesaurierungsmöglichkeiten der Verwaltung erhöht und die Gewinnverwendungskompetenzen der Hauptversammlung bis auf Null reduziert werden können, werden Unsicherheiten auf Seiten der Minderheitsaktionäre induziert. Von diesen Unsicherheiten sind sowohl die aktuellen als auch die potentiellen Minderheitsaktionäre betroffen, da eine Satzungsänderung jederzeit mit Dreiviertelmehrheit ( $\$ 179$ Abs. 2 AktG) beschlossen werden kann und ihre Interessen dabei unberücksichtigt bleiben können. Im Gegensatz zu Gesellschaftern einer GmbH sind aber die Aktionäre von börsennotierten Aktiengesellschaften nicht ,in der Transaktion mit dem Unternehmensmanagement gefangen ${ }^{\text {1027 }}$, da bei einem gut funktionierenden Sekundärmarkt eine jederzeitige Veräußerung ihrer Anteile möglich ist ${ }^{1028}$. Somit erscheint die Öffnungsklausel bei börsennotierten Aktiengesellschaften unproblematisch und weitere Regulierungen zum Minderheitenschutz, wie z.B. der nicht sehr weitreichende Schutzmechanismus des $\S 254$ AktG, unnötig.

Erneut ist auf alternative institutionelle Arrangements hinzuweisen, die ebenfalls in der Lage sind, den Interessen der Unternehmensbeteiligten gerecht zu werden. Zusätzlich zu den bereits angesprochenen Vereinbarungen in der Satzung sind hier verschiedene Formen von Beherrschungs- und Überwachungssystemen, wie z.B. ein mitbestimmter Aufsichtsrat oder privatautonom ausgestaltete Kreditverträge, die auf Eigeninteressen beruhende Sicherungs- und Sanktionsmechanismen beinhalten, zu nennen. Es kann zwar argumentiert werden, die Kapitalschutzregeln als gesetzlich vorgegebener Standardvertrag entfalteten eine transaktionskostensenkende Wirkung. Die Unternehmenspraxis zeigt aber, dass sich z.B. bestimmte Gläubigergruppen trotz der bestehenden gesetzlichen Vorschriften durch detailliert ausgehandelte und den unternehmensindividuellen Gegebenheiten dezidiert Rechnung tragende Kreditvereinbarungen zusätzlich schützen ${ }^{1029}$.

Abschließend sind die Auswirkungen der gesetzlich vorgegebenen HGB-Rechnungslegung auf die Transaktionskosten der Akteure zu beurteilen. Wären die Rechnungslegungsregeln für Aktiengesellschaften nicht gesetzlich vorgeschrieben, müssten sich sowohl die Aktionäre als auch die sonstigen Akteure, insbesondere die Fremdkapitalgeber, auf die anzuwendenden Regeln verständigen. Solche vertraglichen Vereinbarungen würden zu Verhandlungskosten führen, die umso höher ausfallen würden, je größer der Aktionärskreis und je detaillierter die Regeln wären. Durch die gesetzliche Standardisierung werden diese Verhandlungskosten gespart. Zudem kann sich die Standardisierung transaktionskostenmindernd auf die externe Bilanzanalyse auswirken, da sie zu einer erhöhten Vergleichbarkeit der Abschlüsse führt ${ }^{1030}$. Die gläubigerschützende und damit transaktionskostensenkende Wirkung der HGB-Rechnungslegung ist indes aufgrund der zahlreichen Bilanzierungswahlrechte zu relativieren. Wie bereits ausführlich aufgezeigt wurde, gewähren die Gewinnermittlungsregeln dem Management erhebliche bilanzpolitische Spielräume, so dass weder die Aktionäre vor ungerechtfertigten Gewinnverkürzungen noch Gläubiger und Aktionäre vor einer absichtlichen Fehlinformation über die wirtschaftliche Lage des Unternehmens wirksam geschützt werden ${ }^{1031}$. Schließlich ist festzustellen, dass Fremdkapitalgeber in Kreditvereinbarungen in vielfältiger Weise von

1027

1028

1030

1031

Gassen (2001), S. 407.

Allerdings verursacht der Aktienverkauf selbst (geringe) Transaktionskosten. Zudem kommt es zu einer Besteuerung des Veräußerungsgewinns, wenn die Anteile innerhalb der Spekulationsfrist verkauft werden.

Vgl. zu Kreditvereinbarungen in den USA, Großbritannien und Deutschland ausführlich Kapitel V.5.4.1.

Vgl. dazu z.B. Streim (1988), S. 24.

Vgl. Streim (1988), S. 158. Vgl. zu den Gewinnermittlungsregeln nach HGB ausführlich Kapitel III.1.1.3.2. 
den handelsrechtlichen Regeln abweichen ${ }^{1032}$. Mithin ist die transaktionskostenmindernde Wirkung zumindest für die Gruppe der verhandlungsstarken Gläubiger als eher gering einzuschätzen. Sofern die gesetzlichen Vorschriften aus Sicht der Vertragsparteien als zu streng angesehen werden, ist zudem eine davon abweichende vertragliche Übereinkunft unmöglich $^{1033}$.

Im Ergebnis bleibt festzuhalten, dass sich auch aus den transaktionskostentheoretischen Überlegungen eine eindeutige Regulierungsnotwendigkeit für die bestehenden Kapitalschutzregeln von Aktiengesellschaften - insbesondere, wenn sie börsennotiert sind - nicht ableiten lässt.

\subsection{Marktprozesstheorie}

Nachdem in den vorangegangen beiden Kapiteln Denkrichtungen der Neuen Institutionenökonomie zur Beurteilung der Regulierungsnotwendigkeit herangezogen wurden, werden abschließend Ansätze der prozessorientierten Evolutions- und Koordinationstheorie ${ }^{1034}$ bemüht, die auch als Marktprozesstheorie bezeichnet werden können ${ }^{1035}$. In dieser Theoriewelt, der insbesondere Vertreter der Österreichischen Schule um Schumpeter, v. Mises, Kirzner und vor allem $v$. Hayek zugerechnet werden ${ }^{1036}$, stehen Koordinationsinstrumente im Vordergrund, die vor dem Hintergrund sich ständig verändernder Umweltbedingungen Anpassungs- und Entdeckungsprozesse ermöglichen. Die Intensität, Geschwindigkeit und Kosten dieser Prozesse werden als Effizienzmaßstab betrachtet ${ }^{1037}$. Unvollkommene und asymmetrisch verteilte Informationen werden nicht als Problem angesehen, sondern als grundlegende Voraussetzung für Anpassungsprozesse ${ }^{1038}$. Die Anpassungsprozesse werden mit dem individuellen Streben der Wirtschaftssubjekte nach Wettbewerbsvorteilen durch Erweiterung der subjektiven Informationsmenge erklärt ${ }^{1039}$. Es entsteht ein Wettbewerb, der die Informationsaufdeckung und -verbreitung fördert, findiges und innovatives Verhalten und folglich die Herausbildung neuen Wissens begünstigt ${ }^{1040}$. Das wichtigste Koordinationsinstrument für die Wirtschaftssubjekte stellt dabei der Markt- und Preismechanismus dar ${ }^{1041}$, dessen Funktionsfähigkeit zur Vermittlung von Informationen zu sichern ist. Als Ergebnis des Wettbewerbs als „Entdeckungsverfahren" ${ }^{1042}$ können sich Institutionen herausbilden, die Unsicherheiten und Transaktionskosten reduzieren und ein Zeichen für die Selbstorganisationsfähigkeit des Marktes darstellen ${ }^{1043}$. Staatliche Eingriffe in die Handlungsfreiheiten der Akteure werden folglich kritisch

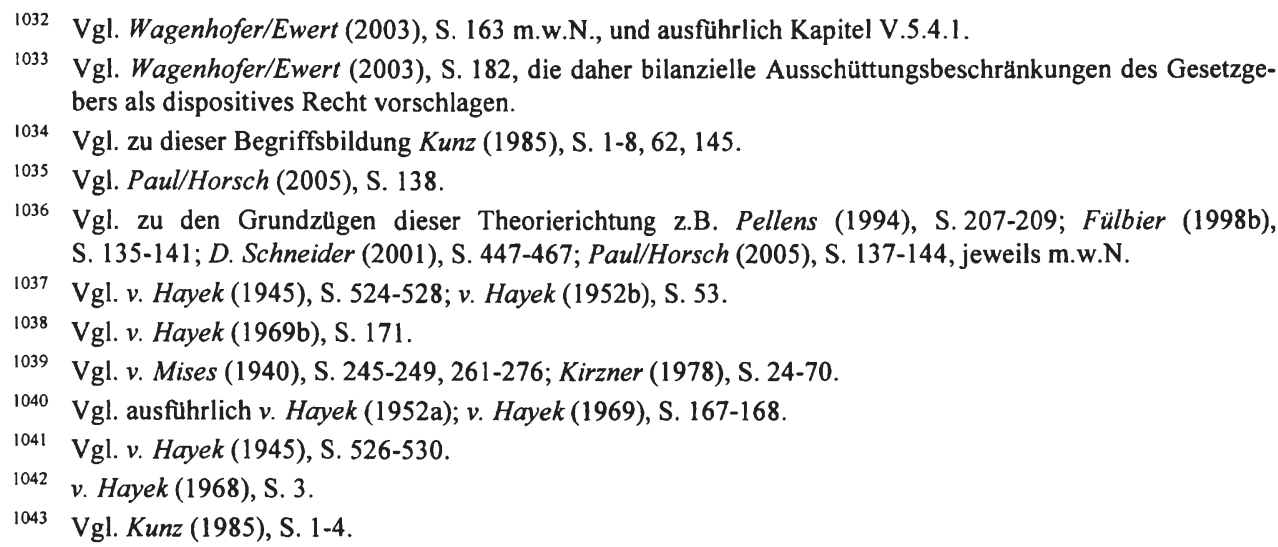


gesehen. Dem Staat wird vielmehr die Aufgabe zugesprochen, die Freiheit der Individuen zu schützen, damit Wettbewerbshandlungen entstehen können ${ }^{1044}$. Positive Rechtsetzungen werden allenfalls dann für zulässig erachtet, wenn sie stabilisierende Wirkung entfalten, indem sie Koordinations- und Anpassungskosten sparen und die Erwartungsbildung der Unternehmensbeteiligten erleichtern ${ }^{1045}$.

Indem die Vorschrift des $\S 58 \mathrm{AktG}$ eine bestimmte Handlung erzwingt, stellt sie eine positive Rechtsetzung dar. Durch $\S 58 \mathrm{AktG}$ ist die Geschäftsleitung grundsätzlich gezwungen, der Hauptversammlung mindestens $50 \%$ des Jahresüberschusses zur Verwendung vorzuschlagen. Fraglich ist nun, ob von dieser Kompetenzverteilungsregel eine stabilisierende Wirkung ausgeht. Vor dem Hintergrund regelmäßiger Veränderungen in der personellen Zusammensetzung der Eigentümerstruktur und der wirtschaftlichen Lage von Aktiengesellschaften mag $\S 58 \mathrm{AktG}$ die Erwartungsbildung der Anteilseigner hinsichtlich künftiger Liquiditätszuflüsse aus ihrem Aktienengagement erleichtern. Ähnliches gilt für die sonstigen Unternehmensbeteiligten, deren Erwartungsbildung über die der Aktiengesellschaft maximal entziehbaren Mittel erleichtert wird. Dem ist allerdings zum einen entgegenzuhalten, dass die Hauptversammlung jederzeit mit Dreiviertelmehrheit die Gewinnverwendungskompetenz der Verwaltung ausweiten oder einschränken kann. Zum anderen wird die Erwartungsbildung dadurch beeinträchtigt, dass die Unternehmensleitung im Rahmen der Gewinnermittlung einen erheblichen bilanzpolitischen Spielraum hat, mit dem sie die Höhe der ausschüttungsfähigen Beträge gezielt beeinflussen kann. Dies gilt in besonderer Weise für Konzernunternehmen ${ }^{1046}$.

Eine Regulierungsnotwendigkeit ist auch vor dem Hintergrund der Fähigkeit des Markts zur Selbstorganisation nicht abzuleiten. In der hier herangezogenen Theoriewelt werden Märkte als spontane und evolutorische Ordnungen verstanden, denen die Tendenz zum Abbau von Koordinations- und Anpassungskosten immanent ist. §58 AktG steht wettbewerblichen Entdeckungsprozessen entgegen. Die bereits angesprochenen institutionellen Alternativen zur aktienrechtlichen Verteilung der Gewinnverwendungskompetenz sind hier ebenso zu nennen wie die möglichen Kosteneinsparpotentiale noch unbekannter, sich evolutorisch entwickelnder „Neuentdeckungen“.

Ein etwas anderes Bild ergibt sich bei der marktprozesstheoretischen Beurteilung der HGBRechnungslegung als Teil des Kapitalschutzkonzepts für Aktiengesellschaften. Eine stabilisierende Wirkung kann sich insofern entfalten, als sich die Unternehmensbeteiligten auf ein vorgegebenes Regelset zur Ermittlung des ausschüttungsfähigen Gewinns verlassen können ${ }^{1047}$. Durch die Prinzipienbasiertheit der HGB-Rechnungslegung ${ }^{1048}$ besteht weiterhin die Möglichkeit, evolutorisch sich herauskristallisierende neue Geschäftsmodelle und Finanzkonstrukte bilanziell abzubilden, ohne dass zunächst eine Bilanzierungsregel geschaffen werden muss. Fraglich ist allerdings, ob die Unternehmensbeteiligten in einem weniger regulierten Umfeld die handelsrechtlichen Bilanzierungsregeln ausgehandelt hätten. Zweifel bestehen hier insbesondere hinsichtlich der vielfältigen expliziten HGB-Bilanzierungswahlrechte, die den Handlungsspielraum des Managements zu Lasten der sonstigen Unternehmensbeteiligten

1044 Vgl. v. Hayek (1969a), S. 113-117; v. Hayek (1981), S. 58-62.

1045 Vgl. v. Hayek (1981), S. 47-49. Zu weiteren Ausnahmen vgl. Fülbier (1998b), S. 197 m.w.N.

1046 Zur Begründung vgl. Kapitel III.1.1.3.3.

1047 Zu einer Analyse des Markts für Rechnungslegungssysteme und der Gefahr des Marktversagens vgl. Pellens/Gassen (1998), S. 635-645; Pellens (2001a), S. 600-604.

1048 Vgl. Moxter (1986), S. 7-8; Leffson (1987), S. 19; Schildbach (2004), S. 133-134; Baetge/Kirsch/Thiele (2005), S. 104-105. 
ausweiten. Zudem ist festzustellen, dass Fremdkapitalgeber deutscher Unternehmen in Kreditverträgen häufig die HGB-Regeln modifizieren ${ }^{1049}$.

Werden die deutschen Kapitalschutznormen insgesamt betrachtet, ist ebenfalls zweifelhaft, ob sie sich auf einem unregulierten Markt in dieser Form durchgesetzt hätten. Obschon ein Vergleich mit den Gegebenheiten in den USA aufgrund unterschiedlicher sozio-ökonomischer Faktoren ${ }^{1050}$ nur eingeschränkt möglich ist ${ }^{1051}$, ist die Entwicklung der Kapitalschutzregeln in den USA in den letzten Jahrzehnten aus marktprozesstheoretischer Sicht interessant. Wie bereits aufgezeigt worden ist, existierten in den USA vor ca. 100 Jahren mit Nennwertaktien, einem Mindestkapitalerfordernis, dem Verbot des stock watering und der trust fund theory Kapitalaufbringungs- und -erhaltungsregeln ${ }^{1052}$, die den aktuellen deutschen bzw. europäischen Vorschriften ähneln ${ }^{1053}$. Im 20. Jahrhundert wurden viele dieser gesetzlichen Vorschriften im Rahmen des Wettbewerbs der einzelstaatlichen Gesellschaftsrechte in der Überzeugung abgeschafft, dass sie als Schutzinstrument für die Unternehmensbeteiligten unbrauchbar seien. Wie ausführlich dargestellt, existiert heutzutage in den meisten Bundesstaaten der USA gesellschaftsrechtlich nur noch ein Mindestschutz, der durch insolvenzrechtliche Schutzmechanismen ergänzt wird ${ }^{1054}$. Im Vergleich zur Situation in Deutschland werden die unternehmerischen Handlungsspielräume im Vorhinein viel weniger eingeschränkt, und Missbräuche werden nachträglich bestraft ${ }^{1055}$. Privatvertraglich ausgehandelte Ausschüttungsrestriktionen in Kreditverträgen haben in den USA hingegen eine lange Tradition ${ }^{1056}$ und können als eine Ausprägung der individualistisch organisierten US-amerikanischen Gesellschaft gesehen werden $^{1057}$. Ein Indiz dafür, dass die aktuellen gesetzlichen Kapitalschutzregeln zumindest aus US-amerikanischer Sicht für zweckmäßig und ausreichend angesehen werden, ist darin zu sehen, dass der Wandel ,in den USA kaum je kontrovers war und mittlerweile jedem Zweifel enthoben ist. Theorie und Praxis, Juristen und Ökonomen stimmen überein, daß der neue $\mathrm{Zu}$ stand dem alten entschieden vorzuziehen ist ${ }^{\text {“1058 }}$.

Zusammenfassend bleibt festzuhalten, dass auch aus marktprozesstheoretischer Sicht eine Regulierungsnotwendigkeit von Kapitalschutzregeln nicht zu erkennen ist.

\subsection{Zwischenergebnis}

Die regulierungstheoretischen Ausführungen unter Berücksichtigung der Principal-AgentTheorie, des Transaktionskostenansatzes und der Marktprozesstheorie haben ergeben, dass

\footnotetext{
1049 Vgl. dazu und der Infragestellung der These, in US-amerikanischen Kreditverträgen würden regelmaßig Rechnungslegungsregeln vereinbart, die mit HGB weitgehend ubereinstimmen, Kapitel V.5.4.1.4.

1050 Vgl. dazu Pellens (2001a), S. 21-28.

1051 Zu den Schwierigkeiten von rechtsvergleichenden Betrachtungen vgl. z.B. Großfeld (1996), S. 106-125.

1052 Vgl. Kapitel III.2.1.

1053 Vgl. auch Kübler (1989), S. 64; Kübler (1994), S. 146.

1054 Vgl. Kapitel III.2.2-III.2.4.

1055 Vgl. auch Kübler (1989), S. 33.

1056 Vertraglich Ausschüttungsrestriktionen waren bereits weit verbreitet als das legal capital-Regime noch existierte. Vgl. Mülbert (2004), S. 157.

$1057 \mathrm{Vgl}$. zur Gegenüberstellung von individualistischen und kollektiven Gesellschaften Pellens (2001a), S. 22.

1058 Kübler (1998b), S. 345. Vgl. ähnlich auch Ackerman/Sterrett (1976), S. 1052, Fn. 2; Peterson/Hawker (1997), S. 176-177 m.w.N.; Grundmann (2001), S. 817; Kübler (2003c), S. 103; Mülbert (2004), S. 157.
} 
der regulierende Eingriff des deutschen bzw. europäischen Gesetzgebers in die Gewinnermittlung und Gewinnverwendung kaum zu rechtfertigen ist. Die theoretischen Betrachtungen sprechen zumindest für börsennotierte Aktiengesellschaften und bei gut funktionierendem Sekundärmarkt vielmehr für eine weitgehende Deregulierung der bestehenden gesetzlichen Vorschriften.

Eine Deregulierung auf europäischer Ebene erscheint allerdings in der näheren Zukunft mehr als unwahrscheinlich. Weder die vorgeschlagene Richtlinie vom 21.09.2004 zur Änderung der Kapitalrichtlinie noch der im Mai 2003 vorgestellte Aktionsplan der EU-Kommission enthalten Hinweise darauf, dass der europäische Gesetzgeber zukünftig auf regulierende Eingriffe in das Kapitalsystem der Aktiengesellschaft verzichten und ausschließlich auf Marktkräfte vertrauen will. Insofern sähen sich Reformvorschläge, die ausschließlich aus den vorstehenden ökonomischen Theorien abgeleitet sind, der berechtigten Kritik ausgesetzt, einen Mangel an Realitätssinn aufzuweisen.

Im weiteren Verlauf der Arbeit soll daher das Augenmerk auf die Ziele gelenkt werden, die der europäische Gesetzgeber bei der ursprünglichen Entwicklung des europäischen Kapitalsystems und dem in den letzten Jahren eingeleiteten Reformprozess verfolgt. Es soll kritisch hinterfragt werden, ob der bestehende Kapitalschutz den selbst gesetzten Ansprüchen des europäischen Gesetzgebers genügt. Die durch die EU-Kommission fomulierten Ziele der Reformmaßnahmen werden sodann den Maßstab bilden, mit dem verschiedene konkrete Reformvorschläge für ein langfristig zu etablierendes Alternativmodell beurteilt werden sollen.

\section{Zielsetzungen des europäischen Gesetzgebers}

\subsection{Ziele des bestehenden Kapitalsystems}

Die beabsichtigten Zwecke des europäischen Kapitalsystems sind bereits an verschiedenen Stellen der Arbeit angeklungen und werden nun noch einmal kurz zusammengefasst. Die Regulierungsnotwendigkeit der Kapitalaufbringung und Kapitalerhaltung der Aktiengesellschaft wird in den Erwägungsgründen der Kapitalrichtlinie erläutert ${ }^{1059}$. Die Kapitalrichtlinie stützt sich auf Art. 44 Abs. 2 g EGV $^{1060}$. Bei dieser Norm handelt es sich um die Ermächtigungsgrundlage, nach welcher der Europäische Rat und die Europäische Kommission in einem durch Art. 251 EGV näher geregelten Verfahren Richtlinien erlassen können, indem sie ,soweit erforderlich die Schutzbestimmungen koordinieren, die in den Mitgliedstaaten den Gesellschaften im Sinne des Artikels 48 Absatz 2 im Interesse der Gesellschafter sowie Dritter vorgeschrieben sind, um diese Bestimmungen gleichwertig zu gestalten. "1061 Die Kapitalrichtlinie ist somit als ein Teil des europäischen Sekundärrechts zu sehen, das der Verwirklichung des europäischen Primärrechts, insbesondere der Vorschriften zur Niederlassungsfreiheit, $\operatorname{dient}^{1062}$.

Art. 44 Abs. 2g EGV zielt aber nicht nur auf die Verwirklichung der Niederlassungsfreiheit $a b$, sondern auch auf die Herstellung gleichartiger Rahmenbedingungen für die Gesellschaften

\footnotetext{
1059 Die Erwăgungsgründe sind gemaßß Art. 253 EGV Bestandteil der Richtlinie.

1060 Dies enspricht Art. 54 Abs. 3g a.F. EGV.

1061 Art. 44 Abs. 1 EGV

1062 Vgl. Habersack (2003), S. 1-2.
} 
in der $\mathrm{EU}^{1063}$. Die Notwendigkeit der Koordinierung der gesellschaftsrechtlichen Vorschriften und des Abbaus der Niederlassungsschranken im Hinblick auf das Kapitalsystem von Aktiengesellschaften wird damit begründet, dass ,,in der Wirtschaft der Mitgliedstaaten die Tätigkeit dieser Gesellschaften vorherrscht und häufig die Grenzen des nationalen Hoheitsgebiets überschreitet. " 1064 Darüber hinaus handelt es sich um diejenige Rechtsform, in der Unternehmen die organisierten Kapitalmärkte in Anspruch nehmen können ${ }^{1065}$.

Die Harmonisierung soll jeden Interessierten in der EU in die Lage versetzen, sich durch die Satzung der Aktiengesellschaft über ihre wesentlichen Eigenschaften und die Zusammensetzung ihres Kapitals zu informieren ${ }^{1066}$. Die Vorschriften über die Gründung der Aktiengesellschaft, die Kapitalerhaltung sowie die Kapitalerhöhungen und -herabsetzungen bezwecken, die Aktionäre der Gesellschaft einerseits und die Gläubiger andererseits gemeinschaftsweit gleich zu behandeln ${ }^{1067}$. Der Schutz der Gläubiger wird besonders hervorgehoben. Um zu gewährleisten, dass das Kapital als Sicherheit für die Gläubiger erhalten bleibt, sollen Ausschüttungen des eingezahlten Kapitals an die Aktionäre verhindert und die Möglichkeiten der Gesellschaften, eigene Aktien zu erwerben, eingeschränkt werden ${ }^{1068}$.

Im Hinblick auf die Ausschüttungsregulierung der Aktiengesellschaft ist die Kapitalrichtlinie in engem Zusammenhang mit der Bilanzrichtlinie zu sehen, denn sie enthält die Rechnungslegungsvorschriften und determiniert damit die Basis, auf welche die Vorschriften der Kapitalrichtlinie anzuwenden sind. Gäbe es die Bilanzrichtlinie nicht, könnten die Ziele der Kapitalrichtlinie nur eingeschränkt oder gar nicht erreicht werden. In den Mitgliedstaaten der EU könnten dann unterschiedliche Rechnungslegungssysteme zur Anwendung kommen, die dem angestrebten Mindestmaß an gemeinschaftsweiter Gleichwertigkeit von Aktionären und Gläubigern zuwiderlaufen und gegebenenfalls die Schutzfunktion des Kapitals aushöhlen würden.

Auch die Bilanzrichtlinie stützt sich auf Art. 44 Abs. 2g EGV. Wie bei der Kapitalrichtlinie wird die Harmonisierungsnotwendigkeit mit der wirtschaftlichen Bedeutung der betroffenen Gesellschaften ${ }^{1069}$ begründet ${ }^{1070}$. Durch die Vorschriften zum Inhalt und zur Offenlegung von Jahresabschluss und Lagebericht sollen die Gesellschafter und Dritte geschützt werden ${ }^{1071}$. Um für die im Wettbewerb miteinander stehenden Gesellschaften gleichwertige rechtliche Mindestbedingungen zu gewährleisten, müssen laut Bilanzrichtlinie der Umfang der zu publizierenden Daten harmonisiert und die Bewertungsmethoden, ,soweit erforderlich“, vereinheitlicht werden ${ }^{1072}$. Bedeutsam ist in diesem Zusammenhang auch, dass die vorgeschriebe-

1063 Darauf ist auch vom EuGH in seiner „Daihatsu“-Entscheidung vom 09.12.1997 hingewiesen worden. Vgl. zum Ganzen Schön (1998); Schwarz (2000), S. 124-128; Habersack (2003), S. 22-24; Grundmann (2004), S. 44-46. Vgl. auch EU-Kommission (2003a), S. 6. 
nen Gliederungsschemata und die Mindestinhalte von Anhang und Lagebericht dem Zweck dienen, mit dem Jahresabschluss ein den tatsächlichen Verhältnissen entsprechendes Bild der Vermögens-, Finanz- und Ertragslage der Gesellschaft zu vermitteln ${ }^{1073}$. Trotz der Verankerung dieses true and fair view-Prinzips britischen Rechts ${ }^{1074}$ in den Erwägungsgründen und insbesondere in Art. 2 Abs. 3 bis 5 ist der Text der Bilanzrichtlinie auch erheblich vom Gläubigerschutzprinzip deutscher Herkunft geprägt, so dass der explizite Vorrang eines der beiden Prinzipien nicht festzustellen ist ${ }^{1075}$. Die grundsätzlich $\mathrm{zu}$ beachtenden Anschaffungs- und Herstellungskosten als Wertobergrenze für Vermögensgegenstände sind beispielsweise eine Ausprägung des Vorsichtsprinzips, wodurch es zu einem Verstoß gegen den Grundsatz des true and fair view kommen kann. Es ist allerdings festzustellen, dass die Rechtsprechung des EuGH zur phasengleichen Gewinnvereinnahmung ${ }^{1076}$ und die Reformen durch die FairValue- und die bereits angesprochene Modernisierungsrichtlinie dazu führen, dass die Bilanzrichtlinie in den letzten Jahren zunehmend von angloamerikanischen Vorstellungen geprägt wird. Durch die große Anzahl an Mitgliedstaatenwahlrechten und Ausschüttungssperren kann auf nationaler Ebene aber weitgehend am bestehenden Kapitalschutzsystem festgehalten werden.

\subsection{Ziele der eingeleiteten Reformmaßnahmen des Kapitalsystems}

Mit einer ganzen Reihe von Maßnahmen im Bereich des Gesellschaftsrechts und der Corporate Governance verfolgt die EU-Kommission das Ziel, die Leistungs- und Wettbewerbsfähigkeit der EU-Unternehmen zu steigern, die Aktionärsrechte zu stärken und den Schutz Dritter zu verbessern ${ }^{1077}$. Eine Reform der Kapitalrichtlinie, einem der „Eckpfeiler des europäischen Gesellschaftsrechts" ${ }^{\circ 1078}$, ist Teil dieses Konzepts. Bei der Modernisierung der Gläubigerschutzvorschriften im Rahmen des Kapitalsystems soll ausdrücklich sichergestellt werden, dass ,ein hoher Qualitätsstandard beibehalten“1079 wird.

Der im September 2004 vorgelegte Vorschlag einer Änderungsrichtlinie trägt diesen Grundsätzen Rechnung. Wie bereits in Kapitel IV.5 im Einzelnen dargestellt, soll kurzfristig eine Reihe von moderaten Korrekturen vorgenommen werden, damit die Unternehmen in der EU kostengünstiger und flexibler auf Marktentwicklungen reagieren können. Damit soll ein Beitrag geleistet werden, die Unternehmen der Gemeinschaft in ihrer Leistungs- und Wettbe-

\footnotetext{
1073 Vgl. BilRL, vierter Erwägungsgrund.

1074 Vgl. § 226 Abs. 2 Companies Act 1985.

1075 So auch Habersack (2003), S. 223; Grundmann (2004), S. 235. A.A. Schwarz (2000), S. 292-293. Hennrichs (1999b), S. 133-151, sieht in dem true and fair view-Grundsatz die Hauptzielsetzung der Bilanzrichtlinie, die bei ihrer Auslegung zu berücksichtigen ist.

1076 Vgl. EuGH, Urteil vom 27.06.1996 - Rs. C-234/94, Slg. 1996, I-3145 - Tomberger. Im vorliegenden Fall ging es um die Frage, ob die Aktivierung von Gewinnansprüchen in der Bilanz des Mutterunternehmens bereits in dem Geschäftsjahr, in dem der Gewinn im Tochterunternehmen angefallen ist, gegen das Vorsichtsprinzip verstößt. Das Gericht hält die phasengleiche Aktivierung für vereinbar mit dem Realisationsprinzip gemäß Art. 31 Abs. 1 BilRL und begründet dies mit dem Grundsatz des true and fair view. Vgl. dazu ausführlich Habersack (2003), S. 232-236 m.w.N.

1078 EU-Kommission (2003a), S. 20.

1079 EU-Kommission (2003a), S. 9.
} 
werbsfähigkeit zu stärken, ohne dass der Gläubigerschutz verringert wird ${ }^{1080}$. Bis mindestens zum Jahre 2009 wird am System des Mindestkapitals und der Nennwertaktien festgehalten.

Werden die Reformvorschläge für die Kapitalrichtlinie und die bereits durchgeführten Reformen der Bilanzrichtlinie zusammen betrachtet, ist aber zumindest eine Akzentverschiebung innerhalb des europäischen Kapitalsystems zu beobachten. Es zeigt sich, dass die Anzahl der Mitgliedstaatenwahlrechte zunimmt, wodurch sich der Gestaltungsspielraum der nationalen Gesetzgeber erhöht. Der größer werdende Spielraum für einen Wettbewerb der nationalen Gesetzgeber untereinander geht einher mit Einbußen bei der europaweiten Harmonisierung des Gesellschaftsrechts. Weiterhin wird bei Regulierungsmaßnahmen in zunehmend stärkerem Maße nicht nur nach Rechtsform und Größe, sondern auch nach Börsennotierung unterschieden.

Als zentrales Ergebnis der vorstehenden Ausführungen kann schließlich Folgendes festgehalten werden: Der EU-Gesetzgeber ist einerseits der festen Ansicht, dass das bestehende Kapitalsystem die Gläubiger in zuverlässiger Weise schützt. Ein Alternativmodell soll andererseits nur eingeführt werden, wenn es die Gläubiger ebenso wirksam schützt und darüber hinaus einen zusätzlichen Nutzen stiftet. Dies gilt es im nachfolgenden Kapitel ökonomisch zu analysieren.

\section{5 Ökonomische Analyse des europäischen Kapitalsystems}

\subsection{Anspruch des europäischen Kapitalsystems}

In der Literatur werden zahlreiche Funktionen und Stärken des europäischen Kapitalsystems diskutiert. Im Wesentlichen werden die folgenden Funktionen und Merkmale des Kapitals genannt:

- Korrelat der Haftungsfreistellung: Die gesetzlichen Kapitalaufbringungs- und Kapitalerhaltungsregeln werden traditionell als Korrelat der Haftungsbeschränkung der Gesellschafter gesehen ${ }^{1081}$. Für die Verbindlichkeiten einer deutschen Aktiengesellschaft haftet nur das Gesellschaftsvermögen ( $§ 1 \mathrm{Abs} .2 \mathrm{AktG})$, so dass die Gläubiger sich mangels einer persönlichen Haftung grundsätzlich nicht an die Aktionäre halten können. Durch das gesetzlich vorgeschriebene Mindestkapital von $25.000 €$ (Art. 6 Abs. 1 KapRL) bzw. $50.000 €(\S 7 \mathrm{AktG})$ sind die Aktionäre verpflichtet, eine Art „Prämie“ für den Genuss der Haftungsfreistellung zu leisten ${ }^{1082}$.

- Seriositätsfunktion: Ein Rechtfertigungsgrund für das Mindestkapitalerfordernis wird darin gesehen, dass es die Funktion eines Seriositätstests für Unternehmensgründungen

1081 Vgl. Müller-Erzbach (1928), S. 246; Lutter (1964), S. 41; Wiedemann (1968), S. 6, 18; Wiedemann (1980), S. 557-558; Lutter (1983), S. 167-168; Niedernhuber (1988), S. 37; Kübler (1991), S. 397, 403-412; Gansen (1992), S. 3-4; Kübler (1995b), S. 552; U. Hansen (1996), S. 133; Lutter (1998b), S. 375; Bayer (2000), S. 1016; Fleischer (2000), S. 1015; Schwarz (2000), S. 369; Watrin (2001a), S. 212; Baldamus (2002), S. 79; K. Schmidt (2002), S. 540-541; Habersack (2003), S. 113; Hueck/Windbichler (2003), S. 252; Hennrichs (2004), S. 125; Merkt (2004a), S. 312; Schön (2004a), S. 166; Hüffer (2006), §1, Tz. 10.

Vgl. Lutter (1983), S. 167. 
wahrnimmt ${ }^{1083}$. Gesellschafter, die nicht in der Lage sind, den gesetzlich vorgesehenen Kapitalbetrag für die Gründung einer Aktiengesellschaft aufzubringen, sollen das Haftungsprivileg nicht in Anspruch nehmen dürfen. Da unternehmerische Tätigkeit für Gläubiger und sonstige Unternehmensbeteiligte auch mit Risiken verbunden ist, soll dazu nur derjenige befugt sein, der bei einem wirtschaftlichen Zusammenbruch auch sein eigenes Kapital aufs Spiel setzt. Die zwingende Ausstattung mit Eigenkapital soll auf diese Weise zum einen das wirtschaftliche Umfeld, insbesondere die Gläubiger der Aktiengesellschaft, schützen und zum anderen unternehmerisch Unbedarfte vor eigenem Schaden bewahren $^{1084}$. Das Mindestkapital soll auch verhindern, dass Kleinstunternehmen die Rechtsform einer Kapitalgesellschaft für ihre wirtschaftliche Tätigkeit wählen ${ }^{1085}$.

- Betriebskapitalfunktion: Das von den Aktionären eingezahlte Kapital steht der Gesellschaft als Startkapital zur Aufnahme der Geschäftstätigkeit und für Investitionszwecke zur Verfügung und hat damit die Eigenschaft von Betriebskapital ${ }^{1086}$. Dieses Betriebskapital ist insbesondere in der Anfangsphase eines Unternehmens notwendig, da die üblicherweise anfallenden Anlaufverluste bei vollständiger Fremdkapitalfinanzierung zur Insolvenz durch Überschuldung führen würden. Es wird zudem darauf hingewiesen, dass die Kapitalregeln einen - wenn auch unzureichenden - Beitrag zur angemessenen Eigenkapitalausstattung der Aktiengesellschaft leisten ${ }^{1087}$.

- Verlustpufferfunktion: Das Mindestkapital schützt nicht nur in der Start- und Anlaufphase der Aktiengesellschaft vor einer unmittelbaren Überschuldung, sondern stellt auch in der Folgezeit einen gewissen Risikopuffer für eine unerwartet auftretende negative wirtschaftliche Entwicklung dar ${ }^{1088}$. Dahinter verbirgt sich die These, dass die Gläubiger bei Verlusten der Gesellschaft umso besser vor einem Ausfall ihrer Ansprüche geschützt werden, je höher dieser Puffer ist.

- Warnlampenfunktion: Lutter weist auf eine nützliche Eigenschaft des Eigenkapitals hin, die eng mit der Pufferfunktion verknüpft ist und das Management in Krisensituationen frühzeitig zum Handeln zwingt ${ }^{1089}$. Die wirtschaftliche Situation der Aktiengesellschaft wird mit einer Ampel verglichen. Solange das Unternehmen über Rücklagen verfügt, steht sie auf grün. Haben die Verluste die Rücklagen aufgezehrt, springt die Ampel auf gelb, da nun Teile des eingezahlten Eigenkapitals aufgebraucht werden. Die Ampel zeigt gelb-rot,

Vgl. Ballerstedt (1971), S. 385; Wiedemann (1980), S. 565; Lutter (1983), S. 168; Lutter (1998b), S. 375; Fleischer (2000), S. 1020; Hirte (2000c), S. 221; Lutter (2000b), S. 136-137; Fleischer (2001), S. 13; Merkt (2001a), S. 148; Arbeitsgruppe Europäisches Gesellschaftsrecht (2002), S. 1316; Baldamus (2002), S. 85; High Level Group (2002c), S. 88; K. Schmidt (2002), S. 523, 540; Priester (2005), S. 921; Hüffer (2006), § 7, Tz. 1. Diese Funktion wird zum Teil auch im britischen Schriftum akzeptiert. Vgl. Freedman (2000), S. 337-338 m.w.N. Auf das letztere Argument weist Micheler (2004), S. 333, hin und stellt es sodann in Frage. So Wiedemann (1980), S. 565.

Vgl. Müller-Erzbach (1928), S. 246; Lutter (1964), S. 51; Gansen (1992), S. 8; Süchting (1995), S. 80; U. Hansen (1996), S. 133-134; Klose-Mokroß (1997), S. 172 m.w.N.; Lutter (1998b), S. 375.

1087 Vgl. Lutter (1998b), S. 375.

1088 Vgl. Lutter (1964), S. 50; Wiedemann (1980), S. 557; Lutter (1982), S. 249; Lutter (1983), S. 168; Lutter (1998b), S. 375-376; Walter (1998), S. 370; Baldamus (2002), S. 82-83; Böckmann (2005), S. 53-54; Priester (2005), S. 921. Vgl. zu dieser Argumentation in Bezug auf gesetzliche Vorschriften zur Eigenkapitalunterlegung von Kreditinstituten Süchting (1982), S. 399-400.

1089 Vgl. Lutter (1998b), S. 376. Vgl. auch Escher-Weingart (2001), S. 238; Arbeitsgruppe Europäisches Gesellschaftsrecht (2002), S. 1317; Priester (2005), S. 921. 
wenn schwere Verluste des gezeichneten Kapitals (Art. 17 Abs. 1 KapRL) - nach deutschem Aktienrecht ein Verlust in Höhe des hälftigen Grundkapitals ( 92 Abs. 1 AktG) eingetreten ist und die Aktionäre durch den Vorstand darüber informiert werden müssen. Die Ampel springt schließlich bei Eintritt der Überschuldung mit der Konsequenz auf rot, dass der Vorstand ein Insolvenzverfahren einleiten muss, keine Zahlungen mehr leisten darf ( $§ 92$ Abs. 2-3 AktG) und über Sanierung oder Liquidation entschieden werden muss. Dem Kapitalsystem kommt somit auch eine Stabilitätsfunktion zu, da eine Krise frühzeitig angezeigt wird und Zeit für unternehmerische Gegenmaßnahmen bleibt ${ }^{1090}$.

- Signaling-Funktion: Während die Warnlampenfunktion insbesondere auf die Selbstinformation der Unternehmensleitung abstellt, soll die Signaling-Funktion des bei der Gründung eingezahlten Eigenkapitals zu einem Abbau von Informationsasymmetrien in der Principal-Agent-Beziehung zwischen den unternehmensexternen Geldgebern (Principals) und den Unternehmensgründern (Agents) führen können ${ }^{1091}$. Indem die Unternehmensgründer einen hohen Eigenkapitalbetrag festlegen, senden sie nach dieser Ansicht ein Bonitätssignal, das potentielle Kreditgeber von den guten Zukunftsaussichten des Unternehmens und dem hohen Arbeitseinsatz der Unternehmensgründer und ihrem Handeln im Interesse der außenstehenden Geldgeber überzeugt.

- Garantiefunktion: Eine weitere grundlegende Funktion des Eigenkapitals wird darin gesehen, dass sich die aktuellen und zukünftigen Gläubiger auf die Existenz des in der Satzung und in der Bilanz ausgewiesenen Grundkapitals verlassen können ${ }^{1092}$. Zum Schutz des Grundkapitals verfügt das Aktienrecht über ,ein ganzes Arsenal von Instrumenten" ${ }^{\text {"1093, }}$, von denen die wichtigsten bereits genannt worden sind (z.B. Verbot der Unterpariemission nach Art. 8 Abs. 1 KapRL bzw. $\S 9$ Abs. 1 AktG, Verbot der Einlagenrückgewähr gemäß Art. 15 Abs. la KapRL bzw. § 57 AktG) ${ }^{1094}$.

Schließlich fungiert das Grundkapital als Ausschüttungssperre ${ }^{1095}$. Erst wenn die Aktiva der Gesellschaft die Schulden zuzüglich des Grundkapitals übersteigen, kann ein Gewinn ausgeschüttet werden. Das Garantiekapital wird aus diesem Grund anschaulich mit einer Staumauer verglichen ${ }^{1096}$. Indem das Grundkapital in der Bilanz der Aktiengesellschaft als gezeichnetes Kapital auf der Passivseite der Bilanz zum Nennwert bewertet ausgewiesen bichler (2003), S. 252-254; Schön (2004a), S. 168. Auch die US-amerikanischen Ausschulttungsrestriktionen sollen grundsătzlich dem Zweck dienen, dass das Grundkapital der Gesellschaft nicht an die Aktionäre zurückfließt. Vgl. dazu z.B. Hamilton (2000), S. 585. S. 195-196.

1096 
wird ( $§ 152$ Abs. 1 AktG, §§ 266 Abs. 3 A I, 272 Abs. 1, 283 HGB), „ordnen die Gesetze einen ,bilanztechnischen Sparstrumpf' an. “1097

Die Garantiefunktion des Grundkapitals wird zudem durch das Zusammenspiel von Kapital- und Bilanzrichtlinie - bzw. von aktienrechtlichen Gewinnverwendungsvorschriften und handelsrechtlichen Gewinnermittlungsregeln - gestärkt. Der für Dividenden zur Verfügung stehende „Überschuss“ wird durch das vom Vorsichtsprinzip geprägte Bilanzrecht begrenzt, indem die Aktiva der Gesellschaft tendenziell unterbewertet, Schulden tendenziell überbewertet und nur realisierte Gewinne ausgewiesen werden. Da die daraus resultierenden stillen Reserven die Gläubiger in der wirtschaftlichen Krise wie ein Kissen vor dem harten Aufprall schützen sollen, spricht Kübler anschaulich von der „Kissenfunktion ${ }^{\text {1098 }}$ des deutschen Bilanzrechts.

- Schließlich existieren zahlreiche weitere Funktionen des Grundkapitals, so z.B. seine Bedeutung für die Bestimmung des Stimmrechts und der Beteiligungsquote, die Höhe des Gewinn- und Liquidationsanteils und den Schutz des Gleichbehandlungsgebots der Anteilseigner $^{1099}$.

Die vorstehend genannten Eigenschaften des Kapitals dienen primär dem Schutz der Gläubiger. Die herausragende Bedeutung des gesetzlichen Kapitalschutzes wird darin gesehen, dass er alle Gläubigergruppen ex ante in gleicher Weise zu schützen vermag und somit die negativen Folgen des Marktversagens für verhandlungsschwache Gläubiger und Deliktsgläubiger verhindert ${ }^{1100}$. Im nun folgenden Kapitel werden die dargestellten Argumente kritisch gewürdigt.

\subsection{Infragestellung der Argumente zugunsten des europäischen Kapitalsystems}

Die vorstehenden Rechtfertigungsgründe für die europäischen Mindestkapitalregeln sind in vielfältiger Weise zu kritisieren. Die Seriositätsfunktion des gesetzlichen Garantiekapitals vermag nicht $\mathrm{zu}$ überzeugen ${ }^{101}$, da ihre qualitätsichernde Wirkung empirisch nicht nachgewiesen ist. Zum einen ist nicht belegt, dass die Fähigkeit, den vergleichsweise geringen Betrag von 25.000 bzw. $50.000 €$ aufzubringen, für unternehmerische Qualifikation bürgt. Zum anderen erscheint es denkbar, dass unternehmerischer Erfolg auch mit einem geringeren oder gar keinem Eigenkapital als Startkapital möglich ist. In solchen Fällen werden möglichweise sogar Kleinstunternehmer durch die zwingende Kapitalaufbringung abgeschreckt, was aus

1097 Wiedemann (1980), S. 557.

1098 Kübler (1995b), S. 553. Vgl. auch Kübler (1995c), S. 363 mit Verweis auf Gernon/Meek (2001), S. 4. Auch im US-amerikanischen Schriftum wird der theoretische Anspruch des Nennwertsystems darin gesehen, ,a cushion to protect creditors" zu bieten. So Klein/Coffee (2003), S. 218. Vgl. z.B. auch Ballantine (1946), S. 570; Ralston (1983), S. 1025, Bainbridge (2002), S. 769.

1099 Vgl. dazu z.B. Gansen (1992), S. 7; U. Hansen (1996), S. 136; Klose-Mokroß (1997), S. 60-61, $171-176$. Vgl. auch Hennrichs (2004), S. 129-130, der auf die Bedeutung des Eigenkapitals im Bankaufsichtsrecht und in der Versicherungsbranche hinweist.

1100 Vgl. z.B. Schön (2001), S. 78.

1101 Die Seriositätsfunktion wird ebenfalls kritisiert von Bauer (1995), S. 136-137; Roth/Altmeppen (2003), Einl., Tz. 26; Merkt (2004a), S. 317-318; Micheler (2004), S. 333-334; Schön (2004a), S. 165; Schön (2004b), S. 436-437. Auch Mülbert/Birke (2002), S. 721, relativieren die Wirksamkeit des Mindestkapitals als Zulassungstest für Unternehmensgründer: „hardly serves as an effective deterrent“. Vgl. auch Fleischer (2000), S. 1020 . 
volkswirtschaftlicher Sicht von Nachteil wäre ${ }^{1102}$. Eine Hürde in bestimmten Branchen kann ferner in dem Verbot von Sacheinlagen in der Form von Verpflichtungen zu Arbeits- oder Dienstleistungen gemäß Art. 7 KapRL bzw. $§ 27$ Abs. 2 AktG gesehen werden ${ }^{1103}$.

Gegen die Betriebskapitalfunktion lässt sich vorbringen, dass eine „angemessene“ Höhe des Eigenkapitals betriebswirtschaftlich nicht zu bestimmen ist ${ }^{1104}$. Zwar erscheint es intuitiv einsichtig, dass das Vorhandensein von Eigenkapital gerade erst gegründete Unternehmen vor dem Ausscheiden aus dem Markt wegen Überschuldung durch Anfangsverluste bewahren kann. Auch ist es sinnvoll, im Rahmen der Unternehmensplanung Eigenkapital zum Schutz vor Verlusten durch unvorhersehbare Umweltlagen vorzuhalten ${ }^{1105}$. Allerdings ist es gerade aufgrund dieser Unsicherheit nicht möglich, eine gesamtwirtschaftlich effiziente Eigenkapitalausstattung zu bestimmen. Somit entpuppen sich die gesetzlichen Vorgaben als willkürlich, was auch von den Befürwortern des gesetzlichen Mindestkapitals eingeräumt wird ${ }^{106}$.

Darüber hinaus ist zu bezweifeln, dass die Hypothese, eine höhere Eigenkapitalquote mindere das Insolvenzrisiko ${ }^{1107}$, empirisch überhaupt nachprüfbar ist ${ }^{108}$. Die Zweifel liegen erstens darin begründet, dass das Insolvenzrisiko nicht messbar ist. Sie resultieren zweitens daraus, dass die Eigenkapitalausstattung eines Unternehmens in praxi nicht zwingend einen wirksamen Verlustpuffer darstellt ${ }^{1109}$. Die These trifft z.B. dann nicht $\mathrm{zu}$, wenn sich das kreditnehmende Unternehmen vertragswidrig verhält und die rechtlichen Ansprüche der Gläubiger nach einem betrügerischen Bankrott nicht durchsetzbar sind. Weiterhin kann es zu Vertragsverletzungen durch Ex-post-Verluste kommen. Die Fremdkapitalgeber sind trotz der Eigenkapitalausstattung des Unternehmens alleinige Leidtragende einer Insolvenz, wenn die Eigenkapitalgeber in den Vorperioden mehr als ihre ursprünglich zur Verfügung gestellten Mittel in

1102 Vgl. Micheler (2004), S. 334. Vgl. ähnlich auch Mülbert/Birke (2002), S. 721; Grunewald/Noack (2005), S. 190.

1103 Vgl. dazu Kapitel V.5.3.3.

1104 Vgl. insbesondere D. Schneider (1986a), S. 564-565; D. Schneider (1986b), S. 2297-2298; D. Schneider (1987), S. 93-98; D. Schneider (1992), S. 574-576. Vgl. auch Kübler/Schmidt (1988), S. 115-156, insbesondere S. 133-134; Kübler (1989), S. 15, Fn. 52; Bauer (1995), S. 112-114, 119-128; Klose-Mokroß (1997), S. 69; Walter (1998), S. 371; Schreiber (1999), S. 884; Escher-Weingart (2001), S. 149, 249-250; Fleischer (2001), S. 10-11; Kahle (2002b), S. 137-138; Baetge/Kirsch/Thiele (2004a), S. 234; Coenenberg (2005), S. 995.

1105 In einer solchen Situation bestehen Informationsrisiken. Der Handelnde kann sich nicht sicher sein, dass in seinem Entscheidungsmodell alle denkbaren zukünftigen Umweltzustände enthalten sind, so dass es zu Expost-Überraschungen kommen kann. Vgl. dazu ausführlich D. Schneider (1992), S. 38-40. Vgl. auch KloseMokroß (1997), S. 86, Fn. 10, die in diesem Zusammenhang auf die erheblichen Schadenssummen der Katastrophen von Seweso, Bhopal und dem Tankerunglück der Exxon Valdez vor Alaska hinweist.

1106 Vgl. Lutter (1983), S. 169; Priester (1992), S. 160. Nichtsdestotrotz ist beispielsweise Lutter (1998b), S. 375, der Ansicht, die bestehenden Kapitalregeln seien „doch mehr als nichts“.

1107 Dies wird z.B. behauptet von K. Schmidt (1984), S. 772-773; Walter (1998), S. 370; Mülbert (2001), S. 1942; Mülbert/Birke (2002), S. 719; Helm (2004a), S. 7; Mülbert (2004), S. 154; Kuhner (2005), S. 772.

$1108 \mathrm{Vgl}$. hier und im Folgenden D. Schneider (1986a), S. 561-562, 565-567; D. Schneider (1986b), S. 2296-2297; D. Schneider (1987), S. 89-93, 99-100; D. Schneider (1992), S. 588-592; D. Schneider (1997a), S. 222-224. A.A. wohl Baetge/Kirsch/Thiele (2004a), S. 232: „Die herausragende Bedeutung des Eigenkapitals für die Beurteilung der finanziellen Stabilität von Unternehmen kann auch empirisch unterstrichen werden."

1109 Bei normalem Geschäftsverlauf kann allerdings die Insolvenz aufgrund von Überschuldung durch eine höhere Eigenkapitalausstattung länger herausgezögert werden. 
Form von Gewinnausschüttungen erhalten haben ${ }^{1110}$. Schließlich trifft die Hypothese auch dann nicht $\mathrm{zu}$, wenn bei steigendem Verschuldungsgrad das leistungswirtschaftliche Risiko der durchgeführten Investitionen stärker fällt als das Kapitalstrukturrisiko - annahmegemäß aufgrund der höheren Verschuldung - steigt.

Auch die Tatsache, dass Kreditinstitute trotz des Theoriedefizits bei der Kreditvergabeentscheidung regelmäßig auch kennzahlenbasierte Kreditwürdigkeitsanalysen durchführen oder bestimmte Finanzierungsregeln als eine Art „Beruhigungsdroge "1111 vorschreiben, vermag als Rechtfertigung einer gesetzlichen Regulierung nicht zu überzeugen. Denn zum einen berücksichtigen auch Banken zusätzlich subjektive und qualitative Faktoren. Zum anderen existieren zahlreiche verschiedene Kennzahlensysteme, welche die Besonderheiten des Einzelfalls berücksichtigen sollen - wie z.B. Branche und Größe des Unternehmens, Laufzeit und Höhe des Kredits - und von Bank zu Bank unterschiedlich sind ${ }^{1112}$. Es ist daher nahezu unmöglich, diese umfangreichen und differenzierten Regelungen auf privatvertraglicher Ebene gesetzlich zu verankern.

Auch versicherungsaufsichtsrechtliche Bilanzkennzahlen der Bundesanstalt für Finanzdienstleistungsaufsicht (BaFin), die inländische Unternehmen erfüllen müssen, damit Versicherungsunternehmen ihnen Schuldscheindarlehen vergeben dürfen ${ }^{113}$, sind für ein Gesetz ungeeignet. Unter Vernachlässigung von bestimmten Modifizierungen schreiben diese Kriterien im Kern eine Eigenkapitalquote von mindestens $20 \%$, eine Gesamtkapitalrendite von mehr als $6 \%$, einen Finanzierungskoeffizienten von $\leq 2$ und eine Entschuldungsdauer von $\leq 7$ Jahre vor. Vor dem Hintergrund von durchschnittlichen Eigenkapitalquoten im deutschen Mittelstand von ca. 7,5\% ${ }^{1114}$ wird unmittelbar deutlich, dass solche Bestimmungen für eine Gesetzesnorm als zu undifferenziert und in vielen Fällen als zu strikt abzulehnen sind.

Neben der unzulänglichen Verlustpufferfunktion des Mindestkapitals ist auch die Warnlampenfunktion kritsch zu hinterfragen. Nicht nur die gesetzlich vorgeschriebenen absoluten Mindestbeträge, sondern auch die tatsächlichen Eigenkapitalquoten der Unternehmen sind in der Regel so gering, dass sie durch Verluste schnell aufgebraucht sein können. Somit verbleibt in wirtschaftlichen Krisenzeiten für das Einleiten von unternehmerischen Gegenmaßnahmen wenig Zeit. Es ist zu bezweifeln, das Management könne so lange warten, über die weiteren Perspektiven des Unternehmens nachzudenken, bis die „gelbe Ampel“ leuchtet. Selbst bei „grünem Licht“ ist die Sicherheit gegebenenfalls trügerisch. Um langfristig erfolgreich zu sein, wird es vielmehr in den meisten Fällen dringend notwendig sein, negative Entwicklungen viel früher zu erkennen und Strategien zu ihrer Überwindung einzuleiten.

Auch die Signaling-Funktion kann nicht überzeugen. Allein die Bereitstellung von Eigenkapital kann nicht verhindern, dass die Gründerunternehmer einen Informationsvorsprung gegenüber den unternehmensexternen Geldgebern behalten und diesen zu ihrem Vorteil nutzen können $^{115}$. Da die gesetzlichen Mindestkapitalvorschriften nicht am Vermögenseinsatz der

1110 Watrin (2001a), S. 216, sieht hingegen in dem Mindestkapitalerfordernis einen „Selbstbehalt“ der Eigenkapitalgeber.

1111 D. Schneider (1992), S. 580; D. Schneider (1997a), S. 221.

1112 Vgl. Paul (2005a).

1113 Vgl. insbesondere Bald et al. (2000), S. 12-14, 28-29. Vgl. auch Linnhoff/Pellens (1994); Bonse/Linnhoff/ Pellens (2002b), S. 391-397.

1114 Vgl. dazu DSGV (2005), S. 4, 23.

1115 Vgl. insbesondere D. Schneider (1987), S. 103; D. Schneider (1992), S. 653. Vgl. auch Bitz/Hemmerdel Rausch (1986), S. 143-149. 
Unternehmensleitung anknüpfen, ist ihre Anreizwirkung für ein Handeln im Sinne der Geldgeber eher gering. Selbst wenn von einer Signaling-Wirkung ausgegangen wird, kann sie nicht zur Rechtfertigung der existierenden Mindestnormen herangezogen werden. Handelte es sich nämlich aus Gründer- oder Unternehmenssicht um ein nützliches Instrument, würde es sich auch ohne gesetzlichen Zwang auf vertraglicher Basis durchsetzen ${ }^{116}$. Eine gesetzliche Vorgabe wäre zudem sogar kontraproduktiv, da sie den Spielraum für ein Bonitätssignal zur Verminderung von Informationsnachteilen einschränkt ${ }^{1117}$. Selbstverständlich können bei der Unternehmensgründung - in der Hoffnung auf eine positive Signalwirkung - auch bedeutend höhere Beträge als Eigenkapital ausgewiesen werden. Die gesetzliche Regelung ist dafür allerdings entbehrlich.

Gegen die Garantiefunktion des Eigenkapitals lässt sich schließlich vorbringen, dass sich die Gläubiger lediglich im Zeitpunkt der Unternehmensgründung sicher sein können, dass das Kapital - sofern es bereits vollständig einbezahlt ist - zu ihrem Schutz zur Verfügung steht. In der Folgezeit wird es hingegen für Investitionszwecke eingesetzt ${ }^{118}$. Die Aktivseite der Bilanz gibt dabei Auskunft darüber, in welchen Vermögenswerten das Kapital gebunden ist ${ }^{111}$. Die Passivseite wiederum informiert darüber, in welchem Verhältnis diese Vermögenswerte mit Eigen- und Fremdkapital finanziert sind. Weder das bei der Gründung aufgebrachte Mindestkapital noch die in den folgenden Geschäftsperioden angesammelten Eigenkapitalbeträge stellen einen in bar jederzeit zur Befriedigung der Gläubigeransprüche bestehenden Haftungsfonds dar. Es ist vielmehr notwendig, dass - sofern die liquiden Mittel der Gesellschaft nicht ausreichen - weitere Kredite aufgenommen oder Vermögenswerte verkauft werden, um mit dem Verkaufserlös die Ansprüche der Fremdkapitalgeber bedienen zu können. Möglicher Verwertungsgegenstand im Liquidations- oder Insolvenzfall ist mithin nicht das Eigenkapital, sondern das Vermögen der Gesellschaft ${ }^{1120}$. Dies ist aus Gläubigersicht in den Fällen problematisch, in denen die in Frage kommenden Vermögenswerte nur eingeschränkt liqidierbar sind. Weiterhin können die gesetzlichen Kapitalaufbringungs- und Kapitalerhaltungsregeln nicht verhindern, dass das bei der Gründung der Gesellschaft eingezahlte Garantiekapital durch Verluste infolge von Rezessionen, Managementfehlern oder überraschenden Marktänderungen aufgezehrt wird ${ }^{1121}$.

Darüber hinaus kann die bilanzielle Abbildung der Vermögenswerte und Schulden den Interessen der Gläubiger entgegenstehen. Wie an anderen Stellen der Arbeit bereits ausführlich herausgestellt worden ist, soll das im HGB auf der Grundlage der Bilanzrichtlinie verankerte Vorsichtsprinzip zwar Gläubiger schützen, indem eine frühzeitige Ausschüttung unrealisierter Gewinne verhindert und durch die Bildung stiller Reserven ein zusätzlicher Verlustpuffer

\footnotetext{
1116 Vgl. Mülbert/Birke (2002), S. 729.

1117 Vgl. D. Schneider (1987), S. 103; D. Schneider (1992), S. 653. Vgl. auch Enriques/Macey (2001), S. 1186 Fn. 98.

1118 Vgl. Fabricius (1970), S. 139-140; Kübler (1989), S. 30; Bauer (1995), S. 135, 212-213; Klose-Mokroß (1997), S. 62-64; Escher-Weingart (2001), S. 236-237; Kahle (2002b), S. 137; Mülbert/Birke (2002), S. 719.

1119 Die Bilanzinformationen werden allerdings in der Regel unvollstăndig sein, da nicht alle wirtschaftlichen Güter, in die das Management Kapital investiert, die Ansatzkriterien für die Aufnahme in die Bilanz erfulllen. Als Beispiele seien bestimmte Leasingverträge, Forschungs- und Entwicklungskosten, selbsterstellte Patente, Mitarbeiterschulungen genannt.

1120 Vgl. Süchting (1995), S. 80.

1121 Darauf ist bereits früh hingewiesen worden. Vgl. Müller-Erzbach (1928), S. 246. Vgl. auch Kübler (1989), S. 30; Klose-Mokroß (1997), S. 63; Kübler (1999b), S. 153.
} 
angelegt wird. Die stillen Reserven können aber ebenso still wieder aufgelöst werden, indem z.B. zur Herstellungskostenuntergrenze bewertete Gegenstände des Vorratsvermögens verkauft werden ${ }^{1122}$. Die Gewinnsituation kann darüber hinaus - in den Grenzen des Stetigkeitsprinzips gemäß Art. 31 Abs. 1b BilRL bzw. $\S 252$ Abs. 1 Nr. 6 HGB - dadurch verschleiert werden, dass die handelsrechtlichen Bewertungswahlrechte geschickt ausgenutzt und Bewertungsverfahren geändert werden (z.B. Wechsel von degressiver zu linearer Abschreibung). Solange die Gläubiger keine Jahresabschlussanalyse durchführen und den Anhang zum Jahresabschluss nicht studieren, können sie über die tatsächliche wirtschaftliche Lage des Schuldnerunternehmens getäuscht werden. Es kann somit viel Zeit verstreichen, bis ungünstige Unternehmensentwicklungen, Verluste im operativen Kerngeschäft und mangelhafte Kreditwürdigkeit offensichtlich werden ${ }^{1123}$.

Insgesamt wird deutlich, dass die dem gesetzlichen Mindestkapitalsystem zugeschriebenen positiven Funktionen einzuschränken sind. Damit ist ihre vielfach behauptete gläubigerschützende Wirkung erheblich zu relativieren. Im folgenden Kapitel soll nun genauer untersucht werden, welche Kosten und weiteren Nachteile mit dem europäischen Kapitalsystem verbunden sind.

\subsection{Mängel des europäischen Kapitalsystems}

\subsubsection{Einleitung und Überblick}

Die bisherigen Ausführungen haben ergeben, dass die vorgebrachten vielfältigen Vorzüge der Mindestkapitalnormen nur eingeschränkt bestehen und die Gläubiger in unzulänglicher Weise geschützt werden. Aus Sicht der normativen Regulierungstheorie, nach der Eingriffe des Gesetzgebers in die Handlungs- und Vertragsfreiheit der Wirtschaftssubjekte zu begründen $\operatorname{sind}^{1124}$, wäre dieses Resultat allein schon ein deutliches Anzeichen für eine zweifelhafte Rechtfertigung und eine Deregulierungsnotwendigkeit.

In der Literatur wird aber vielfach die Auffassung vertreten, die bisherige Argumentation könne nicht ausreichen, um das Kapitalsystem grundlegend zu reformieren und die Mindestnennkapitalziffer abzuschaffen. So vertritt beispielsweise die High Level Group die Ansicht, „dass die einzige Funktion des Mindesteigenkapitals in der Abschreckung vor einer leichtfertigen Gründung von Aktiengesellschaften besteht. Wir sind nicht davon überzeugt, dass das

1122 In der Literatur wird vielfach der Begriff der stillen Reserven auf unrealisierte Gewinne ausgedehnt. Danach stellt z.B. die Differenz zwischen Buch- und höherem Marktwert eines Grundstücks eine stille Reserve dar. Vgl. so z.B. Kübler (1999b), S. 273; Coenenberg (2005), S. 321; Großfeld/Luttermann (2005), S. 130. D. Schneider (1997a), S. 195, kritisiert dies als sinnwidrige Erweiterung des Begriffs. Vgl. zu einer ausführlichen Begriffsbestimmung und einem Literaturüberblick auch Hennrichs (1999b), S. 8-13; Thiele (1999), S. 7-12.

1123 Auf diese Zusammenhänge ist vielfach hingewiesen worden. Vgl. z.B. Passow (1922), S. 276-280; Stützel (1967), S. 1967, S. 329-330; D. Schneider (1981), S. 32-33; Süchting (1981), S. 209-211; Leffson (1987), S. 84-88, 466; Streim (1988), S. 158; Budde (1994), S. 48-49; Busse von Colbe (1994), S. 46; Schildbach (1994), S. 704; Kübler (1995b), S. 563; Schulze-Osterloh (1995), S. 128; Walz (1997), S. 558; Hommelhoff (1998), S. 389; Hennrichs (1999b), S. 12-13, 70-71; Thiele (1999), S. 59-62, 95-96; Grundmann (2004), S. 143, 235; Baetge/Kirsch/Thiele (2005), S. 138; Bezzenberger (2005), S. 149-150; Großfeld/Luttermann (2005), S. 155-156, 179; Wöhe (2005), S. 1048-1049.

1124 Vgl. Fülbier (1998), S. 19 m.w.N. 
Mindesteigenkapital in seiner derzeitigen Höhe irgendeine andere nützliche Funktion erfüllt, aber es gibt auch keine Belege dafür, dass es ein Hindernis für die Geschäftstätigkeit darstellt", und zieht daraus folgenden Schluss: „Das vorgeschriebene Mindesteigenkapital sollte weder abgeschafft noch angehoben werden."1125

Die mit namhaften Vertretern der Rechtswissenschaft besetzte Arbeitsgruppe Europäisches Gesellschaftsrecht schließt sich dieser Sichtweise an: „Es entspricht Lebenserfahrung und Pfadabhängigkeit, im Zweifel an der bisherigen Rechtsordnung oder Rechtsprechung festzuhalten, wenn sie trotz gewisser Schwächen keine wesentlichen Nachteile mit sich bringt und die Alternativen ihrerseits keine erhebliche Verbesserung versprechen. “1126

Im Folgenden wird zunächst ein Versuch unternommen, eine Reihe von Schwächen und Nachteilen des bestehenden Kapitalsystems aufzuzeigen, die für eine Reform spricht. Im Anschluss daran werden Reformmöglichkeiten diskutiert.

\subsubsection{Komplexität und Kosten}

Das hergebrachte System ist kompliziert, zeitaufwendig und kostenintensiv. Wie bereits angesprochen, haben die Unternehmensgründer bei der Kapitalaufbringung eine ganze Reihe von strikten Bestimmungen zu beachten, wodurch die Gründung von Aktiengesellschaften erschwert wird ${ }^{1127}$. Dies liegt unter anderem darin begründet, dass Verpflichtungen zu Arbeitsund Dienstleistungen nicht Gegenstand einer Sacheinlage sein können (Art. 7 S. 2 KapRL, $\S 27$ Abs. 2 AktG). Das beeinträchtigt Unternehmensgründungen in der Rechtsform der Aktiengesellschaft beispielsweise in der Hochtechnologiebranche, weil die Gründer ihre innovativen Ideen nicht als Einlage in Form von zukünftigen Diensten erbringen können ${ }^{1128}$.

Besonders zeit- und kostenintensiv sind weiterhin die Modalitäten der Sacheinlagenprüfung $^{1129}$. Die in den Kapitel III.1.1.2 und III.1.2.1.2 bereits erläuterterten Gründungsvoraussetzungen bei Sacheinlagen (Art. $10 \mathrm{KapRL}$ bzw. $\S 33 \mathrm{AktG}$ ) nehmen Zeit in Anspruch und verursachen Beurkundungs-, Gerichts- und durch die Hinzuziehung von Sachverständigen in der Regel von Wirtschaftsprüfern bzw. Wirtschaftsprüfungsgesellschaften ${ }^{1130}$ - Prüfungskosten. Zeitaufwand, Kosten sowie die Offenlegungspflicht der Sachgründung führen dazu, dass in der Praxis die eigentliche Sacheinlage häufig aufgesplittet wird in eine Bareinlage und

1125 High Level Group (2002c), S. 88 (beide Zitate). Vgl. zur Kritik dieser Auffassung Rickford (2004), S. 931, Fn. 33: „In our view useless provisions are always worth repealing.“ Vgl. ebenfalls kritisch Micheler (2004), S. 334: „An den Hausverstand appellierende Argumente reichen zum Beweis der Sinnhaftigkeit einer Mindestkapitalregel nicht aus. Gefragt ist ein substantieller Nachweis, dass einerseits bestimmte Interessen gefährdet sind und andererseits die getroffene Maßnahme diesen Interessen in angemessener Weise Rechnung trägt.“

1126 Arbeitsgruppe Europäisches Gesellschaftsrecht (2003), S. 872. Vgl. zu einer ähnlichen Argumentation auch Matschke (1981), S. 556; Niederleithinger (1998), S. 378; Rammert (2004), S. 592.

1127 Vgl. Kübler (1989), S. 33; Enriques/Macey (2001), S. 1195; Kübler (2003c), S. 102-103.

1128 Vgl. Enriques/Macey (2001), S. 1195; High Level Group (2002c), S. 90; Mülbert/Birke (2002), S. 722; Kübler (2003c), S. 108; Grundmann (2004), S. 144, 149; Rickford (2004), S. 937. A.A. Niederleithinger (1998), S. 378; Fleischer (2001), S. 13-14.

1129 Vgl. dazu kritisch Kübler (1993), S. 207-211; Priester (1994); Klose-Mokroß (1997), S. 193-195; Kübler (2003c), S. 98-99, 101-102; Grundmann (2004), S. 144; Micheler (2004), S. 335; Rickford (2004), S. 934-936. A.A. Schön (2004b), S. 442.

1130 Vgl. K. Schmidt (2002), S. 786. 
ein Verkehrsgeschäft über die Einlagegegenstände ${ }^{1131}$. Die in Deutschland von Wissenschaft und Rechtsprechung entwickelte Lehre von der verdeckten Sacheinlage führt dazu, dass bei einem Verstoß gegen die Sachgründungsvorschriften die Geldleistungspflicht fortdauert. Die Rechtsfolgen sind für die Einleger insbesondere bei Insolvenz der Gesellschaft dramatisch, da der Insolvenzverwalter die Zahlung der Bareinlage verlangen kann. Die betroffenen Aktionäre haben zwar einen Bereicherungsanspruch auf Rückgewähr der Leistung; dieser ist allerdings mit der Insolvenzquote zu bedienen und folglich in der Regel wirtschaftlich wertlos ${ }^{1132}$.

Aber selbst bei Bareinlagen kann es zu Verzögerungen kommen ${ }^{1133}$. In Deutschland entsteht die Aktiengesellschaft als juristische Person erst durch die Eintragung ins Handelsregister (§ $41 \mathrm{AktG})$. Der Eintragung vorgelagert ist ein in mehreren Schritten verlaufender Gründungsvorgang $(\S \S 23-53 \mathrm{AktG})^{1134}$ : Die Gründer haben über den Gründungsvorgang einen Gründungsbericht zu erstatten, der zusammen mit weiteren Unterlagen Grundlage der Gründungsprüfung durch Vorstand und Aufsichtsrat ist. In den in $\S 33$ Abs. 2 AktG genannten Fällen schließt sich eine Prüfung durch einen gerichtlich bestellten Gründungsprüfer an. Anschließend wird die Gesellschaft zur Eintragung bei dem zuständigen Registergericht angemeldet. Daraufhin findet die gerichtliche Prüfung der Anmeldung statt. Anmeldevoraussetzung ist unter anderem der Nachweis, dass der eingezahlte Betrag endgültig zur freien Verfügung des Vorstands steht $(\S 37 \text { Abs. } 1 \text { S. } 2 \text { AktG) })^{1135}$. Im Fall der Überweisung ist eine Bankbestätigung notwendig, für deren Richtigkeit die Bank der zukünftigen Aktiengesellschaft verantwortlich ist ( $\$ 37$ Abs. 1 S. 3-4 AktG). Sieht das Kreditinstitut unkalkulierbare Haftungsrisiken, ist zu befürchten, dass es die Bestätigung verweigert.

Die Kapitalaufbringungsregeln wirken sich auch in den folgenden Geschäftsperioden bei Kapitalerhöhungen negativ aus, da sie den Prozess der Kapitalbeschaffung verlangsamen. Die Flexibilität der Aktiengesellschaft bei der Aufnahme von zusätzlichem Eigenkapital ist somit erheblich eingeschränkt. Gleichfalls begrenzt sind die Möglichkeiten zur Durchführung von Aktienrückkäufen, wodurch das Management unter Umständen gehindert wird, die sich bietenden Rendite- und Kurspotentiale der Gesellschaft vollständig zu nutzen ${ }^{1136}$.

Sowohl die Kapitalschutzregeln im Allgemeinen als auch die Vorschriften zum Aktienrückkauf im Besonderen können zudem dazu führen, dass Unternehmen trotz mangelnder unternehmensinterner Investitionsprojekte mit positivem Kapitalwert und überschüssiger Liquidität den Free Cashflow nicht ausschütten können bzw. zur Durchführung einer Kapitalherabsetzung gezwungen sind ${ }^{1137}$. Dies wiederum kann die Eigenkapitalfinanzierung verteuern.

\footnotetext{
1131 Vgl. Hüffer (2006), § 27, Tz. 9.
}

1132 Vgl. dies kritisierend Kübler (1999b), S. 176. Nach Merkt (2004a), S. 311, haben die Regeln „zur verschleierten Sacheinlage im Laufe der Zeit nach verbreiteter Ansicht selbst jener, die dem deutschen Modell im Prinzip positiv gegenuberstehen, ein $\mathrm{Maß}$ an Überzuchtung erreicht, das sich durch den Zweck des Gläubigerschutzes kaum rechtfertigen lässt.“

1133 Vgl. Kübler (1999b), S. 174-175; Kübler (2003c), S. 102.

1134 Vgl. dazu überblicksartig Süchting (1995), S. 41-42. Vgl. ausführlich z.B. K. Schmidt (2002), S. 784-796; Hueck/Windbichler (2003), S. 262-277; Grunewald (2005), S. 231-245. Zu den Formalităten, den Kosten und der Dauer der Gründung einer Aktiengesellschaft im Vergleich zur Delaware Corporation vgl. uberblicksartig Mellert (2006), S. 8-9.

1135 Vgl. zu den damit einhergehenden Problemen ausführlich Kübler (1993).

1136 Vgl. Schremper (2002), S. 20; Kübler (2003c), S. 102; Micheler (2004), S. 335-336.

1137 Vgl. Armour (2000b), S. 374; Enriques/Macey (2001), S. 1196-1197; Mülbert/Birke (2002), S. $721-722$.

Vgl. dazu kritisch Kuhner (2005), S. 773, Fn. 65. 
Das Nennkapitalsystem kann darüber hinaus weitere ökonomisch sinnvolle Transaktionen behindern. So erschwert das gesetzlich vorgeschriebene Nennkapital in Verbindung mit dem Verbot der Unterpariemission die Sanierung von Gesellschaften, deren Aktiva im Wert unter das in der Satzung festgelegte Grundkapital gesunken sind ${ }^{1138}$. Da kein Investor bereit sein wird, Aktien zu zeichnen, deren Marktwert unter dem zu bezahlenden Nennwert liegt, muss zunächst das Grundkapital herabgesetzt werden ${ }^{1139}$. Das Verzögern von Sanierungen steht in offensichtlichem Widerspruch zu den Interessen der Gläubiger ${ }^{1140}$.

\subsubsection{Mangelnde Flexibilität}

Um einen wirksamen Gläubigerschutz zu gewährleisten, müsste das als Risikopuffer gedachte (Mindest-)Eigenkapital in kausalem Zusammenhang zum leistungswirtschaftlichen Risiko des jeweiligen Schuldnerunternehmens stehen. Vor dem Hintergrund der Ausführungen in Kapitel V.5.2 handelt es sich dabei vom theoretischen Standpunkt aus um ein aussichtsloses Unterfangen. Aufgrund von bisher ungelösten Messproblemen kann die betriebswirtschaftliche Theorie keine Antwort auf die Frage nach der angemessenen Eigenkapitalausstattung liefern ${ }^{1141}$. Trotz der mangelnden theoretischen Begründbarkeit erscheint es allerdings intuitiv sinnvoll, wenn Gesellschaften mit höheren unternehmerischen Risiken auch ein höheres Eigenkapital vorhalten, damit die tendenziell größer ausfallenden Verluste durch Ex-post-Überraschungen absorbiert werden können.

Im Gegensatz dazu schreibt das europäische Kapitalschutzregime allen Aktiengesellschaften dasselbe Mindestkapital und dieselben Ausschüttungsrestriktionen vor. Differenzierungen nach Geschäftstätigkeit, Konjunkturanfälligkeit oder spezifischen unternehmensindividuellen Risiken werden grundsätzlich ebenso wenig vorgeschrieben wie gröbere Unterscheidungen hinsichtlich Größe oder Branche ${ }^{1142}$ der Unternehmen. Aufgrund der Tatsache, dass die Kapitalrichtlinie an Aktiengesellschaften z.B. in der Atom- und Tabakindustrie dieselben Anforderungen wie an solche in der Energieversorgungswirtschaft, der Lebensmittelbranche oder im Verlagswesen stellt, und darüber hinaus keine Eigenkapitalausstattung in Relation zur Bilanzsumme, sondern absolute Beträge vorsieht, sind die Vorschriften vielfach als zu starr und un-

1138 Vgl. Kübler (1989), S. 12; Enriques/Macey (2001), S. 1198; Mülbert/Birke (2002), S. 721; Meilicke (2003), S. 808; Micheler (2004), S. 334-335; Rickford (2004), S. 934; Sandrock (2004b), S. 64.

1139 Diese Probleme existieren in einem nennwertlosen System nicht, da dort neue Aktien auch zu einem Preis ausgegeben werden dürfen, der weit unter dem ursprünglichen Emissionskurs liegt. Vgl. dazu und zur Forderung der Einführung nennwertloser Aktien und Abschaffung des Nennkapitals Kübler (1989), S. 10-12, 59-62 m.w.N.

$1140 \mathrm{Vgl}$. zu einer noch weitergehenden Kritik an den deutschen Kapitalaufbringungsregeln Meilicke (2003), S. 808: „Sie sind dem Glăubigerschutz sogar schädlich, weil sie die Sanierung durch Umwandlung von Fremdkapital in Eigenkapital behindern und unter wirtschaftlich vernünftigen Bedingungen unmoglich machen.“ Zur These, verhandlungsstarke Gläubiger könnten in bestimmten Situationen die Kosten der Kapitalregeln an die kleinen und verhandlungsschwachen Gläubiger überwălzen, vgl. Enriques/Macey (2001), S. 1198.

1141 Vgl. insbesondere D. Schneider (1997a), S. 222-224.

1142 Besondere Vorschriften existieren aber z.B. für Kreditinstitute und Versicherungen. Vgl. dazu Mayer (2005), Art. 4, Tz. 18. 
flexibel kritisiert worden ${ }^{1143}$. Dieser Einschätzung stimmen grundsätzlich auch die Verfechter des europäischen Kapitalsystems $\mathrm{zu}^{1144}$.

Der in Art. 15 KapRL kodifizierte Bilanztest wird weiterhin als ineffizient kritisiert, da er zur Ermittlung der zulässigen Höchstausschüttung ausschließlich auf historische Buchwerte abstellt. Der Marktwert des Eigenkapitals sei besser in der Lage, den „wahren“ Wert des Unternehmens anzuzeigen, so dass in Zeiten hoher Markt-/Buchwert-Verhältnisse ökonomisch unbedenkliche Ausschüttungen verhindert würden ${ }^{1145}$. Das gesetzlich festgeschriebene Mindestkapital und die Ausschüttungsregeln bieten darüber hinaus auch deshalb nur einen ineffizienten Schutz, weil sie die wirtschaftlichen Besonderheiten des Einzelfalles nicht berücksichtigen können ${ }^{1146}$. Wollen sich die Gläubiger vor unternehmensspezifischen Risiken schützen, werden sie sich in aller Regel zu einer weiteren vertraglichen Absicherung gezwungen fühlen. Daher ist die transaktionskostensenkende Wirkung des gesetzlichen Kapitalschutzes als eher gering einzuschätzen. Gläubiger, die ausschließlich auf die Garantiefunktion des Kapitals vertrauen, befinden sich in der Regel in einer Scheinsicherheit.

Es verwundert daher nicht, dass insbesondere Kreditinstitute in ihrem Firmenkundengeschäft differenzierte Verfahren zur besseren Abschätzung des Ausfallrisikos entwickelt haben. Der Befund, dass die Nennkapitalziffer bei der Kreditvergabeentscheidung kaum eine Rolle spielt, wird auch durch Aussagen von Vertretern der Praxis ${ }^{1147}$ sowie durch empirische Studien ${ }^{1148}$ gestützt. Aber auch andere Gläubigergruppen bedienen sich zusätzlicher Schutzmaßnahmen, ziehen weitere Informationen über das jeweilige Unternehmen heran oder orientieren sich an extern erstellten Ratingurteilen. Auf alle diese Selbstschutzmöglichkeiten wird in Kapitel V.5.4 noch näher eingegangen.

1143 Vgl. Klose-Mokroß (1997), S. 65-66; Davies (1998), S. 353; Armour (2000b), S. 371; Enriques/Macey (2001), S. 1186; Niehues (2001), S. 1215-1216; Mülbert/Birke (2002), S. 718; Kübler (2003c), S. 100; Grundmann (2004), S. 142; Micheler (2004), S. 332-333; Mülbert (2004), S. 154; Rickford (2004), S. 931; Grunewald/Noack (2005), S. 190. Zu ähnlichen Kritikpunkten am legal capital-System im USamerikanischen Schriftum vgl. die Nachweise in Kapitel III.2.2.1.1.

1144 Vgl. Wiedemann (1968), S. 18; Wiedemann (1980), S. 565; Lutter (1983), S. 169; Priester (1992), S. 160; Watrin (2001a), S. 216; Arbeitsgruppe Europäisches Gesellschaftsrecht (2003), S. 874; Rammert (2004), S. 582; Schön (2004a), S. 165; Schön (2004b), S. 437; Kuhner (2005), S. 773.

1145 Vgl. Enriques/Macey (2001), S. 1196.

1146 Vgl. Fabricius (1970), S. 140; Gansen (1992), S. 4; Bauer (1995), S. 136; Cheffins (1997), S. 533, 537; Klose-Mokroß (1997), S. 176; Armour (2000a), S. 11; Niehues (2001), S. 1216; Mülbert/Birke (2002), S. 731; Grundmann (2004), S. 143; Micheler (2004), S. 332; Mülbert (2004), S. 160; Sandrock (2004b), S. 65. A.A. Schön (2004b), S. 441: „The traditional system of capital protection is therefore able to offer an efficient contractual instrument to companies and their creditors".

1147 Vgl. Walter (1998), S. 372: „Insgesamt bleibt somit festzuhalten, daß die derzeitigen Regelungen zum Mindesteigenkapital aus Sicht einer Bank unnötig und unzweckmäßig sind.“ Vgl. auch Schuster (1998), S. 380: „für Gläubigerbanken von Hoechst dürfte das Grundkapital in Höhe von 2,9 Mrd. DM bei der Kreditvergabe keine Bedeutung haben. Allein von Interesse ist hier die Erwartung, wie das Unternehmen aus dem zukünftigen freien Cashflow den Kapitaldienst erfüllen kann." Vgl. bezogen auf die Kreditvergabe an corporations in den USA Kübler (1989), S. 31.

$1148 \mathrm{Vgl}$. die Befragungsstudien zur Kreditvergabe von Banken in Großbritannien von Berry/Faulkner/Hughes/ Jarvis (1993); Deakins/Hussain (1994); und zu einer Einschätzung der Ergebnisse auch Armour (2000a), S. 13; Micheler (2004), S. 334. 


\subsubsection{Einfluss durch Lobbyismus}

Da die Kapitalaufbringungsregeln Kosten und Ineffizienzen verursachen und ihr Beitrag zum Schutz der Gläubiger, wie bereits im vorherigen Kapitel gezeigt wurde, gering ist, stellt sich die Frage, ob andere Unternehmensbeteiligte von den Vorschriften profitieren. Es könnte beispielsweise argumentiert werden, dass sie einen Beitrag zum Schutz der Aktionäre leisten. Die Kapitalschutzregeln stellen sicher, dass Aktionäre auf ihre Gleichbehandlung vertrauen können. Allerdings ist darin nur eine sehr schwache Regulierungsrechtfertigung zu sehen. Denn zum einen sind auch die Aktionäre unmittelbar von der geringeren Rendite infolge der Regulierungskosten betroffen. Zum anderen wäre zunächst zu prüfen, ob die Gleichbehandlung nicht auf effizientere Weise ohne Eingriff des Staates zu erreichen ist ${ }^{1149} . \mathrm{Zu}$ denken wäre beispielsweise an eine persönliche Ex-post-Haftung für die ordnungsmäßige Einlageerbringung ${ }^{1150}$.

Es existieren hingegen Hinweise auf „eine ,Gefangennahme' des Gesetzgebers und der Behörden durch Einzelgruppen von Finanzmarktunternehmungen zu deren Einkommenssicherung “1151. Verschiedene Berufsgruppen profitieren nämlich von den komplexen Regeln. Dazu gehören z.B. Rechnungslegungsexperten, die von den Gerichten als Sachverständige bestellt werden. Darüber hinaus werden in der Regel sowohl bei der Gründung als auch bei Kapitalmaßnahmen auf freiwilliger Basis unternehmensexterne Experten, insbesondere Rechtsanwälte und Wirtschaftsprüfer, hinzugezogen, die über die notwendigen gesellschaftsrechtlichen Kenntnisse verfügen. Es ist daher nicht verwunderlich, dass die komplizierten Regeln „,-nicht ohne Eigeninteresse - von Rechtsanwälten und Akademikern vehement verteidigt" " 1152 werden.

Auch die Kredit- und Versicherungswirtschaft gehört in Deutschland traditionell zu den Befürwortern und Nutznießern der bestehenden Regulierungsdichte ${ }^{1153}$. Ihr Einfluss hat entscheidend dazu beigetragen, dass sich insbesondere in Deutschland ein Rechnungslegungssystem entwickelt hat, das den Gläubigerschutz durch vorsichtige Gewinnermittlungsregeln und nicht die Informationsvermittlung der Eigenkapitalgeber in den Mittelpunkt stellt. Fremdkapitalgeber werden demnach traditionell gegenüber Eigenkapitalgebern privilegiert ${ }^{1154}$. Allerdings ist festzustellen, dass insbesondere die deutschen Großbanken zunehmend das Ertrags-

1149 Vgl. Grundmann (2004), S. 144.

1150 Vgl. Klose-Mokroß (1997), S. 194. Vgl. auch den nach Größe und Börsennotierung der Gesellschaften differenzierenden Vorschlag von Escher-Weingart (2001), S. 243-245.

1151 D. Schneider (1987), S. 85, in Bezug auf den vermeintlichen Gläubigerschutz von Mindestnormen zur Eigenkapitalausstattung. Vgl. auch D. Schneider (1992), S. 650-653.

1152 Hopt (2002a), S. 1018. Vgl. so auch o.V. (2006b). Vgl. zu dieser Argumentation ebenfalls zu Recht Enriques/Macey (2001), S. 1202-1203; und dazu die scharfe Kritik von Kuhner (2005), S. 756, der den Autoren Polemik, analytischen Zynismus und mangelnde Kenntnis der europäischen Gesellschaftsrechte attestiert. Auch im US-amerikanischen Schriftum ist auf die materiellen Vorteile für diese Berufsgruppen im legal capital-Regime hingewiesen worden. Vgl. z.B. Kummert (1984), S. 210; Peterson/Hawker (1997), S. 200.

1153 Vgl. dazu D. Schneider (1987), S. 102 m.w.N. D. Schneider (1992), S. 652, argumentiert, dass die Gefahr eines Bankrun als Regulierungsrechtfertigung von der Kreditwirtschaft ubertrieben worden ist, denn solange „ein Einlagensicherungsfonds und die Notenbank als ,lender of the last resort' bereitstehen, wird mit dem Verweis auf die Gefahr eines Bankruns der Bankkundschaft ein Ausmaß an finanzieller Unvernunft unterstellt, das (falls begründet) die Bankenaufsicht auch nicht durch noch schärfere Mindestnormen zur Eigenkapitalausstattung verringern könnte.“

Vgl. Mülbert (2004), S. 153 m.w.N. 
potential des Kreditsicherungsgeschäfts erkennen und sich verstärkt für einen mehr marktund informationsorientierten Gläubigerschutz interessieren ${ }^{1155}$.

\subsubsection{Probleme des Zusammenspiels von Auschüttungsregeln und EU-Bilanzrecht}

Wie in Kapitel V.4 bereits ausgeführt wurde, besteht ein zentrales Motiv der europäischen Gesetzgebung darin, den Kapitalschutz der Aktiengesellschaft und ihr entsprechende Rechtsformen in den EU-Mitgliedstaaten zu harmonisieren. Fraglich ist, ob diesem Ziel rechtstatsächlich entsprochen wird. Dazu wäre es notwendig, dass die Regelungen der Kapitalrichtlinie zum Kapitalschutz auf vergleichbare Rechnungslegungsdaten zugreifen. Das gilt insbesondere für die Durchführung der Bilanztests zum Zwecke der Ausschüttungsbegrenzung sowie für die Ermittlung der Höhe des Eigenkapitals. Die Vorschriften der Bilanzrichtlinie müssten folglich sicherstellen, dass sich wirtschaftlich gleiche Sachverhalte in den Jahresabschlüssen der Unternehmen in der EU auch in vergleichbarer Weise niederschlagen. In Anbetracht der unterschiedlichen sozio-ökonomischen und kulturellen Rahmenbedingungen in den EU-Mitgliedsstaaten ist hingegen eine vollständige Standardisierung bzw. Vereinheitlichung des Bilanzrechts weder das Ziel des europäischen Gesetzgebers noch wäre dies ökonomisch sinnvoll ${ }^{1156}$. Das Ziel besteht folglich darin, die Vergleichbarkeit im Sinne von Gleichwertigkeit der Rechnungslegungsinformationen zu erreichen ${ }^{1157}$. In der Unternehmenspraxis ließe sich ferner auch deshalb eine völlige Standardisierung nicht erreichen, weil jedes Rechnungslegungssystem den Bilanzerstellern zwangsläufig Ermessensspielräume eröffnet, so z.B. bei der Festlegung von Nutzungsdauern von Vermögenswerten oder der Bewertung von langfristigen Rückstellungen.

Die Bilanzrichtlinie - auch das ist oben bereits ausführlicher besprochen worden - gewährt allerdings eine Reihe von expliziten Mitgliedstaatenwahlrechten (z.B. Art. 33 BilRL: Ausnahmen vom Anschaffungs- und Herstellungskostenprinzip; Art. 42a BilRL: Bewertung von Finanzinstrumenten zum beizulegenden Zeitwert), die von den nationalen Gesetzgebern auch in unterschiedlicher Weise genutzt worden sind ${ }^{1158}$. Es ist offensichtlich, dass dadurch die Vergleichbarkeit leidet, weil von Mitgliedstaat zu Mitgliedstaat unterschiedlich hohe Anforderungen an die Höhe des zu schützenden Kapitals gestellt werden ${ }^{1159}$. Weiterhin existieren zahllose Unternehmenswahlrechte ${ }^{1160}$ (z.B. Art. 35 Abs. 3-4 BilRL: Wahlrechte hinsichtlich der Höhe der Herstellungskosten; Art. 37 BilRL: Aktivierungswahlrecht von Forschungs- und

1155 Vgl. Hopt (2002a), S. 1019; Kübler (2003c), S. 107, mit Verweis auf Walter (1998), S. 372; Merkt (2004a), S. 314. Vgl. zu einer ähnlichen Einschätzung Schuster (1998), S. 380. Vgl. auch M. Schneider (1998).

1156 Vgl. zu einer Analyse der Harmonisierung der Rechnungslegungsregeln unter Berücksichtigung von Kosten-Nutzen-Überlegungen Pellens (2001a), S. 388-393.

1157 Vgl. zu unterschiedlichen Harmonisierungsgraden und einer Begriffsabgrenzung von „Vergleichbarkeit“", "Gleichwertigkeit" und „Einheitlichkeit“" Pellens (2001a), S. 385-388.

1158 Vgl. dazu ausführlich Niehus (1985), S. 543-564; Niessen (1995), S. 986-994; Pellens (2001a), S. 405-409.

1159 Das gilt für die Wahlrechte, wie z.B. das des Art. 42a BilRL, die keine Ausschüttungssperren vorsehen.

1160 Baetge/Kirsch/Thiele (2005), S. 27, sprechen von ca. 40 nationalen Wahlrechten. Habersack (2003), S. 224, zufolge hat der ,deutsche Gesetzgeber (...) nicht nur von 41 Wahlrechten, die die Richtlinie den Mitgliedstaaten eröffnet, Gebrauch gemacht; er hat vielmehr auch die 35 Wahlrechte, die der nationale Gesetzgeber den betroffenen Gesellschaften einräumen kann, an diese weitergegeben." Vgl. so auch Niehus (1985), S. 537; Küting (1993), S. 31. Die bei dieser Zählweise enthaltenen Ausweiswahlrechte spielen für die hier diskutierte Problematik allerdings keine Rolle. 
Entwicklungskosten, Wahlrecht bezüglich des Abschreibungszeitraums von Geschäfts- und Firmenwerten), so dass die Aktiengesellschaften in der EU in die wenig zielführende Lage versetzt werden, „das Maß ihrer Kapitalerhaltung selbst zu beeinflussen. “1161 Eng damit verbunden ist die gläubigerschädigende Wirkung der gesetzlich erlaubten Bildung und Auflösung von stillen Reserven ${ }^{1162}$.

Eine Lücke im europäischen Kapitalschutzsystem ist auch darin zu sehen, dass die Bilanzrichtlinie lediglich in bestimmten Fällen Ausschüttungssperren vorschreibt, aber keine grundsätzliche Ausschüttungssperre für unrealisierte Gewinne vorsieht. Entstehen unter expliziter Beachtung von Art. 2 Abs. 3 BilRL unrealisierte Gewinne, weil von einzelnen Vorschriften der Bilanzrichtlinie aufgrund des übergeordneten true and fair view-Grundsatzes abgewichen werden muss, wird die Ausschüttung dieser Gewinne durch keine Ausschüttungssperre verhindert. Die Vergleichbarkeit ist in den letzten Jahren durch Reformmaßnahmen auf dem Gebiet der Bilanzrichtlinie sogar noch weiter eingeschränkt worden. Die Möglichkeit, bestimmte Finanzinstrumente zum beizulegenden Zeitwert zu bewerten, die durch die Fair-ValueRichtlinie $^{1163}$ eingeführt worden ist, sieht überhaupt keine Ausschüttungssperre vor. Schließlich ist eine Reihe von bedeutenden Bilanzierungsproblemen, wie z.B. die Bilanzierung von Leasingverträgen, Aktienoptionen und Pensionsverpflichtungen, nicht bzw. nicht abschlieBend geregelt ${ }^{1164}$. Insgesamt ist somit zu konstatieren, dass ,eine substantielle Angleichung des Bilanzrechts bislang nicht erreicht ist ${ }^{\text {"1165 }}$. Somit ist auch der Kapitalschutz in Europa im Ergebnis unterschiedlich ausgeprägt.

Die im Schrifttum vielfach vorgetragene Auffassung, an den europäischen bzw. handelsrechtlichen Gewinnermittlungsregeln zum Zwecke des Gläubigerschutzes bedingungslos festhalten $\mathrm{zu}$ müssen, ist in diesem Zusammenhang nochmals zu kritisieren. Zusammen mit den Gewinnverwendungsregeln sind diese Vorschriften kaum in der Lage, die Ansprüche der Gläubiger im Verhältnis zu denen der Aktionäre besser zu stellen.

In Wirklichkeit verbleibt der Unternehmensleitung ein erheblicher Spielraum „zur Täuschung über Geschehenes ${ }^{\text {“1166 }}$ zu Lasten der Kapitalgeber aus. Die Möglichkeiten des Managements, „eine Verschleierung in gesetzlich zulässiger Weise ${ }^{61167}$ zu bewerkstelligen, werden im Konzernverbund sogar noch erheblich erweitert. In der Principal-Agent-Beziehung zwischen den Kapitalgebern als Auftraggeber und den zur Unternehmensleitung Beauftragten führen die gesetzlichen Kapitalschutzregelungen somit zu einer Machtverschiebung zugunsten der Be-

\footnotetext{
1161 Niehues (2001), S. 1216. A.A. Schön (2000), S. 718: „ohne den einheitlichen Kapitalschutz zu gefährden.“

1162 Vgl. zu dieser Problematik ausfuhrlich Kapitel V.5.2.

1163 Vgl. Habersack (2003), S. 220.

1164 Vgl. Küting (1993), S. 31; Pellens (2001a), S. 405-406. Vgl. auch Rost (1991), S. 185-201.

1165 Habersack (2003), S. 223. Vgl. zu dieser Einschätzung auch Lanfermann (1992), S. 442; Niehus (1992), S. 443-444; Streim (1992), S. 444; Busse von Colbe (1993), S. 21; Küting (1993), S. 31-32, 38; Ordelheide (1995), S. 486; Schön (1997b), S. 153-154; Hopt (2000), S. 792-793; Schwarz (2000), S. 269; Pellens (2001a), S. 405-409; Niehus (2002), S. 1389-1390. A.A. Lutter (2000b), S. 128: „Insgesamt haben diese Richtlinien zu einer hohen Standardisierung des Rechenwerks (...) in Europa geführt." Vgl. zu einer positiveren (frühen) Einschätzung Niehus (1985), S. 565; und die Problematik relativierend Grundmann (2004), S. $228,261$.

1166 D. Schneider (1987), S. 107. Die gesetzlich zulässigen „Täuschungsmöglichkeiten“ sind besonders ausgeprägt bei Kreditinstituten. Vgl. dazu D. Schneider (1992), S. 656, mit Verweis auf die Bewertungswahlrechte fur Kreditinstitute in $\S 340$ f HGB.

1167 D. Schneider (1987), S. 106.
} 
auftragten $^{1168}$. Das vorrangige Ziel der zukünftigen Regulierung des Kapitalsystems der Aktiengesellschaft in Europa sollte folglich darin bestehen, eine bessere Informationsverteilung zwischen den beiden Gruppen sicherzustellen, so dass die Aktionäre die Dividendenpolitik der Unternehmensleitung besser beurteilen können ${ }^{1169}$. Eine Reform der starren Vorschriften der Kapitalrichtlinie könnte ferner die Effizienz des europäischen Kapitalmarkts steigern ${ }^{1170}$.

\subsection{Selbstschutzmöglichkeiten verschiedener Gläubigergruppen}

Aufgrund der geschilderten Defizite des Kapitalsystems als Instrument des Gläubigerschutzes werden in der Unternehmenspraxis häufig zusätzliche Schutzmaßnahmen auf privatvertraglicher Basis vereinbart. Darüber hinaus existieren neben den Vorschriften zum gesetzlichen Garantiekapital weitere Mechanismen, durch die Gläubiger geschützt werden. Vor diesem Hintergrund drängt sich daher die Frage auf, ob die als schwerfällig und kostenintensiv empfundenen Kapitalaufbringungs- und Kapitalerhaltungsregeln nicht überflüssig sind.

Ziel der folgenden Ausführungen ist es, die wichtigsten Selbstschutzmöglichkeiten der Gläubiger aufzuzeigen und auf ihre Wirksamkeit hin zu überprüfen. Da die Gläubiger keine homogene Gruppe darstellen, werden sie nach ihrer jeweiligen Verhandlungsmacht in verhandlungsstarke, vergleichsweise verhandlungsschwache und unfreiwillige Gläubiger unterteilt $^{1171}$. Die Analyse beschränkt sich dabei weitestgehend auf das rechtliche Umfeld in Deutschland; lediglich der Überblick über die Wirkungsweise von Kreditverträgen schließt Angaben zu den Besonderheiten der in den USA weit verbreiteten covenants mit ein.

\subsubsection{Verhandlungsstarke Gläubiger}

\subsubsection{1 Überblick}

Kreditinstitute und weitere Finanzgläubiger ${ }^{1172}$ verfügen in der Regel über vielfältige und weitreichende Möglichkeiten, sich vor Forderungsausfällen selbst zu schützen ${ }^{1173}$. Sie sind in

1168 Vgl. D. Schneider (1987), S. 106-108; D. Schneider (1992), S. 656-657. Vgl. ähnlich auch Budde (1994), S. 48; Kübler (1995b), S. 563; Kübler (1995c), S. 373; Busse von Colbe (2000), S. 489-491; Enriques/Macey (2001), S. 1202; Kübler (2003c), S. 101.

1169 Vgl. ähnlich D. Schneider (1992), S. 657. Vgl. auch den darüber hinaus gehenden Vorschlag zur grundsătzlichen Verbesserung der Allokation auf den Arbeits- und Finanzmärkten von D. Schneider (1987), S. 107, unter Verweis auf Arbeiten von Böhm und Schüller. Danach wären Aktien in Kapitalentzugsrechte einerseits und in Stimmrechte zur Bestellung des Managements andererseits aufzuspalten.

1170 Darauf weisen Enriques/Macey (2001), S. 1203, hin.

1171 Vgl. zu einer sehr breit angelegten Analyse der Selbstschutzmöglichkeiten von verschiedenen Zwangsglăubigern einerseits und zahlreichen Vertragsglăubigern andererseits Klose-Mokroß (1997), S. 79-167.

$1172 \mathrm{Zu}$ den Finanzgläubigern können neben den Kreditinstituten, die in Deutschland in $\S 1$ Kreditwesengesetz (KWG) definiert sind, z.B. auch Finanzierungsleasingunternehmen und Factoring-Institute gezählt werden. Vgl. Klose-Mokroß (1997), S. 94-95 m.w.N.

1173 Offensichtlicherweise ist die Verhandlungsmacht in dieser Gläubigergruppe unterschiedlich stark ausgeprägt. Beispielsweise wird eine kleine Stadtsparkasse eine geringere Marktmacht aufweisen als ein international operierender Bankkonzern. Darüber hinaus können neben den Finanzgläubigern im Einzelfall auch andere Gläubiger über erhebliche Verhandlungsmacht verfügen, wie z.B. wirtschaftlich und strategisch bedeutende Zulieferer. 
der Lage, sich bereits vor Vertragsabschluss ein genaues Bild der wirtschaftlichen Verhältnisse des potentiellen Schuldnerunternehmens zu machen und das eingeschätzte Risiko bei der Vertragsgestaltung zu berücksichtigen ${ }^{1174}$. Bei der Kreditvergabe an Aktiengesellschaften profitieren sie von den Berichtspflichten dieser Unternehmen. Die in Kapitel II ausführlich erläuterten Informationen, die (börsennotierte) Aktiengesellschaften bzw. corporations zur Erfüllung der Informationsrechte ihrer Aktionäre veröffentlichen müssen, stehen den Aktionären nicht exklusiv zur Verfügung. Finanzgläubiger verfügen in der Regel über die notwendige Zeit und Expertise, die Fülle an Unternehmensinformationen auszuwerten. Auch während der Laufzeit des Kreditvertrags können sie die jährlichen und unterjährigen, häufig zeitnah erstell$\operatorname{ten}^{1175}$ Informationen nutzen, die Unternehmen entweder in gesetzlich erzwungener Weise oder auch freiwillig, z.B. auf den Internetseiten, zur Verfügung stellen. Wenngleich eine umfassende Informationsversorgung der Unternehmensexternen grundsätzlich wünschenswert erscheint, so muss darauf hingewiesen werden, dass die Informationsbereitstellung der Aktiengesellschaft Kosten verursacht und im Einzelfall mit Wettbewerbsnachteilen einhergehen kann $^{1176}$. Diese Nachteile der Unternehmenspublizität können die Vorteile kompensieren und sich negativ auf den Wert des Eigenkapitals auswirken. Aus regulierungstheoretischer Sicht ist weiterhin zu bezweifeln, dass eine staatliche Regulierung der Unternehmenspublizität einer freiwilligen Offenlegung vorzuziehen ist ${ }^{177}$. Vor dem Hintergrund der aktuellen Bestrebungen zu erneut umfangreicheren Publizitätspflichten stellt sich schließlich die Frage, ob die Adressaten die Masse an Informationen überhaupt noch sinnvoll verarbeiten können ${ }^{1178}$.

Verhandlungsstarke Finanzgläubiger können für ihre Kreditwürdigkeitsanalyse von den kreditsuchenden Unternehmen ausführliche Informationen verlangen, die über die angesprochenen öffentlich zugänglichen Daten hinausgehen. Mit Hilfe der zusätzlichen Informationsquellen versuchen die Kreditinstitute, ,sich eine Vorstellung von der künftigen Entwicklung des Kreditnehmers zu machen, und sich von seiner Fähigkeit, ausreichende Finanzüberschüsse zu erwirtschaften, um die vereinbarten Zins- und Tilgungsleistungen aufbringen zu können, zu überzeugen. " ${ }^{1179}$ In Extremfällen kann die Macht der Großbanken so weit gehen, dass sie die unternehmerischen Entscheidungen im Schuldnerunternehmen mittels verschiedener Einwirkungs- und Gestaltungsrechte oder über Aufsichtsratsmandate beeinflussen können ${ }^{1180}$.

Weder der gesetzliche Zwang, ein bestimmtes Mindesteigenkapital zu erhalten, noch das vergangenheitsorientierte Zahlenmaterial in Bilanz und Gewinn- und Verlustrechnung können zu diesem Zweck allein weiterhelfen. Anstelle dessen verlangen Banken in der Regel zu unternehmensinternen Steuerungszwecken erstellte Finanz- bzw. Businesspläne, d.h. mehrjährige

\footnotetext{
1174 Nach $\S 18 \mathrm{KWG}$ sind Kreditinstitute bei einem Kredit von über $250.000 €$ grundsätzlich verpflichtet, sich vor und wăhrend der Kreditlaufzeit die wirtschaftlichen Verhăltnisse des Kreditnehmers insbesondere durch Vorlage von Jahresabschlüssen offen legen zu lassen und sie zukunftsgerichtet auszuwerten. Vgl. dazu etwa Wittig (2003), S. 63-64.

$1175 \mathrm{Vgl}$. zu den Veröffentlichungsfristen nach HGB, IFRS und US-GAAP im Vergleich Hayn/Waldersee (2004), S. 54-55, 302-303

1176 Vgl. Ewert/Wagenhofer (1992), S. 311-314; Fülbier (1998b), S. 179; Wagenhofer/Ewert (2003), S. 292-323; Pellens/Crasselt (2004), Sp. 1467.

1177 Vgl. Feldhoff (1992), S. 150-151, 184. Vgl. zu Zweifeln an der Regulierungsnotwendigkeit einer Ad-hocPublizităt ausfuhrlich Fülbier (1998b), S. 107-235.

1178 Vgl. Pellens/Crasselt (2004), Sp. 1467; M. Weber (2004), S. 3674; Clement (2005), S. 363.

1179 Walter (1998), S. 370.

1180 Vgl. dazu Süchting (1995), S. 207; Franken (2001), S. 71-74; Franke/Hax (2004), S. 48-51.
} 
Prognoserechnungen auf Basis von Cashflows, um die Kreditwürdigkeit zu beurteilen ${ }^{1181}$. Da ausführliche Kreditwürdigkeitsanalysen für die Banken zeit- und kostenintensiv sind und folglich den Gewinn aus dem Kreditgeschäft schmälern, wird der Analyseumfang auch von der Kredithöhe abhängig gemacht ${ }^{182}$. Bei niedrigen Kreditvolumina wird die Bank daher die zukünftige Ertrags- und Finanzkraft des Kreditnehmers aus der vergangenen Unternehmensentwicklung ableiten und lediglich auf Plausibilität hin überprüfen ${ }^{1183}$.

Hinweise auf die starke Verhandlungsposition der Banken geben auch empirische Untersuchungen, nach denen Kreditinstitute in Deutschland mehr als zwei Drittel ihrer kurz- und mittelfristigen Kredite besichern ${ }^{1184}$. Zu den vielfältigen Sicherungsmöglichkeiten zählen zum einen die vom Gesetzgeber vorgegebenen Sicherungsrechte: die Bürgschaft ( $\$$ 765-778 BGB), das Grundpfandrecht der Hypothek ( $\S 1113-1190$ BGB), die Grundschuld (§§ 1191-1198 BGB) und das Pfandrecht an beweglichen Sachen und Rechten (§§ 1204-1296 BGB). Zum anderen sind in der Praxis weitere Sicherungsrechte entwickelt worden, so z.B. die Sicherungsübereignung von beweglichen Sachen und die Sicherungszession. Darüber hinaus existieren personale Sicherungsformen, wie z.B. die Schuldmitübernahme, das abstrakte Schuldanerkenntnis bzw. -versprechen, der Garantievertrag, der Kreditauftrag und der Depotakzept. Schließlich kommt im Konzern den Patronatserklärungen, den Organschaftserklärungen und den Abkaufverpflichtungen eine Kreditsicherungsfunktion $\mathrm{zu}^{1185}$. Kreditsicherheiten oder auch vorzeitige Tilgungsverpflichtungen bei sich anbahnenden Liquiditätsproblemen sind häufig auch in den Allgemeinen Geschäftsbedingungen (AGB) der Kreditinstitute festge$\operatorname{legt}{ }^{1186}$.

Bei hohen und langfristigen Krediten stellt der Kreditvertrag ein umfangreiches Regelwerk dar, in dem unter anderem die Höhe und die Laufzeit des Kredits, der Zinssatz, Sicherheiten und Sanktionsmechanismen bei Vertragsverletzungen geregelt sind. Klassischer Bestandteil insbesondere in den US-amerikanischen Kreditverträgen ${ }^{1187}$ sind so genannte covenants, die die herkömmlichen Kreditsicherheiten ergänzen oder ersetzen. Auch in Deutschland werden

1181 Vgl. Bauer (1995), S. 306; Day/Taylor (1995), S. 398; Cheffins (1997), S. 517, 532; Eidenmüller (1997), S. 49-50; Schuster (1998), S. 380; Walter (1998), S. 371.

1182 Kreditgeber werden daher versuchen, die entstehenden Kosten der Informationsbeschaffung und -auswertung mit den möglicherweise geringeren Verlusten aufgrund des verbesserten Informationsstands zu vergleichen. Vgl. Süchting (1995), S. 209.

1183 Vgl. Walter (1998), S. 370. Hinzu kommt, dass viele kleine und mittlere Unternehmen nicht uber brauchbare Planungsdaten verfügen. Vgl. Süchting (1995), S. 208.

$1184 \mathrm{Vgl}$. zu Ergebnissen von Befragungen von Banken, Warenkreditgebern und kreditnehmenden Unternehmen Klose-Mokroß (1997), S. 79-83 m.w.N. Zu einem aktuelleren Überblick über empirische Forschungsergebnisse zur Kreditbesicherung vgl. Bigus/Langer/Schiereck (2004).

$1185 \mathrm{Vgl}$. zu den aufgezählten und zu weiteren Kreditsicherungsmöglichkeiten im Einzelnen Streim (1988), S. 16-18; Süchting (1995), S. 154-155, 207-218; Klose-Mokroß (1997), S. 94-124.

1186 Vgl. Schuster (1998), S. 380.

1187 Im US-amerikanischen Schriftum wird zwischen loan agreement und corporate indenture (bond oder debenture indenture) unterschieden. Bei loan agreements handelt es sich um Kreditverträge von Banken oder Versicherungen. Die Vertragswerke bei der Begebung von öffentlich gehandelten Schuldverschreibungen werden als indentures bezeichnet. Bonds sind dinglich gesicherte und debentures sind ungesicherte Schuldverschreibungen. Notes unterscheiden sich von debentures durch die Laufzeit, die bei notes in der Regel zehn Jahre oder weniger und bei debentures mehr als zehn Jahre beträgt. Vgl. dazu z.B. Eisenberg (2000), S. 109-111. Vgl. auch Bauer (1995), S. 307. 
covenants seit einigen Jahren mit offensichtlich wachsender Tendenz vereinbart ${ }^{1188}$. Für die Zukunft wird den covenants eine weiter zunehmende Bedeutung für die deutsche Kreditpraxis vorhergesagt $^{1189}$.

\subsubsection{Covenants als Vertragsbestandteil}

Als covenants werden Vertragsklauseln bezeichnet, durch die der Kreditnehmer für die Dauer des Kredits dem Gläubiger gegenüber zu einem bestimmten Verhalten verpflichtet wird ${ }^{190}$. Aufgrund der großen Bandbreite unterschiedlicher Vertragsgestaltungen in der Praxis ist eine Systematisierung mit Schwierigkeiten verbunden. Häufig werden positive (affirmative) covenants, die dem Kreditnehmer die Verfolgung und Einhaltung bestimmter Ziele auferlegen, und negative covenants, die ein Unterlassen bestimmter Handlungen festlegen, unterschie$\operatorname{den}^{1191}$. Die Klauseln schränken den Handlungsspielraum des Kreditnehmers ein, indem z.B. wichtige Investitions-, Personal- und Gewinnverwendungsentscheidungen nur mit der $\mathrm{Zu}$ stimmung des Kreditgebers umgesetzt werden dürfen.

Einen Eindruck von den vielfältigen Schutzklauseln vermitteln die so genannten Commentaries on Model Debenture Indenture Provisions ${ }^{1192}$. Es handelt sich dabei um eine von der American Bar Foundation kommentierte Vertragsklauselsammlung, die von zahlreichen erfahrenen Vertragspartnern von Kreditverträgen und Beratern bereits in den 1960er Jahren und damit lange Zeit vor Abschaffung des legal capital-Systems im MBCA ${ }^{1193}$ - zusammengestellt wurde und in der Praxis bei der unternehmensindividuellen Vertragsgestaltung häufig herangezogen wird. Einzelne Vertragsbestandteile sind darin bereits als „Schablone“ vorformuliert. Einige besonders typische covenants dieses Regelwerks werden im Folgenden kurz skizziert $^{1194}$.

Die Kreditverträge sehen regelmäßig covenants vor, durch die die weitere Kreditaufnahme des Schuldners detailliert geregelt wird. Die Aufnahme zusätzlicher gesicherter Kredite ist entweder verboten oder nur unter der Bedingung möglich, dass sich die Sicherheiten auch auf den ursprünglichen Kredit erstrecken. Die Aufnahme ungesicherter Kredite wird dadurch li-

\footnotetext{
1188 Vgl. Thießen (1996), S. 143; Fleischer (1998), S. 313; Busse von Colbe (2002a), S. 170; Wittig (2003), S. 68 .

1189 Vgl. Kästle (2003), S. 233. Schackmann/Behling (2004), S. 789, bezeichnen covenants als ein ,in der Praxis inzwischen etabliertes Mittel der nachhaltigen Kreditsicherung“.

1190 Vgl. Süchting (1995), S. 181; Alberth (1997), S. 745; Kästle (2003), S. 27. Zur Abgrenzung von covenants zu Klauseln in den AGBs deutscher Kreditinstitue, wie z.B. bestimmten Informationspflichten, Kundigungs- und Negativklauseln, vgl. Kästle (2003), S. 41-42.

1191 Vgl. z.B. Manning/Hanks (1990), S. 103; Press/Weintrop (1990), S. 67; Mülbert/Birke (2002), S. 723; Ross/Westerfield/Jaffe (2005), S. 573. Kästle (2003), S. 53, 62-71, behandelt als dritte Kategorie financial covenants. Smith/Warner (1979), S. 125, unterscheiden production/investment, dividend, financing und bonding covenants.

1192 Vgl. American Bar Foundation (1986). Es handelt sich dabei um den unveränderten Nachdruck der Ausgabe von 1971 .

1193 Darauf weist auch Mülbert (2004), S. 157, hin. Dessen ungeachtet wird in der Literaur teilweise der Eindruck vermittelt, covenants seien eine Reaktion der US-amerikanischen Gläubiger auf die Abschaffung des Nennkapitals durch die Reform des MBCA.

1194 Vgl. dazu insbesondere Smith/Warner (1979), S. 125-152; Bauer (1995), S. 307-312; Alberth (1997), S. 745-749.
} 
mitiert, dass die Gesellschaft bestimmte Bilanzkennzahlen einhalten muss. Vorgegeben werden beispielsweise Kennzahlen zur Kapitalstruktur. Ist ein bestimmtes Verhältnis von langfristigen Verbindlichkeiten zu den ohne Berücksichtigung von immateriellen Vermögenswerten berechneten Aktiva (net tangible assets) einzuhalten, wird die Kennziffer als gearing bezeichnet. Werden die Verbindlichkeiten ins Verhältnis zu den gesamten Vermögenswerten gesetzt, ist die Bezeichnung leverage ratio üblich. Festgelegt werden weiterhin Gewinn- oder Cashflow-Größen im Verhältnis zu den Zinsaufwendungen (interest coverage ratio) oder die Relation von kurzfristigen Verbindlichkeiten zum Umlaufvermögen (current ratio bzw. working capital). Bei der Ermittlung der Verbindlichkeiten sind zumeist auch nicht in der Bilanz ersichtliche Verpflichtungen, wie z.B. Garantien, Bürgschaften und Leasingverpflichtungen, zu berücksichtigen. Häufig muss über die Vertragslaufzeit ein bestimmtes Mindestniveau an Eigenkapital (net worth) erhalten werden. Unter net worth ist eine Eigenkapitalgröße zu verstehen, bei deren Ermittlung bestimmte immaterielle Vermögenswerte (z.B. Goodwill) und andere Bilanzpositionen (z.B. aktive latente Steuern, Minderheitenanteile) zu eliminieren sind.

Zur Kontrolle der ausgehandelten Restriktionen sehen die Kreditverträge regelmäßig umfangreiche Informationspflichten vor, die über die gesetzlichen Publizitätspflichten hinausgehen und auch interne Prognoserechnungen umfassen. Darüber hinaus werden die Rechtsfolgen bei einem Verstoß des Schuldnerunternehmens gegen die covenants geregelt. Verstöße können z.B. zur Folge haben, dass der Kredit sofort oder vorzeitig zurückgezahlt werden muss oder der Gläubiger ein Mitspracherecht bei der Geschäftsführung erhält. In der Praxis werden Verstöße häufig zum Anlass genommen, die Vertragsbedingungen neu auszuhandeln ${ }^{1195}$.

Die vorstehenden Ausführungen können nur einen ersten Eindruck von der Detailliertheit und Komplexität derartiger Vereinbarungen vermitteln, mit denen die Rechte des Schuldnerunternehmens beschränkt werden ${ }^{1196}$. Es wird aber unmittelbar deutlich, dass gesetzliche Kapitalschutzregeln nicht in der Lage sind, den umfassenden Gläubigerschutz durch vertragliche Regelungen zu substituieren. Es liegt in der Natur der Sache, dass eine gesetzlich kodifizierte Vorschrift nicht allen unternehmensindividuell höchst unterschiedlichen Bedürfnissen gerecht werden $\operatorname{kann}^{1197}$.

Von besonderem Interesse sind in dieser Arbeit die dividend covenants, die ebenfalls einen Bestandteil von US-amerikanischen Kreditverträgen darstellen können ${ }^{1198}$. Durch dividend covenants werden Ausschüttungen an die Aktionäre beschränkt. Teilweise wird die zulässige Höchstausschüttung in einem über die Kreditlaufzeit variablen Betrag (inventory of payable funds) abgebildet, der aus den kumulierten thesaurierten Gewinnen (teilweise auch nur ein bestimmter Prozentsatz davon) und Eigenkapitalerhöhungen seit der Kreditaufnahme, abzüg-

1195 Vgl. zu diesbezüglichen empirischen Befunden bei private debt agreements Dichev/Skinner (2002), S. 1122 .

1196 Bauer (1995), S. 313, weist in diesem Zusammenhang darauf hin, in „Deutschland würden viele dieser amerikanischen Regelungen aber von der Rechtsprechung wohl als sittenwidrige Knebelverträge angesehen werden, die gem. $§ 138$ Abs. 1 BGB nichtig sind." Vgl. zu den Auswirkungen der deutschen Rechtsprechung auf die Anwendbarkeit von covenants in Deutschland Thießen (1996), S. 150-154.

1197 Vgl. auch Bauer (1995), S. 315. Castle (1980), S. 26, weist darauf hin, dass covenants nach einer intensiven Prüfung der finanziellen Lage in Abhăngigkeit von der Bonităt und der Branche des Kreditnehmers sowie der Art des Kredits vereinbart werden.

1198 Vgl. zu dividend covenants insbesondere Smith/Warner (1979), S. 131-136; Bauer (1995), S. 310-311; Alberth (1997), S. 745-746. Zu einem ausfuhrlich erläuterten Praxisbeispiel eines dividend covenant vgl. Manning/Hanks (1990), S. 105-112. 
lich bereits geleisteter Ausschüttungen und zuzüglich bestimmter fixer Beträge besteht. Durch Desinvestitionen oder Kreditaufnahme generierte flüssige Mittel können dann nicht ausgekehrt werden. Andere Vertragsklauseln verbieten sämtliche Ausschüttungen oder machen sie von der Einhaltung bestimmter Kapitalstruktur- oder Liquiditätskennzahlen abhängig, wobei in vielen Fällen Dividenden an Vorzugsaktionäre möglich sind. Nach einer weiteren Variante darf nur der Cashflow der laufenden Geschäftsperiode ausgeschüttet werden.

\subsubsection{Empirische Verbreitung von Covenants}

Die Ausgestaltung von dividend covenants in der US-amerikanischen Praxis ist vielfach analysiert worden ${ }^{1199}$. Empirische Untersuchungen zu den vereinbarten Ausschüttungsrestriktionen und Rechnungslegungsregeln sind im Rahmen dieser Arbeit von Interesse einerseits, weil sie Aufschluss über die Schutzbedürfnisse der Gläubiger geben können. Andererseits liefern sie Hinweise, ob und inwiefern die gesetzlichen Kapitalschutzregeln den vertraglichen Abreden ähneln, die in weniger regulierten Rechtssystemen getroffen werden. Ließe sich nachweisen, dass gesetzliche Regeln mit weit verbreiteten Vorschriften in Kreditverträgen vergleichbar sind, könnte darin ein Hinweis gesehen werden, dass das gesetzliche Kapitalregime einen Beitrag zur Senkung der Transaktionskosten leisten kann ${ }^{1200}$. Im Folgenden werden die zentralen Ergebnisse der empirischen Forschung dargestellt, wobei sich die Ausführungen nicht nur auf die USA beschränken. Es werden mit Großbritannien und Deutschland bewusst auch Länder betrachtet, die vom europäischen Kapitalschutzkonzept betroffen sind.

Zahlreiche empirische Untersuchungen in den USA deuten auf eine weite Verbreitung direkter, gewinnbasierter Ausschüttungsrestriktionen hin ${ }^{1201}$. Die Befunde zeigen auch, dass Unternehmen häufig zusätzlich indirekte Ausschüttungsbeschränkungen in der Form von bestimmten Kennzahlen zu beachten haben. Verbreitet sind insbesondere Vermögens-, Liquiditäts- und Kapitalstrukturkennzahlen, wie z.B. net (tangible) worth, working capital, current ratio und leverage ratio, wobei diese allerdings unterschiedlich definiert werden. Vielfach ähneln die vereinbarten Ausschüttungsrestriktionen denen, die in der oben bereits angesprochenen Musterfassung eines Kreditvertrags der American Bar Foundation empfohlen wer$\operatorname{den}^{1202}$.

Empirische Untersuchungen liefern weiterhin interessante Erkenntnisse über die kreditvertraglich vereinbarten Rechnungslegungsregeln, die die Bemessungsgrundlage für die Ausschüttungsrestriktionen determinieren. Danach basieren die covenants grundsätzlich auf testierten US-GAAP-(Konzern-) Abschlüssen ${ }^{1203}$. Die Kreditverträge sehen allerdings in der Regel ausdrückliche Modifizierungen von den US-GAAP vor, die tendenziell zu einer niedri-

\footnotetext{
1199 Vgl. zu einem Überblick über zahlreiche bis zum Jahr 1996 entstandene empirische Untersuchungen Leuz/Deller/Stubenrath (1998), S. 115-117. Zu neueren Ergebnissen fur die USA vgl. z.B. Begley/Freedman (2004); Chava/Kumar/Warga (2004); Reisel (2004).

1200 Vgl. ähnlich Kuhner (2005), S. 784.

1201 Vgl. z.B. Smith/Warner (1979), S. 123 (23\% der untersuchten Kreditvertrăge enthalten gewinnabhängige Ausschüttungsrestriktionen); Castle (1980), S. $32-33$ (62\%); Kalay (1982), S. 214 (90\%); McDaniel (1986), S. 426, $457-460$ (35\%); El-Gazzar/Lilien/Pastena (1989), S. 222 (58\%); Duke/Hunt (1990), S. 55 (55,1\%); El-Gazzar/Pastena (1990), S. 386 (80\%); Press/Weintrop (1990), S. 74 (61\%); El-Gazzar/Pastena (1991), S. 140 (74\%); Mohrmann (1996), S. 86 (50\%). 
geren Bewertung der Aktiva und einem späteren Gewinnausweis führen. Die folgenden Abweichungen von den US-GAAP scheinen weit verbreitet $\mathrm{zu}$ sein ${ }^{1204}$ : Beteiligungen werden nicht mit der Equity-Methode, sondern mit den Anschaffungskosten bewertet, wodurch Beteiligungserträge erst bei Ausschüttung als realisiert ausgewiesen werden. Unsichere Verbindlichkeiten (contingencies) werden passiviert, selbst wenn ihr Eintritt nicht wahrscheinlich (probable) ist. Goodwill und weitere immaterielle Vermögenswerte werden nicht aktiviert. Wahlrechte bei der Bilanzierung von Leasinggeschäften werden mit der Maßgabe eingeschränkt, dass durch Leasing genutzte Vermögenswerte beim Leasingnehmer aktiviert werden. Aufgrund der kontinuierlichen Fortentwicklung der US-amerikanischen Rechnungslegung werden häufig die bei Abschluss des Kreditvertrags gültigen US-GAAP festgeschrieben $\left(\right.$,fixed GAAP“) ${ }^{1205}$.

Im Gegensatz zu den Befunden für die USA zeigen empirische Untersuchungen von dividend covenants in britischen ${ }^{1206}$ Kreditverträgen, dass sowohl in private debt contracts (Bank- und Versicherungskreditverträge) als auch in in public debt contracts (Kreditverträge bei öffentlich gehandelten Schuldverschreibungen) nur selten direkte Ausschüttungsbeschränkungen auf Basis des bilanziellen Gewinns festgelegt werden ${ }^{1207}$. Indirekte Ausschüttungsrestriktionen werden hingegen häufig in der Form von Bilanzkennzahlen vereinbart, nach denen das Schuldnerunternehmen eine bestimmte Kapital- und Liquiditätsstruktur einhalten muss ${ }^{1208}$. Bemerkenswerterweise scheinen cashflow-orientierte Größen in den Kreditverträgen kaum eine Rolle zu spielen ${ }^{1209}$. Auffällig ist schließlich, dass die Berechnung der Kennzahlen in den Kreditverträgen zwar dezidiert definiert wird, die der Berechnung zugrunde liegende Rechnungslegung nach UK-GAAP aber nur selten modifiziert wird ${ }^{1210}$.

In der - soweit ersichtlich - für Deutschland bislang einzigen empirischen Untersuchung haben Leuz/Deller/Stubenrath Interviews mit Vertretern von acht Banken durchgeführt und 19 Kreditverträge zu öffentlich gehandelten Schuldverschreibungen analysiert ${ }^{1211}$. Die befragten Banken sehen keine direkten Ausschüttungsrestriktionen in ihren Kreditverträgen vor. Auch indirekte Beschränkungen werden von ihnen nur in besonderen Situationen, wie z.B. bei Management-Buy-outs, Projektfinanzierungen und niedrigem Rating vereinbart. Die Rechnungslegung nach HGB wird vertraglich nicht modifiziert. Lediglich zwei der untersuchten Kredit-

\footnotetext{
1204 Vgl. Leftwich (1983), S. 31-35, 39; Frost/Bernard (1989), S. 795-796; El-Gazzar/Lilien/Pastena (1989), S. 222-225; El-Gazzar/Pastena (1990), S. 387-390.

1205 Vgl. Mohrman (1996), S. 84-87. $52 \%$ der von ihr untersuchten Kreditverträge mit accounting-based covenants schreiben die US-GAAP fest. Im Untersuchungszeitraum, der schwerpunktmäßig die Jahre 1983 bis 1990 umfasst, ist eine zunehmende Verbreitung festzustellen. Vgl. auch Beatty/Ramesh/Weber (2002), S. 211-212, die in $55 \%$ der untersuchten Kreditverträge in den Jahren 1994 bis 1996 eine solche Vorschrift finden. Leftwich (1983), S. 36, spricht von „frozen GAAP“.

1206 Die empirischen Untersuchungen beziehen sich strenggenommen auf Kreditverträge im United Kingdom (UK), also im Vereinigten Königreich von Großbritannien und Nordirland.

1207 Vgl. Citron (1992a), S. 23-24; Citron (1992b), S. 326; Citron (1995), S. 144-145; Day/Taylor (1995), S. 397-398; Day/Taylor (1996), S. 320-322.

1208 Verbreitet sind die Kennzahlen net (tangible) worth, interest cover ratio (Zinsdeckungsgrad), gearing, current ratio und leverage ratio. Zu typischen Definitionen dieser Kennzahlen in den Kreditverträgen vgl. z.B. Citron (1992a), S. 25-30; Rich (1992), S. 518-519.

1209 Vgl. Day/Taylor (1995), S. 397.

1210 Vgl. Citron (1992a), S. 24-25; Day/Taylor (1995), S. 400.

1211 Vgl. Leuz/Deller/Stubenrath (1998), S. 122-125.
} 
verträge schreiben die Einhaltung verschiedener Bilanzkennzahlen vor und weisen somit indirekte Ausschüttungsrestriktionen auf ${ }^{1212}$.

Im Gegensatz zu diesen empirischen Befunden finden sich vereinzelte Hinweise in der Literatur, nach denen die covenants in deutschen Kreditverträgen den US-amerikanischen ähneln ${ }^{1213}$. Demnach scheinen auch deutsche Kreditverträge üblicherweise eine Mindesteigenkapitalausstattung sowie Kennzahlen vorzuschreiben, die bestimmte Anforderungen an die Kapitalstruktur, die Liquiditätslage und den Zinsdeckungsgrad stellen. Bemerkenswerterweise wird empfohlen, zur Ermittlung des Eigenkapitals von dem in der HGB-Bilanz ausgewiesenen Betrag einige Positionen abzuziehen, wie z.B. aktivierte Aufwendungen für die Ingangsetzung und Erweiterung des Geschäftsbetriebs, immaterielle Vermögensgegenstände, Zuschreibungen, Anteile und Ausleihungen an sowie Forderungen gegenüber verbundenen Unternehmen und Beteiligungsunternehmen, Verbindlichkeiten im Sinne von $\S 251$ HGB (z.B. Bürgschaften). Auch für die Berechnung des Verschuldungs- und Zinsdeckungsgrads sollen die HGB-Zahlen modifiziert werden ${ }^{1214}$.

\subsubsection{Kritische Würdigung}

Die in empirischen Untersuchungen festgestellten Unterschiede zwischen den kreditvertraglichen Ausschüttungsrestriktionen in den USA auf der einen Seite und Großbritannien und Deutschland auf der anderen Seite werden von einigen deutschen Autoren darauf zurückgeführt, dass europäische Unternehmen bereits einer direkten gesetzlichen Ausschüttungsrestriktion unterlägen und vertragliche Regelungen mithin überflüssig seien ${ }^{1215}$. Die gesetzlichen Vorschriften in Europa substituierten die kreditvertraglichen Vereinbarungen ${ }^{1216}$. In den USA hingegen bestehe eine offensichtliche Nachfrage nach vertraglichen Absprachen, die dem gesetzlichen Kapitalschutzkonzept in Europa ähnelten. Weiterhin wird darauf hingewiesen, dass in den US-amerikanischen Kreditverträgen regelmäßig bestimmte Modifizierungen von den US-GAAP mit der Konsequenz formuliert würden, dass die zur Ausschüttungsbe-

1212 Gleiches gilt grundsătzlich für die Kreditvergabe von Versicherungsgesellschaften. Diese mussen unter bestimmten Voraussetzungen von ihren Schuldnern die Einhaltung bestimmter Kennzahlen verlangen. Vgl. Leuz/Deller/Stubenrath (1998), S. 124. Vgl. zu diesen so genannten BaFin-Kennzahlen bereits Kapitel V.5.2.

1213 Vgl. Wittig (1996), S. 1382-1390; Wittig (2003), S. 67-81 jeweils m. w. N; Schackmann/Behling (2004), S. 789-793. Vgl. dazu im Überblick auch Watrin (2001a), S. 205-207.

1214 Vgl. zu den Modifizierungen ausführlich Wittig (2003), S. 70-73.

1215 Vgl. Leuz (1996), S. 240; Leuz (1998), S. 580-581; Leuz/Deller/Stubenrath (1998), S. 120-121; Schön (2000), S. 727; Schön (2001), S. 78; Schön (2002), S. 4; Kuhner (2005), S. 785. Vgl. dazu kritisch Armour (2000a), S. 15; Armour (2000b), S. 374; Enriques/Macey (2001), S. 1192-1193; Niehues (2001), S. 1215; Mülbert (2004), S. 156-157. Sowohl die deutschen Aktiengesellschaften als auch die britischen public limited companies mulssen die Ausschüttungsrestriktionen gemäß Art. $15 \mathrm{KapRL}$ beachten. Die als Grundlage der Testverfahren dienende Gewinnermittlung muss im Einklang mit der Bilanzrichtlinie stehen. Vgl. dazu detailliert Kapitel III.1.1.3 und Kapitel III.1.2.1.3. Wahrend in Deutschland zur Ausschuttungsbemessung die Rechnungslegungsvorschriften des HGB herangezogen werden, müssen haftungsbeschränkte Unternehmen in Großbritannien nach § 263-264 Companies Act 1985 ihren im Jahresabschluss ausgewiesenen Periodengewinn (accounting profit) in einen ausschüttbaren Gewinn (distibutable profit) überleiten. Vgl. dazu Leuz (1996), S. 239-240.

1216 Vgl. zu dieser so genannten Substitutionsthese Leuz (1996), S. 240. 
messung vorgeschriebene Bilanzierung der HGB-Rechnungslegung sehr nahe komme $\mathrm{e}^{1217}$. Daraus wird der Schluss gezogen, die vom Vorsichtsprinzip geprägte deutsche Rechnungslegung stelle ein zweckmäßiges Gläubigerschutzinstrument dar ${ }^{1218}$.

Die vorstehende Argumentation vermag aus zweierlei Gründen nicht zu überzeugen. Erstens überwiegen - trotz gewisser Gemeinsamkeiten - die grundlegenden Unterschiede zwischen den gesetzlichen und vertraglichen Vorschriften ${ }^{1219}$. Während nach den gesetzlich kodifizierten Regelungen in Europa die seit der Unternehmensgründung erwirtschafteten kumulierten Gewinne ausgeschüttet werden können ${ }^{1220}$, beschränken die US-amerikanischen Kreditverträge die Ausschüttung in der Regel auf die Gewinne seit Beginn des Kreditvertrags. Folglich dürfen corporations häufig keine Ausschüttungen durch die Auflösung von Gewinnrücklagen vornehmen, was in Europa selbst dann möglich ist, wenn die Unternehmen in der abgelaufenen Periode einen Verlust erlitten haben. Kreditverträge beschränken nicht nur Dividendenzahlungen, sondern insbesondere auch die zusätzliche Kreditaufnahme, die durch das statische gesetzliche Kapitalregime nicht geregelt wird. Die kreditvertraglichen Bestimmungen berücksichtigen konsequent die unternehmensindividuellen Gegebenheiten und Zukunftseinschätzungen zum Zeitpunkt der Vertragsschließung, während die Kapitalaufbringungs- und Kapitalerhaltungsregeln keinen Bezug zum spezifischen Unternehmensrisiko aufweisen ${ }^{1221}$. Die Zukunftsorientierung der vertraglichen Gläubigerschutzmechanismen zeigt sich zudem darin, dass sie der Insolvenzprophylaxe dienen ${ }^{1222}$. Im Gegensatz dazu verfolgt das gesetzliche Kapitalsystem primär das Ziel, für den Insolvenzfall genügend Vermögenswerte zur Begleichung der Gläubigeransprüche vorzuhalten. Die vertraglichen Klauseln zeichnen sich auch durch eine höhere Flexibilität aus, da Vertragsverletzungen nicht notwendigerweise das vorzeitige Ende des Kreditengagements bedeuten, sondern vielfach lediglich zu Nachverhandlungen führen. Schließlich ist empirisch zu beobachten, dass Kreditgeber dem durch die Aktienemission eingezahlten Nennkapital bei der Kreditvergabeentscheidung kaum Bedeutung beimessen $^{1223}$. Während die Banken vor Vertragsabschluss die wirtschaftliche Lage und die künftige Finanz- und Ertragskraft des Unternehmens mehr oder weniger intensiv analysieren und das Risiko im Zinssatz berücksichtigen oder gegebenenfalls keinen Kredit vergeben, un-

1217 Vgl. Alberth (1997), S. 747; Alberth (1998), S. 804; Schildbach (1998a), S. 10; Schildbach (1999b), S. 360; Schildbach (2000), S. 194; Schön (2000), S. 729; Franken (2001), S. 218; Schön (2001), S. 78; Kahle (2002b), S. 164-165; Merschmeyer (2005), S. 288.

1218 Vgl. Schildbach (1998b), S. 78-80; Streim (1998), S. 340, der allerdings die Wahlrechte und Ermessensspielrăume kritisiert; Kahle (2002a), S. 701-702; Kahle (2002b), S. 166; Hennrichs (2004), S. 129-130; Küting/Ranker/Wohlgemuth (2004), S. 99; Hennrichs (2005), S. 260.

1219 Vgl. zum Folgenden insbesondere Ralston (1983), S. 1025-1028; Manning/Hanks (1990), S. 113-114; Bauer (1995), S. 312-316; Niehues (2001), S. 1215.

1220 Mit Ausnahme der Gewinne, die in die gesetzlichen und satzungsmäßigen Rücklagen einzustellen sind.

1221 Vgl. dazu ausfuhrlich bereits Kapitel V.5.3.3.

1222 In dem früheren Auslösezeitpunkt wird auch ein Vorteil gegenüber der deutschen Insolvenzordnung gesehen. Vgl. Thießen (1996), S. 154-157. A.A. Wittig (1996), S. 1391. Zu einem Vergleich des Gläubigerschutzes durch covenants und Insolvenzrecht vgl. Burger/Buchhart (2001). Vgl. die Vor- und Nachteile von covenants aus ökonomischer Sicht abwägend Eidenmüller (1997), S. 62-65.

1223 Bezogen auf Großbritannien kann Day (1986), S. 298, nur eine untergeordnete Bedeutung der Nennkapitalziffer feststellen. Den Untersuchungen von Berry/Faulkner/Hughes/Jarvis (1993) und Deakins/Hussain (1994) zufolge spielt sie gar keine Rolle. Vgl. zu ähnlichen Einschätzungen fur Deutschland Kapitel V.5.3.2 und die in Fn. 1132 angegebene Literatur sowie dazu gegensätzlich die Interviewergebnisse von Leuz/Deller/Stubenrath (1998), S. 122. 
terstellt das gesetzliche Kapitalsystem dem eingezahlten Kapital der Aktionäre eine gläubigerschützende Wirkung.

Zweitens ist zu bezweifeln, dass die empirischen Erkenntnisse, die der Argumentation zugrunde liegen, noch die aktuellen Gepflogenheiten der US-amerikanischen Kreditvergabepraxis widerspiegeln. Ein gravierendes Manko der herangezogenen empirischen Untersuchungen liegt darin, dass sie weit zurückliegende Untersuchungszeiträume analysieren ${ }^{1224}$. Die zum Teil 30 bis 50 Jahre alten Befunde als Beweis für die Zweckmäßigkeit des gesetzlichen Nennkapitalsystems zu benutzen, setzt voraus, dass sich die kreditvertraglichen Regelungen in den letzten Jahrzehnten nicht wesentlich verändert haben. Angesichts der rasanten Entwicklungen in der Informationstechnologie, der Datenverarbeitungssysteme, der Rechnungslegung und der Prognosetechniken in diesem Zeitraum ist diese Annahme kritisch zu hinterfragen. Darüber hinaus steht zu vermuten, dass sich die zu beobachtenden Veränderungen im Finanzierungs-, Investitions- und Ausschüttungsverhalten von Unternehmen im Zeitablauf auf die Vertragsgestaltungen auswirken.

Die Zweifel an der weiterhin bestehenden Gültigkeit werden durch aktuellere Studien bekräftigt $^{1225}$. Begley/Freedman untersuchen US-amerikanische Kreditverträge zu Schuldverschreibungen (public debt contracts), die in den Zeiträumen 1975 bis 1979, 1989 bis 1993 und 1999 bis 2000 begeben wurden ${ }^{1226}$. Die Autoren stellen einen erheblichen Rückgang von dividend covenants in den Kreditvereinbarungen von $44 \%$ in den 1970er Jahren über $25 \%$ in den Jahren 1989 bis 1993 auf lediglich noch $9 \%$ im Zeitraum 1999 bis 2000 fest $^{1227}$. Der Rückgang wird auch für Unternehmen nachgewiesen, die Schuldverschreibungen in mehreren der untersuchten Zeiträume begeben haben. Für Unternehmen, die beispielsweise im ersten (1975 bis 1979) und zweiten Zeitraum (1989 bis 1993) Schuldverschreibungen platziert haben, sinkt der Anteil von bilanziellen Ausschüttungsrestriktionen von $20 \%$ auf $9 \%{ }^{1228}$.

Die Autoren untersuchen darüber hinaus die Modalitäten der dividend covenants ${ }^{1229}$. Der bedeutendste Unterschied der vereinbarten Ausschüttungsrestriktionen in den Jahren 1989 bis 1993 und 1999 bis 2000 im Vergleich zu den 1970er Jahren besteht darin, dass nicht mehr das komplette Periodenergebnis (net income) ausgeschüttet werden darf. In der Regel zählen nur $50 \%$ eines Periodengewinns zu den für Ausschüttungen verfügbaren Mitteln, während Verluste in voller Höhe abgezogen werden. In jüngeren Jahren sind Dividendenausschüttungen auch dann verboten, wenn ein bestimmter Zinsdeckungsgrad auf Basis von Cashflows nicht

1224 Smith/Warner (1979) untersuchen die Jahre 1974 bis 1975, Kalay (1982) analysiert die Jahre 1956 bis 1975, Press/Weintrop (1990) das Jahr 1985, Mohrman (1996) die Jahre 1963 bis 1990. Der viel zitierte Aufsatz von Leftwich (1983) analysiert primär die kreditvertraglichen Vereinbarungen der Commentaries on Indentures der American Bar Foundation und zusätzlich lediglich zehn Bank- bzw. Versicherungskreditverträge, die vor 1977 abgeschlossen wurden. Aus dieser Untersuchung allein können kaum repräsentative Aussagen uber die tatsächliche Verbreitung von die US-GAAP modifizierenden Rechnungslegungsregeln in der Praxis getroffen werden. Dessen ungeachtet wird der Aufsatz im deutschen Schrifttum häufig als Beleg für die These herangezogen, eine vorsichtige Rechungslegung sei im Interesse der Gläubiger. Vgl. Begley/Freedman (2004); Chava/Kumar/Warga (2004); Reisel (2004).

Vgl. zum Untersuchungssample ausführlich Begley/Freedman (2004), S. 83-85. Der erste Zeitraum (1970er Jahre) beinhaltet nur debentures, die beiden anderen sowohl debentures als auch notes.

227 Vgl. Begley/Freedman (2004), S. 86-87. Werden ausschließlich debentures betrachtet, ist der Rückgang von bilanziellen Ausschüttungsrestriktionen noch dramatischer: Ihre Verbreitung in den Vertragswerken nimmt von $44 \%$ (1975 bis 1979) über $3 \%$ (1989 bis 1993) auf $0 \%(1999$ bis 2000$)$ ab.

Vgl. Begley/Freedman (2004), S. 87-88.

Vgl. Begley/Freedman (2004), S. 90-92. 
erreicht wird ${ }^{1230}$. Über den 25 jährigen Untersuchungszeitraum insgesamt gesehen ist eine abnehmende Bedeutung der Daten aus Bilanz und Gewinn- und Verlustrechnung zugunsten von Cashflows festzustellen ${ }^{1231}$.

Chava/Kumar/Warga analysieren die covenants von über 9.000 Schuldverschreibungen, die in den Jahren 1983 bis 2003 ausgegeben wurden ${ }^{1232}$. Sie stellen einen erheblichen Rückgang von dividend covenants fest. Sind sie im Zeitraum von 1980 bis 1989 noch in 32,54\% der Kreditverträge enthalten, geht ihr Anteil in den Zeiträumen 1990 bis 1994 (32,13 \%), 1995 bis $1999(23,76 \%)$ und 2000 bis $2003(11,04 \%)$ kontinuierlich zurück ${ }^{1233}$. Umgekehrt ist in den 1990er Jahren ein steigender Anteil von Restriktionen für Aktienrückkäufe festzustellen, der im letzten Zeitraum aber wieder auf das Niveau der 1980er Jahre zurückgeht. Covenants, die Unternehmenszusammenschlüsse beschränken, nehmen hingegen von unter $70 \%$ (1980 bis 1989) auf über $90 \%$ (2000 bis 2003) $\mathrm{zu}^{1234}$. Die Veränderungen lassen sich mit dem Boom von Unternehmensübernahmen in den 1980er bis Mitte der 1990er Jahre, der abnehmenden Bedeutung von Dividenden und der zunehmenden Verbreitung von Aktienrückkäufen in den USA in diesem Zeitraum erklären ${ }^{1235}$.

Als Ergebnis der Ausführungen zu den kreditvertraglichen Ausschüttungsrestriktionen bleibt festzuhalten, dass sie sich in vieler Hinsicht systematisch von den in Europa gesetzlich kodifizierten Bestimmungen unterscheiden. Folglich ist die geäußerte Prognose, „die Bankpraxis würde das tradierte gesetzliche System möglicherweise kautelarisch wiederherstellen “1236, sollte das aus gesellschaftsrechtlichen Kapitalschutzvorschriften und handelsrechtlichen $\mathrm{Bi}$ lanzierungsregeln bestehende Gläubigerschutzkonzept abgeschafft werden, wenig realis$\operatorname{tisch}^{1237}$

\subsubsection{Verhandlungsschwache Gläubiger}

Neben den im vorherigen Kapitel analysierten einflussreichen Kreditinstituten und sonstigen Gläubigern mit Marktmacht existieren weitere rechtsgeschäftliche Gläubiger, die tendenziell als verhandlungsschwach zu bezeichnen sind. Im Gegensatz $\mathrm{zu}$ den verhandlungsstarken Gläubigergruppen haben die kleineren, verhandlungsschwachen Gläubiger kaum Möglichkei-

1230 Interessanterweise wird dazu nicht der operative Cashflow, der in der Kapitalflussrechnung nach SFAS 95 ausgewiesen wird, verwendet, sondern es wird ein Cashflow eigens definiert. Vgl. Begley/Freedman (2004), S. 89-90,

1231 Vgl. Begley/Freedman (2004), S. 90-92, 95.

1232 Vgl. zum Untersuchungssample ausfuhrlich Chava/Kumar/Warga (2004), S. 11, 32.

$1233 \mathrm{Vgl}$. Chava/Kumar/Warga (2004), S. 13, 34. Werden Restriktionen von Dividenden und sonstigen Ausschüttungsformen zusammen betrachtet, ergibt sich folgender Verlauf: $35,70 \%$ (1980 bis 1989), 34,59\% (1990 bis 1994), 27,15\% (1995 bis 1999), 14,98\% (2000 bis 2003). Vgl. auch Reisel (2004), S. 10, 34, die ca. 8.000 Schuldverschreibungen untersucht und für den Zeitraum von 1989 bis 2001 in nur 18,68\% der Kreditvertrăge ausschüttungsbeschränkende covenants feststellt.

1234 Ein ähnlicher Trend ist für covenants, die Sale-and-leaseback-Transaktionen und die Aufnahme nachrangiger Verbindlichkeiten einschränken, festzustellen. Vgl. Chava/Kumar/Warga (2004), S. 33-34.

1235 Vgl. Chava/Kumar/Warga (2004), S. 13.

1236 Hennrichs (2004), S. 129-130. Vgl. ähnlich auch Schildbach (1998b), S. 81; Schön (2001), S. 78.

1237 Auch Watrin (2001a), S. 208-209, weist darauf hin, dass aufgrund der heterogen Präferenzen der Kreditgeber ein allgemein anerkanntes Regelset an Rechnungslegungsvorschriften nicht existiere. 
ten, Einwirkungsrechte oder Kreditverträge durchzusetzen ${ }^{1238} . \mathrm{Zu}$ dieser Gruppe von Gläubigern werden unter anderem Lieferanten, Handwerker, Freiberufler, Arbeitnehmer und Kunden gezählt ${ }^{1239}$.

Die verhandlungsschwachen Gläubiger sind allerdings den Risiken, die mit der Geschäftsbeziehung zu ihrem Schuldnerunternehmen verbunden sind, nicht schutzlos ausgeliefert. Wie die verhandlungsstarken Gläubiger auch, können sie sich dadurch schützen, dass sie die umfangreichen Informationen auswerten, die Aktiengesellschaften aufgrund ihrer gesetzlichen Publizitätspflichten oder auf freiwilliger Basis primär zur Befriedigung der Informationsrechte der Aktionäre zeitnah bereitstellen. Sie können sich darüber hinaus auch mittels weiterer Informationskanäle ein Bild über die wirtschaftliche Lage des Unternehmens machen, wie z.B. durch aktuelle Berichte in der Wirtschaftspresse oder Rating-Urteile ${ }^{1240}$. Die Wirksamkeit dieses auf Eigeninitiative basierenden Gläubigerschutzes durch Informationen wird in der Praxis aber gegebenenfalls dadurch eingeschränkt, dass die hier betrachteten Gläubiger - insbesondere im Gegensatz zu großen Finanzinstituten - in vielen Fällen weder über das notwendige Know-how zur Auswertung der Informationen noch die nötige Zeit ${ }^{121}$ für eine gründliche Analyse haben.

Weiterhin nutzen z.B. Lieferantenkreditgeber und Dienstleistungsgläubiger in der Regel verschiedene vertragliche Sicherungsinstrumente. Verbreitet sind unter anderem dingliche oder persönliche Sicherheiten, Lieferungen unter Eigentumsvorbehalt und die Vereinbarung bestimmter Zahlungsmodalitäten ${ }^{1242}$. Auch ist grundsätzlich davon auszugehen, dass auch diese Gläubiger versuchen werden, das Geschäftsrisiko bei der Kalkulation ihrer Angebotspreise zu berücksichtigen ${ }^{1243}$. Schließlich existieren zahlreiche gesetzliche Sicherungsrechte, auf die im Rahmen dieser Arbeit nicht näher eingegangen werden kann ${ }^{1244}$.

Darüber hinaus werden die verhandlungsschwachen Gläubiger indirekt in den Fällen geschützt, in denen das Unternehmen kreditvertraglichen Restriktionen unterliegt, die Großgläubiger mit Marktmacht durchgesetzt haben ${ }^{1245}$. Die Möglichkeit, als Trittbrettfahrer von

1238 Vgl. Hopt (2002a), S. 1019.

1239 Diese Gläubiger stellen keine homogene Gruppe dar, sondern weisen unterschiedliche Risikopositionen auf. Vgl. z.B. Streim (1988), S. 18. Erneut ist darauf hinzuweisen, dass die aufgezählten Gläubiger im Einzelfall sehr wohl über Verhandlungsmacht verfügen, wie dies z.B. bei Großkunden und strategisch wichtigen Zulieferen häufig der Fall sein wird. Vgl. so auch Enriques/Macey (2001), S. 1189.

1240 Vgl. Kübler (2003c), S. 109-110. Mülbert/Birke (2002), S. 714, weisen in diesem Zusammenhang auf die Dienstleistungen des Vereins Creditreform in Deutschland hin. Zu weiteren Informationsquellen und empirischen Befunden vgl. auch Klose-Mokroß (1997), S. 161-166 m.w.N.

1241 Das gilt insbesondere bei eiligen Reparaturarbeiten, beispielsweise durch einen Klempner nach einem Wasserrohrbruch. Es wird allerdings bezweifelt, dass das deutsche Kapitalschutzkonzept eine adäquate Lösung bietet. Vgl. z.B. Kübler (1989), S. 32: „(...) es gibt keinerlei Anhalt dafurr, daß die Lage des deutschen Klempners generell besser ist als die des amerikanischen plummers.“

1242 Vgl. Kübler (1989), S. 32; Kübler (1995b), S. 559.

1243 Vgl. zu den diesbezüglichen Gepflogenheiten im Handwerk ausführlich Klose-Mokroß (1997), S. 81, 144-145 m.w.N., die daraus folgendes Fazit zieht: „Der vielzitierte ,Handwerkernotfall' erweist sich mithin als Scheinproblematik."Vgl. auch Enriques/Macey (2001), S. 1172, 1188.

$1244 \mathrm{Vgl}$. z.B. die in $\S \S 647$ ff. BGB normierten Sicherungsrechte für Werkvertragsgläubiger. Vgl. zu den gesetzlichen und in der Praxis weit verbreiteten sonstigen Sicherungsmöglichkeiten detailliert Klose-Mokroß (1997), S. 124-161.

1245 Vgl. Enriques/Macey (2001), S. 1172, 1194; Hopt (2002a), S. 1019; Mülbert/Birke (2002), S. 714; Mülbert (2004), S. 157. Vgl. dazu kritisch Schön (2001), S. 78; Hennrichs (2005), S. 260; Kuhner (2005), S. 763-764. 
der Überwachungsfunktion der verhandlungsstarken Gläubiger zu profitieren, gilt allerdings nur so lange wie das Schuldnerunternehmen nicht in eine wirtschaftliche Krise gerät oder gegen die vertraglichen Absprachen verstößt. In solchen Situationen ist anzunehmen, dass die betreffenden Großgläubiger nur im eigenen Interesse handeln und z.B. eine frühzeitige Tilgung des Kredits durchsetzen, was für die Position der übrigen Gläubiger von Nachteil sein $\operatorname{kann}^{1246}$.

\subsubsection{Unfreiwillige Gläubiger}

Zur Gruppe der unfreiwilligen Gläubiger werden insbesondere Deliktsgläubiger gezählt ${ }^{1247}$. Sie zeichnen sich dadurch aus, dass sie sich die Gesellschaft als Schuldner nicht freiwillig ausgesucht haben, sondern ein Opfer unerlaubter Handlungen oder ungerechtfertigter Bereicherung geworden sind ${ }^{1248}$. Ein außenstehender Dritter wird zum Deliktsgläubiger, wenn er beispielsweise durch eine vom Unternehmen verursachte Umweltkatastrophe geschädigt wird, die aufgrund grober Fahrlässigkeit der Unternehmensführung verursacht wurde. Deliktsgläubiger ist auch ein Kunde, der z.B. aufgrund falscher Beratung durch eine Wirtschaftsprüfungsgesellschaft einen Vermögensschaden erleidet, für den er gegenüber der Gesellschaft einen Schadensersatzanspruch geltend machen kann. Folglich haben die unfreiwilligen Gläubiger keine Möglichkeit, sich im Vorhinein durch Auswertung von Informationen ein Bild von der aktuellen und zukünftigen wirtschaftlichen. Lage des Unternehmens zu machen und das dabei identifizierte Risiko bei Preis- oder Vertragsgestaltungen zu berücksichtigen. Die Gefahr dieser Gläubiger besteht darin, dass die Gesellschaft in Verzug gerät oder insolvent wird, und unterscheidet sich nicht wesentlich von derjenigen, die von einer rechtswidrig handelnden natürlichen Person ausgeht ${ }^{1249}$.

Die Schutzvorkehrungen der unfreiwilligen Gläubiger sind im Vergleich zu den in den letzten beiden Kapiteln analysierten Selbstschutzmöglichkeiten der anderen Gläubigergruppen weniger umfangreich. Sie haben aber die Möglichkeit, gegen den unmittelbar rechtswidrig Handelnden als unbeschränkt haftende natürliche Person vorzugehen ${ }^{1250}$. Ein wirksames Schutzinstrument besteht darüber hinaus in Pflichtversicherungen ${ }^{1251}$, die in vielen Bereichen gesetzlich vorgeschrieben sind ${ }^{1252}$. Hinzu kommen in der Praxis weit verbreitete freiwillige Haft-

\footnotetext{
1246 Vgl. Mülbert/Birke (2002), S. 730-731; Merkt (2004a), S. 314; Schön (2004b), S. 441.

1247 Daneben werden auch Steuergläubiger und bestimmte rechtsgeschäftliche Gläubiger (z.B. Arbeitnehmer, kleine Dienstleistungsgläubiger) zu den unfreiwilligen Gläubigern gezăhlt. Zu Ersteren vgl. Klose-Mokroß (1997), S. 90-93. Zu Letzteren vgl. Kübler (1991), S. 408-409.

1248 Vgl. Klose-Mokroß (1997), S. 86; Mülbert/Birke (2002), S. 714; Sandrock (2004b), S. 59-60.

1249 Vgl. Mülbert/Birke (2002), S. 714; Sandrock (2003), S. 478.

1250 Vgl. Kübler (1989), S. 32; Klose-Mokroß (1997), S. 86-87; Blaurock (2005), S. 11.

1251 Dies wird auch von Mülbert (2004), S. 157, betont, der darauf hinweist, dass die Versicherungslosung ,über die Prämienzahlung zudem eine zielgenaue Internalisierung der aus der beschrănkten Haftung resultierenden externen Effekte bewirkt.“

1252 So müssen z.B. Wirtschaftsprufer und Wirtschaftsprüfungsgesellschaften gemäß $\S 54$ WPO i.V.m. $\S 323$ Abs. 2 HGB eine Berufshaftpflichtversicherung abschließen. $\mathrm{Zu}$ weiteren Beispielen vgl. Klose-Mokroß (1997), S. 87-88.
} 
pflichtversicherungen ${ }^{1253}$. Es ist daher festzustellen, dass es sich beim Schutz von Deliktsgläubigern „um ein Problem handelt, das die Praxis bereits befriedigend gelöst hat. “1254

Zusammenfassend bleibt festzuhalten, dass den verhandlungsstarken, den -schwachen und den unfreiwilligen Gläubigern zahlreiche Schutzinstrumente zur Verfügung stehen, worin zumindest ein Indiz für die Entbehrlichkeit des bestehenden Kapitalschutzsystems zu sehen ist $^{1255}$. Die rechtsgeschäftlichen Gläubiger können von der umfangreichen und aktuellen Unternehmensberichterstattung, zu der Aktiengesellschaften gesetzlich verpflichtet sind, profitieren. Indem sie die Unternehmensinformationen auswerten, können sie sich ein Bild von der wirtschaftlichen Lage der (potentiellen) Schuldner machen und das identifizierte Risiko unternehmensindividuell z.B. im Zinssatz, der Risikoprämie oder im Verkaufspreis berücksichtigen, gegebenenfalls Kreditverträge schließen oder im Extremfall auf eine Geschäftsbeziehung verzichten. Die Unternehmensanalyse mag zeit- und kostenintensiv sein und im Einzelfall aufgrund von Kosten-Nutzen-Überlegungen unterbleiben. Dies kann aber nicht darüber hinwegtäuschen, dass die gesetzlichen Kapitalschutzregeln keine echte Alternative darstellen. Wie die Analyse des europäischen bzw. deutschen Kapitalschutzkonzepts ergeben hat ${ }^{1256}$, bietet es keinen wirksamen Gläubigerschutz ${ }^{1257}$. Zudem sind rational agierende Gläubiger in der zunehmend integrierten und globalisierten Wirtschaftswelt geradezu gezwungen, sich auch mit ausländischen Gesellschaften, die anderen Kapitalschutzregeln unterliegen, auseinandersetzen ${ }^{1258}$. Das gilt nicht nur für grenzüberschreitende Transaktionen, sondern auch im Verhältnis zu den im Inland zahlreicher werdenden Unternehmen mit ausländischer Rechtsform, wie z.B. der englischen Limited ${ }^{1259}$.

Ein leicht abweichendes Bild ergibt sich lediglich im Hinblick auf die unfreiwilligen Gläubiger, die vom Informationsmodell nicht profitieren können und denen das Kapitalsystem weitestgehend nur eine Scheinsicherheit bietet. Anstatt den gesetzlichen Kapitalschutz auszuweiten, wäre hier aber eher zu überlegen, etwaig bestehende, gravierende Schutzlücken durch die Einführung weiterer Pflichtversicherungen zu schließen ${ }^{1260}$.

\footnotetext{
1253 Vgl. dazu Klose-Mokroß (1997), S. 88-89 m.w.N.

1254 Klose-Mokroß (1997), S. 90.

1255 Vgl. ähnlich auch Klose-Mokroß (1997), S. 84

1256 Vgl. Kapitel V.5.2-V.5.3
}

1257 Andere Autoren geben hingegen dem bestehenden gesetzlichen Kapitalschutz den Vorzug, da es alle Glaubigergruppen gleichermaßen schütze. Vgl. so z.B. Hommelhoff (2000), S. 150; Schön (2001), S. 78; Watrin (2001b), S. 936; Arbeitsgruppe Europäisches Gesellschaftsrecht (2002), S. 1317; Arbeitskreis Bilanzrecht der Hochschullehrer Rechtswissenschaft (2002), S. 2375-2376; Hennrichs (2005), S. 260.

Vgl. so auch Grundmann (2001), S. 817. „Die Aufgabe des Wirtschaftsrechts sollte es jedenfalls nicht sein, Teilnehmer am Rechtsverkehr und insbesondere Kaufleute davor zu schützen, daß sie auf erkennbare Gefahren nicht reagieren: ,Gleichgultigkeit gegenüber Risiken und Schlafmützigkeit sollten nicht belohnt werden'. "So Kübler (1991), S. 403 mit Verweis auf Lehmann.

1259 Schătzungen zur Folge existierten im Jahre 2004 bereits mehr als 15.000 englische Limiteds in Deutschland. Vgl. Stiller (2004), S. 20. Mittlerweile sind es ca. 30.000. Vgl. o.V. (2006b). Vgl. zu den Besonderheiten sowie den Vor- und Nachteilen der Limited v. Bernstorff (2004), S. 501-502; Bäuml/Gageur (2005); Triebel/Otte/Kimpel (2005); Zöllner (2006). Vgl. zum Gläubigerschutz bei der Limited ausfühlich Schall (2005). Zur wohl ersten Landgerichtsentscheidung, nach der einem director einer Limited bei Verstoßßen gegen deutsches Insolvenzrecht persönliche Haftung und Strafverfahren drohen, vgl. o.V. (2006c).

1260 Vgl. zu dieser Forderung auch Grundmann (2001), S. 819-820; Kahle (2002a), S. 705; Schön (2004b), S. 438 . 


\subsection{Kosten und Nutzen eines Systemwechsels}

Vor dem Hintergrund der aktuellen Diskussion über die Reform der Kapitalrichtlinie steht möglicherweise in den nächsten Jahren ein grundlegender Systemwechsel hinsichtlich des europäischen Kapitalschutzregimes an ${ }^{1261}$. Setzen sich die Vorschläge der High Level Group durch, wird zum einen die bisherige Pflicht zur Aufbringung eines Mindestkapitals abgeschafft werden. Zum anderen wird ein Bilanztest zur Überschuldungsmessung um einen Solvenztest ergänzt werden. Dieser soll sicherstellen, dass die Gesellschaft nur dann eine Ausschüttung vornehmen kann, wenn die Tilgung der Unternehmensverbindlichkeiten bei Fälligkeit in einem bestimmten Zeitraum nach der Ausschüttung gewährleistet ist. Ungeklärt ist bisher noch, welche Bilanzierungsregeln für Zwecke des Bilanztests anzuwenden wären. In Anbetracht der Tatsache, dass alle kapitalmarktorientierten Konzern-Mutterunternehmen in der EU aufgrund der IAS-Verordnung zur Konzernrechnungslegung nach IFRS gezwungen sind und bereits heutzutage Gesellschaften vieler EU-Staaten die IFRS auch für den Einzelabschluss wahlweise oder verpflichtend anwenden, erscheint eine allgemeine IFRS-Pflicht für alle von einer reformierten Kapitalrichtlinie betroffenen Unternehmen plausibel. Alternativ wäre zu überlegen, nur die kapitalmarktorientierten Unternehmen auch zur Anwendung der IFRS im Einzelabschluss zu verpflichten und das neue Kapitalschutzkonzept ebenfalls nur diesen Unternehmen vorzuschreiben. Bevor in Kapitel V.6 ausgewählte alternative Kapitalschutzregeln zu analysieren sind, sollen im Folgenden die grundsätzlich mit einem Systemwechsel verbundenen Kosten und Nutzen kurz beleuchtet werden. Nur wenn verlässliche Hinweise dafür existieren, dass der Nutzen die Kosten übersteigt, erscheint ein Wechsel sinnvoll.

Befürworter des bisherigen Kapitalschutzsystems machen geltend ${ }^{1262}$, dass es Transaktionskosten spare, indem es für alle Gläubigergruppen einen standardisierten, kollektiven und ex ante wirkenden Schutz biete. Für die Beibehaltung sprächen auch Gründe der Rechtskontinuität und Pfadabhängigkeit ${ }^{1263}$ sowie die hohen Kosten, die ein ,abrupter“ “1264, „umstürzlerischer “1265 Systemwechsel nach sich zöge ${ }^{1266}$. Die Kosten setzen sich dabei zum einen aus den Gesetzgebungs- und Implementierungskosten ${ }^{1267}$ eines neuen Modells sowie den gegebenenfalls veränderten Kosten der gerichtlichen Durchsetzung der neuen Rechtsinstitute zusammen. Teilweise wird sogar argumentiert, das Alternativsystem könne die Schutzbedürftigkeit be-

1261 Vgl. zu den Reformvorschlägen im Einzelnen Kapitel IV.

1262 Vgl. zu einem prägnanten Überblick über die wesentlichen Vor- und Nachteile eines Systemwechsels Fleischer (2002), S. 575-576; Merkt (2004a), S. 320-322 jeweils m.w.N.

1263 Vgl. zur Pfadabhăngigkeit North (1990), S. 93-104; Richter/Furubotn (2003), S. 32-34. Vgl. dazu anschaulich Kübler (1998b), S. 345: „Unsere amerikanischen Kollegen sprechen von der „path dependency“, der Pfadabhängigkeit rechtlicher Ordnungen; dahinter steht das Bild von dem Indianerpfad, der einen großen Bogen um die Höhle des bösen Bären machte. Aus ihm wurde ein Weg und spăter eine Straße, die sich nicht mehr begradigen läßt, weil das den Abriß all' der Hochhäuser verlangte, die in dem längst nicht mehr sinnvollen Bogen um die Bärenhöhle entstanden sind.“

1264 Fleischer (2001), S. 13.

1265 Hennrichs (2005), S. 262.

1266 Vor dem Hintergrund der Tatsache, dass uber eine Reform der Kapitalrichtlinie bereits seit 1999 (SLIMInitiative) diskutiert wird und das Alternativkonzept frühestens im Jahr 2009 (wahlweise) anzuwenden sein wird, erscheint diese Wortwahl ubertrieben.

1267 Zusătzlich zum AktG müssten Änderungen z.B. im KWG, KAGG, im Steuer- und Versicherungsrecht vorgenommen werden. Vgl. Kübler (1989), S. 61; Assmann (1992), Einl., Tz. 487; Hennrichs (2004), S. 129-130; Merkt (2004a), S. 322. 
stimmter Gläubiger mit der Folge erhöhen, dass die Verbreitung von covenants zunehme. Dies könne zu dem negativen Effekt führen, dass Gesellschaften, die den strengeren Ausschüttungsbeschränkungen der Kreditvereinbarungen unterliegen, für risikofreudige Anlegergruppen (z.B. Venture Capital-Geber) uninteressant würden ${ }^{1268}$.

Für ein alternatives Kapitalschutzkonzept sprechen beispielsweise Kostenvorteile, die darin bestehen, dass Unternehmensgründungen und die Eigenkapitalbeschaffung vereinfacht werden. So entfallen bei Abschaffung des Mindestkapitals die im bisherigen Konzept bei der Gründung und Kapitalerhöhungen anfallenden Gerichts-, Gutachter-, Notar- und Anwaltskos$\operatorname{ten}^{1269}$. Dieser Vorteil wird gegebenenfalls durch gerichtliche Ex-post-Kontrollen bei Verstößen des Managements gegen ihre Sorgfaltspflichten und die dabei entstehenden Kosten geschmälert. Befürchtungen, nach denen erhöhte Haftungsanforderungen an die Mitglieder der Unternehmensführung z.B. bei der Festlegung der Ausschüttungshöhe zu mit erheblichen Nachteilen verbundenen Unsicherheiten auf Seiten des Managements führen ${ }^{1270}$, kann zumindest bei der Mehrheit der in Deutschland von der Kapitalrichtlinie betroffenen Aktiengesellschaften bezweifelt werden. Es handelt sich in der Regel um Großunternehmen mit Rechnungswesen- und Controlling-Abteilungen, die sowohl für Rechnungslegungs- als auch für interne Steuerungszwecke regelmäßig Cashflow-basierte und zukunftsgerichtete Zahlenwerke (z.B. Kapitalflussrechnungen, Finanzpläne) anfertigen, die für die Solvenzbescheinigung benötigt werden und bei ordnungsgemäßer Erstellung eine nachträgliche Haftung ausschließen.

Die Hauptvorteile eines Alternativkonzepts sind aber in einem wirkungsvolleren Gläubigerschutz und einer erhöhten Harmonisierung des Kapitalsystems in Europa zu sehen. Gläubiger werden insofern eher geschützt, als die bei einer Dividendenzahlung vom Management auszustellende Solvenzbescheinigung ein zukunftsorientiertes Element enthält, das dem Interesse der Gläubiger an künftigen Zins- und Tilgungszahlungen des Unternehmens eher entspricht. Wenngleich ein optimaler Gläubigerschutz nur unternehmensindividuell und nicht durch standardisierte gesetzliche Regelungen zu gewährleisten ist ${ }^{1271}$, sprechen überzeugende Gründe gegen die These, ein wirkungsvoller Gläubigerschutz sei nur im bestehenden Kapitalregime sichergestellt. Wie in dieser Arbeit ausführlich herausgearbeitet worden ist, bietet die vermeintlich gläubigerschützende handelsrechtliche Rechnungslegung in Deutschland dem Management erhebliche bilanzpolitische Spielräume ${ }^{1272}$. Durch geschicktes Ausnutzen von Wahlrechten und Ermessensspielräumen und die Möglichkeit, stille Reserven zu legen und zu heben, kann der ausschüttungsfähige Gewinn erheblich beeinflusst werden. Einen noch größeren Spielraum - darauf wird im Schriftum zur aktuellen Reformdebatte zumeist nicht hingewiesen ${ }^{1273}$ - gewähren die aktien- und handelsrechtlichen Regelungen dem Management einer Konzern-Muttergesellschaft, so dass der Gläubigerschutz im Konzern auf legale Weise weitestgehend ausgehöhlt werden kann. Vor diesem Hintergrund ist die Vehemenz, mit der zahl-

\footnotetext{
1268 Vgl. Merkt (2004a), S. 321. Dem ist entgegen zu halten, dass auch in Deutschland covenants verbreitet sind, so dass es sich nicht um ein spezifisch mit dem jeweiligen Kapitalschutzsystem in Verbindung stehendes Problem handelt.

Vgl. z.B. Enriques/Macey (2001), S. 1195-1199; Merkt (2004a), S. 311; Kuhner (2005), S. 774. Vgl. auch Kapitel V.5.3.2.

1270 Vgl. Lutter (1998b), S. 377; Watrin (2001b), S. 938.

1271 Vgl. Wagenhofer/Ewert (2003), S. 191.

1272 Vgl. Kapitel III.1.1.3.2.

1273 Vgl. aber Pellens/Jödicke/Richard (2005), S. 1394.
} 
reiche Autoren für die Beibehaltung der tradierten Kapitalaufbringungs- und -erhaltungsregeln plädieren, nicht nachzuvollziehen.

Ein alternatives Kapitalschutzkonzept, das einhergeht mit einer verpflichtenden IFRSRechnungslegung aller Aktiengesellschaften und ihr entsprechender Rechtsformen in Europa, würde auch der Zielsetzung des europäischen Gesetzgebers, EU-weit gleichartige Rahmenbedingungen für die Gesellschaften und eine gemeinschaftsweite Gleichbehandlung der Unternehmensbeteiligten $\mathrm{zu}$ erreichen ${ }^{1274}$, weit mehr entsprechen als das bestehende Zusammenspiel von Vorschriften der Kapitalrichtlinie und der Bilanzrichtlinie, die den bilanzierenden Unternehmen zahllose Wahlrechte einräumen. Kapitalmarktorientierte Mutterunternehmen könnten in einem solchen System Kosten sparen, weil sie zusätzlich zur IFRS-Rechnungslegung keinen HGB-Einzelabschluss mehr erstellen müssten ${ }^{1275}$. Zusätzliche Kosten durch die Umstellung der Rechnungslegung auf IFRS kämen auf die nicht kapitalmarktorientierten Gesellschaften in Europa zu, die bisher weder freiwillig noch im Einzelfall aufgrund nationalen Rechts gesetzlich verpflichtet nach IFRS bilanzieren. Dabei fallen diese Kosten im Wesentlichen einmalig im Rahmen der Umstellung an. Für die Zukunft erscheint es plausibel, dass die laufenden Kosten der IFRS-Bilanzierung nicht wesentlich höher als die der bisherigen Bilanzierung nach nationalen Vorschriften sind. Dafür spricht zum einen die zunehmende Verbreitung und Akzeptanz der IFRS ${ }^{1276}$ und zum anderen die aktuellen Bestrebungen des IASB, die Rechnungslegung für nicht kapitalmarktorientierte Unternehmen insbesondere hinsichtlich der Publizitätspflichten zu vereinfachen. Dadurch, dass das Alternativkonzept frühestens ab dem Jahre 2009 anzuwenden wäre, verbliebe den Unternehmen für die Umstellung auch genügend Zeit.

Ein ungelöstes Problem stellt die mangelnde Quantifizierbarkeit der aufgezeigten Kosten und Nutzen der beiden Kapitalregime dar ${ }^{1277}$. Wird unterstellt, dass die Kosten des Systemwechsels, die aus den notwendigen Gesetzesanpassungen resultieren, mittel- bis langfristig kaum ins Gewicht fallen ${ }^{1278}$ und die Kosten der Rechtsdurchsetzung in beiden Systemen in etwa identisch sind, kann der Vergleich auf den jeweiligen Nutzen der Modelle beschränkt werden. Wie ausführlich aufgezeigt worden ist, ist das bestehende System weder bei konzernunverbundenen noch bei Aktiengesellschaften in der vorherrschenden Organisationsform des Konzerns in der Lage, Gläubiger wirksam zu schützen. Das Alternativsystem mit einem auf zukünftigen Cashflows basierenden Solvenztest, Haftungsregeln und Ex-post-Kontrollmechanismen scheint für Gläubigerschutzzwecke grundsätzlich besser geeignet zu sein. Bilanztests auf der Basis von IFRS-Einzel- und/oder -Konzernabschlüssen anstelle einer Rechnungslegung, die lediglich der Bilanzrichtlinie mit ihren zahlreichen expliziten Bilanzierungswahlrechten genügen muss, würden die europäische Vergleichbarkeit des Kapitalschutzes erheb-

\footnotetext{
1274 Vgl. Kapitel V.4.

1275 Dies gilt insbesondere auch deshalb, weil die Steuerbilanz - wie bereits angesprochen - aufgrund vielfältiger Durchbrechungen der Maßgeblichkeit ein weitgehend eigenständiges Rechenwerk darstellt.

1276 Mit zunehmender Verbreitung der IFRS könnte es für die Unternehmen in der Zukunft sogar schwieriger und mithin kostspieliger werden, HGB-Experten zu finden.

1277 Vgl. etwa Merkt (2004a), S. 322: „Wir können also gar nicht sagen, dieses (oder kein) System ist effizienter als das andere." Vgl. auch Eidenmüller/Engert (2005), S. 437.

1278 Vgl. ăhnlich Kübler (2000), S. 559-560; Kübler (2003c), S. 106.
} 
lich erhöhen ${ }^{1279}$. Der höhere Grad der Harmonisierung dürfte auch im Interesse der Aktionäre sein, die europaweit investieren. Schließlich würden die Gesellschaften möglicherweise von der höheren Flexibilität bei der Unternehmensfinanzierung und dem Finanzmanagement profitieren, was sich tendenziell positiv auf den Unternehmenswert auswirken kann und damit im Interesse aller Unternehmensbeteiligten ist. Zusammenfassend kann daher festgehalten werden, dass Kosten-Nutzen-Überlegungen tendenziell für einen Systemwechsel sprechen ${ }^{1280}$.

\section{6 Ökonomische Analyse von alternativen Kapitalschutzregeln}

\subsection{Vorgehensweise im Überblick}

Im Folgenden werden ausgewählte alternative Kapitalschutzregeln, die in den Kapiteln III.2 und IV.6 ausführlich dargestellt worden sind, daraufhin überprüft, ob sie bei der anstehenden Reform des europäischen Kapitalsystems als Vorbild herangezogen werden sollten. Den Beurteilungsmaßstab bilden erneut die selbst gesteckten Ziele und Vorgaben des europäischen Gesetzgebers $^{1281}$.

In einem ersten Schritt werden Solvenztests, die in allen Bundesstaaten der USA aufgrund von gesellschafts- oder insolvenzrechtlichen Bestimmungen zu beachten sind und den Kern des Rickford-Reformvorschlags bilden, analysiert. Dabei wird auch auf die überall geltenden Sorgfaltspflichten und Haftungsregeln kurz eingegangen. Sodann werden die sonstigen Kapitalschutzregeln des MBCA, von Delaware und von Kalifornien kritisch gewürdigt. Dabei stehen jeweils die Ausschüttungsrestriktionen der Bilanztestverfahren und die ihnen zugrunde liegenden Rechnungslegungsnormen im Mittelpunkt der Betrachtungen. Auf eine ausführliche Würdigung der jeweiligen Kapitalaufbringungsregeln wird dem Fokus dieser Arbeit entsprechend verzichtet.

\subsection{Solvenztests}

Die US-amerikanischen Solvenztests werden von großen Teilen des deutschen Schrifttums kritisch beurteilt und als alternatives Gläubigerschutzinstrument überwiegend kategorisch abgelehnt ${ }^{1282}$. Kritisiert wird zum einen das Fehlen einer allgemein gültigen und einheitlichen Definition der equity insolvency. Zum anderen wird bemängelt, dass in den USA kein kon-

1279 Sollte das Alternativmodell als Mitgliedstaatenwahlrecht in der Kapitalrichtlinie verankert werden, stunde dies gegebenenfalls der europaweiten Harmonisierung des Kapitalschutzes entgegen. Ein solches Wahlrecht könnte indes zu mehr Wettbewerb der nationalen Gesetzgeber in der EU führen. Vgl. dazu auch Mülbert/Birke (2002), S. 731-732, die auf die diesbezuglichen Vorteile hinweisen.

1280 Andere Autoren sehen hingegen insgesamt ein argumentatives Patt. Vgl. Fleischer (2001), S. 13; Rammert (2004), S. 592; Hennrichs (2005), S. 261; Kuhner (2005), S. 787.

1281 Vgl. dazu Kapitel V.4.

1282 Vgl. hier und im Folgenden z.B. Bauer (1995), S. 235-237, 320; Wüstemann (1996), S. 426; Schildbach (1998b), S. 76; Wüstemann (1999), S. 56-57; Schön (2001), S. 77-78; Watrin (2001a), S. 231-232; Watrin (2001b), S.937-938; Arbeitskreis Bilanzrecht der Hochschullehrer Rechtswissenschaft (2002), S. 2375-2376; Kahle (2002b), S. 157; Arbeitsgruppe Europäisches Gesellschaftsrecht (2003), S. 874; Rammert (2004), S. 590-591; Baetge/Kirsch/Thiele (2005), S. 152; Bezzenberger (2005), S. 194; Hennrichs (2005), S. 259-262; Kuhner (2005), S. 777-780; Moxter (2006). 
kretes Verfahren zur Bestimmung der Solvenz vorgegeben wird und die Gesetzestexte eine Vielzahl von unbestimmten Rechtsbegriffen aufweisen. Die Ausgestaltung des Testverfahrens obliege vielmehr der Rechtsprechung, die aufgrund der einzelstaatlichen Kompetenz auf dem Gebiet des Gesellschaftsrechts in den USA von Staat zu Staat unterschiedlich sei. Zum Teil wird der Eindruck vermittelt, der Solvenztest sehe lediglich ,situative Ausschüttungssperren “ ${ }^{1283}$ in der Form, „eines ad hoc aufgestellten Überschuldungsstatus, der die Tageswerte des Gesellschaftsvermögens unter Einschluss stiller Reserven ausweist“"1284, vor.

Der gegebenenfalls anzufertigende Finanzplan auf Basis von zukünftig erwarteten Cashflows eröffne der Unternehmensleitung einen erheblichen Ermessensspielraum, so dass ein wirksamer Gläubigerschutz nicht gegeben sei. Die mangelnde Objektivierbarkeit der US-amerikanischen Solvenztests führe weiterhin dazu, dass sie in Gerichtsverfahren nicht justitiabel seien und folglich eine Ex-post-Kontrolle des Managements im Hinblick auf die Dividendenpolitik mit erheblichen Schwierigkeiten verbunden wäre. In der Praxis sei ein kausaler Zusammenhang von zu hohen Ausschüttungen und der in der Folgezeit eingetretenen Insolvenz der Gesellschaft kaum nachweisbar. Das Fehlen von expliziten Handlungsanweisungen führe auch zu erheblichen Unsicherheiten auf Seiten der Geschäftsführung. Das Management müsse jederzeit mit gerichtlich angeordneten Sanktionen rechnen, wodurch ein risikoaverses Verhalten provoziert werde. Sollte der Solvenztest den Kern eines reformierten europäischen Kapitalsystems darstellen, müssten sich die Unternehmensleitungen europäischer Gesellschaften ebenfalls auf eine ausgeweitete persönliche Geschäftsführerhaftung einstellen.

Die vorgetragenen Argumente überzeugen nicht. Es ist zwar richtig, dass die gesellschaftsund insolvenzrechtlichen Vorschriften in den USA keine konkreten Handlungsempfehlungen für die Durchführung des Solvenztests geben. Eine gerichtliche Überprüfung ist dadurch aber nicht gänzlich ausgeschlossen. Wie im Rahmen der Ausführungen zu den equity insolvency tests in den USA gezeigt wurde ${ }^{1285}$, haben zahlreiche Gerichte eine Überprüfung vorgenommen, bestimmte Verfahrensweisen gebilligt und andere als unzureichend abgelehnt. Schwierigkeiten bei der gerichtlichen Nachprüfbarkeit in den USA sprechen auch nicht gegen die grundsätzliche Eignung dieses Testverfahrens. Es erscheint beispielsweise denkbar, dass der europäische Gesetzgeber den Grundgedanken dieses Schutzinstruments übernimmt und gleichzeitig eine bestimmte Methodik im Sinne von „Grundsätzen ordnungsmäßiger Solvenzberichterstattung“ vorgibt ${ }^{1286}$. Erste Vorschläge, wie ein Solvenztest ausgestaltet sein könnte, sind in der Literatur bereits unterbreitet worden, worauf im weiteren Verlauf noch eingegangen wird ${ }^{1287}$. Sollten diese oder andere konkrete Vorschläge Eingang in das zukünftige europäische Gesellschaftsrecht finden, wären die Schwierigkeiten der gerichtlichen Kontrolle zumindest abgemildert. Ebenfalls wären sowohl die Ermessensspielräume als auch die Unsicherheiten der Unternehmensleitung bei der Durchführung des Tests reduziert. Selbst wenn eine reformierte Kapitalrichtlinie im Zusammenhang mit der Solvenzprüfung noch unbestimmte Rechtsbegriffe aufweisen würde ${ }^{1288}$, kann dies nicht als entscheidendes Argument

\footnotetext{
1283 Hennrichs (2005), S. 259.

1284 Schön (2001), S. 78. Vgl. ähnlich auch Arbeitskreis Bilanzrecht der Hochschullehrer Rechtswissenschaft (2002), S. 2375.

1285 Vgl. Kapitel III.2.2.1.3.1.1 (MBCA), III.2.2.2.1 (UFCA, UFTA), III.2.3.2.3.2.1 (Kalifornien).

1286 Vgl. dazu bereits Müchler (1992), S. 218-239.

1287 Vgl. Rickford (2004), S. 921-922, 968-988; Pellens/Jödicke/Richard (2005), S. 1398-1401; Engert (2006), S. 325-333.

1288 Dies wird von Kuhner (2005), S. 777, in Bezug auf § 4(a)(2) UFTA kritisiert.
} 
gegen eine solche Regulierung angeführt werden, denn auch die bestehenden aktien- und bilanzrechtlichen Vorschriften in Deutschland und Europa weisen zahlreiche unbestimmte Rechtsbegriffe auf, die durch die Anwendungspraxis, die Kommentarliteratur und die Rechtsprechung ausgefüllt werden ${ }^{1289}$.

Damit der Solvenztest seine gläubigerschützende Wirkung entfalten kann, müssen Verstöße des Managements Sanktionen nach sich ziehen ${ }^{1290}$. Dass mögliche Sanktionen die Unternehmensleitung zu einer übervorsichtigen und aus Aktionärssicht zu restriktiven Dividendenpolitik verleiten würden, leuchtet nicht ein. Wie die Ausführungen zu ausgewählten US-amerikanischen Haftungsregeln gezeigt haben ${ }^{1291}$, brauchen directors nachträgliche Sanktionen nicht $\mathrm{zu}$ befürchten, wenn sie bestimmte Sorgfaltspflichten eingehalten haben. Ihre Entscheidungen werden von der business judgment rule geschützt, und eine Haftung für unvorhersehbare negative Entwicklungen ist explizit ausgeschlossen. Auch die Aktionäre haften nach den gesellschaftsrechtlichen Vorschriften nur dann, wenn sie von der Unzulässigkeit der Ausschüttung wussten.

Schließlich ist die Charakterisierung des equity insolvency test als ein ad hoc aufzustellender Überschuldungsstatus zurückzuweisen ${ }^{1292}$. Nach den US-amerikanischen Gesetzen ist der equity insolvency test vom Grundsatz her nur erfüllt, wenn die Gesellschaft im Anschluss an die Ausschüttung weiterhin in der Lage ist, ihre im gewöhnlichen Geschäftsverlauf fällig werdenden Verbindlichkeiten zu begleichen. Eine ausschließlich stichtagsbezogene Betrachtung auf Basis von Bilanzdaten reicht dabei nicht aus. Die genaue Länge des zu berücksichtigenden Zeitraums ist gesetzlich zwar nicht geregelt. Hinweise im Fachschrifttum weisen aber auf die Dauer eines Geschäftsjahres hin. Einschlägigen Gerichtsurteilen ist zu entnehmen, dass in der Unternehmenspraxis teilweise erheblich längere Zeiträume betrachtet werden. Darüber hinaus haben sowohl die High Level Group als auch die Rickford-Gruppe einen mindestens zwölf Monate umfassenden Analysezeitraum vorgeschlagen ${ }^{1293}$. Der Arbeitskreis „Kapital in Europa“ sieht einen Zeitraum von 24 Monaten vor ${ }^{1294}$.

Wie bereits erwähnt, hat die Unternehmensleitung nach Ansicht des US-amerikanischen Fachschrifttums zur Beurteilung der Solvenz im Zweifelsfall eine Plan-Cashflow-Rechnung durchzuführen. Auch die Reformvorschläge der High Level Group, der Rickford-Gruppe und des Arbeitskreises „Kapital in Europa“ sehen im Kern einen solchen Finanzplan vor. In der betriebswirtschaftlichen Literatur besteht seit langem die einstimmige Ansicht, dass ein Finanzplan als zukunftsorientiertes Rechenschaftsinstrument theoretisch besser geeignet ist, Gläubiger zu schützen ${ }^{1295}$. „Die aktuellen und potentiellen Gläubiger interessieren sich vor

\footnotetext{
1289 Vgl. dazu z.B. Leffson (1987), S. 21-26.

1290 Vgl. so auch Niehues (2001), S. 1218; Micheler (2004), S. 343-344.

1291 Vgl. dazu Kapitel III.2.2.1.4 (MBCA), III.2.3.1.3 (Delaware), III.2.3.2.4 (Kalifornien).

1292 Unzutreffend ist in diesem Zusammenhang auch die Einschätzung von Merschmeyer (2005), S. 291, der Solvenztest gemäß $\S 6.40$ (c)(1) MBCA könne auf Basis einer IFRS-Rechnungslegung nicht gläubigerschützend sein. Da dieser Solvenztest auf Zahlungsgrőßen basiert, ist er von Bilanzdaten unabhängig. Zudem ist anzumerken, dass der MBCA nicht das Einzelstaatenrecht von Massachusetts darstellt.

1293 Vgl. High Level Group (2002c), S. 95; Rickford (2004), S. 921. Gleiches gilt für den Vorschlag von Pellens/Jödicke/Richard (2005), S. 1398.

1294 Vgl. Pellens/Sellhorn (2006), S. 485.

1295 Vgl. z.B. Busse von Colbe (1966a), S. 96-99, 109-112, der prospektive Kapitalflussrechnungen vorschlägt; Moxter (1984), S. 151-155; Leffson (1987), S. 88-89; Ballwieser (1996), S. 16-17; D. Schneider (1997a), S. 220; Schreiber (1999), S. 881; Streim (2000), S. 120.
} 
allem dafür, inwieweit das Unternehmen die vertraglich vereinbarten Zins- und Tilgungsauszahlungen fristgerecht leisten kann und wie groß die Wahrscheinlichkeit einer künftigen Insolvenz sowie der Höhe der Kreditverluste ist. (...) Über diese Fähigkeit informiert am besten ein Finanzplan. “1296 Auch im US-amerikanischen Schrifttum werden die Vorzüge des auf Prognosezahlen basierenden Solvenztests betont ${ }^{1297}$. Der equity insolvency test analysiere die zukünftige Liquiditätssituation der Gesellschaft und stelle damit im Gegensatz zu den bilanziellen Ausschüttungsrestriktionen auf das primäre Interesse der Gläubiger ab.

Die in der aktuellen Reformdebatte vielfach vorgetragene pauschale Ablehnung des Solvenztests auf Basis eines Finanzplans aufgrund von zu hoher Manipulationsanfälligkeit und mangelnder Nachprüfbarkeit erscheint in mehrfacher Hinsicht überzogen. Zunächst ist darauf hinzuweisen, dass auch der handelsrechtliche Jahresabschluss zukunftsorientierte Elemente enthält ${ }^{1298}$. Bilanz und Gewinn- und Verlustrechnung sind zwar insofern vergangenheitsorientiert, als sie die wirtschaftliche Lage des Unternehmens zum Geschäftsjahresende darstellen und in der Regel erst einige Monate später veröffentlicht werden. Bei der Abbildung vieler Bilanz- und Gewinn- und Verlustrechnungspositionen fließen aber Einschätzungen über den weiteren Verlauf in der Zukunft mit ein. So muss das bilanzierende Unternehmen beispielsweise für Vermögensgegenstände des Anlagevermögens Nutzungsdauern schätzen und der Abnutzung entsprechende Abschreibungsmethoden heranziehen. Die Unternehmensleitung hat weiterhin z.B. die Werthaltigkeit von Forderungen und des Vorratsvermögens zu beurteilen. Vielfältige Schätzungen sind auch hinsichtlich der zu bildenden Rückstellungen durchzuführen, die in der Regel eine bedeutende Bilanzposition darstellen und teilweise Verpflichtungen abbilden, welche die folgenden Jahre und sogar Jahrzehnte betreffen (z.B. Rückstellungen für Pensionsverpflichtungen, Restrukturierungen, Entsorgungsverpflichtungen und Prozessrisiken). Weitere prognoseorientierte Informationen sind im Rahmen der Lageberichterstattung gemäß $\S \S 289,315$ HGB anzugeben ${ }^{1299}$. Die vorstehenden Beispiele verdeutlichen den der Rechnungslegung immanenten Ermessens- und Beurteilungsspielraum. Sie zeigen auch, dass Abschlussprüfer bereits bei der Prüfung von handelsrechtlichen Jahresabschlüssen Einschätzungen der Unternehmensleitung über die zukünftige Entwicklung zu beurteilen haben und dazu unter anderem fundierte Kenntnisse über das Unternehmen, seine Branche und die konjunkturelle Lage benötigen. Die mit der Erstellung und Prüfung verbundenen Schwierigkeiten nehmen bei nach IFRS oder US-GAAP erstellten Abschlüssen in der Regel noch zu, weil z.B. durch die im Vergleich zum HGB häufigere fair value-Bewertung oder den Goodwill-Impairment-Test detaillierte Cashflow-Prognosen durchzuführen und zu prüfen sind ${ }^{1300}$.

Die Ermittlung und Verwendung zukunftsorientierter Zahlenwerke ist darüber hinaus in der Unternehmenspraxis weit verbreitet, wie die folgenden Beispiele zeigen ${ }^{1301}$. Im Rahmen der Kreditwürdigkeitsanalyse beurteilen Banken und spezialisierte Ratinggesellschaften die zu-

1296 Streim (1995), S. 718. Zur Finanzplanung und der Ausgestaltung von Finanzplänen vgl. ausfuhrlich Süchting (1995), S. 275-292; Franke/Hax (2004), S. 101-114, 127-130; Perridon/Steiner (2004), S. 623-667.

1297 Vgl. z.B. Eisenberg (1983), S. 202; Ralston (1983), S. 1035; Clark (1986), S. 616; Palmiter (2003), S. 521.

1298 Vgl. hierzu auch Moxter (2003), S. 252-253.

1299 Gesellschaften müssen z.B. hinsichtlich ihrer Finanzinstrumente die Preisänderungs-, Ausfall- und Liquiditätsrisiken sowie die Risiken aus Zahlungsstromschwankungen, denen die Gesellschaft zukünftig ausgesetzt sind, angeben ( $\$ 289$ Abs. 2 Nr. 3b HGB).

1300 Vgl. zum Vorgehen von Wirtschaftsprüfern bei der Prüfung von geschätzten Werten und fair values Bieker (2006), S. 207-213 m.w.N. Vgl. zu den Problemen der Prognoseprüfung grundlegend Rückle (1984).

1301 Vgl. im Folgenden ausführlich Pellens/Jödicke/Richard (2005), S. 1398-1400 m.w.N. 
künftige Ertragskraft bzw. Bonität von Unternehmen. Die Gesellschaften selbst müssen regelmäßig die Fähigkeit zur Unternehmensfortführung prüfen. Wirtschaftsprüfer haben sodann die Angemessenheit der Prämisse der Unternehmensfortführung innerhalb der Abschlussprüfung zu beurteilen und darüber hinaus fallweise den Eintritt oder das Drohen einer Zahlungsunfähigkeit zu prüfen ${ }^{1302}$. Bestehen Zweifel am Fortbestand des Unternehmens haben sie dazu den unternehmensintern erstellten Finanzplan heranzuziehen ${ }^{1303}$. Zur Beurteilung einer drohenden Zahlungsunfähigkeit ist schließlich ein Finanzplan zu prüfen, dessen Prognosezeitraum in der Regel das laufende und kommende Geschäftsjahr umfasst ${ }^{1304}$.

Neben der Unternehmensleitung, Wirtschaftsprüfern und weiteren Unternehmensbeteiligten sind auch Gerichte mit dem Umgang von Plandaten vertraut. Gerichte haben beispielsweise bei der Überprüfung der Angemessenheit von Abfindungszahlungen für ausscheidende Anteilseigner oder bei der Prüfung eines Verschmelzungsberichts Zukunftsprognosen zu beurteilen. Dazu werden regelmäßig investitionstheoretische Verfahren herangezogen ${ }^{1305}$, die im Vergleich zu einem Solvenztest weitaus schwieriger zu beurteilen sind. Einerseits umfassen diese Methoden erheblich längere Prognosezeiträume ${ }^{1306}$, und andererseits müssen zusätzlich angemessene Kalkulationszinsfüße bestimmt werden ${ }^{1307}$. Insgesamt ist daher festzustellen, dass zukunftsorientierte Instrumente zur Bewertung und Solvenzeinschätzung von Unternehmen in der Praxis bereits weit verbreitet sind.

Für einen Solvenztest spricht auch, dass von der Verfügbarkeit der dazu benötigten Informationen bei den in Deutschland von der Kapitalrichtlinie betroffenen Gesellschaften wohl sicher auszugehen ist. Einerseits sind Aktiengesellschaften beispielsweise aufgrund der durch das BilReG erweiterten Lageberichterstattungsanforderungen nach $\S \S 289,315$ HGB gesetzlich zur Angabe prognoseorientierter Daten gezwungen. Andererseits sollte jede Aktiengesellschaft zur Sicherung ihrer Rentabilität und Liquidität über interne Plandaten, wie z.B. PlanBilanzen und Plan-Kapitalflussrechnungen, im Rahmen ihres Controllingsystems verfügen. Die Erstellung eines Finanzplans für Zwecke des Solvenztests aus dem internen Rechnungswesen dürfte daher ohne wesentliche Zusatzkosten möglich sein.

Aufgrund der bisherigen Ausführungen kann somit festgehalten werden, dass ein Solvenztest als Gläubigerschutzinstrument grundsätzlich geeignet erscheint. Damit Gläubiger wirksam geschützt werden, sollte er allerdings bestimmte Kriterien erfüllen ${ }^{1308}$. Neben der bereits ausführlich erwähnten Zukunfts- und Cashflow-Orientierung sollte der Verfälschungsgefahr zukunftsorientierter Rechenwerke entgegengewirkt und konzernspezifische Risiken explizit berücksichtigt werden. Da ein Solvenztest wie jede Form der Rechenschaftslegung manipulationsanfällig ist, sollte dem Management eine bestimmte Methodik vorgegeben werden ${ }^{1309}$. Der

Vgl. IDW PS 270. Vgl. dazu auch Marten/Quick/Ruhnke (2003), S. 387-395.

1303 Vgl. IDW PS 270.10, 270.29.

1304 Vgl. IDW PS 800.12.

$1305 \mathrm{Vgl}$. zu einem ausführlichen Überblick zu den Bewertungsverfahren, die Grundlage richterlicher Wertfindung waren, Richardt (2000), S. 1927-1928. Vgl. auch Großfeld (2002), S. 44-45; Olbrich (2005), S. 414-417.

1306 Darauf weist auch Engert (2006), S. 321, 335, hin

1307 Vgl. zu den investitionstheoretischen Verfahren ausfuhrlich Dirrigl (1988), S. 229-319; Mandl/Rabel (1997), S. 31-42, 108-257, 285-385; Tomaszewski (2000), S. 13-20, 57-84; Siepe (2002), S. 87-125; Drukarczyk (2003), S. 119-337; Ballwieser (2004), S. 12-180; Baetge/Niemeyer/Kümmel (2005).

1308 Vgl. Pellens/Jödicke/Richard (2005), S. 1398.

1309 Vgl. hier und im Folgenden Pellens/Jödicke/Richard (2005), S. 1400.
} 
Finanzplan könnte z.B. hinsichtlich des Aufbaus an die Kapitalflussrechnung nach IAS 7 angelehnt werden. Im Hinblick auf den zu berücksichtigenden Zeitraum könnte er in Anlehnung an das übliche Vorgehen bei Unternehmensbewertungen zwei Phasen umfassen. Dabei sollte der mindestens zwölf Monate berücksichtigende Detailprognosezeitraum um eine zweite Phase, die eine langfristige, grobe Kapitalbedarfsplanung beinhaltet, ergänzt werden. Ausschüttungen wären so lange möglich, wie die Gesellschaft trotz der Ausschüttung im Detailprognosezeitraum auf Basis des Finanzplans über ausreichende liquide Mittel zur Fortführung der Geschäftstätigkeit verfügt und aus der langfristigen Kapitalbedarfsplanung keine existenzbedrohenden Risiken abzuleiten sind. In Anlehnung an das kalifornische Gesellschaftsrecht sollte der Solvenztest sowohl auf Ebene der rechtlich selbständigen Einzelunternehmen als auch auf Konzernebene durchzuführen sein.

Die Unternehmensleitung sollte in Höhe der unzulässigen Ausschüttung persönlich haften, wenn sie bei der Durchführung des Solvenztests ihre Sorgfaltspflichten fahrlässig oder vorsätzlich missachtet hat. Der Solvenztest sollte weiterhin zwingend durch Wirtschaftsprüfer auf Plausibilität der Planungsannahmen hin geprüft und testiert werden. Aufgrund der unternehmensinternen, vertraulichen Daten des Finanzplans sollte lediglich das Testergebnis in Form einer Solvenzbescheinigung, nicht hingegen der dem Testverfahren zugrunde liegende Finanzplan selbst offenlegungspflichtig sein. Bei einer Insolvenz der Gesellschaft im Anschluss an eine Ausschüttung könnten geschädigte Gläubiger ausgehend von der letzten Solvenzbescheinigung die ordnungsgemäße Durchführung des Solvenztests gerichtlich überprüfen lassen.

Zusammenfassend kann festgehalten werden, dass ein solcher Solvenztest dem tradierten Kapitalschutzkonzept überlegen ist. Durch seine zukunfts- und liquiditätsorientierte Ausrichtung beruht der Solvenztest auf einem Datenmaterial, das aus Gläubigersicht eine höhere Relevanz aufweist, und berücksichtigt somit konsequent das primäre Interesse der Gläubiger. Bei ordnungsmäßiger Durchführung kann er die Gläubiger wirkungsvoller schützen, weil Ausschüttungen nur dann möglich sind, wenn sämtliche Ansprüche der Gläubiger in dem festgelegten Zeitraum erfüllt werden können. Die Prognose der künftigen Cashflows ist einer intersubjektiven Überprüfung nicht zugänglich, sehr wohl aber die Plausibilität der Prognose-Prämissen. Einen perfekten Schutz der Gläubiger kann allerdings auch ein Solvenztest nicht bieten, weil Ex-post-Überraschungen selbst bei gewissenhaftester Planung nicht auszuschließen sind. Die hier vorgeschlagene Ausgestaltung des Solvenztests verringert aber den Spielraum, den die US-amerikanischen Regulierungen der Unternehmensleitung bei der Durchführung des Testverfahrens gewähren. Durch die zwingende Testierung der Solvenzbescheinigung durch Wirtschaftsprüfer wird die Vertrauenswürdigkeit dieses Instruments ebenfalls erhöht.

In Anbetracht dieses Ergebnisses erscheint ein daneben durchzuführender Bilanztest überflüssig. Die Reformvorschläge der High Level Group und des Arbeitskreises „Kapital in Europa“ sehen aber einen Bilanztest vor. Zudem kann zum jetzigen Zeitpunkt nicht ausgeschlossen werden, dass der europäische Gesetzgeber bei Einführung eines Solvenztests an einem traditionellen Bilanztest als zweiten Bestandteil der Solvenzprüfung festhalten will. Daher werden im Folgenden ausgewählte US-amerikanische Vorgehensweisen daraufhin überprüft, ob sie bei der möglichen Regulierung eines europäischen Bilanztests berücksichtigt werden sollten. Dies wäre dann geboten, wenn dadurch die in dieser Arbeit aufgezeigten Mängel des bestehenden europäischen Bilanztests vermieden oder zumindest verringert würden. 


\subsection{Model Business Corporation Act}

Fraglich ist, ob die in Kapiel II.2.2.1.3 ausführlich erläuterte Ausgestaltung des Bilanztests des MBCA ein Vorbild für das zukünftige europäische Kapitalsystem sein könnte. Erfüllt die Gesellschaft den Solvenztest nach $\S 6.40$ (c)(1) MBCA, sind Ausschüttungen nach dem balance sheet test des $\S 6.40(\mathrm{c})(2) \mathrm{MBCA}$ zulässig, solange im Anschluss daran die Vermögenswerte die Schulden und die Ansprüche der Vorzugsaktionäre auf den Liquidationserlös decken. Hat die Gesellschaft keine Vorzugsaktionäre, kann die Eigenkapitalquote im Extremfall bis auf $0 \%$ sinken. Der Test verhindert somit lediglich die Überschuldung der Gesellschaft im Anschluss an eine Ausschüttung; ein bilanzieller Puffer ist nicht vorgeschrieben.

Die Beibehaltung des balance sheet test war im Zuge der grundlegenden Überarbeitung des MBCA Anfang der 1980er Jahre umstritten ${ }^{1310}$. Die Kritiker wandten ein, eine bilanzielle Ausschüttungsrestriktion stehe in keinem Zusammenhang zum Liquiditätsinteresse der Gläubiger und sei damit als Gläubigerschutzinstrumentarium unzweckmäßig. Der Bilanztest wurde letztendlich beibehalten, um einerseits die Chance einer zahlreichen Übernahme des MBCA in die einzelstaatlichen Gesellschaftsrechte nicht zu schmälern. Andererseits wiesen die Befürworter auf die vermeintliche Objektivität der bilanziellen Ausschüttungsrestriktion hin. Vor dem Hintergrund der Tatsache, dass der MBCA kein Rechnungslegungssystem vorschreibt und der Bilanztest somit in Abhängigkeit von der jeweiligen Bilanzierungsweise der Unternehmen auf eine unterschiedliche Datenbasis zugreift, ist dieses Argument nicht sonderlich überzeugend. Es ist nicht ausgeschlossen, dass die Ausschüttungsrestriktionen bei zwei wirtschaftlich identischen Unternehmen, die sich nur durch ihr angewandtes Rechnungslegungssystem unterscheiden, zu abweichenden Ergebnissen führen.

Die Vorschrift des MBCA kann insofern positiv beurteilt werden, als sie unternehmerische Flexibilität durch eine einzige, leicht nachvollziehbare und transparente Bestimmung sicherstellt. Auch die Rechnungslegungsvorschriften des §6.40(d) MBCA, welche die Grundlage der Ausschüttungsrestriktionen bilden, gewähren dem Management einen erheblichen Spielraum. Dieser Regelung ist weiterhin zugute zu halten, dass sie es allen corporations ermöglicht, an den jeweils genutzen Rechnungslegungspraktiken auch für Ausschüttungszwecke festhalten zu können. Insbesondere kleinere und nicht börsennotierte Gesellschaften sind daher nicht gezwungen, allein aufgrund der Ausschüttungsregulierung ihren Jahresabschluss z.B. nach US-GAAP aufzustellen. Darüber hinaus ist es allen Gesellschaften gestattet, den balance sheet test auf eine Bilanz anzuwenden, die von der herkömmlichen Bilanzierung des Unternehmens abweicht und z.B. durchgehend auf Marktwertbasis erstellt ist.

Aufgrund der erheblichen Spielräume ist ein Schutz der Gläubiger durch den Bilanztest, der über den des Solvenztests hinausginge, nicht ersichtlich ${ }^{1311}$. Durch die zulässige Bilanzierungsvielfalt wirken sich die Ausschüttungsrestriktionen des Bilanztests im Unternehmensvergleich zudem in unterschiedlicher Weise aus, so dass eine Harmonisierung der Ausschüttungsbeschränkungen nicht erreicht wird. Denkbare Differenzierungen hinsichtlich der Branche, der Größe oder dem Risikoprofil der Gesellschaften werden ebenfalls nicht formuliert. Somit hat beispielsweise ein Unternehmen mit hoher Kreditwürdigkeit, das in einer konjunkturunanfälligen Branche tätig ist, dieselbe Möglichkeit, den bilanziellen Verlustpuffer durch Ausschüttungen bis auf Null zu reduzieren, wie ein konjunkturanfälliges Technologieunter-

\footnotetext{
1310 Vgl. hier und im Folgenden Committee on Corporate Laws (1986), S. 259.

1311 Vgl. zu dieser Einschätzung auch Bauer (1995), S. 321-322.
} 
nehmen. Würde der balance sheet test des MBCA in geltendes europäisches Recht bei ansonsten unveränderten Regelungen übertragen, wäre eine Rechnungslegung im Einklang mit europäischem Bilanzrecht zu beachten und somit ein höherer Grad an Harmonisierung erreicht. Die zahlreichen Wahlrechte der Bilanzrichtlinie, die einem gleichartigen Kapitalschutz aller Aktiengesellschaften in der EU zuwider laufen, würden aber zu ähnlichen Problemen führen wie in den USA.

Folglich können die Vorschriften des MBCA zum Bilanztest die bestehenden Mängel der europäischen Vorgehensweise nicht beheben, so dass sie in einem künftigen europäischen Alternativsystem nicht berücksichtigt werden sollten.

\subsection{Delaware}

Nach Auffassung des Delaware Supreme Court verfolgen die gesellschaftsrechtlichen Ausschüttungsbeschränkungen von Delaware das Ziel: „to prevent boards from draining corporations of assets to the detriment of creditors and the long-term health of the corporation. ${ }^{.1312}$ Es ist allerdings zweifelhaft, ob die Vorschriften Delawares dieses Ziel erfüllen können ${ }^{1313}$. Gegen die Bestimmungen lässt sich beispielsweise vorbringen, dass die directors das bei der Ausgabe von Aktien erhaltene Kapital willkürlich auf die Eigenkapitalpositionen capital und surplus aufteilen können. Je nachdem wie die Aufteilung ausfällt, kann es in der Folge zu legalen Dividendenzahlungen kommen, die den bilanziellen Verlustpuffer aus Gläubigersicht auf ein bedrohliches Minimum reduzieren. Es kann aber auch eine Konstellation eintreten, in der das Unternehmen keine Dividende zahlen darf, obwohl eine Ausschüttung die Risikoposition der Gläubiger kaum verändern würde. Das folgende Beispiel soll diese Problematik verdeutlichen $^{1314}$.

Betrachtet wird eine Gesellschaft, die durch die Ausgabe von 1 Mio. Aktien (Nennwert: 10 US-\$) zu einem Emissionskurs von 10 US-\$ je Aktie gegründet worden ist. Nach einigen Geschäftsjahren verfügt sie über assets in Höhe von 15 Mio. US-\$ und liabilities von 5 Mio. US$\$ 1315$.

Bilanz (in Tsd. US-\$)

\begin{tabular}{lr|rr}
\hline Assets & 15.000 & Liabilities & 5.000 \\
& & $\begin{array}{l}\text { Shareholders' Equity } \\
\text { Capital } \\
\text { Surplus }\end{array}$ & 10.000 \\
& 15.000 & & 0 \\
\hline
\end{tabular}

1312 Klang v. Smith's Food \& Drug Centers, Inc., 702 A.2d 150 (Del. 1997), hier S. 154. Vgl. zu diesem Urteil auch die Ausfuhrungen in Kapitel III.2.3.1.2.1.1.

1313 Vgl. dazu ausführlich Kapitel III.2.3.1.

1314 Ein ähnliches Beispiel zum legal capital-System in Kalifornien vor der Gesellschaftsrechtsreform von 1977 findet sich bei Marsh/Finkle/Sonsini (2005), § 14.02.

1315 Aus Gründen der Genauigkeit werden die Bilanzpositionen im Rahmen dieses Beispiels nicht ins Deutsche ubersetzt. Zur Bedeutung der Eigenkapitalpositionen im Gesellschaftsrecht von Delaware vgl. Kapitel III.2.2.1.1 und III.3.3.1. 
Die Gesellschaft weist demnach eine Fremdkapitalquote von ca. $33 \%$ auf. Bei einer gewünschten Dividendenzahlung von 1 Mio. US-\$ würde sich die Fremdkapitalquote nur unwesentlich auf ca. $36 \%$ erhöhen. Eine Ausschüttung ist aber bei ausschließlicher Betrachtung des surplus test nach $\S 170(a)$ Del.GCL nicht möglich, da kein surplus existiert.

Das Beispiel wird nun modifiziert: Die ansonsten identische Gesellschaft hat Aktien mit einem Nennwert von von 1 Cent ausgegeben. Damit hat die Bilanz folgendes Aussehen:

Bilanz (in Tsd. US-\$)

\begin{tabular}{|c|c|c|c|}
\hline Assets & 15.000 & $\begin{array}{l}\text { Liabilities } \\
\text { Shareholders' Equity } \\
\text { Capital } \\
\text { Surplus }\end{array}$ & $\begin{array}{r}10 \\
9.990\end{array}$ \\
\hline & 15.000 & & 15.000 \\
\hline
\end{tabular}

In einer solchen Situation kann die Unternehmensleitung zulässigerweise 9,99 Mio. US-\$ ausschütten, obwohl sich dadurch die Fremdkapitalquote von ca. $33 \%$ auf mehr als $99 \%$ erhöht. Anders ausgedrückt verschlechtert sich das Verhältnis von Fremdkapital zu Eigenkapital von 1:2 auf 500:1 mit der Maßgabe, dass der verbleibende Verlustpuffer gegen Null tendiert. Das Beispiel zeigt den erheblichen Spielraum, den der Gesetzgeber Delawares dem Management bei seiner Dividendenpolitik gewährt. Selbst wenn die Unternehmensleitung im Zeitpunkt der Gründung der Gesellschaft einen geringeren Anteil des erhaltenen Kapitals im surplus ausgewiesen hat, kann sie in der Folgezeit gemäß § 244 Del.GCL ohne Zustimmung der Aktionäre Beträge vom capital ins surplus transferieren ${ }^{1316}$. Zu berücksichtigen ist allerdings, dass ein solcher Schritt von den Aktionären und den übrigen Unternehmensbeteiligten im veröffentlichten Jahresabschluss nachzuvollziehen ist und von ihm gegebenenfalls eine negative Signalwirkung ausgeht.

Der unternehmerische Spielraum wird dadurch noch vergrößert, dass die directors für Ausschüttungszwecke die Bilanzpositionen über die Anschaffungs- und Herstellungskosten hinaus zum aktuellen Marktwert bewerten dürfen und der daraus resultierende surplus für Ausschüttungen zur Verfügung steht. In diesem Zusammenhang ist es auch als problematisch anzusehen, dass im Jahresabschluss nicht offen gelegt werden muss, wie viel die Gesellschaft maximal ausschütten darf und welche Ausschüttungsrestriktionen sie zu beachten hat ${ }^{1317}$.

Der Spielraum der Unternehmensführung wird darüber hinaus durch den alternativen net profits test gemäß $\S 170(a)(2)$ Del.GCL erweitert. Die darin vorgesehene Möglichkeit, nimble dividends auszuschütten, wird in der US-amerikanischen Literatur weitgehend positiv beurteilt. Ein Vorteil der Regelung wird z.B. darin gesehen, dass sie einen Ausgleich zu dem als

1316 Vgl. zu den Möglichkeiten der Kapitalherabsetzung in Delaware Kapitel III.2.3.1.2.1.2.

1317 Dies kann an folgendem Praxisbeispiel verdeutlicht werden kann: Die in Delaware gegründete Holiday Corporation wies für das Geschäftsjahr 1987 ein Eigenkapital in Höhe von 639 Mio. US-\$ aus. Der Jahresabschluss des Jahres 1988 offenbarte ein negatives Eigenkapital (deficit) von 770 Mio. US-\$. Die Gesellschaft hatte während des Jahres zur Abwehr einer feindlichen Übernahme eine Dividende von 65 US-\$ je Aktie und damit insgesamt 1,55 Mrd. US-\$ ausgeschüttet. Da die Vermögenswerte auf Marktwertbasis die Verbindlichkeiten nach der Ausschuttung überstiegen, stand die Ausschüttung im Einklang mit dem Recht Delawares. Vgl. Kieso/Weygandt/Warfield(2001), S. 814. 
statisch und wenig flexibel angesehenen surplus test bietet ${ }^{1318}$. Wäre der surplus test allein maßgeblich, könnten Unternehmen, die einen hohen Verlust erlitten haben und kein oder sogar ein negatives surplus aufweisen, keine Dividenden zahlen, selbst wenn sie aktuell wieder einen Gewinn erwirtschaften. Unter Umständen könnte ein profitabel wirtschaftendes Unternehmen über Jahre hinweg keine Dividende zahlen, obwohl es solvent ist, d.h. seine Verbindlichkeiten bei Fälligkeit zahlen kann. Durch die Möglichkeit, nimble dividends auszuschütten, könne die Gesellschaft hingegen das Defizit über einen längeren Zeitraum hinweg schrittweise abbauen und gleichzeitig die Aktionäre an den erwirtschafteten Gewinnen beteiligen ${ }^{1319}$. Zudem könne die Zahlung von vereinbarten Vorzugsdividenden fortgesetzt werden, so dass die Gesellschaft mit dem Vorzugsbetrag nicht (weiter) in Rückstand gerät ${ }^{1320}$. Nimble dividends können darüber hinaus von Bedeutung sein, wenn das Unternehmen für Sanierungszwecke neues Eigenkapital aufnehmen möchte und sich durch die Aussicht baldiger Dividendenzahlungen bei potentiellen Investoren attraktiv machen kann ${ }^{1321}$.

In dem Instrumentarium wird auch ein „fairer“ Ausgleich zwischen Gläubiger- und Anteilseignerinteressen gesehen ${ }^{1322}$. Nach dieser Ansicht interessieren sich Gläubiger primär dafür, dass das Unternehmen die Kredite inklusive Zinsen zurückzahlen kann. Aus Gläubigerperspektive sei insbesondere der Solvenztest und weniger ein auf historischen Daten basierender surplus test relevant. Die Aktionäre wiederum strebten eher nach einer hohen Rendite in Form von Dividenden und Kurssteigerungen als nach einem möglichen Liquidationserlös. Nimble dividends werden darüber hinaus auch deshalb für unproblematisch gehalten, weil sie die wirtschaftliche Lage des Unternehmens im Vergleich zur Situation vor dem aktuellen Gewinn nicht verschlechtern ${ }^{1323}$.

Diesen Argumenten kann gefolgt werden, solange tatsächlich von einer (wieder) erfolgversprechenden Unternehmensfortführung ausgegangen werden kann. Ein Schaden für die Gläubiger tritt allerdings ein, wenn die Gesellschaft aufgelöst werden muss ${ }^{1324}$. Dann weist die Gesellschaft eine geringere Haftungsmasse auf, als wenn sie anstelle der nimble dividends die Gewinne einbehalten und ihr Eigenkapital erhöht hätte. Jedoch ist darauf hinzuweisen, dass das capital in vielen Fällen von vornherein nur einen Bruchteil des ursprünglich eingezahlten Kapitals ausmacht. Nimble dividends stellen damit nichts anderes dar als Auszahlungen aus dem capital. Selbst wenn nimble dividends unzulässig wären, ließe sich auf legale Weise ökonomisch gesehen dasselbe Ergebnis durch eine Kapitalherabsetzung mit anschließender Dividendenzahlung aus dem reduction surplus erzielen. Die zeit- und kostenintensiven Formalitäten einer Kapitalherabsetzung ${ }^{1325}$ können allerdings vermieden werden, was wiederum für die nimble dividends-Regel spricht.

Es gibt aber auch kritische Stimmen. Sie weisen z.B. darauf hin, dass Geschäftsrisiken durch die Unternehmensleitung auf die Gläubiger verlagert werden und ein Defizit im surplus dau-

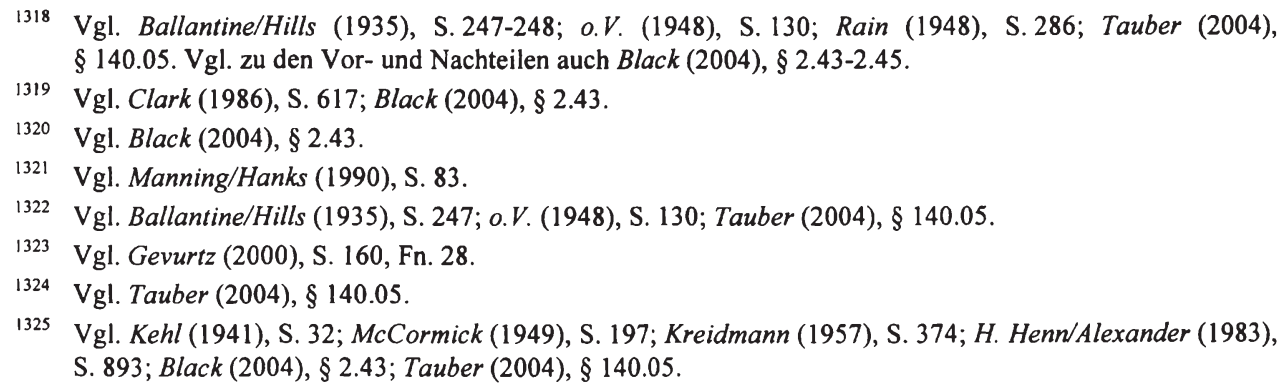


erhaft bestehen kann ${ }^{1326}$. Daher plädieren selbst grundsätzliche Befürworter von nimble dividends schon seit langem für bestimmte Restriktionen, die bisher allerdings nur teilweise von den Gesetzgebern verwirklicht worden sind ${ }^{1327}$. Insgesamt zeigt sich sehr deutlich, dass der ohnehin schon geringe Gläubigerschutz des surplus test durch die Zulässigkeit von nimble dividends nahezu vollständig ausgehöhlt wird ${ }^{1328}$. Die vorstehend aufgezeigten Vor- und Nachteile der nimble dividends-Vorschrift sollen abschließend an einem Beispiel verdeutlicht werden. Abermals wird eine Gesellschaft unterstellt, die über ein capital von 10 Mio. US-\$ verfügt. Aufgrund von erheblichen Anlaufschwierigkeiten in den ersten Jahren der Geschäftstätigkeit weist das Unternehmen ein Defizit im surplus von 7 Mio. US-\$ auf. Die Bilanz hat somit folgendes Aussehen:

Bilanz (in Tsd. US-\$)

\begin{tabular}{|c|c|c|c|}
\hline Assets & 8.000 & $\begin{array}{l}\text { Liabilities } \\
\text { Shareholders' Equity } \\
\text { Capital } \\
\text { Surplus }\end{array}$ & $\begin{array}{l}10.000 \\
-7.000\end{array}$ \\
\hline & 8.000 & & 8.000 \\
\hline
\end{tabular}

Annahmegemäß hat die Gesellschaft in der abgelaufenen Periode erstmals einen Gewinn in Höhe von 2 Mio. US-\$ erwirtschaftet, den das Management in voller Höhe in Form von nimble dividends an die Anteilseigner ausschüttet. Die Gesellschaft weist somit eine Fremdkapitalquote von $62,5 \%$ auf. Die nimble dividends-Vorschrift verhindert somit, dass sich in diesem Fall die Haftungsmasse zum Schutz der Gläubiger erhöht. Wäre der Gewinn verwendet worden, um das Defizit zu verringern, hätte sich die Fremdkapitalquote auf $50 \%$ verringert.

Zusätzlich zu den bereits sehr liberalen Ausschüttungsrestriktionen des surplus und net profits test sowie zu der unkomplizierten Durchführung von Kapitalherabsetzungen nach $\S 244$ Del.GCL existieren für wasting asset corporations noch weitergehende Ausschüttungsmöglichkeiten. Wie in Kapitel III.2.3.1.2.2 dargestellt, brauchen diese Gesellschaften bei der Ermittlung von net profits Abschreibungen der Vermögenswerte nicht zu berücksichtigen und können dadurch den potentiellen Ausschüttungsbetrag erhöhen. Diese Regelung wird überwiegend kritisch gesehen ${ }^{1329}$. Es wird darauf hingewiesen, dass sich die Risikoposition der Gläubiger und der Vorzugsaktionäre erhöhe. Gerade weil die Auflösung der Gesellschaft zu befürchten sei, müssten die Unternehmensbeteiligten besonders geschützt werden ${ }^{1330}$.

Dass die wasting asset-Vorschrift zu einer vollständigen Aushöhlung des Gläubigerschutzes führen kann, zeigt sich, indem das Beispiel aus Kapitel III.2.3.1.2.2 wieder aufgegriffen wird. In Abwandlung der Ausgangssituation finanziert das Unternehmen den Kaufpreis der Dia-

\footnotetext{
1326 Vgl. Berle (1929), S. 575-576; Hills (1935), S. 1364; Buxbaum (1954), S. 252; Black (2004), § 2.44.

1327 Vgl. insbesondere Ballantine (1946), S. 582. Vgl. dazu auch Black (2004), § 2.45.

1328 Vgl. Manning/Hanks (1990), S. 83; Eisenberg (2000), S. 1257; Palmiter (2003), S. 525; Black (2004), $\S 2.44 ;$ Emanuel (2005), S. 545.

1329 Vgl. Weiner (1929a), S. 477-482; Ballantine/Hills (1935), S. 248-252; Carpenter (1970), S. 1734; Black (2004), § 2.52 .

1330 Vgl. Carpenter (1970), S. 1734.
} 
mantmine in Höhe von 1 Mrd. US-\$ aber nicht mehr ausschließlich mit Eigenkapital, sondern es nimmt Fremdkapital in Höhe von 600 Mio. US-\$ auf. Die Nutzungsdauer beträgt unverändert zehn Jahre, jedes Jahr wird ein Zehntel des Diamantvorkommens abgebaut und der Restbetrag beträgt 0 . Der Kredit ist in voller Höhe nach zehn Jahren zu tilgen und verursacht jährliche Zinszahlungen von 45 Mio. US-\$. Von dem jährlichen Ertrag von 180 Mio. US-\$ verbleibt unter Berücksichtigung von Zinsaufwand (45 Mio. US-\$), sonstigem Aufwand (30 Mio. US-\$) und Abschreibungsaufwand (100 Mio. US-\$) ein Gewinn von 5 Mio. US-\$. Da der Abschreibungsaufwand bei der Festlegung der ausschüttungsfähigen net profits gemäß $\S 170$ (b) Del.GCL irrelevant ist, kann jedes Jahr eine Dividende von 105 Mio. US- $\$$ an die Aktionäre ausgeschüttet werden. Daraus resultiert zum einen eine kontinuierlich steigende Fremdkapitalquote von $60 \%$ zu Beginn der Geschäftstätigkeit auf $67 \%$ nach einem Jahr, $75 \%$ nach 2 Jahren, $86 \%$ nach 3 Jahren und $100 \%$ nach 4 Jahren. Ab dem 5. Jahr führen die Dividendenzahlungen zu einem Defizit im Eigenkapital, das jährlich um 100 Mio. US-\$ anwächst. Die Fremdkapitalquote steigt folglich von $120 \% \mathrm{im} \mathrm{6.} \mathrm{Jahr} \mathrm{auf} 600 \% \mathrm{im} \mathrm{9.} \mathrm{Jahr.}$ Nach zehn Jahren beträgt die Bilanzsumme 0, so dass keine Aktiva verbleiben, mit denen der Kredit zurückgezahlt werden könnte.

Das Beispiel lässt zwar die Möglichkeit der Fremdkapitalgeber außer Acht, sich bei der Kreditvergabe vertraglich abzusichern und z.B. die schrittweise Rückzahlung des Kredits ab dem zweiten Jahr zu vereinbaren. Ebenfalls unberücksichtigt bleiben sowohl möglicherweise bestehende Ansprüche der Gläubiger aufgrund von Verstößen der Gesellschaft gegen die Vorschriften des UFTA als auch eine eventuell in Frage kommende Haftung des board of directors gemäß $\S 174$ Del.GCL. Das Beispiel verdeutlicht aber, dass die wasting asset-Regelung des $\S 170$ (b) Del.GCL die Zielsetzung der gesellschaftsrechtlichen Ausschüttungsregulierung, die Gläubiger zu schützen, ad absurdum führt.

Vor dem Hintergrund der aufgezeigten Mängel der gesellschaftrechtlichen Regelungen Delawares aus Gläubigersicht verwundert die Einschätzung der Arbeitsgruppe Europäisches Gesellschaftsrecht: „Wichtige und für das Gesellschaftsrecht führende Staaten wie Delaware und New York haben an dem überkommenen und offenbar auch in Amerika für bewährt erachteten System des legal capital festgehalten." ${ }^{1331}$ Wie vorstehend gezeigt wurde, sichern die Kapitalschutzregeln den directors einer in Delaware gegründeten corporation einen überaus groBen Handlungsspielraum. Dies mag im Hinblick auf die unternehmerische Flexibilität im Finanzmanagement positiv zu sehen $\operatorname{sein}^{1332}$. Als Gläubigerschutzinstrument ist das legal capital-System Delawares hingegen weitestgehend ungeeignet, weil es nicht sicherstellt, dass das von den Aktionären eingezahlte Kapital dem Unternehmen als Verlustpuffer erhalten bleibt. Der Beitrag dieser Kapitalschutznormen zum Gläubigerschutz zusätzlich zu den übrigen Schutzmechanismen (z.B. Insolvenzrecht, common law) ${ }^{1333}$ ist daher als sehr gering einzustufen. Dies wird auch im US-amerikanischen Schrifttum überwiegend so gesehen ${ }^{1334}$.

\footnotetext{
1331 Arbeitsgruppe Europäisches Gesellschaftsrecht (2003), S. 874 (Hervorhebung im Original).

1332 Vgl. Manning/Hanks (1990), S. 83.

1333 Vgl. dazu umfassend Fleischer (2005).

1334 Vgl. z.B. Gevurtz (2000), S. 159: „All told, the traditional balance sheet approach typified by Delaware's statute is something of a joke.“ Vgl. anschaulich auch Palmiter (2003), S. 522: „But it is a small comfort to today's law students that legal capital is on its deathbed. The concept of legal capital survives in many jurisdictions - most notably Delaware - and promises to torment at least one more generation of corporate lawyers." Vgl. ebenfalls kritisch Manning/Hanks (1990), S. 82-83; Bainbridge (2002), S. 779-780.
} 
Somit kann festgehalten werden, dass die Bilanztests im Gesellschaftsrecht Delawares bei der Reform des europäischen Kapitalsystems nicht berücksichtigt werden sollten ${ }^{1335}$.

\subsection{Kalifornien}

Abschließend wird die Ausgestaltung der kalifornischen Testverfahren, denen für Ausschüttungszwecke zusätzlich zum Solvenztest genügegetan werden muss und die auf Bilanzdaten basieren ${ }^{1336}$, kritisch gewürdigt. Dazu zählen neben den beiden in $\S 500(\mathrm{~b})(1)$ und (2) Cal.Corp.Code normierten balance sheet tests auch der retained earnings test gemäß $\S 500(\mathrm{a})$ Cal.Corp.Code ${ }^{1337}$.

Die wichtigste Besonderheit der kalifornischen Regulierung ist darin zu sehen, dass die bilanzorientierten Testverfahren auf (Konzern-)Abschlüsse nach US-GAAP anzuwenden sind. Im Gegensatz zu den gesellschaftsrechtlichen Kapitalschutzregulierungen aller anderen Bundesstaaten der USA ist damit die Rechnungslegung einheitlich vorgegeben. Aus Sicht der Gläubiger ist dies grundsätzlich positiv zu beurteilen, weil die Testverfahren nicht durch eine breite Palette von gesetzlich zulässigen Bilanzierungsweisen ausgehölt werden können. Zwar beinhalten auch die US-GAAP - wie wohl jedes Rechnungslegungssystem - Wahlrechte und Ermessensspielräume. Im Vergleich zu den Vorschriften des MBCA oder des Gesellschaftsrechts Delawares wird der Spielraum des Managements aber erheblich eingeschränkt. Es ist in Kalifornien beispielsweise nicht möglich, für Ausschüttungsbemessungszwecke eine durchgehend auf Marktwertbasis erstellte Bilanz zu verwenden und die aus der Höherbewertung der Vermögenswerte resultierenden Erträge an die Aktionäre auszuschütten. Auch die Aktionäre profitieren von der US-GAAP-Bilanzierung, weil das Management unterbleibende Dividendenzahlungen viel weniger leicht mit der Beachtung gesetzlicher Ausschüttungsrestriktionen auf Basis willkürlicher Bilanzierungspraktiken begründen kann.

Durch das zwingend vorgesehene Regelset ist auch eher gewährleistet, dass die Ausschüttungsrestriktionen im Zeitablauf eine vergleichbare Strenge aufweisen. Die Vergleichbarkeit wird lediglich dadurch eingeschränkt, dass sich die US-GAAP kontinuierlich fortentwickeln. Diese Problematik hätte vermieden werden können, wären die im Zeitpunkt des Inkrafttretens des California Corporations Code gültigen US-GAAP festgeschrieben worden, wie es in machen US-amerikanischen Kreditvereinbarungen üblich ist ${ }^{1338}$. Eine solche Regulierung wäre allerdings aus Unternehmenssicht kritisch zu sehen, weil sich die Bilanzierungsregeln der USGAAP in dem Zeitraum von fast drei Jahrzehnten seit Bestehen des Gesetzes insgesamt gesehen erheblich geändert haben. Müssten die Gesellschaften noch immer die im Jahre 1977 gültigen US-GAAP anwenden, wären sie mittlerweile für Ausschüttungszwecke de facto zu einer parallelen Rechnungslegung gezwungen, was mit zusätzlichen Transaktionskosten einherge-

1335 Dies gilt im Übrigen nicht nur für das materielle Recht, sondern auch für den sprachlichen Stil der Gesetzestexte. Selbst Muttersprachler müssen wohl angesichts der Vielzahl an begrifflichen Ungenauigkeiten und Kleist'schen Satzungetümen fast verzweifeln. Dies ist vor dem Hintergrund der herausragenden Bedeutung und dem Vorbildcharakter des Gesellschaftsrechts Delawares verwunderlich. Vgl. kritisch auch Manning/Hanks (1990), S. 83-84.

1336 Vgl. zur ausführlichen Darstellung dieser Testverfahren Kapitel III.2.3.2.3.

1337 Die Besonderheiten bei Vorliegen von Vorzugsaktien werden hingegen vernachlässigt. Vgl. dazu Kapitel III. 2.3.2.3.4

1338 Vgl. zu empirischen Ergebnissen zu US-amerikanischen Kreditverträgen Kapitel V.5.4.1.3. 
hen würde. Zudem ist die Problematik aus Sicht der Gläubiger und der übrigen Unternehmensbeteiligten nicht als gravierend einzuschätzen. Wesentliche Änderungen der Rechnungslegung kündigen sich aufgrund des Standardsetzungsprozesses in der Regel lange Zeit vor ihrer Verabschiedung an, so dass sich die Unternehmensbeteiligten auf die Veränderungen einstellen und ihr Verhalten gegebenenfalls anpassen können.

Die im Rahmen des quantitative solvency test durchzuführenden Modifizierungen der USGAAP (z.B. Eliminierung des Goodwill, aktivierter Forschungs- und Entwicklungskosten und bestimmter Abgrenzungsposten) ${ }^{1339}$ sind hingegen kritisch zu sehen. Im deutschen Schriftum wird vielfach die These vertreten, das Herausrechnen weise auf die mangelnde Werthaltigkeit und Objektivierbarkeit dieser Bilanzpositionen hin $^{1340}$. Dem ist entgegenzuhalten, dass die zu eliminierenden immateriellen Vermögenswerte bei vielen Unternehmen einen erheblichen Wert darstellen und für die künftige Ertragskraft von besonderer Bedeutung sind. Zuzustimmen ist hingegen der verbreiteten Meinung im US-amerikanischen Schrifttum, diese Vermögenswerte könnten im Liquidationsfall der Gesellschaft gegebenenfalls zu geringen oder gar keinen Liquidationserlösen führen ${ }^{1341}$. Trotzdem sind die Modifikationen der US-GAAP abzulehnen. In Übereinstimmung mit dem HGB (§ 252 Abs. 1 Nr. 2 HGB) und den IFRS (IAS 1.23 ) ist bei der Bilanzierung nach US-GAAP von der Fortführung des Unternehmens auszugehen (SFAC 1.42). Die aufgezeigten Abweichungen von den US-GAAP stellen somit einen Verstoß gegen die Prämisse der Unternehmensfortführung dar und verkennen die wirtschaftliche Bedeutung dieser Bilanzpostionen für Unternehmen, die nicht unmittelbar vor der Liquidation stehen. Eine durchgehende Bilanzierung zu Liquidationswerten, die den Wert des Unternehmens im fiktiven Liquidationsfall anzeigen würde, wird ebensowenig erreicht. Schließlich ist eine Eliminierung bestimmter Bilanzpositionen auch deshalb nicht geboten, weil die Bilanztestverfahren nur in den Fällen zur Anwendung kommen, in denen die Gesellschaft den zukunfts- und liquiditätsorientierten Solvenztest besteht, was ebenfalls für die Richtigkeit der Prämisse der Unternehmensfortführung spricht.

Aus europäischer Perspektive ist die Anwendung der Testverfahren auf den Konzernabschluss besonders positiv hervorzuheben. Wie in Kapitel III.1.1.3.3 ausgeführt, können die europäischen Regeln nicht verhindern, dass der angestrebte Kapitalschutz im Konzern auf legale Weise ausgehöhlt wird. Dies liegt darin begründet, dass die Kapitalschutznormen auf die Einzelabschlüsse der Gesellschaften zugreifen, die durch gewinnverändernde und gewinnverlagernde Transaktionen der Konzernleitung erheblich beeinflusst werden können. In Kalifornien hingegen wird den konzernspezifischen Risiken explizit Rechnung getragen, indem die Testverfahren auf einem Abschluss basieren, der durch die Konsolidierungsmaßnahmen um konzerninterne Transaktionen bereinigt ist. Die kalifornische Regelung würde auch die besondere Problematik von $\S 58 \mathrm{AktG}$ im Konzern lösen. Fälle, in denen die Konzernleitung den Aktionären des Konzern-Mutterunternehmens trotz hoher Gewinne im Konzernabschluss keine Dividende zur Ausschüttung anbieten muss, weil der Einzelabschluss des Mutterunternehmens keinen Gewinn ausweist, wären nicht mehr möglich. Das Dividendenrecht dieser Aktionäre wäre mithin erheblich aufgewertet.

Der auf US-GAAP-Zahlen basierende retained earnings test ermöglicht in einem ersten Schritt Ausschüttungen in Höhe der retained earnings. Die balance sheet tests erlauben es dem

\footnotetext{
1339 Vgl. dazu im Detail Kapitel III.2.3.2.3.2.3.1.

1340 Vgl. Wüstemann (1996), S. 427; Wüstemann (1999), S. 62; Kahle (2002a), S. 698-699.

1341 Vgl. z.B. Ben-Dror (1983), S. 384; Marsh/Finkle/Sonsini (2005), Ch. 14, S. 16, 29-30.
} 
Management in einem zweiten Schritt, unter bestimmten Voraussetzungen Ausschüttungen über die retained earnings hinaus vorzunehmen. Unter Berücksichtigung der genannten Abweichungen von den US-GAAP sind nach dem quantitative solvency test Ausschüttungen so lange zulässig, wie die Eigenkapitalquote nicht unter $20 \%$ sinkt. Der liquidity test sieht zusätzlich vor, dass das Umlaufvermögen die kurzfristigen Verbindlichkeiten decken bzw. bei einem Zinsdeckungsgrad $<1$ um $25 \%$ übersteigen muss. Im Vergleich zur starren Ausschüttungssperre in Höhe des zwingend vorgeschriebenen Mindestkapitals in Europa existiert in Kalifornien somit eine flexible Ausschüttungssperre. Der kalifornische Gesetzgeber hat sich erkennbar an ökonomischen Vorgehensweisen in der Unternehmenspraxis orientiert. In den vorgesehenen Kennzahlen kann ein Element zur Insolvenzprophylaxe gesehen werden, das bei Kreditwürdigkeitsanalysen zum Einsatz kommt ${ }^{1342}$. Wie die Auswertung der empirischen Ergebnisse zu den Bestandteilen von Kreditverträgen ergeben hat ${ }^{1343}$, ähneln die dort vereinbarten Kennzahlen den im California Corporations Code kodifizierten. Vor dem Hintergrund des Umfangs und der Detailliertheit der Kreditverträge ist die transaktionskostensenkende Wirkung des kalifornischen Rechts dennoch als eher gering einzuschätzen. Hinzu kommt, dass die vorgegebenen Kennzahlen der Höhe nach aus theoretischer Sicht nicht zu begründen sind. Nichtsdestotrotz werden die in der Praxis zu beobachtenden Interessen der Gläubiger durch das kalifornische Recht besser berücksichtigt als durch die europäischen Kapitalschutznormen. Durch die Einhaltung einer bestimmten Eigenkapitalquote anstelle eines festen Eigenkapitalbetrags werden zwar keine unternehmensindividuellen Risiken, wohl aber der Geschäftsumfang des einzelnen Unternehmens berücksichtigt. Gleichzeitig lässt die kalifornische Regulierung weite unternehmerische Freiräume im Hinblick auf die Dividendenpolitik und die Flexibilität des Finanzmanagements, indem zumindest die Ausschüttung in Höhe der retained earnings ohne Einhaltung von Bilanzkennzahlen möglich ist.

Die gläubigerschützende Wirkung des California Corporations Code ist von Ben-Dror in einer sowohl im US-amerikanischen ${ }^{1344}$ als auch im deutschen Schrifttum ${ }^{1345}$ viel beachteten empirischen Untersuchung überprüft worden ${ }^{1346}$. Ben-Dror analysiert die Fähigkeit des kalifornischen Rechts, Ausschüttungen insolvenzgefährdeter Unternehmen zu verhindern. $\mathrm{Zu}$ diesem Zweck wendet er die Testverfahren des $\S 500$ Cal.Corp.Code auf die Bilanzen von 100 in den USA börsennotierten Industrieunternehmen an, die zwischen 1970 und 1976 Insolvenz angemeldet haben. Er untersucht, wie viele der 100 Unternehmen ein, zwei und drei Jahre vor der Insolvenz durch die kalifornischen Vorschriften an Ausschüttungen gehindert worden wären. Überprüft wird ferner, wie häufig die kalifornischen Ausschüttungsrestriktionen im Untersuchungssample zu Fehlklassifizierungen führen, d.h. wie häufig solvente Gesellschaften als insolvenzgefährdet eingestuft werden und somit keine Dividende ausschütten dürften. Dazu werden die Testverfahren bei einer Kontrollgruppe von 755 im Betrachtungszeitraum solventen, börsennotierten US-Industrieunternehmen durchgeführt.

Folgende Kernergebnisse können festgehalten werden: Die beiden Bilanztests in $\S 500(\mathrm{~b})$ Cal.Corp.Code verhindern bezogen auf das Untersuchungssample Ausschüttungen bei $68 \%$

\footnotetext{
1342 Vgl. Bauer (1995), S. 325. Unzutreffend ist aber die Aussage von Lutter (1983), S. 174, das kalifornische Recht zwinge die Gesellschaften ,zu einer seriősen Finanzierung mit dem Ziel, Eigenkapital und Fremdkapital stăndig in einem Verhältnis von mindestens 1:3 zu halten“.

$1343 \mathrm{Vgl}$. zu den gängigen vertraglich festgelegten Kennzahlen Kapitel V.5.4.1.3.

1344 Vgl. z.B. Black (2004), § 3.12; Marsh/Finkle/Sonsini (2005), § 14.01, S. 3.

1345 Vgl. z.B. Kübler (1989), S. 40; Bauer (1995), S. 329-330; Kuhner (2005), S. 784

1346 Vgl. Ben-Dror (1983), S. 390-412.
} 
der Unternehmen ein Jahr vor der Insolvenz. Die Quote sinkt auf $40 \%$ zwei Jahre bzw. 24 \% drei Jahre vor Eintritt der Insolvenz. Es stellt sich weiterhin heraus, dass sich der quantitative solvency test zur Insolvenzprognose besser eignet als der liquidity test ${ }^{1347}$. Bei Anwendung der Testverfahren auf die Kontrollgruppe der solventen Gesellschaften zeigt sich, dass im Beobachtungszeitraum durchschnittlich $9,14 \%$ der Unternehmen falsch klassifiziert wer$\operatorname{den}^{1348}$.

Zudem wird die Wirksamkeit des retained earnings test nach $\S 500$ (a) Cal.Corp.Code untersucht und somit auch die ihm zugrunde liegende implizite Annahme, retained earnings seien ein Indikator für eine geringere Insolvenzwahrscheinlichkeit eines Unternehmens ${ }^{1349}$. Die Untersuchung ergibt, dass von den insolventen Unternehmen ein Jahr vor der Insolvenz noch $34 \%$ retained earnings aufweisen; zwei Jahre vorher sind es $63 \%$, drei Jahre vorher $74 \%$. Mit anderen Worten werden nur $66 \%$ der insolventen Unternehmen ein Jahr, 37 \% zwei Jahre und $26 \%$ drei Jahre vor der Insolvenz gehindert, Ausschüttungen gemäß $\S 500$ (a) Cal.Corp.Code vorzunehmen. Die Annahme, retained earnings könnten auf die finanzielle Stabilität eines Unternehmens hinweisen, ist nach diesen Ergebnissen eher kritisch zu hinterfragen. Interessant ist weiterhin, dass der retained earnings test die Wirksamkeit der Ausschüttungsrestriktionen insgesamt schmälert.

Ben-Dror zeigt ferner, dass sich die Insolvenzprognosewahrscheinlichkeit erhöhen lässt, wenn die Testverfahren des $\S 500$ (a) und (b) Cal.Corp.Code nicht alternativ, sondern kumulativ erfüllt werden müssen ${ }^{1350}$. Dann hätten $77 \%$ der Gesellschaften ein Jahr, $52 \%$ zwei Jahre und $39 \%$ drei Jahre vor ihrer Insolvenz nichts mehr ausschütten können. Der vorgeschlagene kumulative Test klassifiziert allerdings zwischen $8,79 \%$ und $14,79 \%$ der Unternehmen der Kontrollgruppe fälschlicherweise als insolvenzgefährdet ein.

Der kumulative Test ist differenziert zu beurteilen. Aus Gläubigersicht stellt er eine Verbesserung dar, da ein höherer Anteil der möglicherweise insolvent werdenden Unternehmen daran gehindert wird, Dividenden auszuschütten, wodurch die Gläubiger besser geschützt werden. Aus Sicht des Managements ist es allerdings als problematisch anzusehen, dass noch mehr Unternehmen falsch eingestuft werden. Folglich steigt die Wahrscheinlichkeit, dass die Dividendenpolitik der Unternehmensführung eingeschränkt wird, obwohl das Unternehmen gar nicht insolvenzgefährdet ist. Auch aus dem Blickwinkel der Aktionäre kann dies als unangemessene Beeinträchtigung ihres Dividendenrechts gesehen werden.

Gegen den letzten Kritikpunkt wird in der Literatur teilweise vorgebracht, durch die einbehaltenen Gewinne steige der Unternehmenswert und die Aktionäre könnten einen Teil ihrer Aktien zu dem höheren Kurs verkaufen. Der Schaden der Aktionäre aufgrund einer potentiellen Fehlklassifizierung sei daher allenfalls minimal ${ }^{1351}$. Eine solche Argumentation vernachlässigt aber mögliche Situationen, in denen in einem Unternehmen keine lohnenden Investitionspro-

1347 Vgl. Ben-Dror (1983), S. 394-396.

1348 Vgl. Ben-Dror (1983), S. 400. Anzumerken ist, dass die Interpretation als Fehlklassifizierung nicht unproblematisch ist. Es ist beispielsweise vorstellbar, dass das Management eines insolvenzgefährdeten Unternehmens aufgrund eines rückläufigen Geschăfts Liquiditătsprobleme antizipiert, auf eine Ausschüttung verzichtet und nur deshalb solvent bleibt, weil es neue Geschäftsfelder erschlossen hat. In einem solchen Fall hätten die Testverfahren ein richtiges Ergebnis geliefert; in der Studie wäre dieses Unternehmen dennoch zu den falsch klassifizierten gezählt worden.

1349 Vgl. Ben-Dror (1983), S. 404-408.

1350 Vgl. Ben-Dror (1983), S. 408-412.

1351 Vgl. zu dieser Argumentation Ben-Dror (1983), S. 410-411. 
jekte mehr durchgeführt werden können, die unternehmensinterne Verzinsung der Mittel also geringer als die der alternativen Renditemöglichkeiten der Aktionäre ist. In diesen Fällen würde eine zwangsweise Einbehaltung von Gewinnen zur Fehlallokation der Mittel führen. Darüber hinaus besteht insbesondere bei nicht börsennotierten Unternehmen die Gefahr, dass es nur einen eingeschränkt liquiden Markt für Aktien gibt und die Aktionäre somit nicht ohne weiteres die ausbleibende Dividendenzahlung kompensieren können ${ }^{1352}$. Insgesamt scheinen die Nachteile einer kumulativen Anwendung der bilanziellen Testverfahren die Vorteile zu überwiegen.

Im Hinblick auf die Kennzahlen, die der kalifornische Gesetzgeber zur Insolvenzprophylaxe ausgewählt hat, ist festzustellen, dass mit Hilfe neuerer statistischer Verfahren und Ansätze künstlicher Intelligenz in der Form neuronaler Netze mittlerweile Kennzahlen mit höherer Trenngenauigkeit ermittelt worden sind ${ }^{1353}$. Wird von der grundsätzlichen Kritik der mangelnden betriebswirtschaftlich-theoretischen Fundierung ${ }^{1354}$ dieser statistischen Verfahren abgesehen, könnten sie zu einer Verbesserung des Gläubigerschutzes führen. Die höhere Trenngenauigkeit geht allerdings in der Regel auch mit einer höheren Fehlklassifikation der solventen Unternehmen einher ${ }^{1355}$, wodurch - wie bereits ausgeführt - die Vorteile überkompensiert werden können.

Um die praktischen Auswirkungen der Einführung der kalifornischen Ausschüttungsregulierung aufzuzeigen, werden abschließend die kalifornischen Testverfahren gemäß $\S 500(a)$, (b) Cal.Corp.Code auf die Unternehmen des DAX-30 (mit Ausnahme von Banken und Versicherungen) für die Geschäftsjahre 2003 und 2004 angewandt. Zur Durchführung der balance sheet tests werden die Konzernbilanzen der Unternehmen um aktivierte Entwicklungsaufwendungen, Goodwill, Rechnungsabgrenzungsposten und latente Steuern bereinigt ${ }^{1356}$. Da die Anwendung des kalifornischen Solvenztests ohne interne Plandaten nicht durchgeführt werden kann, wird unterstellt, dass alle Unternehmen des DAX-30 ihn erfüllen und die Ausschüttungshöhe allein durch die übrigen Testverfahren beschränkt wird. Aus Vereinfachungsgründen werden die speziellen Bilanzierungsregeln im Rahmen des liquidity test nach $\S 500(b)(2)$ Cal.Corp.Code (Berücksichtigung von erwarteten Nettobeträgen bei der Ermittlung des Umlaufvermögens) sowie die besonderen Vorschriften für Vorzugsaktien gemäß $\S \S 502-503$ Cal.Corp.Code nicht berücksichtigt ${ }^{1357}$. Schließlich ist anzumerken, dass die DAX-30Unternehmen sowohl IFRS- als auch US-GAAP-Bilanzierer aufweisen, wodurch die Vergleichbarkeit aufgrund bestehender Unterschiede in den beiden Rechnungslegungssystemen (z.B. Wahlrecht zur Neubewertung des Sachanlagevermögens nach IAS 16.31ff., Bilanzierung von Aktienoptionen nach IFRS 2) teilweise eingeschränkt ist.

Tab. 5 zeigt die zulässige Maximalausschüttung bei Anwendung des kalifornischen Rechts und die maximale Ausschüttung unter Berücksichtigung des europäischen Rechts. Zur Ermitt-

\footnotetext{
1352 Darauf weist auch Ben-Dror (1983), S. 410, Fn. 151, hin.

1353 Vgl. Baetge/Kirsch/Thiele (2004a), S. 535-586 m.w.N.

1354 Vgl. D. Schneider (1992), S. 603; Ballwieser (1996), S. 19.

1355 So werden $33,55 \%$ der solventen Unternehmen durch das Künstliche Neuronale Netz BP-14 fảlschlicherweise als insolvent klassifiziert. Vgl. Baetge/Kirsch/Thiele (2004a), S. 562.

1356 Wie bereits erläutert, sind passive latente Steuern gemäß $\S 500(b)(1)$ Cal.Corp.Code von den Schulden abzuziehen. Aktive latente Steuern werden im Gesetz nicht explizit genannt. Sie werden im Folgenden wie die deferred charges von der Summe der Vermögenswerte subtrahiert.

1357

Die Einzelheiten der Berechnung sind dem Anhang zu dieser Arbeit zu entnehmen.
} 
lung der Letzteren wurden die Gewinnrücklagen und die Jahresergebnisse des Jahres 2003 bzw. 2004 auf Basis der Einzelabschlüsse addiert.

\begin{tabular}{|c|c|c|c|c|}
\hline $\begin{array}{c}\text { Konzern } \\
\text { (angewandtes } \\
\text { Rechnungslegungssystem) }\end{array}$ & $\begin{array}{c}\text { A(max) } \\
\text { Cal.Corp.Code } \\
\mathbf{2 0 0 3} \\
\text { Mio } € \\
\end{array}$ & $\begin{array}{c}\text { A }(\max ) \\
\text { KapRL } \\
2003 \\
\text { Mio } €\end{array}$ & \begin{tabular}{|c|}
$\mathbf{A}(\max )$ \\
Cal.Corp.Code \\
$\mathbf{2 0 0 4}$ \\
$\mathbf{M i o} €$ \\
\end{tabular} & $\begin{array}{c}\text { A(max) } \\
\text { KapRL } \\
\mathbf{2 0 0 4} \\
\text { Mio } €\end{array}$ \\
\hline Adidas-Salomon AG (IFRS) & 1.265 & 1.314 & 1.534 & 1.306 \\
\hline Altana AG (IFRS) & 1.477 & 1.751 & 1.755 & 1.801 \\
\hline BASF AG (IFRS) & 11.276 & 7.082 & 12.253 & 6.952 \\
\hline Bayer AG (IFRS) & 10.479 & 3.655 & 8.753 & 2.728 \\
\hline BMW (IFRS) & 12.671 & 2.609 & 14.501 & 2.964 \\
\hline Continental AG (US-GAAP) & 963 & 106 & 1.567 & 163 \\
\hline DaimlerChrysler AG (US-GAAP) & 29.085 & 7.805 & 30.032 & 5.776 \\
\hline Deutsche Börse AG (IFRS) & 760 & 510 & 1.096 & 675 \\
\hline Deutsche Lufthansa AG (IFRS) & 949 & 402 & 1.386 & 667 \\
\hline Deutsche Post AG (IFRS) & 4.924 & 5.225 & 4.451 & 6.036 \\
\hline Deutsche Telekom AG (US-GAAP) & 0 & 11.116 & 0 & 13.997 \\
\hline E.ON AG (US-GAAP) & 16.976 & 3.790 & 20.003 & 5.401 \\
\hline Henkel KG aA (IFRS) & 2.955 & 3.004 & 4.544 & 3.024 \\
\hline FMC AG (US-GAAP, in Mio. \$) & 378 & 441 & 658 & 443 \\
\hline Infineon Technologies AG (US-GAAP) & 2.639 & 0 & 589 & 0 \\
\hline Linde AG (IFRS) & 1.134 & 645 & 1.283 & 659 \\
\hline MAN AG (IFRS) & 1.547 & 497 & 1.795 & 591 \\
\hline Metro AG (IFRS) & 775 & 1.029 & 1.353 & 1.240 \\
\hline RWE AG (IFRS) & 4.856 & 1.712 & 6.290 & 2.253 \\
\hline SAP AG (US-GAAP) & 3.761 & 2.624 & 4.830 & 3.133 \\
\hline Schering AG (IFRS) & 2.685 & 1.034 & 2.859 & 1.078 \\
\hline Siemens AG (US-GAAP) & 23.020 & 6.392 & 23.020 & 7.595 \\
\hline ThyssenKrupp AG (US-GAAP) & 2.790 & 656 & 3.478 & 709 \\
\hline TUI AG (IFRS) & 1.001 & 414 & 1.294 & 414 \\
\hline Volkswagen AG (IFRS) & 18.890 & 4.942 & 18.325 & 5.238 \\
\hline
\end{tabular}

Tab. 5: Maximalausschüttung der DAX-30-Unternehmen auf Basis des California Corporations Code im Vergleich zur Kapitalrichtlinie

Bei Betrachtung der Untersuchungsergebnisse fällt auf, dass in der Mehrzahl der Fälle die zulässige Ausschüttung nach den kalifornischen Testverfahren das maximale Ausschüttungsvolumen nach europäischem Recht übersteigt. Es ist allerdings darauf hinzuweisen, dass sich möglicherweise nach kalifornischem Recht weitere Beschränkungen durch den hier nicht durchführbaren Solvenztest ergeben würden. Unter Vernachlässigung dieser Einschränkung zeigt sich, dass die bilanzorientierten kalifornischen Verfahren vielfach die Ausschüttung sehr hoher Kapitalbeträge ermöglichen würden. Die höheren Ausschüttungen nach kalifornischem Recht resultieren im Wesentlichen daraus, dass die Konzernabschlüsse erheblich größere Gewinnrücklagen als die Einzelabschlüsse aufweisen. Der liquidity test oder der quantitative solvency test sind bei den meisten Gesellschaften nicht erfüllt, so dass eine über die retained earnings hinausgehende Ausschüttung unmöglich ist ${ }^{1358}$

1358 Vgl. zu weiteren Details die Berechnungen im Anhang dieser Arbeit. 
Interessant ist das Ergebnis für die Deutsche Telekom AG. Aufgrund hoher negativer Gewinnrücklagen in den Konzernabschlüssen der Jahre 2003 und 2004 wären nach kalifornischem Recht keine Ausschüttungen möglich. Nach den Vorschriften der Kapitalrichtlinie sind hingegen Ausschüttungen von über $11 \mathrm{Mrd}$. $€$ (2003) bzw. knapp $14 \mathrm{Mrd}$. $€$ (2004) zulässig, die auf positive Gewinnrücklagen im Einzelabschluss zurückzuführen sind. Tatsächlich haben Vorstand und Aufsichtsrat der Deutschen Telekom AG der Hauptversammlung vorgeschlagen, aus dem Jahresüberschuss 2004 eine Dividende in Höhe von 2,6 Mrd. $€$ auszuschütten. Im Jahr davor wurde keine Dividende gezahlt ${ }^{1359}$. Bei kumulativer Anwendung der drei Testverfahren könnten zwölf Unternehmen in 2003 bzw. 2004 keine Dividende zahlen, weil sie entweder den quantitative solvency test oder den liquidity test nicht erfüllen. Die Deutsche Lufthansa AG, die Deutsche Telekom AG, die Metro AG, die TUI AG und die Volkswagen AG bestehen im Jahre 2003 sogar weder den quantitative solvency test noch den liquidity test.

Zusammenfassend kann festgehalten werden, dass die kalifornische Regulierung der bilanziellen Ausschüttungsrestriktionen im Hinblick auf die europäische Reform des Kapitalsystems beachtenswert ist. Wie bereits im Rahmen der Analyse des Solvenztests ausgeführt ${ }^{1360}$, kann zwar der zusätzliche Nutzen eines Bilanztests sowohl aus Gläubigersicht als auch aus der Perspektive der übrigen Unternehmensbeteiligten bezweifelt werden. Sollte der europäische Gesetzgeber dennoch an einem Bilanztest festhalten wollen, ist der kalifornische Ansatz dem bestehenden europäischen System aus ökonomischer Sicht entschieden vorzuziehen. Die Stärken der Regelungen des California Corporations Code liegen beispielsweise darin, dass die Testverfahren auf Konzernabschlüsse anzuwenden sind und somit den konzernspezifischen Risiken explizit Rechnung getragen wird. Die Regelung hat zudem den Charme, das in Deutschland seit Jahrzehnten kontrovers diskutierte Problem des Dividendenrechts der Aktionäre von Konzern-Mutterunternehmen aufgrund von $\S 58 \mathrm{AktG}$ zu lösen. Ein Vorteil ist weiterhin darin zu sehen, dass das kalifornische Recht bei Ausschüttungen über die retained earnings hinaus mit der zwingend einzuhaltenden Eigenkapitalquote von $20 \%$ eine variable Ausschüttungssperre beinhaltet, die der starren und vollkommen undifferenzierten Ausschüttungsschranke in Form des Mindestkapitals in Europa vorzuziehen ist, obwohl auch sie in ihrer konkreten Höhe normativ nicht begründbar ist. Eine kumulative Anwendung der Testverfahren, wie sie von Ben-Dror vorgeschlagen wird, ist abzulehnen. Ein kumulativer Test erhöht die Gefahr von Fehlklassifikationen solventer Unternehmen und folglich die Fehlallokation von Kapital. Überlegenswert erscheint allenfalls die Verwendung anderer, trennschärferer Kennzahlen im Rahmen des liquidity test. Dabei ist aber zu berücksichtigen, dass gesetzlich kodifizierte Kennzahlen möglichst einfach und insbesondere nachvollziehbar sein sollten. Ein solcher Bilanztest wird privatvertragliche Abreden in Kreditvereinbarungen nicht ersetzen können. Er wird aber den empirisch beobachtbaren Verhaltensweisen und Interessen der Gläubiger viel eher gerecht als die bisherigen europäischen Kapitalschutznormen und kommt somit insbesondere auch den verhandlungsschwachen Gläubigergruppen zugute.

\section{Zwischenergebnis}

Ausgehend von der Einschätzung, dass der europäische Gesetzgeber - trotz fraglicher Regulierungsrechtfertigung - auch in der Zukunft in die Gewinnermittlung und die Gewinnver-

\footnotetext{
1359 Vgl. Deutsche Telekom (2004), S. U2, 59, 201.

1360 Vgl. Kapitel V.6.2.
} 
wendung von Aktiengesellschaften regulierend eingreifen will, wurden seine Ziele bei der anstehenden Reform des Kapitalschutzsystems herausgearbeitet. Eine Betrachtung der in der Literatur vielfach vorgetragenen Stärken des Kapitalsystems kommt zu dem Ergebnis, dass sie einer kritischen Analyse weitgehend nicht standhalten und die gläubigerschützende Wirkung des tradierten Kapitalschutzkonzepts zweifelhaft ist. Eine weitergehende Untersuchung des bestehenden Kapitalsystems offenbart zahlreiche Mängel. Insbesondere die enge Verzahnung der Ausschüttungsregeln mit dem europäischen bzw. deutschen Bilanzrecht führt dazu, dass der angestrebte Gläubigerschutz durch das Management - insbesondere im Konzernverbund - auf legale Weise erheblich geschmälert werden kann. Durch die vielen Mitgliedsstaaten- und Unternehmenswahlrechte der Bilanzrichtlinie leidet darüber hinaus die EU-weite Harmonisierung des Kapitalschutzes. Ferner ist festzustellen, dass die Gläubiger über zahlreiche Selbstschutzmöglichkeiten verfügen bzw. in vielen Fällen durch Pflichtversicherungen bereits geschützt werden. Die ausführlichen Kosten-Nutzen-Überlegungen sprechen trotz eingeschränkter exakter Quantifizierbarkeit tendenziell für einen Systemwechsel.

Die Analyse ausgewählter US-amerikanischer Regelungen, die in der aktuellen Reformdebatte zum europäischen Gläubiger- und Kapitalschutzsystem vielfach anklingen, kommt zu dem Ergebnis, dass deren unveränderte Übernahme in EU-Recht nicht zu empfehlen ist. Losgelöst von der Tatsache, dass die isolierte Übertragung einer als effizient beurteilten Regel aus einem anderen Land unter Vernachlässigung der übrigen Regulierungen und der möglicherweise unterschiedlichen sozio-ökonomischen Verhältnisse problematisch ist ${ }^{1361}$, weisen die betrachteten US-Kapitalschutzregeln neben spezifischen Vorteilen auch jeweils bestimmte Nachteile auf, wodurch die aufgezeigten Mängel des europäischen Systems nicht zufriedenstellend behoben werden können.

Aus der Untersuchung der US-amerikanischen Regulierungen lassen sich aber für das zukünftige europäische Kapitalschutzregime wichtige Kriterien ableiten, die einen wirkungsvolleren und effizienteren Gläubigerschutz sicherstellen könnten. Erstens sollte das neue Konzept in Anlehnung an die primären Interessen der Gläubiger eine liquiditäts- und zukunftsorientierte Komponente aufweisen. Die Vorschriften der bestehenden Kapitalrichtlinie stellen lediglich sicher, dass die Gesellschaft trotz Ausschüttung einen Verlustpuffer in Höhe des gesetzlichen Mindestkapitals aufweist und das Testverfahren zur Überprüfung ausreichenden Eigenkapitals auf Bilanzdaten basiert, die auf Basis der Prämisse der Unternehmensfortführung erstellt und vom Abschlussprüfer testiert worden sind. Die in allen Bundesstaaten der USA aufgrund von gesellschafts- oder insolvenzrechtlichen Vorschriften zu beachtenden Solvenztests erfüllen hingegen grundsätzlich das genannte Kriterium. Eingeschränkt wird die Zukunfts- und Liquiditätsorientierung allerdings dadurch, dass in den USA zur Bestimmung der Solvenz unter bestimmten Voraussetzungen von der Aufstellung eines Finanzplans abgesehen werden kann.

Das zukünftige Kapitalsystem sollte bei Beibehaltung eines Bilanztests zweitens auf Rechnungslegungsregeln verweisen, die idealerweise keine Wahlrechte beinhalten, so dass einerseits die Unternehmensleitung nicht durch geschicktes Ausnutzen der Wahlrechte das Ausmaß des materiellen Kapitalschutzes beeinflussen kann und andererseits die Anforderungen an die Aktiengesellschaften EU-weit harmonisiert sind. Aufgrund der zahllosen Wahlrechte der Bilanzrichtlinie ist dieses Kriterium bisher kaum erfüllt. Ein Blick in die USA zeigt, dass die Vorschriften des MBCA und des Gesellschaftsrechts Delawares diese Anforderung ebenfalls nicht erfüllen, da ein bestimmtes Rechnungslegungssystem nicht vorgegeben wird. Die-

1361 Vgl. Pellens (1994), S. 322. 
sem Vorgehen kann zugute gehalten werden, dass es die Flexibilität des Finanzmanagements erhöht und den Gesellschaften die Aufstellung einer ansonsten gegebenenfalls notwendigen Ausschüttungsbilanz erspart. Ein über den Solvenztest hinausgehender Gläubigerschutz ist indes nicht erkennbar. Das Kriterium wird allein in Kalifornien durch die Vorgabe von USGAAP als Basis der Bilanztests erfüllt. Gegenüber der Bilanzrichtlinie sehen die US-GAAP wie die IFRS weniger explizite Wahlrechte vor, so dass die Ergebnisse von Bilanztests eher vergleichbar sind. Eingeschränkt wird diese Vergleichbarkeit durch die auch bei den internationalen Rechnungslegungsregeln bestehenden Ermessensspielräumen. Da diese in allen real existierenden Rechnungslegungssystemen bestehen, sprechen sie gegen die Nützlichkeit von Bilanztests im Allgemeinen und nicht gegen die kalifornische Regulierung im Speziellen.

Um zu verhindern, dass der Kapitalschutz im Konzern ad absurdum geführt werden kann, sollte das europäische Konzept drittens konzernspezifische Risiken explizit berücksichtigen. Dazu sollten alle Testverfahren nicht nur auf Ebene der rechtlich selbständigen Einzelunternehmen, sondern auch auf Ebene des Konzerns bzw. auf Basis des Konzernabschlusses durchgeführt werden. Ein Vergleich der Systeme zeigt, dass diese Anforderung bisher weder in der EU, noch in Delaware oder den Bundesstaaten, die den MBCA umgesetzt haben, erfüllt ist. Erneut kommt der kalifornischen Regulierung ein Vorbildcharakter zu.

Viertens sollten die vorgesehenen Testverfahren nachprüfbar sein, damit Verstöße ex post aufgedeckt werden und Sanktionen nach sich ziehen können. Hinsichtlich der Bilanztests kann die Nachprüfbarkeit zumindest in den Fällen unterstellt werden, in denen Abschlüsse herangezogen werden, die von Wirtschaftsprüfern zu testieren sind. Dies ist somit sowohl in der EU als auch in Kalifornien und darüber hinaus in der Regel auch in Delaware und in den US-Bundesstaaten, die den MBCA umgesetzt haben, der Fall. Im Hinblick auf den Solvenztest sind die Nachprüfbarkeit und die mögliche Sanktionierung nur gegeben, wenn ein konkretes Verfahren zur Durchführung des Solvenztests gegeben ist. Dies ist in den in dieser Arbeit betrachteten Regulierungen bisher nicht der Fall. 


\section{Kapitel VI: Zusammenfassung und Ausblick}

Das in der EU für die Aktiengesellschaft und ihr entsprechende Rechtsformen bereits seit Jahrzehnten kodifizierte Kapitalschutzsystem ist unter Rechtfertigungsdruck geraten und steht vor tiefgreifenden Veränderungen. Es sieht bisher neben einem Mindestkapital von $25.000 €$ bzw. $50.000 €$ vielfältige detaillierte Kapitalaufbringungs- und Kapitalerhaltungsregeln vor, die auf vom Vorsichtsprinzip geprägte Rechnungslegungsdaten im Einzelabschluss zurückgreifen. Auch das Bilanzrecht in Europa ist im Wandel. Seit 2005 (bzw. in Ausnahmefällen spätestens ab 2007) müssen alle kapitalmarktorientierten Mutterunternehmen in der EU ihren Konzernabschluss nach IFRS aufstellen und veröffentlichen. Es kann davon ausgegangen werden, dass sich der Trend zur IFRS-Bilanzierung in den nächsten Jahren fortsetzen und zunehmend auch den Einzelabschluss betreffen wird. Vor diesem Hintergrund hat die von der EU-Kommission eingesetzte High Level Group 2002 einen Vorschlag zur Reform des tradierten Gläubigerschutzsystems durch bilanzielle Kapitalerhaltung vorgelegt, der sich weitgehend an den US-amerikanischen Kapitalschutzregulierungen orientiert und möglicherweise bereits 2009 umgesetzt wird.

Ausgangspunkt dieser Arbeit war die Frage, ob ausgewählte, aus dem US-amerikanischen (Gesellschafts-)Recht entlehnte Kapitalschutzregeln bei der anstehenden Reform des europäischen Gesellschaftsrechts berücksichtigt werden sollten. Im Folgenden werden die wichtigsten Untersuchungsergebnisse thesenförmig zusammengefasst:

1. Die regulierungstheoretische Analyse unter Berücksichtigung der Principal-AgentTheorie, des Transaktionskostenansatzes und der Marktprozesstheorie ergibt, dass der regulierende Eingriff des deutschen bzw. europäischen Gesetzgebers in die Gewinnermittlung und Gewinnverwendung kaum zu rechtfertigen ist. Die theoretischen Betrachtungen sprechen zumindest für börsennotierte Aktiengesellschaften und bei gut funktionierendem Sekundärmarkt vielmehr für eine weitgehende Deregulierung der bestehenden gesetzlichen Vorschriften. Da derzeit aber nicht damit zu rechnen ist, dass der europäische Gesetzgeber bei der bevorstehenden Reform der Kapitalrichtlinie die Kapitalschutzregeln im Zuge von Deregulierungsmaßnahmen abschafft, sind bei der Beurteilung der Reformvorschläge die selbst gesteckten Ziele des europäischen Gesetzgebers als Beurteilungskriterium heranzuziehen. Ziel ist es, den Gläubiger- und Aktionärsschutz mindestens genauso zuverlässig zu gewährleisten wie bisher. Darüber hinaus sollen gleichartige Rahmenbedingungen für die Gesellschaften in der EU erreicht werden.

2. Das in- und externe Corporate-Governance-System der Aktiengesellschaft in Deutschland ist bislang weitgehend gesellschaftsrechtlich geregelt, wird aber zunehmend durch das anglo-amerikanisch geprägte Kapitalmarktrecht beeinflusst. Durch eine Vielzahl von bereits eingeleiteten Reformmaßnahmen und durch weitere Initiativen der europäischen und deutschen Gesetzgeber müssen sich die Aktiengesellschaften auf weitere Veränderungen einstellen.

3. Die Analyse der dem Kapitalsystem in Europa zugeschriebenen Funktionen kommt zu dem Ergebnis, dass seine gläubigerschützende Wirkung erheblich zu relativieren ist. Es erreicht lediglich, dass das von den Aktionären einbezahlte Kapital nicht an sie durch Ausschüttungen zurückfließt und somit ein minimaler Verlustpuffer zum Schutz der Gläubiger aufrechterhalten bleibt. Das Vorhandensein eines Mindesteigenkapitals sorgt ferner dafür, dass gerade erst gegründete Unternehmen durch Anfangsverluste nicht wegen Überschuldung die Insolvenz anmelden müssen. Insbesondere die Seriositäts-, die 
Warnlampen-, die Garantie- und die Signaling-Funktion überzeugen aber nicht. Gegen das bestehende Kapitalsystem ist weiterhin einzuwenden, dass es kompliziert, zeitaufwendig und kostenintensiv ist und folglich Unternehmensgründungen und Kapitalbeschaffungen erschwert.

4. Ein Indiz für die weitgehende Entbehrlichkeit des bestehenden Kapitalschutzsystems ist in den zahlreichen Schutzinstrumenten der Gläubiger zu sehen. Den rechtsgeschäftlichen Gläubigern stehen vielfältige vertragliche Sicherungsrechte zur Verfügung. Zudem können sie von der umfangreichen und aktuellen Unternehmensberichterstattung, zu der Aktiengesellschaften gesetzlich verpflichtet sind, profitieren. Durch die Auswertung der Informationen können sie sich ein Bild von der wirtschaftlichen Lage ihres (potentiellen) Schuldners machen und das identifizierte Risiko unternehmensindividuell berücksichtigen oder im Extremfall auf eine Geschäftsbeziehung verzichten. Unfreiwillige Gläubiger profitieren von dem Informationsmodell nicht. Ihnen bietet aber der gesetzliche Kapitalschutz nur eine Scheinsicherheit, so dass vielmehr über die Einführung weiterer Pflichtversicherungen zu ihrem Schutz nachzudenken wäre.

5. Die Kapitalschutzregeln setzen auf den Rechnungslegungsregeln der Bilanzrichtlinie auf. Eine Analyse der mit der Bilanzrichtlinie in Einklang stehenden Rechnungslegungsregeln nach HGB zeigt, dass die Ziele des Gesetzgebers nur in eingeschränkter Weise zu erreichen sind. Die Bilanzierungsnormen enthalten zahlreiche explizite Wahlrechte und Ermessensspielräume, die der Unternehmensleitung bei der Gewinnermittlung weitreichende Einflussmöglichkeiten gewähren. Das Management von Aktiengesellschaften wird dadurch in die Lage versetzt, das Ausmaß des Kapitalschutzes selbst zu bestimmen.

6. Die Kapitalschutzregeln können im Konzern auf legale Weise umgangen werden. Besonderheiten der Konzernorganisation, von der in Deutschland die überwiegende Mehrzahl der Aktiengesellschaften betroffen ist, führen einerseits dazu, dass das Management von Konzern-Mutterunternehmen durch konzerninterne Erfolgsverlagerungen im Einzelabschluss des Mutterunternehmens noch ausschüttbare Gewinne generieren kann, obwohl der Konzern bereits hohe Verluste aufweist. Andererseits verfügt das Management im Vergleich zu dem eines Einzelunternehmens über erleichterte Innenfinanzierungsmöglichkeiten. Es kann gewinnbringende unternehmerische Aktivitäten in Tochterunternehmen verlagern und die dort anfallenden Gewinne mit der Folge einbehalten, dass die Gewinnverwendungskompetenz der Hauptversammlung des Mutterunternehmens erheblich oder sogar vollständig beschnitten wird. Obwohl diese Problematik im rechts- und wirtschaftswissentschaftlichen Schrifttum seit mehr als 30 Jahren kontrovers diskutiert wird, ist sie bisher vom Gesetzgeber nicht aufgegriffen worden.

7. Das Gesellschaftsrecht fällt in den USA in die Gesetzgebungskompetenz der Einzelstaaten. Daher weichen die gesellschaftsrechtlichen Vorschriften der Bundesstaaten teilweise erheblich voneinander $\mathrm{ab}$. Um der Rechtszersplitterung entgegenzuwirken, sind verschiedene Mustergesetzentwürfe (Uniform Laws, Model Acts) erarbeitet und den Einzelstaaten zur Übernahme in ihr Recht empfohlen worden. Zu einer weitgehenden Vereinheitlichung ist es aber bislang nicht gekommen. Vielmehr herrscht ein Wettbewerb der Systeme.

8. Im Vergleich zu Deutschland ist das Gesellschaftsrecht der USA weitgehend dereguliert. Die vertragliche Gestaltungsfreiheit für die Corporate Governance der corporations wird kaum durch zwingende gesellschaftsrechtliche Vorschriften eingeschränkt. Das Kapitalmarktrecht auf Bundesebene gibt hingegen einen zwingenden Rahmen nicht verhandelba- 
rer Vorschriften für kapitalmarktorientierte Unternehmen vor und sorgt insofern für einen Ausgleich zur einzelstaatlichen Deregulierung.

9. Der Gläubigerschutz steht in den USA auf vielen Standbeinen. Vorschriften zur Kapitalaufbringung und Kapitalerhaltung finden sich in den Kapitalgesellschaftsrechten der Einzelstaaten (z.B. California Corporations Code, Delaware General Corporation Law), den creditors' rights laws auf Ebene der Bundesstaaten bzw. des Bundes, im Steuerrecht (Accumulated Earnings Tax) sowie im common law.

10. Nach den in drei Viertel der Bundesstaaten umgesetzten gesellschaftsrechtlichen Kapitalschutzregeln des MBCA existiert kein Mindestkapital. Als Schutzmechanismus dienen stattdessen verschiedene Testverfahren. Nach dem equity insolvency test ist eine Ausschüttung nur möglich, wenn die Gesellschaft anschließend noch in der Lage ist, ihre im gewöhnlichen Geschäftsverlauf fällig werdenden Verbindlichkeiten zu begleichen. Als weitere Ausschüttungsrestriktion ist der balance sheet test zu beachten, nach dem die Vermögenswerte im Anschluss an die Ausschüttung die Schulden und die Ansprüche der Vorzugsaktionäre auf den Liquidationserlös decken müssen. Hat die Gesellschaft keine Vorzugsaktien ausgegeben, kann das Eigenkapital durch Ausschüttungen bis auf Null reduziert werden.

11. Anders als nach den Vorschriften des MBCA existiert im Gesellschaftsrecht von Delaware noch immer das legal capital-System. Allerdings ist ein Mindestkapital gesetzlich nicht vorgeschrieben. Den Kern der Kapitalschutzregeln des Delaware General Corporation Law bildet der surplus test, der grundsätzlich verhindern soll, dass das von den Aktionären einbezahlte Kapital durch Ausschüttungen an sie zurückfließt. Dieses Ziel kann allerdings auf legale Weise umgangen werden und zwar erstens durch unkompliziert durchführbare Kapitalherabsetzungen, zweitens durch die Zulässigkeit von Dividenden aus aktuellen Gewinnen selbst bei negativem Eigenkapital (nimble dividends) und drittens durch den weiten Anwendungsbereich der wasting assets-Regelung, nach der Abschreibungen von nicht erneuerbaren Vermögenswerten bei der Gewinnermittlung nicht zu berücksichtigen sind.

12. Als erster Bundesstaat schaffte Kalifornien 1977 das legal capital-System ab und ersetzte es durch einen innovativen und in den USA einzigartigen Ansatz. Die Besonderheit des California Corporations Code ist darin zu sehen, dass die Testverfahren zwingend auf (Konzern-)Abschlüsse anzuwenden sind, die - abgesehen von bestimmten Modifizierungen - nach US-GAAP aufzustellen sind, d.h. nach einem Rechnungslegungssystem, das wie die IFRS-Rechnungslegungsregeln ausschließlich der Informationsfunktion dienen soll. Sofern eine in Kalifornien gegründete Gesellschaft den equity insolvency test erfüllt, kann sie eine Ausschüttung aus den retained earnings vornehmen. Darüber hinaus sind Ausschüttungen nur zulässig, wenn die corporation im Anschluss daran unter anderem eine Eigenkapitalquote von mindestens $20 \%$ aufweist.

13. Unter Rückgriff auf empirische Untersuchungen von US-amerikanischen Kreditverträgen der 1960er und 1970er Jahre wird von einigen Autoren die These vertreten, die gesetzlichen Kapitalschutzregeln in Europa würden in den USA in ähnlicher Weise privatvertraglich vereinbart. Zudem würden die vielfach vorgenommenen Modifizierungen der USGAAP zu einer Annäherung an die zur Ausschüttungsbemessung vorgeschriebene HGBBilanzierung führen. Diese Ansichten sind abzulehnen. Zum einen bestehen grundlegende Unterschiede zwischen den gesetzlichen und den vertraglichen Vorschriften. Zum anderen kommt eine Analyse aktueller empirischer Untersuchungen zu dem Ergebnis, dass sich 
die Gepflogenheiten der US-amerikanischen Kreditvergabepraxis in den letzten Jahrzehnten wohl verändert haben. Diese Untersuchungen stellen einen erheblichen Rückgang von vertraglich vereinbarten bilanziellen Ausschüttungsrestriktionen in der Form von dividend covenants fest. Weiterhin wird eine abnehmende Bedeutung der Daten aus Bilanz und Gewinn- und Verlustrechnung zugunsten von Cashflows nachgewiesen.

14. Viele Elemente der US-amerikanischen Regeln finden sich in den europäischen Reformvorschlägen wieder. Aufbauend auf den Arbeiten der SLIM-Initiative von 1999 und der High Level Group von 2002 hat die EU-Kommission am 21.09.2004 einen Vorschlag zur kurzfristigen Änderung der Kapitalrichtlinie unterbreitet. Die Änderungsrichtlinie sieht unter anderem vor, dass die Einbringung von Sacheinlagen erleichert wird, die Gesellschaft durch die Hauptversammlung für bis zu fünf Jahre zum Rückkauf eigener Aktien ermächtigt werden kann und Aktienrückkäufe und Dividendenausschüttungen wie in den USA denselben Restriktionen unterliegen. Nach dem Aktionsplan der EU-Kommission vom Mai 2003 soll die langfristige Einführung eines neuen Kapitalschutzkonzepts geprüft werden. Nach dem Alternativkonzept soll eine Ausschüttung nur dann erlaubt sein, wenn im Anschluss daran die Solvenz der Gesellschaft für einen Zeitraum von zwölf Monaten sichergestellt ist. Zur Beurteilung der Solvenz soll das Management bestimmte Liquiditäts- bzw. Bilanztests durchführen und deren Einhaltung in einer Solvenzbescheinigung schriftlich bestätigen. Bei unzulässigen Ausschüttungen sollen die Mitglieder der Unternehmensleitung haften. Zudem ist die Einführung einer Insolvenzverschleppungshaftung geplant. Der von britischen Gesellschaftsrechtsexperten unterbreitete Vorschlag für ein zukünftiges europäisches Kapitalschutzsystem (Rickford-Bericht) sieht ausschließlich einen auf Zahlungsgrößen basierenden Solvenztest vor. Die Besonderheit der Vorschläge des Arbeitskreises „Kapital in Europa“ besteht schließlich darin, dass die nach IFRS bilanzierenden Unternehmen wahlweise am bestehenden Konzept festhalten können. Alternativ können sie die Kapitalerhaltungsregeln auf Grundlage des IFRS-Einzelabschlusses anwenden. Sie müssen dann aber zusätzlich einen Solvenztest durchführen.

15. Ein Solvenztest erscheint als Gläubigerschutzinstrument grundsätzlich geeignet. Er analysiert die zukünftige Liquiditätssituation der Gesellschaft und stellt damit im Gegensatz zu bilanziellen Ausschüttungsrestriktionen auf das primäre Interesse der Gläubiger ab. Die unveränderte Übernahme des equity insolvency test kann aber nicht empfohlen werden. Wie die ausführliche Untersuchung der US-amerikanischen Solvenztests gezeigt hat, werden weder in den betrachteten gesellschaftsrechtlichen Einzelstaatengesetzen noch durch die Rechtsprechung oder die Kommentarliteratur konkrete Vorgaben für die Durchführung des Solvenztests gegeben. Dadurch ergibt sich für die Unternehmensleitung bei der Ausschüttungsentscheidung ein sehr weiter Ermessensspielraum mit der Konsequenz, dass ein Verstoß des Managements gegen seine Sorgfaltspflichten gerichtlich nur mit Schwierigkeiten nachzuweisen ist. Die gläubigerschützende Wirkung wird dadurch geschmälert.

16. Damit Gläubiger wirksam geschützt werden, sollte der Solvenztest bestimmte Kriterien erfüllen. Er sollte zukunfts- und Cashflow-orientiert sein und konzernspezifische Risiken explizit berücksichtigen. Um der Manipulationsgefahr, die bei einem Solvenztest - wie bei anderen Formen der Rechenschaftslegung in ähnlicher Weise auch - besteht, entgegenzuwirken, sollte dem Management eine bestimmte Methodik vorgegeben werden. Der zu erstellende Finanzplan könnte sich hinsichtlich des Aufbaus an der Kapitalflussrechnung nach IAS 7 orientieren. Im Hinblick auf den zu berücksichtigenden Zeitraum könnte er in Anlehnung an das übliche Vorgehen bei Unternehmensbewertungen zwei Phasen 
umfassen. Dabei sollte der mindestens zwölfmonatige Detailprognosezeitraum um eine zweite Phase, die eine langfristige, grobe Kapitalbedarfsplanung beinhaltet, ergänzt werden. Ausschüttungen wären so lange möglich, wie die Gesellschaft trotz der Ausschüttung im Detailprognosezeitraum über ausreichende liquide Mittel zur Fortführung der Geschäftstätigkeit verfügt und aus der langfristigen Kapitalbedarfsplanung keine existenzbedrohenden Risiken abzuleiten sind. Wie nach kalifornischem Gesellschaftsrecht sollte der Solvenztest sowohl auf Ebene der rechtlich selbständigen Einzelunternehmen als auch auf Konzernebene durchzuführen sein.

17. Die zum Zwecke des Solvenztests vom Management durchzuführenden Zukunftsprognosen, die in einem Finanzplan zu verdichten sind, entziehen sich einer intersubjektiven Nachprüfbarkeit. Die den Prognoserechnungen zugrunde liegenden Prämissen können aber von Experten auf ihre Plausibilität hin überprüft werden. Aktiengesellschaften sollten daher zur Prüfung ihres Solvenztests durch Wirtschaftsprüfer gesetzlich verpflichtet werden.

18. Aufgrund der unternehmensinternen, vertraulichen Daten des Finanzplans sollte lediglich das testierte Ergebnis des Solvenztests in Form einer Solvenzbescheinigung, nicht hingegen der dem Testverfahren zugrunde liegende Finanzplan selbst offenlegungspflichtig sein. Bei einer Insolvenz der Gesellschaft im Anschluss an eine Ausschüttung könnten geschädigte Gläubiger ausgehend von der letzten Solvenzbescheinigung die ordnungsgemäße Durchführung des Solvenztests gerichtlich überprüfen lassen. Bei fahrlässigen oder vorsätzlichen Verstößen gegen ihre Sorgfaltspflichten sollte die Unternehmensleitung in Höhe der unzulässigen Ausschüttung persönlich haften.

19. Ein zusätzlich zum Solvenztest durchzuführender Bilanztest erscheint überflüssig. Zum jetzigen Zeitpunkt kann aber nicht ausgeschlossen werden, dass der europäische Gesetzgeber bei Einführung eines Solvenztests an einem traditionellen Bilanztest als zweiten Bestandteil der Solvenzprüfung festhalten will. Die Vorgehensweisen der verschiedenen USamerikanischen balance sheet tests sollten bei der möglichen Regulierung eines neuen europäischen Bilanztests nur dann berücksichtigt werden, wenn dadurch die in dieser Arbeit aufgezeigten Mängel des bestehenden europäischen Bilanztests vermieden oder zumindest verringert würden.

20. Die gläubigerschützende Wirkung der bilanziellen Testverfahren von Delaware ist als sehr gering einzuschätzen. Die detaillierten Regelungen können nicht verhindern, dass das von den Aktionären einbezahlte Kapital vollständig an sie zurückfließt. Da keine bestimmten Bilanzierungsregeln vorgeschrieben sind, ergeben sich einerseits für die Unternehmensleitung sehr große Spielräume und andererseits wird die Vergleichbarkeit der Anforderungen an den Kapitalschutz im Unternehmensvergleich erheblich eingeschränkt. Ähnliche Kritikpunkte gelten für den balance sheet test des MBCA, der daher ebenfalls unbeachtet bleiben sollte.

21. Beachtenswert erscheinen allein die bilanzorientierten Testverfahren des kalifornischen Rechts. Sie sehen eine variable Ausschüttungssperre vor, was gegenüber der bestehenden starren Ausschüttungssperre in Europa vorzuziehen ist. Weitere Vorzüge sind darin zu sehen, dass die den Testverfahren zugrunde liegende Rechnungslegung eindeutig vorgeschrieben ist und konzernspezifische Sachverhalte explizit berücksichtigt werden. Zu kritisieren sind hingegen einzelne Modifizierungen der grundsätzlich zu beachtenden informationsorientierten Rechnungslegung nach US-GAAP. Auch die vereinzelt vorgeschlagene Kumulierung der Testverfahren ist als zu restriktiv abzulehnen. 
Zusammenfassend lässt sich also feststellen, dass die Abkehr vom traditionellen europäischen Kapitalschutzkonzept zu einem wirkungsvolleren und effizienteren Gläubigerschutz führen kann. Hierzu wäre ein konkret ausgestalteter Solvenztest als Kern des neuen Regimes vorzuschreiben und gegebenenfalls um einen auf dem Konzernabschluss nach IFRS basierenden Bilanztest zu erweitern. Dies würde auch die Chance eröffnen, die EU-weite Harmonisierung der Rechnungslegung im Vergleich zum Status quo erheblich zu erhöhen, indem alle von der Kapitalrichtlinie betroffenen Gesellschaften zur einheitlichen IFRS-Bilanzierung in Einzelund Konzernabschluss verpflichtet werden. Aktiengesellschaften in Deutschland, die bereits freiwillig oder aufgrund der IAS-Verordnung nach IFRS bilanzieren, bräuchten dann keinen Einzelabschluss nach HGB mehr aufzustellen. Die steuerrechtlichen Vorschriften in Deutschland könnten einheitlich und losgelöst von den informationsorientierten Rechenwerken im Einkommensteuergesetz kodifiziert werden. Damit wäre auch eine mögliche Verzerrung der informationsorientierten Rechnungslegung durch steuerrechtliche Einflüsse vermieden.

Ungelöst bliebe das Schicksal der zahlenmäßig dominierenden GmbHs und ihr entsprechende Rechtsformen. Die deutschen GmbHs müssten weiterhin an der HGB-Rechnungslegung und den bestehenden Kapitalschutznormen festhalten. Trifft die Vermutung $\mathrm{zu}$, dass die meisten kleinen und mittelgroßen Gesellschaften keine Planrechnungen durchführen (können) ${ }^{1362}$, wäre das neue Kapitalschutzkonzept nur mit Schwierigkeiten auf diese Gesellschaften übertragbar.

Mit Spannung bleiben das Ergebnis der angekündigten Machbarkeitsstudie und das weitere Vorgehen der EU-Kommission abzuwarten. Die langfristige Einführung eines neuen Kapitalschutzsystems erscheint - soweit die gänzliche Deregulierung nicht als realistische Alternative gesehen wird - wünschenswert und wahrscheinlich. Auch für Verfechter der bestehenden Kapitalschutzregeln ,ist der Zusammenbruch des kontinentalen Konzepts eine realistische Perspektive geworden. Gesellschaftsrechtler sollten sich daran erinnern, dass Brüssel nicht weit von Waterloo entfernt liegt. “ ${ }^{1363}$ Es spricht aber vieles dafür, die Übernahme eines liquiditäts- und zukunftsorientierten Kapitalsystems in europäisches Recht nicht aus der Perspektive Napoleons als Niederlage, sondern vielmehr aus der Sicht von Blücher, Gneisenau und Wellington zu würdigen. Die Antwort auf die sich anschließende Frage, ob und inwiefern dieser Systemwechsel als „Sternstunde[n] der Menschheit“1364 in die Geschichte eingehen wird, ist entscheidend von der noch ausstehenden konkreten Ausschüttungsregulierung der EU abhängig und wird abschließend wohl erst von folgenden Generationen beantwortet werden können.

1362 Vgl. so die Einschătzung von Süchting (1995), S. 208.

1363 Schön (2004a), S. 164.

1364 So der Titel des Buchs von Stefan Zweig, in dem er unter anderem die „Weltminute von Waterloo" literarisch aufarbeitet. Vgl. Zweig (1927), S. 5-22. 


\section{Anlagen}

Anlage 1: Ergebnis der Bilanztests des $\S 500$ (b) Cal.Corp.Code vor Aussschüttung (2003)

Anlage 2: Ergebnis der Bilanztests des $\S 500$ (b) Cal.Corp.Code vor Aussschüttung (2004)

Anlage 3: Ermittlung der Maximalausschüttung nach den Regeln des Cal.Corp.Code für das Geschäftsjahr 2003 (Teil 1)

Anlage 4: Ermittlung der Maximalausschüttung nach den Regeln des Cal.Corp.Code für das Geschäftsjahr 2003 (Teil 2)

Anlage 5: Ermittlung der Maximalausschüttung nach den Regeln des Cal.Corp.Code für das Geschäftsjahr 2003 (Teil 3)

Anlage 6: Ermittlung der Maximalausschüttung nach den Regeln des Cal.Corp.Code für das Geschäftsjahr 2004 (Teil 1)

Anlage 7: Ermittlung der Maximalausschüttung nach den Regeln des Cal.Corp.Code für das Geschäftsjahr 2004 (Teil 2)

Anlage 8: Ermittlung der Maximalausschüttung nach den Regeln des Cal.Corp.Code für das Geschäftsjahr 2004 (Teil 3) 
Anlage 1: Ergebnis der Bilanztests des $\S 500$ (b) Cal.Corp.Code vor Aussschüttung (2003)

\begin{tabular}{|c|c|c|c|c|c|}
\hline $\begin{array}{c}\text { Konzern } \\
\text { (Rechnungslegungs- } \\
\text { vorschrift) }\end{array}$ & QST & $\begin{array}{c}\text { EBIT } \\
\text { Durchschnitt } \\
\text { (2 Jahre) } \\
\text { Mio } €\end{array}$ & \begin{tabular}{|c|} 
Zinssaldo \\
Durchschnitt \\
$\begin{array}{c}\text { (2 Jahre) } \\
\text { Mio } €\end{array}$ \\
\end{tabular} & $\begin{array}{c}\text { EBIT } \\
\text { abzgl. } \\
\text { Zinssaldo } \\
\text { Mio } €\end{array}$ & LT \\
\hline $\begin{array}{l}\text { Adidas-Salomon AG } \\
\text { IFRS }\end{array}$ & $125 \%$ & 468 & -66 & 402 & $196 \%$ \\
\hline $\begin{array}{l}\text { Altana AG } \\
\text { IFRS }\end{array}$ & $249 \%$ & 541 & 13 & 554 & $243 \%$ \\
\hline $\begin{array}{l}\text { BASF AG } \\
\text { IFRS }\end{array}$ & $168 \%$ & 2.562 & -158 & 2.404 & $179 \%$ \\
\hline $\begin{array}{l}\text { Bayer AG } \\
\text { IFRS }\end{array}$ & $135 \%$ & -118 & -401 & -519 & $192 \%$ \\
\hline $\begin{array}{l}\text { BMW AG } \\
\text { IFRS }\end{array}$ & $138 \%$ & 3.498 & -247 & 3.251 & $178 \%$ \\
\hline $\begin{array}{l}\text { Continental AG } \\
\text { US-GAAP }\end{array}$ & $111 \%$ & 775 & -149 & 626 & $112 \%$ \\
\hline $\begin{array}{l}\text { DaimlerChrysler AG } \\
\text { US-GAAP }\end{array}$ & $127 \%$ & 3.616 & -355 & 3.261 & $100 \%$ \\
\hline $\begin{array}{l}\text { Deutsche Börse AG } \\
\text { IFRS }\end{array}$ & $121 \%$ & 407 & 4 & 411 & $113 \%$ \\
\hline $\begin{array}{l}\text { Deutsche Lufthansa AG } \\
\text { IFRS }\end{array}$ & $114 \%$ & 462 & -378 & 84 & $95 \%$ \\
\hline $\begin{array}{l}\text { Deutsche Post AG } \\
\text { IFRS }\end{array}$ & $100 \%$ & 2.574 & -688 & 1.886 & $139 \%$ \\
\hline $\begin{array}{l}\text { Deutsche Telekom AG } \\
\text { US-GAAP }\end{array}$ & $107 \%$ & -8.964 & -3.912 & -12.876 & $59 \%$ \\
\hline $\begin{array}{l}\text { E.ON AG } \\
\text { US-GAAP }\end{array}$ & $128 \%$ & 5.345 & -740 & 4.605 & $109 \%$ \\
\hline $\begin{array}{l}\text { Henkel KGaA } \\
\text { IFRS }\end{array}$ & $98 \%$ & 762 & -147 & 615 & $115 \%$ \\
\hline $\begin{array}{l}\text { Fresenius Medical Care AG } \\
\text { US-GAAP }\end{array}$ & $100 \%$ & 726 & -220 & 507 & $156 \%$ \\
\hline $\begin{array}{l}\text { Infineon Technologies AG } \\
\text { US-GAAP }\end{array}$ & $200 \%$ & -717 & -39 & -756 & $249 \%$ \\
\hline $\begin{array}{l}\text { Linde AG } \\
\text { IFRS }\end{array}$ & $115 \%$ & 472 & -150 & 322 & $102 \%$ \\
\hline $\begin{array}{l}\text { MAN AG } \\
\text { IFRS }\end{array}$ & $135 \%$ & 434 & -173 & 261 & $108 \%$ \\
\hline $\begin{array}{l}\text { Metro AG } \\
\text { IFRS }\end{array}$ & $96 \%$ & 1.225 & -402 & 824 & $71 \%$ \\
\hline $\begin{array}{l}\text { RWE AG } \\
\text { IFRS }\end{array}$ & $94 \%$ & 3.310 & -888 & 2.423 & $112 \%$ \\
\hline $\begin{array}{l}\text { SAP AG } \\
\text { US-GAAP }\end{array}$ & $257 \%$ & 1.433 & 34 & 1.466 & $220 \%$ \\
\hline $\begin{array}{l}\text { Schering AG } \\
\text { IFRS }\end{array}$ & $198 \%$ & 944 & -24 & 921 & $235 \%$ \\
\hline $\begin{array}{l}\text { Siemens AG } \\
\text { US-GAAP }\end{array}$ & $129 \%$ & 3.098 & 282 & 3.379 & $136 \%$ \\
\hline $\begin{array}{l}\text { ThyssenKrupp AG } \\
\text { US-GAAP }\end{array}$ & $118 \%$ & 765 & -238 & 528 & $141 \%$ \\
\hline $\begin{array}{l}\text { TUI AG } \\
\text { IFRS }\end{array}$ & $87 \%$ & 428 & -192 & 237 & $45 \%$ \\
\hline $\begin{array}{l}\text { Volkswagen AG } \\
\text { IFRS }\end{array}$ & $119 \%$ & 2.916 & -177 & 2.740 & $92 \%$ \\
\hline
\end{tabular}


Anlage 2: Ergebnis der Bilanztests des $\S 500$ (b) Cal.Corp.Code vor Aussschüttung (2004)

\begin{tabular}{|c|c|c|c|c|c|}
\hline $\begin{array}{c}\text { Konzern } \\
\text { (Rechnungslegungs- } \\
\text { vorschrift) }\end{array}$ & QST & $\begin{array}{c}\text { EBIT } \\
\text { Durchschnitt } \\
\text { (2 Jahre) } \\
\text { Mio } €\end{array}$ & $\begin{array}{c}\text { Zinssaldo } \\
\text { Durchschnitt } \\
\text { (2 Jahre) } \\
\text { Mio } €\end{array}$ & $\begin{array}{c}\text { EBIT } \\
\text { abzgl. } \\
\text { Zinssaldo } \\
\text { Mio } €\end{array}$ & LT \\
\hline $\begin{array}{l}\text { Adidas-Salomon AG } \\
\text { IFRS }\end{array}$ & $128 \%$ & 503 & -59 & 444 & $202 \%$ \\
\hline $\begin{array}{l}\text { Altana AG } \\
\text { IFRS }\end{array}$ & $272 \%$ & 593 & 11 & 604 & $258 \%$ \\
\hline \begin{tabular}{|l|} 
BASF AG \\
IFRS \\
\end{tabular} & $174 \%$ & 3.462 & -226 & 3.236 & $188 \%$ \\
\hline \begin{tabular}{|l} 
Bayer AG \\
IFRS
\end{tabular} & $146 \%$ & 84 & -314 & -230 & $197 \%$ \\
\hline \begin{tabular}{|l|} 
BMW (IFRS) \\
IFRS \\
\end{tabular} & $138 \%$ & 3.664 & -284 & 3.380 & $183 \%$ \\
\hline $\begin{array}{l}\text { Continental AG } \\
\text { US-GAAP } \\
\end{array}$ & $122 \%$ & 976 & -118 & 858 & $140 \%$ \\
\hline $\begin{array}{l}\text { DaimlerChrysler AG } \\
\text { US-GAAP }\end{array}$ & $125 \%$ & 2.411 & -345 & 2.066 & $92 \%$ \\
\hline $\begin{array}{l}\text { Deutsche Börse AG } \\
\text { IFRS } \\
\end{array}$ & $125 \%$ & 456 & -6 & 450 & $121 \%$ \\
\hline \begin{tabular}{|l|} 
Deutsche Lufthansa AG \\
IFRS \\
\end{tabular} & $126 \%$ & 239 & -336 & -97 & $108 \%$ \\
\hline $\begin{array}{l}\text { Deutsche Post AG } \\
\text { IFRS }\end{array}$ & $101 \%$ & 2.812 & -776 & 2.036 & $144 \%$ \\
\hline $\begin{array}{l}\text { Deutsche Telekom AG } \\
\text { US-GAAP }\end{array}$ & $118 \%$ & 7.533 & -3.564 & 3.969 & $56 \%$ \\
\hline $\begin{array}{l}\text { E.ON AG } \\
\text { US-GAAP } \\
\end{array}$ & $134 \%$ & 7.120 & -1.124 & 5.996 & $116 \%$ \\
\hline \begin{tabular}{|l|} 
Henkel KG aA \\
IFRS
\end{tabular} & $101 \%$ & 753 & -152 & 601 & $114 \%$ \\
\hline $\begin{array}{l}\text { Fresenius Medical Care AG } \\
\text { (in Mio. USD) US-GAAP }\end{array}$ & $107 \%$ & 805 & -198 & 607 & $126 \%$ \\
\hline $\begin{array}{l}\text { Infineon Technologies AG } \\
\text { US-GAAP }\end{array}$ & $137 \%$ & -22 & -47 & -69 & $187 \%$ \\
\hline $\begin{array}{l}\text { Linde AG } \\
\text { IFRS } \\
\end{array}$ & $119 \%$ & 531 & -130 & 401 & $103 \%$ \\
\hline $\begin{array}{l}\text { MAN AG } \\
\text { IFRS }\end{array}$ & $131 \%$ & 551 & -173 & 378 & $106 \%$ \\
\hline \begin{tabular}{|l|} 
Metro AG \\
IFRS \\
\end{tabular} & $99 \%$ & 1.526 & -455 & 1.071 & $76 \%$ \\
\hline \begin{tabular}{|l|} 
RWE AG \\
IFRS \\
\end{tabular} & $100 \%$ & 5.661 & -1.131 & 4.530 & $130 \%$ \\
\hline $\begin{array}{l}\text { SAP AG } \\
\text { US-GAAP }\end{array}$ & $263 \%$ & 1.875 & 50 & 1.925 & $249 \%$ \\
\hline \begin{tabular}{|l|} 
Schering AG \\
IFRS \\
\end{tabular} & $196 \%$ & 703 & -19 & 684 & $249 \%$ \\
\hline $\begin{array}{l}\begin{array}{l}\text { Siemens AG } \\
\text { US-GAAP }\end{array} \\
\end{array}$ & $196 \%$ & 3.431 & 259 & 3.690 & $138 \%$ \\
\hline $\begin{array}{l}\text { ThyssenKrupp AG } \\
\text { US-GAAP }\end{array}$ & $138 \%$ & 1.327 & -205 & 1.122 & $148 \%$ \\
\hline $\begin{array}{l}\text { TUI AG } \\
\text { IFRS } \\
\end{array}$ & $123 \%$ & 608 & -175 & 433 & $56 \%$ \\
\hline \begin{tabular}{|l} 
Volkswagen AG \\
IFRS
\end{tabular} & $87 \%$ & 1.284 & 107 & 1.391 & $114 \%$ \\
\hline
\end{tabular}




\begin{tabular}{|c|c|c|c|c|c|c|c|c|c|c|c|c|}
\hline \multirow{2}{*}{$\begin{array}{c}\text { Konzerm } \\
\text { Rechnungslegungsvorschrift } \\
\text { Werte in Mio } €\end{array}$} & \multirow{2}{*}{$\begin{array}{c}\text { BS } \\
\text { Aktiva }\end{array}$} & \multicolumn{3}{|c|}{$\begin{array}{c}\text { Korrekturen Aktiva } \\
\end{array}$} & \multirow{2}{*}{$\begin{array}{c}\text { BS } \\
\text { Aktiva } \\
\text { korrigiert }\end{array}$} & \multirow{2}{*}{$\begin{array}{c}\text { BS } \\
\text { Passiva } \\
\text { ohne EK }\end{array}$} & \multicolumn{2}{|c|}{ Korrekturen Passiva } & \multirow{2}{*}{$\begin{array}{c}\text { BS } \\
\text { Passiva } \\
\text { korrigiert }\end{array}$} & \multirow{2}{*}{$\begin{array}{l}\text { Eigenkapital } \\
\text { It. Bilanz }\end{array}$} & \multirow{2}{*}{\begin{tabular}{|c} 
Eigenkapital \\
korrigiert
\end{tabular}} & \multirow{2}{*}{\begin{tabular}{|c|} 
GRL(KA) \\
(einschl. \\
Bilanzgewinn)
\end{tabular}} \\
\hline & & \begin{tabular}{|c|} 
Goodwill \\
aktiv. Entwick- \\
lungskosten \\
\end{tabular} & RAP & $\begin{array}{l}\text { Latente } \\
\text { Steuem }\end{array}$ & & & $\begin{array}{l}\text { Latente } \\
\text { Steuern }\end{array}$ & RAP & & & & \\
\hline \begin{tabular}{|l}
$\begin{array}{l}\text { Adidas-Salomon AG } \\
\text { IFRS }\end{array}$ \\
\end{tabular} & 4.188 & 591 & 184 & 179 & 3.234 & 2.832 & 66 & 1 & 2.765 & 1.356 & 469 & 1.265 \\
\hline $\begin{array}{l}\text { Aitana AG } \\
\text { IfFRS }\end{array}$ & 2.532 & 93 & 19 & 79 & 2.341 & 1.087 & 33 & 112 & 942 & 1.445 & 1.399 & 1.477 \\
\hline $\begin{array}{l}\text { BASF AG } \\
\text { IFRS }\end{array}$ & 33.601 & 2.038 & 514 & 1.247 & 29.802 & 18.062 & 484 & 370 & 17.208 & 15.540 & 12.595 & 12.055 \\
\hline $\begin{array}{l}\text { Bayer AG } \\
\text { IFRS }\end{array}$ & 37.445 & 1.936 & 242 & 1.298 & 33.969 & 25.232 & 1.462 & 634 & 23.136 & 12.213 & 10.833 & 11.258 \\
\hline $\begin{array}{l}\text { BMW } \\
\text { IFRS }\end{array}$ & 61.475 & 3.011 & 488 & 175 & 57.801 & 45.325 & 2.501 & 847 & 41.977 & 16.150 & 15.824 & 12.671 \\
\hline $\begin{array}{l}\begin{array}{l}\text { Continental AG } \\
\text { US-GAAP }\end{array} \\
\end{array}$ & 8.299 & 1.424 & 0 & 175 & 6.700 & 6.315 & 253 & 0 & 6.062 & 1.983 & 637 & 963 \\
\hline $\begin{array}{l}\text { DaimlerChrysler AG } \\
\text { US-GAAP }\end{array}$ & 178.268 & 1.816 & 1.095 & 2.688 & 172.669 & 143.787 & 2.736 & 5.331 & 135.720 & 34.481 & 36.949 & 29.085 \\
\hline \begin{tabular}{|l|} 
Deutsche Börse AG \\
IFRS \\
\end{tabular} & 8.289 & 1.173 & 19 & 16 & 7.080 & 5.948 & 92 & 1 & 5.855 & 2.341 & 1.225 & 760 \\
\hline \begin{tabular}{|l|} 
Deutsche Lufthansa AG \\
IFRS \\
\end{tabular} & 16.732 & 828 & 84 & 194 & 15.626 & 14.079 & 208 & 210 & 13.661 & 2.653 & 1.965 & 949 \\
\hline \begin{tabular}{|l|}
$\begin{array}{l}\text { Deutsche Post AG } \\
\text { IFRS }\end{array}$ \\
\end{tabular} & 154.933 & 5.653 & 705 & 916 & 147.659 & 148.827 & 885 & 567 & 147.375 & 6.106 & 284 & 4.924 \\
\hline $\begin{array}{l}\begin{array}{l}\text { Deutsche Telekom AG } \\
\text { US-GAAP }\end{array} \\
\end{array}$ & 116.079 & 24.513 & 772 & 0 & 90.794 & 86.321 & 919 & 703 & 84.699 & 29.758 & 6.095 & -23.063 \\
\hline $\begin{array}{l}\text { E.ONAG } \\
\text { US-GAAP } \\
\end{array}$ & 111.850 & 13.955 & 398 & 1.525 & 95.972 & 82.076 & 6.265 & 1.080 & 74.731 & 29.774 & 21.241 & 16.976 \\
\hline \begin{tabular}{|l|} 
Henkel KGaA \\
IFRS \\
\end{tabular} & 9.362 & 2.280 & 27 & 296 & 6.759 & 6.050 & 181 & 0 & 5.869 & 3.311 & 889 & 2.955 \\
\hline $\begin{array}{l}\text { Fresenius Medical Care AG (in Mio \$) } \\
\text { US-GAAP }\end{array}$ & 7.503 & 3.288 & 0 & 215 & 4.000 & 4.259 & 277 & 0 & 3.982 & 3.244 & 18 & 378 \\
\hline $\begin{array}{l}\text { lnfineon Technologies AG } \\
\text { US-GAAP }\end{array}$ & 10.805 & 216 & 0 & 818 & 9.771 & 5.139 & 71 & 180 & 4.888 & 5.666 & 4.883 & -1.261 \\
\hline
\end{tabular}




\begin{tabular}{|c|c|c|c|c|c|c|c|c|c|c|c|c|}
\hline $\begin{array}{c}\text { Konzern } \\
\text { Rechnungslegungsvorschrift } \\
\text { Werte in Mio } \epsilon\end{array}$ & $\begin{array}{l}\text { BS } \\
\text { Aktiva }\end{array}$ & \begin{tabular}{c}
\multicolumn{2}{c}{ Kor } \\
Goodwill \\
aktiv. Entwick- \\
lungskosten \\
\end{tabular} & $\frac{\operatorname{turen} A}{R A P}$ & $\begin{array}{l}\text { Latente } \\
\text { Steuem }\end{array}$ & $\begin{array}{c}\text { BS } \\
\text { Aktiva } \\
\text { korrigiert }\end{array}$ & $\begin{array}{c}\text { BS } \\
\text { Passiva } \\
\text { ohne EK }\end{array}$ & $\begin{array}{l}\text { Korrektu } \\
\text { Latente } \\
\text { Steuem }\end{array}$ & $\begin{array}{l}\text { Passiva } \\
\text { RAP }\end{array}$ & $\begin{array}{c}\text { BS } \\
\text { Passiva } \\
\text { korrigiert }\end{array}$ & $\begin{array}{c}\text { Eigenkapital } \\
\text { It. Bilanz }\end{array}$ & $\begin{array}{c}\text { Eigenkapital } \\
\text { korrigiert }\end{array}$ & $\begin{array}{c}\text { GRL(KA) } \\
\text { (einschl. } \\
\text { Bilanzgewinn) }\end{array}$ \\
\hline $\begin{array}{l}\text { Linde AG } \\
\text { IFRS }\end{array}$ & 11.915 & 3.004 & 30 & 132 & 8.749 & 8.064 & 266 & 218 & 7.580 & 3.851 & 1.169 & 1.134 \\
\hline $\begin{array}{l}\text { MAN AG } \\
\text { IFRS }\end{array}$ & 9.955 & 372 & 29 & 408 & 9.146 & 7.235 & 391 & 52 & 6.792 & 2.720 & 2.354 & 1.547 \\
\hline \begin{tabular}{|l|} 
Metro AG \\
IFRS
\end{tabular} & 26.580 & 4.095 & 149 & 1.456 & 20.880 & 22.419 & 526 & 129 & 21.764 & 4.161 & -884 & 775 \\
\hline $\begin{array}{l}\text { RWE AG } \\
\text { IFRS }\end{array}$ & 99.142 & 15.783 & 383 & 4.325 & 78.651 & 92.129 & 4.526 & 3.819 & 83.784 & 7.013 & -5.133 & 4.856 \\
\hline $\begin{array}{l}\text { SAPAG } \\
\text { US-GAAP }\end{array}$ & 6.326 & 345 & 68 & 265 & 5.648 & 2.616 & 112 & 305 & 2.199 & 3.710 & 3.449 & 3.761 \\
\hline \begin{tabular}{|l|} 
Schering AG \\
IFRS \\
\end{tabular} & 5.389 & 420 & 0 & 173 & 4.796 & 2.483 & 17 & 0 & 2.466 & 2.902 & 2.326 & 2.685 \\
\hline $\begin{array}{l}\text { Siemens AG } \\
\text { US-GAAP }\end{array}$ & 77.605 & 6.501 & 0 & 4.359 & 66.745 & 53.890 & 1.404 & 921 & 51.565 & 23.715 & 15.180 & 23.020 \\
\hline $\begin{array}{l}\text { ThyssenKrupp AG } \\
\text { US-GAAP } \\
\end{array}$ & 30.141 & 3.152 & 204 & 1.290 & 25.495 & 22.510 & 732 & 108 & 21.670 & 7.631 & 3.825 & 2.790 \\
\hline \begin{tabular}{|l|} 
TUI AG \\
IFRS \\
\end{tabular} & 12.989 & 3.808 & 252 & 188 & 8.741 & 10.507 & 209 & 65 & 10.233 & 2.482 & -1.492 & 1.001 \\
\hline $\begin{array}{l}\text { Volkswagen AG } \\
\text { IFRS }\end{array}$ & 119.136 & 7.676 & 277 & 1.515 & 109.668 & 94.706 & 2.472 & 322 & 91.912 & 24.430 & 17.756 & 18.890 \\
\hline
\end{tabular}




\begin{tabular}{|c|c|c|c|c|c|c|c|c|c|c|c|}
\hline \multirow{2}{*}{$\begin{array}{c}\text { Konzern } \\
\text { Rechnungslegungsvorschrift } \\
\text { Werte in Mio } € \\
\end{array}$} & \multirow{2}{*}{$\begin{array}{l}\text { UV } \\
\text { kurzfr. }\end{array}$} & \multicolumn{2}{|c|}{ kurzfr. Verbindlichkeiten } & \multirow{2}{*}{$\begin{array}{c}\text { Kurzfr.Verb. } \\
\text { gesamt }\end{array}$} & \multirow{2}{*}{$\begin{array}{l}\text { EBIT } \\
2003\end{array}$} & \multirow{2}{*}{$\begin{array}{l}\text { EBIT } \\
2002\end{array}$} & \multirow{2}{*}{\begin{tabular}{|c|} 
EBIT \\
Durchschnitd
\end{tabular}} & \multirow{2}{*}{$\begin{array}{l}\text { Zins- } \\
\text { ergebnis } \\
2003\end{array}$} & \multirow{2}{*}{$\begin{array}{l}\text { Zins- } \\
\text { ergebnis } \\
2002\end{array}$} & \multirow{2}{*}{\begin{tabular}{c|c}
$\begin{array}{c}\text { Zins- } \\
\text { ergebnis } \\
\text { Durchschnitt }\end{array}$ \\
\end{tabular}} & \multirow{2}{*}{$\begin{array}{l}\text { GVV } \\
\text { It. EA }\end{array}$} \\
\hline & & Verb. & $\begin{array}{c}\text { sonstige } \\
\text { RST }\end{array}$ & & & & & & & & \\
\hline $\begin{array}{l}\text { Adidas-Salomon AG } \\
\text { IFRS }\end{array}$ & 2.776 & 731 & 612 & 1.343 & 486 & 450 & 468 & -59 & -73 & -66 & 45 \\
\hline $\begin{array}{l}\text { Altana AG } \\
\text { IFRS } \\
\end{array}$ & 1.589 & 490 & 163 & 653 & 568 & 514 & 541 & 13 & 12 & 13 & 117 \\
\hline $\begin{array}{l}\text { BASF AG } \\
\text { IFRS }\end{array}$ & 12.892 & 5.118 & 2.320 & 7.438 & 2.391 & 2.733 & 2.562 & -223 & -92 & -158 & 779 \\
\hline $\begin{array}{l}\text { Bayer AG } \\
\text { IFRS }\end{array}$ & 17.673 & 6.939 & 2.448 & 9.387 & -1.641 & 1.405 & -118 & -353 & -449 & -401 & 365 \\
\hline $\begin{array}{l}\text { BMW (IFRS) } \\
\text { IFRS }\end{array}$ & 40.600 & 18.917 & 3.879 & 22.796 & 3.486 & 3.509 & 3.498 & -281 & -212 & -247 & 392 \\
\hline $\begin{array}{l}\text { Continental AG } \\
\text { US-GAAP }\end{array}$ & 3.449 & 2.243 & 831 & 3.074 & 855 & 694 & 775 & -133 & -165 & -149 & 70 \\
\hline $\begin{array}{l}\text { DaimlerChrysler AG } \\
\text { US-GAAP }\end{array}$ & 65.051 & 47.619 & 17.289 & 64.908 & 986 & 6.245 & 3.616 & -390 & -320 & -355 & 1.519 \\
\hline $\begin{array}{l}\text { Deutsche Börse AG } \\
\text { IFRS }\end{array}$ & 5.907 & 5.026 & 198 & 5.224 & 453 & 361 & 407 & -5 & 13 & 4 & 135 \\
\hline $\begin{array}{l}\text { Deutsche Lufthansa AG } \\
\text { IFRS }\end{array}$ & 5.569 & 2.533 & 3.299 & 5.832 & -444 & 1.367 & 462 & -341 & -415 & -378 & 0 \\
\hline $\begin{array}{l}\text { Deutsche Post AG } \\
\text { IFRS }\end{array}$ & 138.060 & 97.564 & 1.453 & 99.017 & 2.646 & 2.501 & 2.574 & -731 & -645 & -688 & 490 \\
\hline $\begin{array}{l}\text { Deutsche Telekom AG } \\
\text { US-GAAP }\end{array}$ & 19.656 & 22.325 & 11.247 & 33.572 & 5.174 & -23.102 & -8.964 & -3.776 & -4.048 & -3.912 & 2.035 \\
\hline $\begin{array}{l}\text { E.ON AG } \\
\text { US-GAAP }\end{array}$ & 24.912 & 16.118 & 6.728 & 22.846 & 6.878 & 3.811 & 5.345 & -1.107 & -372 & .740 & 1.312 \\
\hline $\begin{array}{l}\text { Henkel KG aA } \\
\text { IFRS }\end{array}$ & 4.343 & 1.956 & 1.056 & 3.012 & 706 & 818 & 762 & -140 & -154 & -147 & 167 \\
\hline $\begin{array}{l}\text { Fresenius Medical Care AG (in Mio \$) } \\
\text { US-GAAP }\end{array}$ & 2.206 & 1.412 & 0 & 1.412 & 757 & 695 & 726 & -212 & -227 & -220 & 100 \\
\hline $\begin{array}{l}\text { Infineon Technologies AG } \\
\text { US-GAAP }\end{array}$ & 5.306 & 1.490 & 644 & 2.134 & -299 & -1.135 & -717 & -52 & -25 & -39 & 0 \\
\hline
\end{tabular}




\begin{tabular}{|c|c|c|c|c|c|c|c|c|c|c|c|}
\hline \multirow{2}{*}{$\begin{array}{c}\text { Konzern } \\
\text { Rechnungslegungsvorschrift } \\
\text { Werte in Mio } €\end{array}$} & \multirow{2}{*}{$\begin{array}{l}\text { UV } \\
\text { kurzfr. }\end{array}$} & \multicolumn{2}{|c|}{ kurzfr. Verbindlichkeiten } & \multirow{2}{*}{$\begin{array}{c}\text { Kurzfr.Verb. } \\
\text { gesamt }\end{array}$} & \multirow{2}{*}{$\begin{array}{l}\text { EBIT } \\
2003\end{array}$} & \multirow{2}{*}{$\begin{array}{l}\text { EBIT } \\
2002\end{array}$} & \multirow{2}{*}{\begin{tabular}{|c|} 
EBIT \\
Durchschnitt
\end{tabular}} & \multirow{2}{*}{$\begin{array}{c}\text { Zins- } \\
\text { ergebnis } \\
2003\end{array}$} & \multirow{2}{*}{$\begin{array}{l}\text { Zins- } \\
\text { ergebnis } \\
2002\end{array}$} & \multirow{2}{*}{\begin{tabular}{|c|}
$\begin{array}{c}\text { Zins- } \\
\text { ergebnis } \\
\text { Durchschnitt }\end{array}$ \\
\end{tabular}} & \multirow{2}{*}{$\begin{array}{l}\text { GVV } \\
\text { It. EA }\end{array}$} \\
\hline & & Verb. & $\begin{array}{l}\text { sonstige } \\
\text { RST }\end{array}$ & & & & & & & & \\
\hline $\begin{array}{l}\text { Linde AG } \\
\text { IFRS }\end{array}$ & 3.802 & 2.541 & 1.187 & 3.728 & 417 & 526 & 472 & -130 & -170 & -150 & 135 \\
\hline \begin{tabular}{|l|} 
MAN AG \\
IFRS
\end{tabular} & 4.622 & 2.781 & 1.060 & 3.841 & 477 & 391 & 434 & -174 & -172 & -173 & 110 \\
\hline $\begin{array}{l}\text { Metro AG } \\
\text { IFRS }\end{array}$ & 9.769 & 13.488 & 324 & 13.812 & 1.242 & 1.208 & 1.225 & -425 & -378 & -402 & 334 \\
\hline $\begin{array}{l}\text { RWE AG } \\
\text { IFRS }\end{array}$ & 30.239 & 18.737 & 8.272 & 27.009 & 5.346 & 3.366 & 4.356 & -1.131 & -644 & -888 & 703 \\
\hline $\begin{array}{l}\text { SAP AG } \\
\text { US-GAAP }\end{array}$ & 4.207 & 649 & 1.264 & 1.913 & 1.733 & 1.132 & 1.433 & 43 & 24 & 34 & 249 \\
\hline $\begin{array}{l}\text { Schering AG } \\
\text { IFRS }\end{array}$ & 3.170 & 688 & 660 & 1.348 & 720 & 1.168 & 944 & -22 & -25 & -24 & 180 \\
\hline $\begin{array}{l}\text { Siemens AG } \\
\text { US-GAAP }\end{array}$ & 43.489 & 23.144 & 8.884 & 32.028 & 3.067 & 3.128 & 3.098 & 245 & 318 & 282 & 980 \\
\hline $\begin{array}{l}\text { ThyssenKrupp AG } \\
\text { US-GAAP }\end{array}$ & 13.275 & 6.435 & 2.999 & 9.434 & 855 & 675 & 765 & -191 & -284 & -238 & 249 \\
\hline $\begin{array}{l}\text { TUI AG } \\
\text { IFRS }\end{array}$ & 2.718 & 5.127 & 891 & 6.018 & 399 & 457 & 428 & -153 & -230 & -192 & 138 \\
\hline $\begin{array}{l}\text { Volkswagen AG } \\
\text { IFRS }\end{array}$ & 50.495 & 41.936 & 4.885 & 46.821 & 1.381 & 4.451 & 2.916 & 125 & -478 & -177 & 409 \\
\hline
\end{tabular}




\begin{tabular}{|c|c|c|c|c|c|c|c|c|c|c|c|c|c|c|}
\hline $\begin{array}{c}\text { Konzern } \\
\text { (Rechnungslegungs- } \\
\text { vorschrift) }\end{array}$ & QST & $\begin{array}{c}\text { EK/BS } \\
\text { (KA) }\end{array}$ & \begin{tabular}{|c|} 
EBIT \\
$\begin{array}{c}\text { Durchschnitt } \\
\text { (2 Jahree) } \\
\text { Mio } 6\end{array}$ \\
\end{tabular} & 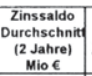 & 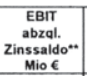 & เT'* & $\begin{array}{l}\text { Maximala } \\
\text { QST } \\
\text { Mio } 6\end{array}$ & $\begin{array}{l}\text { chuttung } \\
\text { LT } \\
\text { Mio } E\end{array}$ & \begin{tabular}{|c|} 
A (max) \\
500 (b) Cal.Corp.Code $\cdots \cdots$ \\
Mio $€$ \\
\end{tabular} & $\begin{array}{l}\text { GRL(KA) } \\
\text { Mio } \epsilon\end{array}$ & $\begin{array}{c}\text { A(max) } \\
\text { Cal.Corp.Code } \\
\text { Mio } E\end{array}$ & $\begin{array}{l}\text { BG (EA) } \\
\text { Mioe }\end{array}$ & $\begin{array}{c}\text { GRL (EA) } \\
\text { Mio } \epsilon \\
\end{array}$ & 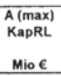 \\
\hline $\begin{array}{l}\text { Adidas-Salomon AG } \\
\text { IFRS }\end{array}$ & $71 \%$ & $32 \%$ & 468 & 66 & 402 & $113 \%$ & 0 & 1.433 & 0 & 1.265 & 1.265 & 577 & 737 & 1.314 \\
\hline $\begin{array}{l}\text { Atrana AG } \\
\text { IIRS }\end{array}$ & $92 \%$ & $57 \%$ & 541 & 13 & 554 & $17 \%$ & 0 & 0 & 0 & 1.477 & 1.477 & 138 & 1.613 & 1.751 \\
\hline $\begin{array}{l}\text { BASF AG } \\
\text { IFSS }\end{array}$ & $108 \%$ & $46 \%$ & 2.562 & -158 & 2.404 & $22 \%$ & 0 & 0 & 0 & 11.276 & 11.276 & 779 & 6.303 & 7.082 \\
\hline $\begin{array}{l}\text { Bayer AG } \\
\text { IFRS }\end{array}$ & $102 \%$ & $33 \%$ & -118 & -401 & 0 & $77 \%$ & 0 & 0 & 0 & 10.479 & 10.479 & 365 & 3.290 & 3.655 \\
\hline 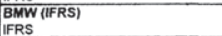 & $108 \%$ & $26 \%$ & 3.498 & -247 & 3.251 & $123 \%$ & 0 & 17.804 & 0 & 12.671 & 12.671 & 392 & 2.217 & 2.609 \\
\hline $\begin{array}{l}\text { Continental AG } \\
\text { US-GAAP }\end{array}$ & $95 \%$ & $24 \%$ & 775 & -149 & 626 & $81 \%$ & 0 & 0 & 0 & 963 & 963 & 71 & 35 & 106 \\
\hline $\begin{array}{l}\text { Daimlerchryster AG } \\
\text { US-GAAP }\end{array}$ & $106 \%$ & $19 \%$ & 3.616 & -355 & 3.261 & $55 \%$ & 0 & 0 & 0 & 29.085 & 29.085 & 1.519 & 6.286 & 7.805 \\
\hline $\begin{array}{l}\text { Deutsche Börse AG } \\
\text { lifRS }\end{array}$ & $108 \%$ & $28 \%$ & 407 & 4 & 411 & $99 \%$ & 0 & 0 & 0 & 760 & 760 & 135 & 375 & 510 \\
\hline $\begin{array}{l}\text { Deutsche Lutthansa AG } \\
\text { IFRS }\end{array}$ & $107 \%$ & $16 \%$ & 462 & -378 & 84 & $79 \%$ & 0 & 0 & 0 & 949 & 949 & 0 & 402 & 402 \\
\hline \begin{tabular}{|l} 
Deutsche Post AG \\
IFRS
\end{tabular} & $97 \%$ & $4 \%$ & 2.574 & -688 & 1.886 & $134 \%$ & 0 & 39.043 & 0 & 4.924 & 4.924 & 1.349 & 3.876 & 5.225 \\
\hline $\begin{array}{l}\text { Deutsche Telekom AG } \\
\text { US-GAAP }\end{array}$ & $107 \%$ & $26 \%$ & -8.964 & -3.912 & -12.876 & $59 \%$ & 0 & 0 & 0 & -23.063 & 0 & 2.035 & 9.081 & 11.116 \\
\hline $\begin{array}{l}\text { O.ONAG } \\
\text { US-GAAP }\end{array}$ & $106 \%$ & $27 \%$ & 5.345 & -740 & 4.605 & $35 \%$ & 0 & 0 & 0 & 16.976 & 16.976 & 1.312 & 2.478 & 3.790 \\
\hline $\begin{array}{l}\text { Henkel KG aA } \\
\text { IFRS }\end{array}$ & $26 \%$ & $43 \%$ & 863 & -147 & 716 & $46 \%$ & 0 & 0 & 0 & 2.955 & 2.955 & 167 & 2.837 & 3.004 \\
\hline $\begin{array}{l}\text { Frosenius Medical Care AG } \\
\text { (in Mo s) US-GAAP }\end{array}$ & $130 \%$ & $35 \%$ & 726 & .220 & 507 & $129 \%$ & 0 & 1.331 & 0 & 378 & 378 & 139 & 302 & 441 \\
\hline $\begin{array}{l}\text { Infineon Technologies AG } \\
\text { US-GAAP }\end{array}$ & $200 \%$ & $52 \%$ & .717 & -39 & .756 & $249 \%$ & 3.661 & 2.639 & 2.639 & -1.261 & 2.639 & -1.339 & 32 & 0 \\
\hline
\end{tabular}

US-GAAP

..... Ergebnisse des $L T$ nach vollstandiger Ausschotung der GRL

田

営

害

연 웅

농

웅

홍 


\begin{tabular}{|c|c|c|c|c|c|c|c|c|c|c|c|c|c|c|}
\hline $\begin{array}{c}\text { Konzern } \\
\text { (Rechnungsiegungs- } \\
\text { vorschritt) }\end{array}$ & ast & $\begin{array}{l}\text { EK/BS } \\
(K A)\end{array}$ & \begin{tabular}{|c} 
EBIT \\
Durchschnit \\
(2 Jahre) \\
Mio $\mathrm{E}$ \\
\end{tabular} & \begin{tabular}{|c|}
$\begin{array}{c}\text { Zinssaldo } \\
\text { Durchschnith } \\
\text { (2 } 2 \text { Jahre) } \\
\text { Mioe }\end{array}$ \\
\end{tabular} & \begin{tabular}{|c|} 
EBIT \\
abzal. \\
Zinssaldo** \\
Mio $€$
\end{tabular} & LT'” & $\begin{array}{l}\text { Maximala } \\
\text { QST } \\
\text { Mio } 6 \\
\end{array}$ & $\begin{array}{l}\text { chuttung } \\
\text { LT } \\
\text { Mio } \epsilon \\
\end{array}$ & \begin{tabular}{|c|c|} 
\$ 500 (b) (max) \\
Mil.corp.Code \\
Mio.-.
\end{tabular} & $\begin{array}{c}\text { GRL(KA) } \\
\text { Mio } € \\
\end{array}$ & \begin{tabular}{|c|}
$A(\max )$ \\
Cal.Corp.Code \\
Mio 6 \\
\end{tabular} & $\begin{array}{l}G \text { (EA) } \\
\text { Miof }\end{array}$ & $\begin{array}{c}\text { GRL (EA) } \\
\text { Mio } \epsilon \\
\end{array}$ & $\begin{array}{l}A(\max ) \\
\text { KapRL } \\
\text { Mio } E\end{array}$ \\
\hline \begin{tabular}{|l|l|l|l|l|l|l} 
LifRS AG \\
If
\end{tabular} & $100 \%$ & $32 \%$ & 472 & -150 & 322 & $72 \%$ & 0 & 0 & 0 & 1.134 & 1.134 & 135 & 510 & 645 \\
\hline $\begin{array}{l}\text { MANAG } \\
\text { IFRS }\end{array}$ & $112 \%$ & $27 \%$ & 434 & .173 & 261 & $80 \%$ & 0 & 0 & 0 & 1.547 & 1.547 & 110 & 387 & 497 \\
\hline $\begin{array}{l}\text { Metro AG } \\
\text { IFRS }\end{array}$ & $92 \%$ & $16 \%$ & 1.225 & -402 & 824 & $65 \%$ & $\circ$ & 0 & $\circ$ & 775 & 775 & 345 & 684 & 1.029 \\
\hline $\begin{array}{l}\text { RWE AG } \\
\text { IFRS }\end{array}$ & $88 \%$ & $7 \%$ & 3.310 & -888 & 2.423 & $94 \%$ & 0 & 0 & 0 & 4.856 & 4.856 & 703 & 1.009 & 1.712 \\
\hline $\begin{array}{l}\text { SAP AG } \\
\text { US-GAAP } \\
\end{array}$ & $86 \%$ & $59 \%$ & 1.433 & 34 & 1.466 & $23 \%$ & 0 & 0 & 0 & 3.761 & 3.761 & 950 & 1.674 & 2.624 \\
\hline $\begin{array}{l}\text { Schering AG } \\
\text { IFRS }\end{array}$ & $88 \%$ & $54 \%$ & 944 & -24 & 921 & $36 \%$ & 0 & 0 & $\circ$ & 2.685 & 2.685 & 223 & 811 & 1.034 \\
\hline $\begin{array}{l}\text { Siemens AG } \\
\text { US-GAAP }\end{array}$ & $85 \%$ & $31 \%$ & 3.098 & 282 & 3.379 & $64 \%$ & 0 & 0 & 0 & 23.020 & 23.020 & 980 & 5.412 & 6.392 \\
\hline $\begin{array}{l}\text { ThyssenKrupp AG } \\
\text { US-GAAP }\end{array}$ & $105 \%$ & $25 \%$ & 765 & .238 & 528 & $111 \%$ & 0 & 3.841 & 0 & 2.790 & 2.790 & 257 & 399 & 656 \\
\hline $\begin{array}{l}\text { TUIAG } \\
\text { IFRS }\end{array}$ & $76 \%$ & $19 \%$ & 428 & -192 & 237 & $29 \%$ & 0 & 0 & 0 & 1.001 & 1.001 & 138 & 276 & 414 \\
\hline $\begin{array}{l}\text { Volkswagen AG } \\
\text { lifRS }\end{array}$ & $99 \%$ & $21 \%$ & 2.916 & -177 & 2.740 & $58 \%$ & 0 & 0 & 0 & 18.890 & 18.890 & 413 & 4.529 & 4.942 \\
\hline
\end{tabular}

"Ergebnisse des QST nach vollstandiger Ausschuttung der G G

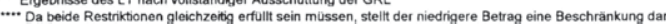




\begin{tabular}{|c|c|c|c|c|c|c|c|c|c|c|c|c|}
\hline \multirow{2}{*}{$\begin{array}{c}\text { Konzern } \\
\text { Rechnungslegungsvorschrift } \\
\text { Werte in Mio } €\end{array}$} & \multirow{2}{*}{$\begin{array}{c}\text { BS } \\
\text { Aktiva }\end{array}$} & \multicolumn{3}{|c|}{ Korrekturen Aktiva } & \multirow{2}{*}{$\begin{array}{c}\text { BS } \\
\text { Aktiva } \\
\text { korrigiert }\end{array}$} & \multirow{2}{*}{$\begin{array}{c}\text { BS } \\
\text { Passiva } \\
\text { ohne EK }\end{array}$} & \multicolumn{2}{|c|}{ Korrekturen Passiva } & \multirow{2}{*}{$\begin{array}{c}\text { BS } \\
\text { Passiva } \\
\text { korrigiert }\end{array}$} & \multirow{2}{*}{$\begin{array}{l}\text { Eigenkapital } \\
\text { It. Bilanz }\end{array}$} & \multirow{2}{*}{$\begin{array}{l}\text { Eigenkapital } \\
\text { korrigiert }\end{array}$} & \multirow{2}{*}{$\begin{array}{c}\text { GRL(KA) } \\
\text { (einschl. } \\
\text { Bilanzgewinn) }\end{array}$} \\
\hline & & $\begin{array}{l}\text { Goodwill/ } \\
\text { aktiv. Entwick- } \\
\text { lungskosten } \\
\end{array}$ & RAP & $\begin{array}{l}\text { Latente } \\
\text { Steuern }\end{array}$ & & & $\begin{array}{l}\text { Latente } \\
\text { Steuern }\end{array}$ & RAP & & & & \\
\hline $\begin{array}{l}\text { Adidas-Salomon AG } \\
\text { IFRS }\end{array}$ & 4.427 & 572 & 214 & 160 & 3.481 & 2.799 & 78 & 11 & 2.710 & 1.628 & 771 & 1.534 \\
\hline $\begin{array}{l}\text { Aitana AG } \\
\text { IFRS }\end{array}$ & 2.699 & 92 & 14 & 46 & 2.547 & 1.038 & 8 & 95 & 935 & 1.661 & 1.612 & 1.755 \\
\hline $\begin{array}{l}\text { BASF AG } \\
\text { IFRS }\end{array}$ & 33.916 & 1.829 & 172 & 1.211 & 30.704 & 18.483 & 453 & 351 & 17.679 & 15.433 & 13.025 & 12.253 \\
\hline $\begin{array}{l}\text { Bayer AG } \\
\text { IFRS }\end{array}$ & 37.804 & 1.877 & 167 & 1.235 & 34.525 & 25.536 & 1.247 & 644 & 23.645 & 12.268 & 10.880 & 9.356 \\
\hline $\begin{array}{l}\text { BMW } \\
\text { IFRS }\end{array}$ & 67.415 & 3.495 & 543 & 296 & 63.081 & 49.898 & 2.596 & 1.576 & 45.726 & 17.517 & 17.355 & 14.501 \\
\hline $\begin{array}{l}\text { Continental AG } \\
\text { US-GAAP }\end{array}$ & 9.684 & 1.425 & 0 & 162 & 8.097 & 6.842 & 217 & 0 & 6.625 & 2.842 & 1.472 & 1.567 \\
\hline $\begin{array}{l}\text { DaimlerChrysler AG } \\
\text { US-GAAP }\end{array}$ & 182.696 & 2.003 & 1.030 & 4.130 & 175.533 & 149.155 & 2.189 & 6.250 & 140.716 & 33.541 & 34.817 & 30.032 \\
\hline $\begin{array}{l}\text { Deutsche Börse AG } \\
\text { IFRS }\end{array}$ & 8.603 & 1.105 & 12 & 19 & 7.467 & 6.058 & 63 & 3 & 5.992 & 2.545 & 1.475 & 1.096 \\
\hline $\begin{array}{l}\text { Deutsche Lufthansa AG } \\
\text { IFRS }\end{array}$ & 18.070 & 685 & 82 & 166 & 17.137 & 14.096 & 285 & 164 & 13.647 & 3.974 & 3.490 & 1.386 \\
\hline $\begin{array}{l}\text { Deutsche Post AG } \\
\text { IFRS } \\
\end{array}$ & 153.357 & 5.856 & 853 & 764 & 145.884 & 146.140 & 927 & 487 & 144.726 & 7.217 & 1.158 & 4.451 \\
\hline $\begin{array}{l}\text { Deutsche Telekom AG } \\
\text { US-GAAP }\end{array}$ & 107.816 & 21.930 & 727 & 0 & 85.159 & 73.898 & 1.243 & 624 & 72.031 & 33.918 & 13.128 & -23.063 \\
\hline $\begin{array}{l}\text { E.ON AG } \\
\text { US-GAAP }\end{array}$ & 114.062 & 14.454 & 344 & 1.551 & 97.713 & 80.502 & 6.605 & 1.102 & 72.795 & 33.560 & 24.918 & 20.003 \\
\hline $\begin{array}{l}\text { Henkel KGaA } \\
\text { IFRS }\end{array}$ & 13.138 & 4.588 & 36 & 327 & 8.187 & 8.550 & 455 & 0 & 8.095 & 4.588 & 92 & 4.544 \\
\hline $\begin{array}{l}\text { Fresenius Medical Care AG (in Mio \$) } \\
\text { US-GAAP }\end{array}$ & 7.962 & 3.445 & 0 & 185 & 4.332 & 4.327 & 282 & 0 & 4.045 & 3.635 & 287 & 658 \\
\hline $\begin{array}{l}\text { Infineon Technologies AG } \\
\text { US-GAAP }\end{array}$ & 10.864 & 151 & 0 & 541 & 10.172 & 4.886 & 21 & 191 & 4.674 & 5.978 & 5.498 & -1.200 \\
\hline
\end{tabular}




\begin{tabular}{|c|c|c|c|c|c|c|c|c|c|c|c|c|}
\hline \multirow{2}{*}{$\begin{array}{c}\text { Konzern } \\
\text { Rechnungslegungsvorschrift } \\
\text { Werte in Mio } €\end{array}$} & \multirow{2}{*}{$\begin{array}{l}\text { BS } \\
\text { Aktiva }\end{array}$} & \multicolumn{3}{|c|}{ Korrekturen Aktiva } & \multirow{2}{*}{$\begin{array}{c}\text { BS } \\
\text { Aktiva } \\
\text { korrigiert }\end{array}$} & \multirow{2}{*}{\begin{tabular}{|c|} 
BS \\
Passiva \\
ohne EK
\end{tabular}} & \multicolumn{2}{|c|}{ Korrekturen Passiva } & \multirow{2}{*}{$\begin{array}{c}\text { BS } \\
\text { Passiva } \\
\text { korrigiert }\end{array}$} & \multirow{2}{*}{$\begin{array}{l}\text { Eigenkapital } \\
\text { It. Bilanz }\end{array}$} & \multirow{2}{*}{$\begin{array}{c}\text { Eigenkapital } \\
\text { korrigiert }\end{array}$} & \multirow{2}{*}{$\begin{array}{c}\text { GRL(KA) } \\
\text { (einschl. } \\
\text { Bilanzgewinn) }\end{array}$} \\
\hline & & $\begin{array}{c}\text { Goodwill' } \\
\text { aktiv. Entwick- } \\
\text { lungskosten } \\
\end{array}$ & RAP & $\begin{array}{l}\text { Latente } \\
\text { Steuern }\end{array}$ & & & $\begin{array}{l}\text { Latente } \\
\text { Steuern }\end{array}$ & RAP & & & & \\
\hline $\begin{array}{l}\text { Linde AG } \\
\text { IFRS }\end{array}$ & 11.591 & 3.045 & 35 & 123 & 8.388 & 7.548 & 294 & 203 & 7.051 & 4.043 & 1.337 & 1.238 \\
\hline $\begin{array}{l}\text { MAN AG } \\
\text { IFRS }\end{array}$ & 11.724 & 381 & 42 & 350 & 10.951 & 8.779 & 352 & 53 & 8.374 & 2.945 & 2.577 & 1.795 \\
\hline $\begin{array}{l}\text { Metro AG } \\
\text { IFRS }\end{array}$ & 28.092 & 3.932 & 188 & 1.527 & 22.445 & 23.353 & 509 & 115 & 22.729 & 4.739 & -284 & 1.353 \\
\hline $\begin{array}{l}\text { RWE AG } \\
\text { IFRS }\end{array}$ & 93.370 & 14.379 & 309 & 3.243 & 75.439 & 83.714 & 4.134 & 4.170 & 75.410 & 9.656 & 29 & 6.290 \\
\hline $\begin{array}{l}\text { SAP AG } \\
\text { US-GAAP }\end{array}$ & 7.585 & 457 & 70 & 206 & 6.852 & 2.991 & 64 & 325 & 2.602 & 4.594 & 4.250 & 4.830 \\
\hline \begin{tabular}{|l|} 
Schering AG \\
IFRS \\
\end{tabular} & 5.590 & 409 & 0 & 156 & 5.025 & 2.581 & 13 & 0 & 2.568 & 3.009 & 2.457 & 2.859 \\
\hline $\begin{array}{l}\text { Siemens AG } \\
\text { US-GAAP }\end{array}$ & 79.518 & 6.476 & 0 & 4.811 & 68.231 & 52.663 & 2.091 & 999 & 49.573 & 26.855 & 18.658 & 25.477 \\
\hline $\begin{array}{l}\text { ThyssenKrupp AG } \\
\text { US-GAAP } \\
\end{array}$ & 31.141 & 3.176 & 220 & 1.148 & 26.597 & 22.814 & 977 & 183 & 21.654 & 8.327 & 4.943 & 3.478 \\
\hline \begin{tabular}{|l|} 
TUI AG \\
IFRS \\
\end{tabular} & 12.319 & 3.763 & 251 & 233 & 8.072 & 9.566 & 223 & 55 & 9.288 & 2.753 & -1.216 & 1.294 \\
\hline $\begin{array}{l}\text { Volkswagen AG } \\
\text { IFRS }\end{array}$ & 126.972 & 5.421 & 0 & 2.056 & 119.495 & 103.107 & 2.251 & 0 & 100.856 & 23.865 & 18.639 & 18.325 \\
\hline
\end{tabular}




\begin{tabular}{|c|c|c|c|c|c|c|c|c|c|c|c|}
\hline \multirow{2}{*}{$\begin{array}{c}\text { Konzern } \\
\text { Rechnungslegungsvorschrift } \\
\text { Werte in Mio } €\end{array}$} & \multirow{2}{*}{$\begin{array}{l}\text { UV } \\
\text { kurzfr. }\end{array}$} & \multicolumn{2}{|c|}{ kurzfr. Verbindlichkeiten } & \multirow{2}{*}{$\begin{array}{c}\text { Kurzfr.Verb. } \\
\text { gesamt }\end{array}$} & \multirow{2}{*}{$\begin{array}{l}\text { EBIT } \\
2004\end{array}$} & \multirow{2}{*}{$\begin{array}{l}\text { EBIT } \\
2003\end{array}$} & \multirow{2}{*}{\begin{tabular}{|c|} 
EBIT \\
Durchschnitt
\end{tabular}} & \multirow{2}{*}{\begin{tabular}{|c|}
$\begin{array}{c}\text { Zins- } \\
\text { ergebnis } \\
2004\end{array}$ \\
\end{tabular}} & \multirow{2}{*}{$\begin{array}{l}\text { Zins- } \\
\text { ergebnis } \\
2003\end{array}$} & \multirow{2}{*}{$\begin{array}{c}\text { Zins- } \\
\text { ergebnis } \\
\text { Durchschnitt }\end{array}$} & \multirow{2}{*}{$\begin{array}{l}\text { GWV } \\
\text { It. EA }\end{array}$} \\
\hline & & Verb. & $\begin{array}{c}\text { sonstige } \\
\text { RST }\end{array}$ & & & & & & & & \\
\hline $\begin{array}{l}\text { Adidas-Salomon AG } \\
\text { IFRS }\end{array}$ & 3.035 & 776 & 725 & 1.501 & 578 & 486 & 532 & -58 & -59 & -59 & 60 \\
\hline \begin{tabular}{|l|} 
Altana AG \\
IFRS \\
\end{tabular} & 1.651 & 455 & 186 & 641 & 617 & 568 & 593 & 9 & 13 & 11 & 133 \\
\hline \begin{tabular}{|l|} 
BASF AG \\
IFRS \\
\end{tabular} & 15.010 & 5.413 & 2.592 & 8.005 & 4.856 & 2.391 & 3.624 & -228 & -223 & -226 & 919 \\
\hline \begin{tabular}{|l} 
Bayer AG \\
IFRS \\
\end{tabular} & 19.547 & 6.674 & 2.969 & 9.643 & 1.808 & -1.641 & 84 & -275 & -353 & -314 & 402 \\
\hline $\begin{array}{l}\text { BMW (IFRS) } \\
\text { IFRS }\end{array}$ & 43.823 & 20.224 & 3.772 & 23.996 & 3.841 & 3.486 & 3.664 & -287 & -281 & -284 & 419 \\
\hline $\begin{array}{l}\text { Continental AG } \\
\text { US-GAAP } \\
\end{array}$ & 4.508 & 2.416 & 810 & 3.226 & 1.097 & 855 & 976 & -103 & -133 & -118 & 116 \\
\hline $\begin{array}{l}\text { DaimlerChrysler AG } \\
\text { US-GAAP }\end{array}$ & 67.593 & 55.031 & 18.649 & 73.680 & 3.835 & 986 & 2.411 & -300 & -390 & -345 & 1.519 \\
\hline $\begin{array}{l}\begin{array}{l}\text { Deutsche Börse AG } \\
\text { IFRS }\end{array} \\
\text { FR }\end{array}$ & 6.440 & 5.232 & 111 & 5.343 & 459 & 453 & 456 & -7 & -5 & -6 & 227 \\
\hline $\begin{array}{l}\text { Deutsche Lufthansa AG } \\
\text { IFRS }\end{array}$ & 6.588 & 2.618 & 3.488 & 6.106 & 922 & -444 & 239 & -331 & -341 & -336 & 137 \\
\hline $\begin{array}{l}\text { Deutsche Post AG } \\
\text { IFRS }\end{array}$ & 136.565 & 92.860 & 1.719 & 94.579 & 2.977 & 2.646 & 2.812 & -821 & -731 & -776 & 445 \\
\hline $\begin{array}{l}\text { Deutsche Telekom AG } \\
\text { US-GAAP }\end{array}$ & 16.652 & 17.230 & 12.250 & 29.480 & 9.892 & 5.174 & 7.533 & -3.351 & -3.776 & -3.564 & 2.602 \\
\hline $\begin{array}{l}\text { E.ON AG } \\
\text { US-GAAP }\end{array}$ & 25.839 & 15.746 & 6.511 & 22.257 & 7.361 & 6.878 & 7.120 & -1.141 & -1.107 & -1.124 & 1.549 \\
\hline $\begin{array}{l}\begin{array}{l}\text { Henkel KG aA } \\
\text { IFRS }\end{array} \\
\end{array}$ & 5.411 & 3.249 & 1.513 & 4.762 & 800 & 706 & 753 & -163 & -140 & -152 & 185 \\
\hline $\begin{array}{l}\text { Fresenius Medical Care AG } \\
\text { (in Mio \$) US-GAAP }\end{array}$ & 2.446 & 1.938 & 0 & 1.938 & 852 & 757 & 805 & -184 & -212 & -198 & 56 \\
\hline $\begin{array}{l}\text { Infineon Technologies AG } \\
\text { US-GAAP }\end{array}$ & 5.376 & 2.315 & 555 & 2.870 & 256 & -299 & -22 & -41 & -52 & -47 & 0 \\
\hline
\end{tabular}




\begin{tabular}{|c|c|c|c|c|c|c|c|c|c|c|c|}
\hline \multirow{2}{*}{$\begin{array}{c}\text { Konzern } \\
\text { Rechnungslegungsvorschrift } \\
\text { Werte in Mio } €\end{array}$} & \multirow{2}{*}{$\begin{array}{l}\text { UV } \\
\text { kurzfr. }\end{array}$} & \multicolumn{2}{|c|}{ kurzfr. Verbindlichkeiten } & \multirow{2}{*}{$\begin{array}{c}\text { Kurzfr.Verb. } \\
\text { gesamt }\end{array}$} & \multirow{2}{*}{$\begin{array}{l}\text { EBIT } \\
2004\end{array}$} & \multirow{2}{*}{$\begin{array}{l}\text { EBIT } \\
2003\end{array}$} & \multirow{2}{*}{\begin{tabular}{|c|} 
EBIT \\
Durchschnitt
\end{tabular}} & \multirow{2}{*}{$\begin{array}{c}\text { Zins- } \\
\text { ergebnis } \\
2004\end{array}$} & \multirow{2}{*}{$\begin{array}{l}\text { Zins- } \\
\text { ergebnis } \\
2003\end{array}$} & \multirow{2}{*}{$\begin{array}{c}\text { Zins- } \\
\text { ergebnis } \\
\text { Durchschnitt }\end{array}$} & \multirow[t]{2}{*}{$\begin{array}{l}\text { GVV } \\
\text { It. EA }\end{array}$} \\
\hline & & Verb. & $\begin{array}{c}\text { sonstige } \\
\text { RST }\end{array}$ & & & & & & & & \\
\hline $\begin{array}{l}\text { Linde AG } \\
\text { IFRS }\end{array}$ & 3.595 & 2.375 & 1.107 & 3.482 & 644 & 417 & 531 & -129 & -130 & -130 & 149 \\
\hline $\begin{array}{l}\text { MAN AG } \\
\text { IFRS }\end{array}$ & 4.513 & 3.055 & 1.217 & 4.272 & 624 & 477 & 551 & -171 & -174 & -173 & 154 \\
\hline $\begin{array}{l}\text { Metro AG } \\
\text { IFRS }\end{array}$ & 11.059 & 14.247 & 310 & 14.557 & 1.809 & 1.242 & 1.526 & -484 & -425 & -455 & 334 \\
\hline $\begin{array}{l}\text { RWE AG } \\
\text { IFRS }\end{array}$ & 29.145 & 14.707 & 7.779 & 22.486 & 5.976 & 5.346 & 5.661 & -1.130 & -1.131 & -1.131 & 844 \\
\hline $\begin{array}{l}\text { SAP AG } \\
\text { US-GAAP }\end{array}$ & 5.685 & 695 & 1.589 & 2.284 & 2.017 & 1.733 & 1.875 & 56 & 43 & 50 & 342 \\
\hline $\begin{array}{l}\text { Schering AG } \\
\text { IFRS }\end{array}$ & 3.179 & 562 & 713 & 1.275 & 686 & 720 & 703 & -15 & -22 & -19 & 194 \\
\hline $\begin{array}{l}\text { Siemens AG } \\
\text { US-GAAP }\end{array}$ & 45.946 & 24.132 & 9.240 & 33.372 & 3.794 & 3.067 & 3.431 & 272 & 245 & 259 & 1.114 \\
\hline $\begin{array}{l}\text { ThyssenKrupp AG } \\
\text { US-GAAP }\end{array}$ & 14.406 & 6.860 & 2.859 & 9.719 & 1.798 & 855 & 1.327 & -218 & -191 & -205 & 299 \\
\hline \begin{tabular}{|l|} 
TUI AG \\
IFRS \\
\end{tabular} & 2.561 & 3.899 & 665 & 4.564 & 817 & 399 & 608 & -196 & -153 & -175 & 138 \\
\hline $\begin{array}{l}\text { Volkswagen AG } \\
\text { IFRS }\end{array}$ & 55.391 & 42.679 & 5.990 & 48.669 & 1.187 & 1.381 & 1.284 & 88 & 125 & 107 & 409 \\
\hline
\end{tabular}




\begin{tabular}{|c|c|c|c|c|c|c|c|c|c|c|c|c|c|c|}
\hline $\begin{array}{c}\text { Konzern } \\
\text { (Rechnungslegungs- } \\
\text { vorschrift) }\end{array}$ & QST & $\begin{array}{l}\text { EK/BS } \\
\text { (KA) }\end{array}$ & \begin{tabular}{|c|} 
EBIT \\
Durchschnitt \\
(2 Jahre) \\
Mio $\epsilon$ \\
\end{tabular} & \begin{tabular}{|c|} 
Zinssaldo \\
Durchschnitt \\
(2 Jahre) \\
Mio $€$ \\
\end{tabular} & \begin{tabular}{|c|} 
EBIT \\
abzgil. \\
Zinssaldo** \\
Mio $\epsilon$
\end{tabular} & LT"** & \begin{tabular}{|c} 
Maximala \\
QST \\
Mio $\epsilon$ \\
\end{tabular} & $\begin{array}{c}\text { chüttung } \\
\text { LT } \\
\text { Mio } \epsilon\end{array}$ & \begin{tabular}{|c|}
$\begin{array}{c}\text { (max) } \\
\$ 500(\mathrm{~b}) \\
\text { Cal.Corp.Code } \\
\text { Mio } €\end{array}$ \\
\end{tabular} & $\begin{array}{l}\text { GRL(KA) } \\
\text { Mio } \epsilon\end{array}$ & \begin{tabular}{|c|}
$\begin{array}{c}A(\max ) \\
\text { Cal.Corp.Code } \\
\text { Mio } €\end{array}$ \\
\end{tabular} & $\begin{array}{l}\text { BG (EA) } \\
\text { Mio } \epsilon\end{array}$ & $\begin{array}{c}\text { GRL (EA) } \\
\text { Mio } \epsilon \\
\end{array}$ & $\begin{array}{c}A(\max ) \\
\text { KapRL } \\
\text { Mio } \epsilon\end{array}$ \\
\hline $\begin{array}{l}\begin{array}{l}\text { Adidas-Salomon AG } \\
\text { IFRS }\end{array} \\
\end{array}$ & $72 \%$ & $37 \%$ & 503 & -59 & 444 & $100 \%$ & 0 & 0 & 0 & 1.534 & 1.534 & 69 & 1.237 & 1.306 \\
\hline $\begin{array}{l}\text { Altana AG } \\
\text { IFRS } \\
\end{array}$ & $85 \%$ & $62 \%$ & 593 & 11 & 604 & $-16 \%$ & 0 & 0 & 0 & 1.755 & 1.755 & 133 & 1.668 & 1.801 \\
\hline $\begin{array}{l}\text { BASF AG } \\
\text { IFRS } \\
\end{array}$ & $104 \%$ & $46 \%$ & 3.462 & -226 & 3.236 & $34 \%$ & 0 & 0 & 0 & 12.253 & 12.253 & 919 & 6.033 & 6.952 \\
\hline \begin{tabular}{|l|} 
Bayer AG \\
IFRS \\
\end{tabular} & $106 \%$ & $32 \%$ & 84 & -314 & -230 & $51 \%$ & 0 & 0 & 0 & 9.356 & 9.356 & 402 & 2.326 & 2.728 \\
\hline \begin{tabular}{|l|} 
BMW (IFRS) \\
IFRS \\
\end{tabular} & $106 \%$ & $26 \%$ & 3.664 & -284 & 3.380 & $122 \%$ & 0 & 19.827 & 0 & 14.501 & 14.501 & 419 & 2.545 & 2.964 \\
\hline \begin{tabular}{|l|} 
Continental AG \\
US-GAAP \\
\end{tabular} & $99 \%$ & $29 \%$ & 976 & -118 & 858 & $91 \%$ & 0 & 0 & 0 & 1.567 & 1.567 & 117 & 46 & 163 \\
\hline $\begin{array}{l}\text { DaimlerChrysler AG } \\
\text { US-GAAP } \\
\end{array}$ & $103 \%$ & $18 \%$ & 2.411 & -345 & 2.066 & $51 \%$ & 0 & 0 & 0 & 30.032 & 30.032 & 1.519 & 4.257 & 5.776 \\
\hline \begin{tabular}{|l|} 
Deutsche Börse AG \\
IFRS \\
\end{tabular} & $106 \%$ & $30 \%$ & 456 & -6 & 450 & $100 \%$ & 0 & 1.097 & 0 & 1.096 & 1.096 & 227 & 448 & 675 \\
\hline $\begin{array}{l}\begin{array}{l}\text { Deutsche Lufthansa AG } \\
\text { IFRS }\end{array} \\
\end{array}$ & $115 \%$ & $22 \%$ & 239 & -336 & -97 & $85 \%$ & 0 & 0 & 0 & 1.386 & 1.386 & 137 & 530 & 667 \\
\hline $\begin{array}{l}\text { Deutsche Post AG } \\
\text { IFRS }\end{array}$ & $98 \%$ & $5 \%$ & 2.812 & -776 & 2.036 & $140 \%$ & 0 & 41.986 & 0 & 4.451 & 4.451 & 1.301 & 4.735 & 6.036 \\
\hline $\begin{array}{l}\text { Deutsche Telekom AG } \\
\text { US-GAAP } \\
\end{array}$ & $118 \%$ & $31 \%$ & 7.533 & -3.564 & 3.969 & $56 \%$ & 0 & 0 & 0 & -23.063 & 0 & 2.881 & 11.116 & 13.997 \\
\hline \begin{tabular}{|l} 
E.ON AG \\
US-GAAP \\
\end{tabular} & $107 \%$ & $29 \%$ & 7.120 & -1.124 & 5.996 & $26 \%$ & 0 & 0 & 0 & 20.003 & 20.003 & 1.549 & 3.852 & 5.401 \\
\hline \begin{tabular}{|l|} 
Henkel KG aA \\
IFRS \\
\end{tabular} & $45 \%$ & $35 \%$ & 753 & -152 & 601 & $18 \%$ & 0 & 0 & 0 & 4.544 & 4.544 & 185 & 2.839 & 3.024 \\
\hline $\begin{array}{l}\text { Fresenius Medical Care AG } \\
\text { (in Mio S) US-GAAP }\end{array}$ & $91 \%$ & $46 \%$ & 805 & -198 & 607 & $145 \%$ & 0 & 1.942 & 0 & 658 & 658 & 56 & 387 & 443 \\
\hline $\begin{array}{l}\text { Infineon Technologies AG } \\
\text { US-GAAP }\end{array}$ & $164 \%$ & $35 \%$ & -22 & -47 & -69 & $187 \%$ & 4.330 & 1.789 & 1.789 & -1.200 & 589 & -1.209 & 32 & 0 \\
\hline
\end{tabular}

"Ergebnisse des QST nach vollständiger Ausschüttung der GRL

- Ist die Größe negativ gilt die verschärtte Restriktion des LT.

.... Da beide Restriktionen gleichzeitig erfült sein müssen, stellt der niedrigere Betrag eine Beschränkung dar. 


\begin{tabular}{|c|c|c|c|c|c|c|c|c|c|c|c|c|c|c|}
\hline $\begin{array}{c}\text { Konzern } \\
\text { (Rechnungslegungs- } \\
\text { vorschrift) }\end{array}$ & QST* $^{*}$ & $\begin{array}{c}\text { EK/BS } \\
\text { (KA) }\end{array}$ & $\begin{array}{c}\text { EBIT } \\
\text { Durchschnitt } \\
\text { (2 Jahre) } \\
\text { Mio } €\end{array}$ & \begin{tabular}{|c|} 
Zinssaldo \\
Durchschnitt \\
(2 Jahre) \\
Mio $€$
\end{tabular} & \begin{tabular}{|c|} 
EBIT \\
abzgl. \\
Zinssaldo** \\
Mio $€$
\end{tabular} & LTW & $\begin{array}{l}\frac{\text { Maximala }}{\text { QST }} \\
\text { Mio } \epsilon\end{array}$ & $\begin{array}{c}\text { hü̈ttung } \\
\text { LT } \\
\text { Mio } €\end{array}$ & \begin{tabular}{c|} 
A (max) \\
$\S 500(b)$ \\
Cal.Corp.Code $\cdots \cdots$ \\
Mio $€$
\end{tabular} & $\begin{array}{c}\text { GRL(KA) } \\
\text { Mio } \epsilon \\
\end{array}$ & $\begin{array}{c}A(\max ) \\
\text { Cal.Corp.Code } \\
\text { Mio } \epsilon \\
\end{array}$ & $\begin{array}{l}\text { BG (EA) } \\
\text { Mio } \epsilon\end{array}$ & $\begin{array}{c}\text { GRL (EA) } \\
\text { Mio } \epsilon \\
\end{array}$ & $\begin{array}{l}A(\max ) \\
\text { KapRL } \\
\text { Mio } \epsilon\end{array}$ \\
\hline $\begin{array}{l}\text { Linde AG } \\
\text { IFRS }\end{array}$ & $101 \%$ & $35 \%$ & 531 & -130 & 401 & $68 \%$ & 0 & 0 & 0 & 1.283 & 1.283 & 149 & 510 & 659 \\
\hline $\begin{array}{l}\begin{array}{l}\text { MAN AG } \\
\text { IFRS }\end{array} \\
\end{array}$ & $109 \%$ & $25 \%$ & 551 & -173 & 378 & $64 \%$ & 0 & 0 & 0 & 1.795 & 1.795 & 154 & 437 & 591 \\
\hline $\begin{array}{l}\text { Metro AG } \\
\text { IFRS }\end{array}$ & $93 \%$ & $17 \%$ & 1.526 & -455 & 1.071 & $67 \%$ & 0 & 0 & 0 & 1.353 & 1.353 & 356 & 884 & 1.240 \\
\hline $\begin{array}{l}\text { RWE AG } \\
\text { IFRS }\end{array}$ & $92 \%$ & $10 \%$ & 5.661 & -1.131 & 4.530 & $102 \%$ & 0 & 6.659 & 0 & 6.290 & 6.290 & 844 & 1.409 & 2.253 \\
\hline $\begin{array}{l}\text { SAP AG } \\
\text { US-GAAP }\end{array}$ & $78 \%$ & $61 \%$ & 1.875 & 50 & 1.925 & $37 \%$ & 0 & 0 & 0 & 4.830 & 4.830 & 1.351 & 1.782 & 3.133 \\
\hline $\begin{array}{l}\text { Schering AG } \\
\text { IFRS }\end{array}$ & $84 \%$ & $54 \%$ & 703 & -19 & 684 & $25 \%$ & 0 & 0 & 0 & 2.859 & 2.859 & 194 & 884 & 1.078 \\
\hline $\begin{array}{l}\text { Siemens AG } \\
\text { US-GAAP }\end{array}$ & $86 \%$ & $34 \%$ & 3.431 & 259 & 3.690 & $61 \%$ & 0 & 0 & 0 & 25.447 & 25.447 & 1.114 & 6.481 & 7.595 \\
\hline $\begin{array}{l}\text { ThyssenKrupp AG } \\
\text { US-GAAP }\end{array}$ & $107 \%$ & $27 \%$ & 1.327 & -205 & 1.122 & $112 \%$ & 0 & 4.687 & 0 & 3.478 & 3.478 & 309 & 400 & 709 \\
\hline \begin{tabular}{|l|} 
TUIAG \\
IFRS \\
\end{tabular} & $73 \%$ & $22 \%$ & 608 & -175 & 433 & $28 \%$ & 0 & 0 & 0 & 1.294 & 1.294 & 138 & 276 & 414 \\
\hline $\begin{array}{l}\text { Volkswagen AG } \\
\text { IFRS }\end{array}$ & $100 \%$ & $19 \%$ & 1.284 & 107 & 1.391 & $76 \%$ & 0 & 0 & 0 & 18.325 & 18.325 & 419 & 4.819 & 5.238 \\
\hline
\end{tabular}

- Ergebnisse des QST nach vollständiger Ausschüttung der GRL

* Ist die Größe negativ gilt die verschärfte Restriktion des LT.

.... Dabisse des LT nach volsther 


\section{Literaturverzeichnis}

Ackerman, Thomas C./Sterrett, James K. (1976), California's New Approach to Dividends and Reacquisitions of Shares, in: UCLA L. Rev., Vol. 23, S. 1052-1093.

Adams, Michael (1994), Die Usurpation von Aktionärsbefugnissen mittels Ringverflechtung in der „Deutschland AG“, in: AG, 39. Jg., S. 148-158.

Adams, Michael (2004), Das Ende der Mitbestimmung, in: WiSt, 33. Jg., S. 693.

Adler, Hans/Düring, Walther/Schmaltz, Kurt (1995), Rechnungslegung und Prüfung der Unternehmen. Teilband 1, 6. Aufl., Stuttgart.

Adler, Hans/Düring, Walther/Schmaltz, Kurt (1997a), Rechnungslegung und Prüfung der Unternehmen. Teilband 4, 6. Aufl., Stuttgart.

Adler, Hans/Düring, Walther/Schmaltz, Kurt (1997b), Rechnungslegung und Prüfung der Unternehmen. Teilband 5, 6. Aufl., Stuttgart.

Adler, Hans/Düring, Walther/Schmaltz, Kurt (1998), Rechnungslegung und Prüfung der Unternehmen. Teilband 6, 6. Aufl., Stuttgart.

Akerlof, George A. (1970), The Market for „Lemons“: Quality Uncertainty and the Market Mechanism, in: QJE, Vol. 84, S. 488-500.

AKEU (2001), Arbeitskreis Externe Unternehmensrechnung der Schmalenbach-Gesellschaft für Betriebswirtschaft, Die Zukunft der Rechnungslegung aus Sicht von Wissenschaft und Praxis - Fachprogramm des Arbeitskreises Externe Unternehmensrechnung im Rahmen des 54. Deutschen Betriebswirtschafter-Tags, in: DB, 54. Jg., S. 160-161.

AKEU (2003), Arbeitskreis Externe Unternehmensrechnung der Schmalenbach-Gesellschaft für Betriebswirtschaft, International Financial Reporting Standards im Einzel- und Konzernabschluss unter der Prämisse eines Einheitsabschlusses für unter Anderem steuerliche Zwecke - Empfehlungen des Arbeitskreises, in: DB, 56. Jg., S. 1585-1588.

Albach, Horst/Corte, Christiane/Friedewald, Rolf/Lutter, Marcus/Richter, Wolf (1988), Deregulierung des Aktienrechts: Das Drei-Stufen-Modell, Gütersloh.

Alberth, Markus R. (1997), USA: Vertraglicher Gläubigerschutz und Ausschüttungsbemessung durch Covenants als Vorbild zur Änderung des deutschen Bilanzrechts, in: WPg, 50. Jg., S. 744-750.

Alberth, Markus R. (1998), US-amerikanische Gläubigerbilanzen durch Covenants in Verträgen, der Versuch einer weltweiten Kategorisierung der Rechnungslegung und Folgen für die internationale Harmonisierungsdiskussion, in: ZfB, 68. Jg., S. 803-824.

American Bar Foundation (1986), Commentaries on Model Debenture Indenture Provisions, Buffalo.

Anderson, Andrew B. III (1976), California's New General Corporation Law: Dividends and Reacquisitions of Shares, in: Pac. L.J., Vol. 7, S. 645-672.

Ankele, Jörg (1970), Zum Vorschlag der Kommission der Europäischen Gemeinschaften für eine Zweite gesellschaftsrechtliche Richtlinie, in: BB, 25. Jg., S. 988-992. 
Arbeitsgruppe Europäisches Gesellschaftsrecht (2002), Zur Entwicklung des Europäischen Gesellschaftsrechts: Stellungnahme der Group of German Experts on Corporate Law zum Konsultationsdokument der High Level Group of Experts on Corporate Law, in: ZIP, 23. Jg., S. 1310-1324.

Arbeitsgruppe Europäisches Gesellschaftsrecht (2003), Zur Entwicklung des Europäischen Gesellschaftsrechts: Stellungnahme der Arbeitsgruppe Europäisches Gesellschaftsrecht (Group of German Experts on Corporate Law) zum Report of the High Level Group of Company Law Experts on a modern Regulatory Framework for Company Law in Europe, in: ZIP, 24. Jg., S. 863-880.

Arbeitskreis Bilanzrecht der Hochschullehrer Rechtswissenschaft (2002), Zur Fortentwicklung des deutschen Bilanzrechts, in: BB, 57. Jg., S. 2372-2381.

Arbeitskreis Bilanzrecht der Hochschullehrer Rechtswissenschaft (2004), Stellungnahme zum Referentenentwurf eines Bilanzrechtsreformgesetzes, in: BB, 59. Jg., S. 546-548.

Armour, John (2000a), Chapter 6: Capital Maintenance, in: http://www.dti.gov.uk/cld/esrc6. pdf (Stand: 31.01.2005).

Armour, John (2000b), Share Capital and Creditor Protection: Efficient Rules for a Modern Company Law, in: Mod. L. Rev., Vol. 63, S. 355-378.

Assmann, Heinz-Dieter (1992), Einl., in: Großkommentar Aktiengesetz, hrsg. von Hopt, Klaus J./Wiedemann, Herbert, 4. Aufl., Berlin.

Assmann, Heinz-Dieter (2003), Corporate Governance im Schnittfeld von Gesellschaftsrecht und Kapitalmarktrecht, in: Bankrecht und Kapitalmarktrecht in der Entwicklung, Festschrift für Siegfried Kümpel, hrsg. von Ekkenga, Jens/Hadding, Walther/Hammen, Horst, Berlin, S. 1-17.

Augustin, Reinhard R. (1994), Ausschüttungspolitik deutscher und amerikanischer börsennotierter Unternehmen, in: RIW, 40. Jg., S. 659-662.

Bachmann, Gregor (2001), Grundtendenzen der Reform geschlossener Gesellschaften in Europa. Dargestellt am Beispiel des britischen Reformprozesses und der Europäischen Privatgesellschaft, in: ZGR, 30. Jg., S. 351-384.

Baetge, Jörg (2002), Grundsätze ordnungsmäßiger Buchführung, in: Handwörterbuch Unternehmensrechnung und Controlling, hrsg. von Küpper, Hans-Ulrich/Wagenhofer, Alfred, 4. Aufl., Stuttgart, Sp. 635-647.

Baetge, Jörg (2003), Meinungsspiegel, in: BFuP, 55. Jg., S. 480-490.

Baetge, Jörg (2005), Januskopf: DCF-Verfahren in der Unternehmensbewertung und in der Bilanzierung, in: BB-Special 7/2005, 60. Jg., S. 1.

Baetge, Jörg/Kirsch, Hans-Jürgen (1995), Grundsätze ordnungsmäßiger Buchführung, in: Handbuch der Rechnungslegung. Band Ia, hrsg. von Küting, Karlheinz/Weber, ClausPeter, 4. Aufl., Stuttgart, S. 135-173.

Baetge, Jörg/Kirsch, Hans-Jürgen/Thiele, Stefan (2005), Bilanzen, 8. Aufl., Düsseldorf.

Baetge, Jörg/Kirsch, Hans-Jürgen/Thiele, Stefan (2004a), Bilanzanalyse, 2. Aufl., Düsseldorf. 
Baetge, Jörg/Kirsch, Hans-Jürgen/Thiele, Stefan (2004b), Konzernbilanzen, 7. Aufl., Düsseldorf.

Baetge, Jörg/Niemeyer, Kai/Kümmel, Jens (2005), Darstellung der Discounted-CashflowVerfahren (DCF-Verfahren) mit Beispiel, in: Praxishandbuch der Unternehmensbewertung, hrsg. von Peemöller, Volker H., 3. Aufl., Herne/Berlin, S. 265-362.

Baetge, Jörg/Thiele, Stefan (1997), Gesellschafterschutz versus Gläubigerschutz - Rechenschaft versus Kapitalerhaltung, in: Handelsbilanzen und Steuerbilanzen: Festschrift zum 70. Geburtstag von Prof. Dr. h.c. Heinrich Beisse, hrsg. von Budde, Wolfgang D./Moxter, Adolf/Offerhaus, Klaus, Düsseldorf, S. 11-24.

Baetge, Jörg/Zülch, Henning (2001), Fair Value-Accounting, in: BFuP, 53. Jg., S. 543-562.

Bäuml, Sven O./Gageur, Patrick (2005), Die GmbH alter Prägung als Auslaufmodell? Bundesregierung reagiert mit einer Reform des GmbH-Gesetzes auf den Wettbewerb zwischen Ltd. und GmbH -, in: StuB, 7. Jg., S. 477-483.

BaFin (2006), Angezeigte Ermächtigungen der Hauptversammlung (HV) zum Erwerb eigener Aktien, in: http://www.bafin.de/datenbanken/wa_hv_export.htm (Stand: 05.06.2006).

Bainbridge, Stephen M. (2002), Corporation Law and Economics, New York.

Baker, Ralph J./Cary, William L. (1959), Cases and Materials on Corporations, 3. Aufl., Brooklyn.

Bald, Ernst-Joachim/Blanik, Karl/Determann, Michael/Hien, Heinz M./Knauth, KlausWilhelm/Wachsmuth, Michael/Wickenkamp, Rolf/Wildhagen, Jürgen (2000), Leitfaden für die Vergabe von Unternehmenskrediten - Schuldscheindarlehen - (Kreditleitfaden), 3. Aufl., Karlsruhe.

Baldamus, Ernst-August (2002), Reform der Kapitalrichtlinie, Köln u.a.

Ballantine, Henry W. (1946), Ballantine on Corporations, Chicago.

Ballantine, Henry W./Hills, George S. (1935), Corporate Capital and Restrictions upon Dividends under Modern Corporation Laws, in: Cal. L. Rev., Vol. 23, S. 229-263.

Ballantine, Henry W./Sterling, Graham L. (2004), California Corporation Law, 4. Aufl., Newark (Stand: Release No. 87, May 2004).

Ballerstedt, Kurt (1971), Gesellschaftsrechtliche Probleme der Reform des GmbH-Rechts, in: ZHR, 135. Jg., S. 383-409.

Ballwieser, Wolfgang (1987), Die Analyse von Jahresabschlüssen nach neuem Recht, in: WPg, 40. Jg., S. 57-68.

Ballwieser, Wolfgang (1990), Ist das Maßgeblichkeitsprinzip überholt?, in: BFuP, 42. Jg., S. 477-498.

Ballwieser, Wolfgang (1994), Adolf Moxter und der Shareholder Value-Ansatz, in: Bilanzrecht und Kapitalmarkt, Festschrift zum 65. Geburtstag von Prof. Dr. Dr. h.c. Dr. h.c. Adolf Moxter, hrsg. von Ballwieser, Wolfgang/Böcking, Hans-Joachim/Drukarczyk, Jochen/Schmidt, Reinhard H., Düsseldorf, S. 1379-1405. 
Ballwieser, Wolfgang (1995), Zur Frage der Rechtsform-, Konzern- und Branchenunabhängigkeit der Grundsätze ordnungsmäßiger Buchführung, in: Rechenschaftslegung im Wandel, Festschrift für Wolfgang Dieter Budde, hrsg. von Förschle, Gerhart/Kaiser, Klaus/Moxter, Adolf, München, S. 43-66.

Ballwieser, Wolfgang (1996), Zum Nutzen handelsrechtlicher Rechnungslegung, in: Rechnungslegung - warum und wie, Festschrift für Hermann Clemm zum 70. Geburtstag, hrsg. von Ballwieser, Wolfgang/Moxter, Adolf/Nonnenmacher, Rolf, München, S. 1-25.

Ballwieser, Wolfgang (2001a), Vor $\S 238$ HGB, in: Münchener Kommentar zum Handelsgesetzbuch, Band 4, hrsg. von Schmidt, Karsten, München.

Ballwieser, Wolfgang (2001b), § 243 HGB, in: Münchener Kommentar zum Handelsgesetzbuch, Band 4, hrsg. von Schmidt, Karsten, München.

Ballwieser, Wolfgang (2001c), § $246 \mathrm{HGB}$, in: Münchener Kommentar zum Handelsgesetzbuch, Band 4, hrsg. von Schmidt, Karsten, München.

Ballwieser, Wolfgang (2001d), § 252 HGB, in: Münchener Kommentar zum Handelsgesetzbuch, Band 4, hrsg. von Schmidt, Karsten, München.

Ballwieser, Wolfgang (2001e), Anforderungen des Kapitalmarkts an Bilanzansatz- und Bilanzbewertungsregeln, in: KoR, 1. Jg., S. 160-164.

Ballwieser, Wolfgang (2003), Enron und die Folgen für die Jahresabschlussprüfung, in: Wirtschaftsprüfer Jahrbuch 2003, hrsg. vom Institut Österreichischer Wirtschaftsprüfer, Wien, S. 9-19.

Ballwieser, Wolfgang (2004), Unternehmensbewertung, Stuttgart.

Ballwieser, Wolfgang/Küting, Karlheinz/Schildbach, Thomas (2004), Fair value - erstrebenswerter Wertansatz im Rahmen einer Reform der handelsrechtlichen Rechnungslegung?, in: BFuP, 56. Jg., S. 529-549.

Balotti, R. Franklin/Finkelstein, Jesse A. (2004), The Delaware Law of Corporations \& Business Organizations. Statutory Deskbook, New York.

Barta, Sebastian (2005), Das Kapitalsystem von GmbH und AG - Inhalt und Zweck der Regelungen über Stamm- bzw. Grundkapital. Zugleich Anmerkungen zum Referentenentwurf eines „Gesetzes zur Neuregelung des Mindestkapitals der GmbH (MindestKapG)“, in: GmbHR, 96. Jg., S. 657-662.

Barton, Alan J. (1975), A Brief Look at the New California General Corporation Law, in: L.A.B.J., Vol. 51, S. 210-220.

Bauer, Markus (1995), Gläubigerschutz durch eine formelle Nennkapitalziffer - Kapitalgesellschaftsrechtliche Notwendigkeit oder überholtes Konzept?, Frankfurt am Main u.a.

Baumann, Jeffrey D./Weiss, Elliott J./Palmiter, Alan R. (2003), Corporations. Law and Policy. Materials and Problems, 5. Aufl., St. Paul.

Baums, Theodor (Hrsg.) (2001), Bericht der Regierungskommission Corporate Governance. Unternehmensführung, Unternehmenskontrolle, Modernisierung des Aktienrechts, Köln. 
Baums, Theodor (2002), Die Europäische Corporate Governance - Empfehlungen des Winter II-Papiers aus deutscher Perspektive. Institut für Bankrecht, Arbeitspapier Nr. 105, in: http://www.kpmg.de/audit-committee-institute/bin/CorporateGovernance-Winter2.pdf (Stand: 20.02.2005).

Baums, Theodor/Stöcker, Mathias (2003), Die Vorschläge der Regierungskommission Corporate Governance und ihre bisherige Umsetzung durch den Deutschen Corporate Governance Kodex und das TransPuG, in: Reform des Aktienrechts, der Rechnungslegung und der Prüfung, hrsg. von Dörner, Dietrich/Menold, Dieter/Pfitzer, Norbert/Oser, Peter, 2. Aufl., Stuttgart, S. 1-39.

Bayer, Walter (2000), Zentrale Konzernfinanzierung, Cash Management und Kapitalerhaltung, in: Deutsches und europäisches Gesellschafts-, Konzern- und Kapitalmarktrecht. Festschrift für Marcus Lutter zum 70. Geburtstag, hrsg. von Schneider, Uwe H./Hommelhoff, Peter/Schmidt, Karsten/Timm, Wolfram/Grunewald, Barbara/Drygala, Tim, Köln, S. 1011-1032.

Bayer, Walter (2003), § 58, in: Münchener Kommentar zum Aktiengesetz, hrsg. von Kropff, Bruno/Semler, Johannes, 2. Aufl. des Geßler/Hefermehl/Eckardt/Kropff, Aktiengesetz, München.

Bayer, Walter (2004a), Aktuelle Entwicklungen im Europäischen Gesellschaftsrecht, in: BB, 59. Jg., S. 1-11.

Bayer, Walter (2004b), Mannesmann-Prämien verletzen das Aktienrecht. Vergleich mit Aktienoptionen an Arbeitnehmer unzulässig, in: FAZ, Nr. 99 vom 28.04.2004, S. 23.

Bea, Franz X./Scheurer, Steffen (1994), Die Kontrollfunktion des Aufsichtsrats, in: DB, 47. Jg., S. 2145-2152.

Beater, Axel (2001), § 264 HGB, in: Münchener Kommentar zum Handelsgesetzbuch, Band 4, hrsg. von Schmidt, Karsten, München.

Beatty, Anne/Ramesh, K./Weber, Joseph (2002), The Imporatnce of Accounting Changes in Debt Contracts: The Cost of Flexibility in Covenant Calculations, in: JAaE, Vol. 33, S. 205-227.

Bebchuk, Lucian A. (1992), Federalism and the Corporation: The Desirable Limits on State Competition in Corporate Law, in: Harv. L. Rev., Vol. 105, S. 1437-1510.

Bebchuk, Lucian A./Cohen, Alma (2003), Firms' Decisions Where to Incorporate, in: J.L. \& Econ., Vol. 46, S. 383-425.

Bebchuk, Lucian A./Cohen, Alma/Ferrell, Allen (2002), Does the Evidence Favor State Competition in Corporate Law?, in: Cal. L. Rev., Vol. 90, S. 1775-1821.

Bebchuk, Lucian A./Ferrell, Allen (1999), Federalism and Corporate Law: The Race to Protect Managers from Takeovers, in: Colum. L. Rev., Vol. 99, S. 1169-1199.

Bebchuk, Lucian A./Ferrell, Allen (2001), A New Approach to Takeover Law and Regulatory Competition, in: Va. L. Rev., Vol. 87, S. 111-164.

Bebchuk, Lucian A./Hamdani, Assaf (2002), Vigorous Race or Leisurely Walk: Reconsidering the Competition over Corporate Charters, in: Yale L.J., Vol. 112, S. 553-615.

Beck, Heiko (2004), § 2 WpHG, in: Kapitalmarktrechts-Kommentar, hrsg. von Schwark, Eberhard, 3. Aufl., München. 
Beckmann, Ralph (1989), Zur Rücklagenbildung im Konzern, in: DB, 42. Jg., S. 940-943.

Begley, Joy/Freedman, Ruth (2004), The Changing Role of Accounting Numbers in Public Lending Agreements, in: AH, Vol. 18, S. 81-96.

Beisse, Heinrich (1989), Die Generalnorm des neuen Bilanzrechts und ihre steuerrechtliche Bedeutung, in: Handelsbilanz und Steuerbilanz. Beiträge zum neuen Bilanzrecht, Band 2, hrsg. von Mellwig, Winfried/Moxter, Adolf/Ordelheide, Dieter, Wiesbaden, S. 15-31.

Beisse, Heinrich (1993), Gläubigerschutz - Grundprinzip des deutschen Bilanzrechts, in: Festschrift für Karl Beusch zum 68. Geburtstag, hrsg. von Beisse, Heinrich/Lutter, Marcus/Närger, Heribald, Berlin/New York.

Beisse, Heinrich (1999), Normqualität und Normstruktur von Bilanzvorschriften und Standards, in: BB, 54. Jg., S. 2180-2186.

Ben-Dror, Yoav (1983), An Empirical Study of Distribution Rules under California Corporations Code $\S 500$ : Are Creditors Adequately Protected?, in: U.C. Davis L. Rev., Vol. 16, S. 375-418.

Benckendorff, Andreas (1998), Erwerb eigener Aktien im deutschen und USamerikanischen Recht, Baden-Baden.

Berle, Adolf A. (1929), Investors and the Revised Delaware Act, in: Colum. L. Rev., Vol. 29, S. 563-581.

Bernstorff, Christoph Graf von (2004), Das Betreiben einer englischen Limited in Deutschland, in: RIW, 50. Jg., S. 498-502.

Berry, A. J./Faulkner, S./Hughes, M./Jarvis, R. (1993), Financial Information, the Banker and the Small Business, in: BAR, Vol. 25, S. 131-150.

Beusch, Karl (1987), Rücklagenbildung im Konzern, in: Bilanz- und Konzernrecht, Festschrift zum 65. Geburtstag von Dr. Dr. h.c. Reinhard Goerdeler, hrsg. von Havermann, Hans, Düsseldorf, S. 25-44.

Bezzenberger, Tilman (2005), Das Kapital der Aktiengesellschaft. Kapitalerhaltung, Vermögensbindung, Konzernrecht, Köln.

Bhagat, Sanjai/Romano, Roberta (2002), Event Studies and the Law: Part II: Empirical Studies of Corporate Law, in: ALER, Vol. 4, S. 380-423.

Bieker, Marcus (2006), Ökonomische Analyse des Fair Value Accounting, Frankfurt am Main u.a.

Bieker, Marcus/Schmidt, Lars (2002), Der Vorschlag der Europäischen Kommission zur Änderung der Bilanzrichtlinien. Darstellung und Beurteilung des Umsetzungsbedarfs für den deutschen Gesetzgeber, in: KoR, 2. Jg., S. 206-219.

Bigus, Jochen/Langer, Thomas/Schiereck, Dirk (2004), Wie werden Kreditsicherheiten in der Praxis eingesetzt? - Ein Überblick über empirische Befunde, in: ZBB, 16. Jg., S. 465-480.

Binz, Mark/Sorg, Martin (2004), Esser und Ackermann müssen Pyrrhussiege fürchten, in: FAZ, Nr. 105 vom 06.05.2004, S. 12.

Bitz, Michael/Hemmerde, Wilhelm/Rausch, Werner (1986), Gesetzliche Regelungen und Reformvorschläge zum Gläubigerschutz. Eine ökonomische Analyse, Berlin u.a. 
Black, Barbara (2004), Corporate Dividends and Stock Repurchases, Eagan (Stand: 12/2004).

Blatt, Dana L. (Hrsg.) (2003), High Court Case Summaries, Eagan.

Blaurock, Uwe (2005), Mindestkapital und Haftung bei der GmbH, in: Festschrift für Thomas Raiser zum 70. Geburtstag am 20. Februar 2005, hrsg. von Damm, Reinhard/Heermann, Peter W./Veil, Rüdiger, Berlin.

Blumenwitz, Dieter (2003), Einführung in das anglo-amerikanische Recht, 7. Aufl., München.

BMJ (2002), Bundesministerium der Justiz, Entwurf eines Gesetzes zur weiteren Reform des Aktien- und Bilanzrechts, zu Transparenz und Publizität (Transparenz- und Publizitätsgesetz), in: http://www.bmj.bund.de/media/archive/301.pdf (Stand: 29.03.2004), S. 1-79.

BMJ (2003), Bundesministerium der Justiz, Referentenentwurf Gesetz zur Einführung internationaler Rechnungslegungsstandards und zur Sicherung der Qualität der Abschlussprüfung (Bilanzrechtsreformgesetz - BilReG), in: http://www.bmj.bund.de/media/archive/ 512.pdf (Stand: 17.05. 2005).

BMJ (2005a), Bundesministerium der Justiz, Referentenentwurf eines Gesetzes über elektronische Handelsregister und Genossenschaftsregister sowie das Unternehmensregister (EHUG), in: http://www.bmj.bund.de/media/archive/890.pdf (Stand: 29.08.2005).

BMJ (2005b), Bundesministerium der Justiz, Referentenentwurf. Entwurf eines Gesetzes zur Neuregelung des Mindestkapitals der GmbH (MindestkapG), in: http://www.bmj.de/media/ archive/908. pdf (Stand: 19.05.2005).

BMJ (2006), Bundesministerium der Justiz, Zeit für Gründer - die GmbH-Reform, in: http://www.bmj.bund.de/enid/7cdc7100e4daafb512593dcd54df2fa3,c6eeea 70726573736 5617274696b656c5f6964092d0932343639093a096d795f79656172092d0932303036093 a096d795f6d6f6e7468092d093035093a095f7472636964092d0932343639/Presse/Pressemitteilungen_58.html (Stand: 05.06.2006).

Böcking, Hans-Joachim (2001), IAS für Konzern- und Einzelabschluss?, in: WPg, 54. Jg., S. 1433-1440.

Böcking, Hans-Joachim (2002), IAS/IFRS und Corporate Governance, in: Vom Financial Accounting zum Business Reporting - Kapitalmarktorientierte Rechnungslegung und integrierte Unternehmenssteuerung, Stuttgart, S. 423-443.

Böcking, Hans-Joachim (2004), Internationalisierung der Rechnungslegung und ihre Auswirkungen auf die Grundprinzipien des deutschen Rechts, in: Der Konzern, 2. Jg., S. 177-183.

Böcking, Hans-Joachim/Busam, Dirk/Dietz, Stephanie (2003), IFRS 1. First-time Adoption of International Financial Reporting Standards vom 19.6.2003 - Zur Umstellung der Rechnungslegung von HGB auf IFRS und zur Bedeutung des Framework -, in: Der Konzern, 1. Jg., S. 457-476.

Böcking, Hans-Joachim/Herold, Christian/Müßig, Anke (2004a), IFRS für nicht kapitalmarktorientierte Unternehmen - unter besonderer Berücksichtigung mittelständischer Belange -, in: Der Konzern, 2. Jg., S. 664-672. 
Böcking, Hans-Joachim/Herold, Christian/Müßig, Anke (2004b), Zur Notwendigkeit modifizierter IFRS für kleine und mittelgroße Unternehmen - Das IASB-Diskussionspapier „Preliminary Views on Accounting Standards for Small and Medium-sized Entities“ -, in: Der Konzern, 2. Jg., S. 789-796.

Böcking, Hans-Joachim/Herold, Christian/Wiederhold, Philipp (2003), Modernisierung des HGB in Richtung IAS/IFRS - Auswirkungen der Änderungen der 4. und 7. EURichtlinie vom 6.5.2003 -, in: Der Konzern, 1. Jg., S. 394-409.

Böckmann, Tobias (2005), Gläubigerschutz bei $\mathrm{GmbH}$ und close corporation. Eine rechtsvergleichende Untersuchung nach deutschem und US-amerikanischem Recht unter besonderer Berücksichtigung des Rechts von Delaware, Kalifornien und New York, Köln u.a.

Böhm, Steffen (1979), Der Konzerngewinn als Grundlage für Dividendenausschüttung und Steuerbemessung - Ein Vorschlag für eine Neuregelung -, Göttingen.

Bohl, Elke (2003), Die Mitbestimmung irritiert die ausländischen Investoren, in: FAZ vom 20.09.2003, Nr. 219, S. 14.

Bonse, Andreas (2004), Informationsgehalt von Konzernabschlüssen nach HGB, IAS und US-GAAP. Eine empirische Analyse aus Sicht der Eigenkapitalgeber, Frankfurt am Main u.a.

Bonse, Andreas/Linnhoff, Ulrich/Pellens, Bernhard (2002a), Jahresabschluss, in: Betriebswirtschaft für Führungskräfte, hrsg. von Busse von Colbe, Walther/Coenenberg, Adolf G./Kajüter, Peter/Linnhoff, Ulrich, 2. Aufl., Stuttgart, S. 315-354.

Bonse, Andreas/Linnhoff, Ulrich/Pellens, Bernhard (2002b), Jahresabschlussanalyse, hrsg. von Busse von Colbe, Walther/Coenenberg, Adolf G./Kajüter, Peter/Linnhoff, Ulrich, Stuttgart, S. 389-412.

Booth, Richard A. (2000), A Chronology of the Evolution of the MBCA, in: Bus. Law., Vol. 56, S. 63-67.

Bormann, Michael/Gucht, Christiane (2003), Übermittlung des Prüfungsberichts an den Aufsichtsrat - ein Beitrag zu $§ 170$ Abs. 3 S. 2 AktG, in: BB, 58. Jg., S. 1887-1894.

Bott, Claudia (2002), Aktionärsstruktur, Kontrolle und Erfolg von Unternehmen, Wiesbaden.

Brealey, Richard A./Myers, Stewart C. (2000), Principles of Corporate Finance, 6. Aufl., Boston u.a.

Brönner, Herbert/Bareis, Peter (1991), Die Bilanz nach Handels- und Steuerrecht, 9. Aufl., Stuttgart.

Broer, Frank Daniel (2001), Maßgeblichkeitsprinzip und Harmonisierung der Rechnungslegung, Baden-Baden.

Buchheim, Regine, Die Jahres- und Zwischenberichterstattung im Entwurf der EU-Transparenz-Richtlinie, in: KoR, 3. Jg., S. 241-248.

Buchheim, Regine/Burger, Anton/Ulbrich, Philipp (2004), Publizitätspflichten aufgrund der Transparenz-Richtlinie, in: WISU, 33. Jg., S. 1389-1395.

Buchheim, Regine/Gröner, Susanne (2003), Anwendungsbereich der IAS-Verordnung an der Schnittstelle zu deutschem und zu EU-Bilanzrecht, in: BB, 58. Jg., S. 953-955. 
Buchheim, Regine/Gröner, Susanne/Kühne, Mareike (2004), Übernahme von IAS/IFRS in Europa: Ablauf und Wirkung des Komitologieverfahrens auf die Rechnungslegung, in: BB, 59. Jg., S. 1783-1788.

Buchholz, Rainer (2002), IAS für mittelständische Unternehmen? - Vor- und Nachteile neuer Rechnungslegungsvorschriften in Deutschland, in: DStR, 40. Jg., S. 1280-1284.

Buchta, Jens/Kann, Jürgen van (2003), Die Haftung des Aufsichtsrats einer Aktiengesellschaft - aktuelle Entwicklungen in Gesetzgebung und Rechtsprechung, in: DStR, 41. Jg., S. $1665-1670$.

Budde, Wolfgang D. (1994), Rechenschaftslegung im Spannungsfeld des Grundgesetzes, in: Bilanzrecht und Kapitalmarkt. Festschrift zum 65. Geburtstag von Professor Dr. Dr. h.c Dr. h.c. Adolf Moxter, hrsg. von Ballwieser, Wolfgang/Böcking, Hans-Joachim/Drukarczyk, Jochen/Schmidt, Reinhard H., Düsseldorf, S. 35-59.

Budde, Wolgang D. (1997), Konzernrechnungslegung nach IAS und US-GAAP und ihre Rückwirkungen auf den handelsrechtlichen Einzelabschluß, in: Handelsbilanzen und Steuerbilanzen. Festschrift zum 70. Geburtstag von Prof. Dr. h.c. Heinrich Beisse, hrsg. von Budde, Wolfgang D./Moxter, Adolf/Offerhaus, Klaus, Düsseldorf, S. 105-121.

Budde, Wolfgang D./Steuber, Elgin (1996), Rechnungslegung im Spannungsfeld zwischen Gläubigerschutz und Information der Gesellschafter, in: AG, 41. Jg., S. 542-550.

Bundesregierung (2002), Stellungnahme der Bundesregierung $\mathrm{zu}$ dem Konsultationspapier der Hochrangigen Expertengruppe auf dem Gebiet des Gesellschaftsrechts: „Moderne gesellschaftsrechtliche Rahmenbedingungen in Europa", in: http://www.rws-verlag.de/ volltext-2002/02lutter3. htm (Stand: 17.01.2005).

Bundesregierung (2003), Bundesregierung stärkt Anlegerschutz und Unternehmensintegrität. Mitteilung für die Presse, Nr. 10/03, in: http://www.bmj.bund.de/ger/service/gesetzgebungsvorhaben/10000668 (Stand: 25.02.2003).

Bungert, Hartwin (2003), Gesellschaftsrecht in den USA, 3. Aufl., München/Berlin.

Bungert, Hartwin (2004), Festschreibung der ungeschriebenen „Holzmüller“-Hauptversammlungszuständigkeiten bei der Aktiengesellschaft, in: BB, 59. Jg., S. 1345-1352.

Burger, Anton/Buchhart, Anton (2001), Financial Covenants statt Insolvenzordnung?, in: FB, 3. Jg., S. 99-104.

Busse von Colbe, Walther (1960), Der Jahresabschluß des Konzerns. Unter Berücksichtigung des Regierungsentwurfs eines Aktiengesetzes, in: AG, 5. Jg., S. 145-148 (Teil I), S. 181-186 (Teil II).

Busse von Colbe (1966a), Aufbau und Informationsgehalt von Kapitalflußrechnungen, in: ZfB, 36. Jg., S. 82-114.

Busse von Colbe, Walther (1966b), Der Konzernabschluß nach neuem Aktienrecht, in: AG, 11. Jg., S. 269-274 (Teil I), S. 308-319 (Teil II), S. 350-353 (Teil III).

Busse von Colbe, Walther (1986), Meinungsspiegel, in: BFuP, 38. Jg., S. 357-372.

Busse von Colbe, Walther (1987a), Der Konzernabschluß als Bemessungsgrundlage für die Gewinnverwendung, in: Bilanz- und Konzernrecht: Festschrift zum 65. Geburtstag von Dr. Dr. h.c. Reinhard Goerdeler, hrsg. von Havermann, Hans, Düsseldorf, S. 61-77. 
Busse von Colbe, Walther (1987b), Die neuen Rechnungslegungsvorschriften aus betriebswirtschaftlicher Sicht, in: WPg, 40. Jg., S. 117-126.

Busse von Colbe, Walther (1993), Die Entwicklung des Jahresabschlusses als Informationsinstrument, in: ZfbF-Sonderheft 32, Ökonomische Analyse des Bilanzrechts - Entwicklungslinien und Perspektiven -, hrsg. von Wagner, Franz W., Düsseldorf/Frankfurt am Main, S. 11-29.

Busse von Colbe, Walther (1994), Unternehmenskontrolle durch Rechnungslegung, in: Internationale Unternehmenskontrolle und Unternehmenskultur. Beiträge zu einem Symposium. Professor Dr. Bernhard Großfeld zum 60. Geburtstag, hrsg. von Sandrock, Otto/ Jäger, Wilhelm, Tübingen, S. 37-57.

Busse von Colbe, Walther (1997), Was ist und was bedeutet Shareholder Value aus betriebswirtschaftlicher Sicht?, in: ZGR, 27. Jg., S. 271-290.

Busse von Colbe, Walther (2000), Rechnungslegungsziele und Ansätze zur internationalen Harmonisierung der Rechnungslegung deutscher Unternehmen, in: US-amerikanische Rechnungslegung. Grundlagen und Vergleiche mit deutschem Recht, hrsg. von Ballwieser, Wolfgang, 4. Aufl., Stuttgart, S. 485-508.

Busse von Colbe, Walther (2002a), Die deutsche Rechnungslegung vor einem Paradigmawechsel, in: ZfbF, 54. Jg., S. 159-172.

Busse von Colbe, Walther (2002b), Internationalisierung und Erweiterung der Rechnungslegung, in: Betriebswirtschaft für Führungskräfte, hrsg. von Busse von Colbe, Walther/ Coenenberg, Adolf G./Kajüter, Peter/Linnhoff, Ulrich, Stuttgart, S. 355-388.

Busse von Colbe, Walther (2002c), Jahresabschluss, in: Handwörterbuch Unternehmensrechnung und Controlling, hrsg. von Küpper, Hans-Ulrich/Wagenhofer, Alfred, 4. Aufl., Stuttgart, Sp. 887-895.

Busse von Colbe, Walther (2002d), Vorschlag der EG-Kommission zur Anpassung der Bilanzrichtlinien an die IAS - Abschied von der Harmonisierung?, in: BB, 57. Jg., S. 1530-1536.

Busse von Colbe, Walther/Ordelheide, Dieter/Gebhardt, Günther/Pellens, Bernhard (2003), Konzernabschlüsse, 7. Aufl., Wiesbaden.

Buxbaum, Richard M. (1954), Preferred Stock - Law and Draftsmanship, in: Cal. L. Rev., Vol. 42, S. 243-309.

Carney, William J. (1998), The Production Of Corporate Law, in: S. Cal. L. Rev., Vol. 71, S. 715-780.

Carpenter, Charles G. (1970), A Critical Evaluation of the Wasting Asset Distribution, in: Bus. Law., Vol. 25, S. 1733-1739.

Cary, William L. (1974), Federalism and Corporate Law: Reflections upon Delaware, in: Yale L.J., Vol. 83, S. 663-705.

Castle, Grover R. (1980), Term Lending - A Guide to Negotiating Term Loan Covenants and Other Financial Restrictions, in: JoCBL, Vol. 63, S. 26-39.

Chava, Sudheer/Kumar, Praveen/Warga, Arthur (2004), Agency Costs and the Pricing of Bond Covenants, in: http://ssrn.com/abstract=611801 (Stand: 08.06.2005). 
Cheffins, Brian R. (1997), Company Law: Theory, Structure, and Operation, Oxford.

Chmielewicz, Klaus (1984), Der Neuentwurf einer 5. EG-Richtlinie (Struktur der AG) - Darstellung und Kritik, in: DBW, 44. Jg., S. 393-409.

Choper, Jesse H./Coffee, John C./Gilson, Ronald J. (2004), Cases and Materials on Corporations, 6. Aufl., New York.

Citron, David B. (1992a), Accounting Measuement Rules in UK Bank Loan Contracts, in: ABR, Vol. 23, S. 21-30.

Citron, David B. (1992b), Financial Ratio Covenants in UK Bank Loan Contracts and Accounting Policy Choice, in: ABR, Vol. 22, S. 322-335.

Citron, David B. (1995), The Incidence of Accounting-based Covenants in UK Public Debt Contracts: An Empirical Analysis, in: ABR, Vol. 25, S. 139-150.

Clark, Robert C. (1977), The Duties of the Corporate Debtor to Its Creditors, in: Harv. L. Rev., Vol. 90, S. 505-562.

Clark, Robert C. (1986), Corporate Law, Boston/Toronto.

Claussen, Carsten P. (1974), Sinngehalt und Ausformung der Sonderprüfung wegen Unterbewertung, in: Wirtschaftsfragen der Gegenwart, Festschrift für Carl H. Barz zum 65. Geburtstag, hrsg. von Fischer, Robert/Möhring, Philipp/Westermann, Harry, Berlin/New York, S. 317-333.

Claussen, Carsten P. (1996), Das Gesetz über die kleine Aktiengesellschaft - und die ersten praktischen Erfahrungen, in: WM, 50. Jg., S. 609-619.

Clement, Reiner (2005), Anlegerschutz aus Sicht der Principal-Agent-Theorie, in: WISU, 34. Jg., S. 360-367.

Clemm, Hermann (1987), Unternehmerische Rechnungslegung - Aufgaben, Möglichkeiten und Grenzen -, in: Bilanz- und Konzernrecht, Festschrift zum 65. Geburtstag von Dr. Dr. h.c. Reinhard Goerderler, hrsg. von Havermann, Hans, Düsseldorf, S. 93-126.

Coates, John C. IV. (2001), Explaining Variation in Takeover Defenses: Blame the Lawyers, in: Cal. L. Rev., Vol. 89, S. 1301-1421.

Coenenberg, Adolf G. (2005), Jahresabschluss und Jahresabschlussanalyse, 20. Aufl., Stuttgart.

Committee on Corporate Laws (1979), Changes in the Model Business Corporation Act Affecting Indemnification of Corporate Personnel, in: Bus. Law., Vol. 34, S. 1595-1615.

Committee on Corporate Laws (1986), Changes in the Model Business Corporation Act Amendments Pertaining to Distributions, in: Bus. Law., Vol. 42, S. 259-269.

Cox, James D./Hazen, Thomas L. (2003), Cox \& Hazen on Corporations, Volume III, 2. Aufl., New York.

Crasselt, Nils (2003), Wertorientierte Managemententlohnung, Unternehmensrechnung und Investitionssteuerung, Frankfurt am Main u.a.

Cumming, Douglas J./MacIntosh, Jeffrey G. (2002), The Rationales Underlying Reincorporation and Implications for Canadian Corporations, in: Int. Rev. L. Econ., Vol. 22, S. 277-330. 
Daines, Robert (2001), Does Delaware Law Improve Firm Value?, in: JoFE, Vol. 62, S. 525-558.

Dallmann, Holger/Ull, Thomas (2004), IFRS-Rechnungslegung für kleine und mittlere Unternehmen - Das Diskussionspapier des IASB -, in: KoR, 4. Jg., S. 321-331.

DAV (2003a), Stellungnahme zum Aktionsplan der EU-Kommission zur Modernisierung des Gesellschaftsrechts und Verbesserung der Corporate Governace in der Europäischen Union, in: NZG, 6. Jg., S. 1008-1014.

DAV (2003b), Stellungnahme zum Bilanzrecht: IAS-VO und Reform des HGB, in: ZIP, 24. Jg., S. 459-460.

David, René/Grasmann, Günther (1988), Einführung in die großen Rechtssysteme der Gegenwart, 2. Aufl., München, auf der Grundlage „Les grands systèmes de droit contemporais“ von David, René/Spinosi, Camille J., 8. Aufl., Paris, 1982.

Davies, Paul (1998), Legal Capital in Private Companies in Great Britain, in: AG, 43. Jg., S. 346-354.

Day, Judith F. (1986), The Use of Annual Reports by UK Investment Analysts, in: ABR, Vol. 16, S. 295-307.

Day, Judy F./Taylor, Peter J. (1995), Evidence on the Practices of UK Bankers in Contracting for Medium-term Debt, in: JIBL, o. Vol., S. 394-401.

Day, Judy F./Taylor, Peter J. (1996), Loan Contracting by UK Corporate Borrowers, in: JIBL, o. Vol., S. 318-325.

Deakins, David/Hussain, Guhlum (1994), Financial Information, the Banker and the Small Business: A Comment, in: BAR, Vol. 26, S. 323-335.

Deering's (2004), Deering's California Codes Annotated, Newark (Stand: Mai 2004).

Deutsche Bundesbank (2002), Rechnungslegungsstandards für Kreditinstitute im Wandel, in: Deutsche Bundesbank Monatsbericht Juni 2002, 54. Jg., S. 41-57.

Deutsche Telekom (2004), Geschäftsbericht.

Deutsches Aktieninstitut (2005), DAI-Factbook 2005, Frankfurt am Main.

Dichev, Ilia D./Skinner, Douglas J. (2002), Large-Sample Evidence on the Debt Covenant Hypothesis, in: JAR, Vol. 40, S. 1091-1123.

Dietrich, Christian (2003), Der neue $\S 111$ Abs. 4 Satz 2 AktG. Zustimmungsvorbehaltspflicht auch für unternehmerisches Unterlassen?, in: DStR, 41. Jg., S. 1577-1579.

Dirrigl, Hans (1988), Die Bewertung von Beteiligungen an Kapitalgesellschaften - Betriebswirtschaftliche Methoden und steuerlicher Einfluß -, Hamburg.

Dirrigl, Hans (1998), Wertorientierung und Konvergenz in der Unternehmensrechnung, in: BFuP, 50. Jg., S. 540-579.

Dirrigl, Hans/Wagner, Franz W. (1993), Ausschüttungspolitik unter Berücksichtigung der Besteuerung, in: Handbuch des Finanzmanagements, hrsg. von Gebhardt, Günther/Gerke, Wolfgang/ Steiner, Manfred, München, S. 261-286.

Döllerer, Georg (1959), Grundsätze ordnungsmäßiger Bilanzierung, deren Entstehung und Ermittlung, in: BB, 14. Jg., S. 1217-1221. 
Dooley, Michael P./Goldman, Michael D. (2001), Some Comparisons Between the Model Business Corporation Act and the Delaware General Corporation Law, in: Bus. Law., Vol. 56, S. 737-766.

Doralt, Peter (2004), Haftung und Schadensersatz, in: Arbeitshandbuch für Aufsichtsratsmitglieder, hrsg. von Semler, Johannes/Schenck, Kersten von, 2. Aufl., München, S. 787-839.

Dreyfuss, Gilbert (1976), Distributions to Shareholders under the New California General Corporation Law, in: Loy. L.A. L. Rev., Vol. 9, S. 839-864.

Drinkuth, Henrik (1998), Die Kapitalrichtlinie - Mindest- oder Höchstnorm?, Köln.

Drobnig, Ulrich (1959), Haftungsdurchgriff bei Kapitalgesellschaften, Frankfurt am Main/ Berlin.

Drukarczyk, Jochen (2003), Unternehmensbewertung, 4. Aufl., München.

Drygala, Tim (2001), Die Vorschläge der SLIM-Arbeitsgruppe zur Vereinfachung des Europäischen Gesellschaftsrechts, in: AG, 46. Jg., S. 291-299.

DSGV (2005), Deutscher Sparkassen- und Giroverband, Diagnose Mittelstand 2005. Mittelstand stärken - Breitere Basis für Wachstum schaffen, in: http://www.dsgv.de/owx medien/medial 1/ 1187.pdf (Stand: 23.05.2005).

DSW (2005), HV-Präsenzen der DAX 30-Unternehmen (1998-2005), in: http://www.dswinfo.de/uploads/media/HV-Praesenz_2005.pdf (Stand: 05.06.2006).

DTI (1998), Department of Trade and Industry, Modern Company Law for a Competitive Economy, in: http:/www.dti.gov.uk/cld/comlaw/comlaw.pdf (Stand: 29.08.2005).

DTI (1999), Department of Trade and Industry, Modern Company Law for a Competitive Economy. Company Formation and Capital Maintenance, in: http://www.dti.gov.uk/cld/ 1843cptl.pdf (Stand: 29.08.2005).

DTI (2000), Department of Trade and Industry, Modern Company Law for a Competitive Economy. Capital Maintenance: Other Issues, in: http://www.dti.gov.uk/cld/capm.pdf (Stand: 29.08.05).

DTI (2001), Department of Trade and Industry, Modern Company Law for a Competitive Economy. Final Report, in: http://www.dti.gov.uk/cld/final_report/index.htm (Stand: 29.08.2005).

DTI (2002), Department of Trade and Industry, Modernising Company Law, Presented to Parliament by the Secretary of State for Trade and Industry by Command of Her Majesty, in: http://www.dti.gov.uk/companiesbill/whitepaper.htm (Stand: 29.08.2005).

Duke, Joanne C./Hunt III, Herbert G. (1990), An Empirical Examination of Debt Covenant Restrictions and Accounting-Related Debt Proxies, in: JAaE, Vol. 12, S. 45-63.

Dziadkowski, Dieter/Henselmann, Klaus (2004), Verhältnis von Handelsbilanz und Steuerbilanz, in: Beck'sches Handbuch der Rechnungslegung, Band I, hrsg. von Castan, Edgar/Böcking, Hans-Joachim/Heymann, Gerd/Pfitzer, Norbert/Scheffler, Eberhard, München, B 120.

Easterbrook, Frank H./Fischel, Daniel R. (1991), The Economic Structure of Corporate Law, Cambridge, Mass./London. 
Ebenroth, Carsten-Thomas (1987), Konzernbildungs- und Konzernleitungskontrolle - Ein Beitrag zu den Kompetenzen von Vorstand und Hauptversammlung, Konstanz.

Ebenroth, Carsten-Thomas (1988), Die Kompetenzen des Vorstands und der Aktionärsschutz in der Konzernobergesellschaft, in: AG, 33. Jg., S. 1-7.

Eichholz, Rainer (1993), Das Recht konzerninterner Darlehen, Berlin.

Eidenmüller, Horst (1997), Vertragliche Vorkehrungen gegen Insolvenzrisiken, in: Privatrecht im „Risikostaat“, hrsg. von Hart, Dieter, Baden-Baden, S. 43-72.

Eidenmüller, Horst/Engert, Andreas (2005), Rechtsökonomik des Mindestkapitals im GmbH-Recht, in: GmbHR, 96. Jg., S. 433-438.

Eilmann, Götz/Seulen, Günther (2005), Die Reform des GmbH-Rechts bleibt wirkungslos. Erst weitere Änderungen können Attraktivität steigern, in: FAZ, Nr. 103 vom 04.05.2005, S. 25.

Eisenberg, Melvin A. (1974), The Model Business Corporation Act and the Model Business Corporation Act Annotated, in: Bus. Law., Vol. 29, S. 1407-1428.

Eisenberg, Melvin A. (1983), The Modernization of Corporate Law: An Essay for Bill Cary, in: U. Miami L. Rev., Vol. 37, S. 187-212.

Eisenberg, Melvin A. (2000), Corporations and other Business Organizations, 8. Aufl., New York.

Eisenberg, Melvin A. (2004), Die Sorgfaltspflicht im amerikanischen Gesellschaftsrecht, in: Der Konzern, 2. Jg., S. 386-405.

Eisenhardt, Ulrich (2003), Gesellschaftsrecht, 11. Aufl., München.

Ekkenga, Jens (2001), Neuordnung des Europäischen Bilanzrechts für börsennotierte Unternehmen: Bedenken gegen die Strategie der EG-Kommission, in: BB, 56. Jg., S. $2362-2369$.

Ekkenga, Jens (2006), Einzelabschlüsse nach IFRS - Ende der aktien- und GmbH-rechtlichen Kapitalerhaltung?, in: AG, 51. Jg., S. 389-397.

El-Gazzar, Samir/Lilien, Steven/Pastena, Victor (1989), The Use of Off-Balance Sheet Financing to Circumvent Financial Covenant Restrictions, in: JAAF, Vol. 4, S. 217-231.

El-Gazzar, Samir/Pastena, Victor (1990), Negotiated Accounting Rules in Private Financial Contracts, in: JAaE, Vol. 12, S. 381-396.

El-Gazzar, Samir/Pastena, Victor (1991), Factors Affecting the Scope and Initial Tightness of Covenant Restrictions in Private Lending Agreements, in: CAR, Vol. 8, S. 132-151.

Elschen, Rainer (1998), Principal-Agent, in: Lexikon des Rechnungswesens, hrsg. von Busse von Colbe, Walther/Pellens, Bernhard, 4. Aufl., München/Wien, S. 557-560.

Emanuel, Steven L. (2005), Corporations, 5. Aufl., New York.

Emmerich, Volker /Habersack, Mathias (2005), Konzernrecht, 8. Aufl., München.

Engert, Andreas (2006), Solvenzanforderungen als gesetzliche Ausschüttungssperre bei Kapitalgesellschaften, in: ZHR, 170. Jg., S. 296-335.

Enriques, Luca/Macey, Jonathan R. (2001), Creditors versus Capital Formation: The Case against the European Legal Capital Rules, in: Cornell L. Rev., Vol. 86, S. 1166-1204. 
Epstein, David G./Freer, Richard D./Roberts, Michael J. (2002), Business Structures, St. Paul.

Erlei, Mathias/Jost, Peter-J. (2001), Theoretische Grundlagen des Transaktionskostenansatzes, in: Der Transaktionskostenansatz in der Betriebswirtschaftslehre, hrsg. von Jost, Peter-J., Stuttgart, S. 35-75.

Erlei, Mathias/Leschke, Martin/Sauerland, Dirk (1999), Neue Institutionenökonomik, Stuttgart.

Ernst, Christoph (2003), Auswirkungen des 10-Punkte-Programms „Unternehmensintegrität und Anlegerschutz" auf das Bilanzrecht, in: BB, 58. Jg., S. 1487-1491.

Ernst, Christoph (2004), Die Wahlrechte der EU-Verordnung zur IAS-Anwendung und Umsetzungsmöglichkeiten in Deutschland, in: Übergang der Rechnungslegung vom HGB zu den IFRS. Vorträge und Diskussionen zum 19. Münsterischen Tagesgespräch des Münsteraner Gesprächskreis Rechnungslegung und Prüfung e.V. am 22. Mai 2003, hrsg. von Baetge, Jörg, Düsseldorf, S. 25-41.

Ernst, Christoph/Seibert, Ulrich/Stuckert, Fritz (1998), KonTraG, KapAEG, StückAG, EuroEG, Düsseldorf.

Ernst, Edgar/Gassen, Joachim/Pellens, Bernhard (2005), Verhalten und Präferenzen deutscher Aktionäre. Eine Befragung privater und institutioneller Anleger zu Informationsverhalten, Dividendenpräferenz und Wahrnehmung von Stimmrechten, Studien des Deutschen Aktieninstituts, Heft 29, hrsg. von Rosen, Rüdiger von, Frankfurt am Main.

Escher-Weingart, Christina (2000), Corporate Governance Strukturen - ein deutsch-U.S.amerikanischer Rechtsvergleich, in: ZVglRWiss, 99. Jg., S. 387-409.

Escher-Weingart, Christina (2001), Reform durch Deregulierung im Kapitalgesellschaftsrecht. Eine Analyse der Reformmöglichkeiten unter besonderer Berücksichtigung des Gläubiger- und Anlegerschutzes, Tübingen.

Escher-Weingart, Christina/Kübler, Friedrich (1998), Erwerb eigener Aktien. Deutsche Reformbedürfnisse und europäische Fesseln?, in: ZHR, 162. Jg., S. 537-562.

EU-Kommission (1999), Finanzdienstleistungen: Umsetzung des Finanzmarktrahmens: Aktionsplan, KOM (1999) 232, in: http://europa.eu.int/comm/internal_market/finances/ docs/actionplan/index/action_de.pdf (Stand: 29.08.2005).

EU-Kommission (2002a), Mitteilung der Kommission betreffend die soziale Verantwortung der Unternehmen: ein Unternehmensbeitrag zur nachhaltigen Entwicklung, KOM (2002) 347, in: http://europa.eu.int/comm/employment_social/soc-dial/csr/csr2002_de.pdf (Stand: 29.08.2005).

EU-Kommission (2002b), Mitteilung der Kommission. Industriepolitik in einem erweiterten Europa, KOM (2002) 714, in: http://europa.eu.int/comm/enterprise/enterprise_policy/industry/doc/com 714_2002_de.pdf (Stand: 29.08.2005).

EU-Kommission (2003a), Modernisierung des Gesellschaftsrechts und Verbesserung der Corporate Governance in der Europäischen Union - Aktionsplan, in: http://eur-lex.europa.eu/LexUriServ/site/de/com/2003/com2003_0284de01.pdf (Stand: 01.06.2006). 
EU-Kommission (2003b), Mitteilung der Kommission. Stärkung der Abschlussprüfung in der EU, KOM (2003) 286, in: http://europa.eu.int/eur-lex/lex/LexUriServ/site/de/com/ 2003/com2003_0286 de01.pdf (Stand: 29.08.2005).

EU-Kommission (2004), Vorschlag für eine Richtlinie des europäischen Parlaments und des Rates zur Änderung der Richtlinie 77/91/EWG des Rates in Bezug auf die Gründung von Aktiengesellschaften und die Erhaltung und Änderung ihres Kapitals, in: http://europa.eu.int/comm/internal_market/company/docs/capital/2004-proposal/proposal_de.pdf (Stand: 17.05.2005).

EU-Kommission (2005a), Planned Implementationof the IAS Regulation (1606/2002) in the EU and EEA, in: http://europa.eu.int/comm/internal_market/accounting/docs/ias/ias-useof-options_en.pdf (Stand: 24.08.2005).

EU-Kommission (2005b), Rechnungslegungsstandards: EU-Kommissionsmitglied McCreevy sieht Vereinbarung mit der US-amerikanischen SEC als Fortschritt auf dem Gebiet der Gleichwertigkeit, in: Pressemitteilung IP/05/469 vom 22.04.2005, http://www.europa.eu.int/rapid/.

Euler, Roland (2002), Paradigmenwechsel im handelsrechtlichen Einzelabschluss: Von den GoB zu den IAS?, in: BB, 57. Jg., S. 875-880.

Ewert, Ralf (1986), Rechnungslegung, Gläubigerschutz und Agency-Probleme, Wiesbaden.

Ewert, Ralf (1998), Anlegerschutz, in: Lexikon des Rechnungswesens, hrsg. von Busse von Colbe, Walther/Pellens, Bernhard, 4. Aufl., München/Wien, S. 45-48.

Ewert, Ralf/Wagenhofer, Alfred (1992), Unternehmenspublizität und Konkurrenzwirkungen, in: ZfB, 62. Jg., S. 297-324.

Fabricius, Fritz (1970), Das Stammkapital der GmbH - Zur Frage seiner Rechtfertigung und der Rechtfertigung seiner Höhe. Gedanken zum Referentenentwurf eines GmbH-Gesetzes 1969, in: GmbHR, 61. Jg., S. 137-144.

Fallgatter, Michael J. (2003), Variable Vergütung von Mitgliedern des Aufsichtsrates: Resultiert eine verbesserte Unternehmensüberwachung?, in: DBW, 63. Jg., S. 703-713.

Fama, Eugene F./Jensen, Michael C. (1983), Separation of Ownership and Control, in: J. L. \& Econ., Vol. 26, S. 301-325.

Fankhauser, Roger (2001), Gemeinschaftsrechtliche Publizitäts- und Kapital-Richtlinie: Anpassungsbedarf des Schweizer Rechts. Ein Beitrag zur Diskussion über die Europaverträglichkeit des Schweizer Aktienrechts, Bern.

Faß, Joachim (1992), Konzernierung und konsolidierte Rechnungslegung. Eine Analyse der Eignung des Konzernabschlusses als Informationsinstrument und als Grundlage der Ausschüttungsbemessung konzernverbundener Unternehmen, Frankfurt am Main u.a.

Fédération des Experts Comptables Européens (2001), Discussion Paper on Modernisation of the Accounting Directives, in: http://www.iasplus.com/resource/feepaper.pdf (Stand: 13.10.2005).

Feldhoff, Michael (1992), Die Regulierung der Rechnungslegung. Eine systematische Darstellung der Grundlagen mit einer Anwendung auf die Frage der Publizität, Frankfurt am Main u.a. 
Ferran, Eilís (2003), Legal Capital Rules and Modern Securities Markets - the Case for Reform, as Illustrated by the U.K. Equity Markets, in: Capital Markets and Company Law, hrsg. von Hopt, Klaus J./Wymeersch, Eddy, Oxford, S. 115-143.

Fischbach, Dorian (2003), Der Bilanzprüfungsausschuss des Aufsichtsrats und seine Zusammenarbeit mit dem Abschlussprüfer, Lohmar/Köln.

Fischel, Daniel R. (1982), The „Race to the Bottom“ Revisited: Reflections on Recent Developments in Delaware's Corporation Law, in: Nw. U. L. Rev., Vol. 76, S. 913-945.

Flämig, Christian (1968), Die Umkehrung des Maßgeblichkeitsprinzips der Handelsbilanz für die Steuerbilanz, in: DB, 21. Jg., S. 2045-2048.

Fleischer Holger(1998), Covenants und Kapitalersatz, in: ZIP, 19. Jg., S. 313-321.

Fleischer, Holger (2000), Gläubigerschutz in der kleinen Kapitalgesellschaft: Deutsche $\mathrm{GmbH}$ versus englische private limited company, in: DStR, 38. Jg., S. 1015-1021.

Fleischer, Holger (2001), Grundfragen der ökonomischen Theorie im Gesellschafts- und Kapitalmarktrecht, in: ZGR, 30. Jg., S. 1-32.

Fleischer, Holger (2002), Systematische Darstellung 6. Die Finanzierung der GmbH, in: GmbHG. Kommentar, hrsg. von Michalski, Lutz, München, S. 547-588.

Fleischer, Holger (2003), Vorstandsverantwortlichkeit und Fehlverhalten von Unternehmensangehörigen - Von der Einzelüberwachung zur Errichtung einer Compliance-Organisation, in: AG, 48. Jg., S. 291-300.

Fleischer, Holger (2004a), Die „Business Judgement Rule“: Vom Richterrecht zur Kodifizierung, in: ZIP, 25. Jg., S. 685-692.

Fleischer, Holger (2004b), Ungeschriebene Hauptversammlungszuständigkeiten im Aktienrecht: Von „Holzmüller“ zu „Gelatine“, in: NJW, 57. Jg., S. 2335-2339.

Fleischer, Holger (2005), Gläubigerschutz im Recht der Delaware corporation, in: RIW, 51. Jg., S. 92-97.

Flume, Werner (1983), Allgemeiner Teil des Bürgerlichen Rechts. Erster Band. Zweiter Teil. Die juristische Person, Berlin u.a.

Förschle, Gerhart (2006), § 243 HGB, in: Beck'scher Bilanzkommentar, hrsg. von Ellrott, Helmut/Förschle, Gerhart/Hoyos, Martin/Winkeljohann, Norbert, 6. Aufl., München.

Förschle, Gerhart/Holland, Bettina/Kroner, Matthias (2001), Internationale Rechnungslegung: US-GAAP, HGB und IAS, 5. Aufl., Heidelberg.

Förschle, Gerhart/Kroner, Matthias (2006), § 246 HGB, in: Beck'scher Bilanz-Kommentar, hrsg. von Ellrott, Helmut/Förschle, Gerhart/Hoyos, Martin/Winkeljohann, Norbert, 6. Aufl., München.

Folk, Ernest L./Ward, Rodman/Welch, Edward P. (1988), Folk on the Delaware General Corporation Law, 2. Aufl., Boston/Toronto.

Fonk, Hans-Joachim (2004), Personalentscheidungen des Aufsichtsrats, in: Arbeitshandbuch für Aufsichtsratsmitglieder, hrsg. von Semler, Johannes/Schenck, Kersten von, 2. Aufl., München, S. 479-656.

Franke, Günter/Hax, Herbert (2004), Finanzwirtschaft des Unternehmens und Kapitalmarkt, 5. Aufl., Berlin u.a. 
Franken, Lars (2001), Gläubigerschutz durch Rechnungslegung nach US-GAAP, Frankfurt am Main u.a.

Freedman (2000), Limited Liability: Large Company Theory and Small Firms, in: Mod. L. Rev., Vol. 63, S. 317-354.

Freudenberg, Tobias (2004), Noch kein fundamentaler Wandel in der Aufsichtsratsvergütung, in: AG, 49. Jg., S. R48.

Frey, Günther (1966), Die Sonderprüfung wegen unzulässiger Unterbewertung nach $\S \S 258$ ff. AktG, in: WPg, 19. Jg., S. 633-641.

Friedman, Lawrence M. (1985), A History of American Law, 2. Aufl., New York.

Frodermann, Jürgen (1994), Möglichkeiten und Grenzen der Gewinnthesaurierung im Konzern, Berlin.

Frost, Carol A./Bernard, Victor L. (1989), The Role of Debt Covenants in Assesing the Economic Consequences of Limiting Capitalization of Exploration Costs, in: AR, Vol. 64, S. 788-808.

Fulda, Carl H. (1966), Einführung in das Recht der USA, Baden-Baden.

Fülbier, Rolf Uwe (1998a), Ad-hoc-Publizität, in: Lexikon des Rechnungswesens, hrsg. von Busse von Colbe, Walther/Pellens, Bernhard, 4. Aufl., München/Wien, S. 15-18.

Fülbier, Rolf Uwe (1998b), Regulierung der Ad-hoc-Publizität. Ein Beitrag zur ökonomischen Analyse des Rechts, Wiesbaden, 1998.

Fülbier, Rolf Uwe (1999), 5 Jahre Ad-hoc-Publizität: Ein Zwischenergebnis, in: StuB, 1. Jg., S. $1260-1267$.

Fülbier, Rolf Uwe/Honold, Dirk/Klar, Alexander (2000), Bilanzierung immaterieller Vermögenswerte. Möglichkeiten und Grenzen der Bilanzierung nach US-GAAP und IAS bei Biotechnologieunternehmen, in: RIW, 46. Jg., S. 833-844.

Fuhrmann, Lambertus (2004), „Gelatine“ und die Holzmüller-Doktrin: Ende einer juristischen Irrfahrt?, in: AG, 49. Jg., S. 339-342.

Gabriel, Claudia/Ernst, Christoph (2004), Die Entwürfe des Bilanzkontrollgesetzes und des Bilanzrechtsreformgesetzes: Stärkung von Unternehmensintegrität und Anlegerschutz, in: Der Konzern, 2. Jg., S. 102-109.

Gansen, Georg (1992), Harmonisierung der Kapitalaufbringung im englischen und deutschen Kapitalgesellschaftsrecht. Vergleichende Studie zur Zweiten Gesellschaftsrechtlichen EG-Richtlinie, Frankfurt am Main u.a.

Ganske, Joachim (1978), Das Zweite gesellschaftsrechtliche Koordinierungsgesetz vom 13. Dezember 1978, in: DB, 31. Jg., S. 2461-2465.

Gassen, Joachim (2000), Datenbankgestützte Rechnungslegungspublizität. Ein Beitrag zur Evolution der Rechnungslegung, Frankfurt am Main u.a.

Gassen, Joachim (2001), Rechnungslegung, in: Der Transaktionskostenansatz in der Betriebswirtschaftslehre, hrsg. von Jost, Peter-J., Stuttgart, S. 395-413. 
GD Binnenmarkt (2003), Zusammenfassung der Antworten auf die Mitteilung der Kommission an den Rat und das Europäische Parlament „Modernisierung des Gesellschaftsrechts und Verbesserung der Corporate Governance in der Europäischen Union - Aktionsplan“, in: http://europa.eu.int/comm/internal_market/en/company/company/modern/governance-consult-responses_de.pdf (Stand: 19.05.05).

Gelter, Martin (2004), Kapitalerhaltung und internationale Rechnungslegung, in: GesRZ, 33. Jg., S. 177-188.

Gernon, Helen/Meek, Gary K. (2001), Accounting. An International Perspective, 5. Aufl., Boston u.a.

Geßler, Ernst (1985a), Rücklagenbildung bei Gewinnabführungsverträgen, in: Beiträge zum Zivil-, Steuer- und Unternehmensrecht. - Festschrift für Heinz Meilicke -, hrsg. vom Fachinstitut der Steuerberater e.V., Berlin u.a., S. 18-30.

Geßler, Ernst (1985b), Rücklagenbildung im Konzern, in: AG, 30. Jg., S. 257-263.

Gevurtz, Franklin A. (2000), Corporation Law, St. Paul/Minn.

Gierke, Otto von (1887), Die Genossenschaftstheorie und die Deutsche Rechtsprechung, Berlin.

Goerdeler, Reinhard (1986), Rücklagenbildung nach § 58 Abs. 2 AktG 1965 im Konzern, in: WPg, 39. Jg., S. 229-237.

Götz, Heinrich (1984), Die Sicherung der Rechte der Aktionäre der Konzernobergesellschaft bei Konzernbildung und Konzernleitung - zugleich auch eine Besprechung der „Holzmüller"-Entscheidung des Bundesgerichtshofs -, in: AG, 29. Jg., S. 85-94.

Götze, Cornelius (2004), „Gelatine“ statt „Holzmüller“ - Zur Reichweite ungeschriebener Mitwirkungsbefugnisse der Hauptversammlung, in: NZG, 7. Jg., S. 585-589.

Göz, Philipp (1998), Statusverfahren bei Änderungen in der Zusammensetzung des Aufsichtsrats, in: ZIP, 19. Jg., S. 1523-1528.

Goddard, Robert (2003), „Modernising Company Law“: The Government's White Paper, in: Mod. L. Rev., Vol. 66, S. 402-424.

Gollnick, Axel (1991), Gewinnverwendung im Konzern, Köln u.a.

Gollnick, Axel (1992), Gewinnverwendung im Konzern, in: JA, 24. Jg., S. 18-25.

Gräfer, Horst (1992), Annual Report - der US-amerikanische Jahresabschluß, Stuttgart.

Grice, John S. (2003), Other Comprehensive Basis of Accounting Methods: Non-GAAPBased Financial Statements, in: NPA, Vol. 48, S. 16-19.

Grossekettler, Heinz (1989), Deregulierung und Privatisierung. Erscheinungsformen, Legitimationskriterien und politische Verhaltenstendenzen, in: WiSt, 18. Jg., S. 437-445.

Groß, Wolfgang (1997), Informations- und Auskunftsrecht des Aktionärs, in: AG, 42. Jg., S. $97-107$.

Großfeld, Bernhard (1968), Aktiengesellschaft, Unternehmenskonzentration und Kleinaktionär, Tübingen.

Großfeld, Bernhard (1996), Kernfragen der Rechtsvergleichung, Tübingen.

Großfeld, Bernhard (1998), Bilanzrecht, 3. Aufl., Heidelberg. 
Großfeld, Bernhard (2002), Unternehmens- und Anteilsbewertung im Gesellschaftsrecht, 4. Aufl., Köln.

Großfeld, Bernhard/Luttermann, Claus (2005), Bilanzrecht, 4. Aufl., Heidelberg.

Grundmann, Stefan (2001), Wettbewerb der Regelgeber im Europäischen Gesellschaftsrecht - jedes Marktsegment hat seine Struktur, in: ZGR, 30. Jg., S. 783-832.

Grundmann, Stefan (2004), Europäisches Gesellschaftsrecht. Eine systematische Darstellung unter Einbeziehung des Europäischen Kapitalmarktrechts, Heidelberg.

Grunewald, Barbara (2005), Gesellschaftsrecht, 6. Aufl., Tübingen.

Grunewald, Barbara/Noack, Ulrich (2005), Zur Zukunft des Kapitalsystems der GmbH Die Ein-Euro-GmbH in Deutschland, in: GmbHR, 96. Jg., S. 189-195

Haberer, Thomas (2003), The Road Ahead: Zur Zukunft des europäischen Gesellschaftsrechts, in: GesRZ, 32. Jg., S. 211-220.

Habersack, Mathias (2003), Europäisches Gesellschaftsrecht, 2. Aufl., München.

Habersack, Mathias (2004), Europäisches Gesellschaftsrecht im Wandel - Bemerkungen zum Aktionsplan der EG-Kommission betreffend die Modernisierung des Gesellschaftsrechts und die Verbesserung der Corporate Governance in der Europäischen Union, in: NZG, 7. Jg., S. 1-9.

Halbhuber, Harald (2001), National Doctrinal Structures and European Company Law, in: CML Rev., Vol. 38, S. 1385-1420.

Haller, Axel (1994), Die Grundlagen der externen Rechnungslegung in den USA. Unter besonderer Berücksichtigung der rechtlichen, institutionellen und theoretischen Rahmenbedingungen, 4. Aufl., Stuttgart.

Haller, Axel/Eierle, Brigitte (2004), Accounting Standards for Small and Medium-sized Entities - erste Weichenstellungen durch das IASB, in: BB, 59. Jg., S. 1838-1845.

Hamilton, Robert W. (2000), The Law of Corporations, 5. Aufl., St. Paul, Minn.

Hannemann, Wilhelm (1934), Das Bewertungsproblem in den Konzernbilanzen vom Standpunkt der Aktienrechtsreform, Königsberg in Preußen.

Hans Böckler Stiftung (2004), Zur aktuellen Kritik der Mitbestimmung im Aufsichtsrat, in: http://www.boeckler.de/pdf/mitbestimmung_2004.pdf (Stand: 05.03.2004).

Hansen, Herbert (2004), Der gestiegene wirtschaftliche Stellenwert der GmbH, in: GmbHR, 95. Jg., S. 39-42.

Hansen, Ulrike (1996), Die verdeckten Sacheinlagen in Frankreich, Belgien und Deutschland und ihre Behandlung durch die zweite EU-Gesellschaftsrechtsrichtlinie, Frankfurt am Main u.a.

Harrer, Herbert/Fischer, Raymond/Evans, Jasper (2003), Der amtliche Markt an der Frankfurter Wertpapierbörse im Vergleich zur Notierung an der NYSE und an der LSE, in: RIW, 49. Jg., S. 81-97.

Hasselbach, Kai/Wicke, Hartmut (2001), Sachausschüttungen im Aktienrecht, in: NZG, 4. Jg., S. 599-602.

Hay, Peter (2002), US-amerikanisches Recht, 2. Aufl., München. 
Hayek, Friedrich A. von (1945), The Use of Knowledge in Society, in: AER, Vol. 35, S. 519-530.

Hayek, Friedrich A. von (1952a), Der Sinn des Wettbewerbs, in: Individualismus und wirtschaftliche Ordnung, hrsg. von Hayek, Friedrich A., Erlenbach-Zürich, S. 122-140.

Hayek, Friedrich A. von (1952b), Wirtschaftstheorie und Wissen, hrsg. von Hayek, Friedrich A., Erlenbach-Zürich, S. 49-77.

Hayek, Friedrich A. von (1968), Der Wettbewerb als Entdeckungsverfahren, in: Kieler Vorträge gehalten im Institut für Weltwirtschaft an der Universität Kiel, hrsg. von Schneider, Erich, Nr. 56, Kiel.

Hayek, Friedrich A. von (1969a), Grundzüge einer liberalen Gesellschaftsordnung, in: Freiburger Studien. Gesammelte Aufsätze von F. A. von Hayek, hrsg. vom Walter Eucken Institut, Tübingen, S. 108-125.

Hayek, Friedrich A. von (1969b), Rechtsordnung und Handelsordnung, in: Freiburger Studien. Gesammelte Aufsätze von F. A. von Hayek, hrsg. vom Walter Eucken Institut, Tübingen, S. 161-198.

Hayek, Friedrich A. von (1981), Recht, Gesetzgebung und Freiheit. Band 2: Die Illusion der sozialen Gerechtigkeit, Landberg am Lech.

Hayn, Sven/Waldersee, Georg Graf (2004), IFRS/US-GAAP/HGB im Vergleich. Synoptische Darstellung für den Einzel- und Konzernabschluss, 5. Aufl., Stuttgart.

Hefermehl, Wolfgang/Bungeroth, Erhard (1983), § 58 AktG, in: Aktiengesetz, Band 1, hrsg. von Geßler, Ernst/Hefermehl, Wolfgang/Eckardt, Ulrich/Kropff, Bruno, München.

Heintges, Sebastian (2005), Bilanzkultur und Bilanzpolitik in den USA und in Deutschland. Einflüsse auf die Bilanzpolitik börsennotierter Unternehmen, 3. Aufl., Sternenfels.

Helm, Ronald (2003), Vergütungsstrukturen des Aufsichtsrats mittelständischer, nicht börsennotierter Aktiengesellschaften, in: DB, 56. Jg., S. 2718-2723.

Helm, Roland (2004a), Die Aktiengesellschaft und ihr Aufsichtsrat im Mittelstand, Lohmar/Köln.

Helm, Roland (2004b), Motive der Rechtsformwahl: Die Aktiengesellschaft als Rechtsform mittelständischer Unternehmen, in: AG, 49. Jg., S. R369-371.

Helm, Roland (2004c), Zufriedenheit mit der Entscheidung für die Aktiengesellschaft als Rechtsform bei mittelständischen Unternehmen, in: AG, 49. Jg., S. R407-410.

Henn, Günter (2002), Handbuch des Aktienrechts, 7. Aufl., Heidelberg.

Henn, Harry G./Alexander, John R. (1983), Laws of Corporations and other Business Enterprises, 3. Aufl., St. Paul.

Hennrichs, Joachim (1999a), Der steuerrechtliche sog. Maßgeblichkeitsgrundsatz gem. § 5 EStG - Stand und Perspektiven, in: StuW, 76. Jg., S. 138-153.

Hennrichs, Joachim (1999b), Wahlrechte im Bilanzrecht der Kapitalgesellschaften unter besonderer Berücksichtigung der EG-Bilanz-Richtlinie, Köln. 
Hennrichs, Joachim (2004), IAS für die Einzelbilanz? - Nationale und europarechtliche Aspekte, in: Gesellschaftsrecht 2003. Tagungsband zum RWS-Forum am 8. und 9. Mai 2003 in Berlin, hrsg. von Henze, Hartwig/Hoffmann-Becking, Michael, Köln, S. 101-138.

Hennrichs, Joachim (2005), Bilanzgestützte Kapitalerhaltung, HGB-Jahresabschluß und Maßgeblichkeitsprinzip - Dinosaurier der Rechtsgeschichte?, in: StuW, 82. Jg., S. 256-264.

Henze, Hartwig (2003), Holzmüller vollendet das 21. Lebensjahr, in: Festschrift für Peter Ulmer zum 70. Geburtstag, hrsg. von Habersack, Mathias/Hüffer, Uwe/Hommelhoff, Peter/Schmidt, Karsten, Berlin, S. 211-242.

Herzig, Norbert (2001), Notwendigkeit und Umsetzungsmöglichkeiten eines gespaltenen Rechnungslegungsrechts (Handels- und Steuerbilanz), in: KoR, 1. Jg., S. 154-159.

High Level Group (2002a), Bericht der Hochrangigen Gruppe von Experten auf dem Gebiet des Gesellschaftsrechts über die Abwicklung von Übernahmeangeboten, Brüssel, 10. Januar 2002, in: http://europa.eu.int/comm/internal_market/company/docs/takeoverbids/ 2002-01-hlg-report_de.pdf (Stand: 29.05.2005).

High Level Group (2002b), Moderne gesellschaftsrechtliche Rahmenbedingungen in Europa: Ein Konsultationspapier der Hochrangigen Expertengruppe auf dem Gebiet des Gesellschaftsrechts, in: http://europa.eu.int/comm/internal_market/de/company/company/ modern/consult/consult_de.pdf (Stand: 17.05.2005).

High Level Group (2002c), Bericht der Hochrangigen Gruppe von Experten auf dem Gebiet des Gesellschaftsrechts über moderne gesellschaftsrechtliche Rahmenbedingungen in Europa, Brüssel, 4. November 2002, in: http://ec.europa.eu/internal_market/company/docs/ modern/report_de.pdf (Stand: 01.06.2006).

Hillebrandt, Franca (2001), Entflechtung der „Deutschland $A G$ “ durch Steuerfreiheit von Veräußerungsgewinnen?, in: DBW, 61. Jg., S. 711-726.

Hills, George S. (1935), Model Corporation Act, in: Harv. L. Rev., Vol. 48, S. 1334-1380.

Hinz, Michael (2002), Der Konzernabschluss als Instrument zur Informationsvermittlung und Ausschüttungsbemessung, Wiesbaden.

Hirte, Heribert (2000a), Ausgewählte Fragen zu Stock-option-Plänen und zum Erwerb eigener Aktien, in: Gesellschaftsrecht 1999. Tagungsband zum RWS-Forum am 13. und 14. September 1999 in Berlin, hrsg. von Schmidt, Karsten/Riegger, Bodo, Köln, S. 211-249.

Hirte, Heribert (2000b), Der Einfluß neuer Informationstechniken auf das Gesellschaftsrecht und die corporate-governance-Debatte, in: Corporations, Capital Markets and Business in the Law, Liber Amicorum Richard M. Buxbaum, hrsg. von Baums, Theodor/Hopt, Klaus J./Horn, Norbert, London et al., S. 283-297.

Hirte, Heribert (2000c), Kapitalschutz (Gläubiger- und Eignerschutz) im Europäischen Recht, in: Systembildung und Systemlücken in Kerngebieten des Europäischen Privatrechts, hrsg. von Grundmann, Stefan, Tübingen, S. 211-234.

Hirte, Heribert (2002), Die Europäische Aktiengesellschaft, in: NZG, 5. Jg., S. 1-10.

Hirte, Heribert (2003), Kapitalgesellschaftsrecht, 4. Aufl., Köln. 
Hirte, Heribert (2005), Was bringt das abgesenkte Startkapital bei GmbHs?, in: FAZ, Nr. 148 vom 29.06.2005, S. 23.

Hirth, Hans/Neus, Werner (2001), Ad-hoc-Publizität und Wettbewerb beim Insiderhandel, in: WiSt, 30. Jg., S. 101-104.

Hitz, Jörg-Markus (2005), Fair value in der IFRS-Rechnungslegung - Konzeption, Inhalt und Zweckmäßigkeit -, in: WPg, 58. Jg., S. 1013-1027.

Hoffmann, Wolf-Dieter/Lüdenbach, Norbert (2004), Bilanzrechtsreformgesetz - Seine Bedeutung für den Einzel- und Konzernabschluß der $\mathrm{GmbH}$, in: GmbHR, 95. Jg., S. 145-150.

Hoffmann, Wolf-Dieter/Zeimes, Markus (2004), § 6: Erstmalige Anwendung, in: Haufe IAS/ IFRS-Kommentar, hrsg. von Lüdenbach, Norbert/Hoffmann, Wolf-Dieter, 2. Aufl., Freiburg im Breisgau.

Hoffmann-Becking, Michael (1999), Gewinnverwendung, in: Münchener Handbuch des Gesellschaftsrechts. Band 4. Aktiengesellschaft, hrsg. von Hoffmann-Becking, Michael, 2. Aufl., München, S. 610-618.

Holzborn, Timo/Bunnemann, Jan (2003), Gestaltung einer Sachausschüttung und Gewährleistung im Rahmen der Sachdividende, in: AG, 48. Jg., S. 671-678.

Hommelhoff, Peter (1998), Europäisches Bilanzrecht im Aufbruch, in: RabelsZ, 62. Jg., S. 381-404.

Hommelhoff, Peter (2000), Konzeptionelle Grundfragen einer Bilanzrechtsreform, in: Die Zukunft des deutschen Bilanzrechts im Zeichen internationaler Rechnungslegung und privater Standardsetzung, hrsg. von Kleindiek, Detlef/Oehler, Wolfgang, Köln, S. 141-159.

Hommelhoff, Peter (2001), Einige Bemerkungen zur Organisationsverfassung der Europäischen Aktiengesellschaft, in: AG, 46. Jg., S. 279-288.

Hopt, Klaus J. (1977), Vom Aktien- und Börsenrecht zum Kapitalmarktrecht? Teil 2: Die deutsche Entwicklung im internationalen Vergleich, in: ZHR, 141. Jg., S. 389-441.

Hopt, Klaus J. (2000), Gemeinsame Grundsätze der Corporate Governance in Europa? Überlegungen zum Einfluß der Wertpapiermärkte auf Unternehmen und ihre Regulierung und zum Zusammenwachsen von common law und civil law im Gesellschafts- und Kapitalmarktrecht, in: ZGR, 29. Jg., S. 779-818.

Hopt, Klaus J. (2001), Auf dem Weg zum deutschen Übernahmegesetz. - Gemeinsamer Standpunkt des Rates zur 13. Richtlinie und Diskussionsentwurf des Übernahmegesetzes -, in: Festschrift für Hans Georg Koppensteiner zum 65. Geburtstag, hrsg. von Kramer, Ernst, Wien, S. 61-89.

Hopt, Klaus J. (2002a), Gesellschaftsrecht im Wandel, in: Festschrift für Herbert Wiedemann zum 70. Geburtstag, hrsg. von Wank, Ralf/Hirte, Heribert/Frey, Kaspar, München, S. 1013-1032.

Hopt, Klaus J. (2002b), Grundsatz- und Praxisprobleme nach dem Wertpapiererwerbs- und Übernahmegesetz, in: ZHR, 166. Jg., S. 383-432.

Hopt, Klaus J. (2002c), Takeover Regulations in Europe - The Battle for the 13th directive on takeovers, in: AJCL, Vol. 15., S. 1-18. 
Hopt, Klaus J. (2002d), Unternehmensführung, Unternehmenskontrolle, Modernisierung des Aktienrechts - Zum Bericht der Regierungskommission Corporate Governance, in: Corporate Governance, hrsg. von Hommelhoff, Peter/Lutter, Marcus/Schmidt, Karsten/ Schön, Wolfgang/Ulmer, Peter, Heidelberg, S. 27-67.

Hopt, Klaus J. (2003), Corporate Governance und Gesellschaftsrecht in Europa: Der Rahmenplan der Europäischen Kommission, in: Wirtschaftsdienst, 83. Jg., S. 423-427.

Hopt, Klaus J. (2005), Europäisches Gesellschaftsrecht und deutsche Unternehmensverfassung - Aktionsplan und Interdependenzen, in: ZIP, 26. Jg., S. 461-474.

Horsch, Andreas/Richard, Marc (2003), Perspektiven der internationalen Kapitalmarktregulierung. Bericht über einen Workshop an der Ruhr-Universität Bochum anlässlich des 75. Geburtstags von Prof. Dr. Dr. h.c. mult. Walther Busse von Colbe sowie des 70. Geburtstags von Prof. Dr. Dr. h.c. Joachim Süchting, in: KoR, 3. Jg., S. 360-364.

Hübner, Ulrich (1985), Die Ausgliederung von Unternehmensteilen in aktien- und aufsichtsrechtlicher Sicht, in: Festschrift für Walter Stimpel zum 68. Geburtstag, hrsg. von Lutter, Marcus/Mertens, Hans-Joachim/Ulmer, Peter, Berlin/New York, S. 791-809.

Hueck, Götz (1991), Gesellschaftsrecht, 19. Aufl., München.

Hueck, Götz/Windbichler, Christine (2003), Gesellschaftsrecht, 20. Aufl., München.

Hüffer, Uwe (1979), Harmonisierung des aktienrechtlichen Kapitalschutzes. Die Durchführung der Zweiten EG-Richtlinie zur Koordinierung des Gesellschaftsrechts, in: NJW, 32. Jg., S. 1065-1070.

Hüffer, Uwe (2003), Mannesmann/Vodafone: Präsidiumsbeschlüsse des Aufsichtsrats für die Gewährung von „Appreciation Awards“ an Vorstandsmitglieder, in: BB, Beilage $7 \mathrm{zu}$ Heft 43, 58. Jg., S. 1-38.

Hüffer, Uwe (2004), Die Kritik der Staatsanwaltschaft bleibt im Allgemeinen stecken und trifft auch nicht zu, in: FAZ, Nr. 17 vom 21.01.2004, S. 16.

Hüffer, Uwe (2006), Aktiengesetz, 7. Aufl., München.

Huke, Rainer/Prinz, Thomas (2004), Das Drittelbeteiligungsgesetz löst das Betriebsverfassungsgesetz $1952 \mathrm{ab}$, in: BB, 59. Jg., S. 2633-2639.

Hulle, Karel van (2000), Aktuelle Entwicklungen im europäischen Gesellschaftsrecht, in: EWS, 11. Jg., S. 521-526.

Hulle, Karel van/Lanfermann, Georg, Mitteilung der Europäischen Kommission zur Stärkung der Abschlussprüfung, in: BB, 58. Jg., S. 1323-1328.

Hulle, Karel van/Maul, Silja (2004), Aktionsplan zur Modernisierung des Gesellschaftsrechts und Stärkung der Corporate Governance, in: ZGR, 33. Jg., S. 484-505.

IASB (2004), Preliminary Views on Accounting Standards for Small and Medium-sized Entities. Discussion Paper, June 2004, in: http://www.iasb.org/uploaded_files/documents/8_891_pv-sme.pdf (Stand: 09.05.2005).

IASB (2005), Accounting Standards for Non-Publicly Accountable Entities (NPAEs), in: IASB Update, February 2005, S. 1. 
IDW (2002a), IDW Stellungnahme: A Modern Regulatory Framework for Company Law in Europe: A Consultative Document of the High Level Group of Company Law Experts, in: WPg, 55. Jg., S. 776-777.

IDW (2002b), IDW Stellungnahme: EU-Verordnung zur Anwendung internationaler Rechnungslegungsstandards; Vorschlag für eine Richtlinie zur Änderung der EU-Bilanzrichtlinien; Empfehlungen der EU-Kommisssion zur Unabhängigkeit des Abschlussprüfers, in: WPg, 55. Jg., S. 983-990.

IDW (2005), IDW Stellungnahme: Vorschläge der EU-Kommission zur Änderung der 2. EURichtlinie (77/91/EWG), in: WPg, 58. Jg., S. 178-181.

Ihlas, Horst (1997), Organhaftung und Haftpflichtversicherung, Berlin.

Ihrig, Hans-Christoph (2005), Reform des GmbH-Rechts: MindestkapG - Papiertiger oder praxisgerechte Gesetzgebung? BB-Kurzinterview, in: BB, 60. Jg., Heft 20, S. IV-VI.

Jaeger, Michael (2004), Aktienrückerwerb bei asymmetrischer Informartionsverteilung, Frankfurt am Main u.a.

Jensen, Michael C./Meckling, William H. (1976), Theory of the Firm: Managerial Behavior, Agency Costs and Ownership Structure, in: JoFE, Vol. 3, S. 305-360.

Jensen, Michael C./Ruback, Richard S. (1983), The Market for Corporate Control: The Scientific Evidence, in: JoFE, Vol. 11, S. 5-50.

Jessen, Ulf/Weller, Heino (2005), Fortentwicklung des deutschen Bilanzrechts - Die Möglichkeiten eines Bilanzrechtsmodernisierungsgesetzes für den Einzelabschluss (Teil I), in: DStR, 43. Jg., S. 489-493.

Kästle, Martina (2003), Rechtsfragen der Verwendung von Covenants in Kreditverträgen, Berlin.

Kahan, Marcel (2003), Legal Capital Rules and the Structure of Corporate Law: Some Observations on the Differences Between European and U.S. Approaches, in: Capital Markets and Company Law, hrsg. von Hopt, Klaus J./Wymeersch, Eddy, Oxford, S. 145-149.

Kahan, Marcel/Kamar, Ehud (2002), The Myth of State Competition in Corporate Law, in: Stan. L. Rev., Vol. 55, S. 679-749.

Kahle, Holger (2002a), Bilanzieller Gläubigerschutz und internationale Rechnungslegungsstandards, in: ZfB, 72. Jg. 2002, H. 7, S. 695-711.

Kahle, Holger (2002b), Internationale Rechnungslegung und ihre Auswirkungen auf Handels- und Steuerbilanz, Wiesbaden.

Kahle, Holger (2003), Zur Zukunft der Rechnungslegung in Deutschland: IAS im Einzelund Konzernabschluss?, in: WPg, 56. Jg., S. 262-275.

Kaiser, Karin (2005), Erweiterung der zukunftsorientierten Lageberichterstattung: Folgen des Bilanzrechtsreformgesetzes für Unternehmen, in: DB, 58. Jg., S. 345-353.

Kajüter, Peter (2004a), Berichterstattung über Chancen und Risiken im Lagebericht. Auswirkungen des Referentenentwurfs für das Bilanzrechtsreformgesetz, in: BB, 59. Jg., S. 427-433. 
Kajüter, Peter (2004b), Der Lagebericht als Instrument einer kapitalmarktorientierten Rechnungslegung - Umfassende Reformen nach dem Entwurf zum BilReG und E-DRS 20 -, in: DB, 57. Jg., S. 197-203.

Kalay, Avner (1982), Stockholder-Bondholder Conflict and Dividend Constraints, in: JoFE, Vol. 10, S. 211-233.

Kallmeyer, Harald (2001), SLIM. Schlankheitskur für das EU-Gesellschaftsrecht, in: AG, 46. Jg., S. 406-409.

Kaminski, Horst (1972), Vorschlag einer 5. Richtlinie der Kommission der Europäischen Gemeinschaften, in: WPg, 25. Jg., S. 633-638.

Karsten, Johann-Friedrich (1967), Die Deformierung der handelsrechtlichen Rechnungslegung durch steuerliche Maßnahmen der Wirtschaftsförderung, in: BB, 22. Jg., S. 425-428.

Kehl, Donald (1941), Corporate Dividends. Legal and Accounting Problems Pertaining to Corporate Distributions, New York.

Keitz, Isabel von/Stibi, Bernd (2004), Rechnungslegung nach IAS/IFRS - auch ein Thema für den Mittelstand? - Ergebnisse einer Befragung mittelständischer Unternehmen -, in: KoR, 4. Jg., S. 423-429.

Kern, Konrad (2004), Überseering - Rechtsangleichung und gegenseitige Anerkennung. Eine Untersuchung zum Wettbewerb der Gesetzgeber im Europäischen Gesellschaftsrecht, Berlin.

Keustermans, Jeff (1986), Countertrends in Financial Provisions for the Protection of Corporate Creditors: The Model Business Corporation Act and the E.E.C. Corporate Directives, in: Denv. J. Int'l L. \& Pol'y, Vol. 14, S. 275-298.

Kiel, Peter (1994), Internationales Kapitalanlegerschutzrecht, Berlin/New York.

Kieso, Donald E./Weygandt, Jerry J./Warfield, Terry D. (2001), Intermediate Accounting, 10. Aufl., New York u.a.

Kieso, Donald E./Weygandt, Jerry J./Warfield, Terry D. (2004), Intermediate Accounting, 11. Aufl., New York u.a.

Kirchner, Christian (1985), Ökonomische Überlegungen zum Konzernrecht, in: ZGR, 14. Jg., S. 214-234.

Kirsch, Hans-Jürgen (2002), Vom Bilanzrichtlinien-Gesetz zum Transparenz- und Publizitätsgesetz - Die Entwicklung der deutschen Bilanzierungsnormen in den vergangenen 20 Jahren -, in: WPg, 55. Jg., S. 743-755.

Kirsch, Hans-Jürgen (2003), Zur Frage der Umsetzung der Mitgliedstaatenwahlrechte der EU-Verordnung zur Anwendung der IAS/IFRS, in: WPg, 56. Jg., S. 275-278.

Kirsch, Hans-Jürgen (2005), Die Umsetzung der Fair Value-Richtlinie, in: Anpassung des deutschen Bilanzrechts an internationale Standards - Bilanzrechtsreformgesetz und Bilanzkontrollgesetz -, Vorträge und Diskussionen zum 20. Münsterischen Tagesgespräch des Münsteraner Gesprächskreis Rechnungslegung und Prüfung e.V. am 27. Mai 2004, hrsg. von Baetge, Jörg/Kirsch, Hans-Jürgen, Düsseldorf, S. 11-33. 
Kirsten, Roland (2004), Deutscher Corporate Governance-Kodex: Die rechtmäßige Besetzung von Aufsichtsratsausschüssen am Beispiel des Prüfungsausschusses, in: BB, 59. Jg., S. 173-175.

Kirzner, Israel M. (1978), Wettbewerb und Unternehmertum, Tübingen.

Klausner, Michael (1995), Corporations, Corporate Law, and Networks of Contracts, in: Va. L. Rev., Vol. 81, S. 757-852.

Klein, William A./Coffee, John C. Jr (2002), Business Organisation and Finance. Legal and Economic Principles, 8. Aufl., Westbury.

Kleindiek, Detlef (2001), Entstehung und Fälligkeit des Verlustausgleichsanspruchs im Vertragskonzern, in: ZGR, 30. Jg., S. 479-496.

Klose-Mokroß, Lydia (1997), Gläubigerschutz im Kapitalgesellschaftsrecht am Beispiel der Lehre von der verdeckten Sacheinlage, Frankfurt am Main u.a.

Klühs, Hannes (2006), Präsenzbonus für die Teilnahme an der Hauptversammlung, in: ZIP, 27. Jg., S. 107-118.

Klunzinger, Eugen (2004), Grundzüge des Gesellschaftsrechts, 13. Aufl., München.

Knobbe-Keuk, Brigitte (1993), Bilanz- und Unternehmenssteuerrecht, 9. Aufl., Köln.

Knorr, Liesel/Zeimes, Markus (2005), IASB-Projekt zu Accounting Standards for NonPublicly Accountable Entities: Status der Diskussion, in: BB-Beilage 3, 60. Jg., S. 20-22.

Königsegger WalderBräu AG (2003), Geschäftsbericht vom 01.04.-31.12.2003.

Kohl, Reinhard (1991), Die Kompetenz zur Bildung von Gewinnrücklagen im Aktienkonzern. Eine Untersuchung unter Einschluß methodologischer und rechtshistorischer Aspekte, Berlin.

Kolvenbach, Walter (1983), Die Fünfte EG-Richtlinie über die Struktur der Aktiengesellschaft (Strukturrichtlinie), in: DB, 36. Jg., S. 2235-2241.

Koppensteiner, Hans-Georg (2004a), Vorb. § 291, in: Kölner Kommentar zum Aktiengesetz, hrsg. von Zöllner, Wolfgang/Noack, Ulrich, 3. Aufl., Köln u.a.

Koppensteiner, Hans-Georg (2004b), Vorb. § 300, in: Kölner Kommentar zum Aktiengesetz, hrsg. von Zöllner, Wolfgang, 2. Aufl., Köln u.a.

Koppensteiner, Hans-Georg (2004c), „Holzmüller“ auf dem Prüfstand des BGH, in: Der Konzern, 2. Jg., S. 381-386.

Kornblum, Udo (2003a), Aktuelle bundesweite Rechtstatsachen zum Unternehmens- und Gesellschaftsrecht, in: GmbHR, 94. Jg., S. 1157-1173.

Kornblum, Udo (2003b), Bemerkungen zum e.V., in: NJW, 56. Jg., S. 3671-3673.

Kornblum, Udo (2004), Gesellschaften in Bewegung, in: BB, 59. Jg., Heft 25, S. I.

Kostrzewa, Beate (1995), Feststellung des Jahresabschlusses und Gewinnverwendung bei Kapitalgesellschaften nach geplantem EG-Recht, Aachen.

Koziol, Tina (2004), Der Überweisungsvertrag. Eine rechtliche Analyse unter besonderer Berücksichtigung der Rechte und Pflichten aus dem Verhältnis zwischen Überweisendem und überweisendem Kreditinstitut, Hamburg. 
KPMG (2003), Rechnungslegung nach US-amerikanischen Grundsätzen. Grundlagen der US-GAAP und SEC-Vorschriften, 3. Aufl., Düsseldorf.

KPMG/Fachhochschule Münster (Hrsg.) (2004), Rechnungslegung nach IAS/IFRS - auch ein Thema für den Mittelstand? Ergebnisse einer empirischen Befragung des (gehobenen) Mittelstands in Nordrhein-Westfalen, in: http:/www.kpmg.de/library/pdf/ 040702 Rechnungslegung_nach_IAS_IFRS_fuer_den_mittelstand_de.pdf (Stand:13.10.2005).

Kraft, Alfons (1986), $\S 11$, in: Kölner Kommentar zum Aktiengesetz, hrsg. von Zöllner, Wolfgang, 2. Aufl., Köln u.a.

Kraft, Alfons/Kreutz, Peter (2000), Gesellschaftsrecht, 11. Aufl., Neuwied.

Kreidmann, Arthur M. (1957), Dividends - Changing Patterns, in: Colum. L. Rev., Vol. 57, S. 372-385.

Kretschik, Klaus (1992), Die Gewinnverwendung im Konzern unter Berücksichtigung konzernhaftungsrechtlicher Rahmenbedingungen, Bochum.

Krieger, Gerd (1999), Abhängige Unternehmen und faktische Konzerne, in: Münchener Handbuch des Gesellschaftsrechts. Band 4. Aktiengesellschaft, hrsg. von HoffmannBecking, Michael, 2. Aufl., München, S. 950-1015.

Kronstein, Heinrich/Claussen, Carsten P. (1960), Publizität und Gewinnverteilung im neuen Aktienrecht, Frankfurt am Main.

Kropff, Bruno (1965), Aktiengesetz, Düsseldorf.

Kropff, Bruno (1991), 25 Jahre Aktiengesetz - was waren die Ziele und was wurde erreicht?, in: 25 Jahre Aktiengesetz. Ein Symposium der Deutschen Schutzvereinigung für Wertpapierbesitz e.V. (DSW) am 30. Oktober 1990 in Bonn, hrsg. von Lutter, Marcus, Düsseldorf, S. 19-51.

Kropff, Bruno (2004), Mitwirkung des Aufsichtsrats bei einzelnen Maßnahmen der Geschäftsführung, in: Arbeitshandbuch für Aufsichtsratsmitglieder, hrsg. von Semler, Johannes/Schenck, Kersten von, 2. Aufl., München, S. 379-478.

Kroschel, Jörg (2000), Die Federal Income Tax der Vereinigten Staaten von Amerika, Düsseldorf.

Krumnow, Jürgen (1994), Die deutsche Rechnungslegung auf dem Weg ins Abseits? Ein Ausblick nach der vorläufig abgeschlossenen EG-Harmonisierung, in: Bilanzrecht und Kapitalmarkt, Festschrift zum 65. Geburtstag von Prof. Dr. Dr. h.c. Dr. h.c., hrsg. von Ballwieser, Wolfgang/Böcking, Hans-Joachim/Drukarczyk, Jochen/Schmidt, Reinhard H., Düsseldorf, S. 681-698.

Kübler, Friedrich (1989), Aktie, Unternehmensfinanzierung und Kapitalmarkt, Köln.

Kübler, Friedrich (1990), Kapitalmarktgerechte Aktien?, in: WM, 44. Jg., S. 1853-1858.

Kübler, Friedrich (1991), Haftungstrennung und Gläubigerschutz im Recht der Kapitalgesellschaften. - Zur Kritik der „Autokran“-Doktrin des Bundesgerichtshofes -, in: Festschrift für Theodor Heinsius zum 65. Geburtstag, hrsg. von Kübler, Friedrich/Mertens, Hans-Joachim/Werner, Winfried, Berlin/New York, S. 397-424. 
Kübler, Friedrich (1993), Bankenhaftung als Notbehelf der präventiven Kapitalaufbringungskontrolle? Überlegungen zum Anwendungsbereich von $\S 37$ Abs. 1 S. 4 AktG, in: ZHR, 157. Jg., S. 196-212.

Kübler, Friedrich (1994), Aktienrechtsreform und Unternehmensverfassung, in: AG, 39. Jg., S. 141-148.

Kübler, Friedrich (1995a), Gesellschaftsrecht versus Kapitalmarktrecht - zwei Ansätze?, in: SZW/ RSDA, 67. Jg., S. 223-227.

Kübler, Friedrich (1995b), Institutioneller Gläubigerschutz oder Kapitalmarkttransparenz? Rechtsvergleichende Überlegungen zu den „stillen Reserven“, in: ZHR, 159. Jg., S. 550-566.

Kübler, Friedrich (1995c), Vorsichtsprinzip versus Kapitalmarktinformation - Bilanzprobleme aus der Perspektive der Gesellschaftsrechtsvergleichung -, in: Rechenschaftslegung im Wandel, Festschrift für Wolfgang Dieter Budde, hrsg. von Förschle, Gerhart/Kaiser, Klaus/Moxter, Adolf, München, S. 361-375.

Kübler, Friedrich (1998a), Shareholder Value: Eine Herausforderung für das Deutsche Recht?, in: Festschrift für Wolfgang Zöllner zum 70. Geburtstag, hrsg. von Lieb, Manfred/Noack, Ulrich/Westermann, Harm P., Köln u.a., S. 321-335.

Kübler, Friedrich (1998b), Unternehmensfinanzierung und gesetzliches Garantiekapital in Europa. Einführung, in: AG, 43. Jg., S. 345.

Kübler, Friedrich (1999a), Aufsichtsratsmitbestimmung im Gegenwind der Globalisierung, in: The International Lawyer, Freudesgabe für Wulf $\mathrm{H}$. Döser, hrsg. von Kübler, Friedrich/Scherer, Joachim/Treek, Joachim, Baden-Baden.

Kübler, Friedrich (1999b), Gesellschaftsrecht, 5. Aufl., Heidelberg.

Kübler, Friedrich (2000), Fragen und Wünsche des Gesellschafts- und Kapitalmarktrechts an das Recht der Rechnungslegung, in: ZGR, 29. Jg., S. 550-564.

Kübler, Friedrich (2002), The Organization of Global Financial Markets, in: JITE, Vol. 158, S. 5-23.

Kübler, Friedrich (2003a), Leitungsstrukturen der Aktiengesellschaft und die Umsetzung des SE-Statuts, in: ZHR, 167. Jg., S. 222-234.

Kübler, Friedrich (2003b), Rechnungslegung im Dienste finanzieller Stabilität?, in: NZG, 6. Jg., S. 358-362.

Kübler, Friedrich (2003c), The Rules of Capital Under Pressure of the Securities Markets, in: Capital Markets and Company Law, hrsg. von Hopt, Klaus J./Wymeersch, Eddy, Oxford, S. 95-114.

Kübler, Friedrich/Schmidt, Reinhard H. (1988), Gesellschaftsrecht und Konzentration, Berlin.

Kühnberger, Manfred/Schmidt, Thorsten (1999), Der Konzernabschluß als Ausschüttungsbemessungsgrundlage. Eine theoretische Analyse und eine empirische Bestandsaufnahme zur Ausschüttungspolitik deutscher Aktienkonzerne, in: ZfB, 69. Jg., S. 1263-1291.

Kümpel, Siegfried (2004), Bank- und Kapitalmarktrecht, 3. Aufl., Köln. 
Küting, Karlheinz (1993), Europäisches Bilanzrecht und Internationalisierung der Rechungslegung, in: BB, 48 Jg., S. 30-38.

Küting, Karlheinz (1997), Der Wahrheitsgehalt deutscher Bilanzen, in: DStR, 35. Jg., S. 84-91.

Küting, Karlheinz (2004a), Die Bilanzierung im Umbruch - Einführungsreferat zum Experten-Streitgespräch in Saarbrücken am 30.6.2004, in: StuB, 6. Jg., S. 683-686.

Küting, Karlheinz (2004b), Saarbrücker Thesen zur Fortentwicklung des deutschen Bilanzrechts, in: BB, 59. Jg., Heft 30, S. I.

Küting, Karlheinz (2005), Fair value - ein Garant für Fair play, in: FAZ, Nr. 194 vom 22.08.2005, S. 20.

Küting, Karlheinz/Ranker, Daniel/Wohlgemuth, Frank (2004), Auswirkungen von Basel II auf die Praxis der Rechnungslegung - Ist eine ausschließlich ratinginduzierte Umstellung der Rechnungslegung auf IFRS sinnvoll? -, in: FB, 6. Jg., S. 93-104.

Küting, Karlheinz/Reuter, Michael (2005), Werden stille Reserven in Zukunft (noch) stiller? - Machen die IFRS die Bilanzanalyse überflüssig oder weitgehend unmöglich?, in: BB, 60. Jg., S. 706-713.

Küting, Karlheinz/Weber, Claus-Peter (2005), Der Konzernabschluss, 9. Aufl., Stuttgart.

Kuhner, Christoph (2005), Zur Zukunft der Kapitalerhaltung durch bilanzielle Ausschüttungssperren im Gesellschaftsrecht der Staaten Europas, in: ZGR, 34. Jg., S. 753-787.

Kummert, Richard O. (1980), State Statutory Restrictions on Financial Distributions by Corporations to Shareholders, Part I, in: Wash. L. Rev., Vol. 55, S. 359-403.

Kummert, Richard O. (1984), State Statutory Restrictions on Financial Distributions by Corporations to Shareholders, Part II, in: Wash. L. Rev., Vol. 59, S. 187-287.

Kunz, Harald (1985), Marktsystem und Information. ,Konstitutionelle Unwissenheit' als Quelle von, Ordnung', Tübingen.

Kuthe, Thorsten (2004), Die Fortsetzung der Aktienrechtsreform durch den Entwurf eines Gesetzes zur Unternehmensintegrität und Modernisierung des Anfechtungsrechts, in: BB, 59. Jg., S. 449-451.

Lanfermann, Georg (2004), Vorschlag der EU-Kommission zur Modernisierung der EUPrüferrichtlinie, in: DB, 57. Jg., S. 609-613.

Lanfermann, Georg/Maul, Silja (2003), SEC-Ausführungsregelungen zum Sarbanes-Oxley Act - Auswirkungen auf Rechnungslegung und Abschlussprüfung europäischer Unternehmen -, in: DB, 56. Jg., S. 349-355.

Lanfermann, Georg/Maul, Silja (2004), EU-Übernahmerichtlinie: Aufstellung und Prüfung des Lageberichts, in: BB, 59. Jg., S. 1517-1521.

Lanfermann, Josef (1992), Meinungsspiegel, in: BFuP, 44. Jg., S. 441-455.

Lange, Knut W. (2004), Berichterstattung in Lagebericht und Konzernlagebericht nach dem geplanten Bilanzrechtsreformgesetz, in: ZIP, 25. Jg., S. 981-987.

Lange, Oliver (2003), Zustimmungsvorbehaltspflicht und Kataloghaftung des Aufsichtsrats nach neuem Recht, in: DStR, 41. Jg., S. 376-381. 
Langguth, Heike/Engelmann, Andreas (2005), Empirische Untersuchung zur Segmentberichterstattung am deutschen Kapitalmarkt, in: DB, 58. Jg., S. 621-628.

Larenz, Karl (1991), Methodenlehre der Rechtswissenschaft, 6. Aufl., Berlin u.a.

Lee, Won-Ho (1987), Der Schutz der Minderheitsaktionäre der Obergesellschaft, Münster.

Leffson, Ulrich (1987), Die Grundsätze ordnungsmäßiger Buchführung, 7. Aufl., Düsseldorf.

Leftwich, Richard (1983), Accounting Information in Private Markets: Evidence from Private Lending Agreements, in: AR, Vol. 58., S. 23-42.

Lehertshuber, Bonaventura (1986a), Unternehmensvertragsrecht und Konzernhandelsbilanz, Frankfurt am Main u.a.

Lehertshuber, Bonaventura (1986b), Unternehmensvertragsrecht und Konzernhandelsbilanz, in: BFuP, 38. Jg., S. 326-340.

Lehertshuber, Bonaventura (1989), Rücklagenbildung im Konzern - Regelungslücke des Aktienrechts? - Erwiderung zu dem Beitrag von Beckmann, DB 1989 S. 940 -, in: DB, 42. Jg., S. 1534-1535.

Leinekugel, Magdalena (2001), Die Sachdividende im deutschen und europäischen Aktienrecht, Köln u.a.

Leippe, Britta (2002), Die Bilanzierung von Leasinggeschäften nach deutschem Handelsrecht und US-GAAP, Frankfurt am Main u.a.

Leuz, Christian (1996), Rechnungslegung und Kreditfinanzierung. Zum Zusammenhang von Ausschüttungsbegrenzung, bilanzieller Gewinnermittlung und vorsichtiger Rechnungslegung, Frankfurt am Main u.a.

Leuz, Christian (1998), The Role of Accrual Accounting in Restricting Dividends to Shareholders, in: EAR, Vol. 7, S. 579-604.

Leuz, Christian/Deller, Dominic/Stubenrath, Michael, An International Comparison of Accounting-Based Payout Restrictions in the United States, United Kingdom and Germany, in: ABR, Vol. 28., S. 111-129.

Leven, Franz-Josef (2003), Aktiengesellschaften in Deutschland, in: AG, 48. Jg., S. R189-192.

Lieder, Jan (2004), Zustimmungsvorbehalte des Aufsichtsrats nach neuer Rechtslage, in: DB, 57. Jg., S. 2251-2255.

Linnhoff, Ulrich/Pellens, Bernhard (1987), Ausschüttungspolitik deutscher Konzerne. Eine empirische Untersuchung zum Ausschüttungsverhalten deutscher Konzernobergesellschaften, in: ZfbF, 39. Jg., S. 987-1006.

Linnhoff, Ulrich/Pellens, Bernhard (1994), Kreditwürdigkeitsprüfung mit den neuen Jahresabschlußkennzahlen des Bundesaufsichtsamts für das Versicherungswesen (BAV), in: DB, 47. Jg., S. 589-594.

Lüdenbach, Norbert/Hoffmann, Wolf-Dieter (2002), Enron und die Umkehrung der Kausalität bei der Rechnungslegung, in: DB, 55. Jg., S. 1169-1175.

Lutter, Marcus (1964), Kapital, Sicherung der Kapitalaufbringung und Kapitalerhaltung in den Aktien- und GmbH-Rechten der EWG, Karlsruhe. 
Lutter, Marcus (1974a), Teilfusionen im Gesellschaftsrecht, in: Wirtschaftsfragen der Gegenwart, Festschrift für Carl Hans Barz zum 65. Geburtstag, hrsg. von Fischer, Robert/ Möhring, Philipp/Westermann, Harry, Berlin/New York, S. 199-218.

Lutter, Marcus (1974b), Zur Binnenstruktur des Konzerns, in: Festschrift für Harry Westermann zum 65. Geburtstag, hrsg. von Hefermehl, Wolfgang/Gmür, Rudolf/Brox, Hans, Karlsruhe, S. 347-368.

Lutter, Marcus (1975), Die Entwicklung des Gesellschaftsrechts in Europa, in: EuR, 10. Jg., S. 44-72.

Lutter, Marcus (1978), Zur Europäisierung des deutschen Aktienrechts, in: Konflikt und Ordnung. Festschrift für Murad Ferid zum 70. Geburtstag, hrsg. von Heldrich, Andreas/Henrich, Dieter/Sonnenberger, Hans Jürgen, München, S. 599-620.

Lutter, Marcus (1982), Die zivilrechtliche Haftung in der Unternehmensgruppe, in: ZGR, 11. Jg., S. 244-275.

Lutter, Marcus (1983), Vom formellen Mindestkapital zu materiellen Finanzierungsregeln im Recht der Kapitalgesellschaften, in: Festschrift für Stefan Riesenfeld aus Anlass seines 75. Geburtstages, hrsg. von Jayme, Erik/Kegel, Gerhard/Lutter, Marcus, Heidelberg, S. 165-185.

Lutter, Marcus (1987), Rücklagenbildung im Konzern, in: Bilanz- und Konzernrecht, Festschrift zum 65. Geburtstag von Dr. Dr. h. c. Reinhard Goerdeler, hrsg. von Havermann, Hans, Düsseldorf, S. 327-348.

Lutter, Marcus (1988a), § 55, in: Kölner Kommentar zum Aktiengesetz, hrsg. von Zöllner, Wolfgang, 2. Aufl., Köln u.a.

Lutter, Marcus (1988b), $\S 58$, in: Kölner Kommentar zum Aktiengesetz, hrsg. von Zöllner, Wolfgang, 2. Aufl., Köln u.a.

Lutter, Marcus (1988c), Zur Abwehr räuberischer Aktionäre, in: Festschrift 40 Jahre Der Betrieb, Stuttgart, S. 193-210.

Lutter, Marcus (1989), $\S 186$, in: Kölner Kommentar zum Aktiengesetz, hrsg. von Zöllner, Wolfgang, 2. Aufl., Köln u.a.

Lutter, Marcus (1994a), Das neue „Gesetz für kleine Aktiengesellschaften und zur Deregulierung des Aktienrechts“, in: AG, 39. Jg., S. 429-447.

Lutter, Marcus (1994b), Der Aufsichtsrat: Konstruktionsfehler, Inkompetenz seiner Mitglieder oder normales Risiko?, in: AG, 39. Jg., S. 176-177.

Lutter, Marcus (1995a), Das dualistische System der Unternehmensverwaltung, in: Schriften zur Unternehmensführung - Corporate Governance, hrsg. von Scheffler, Eberhard, Wiesbaden, S. 5-26.

Lutter, Marcus (1995b), Defizite für eine effiziente Aufsichtsratstätigkeit und gesetzliche Möglichkeiten der Verbesserung, in: ZHR, 159. Jg., S. 287-309.

Lutter, Marcus (1995c), Professionalisierung der Aufsichtsräte, in: NJW, 48. Jg., S. 1133-1134.

Lutter, Marcus (1996), Europäisches Unternehmensrecht. ZGR-Sonderheft, 4. Aufl., Berlin/New York. 
Lutter, Marcus (1997), Stellungnahme zur Aktienrechtsreform 1997, in: AG-Sonderheft August 1997, 42. Jg., S. 52-57.

Lutter, Marcus (1998a), Das Recht der Gewinnverwendungspolitik im Konzern, in: Handbuch der Konzernfinanzierung, hrsg. von Lutter, Marcus/Scheffler, Eberhard/Schneider, Uwe H., Köln, S. 400-420.

Lutter, Marcus (1998b), Gesetzliches Garantiekapital als Problem europäischer und deutscher Rechtspolitik, in: AG, 43. Jg., S. 375-377.

Lutter, Marcus (2000a), Das Europäische Unternehmensrecht im 21. Jahrhundert, in: ZGR, 29. Jg., S. 1-18.

Lutter, Marcus (2000b), Konzepte, Erfolge und Zukunftsaufgaben Europäischer Gesellschaftsrechtsharmonisierung, in: Systembildung und Systemlücken in Kerngebieten des Europäischen Privatrechts, hrsg. von Grundmann, Stefan, Tübingen, S. 121-143.

Lutter, Marcus (2006), Das (feste Grund-)Kapital der Aktiengesellschaft in Europa. Zusammenfassung der Überlegungen des Arbeitskreises „Kapital in Europa“, in: ZGR-Sonderheft 17, Das Kapital der Aktiengesellschaft in Europa, Berlin, S. 1-14.

Lutter, Marcus (Hrsg.) (2006), ZGR-Sonderheft 17, Das Kapital der Aktiengesellschaft in Europa, Berlin.

Lutter, Marcus/Krieger, Gerd (2002), Rechte und Pflichten des Aufsichtsrats, 4. Aufl., Köln.

Lutter, Marcus/Leinekugel, Magdalena/Rödder, Thomas (2002), Die Sachdividende Gesellschaftsrecht und Steuerrecht -, in: ZGR, 31. Jg., S. 204-240.

Lutter, Marcus/Zöllner, Wolfgang (2004), „Die Mannesmann-Prämien durften nicht gezahlt werden“, in: FAZ, Nr. 34 vom 10.02.2004, S. 12.

Mag, Wolfgang (2003), Personalplanung und Mitbestimmung, Teil 1, in: WiSt, 32. Jg., S. 83-87.

Maier, Arno (1986), Der Grundsatz der Kapitalerhaltung und die Durchgriffshaftung wegen Unterkapitalisierung im deutschen und amerikanischen Gesellschaftsrecht. Unter besonderer Berücksichtigung des Rechts von New York, Kalifornien und Delaware sowie des Model Business Corporation Act, Frankfurt am Main u.a.

Mandl, Gerwald/Rabel, Klaus (1997), Unternehmensbewertung, Wien.

Manning, Bayless (1985), Assets in and Assets out: Chapter VI of the Revised Model Business Corporation Act, in: Tex. L. Rev., Vol. 63, S. 1527-1535.

Manning, Bayless/Hanks, James J. Jr. (1990), Legal Capital, 3. Aufl., Westbury.

Marsch-Barner, Reinhard (2004), Schutz der Gesellschaft und der Anteilseigner, in: Arbeitshandbuch für Aufsichtsratsmitglieder, hrsg. von Semler, Johannes/Schenck, Kersten von, 2. Aufl., München, S. 705-785.

Marsh, Harold/Finkle, R. Roy/Sonsini, Larry W. (2005), Marsh's California Corporation Law, 4. Aufl., New York.

Marten, Kai-Uwe/Quick, Reiner/Ruhnke, Klaus (2003), Wirtschaftsprüfung, 2. Aufl., Stuttgart. 
Martens, Klaus-Peter (1992), Der Ausschluß des Bezugsrechts, in: ZIP, 13. Jg., S. 1677-1697.

Martens, Klaus-Peter (1996), Erwerb und Veräußerung eigener Aktien im Börsenhandel. Überlegungen de lege ferenda, in: AG, 41. Jg., S. 337-349.

Martens, Klaus-Peter (2003), Leitfaden für die Leitung der Hauptversammlung einer Aktiengesellschaft, 3. Aufl., Köln.

Matschke, Manfred J. (1981), Die Maßnahmen zur Verbesserung des Gläubigerschutzes bei der GmbH nach der GmbH-Novelle 1980, in: DBW, 41. Jg., S. 553-570.

Maul, Silja (2003), Vorschläge der Expertengruppe zur Reform des EU-Gesellschaftsrechts, in: DB, 56. Jg., S. 27-31.

Maul, Silja/Eggenhofer, Erich/Lanfermann, Georg (2004), Deregulierung der EURegelungen zur Kapitalaufbringung und -erhaltung, in: BB-Special 6/2004, 59. Jg., S. 5-8.

Maul, Silja/Lanfermann, Georg/Eggenhofer, Erich (2003), Aktionsplan der Europäischen Kommission zur Reform des Europäischen Gesellschaftsrechts, in: BB, 58. Jg., S. 1289-1295.

Maul, Silja/Muffat-Jeandet, Daniéle (2004), Die EU-Übernahmerichtlinie - Inhalt und Umsetzung in nationales Recht, in: AG, 49. Jg., S. 221-234 (Teil I) und S. 306-318 (Teil II).

Mayer, Barbara (2005), Art. 4, in: Europäische Aktiengesellschaft SE. Nomos Kommentar, hrsg. von Manz, Gerhard/Mayer, Barbara/Schröder, Albert, Baden-Baden.

MBCA Ann. (2002), Model Business Corporation Act Annotated, 3. Aufl., Chicago.

McCormick, Eleanor (1949), Nimble Dividends: Some States Do Permit Dividends Despite Deficit in Accumulated Earnings, in: JoA, Vol. 88, S. 196-207.

McDaniel, Morey W. (1986), Bondholders and Corporate Governance, in: Bus. Law, Vol. 41, S. 413-460.

McGough, Philip (1987), Statutory Limits on a Corporations's Right to Make Distributions to Shareholders: The Law of Distribution in the 1984 Revised Model Business Corporation Act, in: Akron L. Rev., Vol. 21, S. 27-44.

Meilicke, Wienand (2003), Die Niederlassungsfreiheit nach „Überseering“. Rückblick und Ausblick nach Handelsrecht und Steuerrecht, in: GmbHR, 94. Jg., S. 793-809.

Meilicke, Wienand/Heidel, Thomas (2004), UMAG: „Modernisierung“ des Aktienrechts durch Beschränkung des Eigentumsschutzes der Aktionäre, in: DB, 57. Jg., S. 1479-1487.

Meinhövel, Harald (2005), Grundlagen der Principal-Agent-Theorie, in: Institutionenökonomie und Betriebswirtschaftslehre, hrsg. von Horsch, Andreas/Meinhövel, Harald/Paul, Stephan, München, S. 65-80.

Mellert, Christofer R. (2006), Ausländische Kapitalgesellschaften als Alternative zu AG und $\mathrm{GmbH}$ - eine Synopse, in: BB, 61. Jg., S. 8-11.

Melot de Beauregard, Paul (2004), Das Zweite Gesetz zur Vereinfachung der Wahl der Arbeitnehmervertreter in den Aufsichtsrat, in: DB, 57. Jg., S. 1430-1431. 
Menner, Stefan/Broer, Frank (2003), Steuerliche Gestaltungsmöglichkeiten bei Umstrukturierungen im Konzern - Alternativen zur Spaltung von Kapitalgesellschaften unter besonderer Berücksichtigung von Sachdividenden, in: DB, 56. Jg., S. 1075-1080.

Menzies, Christof (Hrsg.) (2004), Sarbanes-Oxley Act. Professionelles Management interner Kontrollen, Stuttgart.

Merkt, Hanno (1995), Das Europäische Gesellschaftsrecht und die Idee des „Wettbewerbs der Gesetzgeber", in: RabelsZ, 59. Jg., S. 545-568.

Merkt, Hanno (1996), Vom Konzessionssystem zum Delaware-Effekt: Die Entwicklung des US-amerikanischen Gesellschaftsrechts, in: ZfRV, 37. Jg., S. 1-11.

Merkt, Hanno (2001a), Entwicklungen des Gesellschafts- und Kapitalmarktrechts in den USA - Vorbild für Deutschland und Europa?, in: KoR, 1. Jg., S. 142-150.

Merkt, Hanno (2001b), Unternehmenspublizität. Offenlegung von Unternehmensdaten als Korrelat der Marktteilnahme, Tübingen, 2001.

Merkt, Hanno (2003), Zum Verhältnis von Kapitalmarktrecht und Gesellschaftsrecht in der Diskussion um die Corporate Governance, in: AG, 48. Jg., S. 126-136.

Merkt, Hanno (2004a), Der Kapitalschutz in Europa - ein rocher de bronze?, in: ZGR, 33. Jg., S. 305-323.

Merkt, Hanno (2004b), Die Pluralisierung des europäischen Gesellschaftsrechts, in: RIW, 50. Jg., S. 1-7.

Merkt, Hanno (2006a), § 264 HGB, in: Handelsgesetzbuch, hrsg. von Hopt, Klaus J./Merkt, Hanno, 32. Aufl., München.

Merkt, Hanno (2006b), IFRS und die Folgen für den Kapitalschutz im Gesellschaftsrecht, in: IFRS in Rechnungswesen und Controlling. Kongress-Dokumentation. 59. Deutscher Betriebswirtschafter-Tag 2005, hrsg. von Börsig, Clemens/Wagenhofer, Alfred, Stuttgart, S. 89-109.

Merkt, Hanno/Göthel, Stephan R. (2006), US-amerikanisches Gesellschaftsrecht, 2. Aufl., Frankfurt am Main.

Merschmeyer, Marc (2005), Die Kapitalschutzfunktion des Jahresabschlusses und Übernahme der IAS/IFRS für die Einzelbilanz, Frankfurt am Main u.a.

Mertens, Hans-Joachim (1988a), § 76, in: Kölner Kommentar zum Aktiengesetz, hrsg. von Zöllner, Wolfgang, 2. Aufl., Köln u.a.

Mertens, Hans-Joachim (1988b), § 82, in: Kölner Kommentar zum Aktiengesetz, hrsg. von Zöllner, Wolfgang, Band 2, 2. Aufl., Köln u.a. 1988.

Mertens, Hans-Joachim (1988c), § 93, in: Kölner Kommentar zum Aktiengesetz, hrsg. von Zöllner, Wolfgang, 2. Aufl, Köln u.a.

Mertens, Hans-Joachim (1994), Satzungs- und Organisationsautonomie im Aktien- und Konzernrecht, in: ZGR, 23. Jg., S. 426-441.

Mertens, Hans-Joachim (1995), $\S 111$, in: Kölner Kommentar zum Aktiengesetz, hrsg. von Zöllner, Wolfgang, 2. Aufl., Köln u.a. 
Mestmäcker, Ernst-Joachim (1958), Verwaltung, Konzerngewalt und Rechte der Aktionäre. Eine rechtsvergleichende Untersuchung nach deutschem Aktienrecht und dem Recht der Corporations in den Vereinigten Staaten, Karlsruhe.

Meyer-Löwy, Bernd/Poertzgen, Christoph/Eckhoff, Lars (2005), Einführung in das USamerikanische Insolvenzrecht, in: ZInsO, 8. Jg., S. 735-740.

Micheler, Eva (2004), Gläubigerschutz im englischen Gesellschaftsrecht. Reformvorschläge mit Implikationen für Europa, in: ZGR, 33. Jg., S. 324-347.

Micker, Lars (2003), Europarechtswidrigkeit der Organschaftsbesteuerung im Körperschaftund Gewerbesteuerrecht?, in: DB, 56. Jg., S. 2734-2738.

Mises, Ludwig von (1940), Nationalökonomie: Theorie des Handelns und Wirtschaftens, Genf.

Mitental, Daniel/Anders, Dietmar (2003), Erste Erfahrungen mit den neuen Aktienmarktsegmenten der Frankfurter Wertpapierbörse, in: DStR, 41. Jg., S. 1893-1900.

Möllers, Thomas M. J. (2003), Das europäische Kapitalmarktrecht im Umbruch. Ein Zwischenbericht zu den kapitalmarktrechtlichen Informationspflichten unter rechtsvergleichender Perspektive, in: ZBB, 15. Jg., S. 390-409.

Mohrman, Mary B. (1996), The Use of Fixed GAAP Provisions in Debt Contracts, in: AH, Vol. 10, S. 78-91.

Morawetz, Victor (1886), A Treatise on the Law of Private Corporations, 2. Aufl., Boston.

Mosel Weinberg AG (2003), Satzung der Mosel Weingberg AG. AG Trier 14 HR B 3852 v. 25.02.2003.

Moxter, Adolf (1979), Die Jahresabschlußaufgaben nach der EG-Bilanzrichtlinie: Zur Auslegung von Art. 2 EG-Bilanzrichtlinie, in: AG, 24. Jg., S. 141-146.

Moxter, Adolf (1984), Bilanzlehre. Band I: Einführung in die Bilanztheorie, 3. Aufl., Wiesbaden.

Moxter, Adolf (1986), Bilanzlehre. Band II: Einführung in das neue Bilanzrecht, 3. Aufl., Wiesbaden.

Moxter, Adolf (1999), Bilanzrechtsprechung, 5. Aufl., Tübingen.

Moxter, Adolf (2001), Die Zukunft der Rechnungslegung? - Anmerkungen zu den Thesen eines Arbeitskreises der Schmalenbach-Gesellschaft -, in: DB, 54. Jg., S. 605-607.

Moxter, Adolf (2003), Grundsätze ordnungsgemäßer Rechnungslegung, Düsseldorf.

Moxter, Adolf (2004), Gewinnrealisierung nach den IAS/IFRS: Erosion des HGB-Realisationsprinzips, in: ZVglRWiss, 103. Jg., S. 268-280.

Moxter, Adolf (2006), Absehbarer Abschied von der HGB-Bilanzierung?, in: BB, 61. Jg., Heft 13, S. I.

Müchler, Thomas (1992), Der Solvenzbericht. Ein Informationsinstrument zur Verbesserung des Gläubigerschutzes im Insolvenzverfahren, Frankfurt am Main u.a.

Mülbert, Peter O. (1996), Aktiengesellschaft, Unternehmensgruppe und Kapitalmarkt. Die Aktionärsrechte bei Bildung und Umbildung einer Unternehmensgruppe zwischen Verbands- und Anlegerschutzrecht, 2. Aufl., München. 
Mülbert, Peter O. (1997), Shareholder Value aus rechtlicher Sicht, in: ZGR, 26. Jg., S. 129-172.

Mülbert, Peter O. (2000), Kapitalschutz und Gesellschaftszweck bei der Aktiengesellschaft, in: Deutsches und europäisches Gesellschafts-, Konzern- und Kapitalmarktrecht. Festschrift für Marcus Lutter zum 70. Geburtstag, hrsg. von Schneider, Uwe H./Hommelhoff, Peter/Schmidt, Karsten/Timm, Wolfram/Grunewald, Barbara/Drygala, Tim, Köln, S. 535-555.

Mülbert, Peter O. (2001), Abschied von der „TBB“-Haftungsregel für den qualifiziert faktischen GmbH-Konzern, in: DStR, 39. Jg., S. 1937-1947.

Mülbert, Peter O. (2004), Zukunft der Kapitalaufbringung/Kapitalerhaltung, in: Der Konzern, 2. Jg., S. 151-162.

Mülbert, Peter O./Birke, Max (2002), Legal Capital - Is There a Case against the European Legal Capital Rules?, in: EBOR, Vol. 3, S. 695-732.

Müller, Hans-Peter (1977), Änderungen in der Organisation der deutschen Aktiengesellschaft durch die Angleichung des Aktienrechts in der EG? - Zum Kommissionsvorschlag einer 5. EG-Richtlinie, in: DB, 30. Jg., S. 1883-1888.

Müller, Hans-Peter (1991), Bilanzrecht und Organverantwortung, in: Festschrift für Karlheinz Quack zum 65. Geburtstag, hrsg. von Westermann, Harm P./Rosener, Wolfgang, Berlin/New York, S. 345-357.

Müller, Welf (1978), Zum Entwurf eines Gesetzes zur Durchführung der Zweiten Richtlinie des Rates der Europäischen Gemeinschaften zur Koordinierung des Gesellschaftsrechts (Kapitalschutzrichtlinie), in: WPg, 31. Jg., S. 565-574.

Müller, Welf (2002), Die Änderungen im HGB und die Neuregelung der Sachdividende durch das Transparenz- und Publizitätsgesetz, in: NZG, 5. Jg., S. 752-759.

Müller-Erzbach, Rudolf (1928), Deutsches Handelsrecht, 2./3. Aufl, Tübingen.

Müller-Thiemens, Friederike (2004), Vortragsveranstaltung der Juristischen Gesellschaft zu Berlin, in: JR, o. Jg., S. 60-61.

Mujkanovic, Robin (2002), Fair Value im Financial Statement nach International Accounting Standards, Stuttgart.

Murphy, Daniel T. (1981), Equity Insolvency and the New Model Business Corporation Act, in: U. Rich. L. Rev., Vol. 15, S. 839-871.

Mutter, Stefan (2004), Plädoyer für die Listenwahl von Aufsichtsräten, in: AG, 49. Jg., S. 305-306.

Nahr, J. Christian (2003), Publizitätspflicht in den USA, in: RIW, 49. Jg., S. 115-118.

NCCUSL (1984), Uniform Fraudulent Transfer Act, in: http://www.law.upenn.edu/bll/ulc/ fnact99/ 1980s/ufta84.pdf (Stand: 18.10.2004).

Netter, Oskar (1928), Die aktienrechtliche Auskunftspflicht, Berlin.

Neun, Josef (2005), Gründung, in: Die Europäische Aktiengesellschaft. Recht, Steuern und Betriebswirtschaft der Societas Europaea (SE), hrsg. von Theisen, Manuel R./Wenz, Martin, 2. Aufl., Stuttgart, S. 57-187. 
Neye, Hans-Werner (1999), SLIM - Schlankheitskur für EU-Gesellschaftsrecht. Einführung, in: ZIP, 20. Jg., S. 1944.

Niedenhoff, Horst-Udo (2002), Mitbestimmung in der Bundesrepublik Deutschland, 13. Aufl., Köln.

Niederleithinger, Ernst (1998), Gesetzliches Garantiekapital als Problem europäischer und deutscher Rechtspolitik, in: AG, 43. Jg., S. 377-379.

Niedernhuber, Günter (1985), Zur Reform der Gewinnverwendung von Aktiengesellschaften im Entwurf der 5. EG-Richtlinie, in: WPg, 38. Jg., S. 6-14.

Niedernhuber, Günter (1988), Ausschüttungsregelungen für Aktiengesellschaften. Eine ökonomische Analyse, Hamburg.

Niehues, Michael (2001), EU-Rechnungslegungsstrategie und Gläubigerschutz, in: WPg, 54. Jg., S. 1209-1222.

Niehus, Rudolf J. (1985), Zur Transformation der 4. EG-(Bilanz-)Richtlinie in den Mitgliedstaaten der Europäischen Gemeinschaft - Überblick und erste Würdigung -, in: ZGR, 14. Jg., S. 536-566.

Niehus, Rudolf J. (1992), Meinungsspiegel, in: BFuP, 44. Jg., S. 441-455.

Niehus, Rudolf J. (1998), Die Prüfung der internationalen Rechnungslegung von deutschen Kapitalgesellschaften - $\mathrm{Zu}$ Auswirkungen für den Abschlussprüfer und seinen Berufsstand - , in: Unternehmensberatung und Wirtschaftsprüfung, Festschrift für Professor Dr. Günter Sieben zum 65. Geburtstag, hrsg. von Matschke, Manfred J./Schildbach, Thomas, Stuttgart, S. 483-514.

Niehus, Rudolf J. (2001), „Auch für Einzelabschlüsse gelten grundsätzlich die IAS“? - Ein Beitrag zu den (möglichen) Grenzen einer „Internationalisierung“ der Rechnungslegung im Einzelabschluss -, in: WPg, 54. Jg., S. 737-752.

Niehus, Rudolf J. (2002), Der EU-Vorschlag für eine „Modernisierung“ der Bilanzrichtlinien - Überblick und erste Wertung -, in: DB, 55. Jg., S. 1385-1390.

Niehus, Rudolf J./Thyll, Alfred (2000), Konzernabschluß nach U.S. GAAP. Grundlagen und Gegenüberstellung mit den deutschen Vorschriften, 2. Aufl., Stuttgart.

Nienhaus, Julia (2002), Kapitalschutz in der Aktiengesellschaft mit atypischer Zwecksetzung. Eine rechtsvergleichende/europarechtliche Untersuchung für Deutschland, Frankreich, Belgien, Großbritannien und Irland, Köln u.a.

Niessen, Hermann (1995), Bindungen und Freiheiten der Mitgliedsstaaten der Europäischen Union bei der Umsetzung von Richtlinien am Beispiel der Angleichung des Bilanzrechts, in: Festschrift für Ulrich Everling, Band II, hrsg. von Due, Ole/Lutter, Marcus/Schwarze, Jürgen, Baden-Baden, S. 971-1000.

Nippel, Peter/Schweizer, Thilo (1996), Bezugsrechtsausschluß, Kapitalverwässerung und Ankündigungseffekt, in: WiSt, 25. Jg., S. 531-534.

Noack, Ulrich (2002), Erleichterungen grenzüberschreitender Stimmrechtsausübung - Bericht über eine Initiative der niederländischen Regierung und der Europäischen Union, in: ZIP, 23. Jg., S. 1215-1216. 
Nobel, Peter (1998), Börsengesellschaftsrecht?, in: Aktienrecht 1992-1997. Versuch einer Bilanz. Zum 70. Geburtstag von Rolf Bär, hrsg. von Büren, Roland von/Hausheer, Heinz/Wiegand, Wolfgang, Bern, S. 301-310.

North, Douglass C. (1990), Institutions, Institutional Change and Economic Performance, Cambridge u.a.

Nowak, Eric (2001), Eignung von Sachverhalten in Ad-hoc-Mitteilungen zur erheblichen Kursbeeinflussung, in: ZBB, 13. Jg., S. 449-465.

Obermüller, Walter/Werner, Winfried/Winden, Kurt (2001), Die Hauptversammlung der Aktiengesellschaft, 4. Aufl., Stuttgart.

Oechsler, Jürgen (2006), Die Änderung der Kapitalrichtlinie und der Rückerwerb eigener Aktien, in: ZHR, 170. Jg., S. 72-89.

Olbrich, Michael (2005), Zur Unternehmensbewertung bei Scheidung des Unternehmers, in: DBW, 65. Jg., S. 411-426.

Ordelheide, Dieter (1986), Der Konzern als Gegenstand betriebswirtschaftlicher Forschung, in: BFuP, 38. Jg., S. 293-312.

Ordelheide, Dieter (1987), Konzernerfolgskonzeptionen und Risikokoordination. - Grundlagen handels- und steuerrechtlicher Erfolgsermittlung für Konzerne -, in: ZfbF, 39. Jg., S. 975-986.

Ordelheide, Dieter (1995), Entwicklung und Arbeit des Accounting Advisory Forums der EU-Kommission, in: Rechenschaftslegung im Wandel. Festschrift für Wolfgang Dieter Budde, hrsg. von Förschle, Gerhart/Kaiser, Klaus/Moxter, Adolf, München, S. 483-504.

Ordelheide, Dieter (1998), Externes Rechnungswesen, in: Vahlens Kompendium der Betriebswirtschaftslehre. Band 1, hrsg. von Bitz, Michael/Dellmann, Klaus/Domsch, Michel/Wagner, Franz W., München.

Orth, Manfred (2004), Sachdividenden - Zu deren Kodifizierung und den offen gebliebenen aktienrechtlichen, bilanzrechtlichen und steuerrechtlichen Fragen, in: WPg, 57. Jg., S. 777-793 (Teil 1), S. 841-855 (Teil 2).

o.V. (1948), Corporations - Dividends - Virginia Statute Construed to Allow Dividends from Current Profits Despite Capital Deficit, in: Harv.L.Rev., Vol. 62, S. 130-131.

o.V. (2001), Mit Strafsteuern erzwingt Amerika eine Ausschüttung von Gewinnen. - Unternehmen sollen von übermäßiger Thesaurierung abgehalten werden / Der Mittelstand wird bevorzugt -, in: FAZ, Nr. 5 vom 06.01.2001, S. 23.

o.V. (2004), Staatsanwaltschaft will Esser Widersprüche nachweisen, in: FAZ, Nr. 25 vom 30.01.2004, S. 13 .

o.V. (2005a), Aktienrückkäufe in Amerika populär wie nie. Unternehmen geben an der Wall Street Milliarden für eigene Aktien aus, in: FAZ, Nr. 190 vom 17.08.2005, S. 19.

o.V. (2005b), Anlegerschutz verunsichert die Unternehmen. Unklare Gesetzeslage verwirrt Emittenten und Anleger. Mehr Aktionärsklagen möglich, in: FAZ, Nr. 42 vom 19.02.2005, S. 19.

o.V. (2005c), Allianz SE, in: FAZ, Nr. 213 vom 13.09.2005, S. 13. 
o.V. (2005d), Die Allianz ist Vorreiter bei der Europa AG. Das hohe Maß an Mitbestimmung der Arbeitnehmer gilt als unattraktiv. Originär europäischer Charakter, in: FAZ, Nr. 213 vom 13.09.2005, S. 21.

o.V. (2006a), Weniger Vorschriften für die $\mathrm{GmbH}$. Bundesjustizministerin Zypries will Gründungen beschleunigen und den Betrieb erleichtern, in: FAZ, Nr. 124 vom 30.05.2006, S. 11 .

o.V. (2006b), Markt \& Meinung. Die GmbH lebt, in: FAZ, Nr. 124 vom 30.05.2006, S. 18.

0.V. (2006c), Ltd.-Geschäftsführer haften persönlich. Landgericht: Bei Zahlungsunfähigkeit gilt deutsches GmbH-Recht, in: FAZ, Nr. 116 vom 19.05.2006, S. 14.

Palmiter, Alan R. (2003), Corporations. Examples and Explanations, 4. Aufl., New York.

Paefgen, Walter G. (2002), Unternehmerische Entscheidungen und Rechtsbindung der Organe in der AG, Köln.

Paefgen, Walter G. (2004a), Börsenpreisorientierte Vergütung und Überwachungsaufgabe des Aufsichtsrats, in: WM, 58. Jg. 2004, S. 1169-1175.

Paefgen, Walter G. (2004b), Dogmatische Grundlagen, Anwendungsbereich und Formulierung einer Business Judgment Rule im künftigen UMAG, in: AG, 49. Jg., S. 245-261.

Pannen, Michael (2000), Meßtheoretische Grundprobleme des Maßgeblichkeitsprinzips, Lohmar/Köln.

Passow, Richard (1903), Die Entstehung des Aufsichtsrats der Aktiengesellschaft, in: ZHR, 64. Jg., S. 27-57.

Passow, Richard (1922), Die Aktiengesellschaft. Eine wirtschaftswissenschaftliche Studie, Jena.

Paul, Stephan (2004), Basel II im Überblick, in: Basel II und MaK - Regulatorische Vorgaben, bankinterne Verfahren, Bewertungen, hrsg. von Hofmann, Gerhard, 2. Aufl., Frankfurt am Main, S. 5-55.

Paul, Stephan (2005a), Rückfallgefahr. Die deutschen Banken haben ihre Krise noch nicht überwunden - insbesondere die ungelöste Preispolitik birgt noch erhebliche Risiken, in: FAZ, Nr. 79 vom 06.04.2005, S. B1.

Paul, Stephan (2005b), Unternehmerfunktionen und Wettbewerbsfähigkeit. Die zentrale Rolle von Ressourcen, Kompetenzen und Innovationen, in: Institutionenökonomie und Betriebswirtschaftslehre, hrsg. von Horsch, Andreas/Meinhövel, Harald/Paul, Stephan, München, S. 157-175.

Paul, Stephan/Horsch, Andreas (2005), Evolutorische Ökonomik und Lehre von den Unternehmerfunktionen, in: Institutionenökonomie und Betriebswirtschaftslehre, hrsg. von Horsch, Andreas/Meinhövel, Harald/Paul, Stephan, München, S. 137-156.

Paul, Stephan/Stein, Stefan (2002), Rating, Basel II und die Unternehmensfinanzierung, Köln.

Pausenberger, Ehrenfried (1986), Meinungsspiegel, in: BFuP, 38. Jg., S. 357-372.

Peemöller, Volker H./Spanier, Günter/Weller, Heino (2002), Internationalisierung der externen Rechnungslegung: Auswirkungen auf nicht kapitalmarktorientierte Unternehmen, in: BB, 57. Jg., S. 1799-1803. 
Pellens, Bernhard (1989), Der Informationswert von Konzernabschlüssen. Eine empirische Untersuchung deutscher Börsengesellschaften, Wiesbaden.

Pellens, Bernhard (1994), Aktionärsschutz im Konzern. Empirische und theoretische Analyse der Reformvorschläge der Konzernverfassung, Wiesbaden.

Pellens, Bernhard (1996), Berücksichtigung der Aktionärsinteressen bei der Gewinnverwendung im Konzern, in: Unternehmenssicherung und Unternehmensentwicklung, hrsg. von Elschen, Rainer, Stuttgart, S. 163-191.

Pellens, Bernhard (1998), Jahresabschluß (Funktionen), in: Lexikon des Rechnungswesens, hrsg. von Busse von Colbe, Walther/Pellens, Bernhard, 4. Aufl., München/Wien, S 367-370.

Pellens, Bernhard (2001a), Internationale Rechnungslegung, 4. Aufl., Stuttgart.

Pellens, Bernhard (2001b), Publizität, in: Handwörterbuch des Bank- und Finanzwesens, hrsg. von Gerke, Wolfgang/Steiner, Manfred, 3. Aufl., Stuttgart, Sp. 1742-1754.

Pellens, Bernhard (2003), Editorial. Überregulierung der Kapitalmärkte?, in: DBW, 63 Jg., S. 473-476.

Pellens, Bernhard/Bonse, Andreas (1998), Die Innenfinanzierung und die Gewinnverwendungspolitik, in: Handbuch der Konzernfinanzierung, hrsg. von Lutter, Marcus/Scheffler, Eberhard/Schneider, Uwe H., Köln, S. 378-399.

Pellens, Bernhard/Bonse, Andreas (1999), Annäherung des deutschen Aktionärsschutzes an US-amerikanische Vorstellungen, in: Festschrift für Bernhard Großfeld zum 65. Geburtstag, hrsg. von Hübner, Ulrich/Ebke, Werner F., Heidelberg, S. 851-874.

Pellens, Bernhard/Bonse, Andreas/Gassen, Joachim (1998), Perspektiven der deutschen Konzernrechnungslegung. - Auswirkungen des Kapitalaufnahmeerleichterungsgesetzes und des Gesetzes zur Kontrolle und Transparenz im Unternehmensbereich - , in: DB, 51. Jg., S. 785-792.

Pellens, Bernhard/Crasselt, Nils (2004), Transparenz der Unternehmensführung, in: Handwörterbuch Unternehmensführung und Organisation, hrsg. von Schreyögg, Georg/Werder, Axel von, 4. Aufl., Stuttgart.

Pellens, Bernhard/Crasselt, Nils/Rockholtz, Carsten (1998), Wertorientierte Entlohnungssysteme für Führungskräfte - Anforderungen und empirische Evidenz -, in: Unternehmenswertorientierte Entlohnungssysteme, hrsg. von Pellens, Bernhard, Stuttgart, S. 1-28.

Pellens, Bernhard/Detert, Karsten (2003), IFRS 1 „First-time Adoption of International Financial Reporting Standards“. Neue Regelung zur erstmaligen Anwendung der IFRS, in: KoR, 3. Jg., S. 369-376.

Pellens, Bernhard/Fülbier, Rolf Uwe (2000), Differenzierung der Rechnungslegung nach Börsenzulassung, in: ZGR, 29. Jg., S. 572-593.

Pellens, Bernhard/Fülbier, Rolf Uwe/Gassen, Joachim (2006), Internationale Rechnungslegung, 6. Aufl., Stuttgart.

Pellens, Bernhard/Gassen, Joachim (1998), Die Bereitstellung von Rechnungslegungssystemen - Eine Aufgabe des Staates oder des Marktes?, in: Festschrift für Professor Dr. Dr. h.c. Adolf G. Coenenberg zum 60. Geburtstag, hrsg. von Möller, Hans Peter/Schmidt, Franz, Stuttgart, S. 633-650. 
Pellens, Bernhard/Gassen, Joachim (2001), EU-Verordnungsentwurf zur IAS-Konzernrechnungslegung - Gestaltungsmöglichkeiten des deutschen Gesetzgebers -, in: KoR, 1. Jg., S. 137-142.

Pellens, Bernhard/Gassen, Joachim (2002), Zwischenbericht, in: Handwörterbuch Unternehmensrechnung und Controlling, hrsg. von Küpper, Hans-Ulrich/Wagenhofer, Alfred, Stuttgart, Sp. 2187-2198.

Pellens, Bernhard/Gassen, Joachim/Neuhaus, Stefan/Schmidt, André (2006), Die Zukunft der Unternehmensberichterstattung, in: IFRS in Rechnungswesen und Controlling. Kongress-Dokumentation. 59. Deutscher Betriebswirtschafter-Tag 2005, hrsg. von Börsig, Clemens/Wagenhofer, Alfred, Stuttgart, S. 19-35.

Pellens, Bernhard/Gassen, Joachim/Richard, Marc (2003), Ausschüttungspolitik börsennotierter Unternehmen in Deutschland, in: DBW, 63. Jg., S. 309-332.

Pellens, Bernhard/Hillebrandt, Franca (2001), Vorzugsaktien vor dem Hintergrund der Corporate Governance-Diskussion, in: AG, 46. Jg., S. 57-67.

Pellens, Bernhard/Jödicke, Dirk/Richard, Marc (2005), Solvenztests als Alternative zur bilanziellen Kapitalerhaltung?, in: DB, 58. Jg., S. 1393-1401.

Pellens, Bernhard/Schremper, Ralf (2000), Theorie und Praxis des Aktienrückkaufs in den USA und in Deutschland, in: BFuP, 52. Jg., S. 132-156.

Pellens, Bernhard/Sellhorn, Thorsten (2006), Zukunft des bilanziellen Kapitalschutzes, in: ZGR-Sonderheft 17, Das Kapital der Aktiengesellschaft in Europa, hrsg. von Lutter, Marcus, Berlin, S. 451-487.

Pellens, Bernhard/Sürken, Silke (1998), Rechnungslegungspolitische Spielräume im Rahmen der International Accounting Standards, in: Rechnungslegungspolitik, hrsg. von Freidank, Carl-Christian, Berlin u.a., S. 195-228.

Perridon, Louis/Steiner, Manfred (2004), Finanzwirtschaft der Unternehmung, 13. Aufl., München.

Peters, Philip W. (2003), The California Corporation: Legal Aspects of Organization and Operation, Washington, D.C.

Peterson, Craig A./Hawker, Norman W. (1997), Does Corporate Law Matter? Legal Capital Restrictions on Stock Distributions, in: Akron L. Rev., Vol. 31, S. 175-227.

Pfaff, Dieter (1989), Gewinnverwendungsregelungen als Instrument zur Lösung von AgencyProblemen, Frankfurt am Main u.a.

Pfitzer, Norbert/Oser, Peter/Orth, Christian (2004), Offene Fragen und Systemwidrigkeiten des Bilanzrechtsreformgesetzes (BilReG) - Erste Handlungsempfehlungen für eine normkonforme Umsetzung -, in: DB, 57. Jg. 2004, S. 2593-2602.

Pfitzer, No:bert/Oser, Peter/Orth, Christian (2005), Reform des Aktien-, Bilanz-, und Aufsichtsrechts. BilReG, BilKoG, APAG, AnSVG, UMAG sowie weitere Reformgesetze, Stuttgart 2005.

Pick, Johannes J. (1985), Ausschüttungsregelung bei Konzernverflechtung. Versuch einer Deduktion von Ausschüttungsregeln für Konzerngesellschaften, Frankfurt am Main. 
Picot, Arnold/Michaelis, Elke (1984), Verteilung von Verfügungsrechten in Großunternehmungen und Unternehmungsverfassung, in: ZfB, 54. Jg., S. 252-272.

Picot, Arnold/Schuller, Susanne (2001), Corporate Governance, in: Der Transaktionskostenansatz in der Betriebswirtschaftslehre, hrsg. von Jost, Peter-J., Stuttgart, S. 79-105.

Piltz, Klaus (1988), Gewinnverwendungspolitik der Aktiengesellschaft, in: Finanzierungshandbuch, hrsg. von Christians, F. Wilhelm, 2. Aufl., Wiesbaden, S. 627-660.

Pinto, Arthur R./Douglas M. Branson (2004), Understanding Corporate Law, 2. Aufl., Newark.

Pohl, Klaus F. (1983), Die Entwicklung des ertragsteuerlichen Maßgeblichkeitsprinzips, Köln.

Potthoff, Erich (1961), Prüfung und Überwachung der Geschäftsführung, in: ZfhF, 13. Jg., S. $563-580$.

Prantl, Johannes (1994), Konzernbildung, Konzernrecht und Minderheitenschutz in Deutschland. Eine ökonomische Analyse, Frankfurt am Main u.a.

Press, Eric G./Weintrop, Joseph B. (1990), Accounting-Based Constraints in Public and Private Debt Agreements. Their Association with Leverage and Impact on Accounting Choice, in: JAaE, Vol. 12, S. 65-95

Priester, Hans-Joachim (1992), Kapitalaufbringung, in: Festschrift 100 Jahre GmbH-Gesetz, hrsg. von Lutter, Marcus/Ulmer, Peter/Zöllner, Wolfgang, Köln, S. 159-187.

Priester, Hans-Joachim (1994), Wertgleiche Deckung statt Bardepot? Die Verwendung von Geldeinlagen bei Kapitalerhöhung, in: ZIP, 15. Jg., S. 599-604.

Priester, Hans-Joachim (1996), Die kleine AG - ein neuer Star unter den Rechtsformen?, in: BB, 51. Jg., S. 333-338.

Priester, Hans-Joachim (2005), „GmbH light“ - ein Holzweg! in: ZIP, 26. Jg., S. 921-922.

Prinz, Ulrich (2003), Reform der deutschen Rechnungslegung. Gedanken und Anregungen an den Gesetzgeber zur Umsetzung der Mitgliedstaatenwahlrechte der IAS/IFRS-Verordnung aus Praktikersicht, in: DStR, 41. Jg., S. 1359-1364.

Prinz, Ulrich/Schürner, Carl T. (2003), Tracking Stocks und Sachdividenden - ein neues Gestaltungsinstrument für spartenbezogene Gesellschaftsrechte?, in: DStR, 41. Jg., S. 181-189.

Pross, Helge (1965), Manager und Aktionäre in Deutschland. Untersuchungen zum Verhältnis von Eigentum und Verfügungsmacht, Frankfurt am Main.

Quassowski, Leo (1931), Die Vorschriften der Aktienrechtsnovelle über Publizität, eigene Aktien und Einziehung von Aktien, in: JW, 60. Jg., S. 2914-2925.

Rain, Talbot (1948), The Fund Available for Corporate Dividends in Texas, in: Tex. L. Rev., Vol. 26, S. 273-302.

Raiser, Thomas (2001), Recht der Kapitalgesellschaften, 3. Aufl., München.

Ralston, William H. (1983), The 1980 Amendments to the Financial Provisions of the Model Business Corporation Act: A Positive Alternative to the New York Statutory Approach, in: Alb. L. Rev., Vol. 47, S. 1019-1049. 
Ratcliffe, Thomas A. (2003), OCBOA Financial Statements, in: JoA, Vol. 196, S. 71-75.

Rammert, Stefan (2004), Lohnt die Erhaltung der Kapitalerhaltung?, in: BFuP, 56. Jg., S. 578-595:

Rechenberg, Wolf-Georg Freiherr von (1986), Die Hauptversammlung als oberstes Organ der Aktiengesellschaft, Heidelberg.

Regierungskommission Corporate Governance (2001), Abschlussbericht, in: http://www. kpmg.de/audit-committee-institute/bin/RegKGesamt.pdf (Stand: 11.02.2004).

Reisel, Natalia (2004), On the Value of Restrictive Covenants: An Empirical Investigation of Public Bond Issues, in: http://ssm.com/abstract=644522 (Stand: 17.03.2005).

Rezori, Alexander (2004), Die Ausführlichkeit U.S.-amerikanischer Vertragsgestaltung im Vergleich zu Deutschland, Hamburg.

Rheinstein, Max (1987), Einführung in die Rechtsvergleichung, München.

Rich, Matthew (1992), Financial Covenants Revisited - The Banks' Perspective, in: JIBFL, Vol. 12, S. 518-521.

Richardi, Reinhard (2002), $§ 1$, in: Betriebsverfassungsgesetz mit Wahlordnung. Kommentar, hrsg. von Richardi, Reinhard, 8. Aufl., München.

Richardt, Harald (1974), Der aktienrechtliche Abhängigkeitsbericht unter ökonomischen Aspekten, Wiesbaden.

Richardt, Harald (2000), Unternehmensbewertung, in: Beck'sches Steuerberater-Handbuch 2000/2001, München, S. 1911-1974.

Richter, Rudolf/Furubotn, Eirik G. (2003), Neue Institutionenökonomik, 3. Aufl., Tübingen.

Rickford, Jonathan (2004), Reforming Capital. Report of the Interdisciplinary Group on Capital Maintenance, in: EBLR, Vol. 15, S. 919-1027.

Rießer, Jacob (1903), Zur Aufsichtsratsfrage, in: Festgabe für Richard Koch, hrsg. von der Juristischen Gesellschaft zu Berlin, Berlin, S. 293-326.

Roberts, Michael L./Samson, William D./Dugan, Michael T. (1990), The Stockholders' Equity Section: Form Without Substance?, in: AH, Vol. 4, S. 35-46.

Röhricht, Volker (1996), § 27, in: Großkommentar Aktiengesetz, hrsg. von Hopt, Klaus J./Wiedemann, Herbert, 4. Aufl., Berlin.

Romano, Roberta (1993), The Genius of American Corporate Law, Washington, D.C.

Romano, Roberta (2001), The Need for Competition in International Securities Regulation, in: TIL, Vol. 2, S. 387-562.

Ross, Stephen A./Westerfield, Randolph W./Jaffe, Jeffrey (2005), Corporate Finance, 7. Aufl., Boston u.a.

Rost, Peter (1991), Der internationale Harmonisierungsprozeß der Rechnungslegung, Frankfurt am Main u.a.

Roth, Günter H./Altmeppen, Holger (2003), Einleitung, in: GmbHG. Kommentar, hrsg. von Altmeppen, Holger/Roth, Günter H., 4. Aufl., München. 
Rubin, Steven (1984), The House of GAAP, in: JoA, Vol. 157, S. 122-129.

Rudolph, Bernd (2003), Unternehmensfinanzierung und Corporate Governance - Entwicklungen und weiterer Anpassungsbedarf, in: BB, 58. Jg., S. 2053-2060.

Rückle, Dieter (1984), Externe Prognosen und Prognoseprüfung, in: DB, 37. Jg., S. 57-69.

Ruhnke, Klaus/Schmidt, Martin (2003), Überlegungen zur Prüfung von beizulegenden Zeitwerten, in: WPg, ১o. Jg., S. 1037-1051.

Ruhwedel, Franca (2003), Eigentümerstruktur und Unternehmenserfolg. Eine theoretische und empirsche Analyse deutscher börsennotierter Unternehmen, Frankfurt am Main u.a.

Ruhwedel, Peter (2002), Aufsichtsratsplanungssysteme. Theoretische Grundlagen und praktische Ausgestaltung in Publikumsaktiengesellschaften, Frankfurt am Main u.a.

Ruhwedel, Peter/Epstein, Rolf (2003), Eine empirische Analyse der Strukturen und Prozesse in den Aufsichtsräten deutscher Aktiengesellschaften, in: BB, 58. Jg., S. 161-166.

Sandrock, Otto (2003), Die Schrumpfung der Überlagerungstheorie. $\mathrm{Zu}$ den zwingenden Vorschriften des deutschen Sitzrechts, die ein fremdes Gründungsstatut überlagern können, in: ZVglRWiss, 102. Jg., S. 447-504.

Sandrock, Otto (2004a), Gehören die deutschen Regelungen über die Mitbestimmung auf Unternehmensebene wirklich zum deutschen ordre public?, in: AG, 49. Jg., S. 57-66.

Sandrock, Otto (2004b), Was ist erreicht? Was bleibt zu tun? Eine kollisions- und materiellrechtliche Bilanz, in: Deutsches Gesellschaftsrecht im Wettbewerb der Rechtsordnungen. Nach Centros, Überseering und Inspire Art, hrsg. von Sandrock, Otto/Wetzler, Christoph F., Heidelberg, S. 33-100.

Sandrock, Otto/Wetzler, Christoph F. (Hrsg.) (2004), Deutsches Gesellschaftsrecht im Wettbewerb der Rechtsordnungen. Nach Centros, Überseering und Inspire Art, Heidelberg 2004.

Sarbanes-Oxley Act of 2002, http://news.findlaw.com/hdocs/docs/gwbush/sarbanesoxley 072302. pdf (Stand: 13.10.2005).

Sauer, Wilhelm (1940), Juristische Methodenlehre, Stuttgart.

Schackmann, Markus/Behling, Nils (2004), Die Bedeutung von Covenants bei der Akquisitions- und Unternehmensfinanzierung, in: FB, 6. Jg., S. 789-799.

Schall, Alexander (2005), Englischer Gläubigerschutz bei der Limited in Deutschland, in: ZIP, 26. Jg., S. 965-975.

Scheffler, Eberhard (2003), Aufgaben und Zusammensetzung von Prüfungsausschüssen (Audit Committees), in: ZGR, 32. Jg., S. 236-263.

Schenck, Kersten von (2004), Die Überwachung der Geschäftsführung, in: Arbeitshandbuch für Aufsichtsratsmitglieder, hrsg. von Semler, Johannes/Schenck, Kersten von, 2. Aufl., München, S. 303-378.

Schiessl, Maximilian (2002), Deutsche Corporate Governance post Enron, in: AG, 47. Jg., S. 593-604.

Schiessl, Maximilian (2003), Leitungs- und Kontrollstrukturen im internationalen Wettbewerb - Dualistisches System und Mitbestimmung auf dem Prüfstand -, in: ZHR, 167. Jg., S. 235-256. 
Schildbach, Thomas (1986), Jahresabschluß und Markt, Berlin u.a.

Schildbach, Thomas (1993), Der Konzernabschluß als Ausschüttungsbemessungsgrundlage, in: WPg, 46. Jg., S. 53-63 (Teil I) und S. 94-98 (Teil II).

Schildbach, Thomas (1994), Internationale Rechnungslegungsstandards auch für deutsche Einzelabschlüsse?, in: Bilanzrecht und Kapitalmarkt, Festschrift zum 65. Geburtstag von Prof. Dr. Dr. h.c. Dr. h.c. Adolf Moxter, hrsg. von Ballwieser, Wolfgang/Böcking, HansJoachim/Drukarczyk, Jochen/Schmidt, Reinhard H., Düsseldorf, S. 699-721.

Schildbach, Thomas (1998a), Harmonisierung der Rechnungslegung - ein Phantom, in: BFuP, 50. Jg., S. 1-22.

Schildbach, Thomas (1998b), Rechnungslegung nach US-GAAP - ein Fortschritt für Deutschland?, in: ZfbF-Sonderheft 40, Rechnungslegung und Steuern international, hrsg. von Ballwieser, Wolfgang/Schildbach, Thomas, Düsseldorf, S. 55-81.

Schildbach, Thomas (1999a), Öffnung der Jahresabschlüsse für IAS und US-GAAP - ein Fortschritt?, in: StuB, 1. Jg., S. 421-428.

Schildbach, Thomas (1999b), Rechnungslegung nach US-GAAP: Hoffnung und Wirklichkeit, in: BB, 54. Jg., S. 359-365 (Teil I), S. 411-415 (Teil II).

Schildbach, Thomas (2000), Reichweite, Eigenschaften und Legitimation der US-GAAP: Vor überzogenen Erwartungen wird gewarnt!, in: StuB, 2. Jg., S. 192-201.

Schildbach, Thomas (2001), Der Konzernabschluß nach HGB, IAS und US-GAAP, 6. Aufl., München/Wien, 2001.

Schildbach, Thomas (2002), IAS als Rechnungslegungsstandards für alle, in: BFuP, 54. Jg., S. 263-278.

Schildbach, Thomas (2004), Der handelsrechtliche Jahresabschluß, 7. Aufl., Herne/Berlin.

Schilling, Florian (2004), Beurteilung von Aufsichtsräten, in: FAZ, Nr. 39 vom 16.02.2004, S. 22 .

Schlitt, Michael (2003), Die neuen Marktsegmente der Frankfurter Wertpapierbörse: Struktur, Zulassungsvoraussetzungen und Folgepflichten, in: AG, 48. Jg., S. 57-69.

Schmalenbach, Eugen (1910/11), Die Überwachungspflicht des Aufsichtsrats, in: ZfhF, 5. Jg., S. 271-283.

Schmalenbach, Eugen (1933), Grundsätze ordnungsmäßiger Bilanzierung, in: ZfhF, 27. Jg., S. 225-233.

Schmalenbach, Eugen (1950), Die Aktiengesellschaft, 7. Aufl., Köln/Opladen.

Schmalenbach, Eugen (1962), Dynamische Bilanz, 13. Aufl., Köln/Opladen.

Schmidt, Karsten (1984), Die Eigenkapitalausstattung der Unternehmen als rechtspolitisches Problem, in: JZ, 39. Jg., S. 771-786.

Schmidt, Karsten (2002), Gesellschaftsrecht, 4. Aufl., Köln u.a.

Schmidt, Karsten (2005), ... ut aliquid fiat - Von der „GmbH-Reform 2005“ zum Referentenentwurf eines Mindestkapitalgesetzes, in: DB, 58. Jg., S. 1095-1097.

Schmidt, Lutz (1994), Maßgeblichkeitsprinzip und Einheitsbilanz. Geschichte, Gegenwart und Perspektiven des Verhältnisses von Handels- und Steuerbilanz, Heidelberg. 
Schmidt, Reinhard H./Terberger, Eva (1997), Grundzüge der Investitions- und Finanzierungstheorie, 4. Aufl., Wiesbaden.

Schmidt, Reinhard H./Spindler, Gerald (1997), Shareholder-Value zwischen Ökonomie und Recht, in: Wirtschafts- und Medienrecht in der offenen Demokratie. Freudesgabe für Friedrich Kübler zum 65. Geburtstag, hrsg. von Assmann, Heinz-Dieter/Brinkmann, Tomas/Gounalakis, Georgios/Kohl, Helmut/Walz, Rainer, Heidelberg, S. 515-555.

Smith, Clifford W./Warner, Jerold B. (1979), On Financial Contracting. An Analysis of Bond Covenants, in: JoFE, Vol. 7, S. 117-161.

Schmitt, Christian (2003), Treuepflichten der Vorstandsmitglieder einer konzernunabhängigen Aktiengesellschaft nach deutschem und U.S.-amerikanischen Recht. Eine vergleichende Analyse zur Treuepflichtverletzung - insbesondere durch Bestechlichkeit, Frankfurt am Main u.a.

Schmitz, Ronaldo (2003), Konzeption und Praxis des Audit Committee, in: Internationalisierung der Rechnungslegung und Corporate Governance, Festschrift für Klaus Pohle, hrsg. von Werder, Axel von/Wiedmann, Harald, Stuttgart, S. 177-197.

Schneider, Dieter (1963), Bilanzgewinn und ökonomische Theorie, in: ZfhF, 15. Jg., S. 457-474.

Schneider, Dieter (1981), Kapitalmarkteffizienz durch Jahresabschlußreformen?, in: Schriften des Verbandes öffentlicher Banken, Heft 8, hrsg. von Becker, Wolf-Dieter/Falk, Reinhold, Göttingen.

Schneider, Dieter (1983), Rechtsfindung durch Deduktion von Grundsätzen ordnungsmäßiger Buchführung aus gesetzlichen Jahresabschlußzwecken?, in: StuW, 60. Jg., S. 141-160.

Schneider, Dieter (1986a), „Angemessenes haftendes Eigenkapital“ für EuronotesFazilitäten?, in: Die Bank, o. Jg., S. 560-568.

Schneider, Dieter (1986b), Lücken bei der Begründung einer „Eigenkapitallücke“, in: DB, 39. Jg., S. 2293-2298.

Schneider, Dieter (1987), Mindestnormen zur Eigenkapitalausstattung als Beispiele unbegründeter Kapitalmarktregulierung?, in: Kapitalmarkt und Finanzierung, hrsg. von Schneider, Dieter, Schriften des Vereins für Socialpolitik, Neue Folge, Band 165, Berlin, S. 85-108.

Schneider, Dieter (1991), Die Anfänge der „Steuerbilanz“ und die Entstehung des Maßgeblichkeitsprinzips. Ein Beitrag zur Betriebswirtschaftlichen Steuerlehre vor der akademischen Betriebswirtschaftslehre, in: Betriebswirtschaftliche Steuerlehre und Steuerberatung. Gerd Rose zum 65. Geburtstag, hrsg. von Herzig, Norbert, Wiesbaden, S. 175-190.

Schneider, Dieter (1992), Investition, Finanzierung und Besteuerung, 7. Aufl., Wiesbaden.

Schneider, Dieter (1995), Betriebswirtschaftslehre. Band 1: Grundlagen, 2. Aufl., München/ Wien.

Schneider, Dieter (1997a), Betriebswirtschaftslehre. Band 2: Rechnungswesen, 2. Aufl., München/Wien.

Schneider, Dieter (1997b), Betriebswirtschaftslehre. Band 3: Theorie der Unternehmung, München/Wien. 
Schneider, Dieter (1999), Abbau von Steuervergünstigungen durch Skalpierung der Maßgeblichkeit und Verlustverrechnung als „Stärkung der Investitionskraft"?, in: DB, 52. Jg., S. $105-110$.

Schneider, Dieter (2001), Betriebswirtschaftslehre. Band 4: Geschichte und Methoden der Wirtschaftswissenschaft, München/Wien.

Schneider, Mareen (1998), Diskussionsbericht: Gesetzliches Garantiekapital und Kreditentscheidung der Banken, in: AG, 43. Jg., S. 373-375.

Schneider, Sven H. (2005), Selbstbefreiung von der Pflicht zur Ad-hoc-Publizität, in: BB, 60. Jg., S. 897-902.

Schneider, Uwe H. (1984), Das Recht der Konzernfinanzierung, in: ZGR, 13. Jg., S. 497-537.

Schneider, Uwe H. (1986), Die vertragliche Ausgestaltung der Konzernverfassung. - Zur Anpassung von Gesellschaftsverträgen, Geschäftsordnungen, Stimmbindungsverträgen und Konsortialverträgen an die Konzernlage -, in: BB, 41. Jg., S. 1993-1999.

Schneider, Uwe H. (2001), Internationales Kapitalmarktrecht. - Regelungsprobleme, Methoden und Aufgaben - , in: AG, 46. Jg., S. 269-278.

Schnorbus, York (2003), Die Sachdividende, in: ZIP, 24. Jg., S. 509-518.

Schön, Wolfgang (1997a), Deutsches Konzernprivileg und europäischer Kapitalschutz - ein Widerspruch?, in: Aktien- und Bilanzrecht. Festschrift für Bruno Kropff, hrsg. von Forster, Karl-Heinz/Grunewald, Barbara/Lutter, Marcus/Semler, Johannes, Düsseldorf, S. 285-300.

Schön, Wolfgang (1997b), Entwicklung und Perspektiven des Handelsbilanzrechts: vom ADHGB zum IASC, in: ZHR, 161. Jg., S. 133-159.

Schön, Wolfgang (1998), Anmerkung zu EuGH, Urteil v. 4.12.1997 - Rs. C-97/96 Daihatsu, in: JZ, 53. Jg., S. 194-195.

Schön, Wolfgang (2000), Gesellschafter-, Gläubiger- und Anlegerschutz im Europäischen Bilanzrecht, in: ZGR, 29. Jg., S. 706-742.

Schön, Wolfgang (2001), Internationalisierung der Rechnungslegung und Gläubigerschutz, in: WPg-Sonderheft, 54. Jg., S. S74-S79.

Schön, Wolfgang (2002), Editorial. Wer schütz den Kapitalschutz?, in: ZHR, 166. Jg., S. 1-5.

Schön, Wolfgang (2004a), Die Zukunft der Kapitalaufbringung/-erhaltung, in: Der Konzern, 2. Jg., S. 162-170.

Schön, Wolfgang (2004b), The Future of Legal Capital, in: EBOR, Vol. 5, S. 429-448.

Scholz, Oliver (2004), Die Einführung elektronischer Handelsregister im Europarecht, in: EuZW, 15. Jg., S. 172-176.

Schreiber, Ulrich (1999), Rechnungslegung im Einzelabschluß nach internationalen Grundsätzen?, in: Unternehmenspolitik und internationale Besteuerung, Festschrift für Lutz Fischer zum 60. Geburtstag, hrsg. von Kleineidam, Hans-Jochen, Berlin, S. 879-912. 
Schreiber, Ulrich (2000), Die Bedeutung der US-amerikanischen Rechnungslegung für die Besteuerung von Gewinnen und Ausschüttungen, in: US-amerikanische Rechnungslegung. Grundlagen und Vergleiche mit deutschem Recht, hrsg. von Ballwieser, Wolfgang, 4. Aufl., Stuttgart, S. 49-98.

Schremper, Ralf (2002), Aktienrückkauf und Kapitalmarkt. Eine theoretische und empirische Analyse deutscher Aktienrückkaufprogramme, Frankfurt am Main u.a.

Schremper, Ralf (2003), Kapitalmarktrelevanz deutscher Aktienrückkaufprogramme, in: ZfbF, 55. Jg., S. 578-605.

Schüppen, Matthias (2002), To comply or not to comply - that's the question! „Existenzfragen" des Transparenz- und Publizitätsgesetzes im magischen Dreieck kapitamarktorientierter Unternehmensführung, in: ZIP, 23. Jg., S. 1269-1279.

Schütz, Carsten (2004), Neuerungen im Anfechtungsrecht durch den Referentenentwurf des Gesetzes zur Unternehmensintegrität und Modernisierung des Anfechtungsrechts (UMAG), in: DB, 57. Jg., S. 419-426.

Schulze-Osterloh, Joachim (1995), Fortentwicklung der Rechnungslegung auf Kosten gesellschaftsrechtlicher Kapitalschutzmechanismen?, in: Neuorientierung der Rechenschaftslegung, Bericht über die IDW-Fachtagung 1994, Düsseldorf, S. 123-139.

Schulze-Osterloh, Joachim (2003a), Internationale Rechnungslegung für den Einzelabschluß und für Unternehmen, die den öffentlichen Kapitalmarkt nicht in Anspruch nehmen. Zur Ausübung des Mitgliedstaatenwahlrechts nach Art. 5 der IAS-Verordnung, in: ZIP, 24. Jg., S. 93-101.

Schulze-Osterloh, Joachim (2003b), Rückzahlungsbetrag und Abzinsung von Rückstellungen und Verbindlichkeiten - Überlegungen zur Reform des HGB-Bilanzrechts, in: BB, 58. Jg., S. 351-355.

Schulze-Osterloh, Joachim (2004a), HGB-Reform: Der Einzelabschluß nicht kapitalmarktorientierter Unternehmen unter dem Einfluß von IAS/IFRS, in: BB, 59. Jg., S. 2567-2570.

Schulze-Osterloh, Joachim (2004b), Internationalisierung der Rechnungslegung und ihre Auswirkungen auf die Grundprinzipien des deutschen Rechts, in: Der Konzern, 2. Jg., S. 173-177.

Schulze-Osterloh, Joachim (2004c), Vorschläge für ein Bilanzrechtsmodernisierungsgesetz, in: ZIP, 25. Jg., S. 1128-1137.

Schuster, Peter (1998), Gesetzliches Garantiekapital als Problem europäischer und deutscher Rechtspolitik, in: AG, 43. Jg., S. 379-381.

Schwark, Eberhard (1979), Anlegerschutz durch Wirtschaftsrecht. Entwicklungslinien, Prinzipien und Fortbildung des Anlegerschutzes, zugleich ein Beitrag zur Überlagerung bürgerlich-rechtlicher Regelung und gewerbepolizeilicher Überwachung durch Wirtschaftsrecht, München.

Schwark, Eberhard (2002), Corporate Governance: Vorstand und Aufsichtsrat, in: Corporate Governance, hrsg. von Hommelhoff, Peter/Lutter, Marcus/Schmidt, Karsten/Schön, Wolfgang/Ulmer, Peter, Heidelberg, S. 27-67. 
Schwark, Eberhard (2004), Börsengesetz. Einleitung, in: Kapitalmarktrechts-Kommentar, hrsg. von Schwark, Eberhard, 3. Aufl., München.

Schwarz, Günter C. (2000), Europäisches Gesellschaftsrecht. Ein Handbuch für Wissenschaft und Praxis, Baden-Baden.

Seibert, Ulrich (1998), Stock Options für Führungskräfte - zur Regelung im Kontrolle- und Transparenzgesetz (KonTraG), in: Unternehmenswertorientierte Entlohnungssysteme, hrsg. von Pellens, Bernhard, Stuttgart, S. 29-52.

Seibert, Ulrich (2003a), Das 10-Punkte-Programm „Unternehmensintegrität und Anlegerschutz", in: BB, 58. Jg., S. 693-698.

Seibert, Ulrich (2003b), Transparenz- und Publizitätsgesetz (TransPuG) und Corporate Governance - Zum aktienrechtlichen Teil des TransPuG, in: Reform des Aktienrechts, der Rechnungslegung und der Prüfung, hrsg. von Dörner, Dietrich/Menold, Dieter/Pfitzer, Norbert/Oser, Peter, 2. Aufl., Stuttgart, S. 41-66.

Seibert, Ulrich (2005), Entwurf eines Mindestkapitalgesetzes (MindestkapG) - Substanzielle Absenkung des Mindeststammkapitals, in: BB, 60. Jg., S. 1061-1062.

Seibert, Ulrich/Kiem, Roger (Hrsg.) (2000), Handbuch der kleinen AG, 4. Aufl., Köln.

Seibert, Ulrich/Köster, Beate-Katrin/Kiem, Roger (1996), Die kleine AG, 3. Aufl., Köln.

Seibert, Ulrich/Schütz, Carsten (2004), Der Referntenentwurf eines Gesetzes zur Unternehmensintegrität und Modernisierung des Anfechtungsrechts - UMAG, in: ZIP, 25. Jg., S. 252-258.

Seibt, Christoph H. (2003), Effizienzprüfung der Aufsichtsratstätigkeit - Hinweise zur Anwendung von Ziff. 5.6 Deutscher Corporate Governance Kodex - , in: DB, 56. Jg., S. $2107-2112$.

Seibt, Christoph H. (2004), Drittelbeteiligungsgesetz und Fortsetzung der Reform des Unternehmensmitbestimmungsrechts. Analyse des Zweiten Gesetzes zur Vereinfachung der Wahl der Arbeitnehmervertreter in den Aufsichtsrat, in: NZA, 21. Jg., S. 767-776.

Sellhorn, Thorsten (2004), Goodwill Impairment. An Empirical Investigation of Write-Offs under SFAS 142, Frankfurt am Main u.a.

Semler, Johannes (2000), Rechtsvorgabe und Realität der Organzusammenarbeit in der Aktiengesellschaft, in: Deutsches und europäisches Gesellschafts-, Konzern- und Kapitalmarktrecht, FS für Marcus Lutter zum 70. Geburtstag, hrsg. von Schneider, Uwe H./ Hommelhoff, Peter/Schmidt, Karsten/Timm, Wolfram/Grunewald, Barbara/Drygala, Tim, Köln, S. 721-734.

Semler, Johannes (2004), Vorschlags- und Wahlverfahren, Entsendung, Ausscheiden, in: Arbeitshandbuch für Aufsichtsratsmitglieder, hrsg. von Semler, Johannes/Schenck, Kersten von, 2. Aufl., München, S. 76-99.

Siebel, Ulf (2004), Arbeit von Ausschüssen, in: Arbeitshandbuch für Aufsichtsratsmitglieder, hrsg. von Semler, Johannes/Schenck, Kersten von, 2. Aufl., München, S. 239-302. 
Siegel, Theodor (1997), Mangelnde Ernsthaftigkeit des Gläubigerschutzes als offene Flanke der deutschen Rechnungslegungsvorschriften, in: Jahresabschluß und Jahresabschlußprüfung. Probleme, Perspektiven, internationale Einflüsse, Festschrift zum 60. Geburtstag von Jörg Baetge, hrsg. von Fischer, Thomas R./Hömberg, Reinhold, Düsseldorf, S. 117-149.

Siegel, Theodor/Bareis, Peter/Rückle, Dieter/Schneider, Dieter/Sigloch, Jochen/Streim, Hannes/Wagner, Franz W. (1999), Stille Reserven und aktienrechtliche Informationspflichten, in: ZIP, 20. Jg., S. 2077-2085.

Siepe, Günter (2002), Unternehmensbewertung, in: Wirtschaftsprüfer-Handbuch 1998, Band II, hrsg. vom Institut der Wirtschaftsprüfer, 12. Aufl., Düsseldorf, S. 1-149.

Simon, Stefan/Leuering, Dieter (2005), Emittenten erhalten mehr Eigenverantwortung. Eine Befreiung von der Ad-hoc-Pflicht birgt Risiken, in: FAZ, Nr. 15 vom 19.01.2005, S. 25.

Sitkoff, Robert H. (2002), Corporate Political Speech, Political Extortion, and the Competition for Corporate Charters, in: U. Chi. L. Rev., Vol. 69, S. 1103-1166.

SLIM (1999a), Recommendations by the Company Law SLIM Working Group on the Simplification of the First and Second Company Law Directives, in: http://europa.eu.int/ comm/internal_market/en/company/company/official/6037en.pdf (Stand: 19.05.2005).

SLIM (1999b), Empfehlungen der Arbeitsgruppe zur Vereinfachung des Gesellschaftsrechts bezüglich der Vereinfachung der Ersten und Zweiten Gesellschaftsrechts-Richtlinie, in: ZIP, 20. Jg., S. 1944-1948.

Söffing, Günter (1995), Für und Wider den Maßgeblichkeitsgrundsatz, in: Rechenschaftslegung im Wandel, Festschrift für Wolfgang Dieter Budde, hrsg. von Förschle, Gerhart/Kaiser, Klaus/Moxter, Adolf, München, S. 635-673.

Solomon, Lewis D./Schwartz, Donald E./Baumann, Jeffrey D./Weiss, Elliott J. (1994), Corporations. Law and Policy. Materials and Problems, 3. Aufl., St. Paul.

Sonnenberger, Hans Jürgen/Coester, Michael (1974), Feststellung und Prüfung des Jahresabschlusses der Aktiengesellschaften im Gemeinsamen Markt. Kommissionsvorschlag einer 5. Richtlinie zur Angleichung des Gesellschaftsrechts (IV. Kapitel), in: AG, 19. Jg., S. 177-185.

Speckbacher, Gerhard (1997), Shareholder Value und Stakeholder Ansatz, in: DBW, 57. Jg., S. 630-639.

Spindler, Gerald (1998), Deregulierung des Aktienrechts?, in: AG, 43. Jg., S. 53-74.

Spindler, Gerald (2004), Vergütung und Abfindung von Vorstandsmitgliedern, in: DStR, 42. Jg., S. 36-45.

Spindler, Gerald (2005), Das Gesetz über die Offenlegung von Vorstandsvergütungen VorstOG, in: NZG, 8. Jg., S. 689-692.

Spindler, Gerald (2006), Abschied vom Papier? Das Gesetz über elektronische Handelsregister und Genossenschaftsregister sowie das Unternehmensregister, in: WM, 60. Jg., S. 109-116.

Staake, Marco (2004), Das Recht der Aktie, in: JA, 36. Jg., S. 247-254. 
Steiner, Manfred/Mader, Wolfgang/Starbatty, Nikolaus (2003), Aktuelle Entwicklungen in der Unternehmensfinanzierung, in: FB, 5. Jg., S. 513-524.

Stern, Henry L. (1976), The General Standard of Care Imposed on Directors under the New California General Corporation Law, in: UCLA L. Rev., Vol. 23, S. 1269-1281.

Stier-Somlo, Fritz (1903), Die Reform des Aufsichtsraths der Aktiengesellschaft, in: ZHR, 53. Jg., S. 20-78.

Stiller (2004), Die englische Limited mit Verwaltungssitz in Deutschland, in: PWC, JuliHeft, o. Jg., S. 20-21.

Stobbe, Thomas (1991), Die Verknüpfung handels- und steuerrechtlicher Rechnungslegung. Maßgeblichkeitsausprägungen de lege lata et ferenda, Berlin.

Streim, Hannes (1986), Grundsätzliche Anmerkungen zu den Zwecken des Rechnungswesens, in: Entwicklungsperspektiven des öffentlichen Rechnungswesens, Speyerer Forschungsberichte, Band 48, hrsg. von Lüder, Klaus, Speyer, S. 1-27.

Streim, Hannes (1988), Grundzüge der handels- und steuerrechtlichen Bilanzierung, Stuttgart u.a.

Streim, Hannes (1990), Ein Plädoyer für die Einheitsbilanz, in: BFuP, 42. Jg., S. 527-545.

Streim, Hannes (1992), Meinungsspiegel, in: BFuP, 44. Jg., S. 441-455.

Streim, Hannes (1994), Die Generalnorm des $§ 264$ Abs. 2 HGB - Eine kritische Analyse, in: Bilanzrecht und Kapitalmarkt, Festschrift zum 65. Geburtstag von Professor Dr. Dr. h.c. Dr. h.c. Adolf Moxter, hrsg. von Ballwieser, Wolfgang/Böcking, Hans-Joachim/Drukarczyk, Jochen/ Schmidt, Reinhard H., Düsseldorf, S. 391-406.

Streim, Hannes (1995), Zum Stellenwert des Lageberichts im System der handelsrechtlichen Rechnungslegung, in: Unternehmenstheorie und Besteuerung, Festschrift zum 60. Geburtstag von Dieter Schneider, hrsg. von Elschen, Rainer/Siegel, Theodor/Wagner, Franz W., Wiesbaden, S. 703-721.

Streim, Hannes (1998), Internationalisierung von Gewinnermittlungsregeln zum Zwecke der Informationsvermittlung. Zur Konzeptionslosigkeit der Fortentwicklung der Rechnungslegung, in:Unternehmensrechnung und -besteuerung. Grundfragen und Entwicklungen. Festschrift für Dietrich Börner zum 65. Geburtstag, hrsg. von Meffert, Heribert/Krawitz, Norbert, Wiesbaden, S. 323-343.

Streim, Hannes (2000), Die Vermittlung von entscheidungsnützlichen Informationen durch Bilanz und GuV - Ein nicht einlösbares Versprechen der internationalen Standardsetter, in: BFuP, 52. Jg., S. 111-131.

Streim, Hannes/Bieker, Marcus/Esser, Maik (2003), Vermittlung entscheidungsnützlicher Informationen durch Fair Values - Sackgasse oder Licht am Horizont?, in: BFuP, 55. Jg., S. 457-479.

Streim, Hannes/Bieker, Marcus/Esser, Maik (2004), Der schleichende Abschied von der Ausschüttungsbilanz - Grundsätzliche Überlegungen zum Inhalt einer Informationsbilanz, in: Steuern, Rechnungslegung und Kapitalmarkt, Festschrift für Franz W. Wagner zum 60. Geburtstag, hrsg. von Dirrigl, Hans/Wellisch, Dietmar/Wenger, Ekkehard, Wiesbaden, S. 229-244. 
Streim, Hannes/Bieker, Marcus/Leippe, Britta (2001), Anmerkungen zur theoretischen Fundierung der Rechnungslegung nach International Accounting Standards, in: Wolfgang Stützel: Moderne Konzepte für Finanzmärkte, Beschäftigung und Wirtschaftsverfassung, hrsg. von Schmidt, Hartmut/Ketzel, Eberhart/Prigge, Stefan, Tübingen, S. 177-206.

Streim, Hannes/Esser, Maik (2003a), Rechnungslegung nach IAS/IFRS - Ein geeignetes Instrument zur Informationsvermittlung?, in: StuB, 5. Jg., S. 836-840.

Streim, Hannes/Esser, Maik (2003b), Rechnungslegung nach IAS/IFRS - Ein geeignetes Instrument zur Zahlungsbemessung?: Ansatzfragen, in: StuB, 5. Jg., S. 736-742.

Streim, Hannes/Esser, Maik (2003c), Rechnungslegung nach IAS/IFRS - Ein geeignetes Instrument zur Zahlungsbemessung?: Bewertungsfragen, in: StuB, 5. Jg., S. 781-786.

Strobl, Elisabeth (1996), IASC-Rechnungslegung und Gläubigerschutzbestimmungen nach deutschem Recht, in: Festschrift für Hermann Clemm zum 70. Geburtstag, hrsg. von Ballwieser, Wolfgang, München, S. 389-412.

Strunk, Günther (2003), Sachdividenden im Spannungsfeld von Gesellschafts-, Bilanz- und Steuerrecht, in: UM, o. Jg., S. 45-51.

Strunk, Günther/Kolaschnik, Helge F. (2003), TransPuG und Corporate Governance Kodex. Neue gesellschafts-, bilanz- und steuerrechtliche Anforderungen für die Unternehmenspraxis, Berlin.

Stühmer, Jens (2003), SLIM - eine Schlankheitskur für das EU-Gesellschaftsrecht. Die Vorschläge der SLIM-Kommission zur Modifizierung der Zweiten Gesellschaftlichen Richtlinie, Hamburg.

Stützel, Wolfgang (1967), Bemerkungen zur Bilanztheorie, in: ZfB, 37. Jg., S. 314-340.

Stützel, Wolfgang (1981), Die Aktie und die volkswirtschaftliche Allokation, in: Geld und Versicherung. Analysen, Thesen, Perspektiven im Spannungsfeld liberaler Theorie. Festgabe für Wilhelm Seuß, hrsg. von Jung, Michael/Lucius, Ralph Rene/Seifert, Werner, Karlsruhe, S. 193-211.

Süchting, Joachim (1981), Scheinargumente in der Diskussion um stille Reserven bei Kreditinstituten, in: DBW, 41. Jg., S. 207-220.

Süchting, Joachim (1982), Zum Problem des ,angemessenen“ Eigenkapitals von Kreditinstituten, in: ZfbF, 34. Jg., S. 397-415.

Süchting, Joachim (1995), Finanzmanagement. Theorie und Politik der Unternehmensfinanzierung, 6. Aufl., Wiesbaden.

Süchting, Joachim/Paul, Stephan (1998), Bankmanagement, 4. Aufl., Stuttgart.

Sürken, Silke (1999), Abgrenzung der wirtschaftlichen Einheit nach US-GAAP, Frankfurt am Main.

Tauber, Laurence S. (2004), Chapter 140: Permissible Sources of Dividends, in: Cavitch, Zolman, Business Organizations with Tax Planning, hrsg. von Matthew Bender \& Company, Albany (Stand: Release No. 134, August 2004). 
Theisen, Manuel R. (1987), Die Überwachung der Unternehmungsführung. Betriebswirtschaftliche Ansätze zur Entwicklung erster Grundsätze ordnungsmäßiger Überwachung, Stuttgart.

Theisen, Manuel R. (1992), Rücklagenbildung im Konzern, in: ZHR, 156 Jg., S. 174-184.

Theisen, Manuel R. (1999), Zusammensetzung und Struktur der Vergütungen für den Aufsichtsrat nach dem KontraG, in: DB, 52. Jg., S. 1665-1672.

Theisen, Manuel R. (2000), Der Konzern, 2. Aufl., Stuttgart.

Theisen, Manuel R. (2002), Grundsätze einer ordnungsmäßigen Information des Aufsichtsrats, 3. Aufl., Stuttgart.

Theisen, Manuel R. (2003a), Herausforderung Corporate Governance, in: DBW, 63. Jg., S. 441-464.

Theisen, Manuel R. (2003b), Zur Reform des Aufsichtsrats - Eine betriebswirtschaftliche Bestandsanalyse und Perspektive, in: Reform des Aktienrechts, der Rechnungslegung und der Prüfung. KonTraG - Corporate Governance - TransPuG, hrsg. von Dörner, Dietrich/Menold, Dieter/Pfitzer, Norbert/Oser, Peter, 2. Aufl., Stuttgart, S. 431-522.

Theisen, Manuel R./Hölzl, Michael (2005), Corporate Governance, in: Die Europäische Aktiengesellschaft. Recht, Steuern und Betriebswirtschaft der Societas Europaea (SE), hrsg. von Theisen, Manuel R./Wenz, Martin, 2. Aufl., Stuttgart, S. 269-330.

Theisen, Manuel R./Wenz, Martin (2005), Hintergründe, historische Entwicklung und Grundkonzeption, in: Die Europäische Aktiengesellschaft. Recht, Steuern und Betriebswirtschaft der Societas Europaea (SE), hrsg. von Theisen, Manuel R./Wenz, Martin, 2. Aufl., Stuttgart, S. 1-56.

Theisen, Manuel R./Wenz, Martin (Hrsg.) (2005), Die Europäische Aktiengesellschaft. Recht, Steuern und Betriebswirtschaft der Societas Europaea (SE), 2. Aufl., Stuttgart.

Thiele, Konstanze (1999), Stille Reserven in der Rechnungslegung. Vergleich von HGB, US-GAAP und IAS, Wiesbaden.

Thießen, Friedrich (1996), Covenants: Durchsetzungsprobleme und die Folgen, in: Regulierung und Unternehmenspolitik. Methoden und Ergebnisse der betriebswirtschaftlichen Rechtsanalyse, hrsg. von Sadowski, Dieter/Czap, Hans/Wächter, Hartmut, Wiesbaden, S. 143-159.

Thomas, Jürgen (1985), Rücklagenbildung im Konzern, in: ZGR, 14. Jg., S. 365-385.

Thümmel, Roderich C. (1999), Aufsichtsräte in der Pflicht? - Die Aufsichtsratshaftung gewinnt Konturen, in: DB, 52. Jg., S. 885-888.

Thümmel, Roderich C. (2003), Persönliche Haftung von Managern und Aufsichtsräten. Haftungsrisiken bei Managementfehlern, Risikobegrenzung und D \& O-Versicherungen, 3. Aufl., Stuttgart u.a.

Thümmel, Roderich C. (2004a), Aufsichtsratshaftung vor neuen Herausforderungen - Überwachungsfehler, unternehmerische Fehlentscheidungen, Organisationsmängel und andere Risikofelder, in: AG, 49. Jg., S. 83-91. 
Thümmel, Roderich C. (2004b), Organhaftung nach dem Referentenentwurf des Gesetzes zur Unternehmensintegrität und Modernisierung des Anfechtungsrechts (UMAG) - Neue Risiken für Manager?, in: DB, 57. Jg., S. 471-474.

Timm, Wolfram (1980), Die Aktiengesellschaft als Konzernspitze - Die Zuständigkeitsordnung bei der Konzernbildung -, Köln u.a.

Tomaszewski, Claude (2000), Bewertung strategischer Flexibilität beim Unternehmenserwerb. Der Wertbeitrag von Realoptionen, Frankfurt am Main u.a.

Triebel, Volker/Otte, Sabine/Kimpel, Bert (2005), Die englische Limited Liability Partnership in Deutschland: Eine attraktive Rechtsform für deutsche Beratungsgesellschaften?, in: BB, 60. Jg., S. 1233-1241.

Trumpler, Hans (1950), Die Bilanz der Aktiengesellschaft nach deutschem Aktien- und Steuerrecht unter Hinweisen auf das Recht der Vereinigten Staaten, Englands und der Schweiz, Basel.

Ulmer, Peter (1999), Die Aktionärsklage als Instrument zur Kontrolle des Vorstands- und Aufsichtsratshandelns. Vor dem Hintergrund der US-Erfahrungen mit der shareholders' derivative action, in: ZHR, 163. Jg., S. 290-342.

Ulmer, Peter (2002), Editorial. Paritätische Arbeitnehmermitbestimmung im Aufsichtsrat von Großunternehmen - noch zeitgemäß?, in: ZHR, 166. Jg., S. 271-277.

Ulmer, Peter (2004), Haftungsfreistellung bis zur Grenze grober Fahrlässigkeit bei unternehmerischen Fehlentscheidungen von Vorstand und Aufsichtsrat? - Kritische Bemerkungen zur geplanten Kodifizierung der business judgement rule im UMAG-Entwurf ( 93 Abs. 1 Satz 2 AktG) -, in: DB, 57. Jg., S. 859-863.

Unternehmensrechtskommission (1980), Bericht über die Verhandlungen der Unternehmensrechtskommission, hrsg. vom Bundesministerium der Justiz, Köln.

Veit, Klaus-Rüdiger (2003), Verbreitung von Bilanzprüfungsausschüssen in Deutschland, in: DB, 56. Jg., S. 2021-2023.

Vogt, Stefan (1991), Die Maßgeblichkeit des Handelsbilanzrechts für die Steuerbilanz Reichweite, Rechtfertigung und Perspektiven eines Eckpfeilers unseres Bilanzrechts -, Düsseldorf.

Volhard, Rüdiger (1998), „Siemens/Nold“: Die Quittung, in: AG, 43. Jg., S. 397-404.

Waclawik, Erich (2003), Die neue Sachdividende: Was ist sie wert?, in: WM, 57. Jg., S. 2266-2277.

Wagenhofer, Alfred (2005), Internationale Rechnungslegungsstandards - IAS/IFRS, 5. Aufl., Frankfurt am Main.

Wagenhofer, Alfred/Ewert, Ralf (2003), Externe Unternehmensrechnung, Berlin u.a.

Wagner, Franz W. (1988), Allokative und distributive Wirkungen der Ausschüttungskompetenzen von Hauptversammlung und Verwaltung einer Aktiengesellschaft - Eine ökonomische Analyse des Art. 50 des Entwurfs einer 5. EG-Richtlinie -, in: ZGR, 17. Jg., S. 210-239.

Wagner, Franz W. (2000), Welche Kriterien bestimmen die internationale Wettbewerbsfähigkeit der Methoden steuerlicher Gewinnermittlung?, in: BFuP, 52. Jg., S. 183-203. 
Waldersee, Georg Graf/Richardt, Yvonne (2005), Internationale Rahmenbedingungen deutscher Corporate Governance, in: Deutscher Corporate Governance Kodex, hrsg. von Pfitzer, Norbert/ Oser, Peter/Orth, Christian, 2. Aufl., Stuttgart, S. 469-500.

Walter, Bernhard (1998), Gesetzliches Garantiekapital und Kreditentscheidung der Banken, in: AG, 43. Jg., S. 370-372.

Walz, W. Rainer (1997), Strategien zur Überwindung des bilanzrechtlichen Anpassungsbedarfs, in: Wirtschafts- und Medienrecht in der offenen Demokratie. Freudesgabe für Friedrich Kübler zum 65. Geburtstag, hrsg. von Assmann, Heinz-Dieter/Brinkmann, Tomas/Gounalakis, Georgios/Kohl, Helmut/Walz, Rainer, Heidelberg, S. 557-581.

Warschkow, Kirsten (1991), Schutz der Aktionäre der Konzernobergesellschaft, München.

Warrikoff, Alexander (1963), Der Rechtsanspruch der Aktionäre auf Dividende im Vergleich mit dem Recht der Vereinigten Staaten, in: AG, 8. Jg., S. 34-37 (Teil 1), S. 60-66 (Teil 2).

Watrin, Christopf (2001a), Internationale Rechnungslegung und Regulierungstheorie, Wiesbaden.

Watrin, Christoph (2001b), Sieben Thesen zur künftigen Regulierung der Rechnungslegung - Anmerkungen zu den Vorschlägen des Arbeitskreises Externe Rechnungslegung der Schmalenbach-Gesellschaft -, in: DB, 54. Jg., S. 933-938.

Weber, Harald (1972), Zu einigen Grundfragen der Besteuerung verbundener Unternehmen. Zugleich eine Stellungnahme zum Gutachten von Prof. Dr. Harold Rasch zum 49. Deutschen Juristentag 1972, in: JZ, 27. Jg., S. 482-488.

Weber, Martin (2004), Die Entwicklung des Kapitalmarktrechts im Jahre 2004, in: NJW, 57. Jg., S. 3674-3681.

Weber-Grellet, Heinrich (1996), Bilanzrecht im Lichte, Bilanzsteuerrecht im Schatten des EuGH, in: DB, 49. Jg., S. 2089-2092.

Weber-Grellet, Heinrich (1999), Der Maßgeblichkeitsgrundsatz im Lichte aktueller Entwicklungen, in: BB, 54. Jg., S. 2659-2666.

Weiner, Joseph L. (1929a), Theory of Anglo-American Dividend Law: American Statutes and Cases, in: Colum. L. Rev., Vol. 29, S. 461-482.

Weiner, Joseph L. (1929b), The Amount Available for Dividends where No-Par Shares Have Been Issued, in: Colum. L. Rev., Vol. 29, S. 906-917.

Weizsäcker, C. C. von (1980), Barriers to Entry, Berlin u.a.

Wellkamp, Ludger (1998), Aktionärsschutz, Bonn.

Wellkamp, Ludger (2000), Vorstand, Aufsichtsrat und Aktionär, 2. Aufl., Bonn.

Wendlandt, Klaus/Knorr, Liesel (2005), Das Bilanzrechtsreformgesetz - Zeitliche Anwendung der wesentlichen bilanzrechtlichen Änderungen des HGB und Folgen für die IFRSAnwendung in Deutschland -, in: KoR, 5. Jg., S. 53-57.

Wenger, Ekkehard (1981), Unternehmenserhaltung und Gewinnbegriff. Die Problematik des Nominalwertprinzips in handels- und steuerrechtlicher Sicht, Wiesbaden. 
Wenger, Ekkehard (1996), Kapitalmarktrecht als Resultat deformierter Anreitzstrukturen, in: Regulierung und Unternehmenspolitik - Methoden und Ergebnisse der betriebswirtschaftlichen Rechtsanalyse, hrsg. von Sadowski, Dieter/Czap, Hans/Wächter, Hartmut, Wiesbaden, S. 419-458.

Werder, Axel von (1996), Grundsätze ordnungsmäßiger Unternehmensführung (GoF) - Zusammenhang, Grundlagen und Systemstruktur von Führungsgrundsätzen für die Unternehmungsleitung (GoU), Überwachung (GoÜ) und Abschlussprüfung (GoA), in: Grundsätze ordnungsmäßiger Unternehmungsführung (GoF) für die Unternehmungsleitung (GoU), Überwachung (GoÜ) und Abschlussprüfung (GoA), hrsg. von Werder, Axel von, Düsseldorf/Frankfurt am Main, S. 1-26.

Werder, Axel von (2004), Modernisierung der Mitbestimmung, in: DBW, 64. Jg., S. 229-243.

Werner, Winfried (1985), Gewinnverwendung im Konzern, in: Festschrift für Walter Stimpel zum 68. Geburtstag, Berlin, S. 935-953.

Werner, Winfried (1990), Ausgewählte Fragen zum Aktienrecht. Zum Erscheinen der 2. Auflage des Kölner Kommentars zum AktG, in: AG, 35. Jg., S. 1-19.

Westermann, Harm P. (1986), Grundfragen der Rechtsfortbildung im Aktienkonzernrecht, in: Festschrift für Klemens Pleyer zum 65. Geburtstag, hrsg. von Hofmann, Paul/MeyerCording, Ulrich/Wiedemann, Herbert, Köln u.a., S. 421-444.

Wiedemann, Herbert (1968), Haftungsbeschränkung und Kapitaleinsatz in der GmbH - Unter Berücksichtigung des amerikanischen, deutschen und französischen Gesellschaftsrechts -, in: Die Haftung des Gesellschafters in der GmbH, hrsg. von Caemmerer, Ernst von, Frankfurt am Main/Berlin, S. 5-61.

Wiedemann, Herbert (1980), Gesellschaftsrecht. Band I: Grundlagen, München.

Wiedemann, Herbert/Frey, Kaspar (2002), Gesellschaftsrecht, 6. Aufl., München.

Wienke, Dieter (1992), Die Wahlordnungen zum Mitbestimmungsgesetz, 4. Aufl., Bergisch Gladbach.

Wiesner, Peter M. (2002), Binnenmarkt und Wettbewerb bleiben auf der Strecke - Zum Kommissionsvorschlag für eine neue Übernahmerichtlinie, in: ZIP, 23. Jg., S. 1967.

Wiesner, Peter M. (2003), Neue Brüsseler Impulse für Corporate Governance und Gesellschaftsrecht. Zum Endbericht der Hochrangigen Expertengruppe (Winter-Gruppe), in: BB, 58. Jg., S. 213-217.

Wiethölter, Rudolf (1961), Interessen und Organisation der Aktiengesellschaft im amerikanischen und deutschen Recht, Karlsruhe.

Wilhelm, Jan (1998), Kapitalgesellschaftsrecht, Berlin/New York.

Windbichler, Christine (2000), Alternative Dispute Resolution v. Shareholders' Suits?, in: Corporations, Capital Markets and Business in the Law, Liber Amicorum Richard M. Buxbaum, hrsg. von Baums, Theodor/Hopt, Klaus J./Horn, Norbert, London u.a., S. 617-627.

Winkeljohann, Norbert/Geißler, Horst (2006), § 252 HGB, in: Beck'scher BilanzKommentar, hrsg. von Ellrott, Helmut/Förschle, Gerhart/Hoyos, Martin/Winkeljohann, Norbert, 6. Aufl., München. 
Winkeljohann, Norbert/Schellhorn, Mathias (2006), § 264 HGB, in: Beck'scher BilanzKommentar, hrsg. von Ellrott, Helmut/Förschle, Gerhart/Hoyos, Martin/Winkeljohann, Norbert, 6. Aufl., München.

Winter, Ralph K. (1977), State Law, Shareholder Protection, and the Theory of the Corporation, in: J. Legal Stud., 6. Jg. 1977, S. 251-292.

Winter, Ralph K. (1989), The „Race for the Top“ Revisited: A Comment on Eisenberg, in: Colum. L. Rev., Vol. 89, S. 1526-1529.

Wittig, Arne (1996), Financial Covenants im inländischen Kreditgeschäft, in: WM, 50. Jg., S. 1381-1391.

Wittig, Arne (2003), Früherkennung der Krise durch Kreditinstitute, in: Die GmbH in Krise, Sanierung und Insolvenz, hrsg. von Schmidt, Karsten/Uhlenbruck, Wilhelm, 3. Aufl., Köln, S. 60-85.

Wöhe, Günter (2005), Einführung in die Allgemeine Betriebswirtschaftslehre, 22. Aufl., München.

Wolf, Joachim (2005), Organisation, Management, Unternehmensführung, 2. Aufl., Wiesbaden.

Würdinger, Hans (1981), Aktienrecht und das Recht der verbundenen Unternehmen, 4. Aufl., Heidelberg/Karlsruhe.

Wüstemann, Jens (1996), US-GAAP: Modell für das deutsche Bilanzrecht?, in: WPg, 49. Jg., S. 421-431.

Wüstemann, Jens (1999), Generally Accepted Accounting Principles. Zur Bedeutung und Systembildung der Rechnungslegungsregeln der USA, Berlin.

Wymeersch, Eddy (2001), Company Law in Europe and European Company Law, in: http://ssrn.com/abstract=273876 (Stand: 17.03.2005).

Zabel, Martin (2002), IAS zwingend für den Konzern- und Einzelabschluss? - Stellungnahme zu Böcking, WPg 2001, S. 1433 ff.; zugleich ein Plädoyer für eine intensive Diskussion der Vor- und Nachteile kapitalmarktorientierter Rechnungslegungs- und Publizitätsgrundsätze für nicht kapitalmarktorientierte Unternehmen -, in: WPg, 55. Jg., S. 919-924.

Zabel, Martin/Cairns, David (2005), Vereinfachte IFRS für ausgewählte Unternehmen des Mittelstands - Ein Diskussionsbeitrag und eine Bestandsaufnahme zu Bedeutung, Prozess und Lösungsansätzen des IASB-Projekts „Accounting Standards for Small and Mediumsized Entities" -, 5. Jg., S. 207-216.

Zeff, Stephen (1961), Legal Dividend Sources - A National Survey and Critique, in: NYCPA, Vol. 31, S. 741-755 (Teil 1), S. 802-816 (Teil 2).

Zeitler, Franz Christoph (2003), Rechnungslegung und Rechtsstaat - Übernahme der IAS oder Reform des HGB? -, in: DB, 56. Jg., S. 1529-1534.

ZEW (2006), Zentrum für Europäisches Wirtschaftsrecht, Arbeitskreis Kapital in Europa, in: http://www.zew.uni-bonn.de/index.htm?/arbeitskreis.htm (Stand: 05.06.2006).

Ziemann, Wolfgang (1993), Dividendenpolitik International, in: Die deutsche Aktie. Unternehmensfinanzierung und Vermögenspolitik vor neuen Herausforderungen, hrsg. von Fritsch, Ulrich/ Liener, Gerhard/Schmidt, Reinhart, Stuttgart, S. 137-155. 
Zimmer, Daniel (1996), Internationales Gesellschaftsrecht, Heidelberg.

Zöllner, Wolfgang (1973), § 119, in: Kölner Kommentar zum Aktiengesetz, hrsg. von Zöllner, Wolfgang, Köln u.a.

Zöllner, Wolfgang (2006), Konkurrenz für inländische Kapitalgesellschaften durch ausländische Rechtsträger, insbesondere durch die englische Private Limited Company, in: GmbHR, 97. Jg., S. 1-12.

Zülch, Henning (2004), Das IASB Improvement Project - Wesentliche Neuerungen und ihre Würdigung -, in: KoR, 4. Jg., S. 153-167.

Zweig, Stefan (1927), Sternstunden der Menschheit. Fünf historische Miniaturen, Leipzig.

Zweigert, Konrad/Kötz, Hein (1996), Einführung in die Rechtsvergleichung auf dem Gebiete des Privatrechts, 3. Aufl., Tübingen. 


\section{Rechtsprechungsverzeichnis}

\section{Bundesgerichtshof (BGH)}

25.02.1982, Urteil II ZR 174/80

21.04.1997, Urteil II ZR 175/95

16.02.2004, Urteil II ZR 316/02

26.04.2004, Urteil II ZR 154/02

26.04.2004, Urteil II ZR 155/02

\section{Europäischer Gerichtshof (EuGH)}

27.06.1996, Urteil Rs. C-234/94, Slg. 1996, I-3145-Tomberger

09.03.1999, Urteil Rs. C-212/97, Slg. 1999, I-1459-Centros

05.11.2002, Urteil Rs. C-208/00, Slg. 2002, I-09919-Überseering

30.09.2003, Urteil Rs. C-167/01, Slg. 2003, I-10155-Inspire Art

\section{US-amerikanische Urteile}

Angelo, Gordon \& Co. v. Allied Riser Communications Corp., 805 A.2d 221 (Del. Ch. 2002)

Baker v. Mutual Loan \& Investment Co., 213 S.C. 558, 50 S.E.2d 692 (1948)

Black \& Decker Corp. v. American Standard, Inc., 682 F. Supp. 772, 778 (D. Del. 1988)

Com. Transp. Com`r v. Matyiko, 253 Va. 1, 481 S.E.2d 468 (1997)

Commonwealth Transportation Commissioner v. Matyiko, 253 Va. 1, 481 S.E.2d 468 (1997)

Cornell v. Seddinger, 237 Pa. 389, 85 A. 446 (1912)

Credit Lyonnais Bank Nederland N.V. v. Pathe Communications Corp., WL 277613 (Del. Ch. 1991)

Credit Managers Ass'n of Southern California v. Federal Company, 629 F. Supp. 175 (C.D. Cal. 1985)

Dellastatious v. Williams, 242 F.3d 191 (4th Cir. 2001)

Dodge v. Ford Motor Co., 204 Michigan 459, 170 N.W. 668 (1919)

Donahue v. Rodd Electrotype Co. of New England, Inc., 367 Mass. 578, 328 N.E.2d 505 (Mass 1975)

England v. Christensen, 243 Cal.App.2d 413, 52 Cal.Rptr. 402 (1966)

Farland v. Wills, 1 Del. J. Corp. L. 467, 1975 WL 1960 (Del. Ch. 1975) 
Federal Sav. and Loan Ins. Corp. v. Molinaro, 901 F.2d 1490 (9th Cir. 1990)

Flynn v. California Basket Co., 105 Cal. Abb.2d 196, 233 P2d. 131 (1951)

Fried v. Cano, 167 F. Supp. 625 (S.D. N.Y. 1958)

F.T.C. v. Med Resorts Intern., Inc., 2000 WL 1889635 (N.D. Ill. 2000)

Gaillard v. Natomas Co., 208 Cal. App. 3d 1250, 256 Cal. Rptr. 702 (1st Dist. 1989)

Goodnow v. American Writing Paper, 73 N.J.Eq. 692, 69 A. 1014 (N.J.1908)

Gottfried v. Gottfried, 73 N.Y.S.2d 692 (N.Y.Sup.Ct.1947)

Handley v. Stutz, 139 U.S. 417 (1891)

Hanson v. Kake Tribal Corp., 939 P2d 1320 (Alaska 1997)

Hospes v. Northwestern Manufacturing \& Car Co., 48 Minn. 174, 50 N.W. 1117 (1892)

In re Hoffman Associates, Inc., 194 B.R. 943 (Bankr. D. S.C. 1995)

In re Integra Realty Resources, Inc., 198 B.R. 352 (Bankr. D. Colo. 1996)

In re Jacks, 243 B.R. 385 (Bankr. C.D. Cal. 1999). Aber 2001

In re Kettle Fried Chicken of America, Inc., 513 F.2d 807 (6th Cir. 1975)

In re Lake Country Investments, 255 B.R. 588 (Bankr. D. Idaho 2000)

In re Omni Mechanical Contractors, Inc., 114 B.R. 518, 530-531 (Bankr. E.D. Tenn. 1990)

In re R.M.L., Inc., 92 F.3d 139 (3d Cir. 1996)

Jones v. First Nat. Bldg. Corp., 155 F.2d 815 (C.C.A. 10th Cir. 1946)

Johnston v. Wolf, 487 A.2d 1132 (Del. 1985)

Kahn v. United Staates Sugar Corp., No. 7313 (Del. Ch. Dec. 10, 1985)

Klang v. Smith's Food \& Drug Centers, Inc., 702 A.2d 150 (Del.Supr.1997)

Lee v. Neuchatel Asphalte Co., 41 Ch.Div. 1 (C.A.1889)

MacDermot v. Hayes, 175 Cal. 95, 170 P. 616 (1917)

McLaren v. Crescent Planing Mill Co., 117 Mo. App. 40, 93 S.W. 819 (1906)

Meyers v. El Tejon Oil and Refining Co., 29 Cal.2d 184, 174 P.2d 1 (1946) 
Miller v. Magline, Inc., 76 Mich.App. 284, 256 N.W.2d 761 (1977)

Moran v. Household International, Inc., 500 A.2d 1348 (S.Ct.Del. 1985)

Morris v. Standard Gas \& Elec. Co., 31 Del.Ch. 20, 63 A.2d 577 (1949)

Nash v. Rosesteel, 7 Cal.App. 504, 94 P. 850 (1908)

Patton v. Nicholas, 154 Tex. 385, 279 S.W.2d 848 (1955)

Pereira v. Cogan, 294 B.R. 449 (S.D. N.Y. 2003)

Petroleum Rights Corporation v. Midland Royalty Corporation, 167 Atl. 835 (1933)

Powers v. Heggie, 268 Mass. 233, 167 N.E. 314 (1929)

Randall v. Bailey, 23 N.Y.S.2d 173 (N.Y.Sup.1940)

Realty Company, 25 Cal.App. 531, 144 P. 301 (1914)

Resolution Trust Corp. v. Dean, 854 F. Supp. 626 (D. Ariz.1994)

Richards v. Pacific Southwest Discount Corporation, 44 Cal. App.2d 551, 112 P.2d 698 (1941)

Smith v. Atlantic Properties, Inc., 12 Mass.App.Ct. 201, 422 N.E.2d 798 (1981)

Smith v. Taecker, 133 Cal.App. 351, 24 P.2d 182 (1933)

Southdown, Inc. v. Moore McCormack Resources, Inc., 686 F. Supp. 595, 599 (S.D. Tex. 1988)

Telefest, Inc. v. VU-TV, Inc., 591 F. Supp. 1368 (D.N.J. 1984)

Tiedje v. Aluminum Taper Milling Co., Inc., 46 Cal.2d 450, 296 P.2d 554 (1956)

UMF Systems, Inc. V. Eltra Corporation et al., 17 Cal.3d 753, 553 P.2d 225, 132 Cal.Rptr. $129(1976)$

U.S. v. Gleneagles Inv. Co., Inc., 565 F.Supp.556 (MD Pa 1983)

Weinberg v. Baltimore Brick Co., 35 Del. Ch. 225, 114 A.2d 812 (1955)

Wittenberg v. Federal Mining \& Smelting Co., 15 Del.Ch. 147, 133 A. 48 (1926)

Wood v. Dummer, 30 F.Cas. 435 (C.C.D.Me.1824)

Wood v. National City Bank, 24 F.2d 661 (C.C.A. 2d Cir. 1928) 
Marc Richard - 978-3-631-75501-3

Downloaded from PubFactory at 01/11/2019 04:06:06AM

via free access 


\section{Bochumer Beiträge zur Unternehmensführung}

Herausgegeben vom Direktorium des Instituts

für Unternehmensführung der Ruhr-Universität Bochum

Band 1 Busse von Colbe, Walther/Mattessich, Richard (Hrsg.): Der Computer im Dienste der Unternehmungsführung (1968)

Band 2 Busse von Colbe, Walther/Meyer-Dohm, Peter (Hrsg.): Unternehmerische Planung und Entscheidung (1969)

Band 3 Anthony, Robert N.: Harvard-Fälle aus der Praxis des betrieblichen Rechnungswesens. Herausgegeben von Richard V. Mattessich unter Mitarbeit von Klaus Hermberger und Wolf Lange (1969)

Band 4 Mattessich, Richard: Die wissenschaftlichen Grundlagen des Rechnungswesens (1970)

Band 5 Schweim, Joachim: Integrierte Unternehmungsplanung (1969)

Band 6 Busse von Colbe, Walther (Hrsg.): Das Rechnungswesen als Instrument der Unternehmungsführung (1969)

Band 7 Domsch, Michel: Simultane Personal- und Investitionsplanung im Produktionsbereich (1970)

Band 8 Leunig, Manfred: Die Bilanzierung von Beteiligungen. Eine bilanztheoretische Untersuchung (1970)

Band 9 Franke, Reimund: Betriebsmodelle. Rechensystem für Zwecke der kurzfristigen Planung, Kontrolle und Kalkulation (1972)

Band 10 Wittenbrink, Hartwig: Kurzfristige Erfolgsplanung und Erfolgskontrolle mit Betriebsmodellen (1975)

Band 11 Lutter, Marcus (Hrsg.): Recht und Steuer der internationalen Unternehmensverbindungen (1972)

Band 12 Niebling, Helmut: Kurzfristige Finanzrechnung auf der Grundlage von Kosten- und Erlösmodellen (1973)

Band 13 Perlitz, Manfred: Die Prognose des Unternehmenswachstums aus Jahresabschlüssen deutscher Aktiengesellschaften (1973)

Band 14 Niggemann, Walter: Optimale Informationsprozesse in betriebswirtschaftichen Entscheidungssituationen (1973)

Band 15 Richardt, Harald: Der aktienrechtliche Abhängigkeitsbericht unter ökonomischen Aspekten (1974)

Band 16 Backhaus, Klaus: Direktvertrieb in der Investitionsgüterindustrie - Eine Marketing-Entscheiung (1974)

Band 17 Plinke, Wulff: Kapitalsteuerung in Filialbanken (1975)

Band 18 Steffen, Rainer: Produktionsplanung bei Fließbandfertigung (1977)

Band 19 Kolb, Jürgen: Industrielle Erlösrechnung - Grundlagen und Anwendungen (1978)

Band 20 Busse von Colbe, Walther/Lutter, Marcus (Hrsg.): Wirtschaftsprüfung heute: Entwicklung oder Reform? (1977)

Band 21 Uphues, Peter: Unternehmerische Anpassung in der Rezession (1979)

Band 22 Gebhardt, Günther: Insolvenzprognosen aus aktienrechtlichen Jahresabschlüssen (1980)

Band 23 Domsch, Michel: Systemgestützte Personalarbeit (1980)

Band 24 Schmied, Volker: Alternativen der Arbeitsgestaltung und ihre Bewertung (1982) 
Band 25 Wäscher, Gerhard: Innerbetriebliche Standortplanung bei einfacher und mehrfacher Zielsetzung (1982)

Band 26 Weber, Martin: Entscheidungen bei Mehrfachzielen - Verfahren zur Unterstützung von Individual- und Gruppenentscheidungen (1983)

Band 27 Kroesen, Alfred: Instandhaltungsplanung und Betriebsplankostenrechnung (1983)

Band 28 Plinke, Wulf: Erlösplanung im industriellen Anlagengeschäft (1985)

Band 29 Chamoni, Peter: Simulation störanfälliger Systeme (1986)

Band 30 Arning, Andreas: Die wirtschaftliche Bewertung der Zentrenfertigung - Dargestellt am Beispiel einer Fertigungsinsel (1987)

Band 31 Gebhardt, Günther: Finanzielle Planung und Kontrolle bei internationaler Unternehmenstätigkeit

Band 32 Markiewicz, Michael: Ersatzteildisposition im Maschinenbau - Betriebswirtschaftliche Methoden der Planung und Überwachung (1988)

Band 33 Pellens, Bernd: Der Informationswert von Konzernabschlüssen - Eine empirische Untersuchung deutscher Börsengesellschaften (1989)

Band 34 Mrotzek, Rüdiger: Bewertung direkter Auslandsinvestitionen mit Hilfe betrieblicher Investitionskalküle (1989)

Band 35 Deppe, Joachim: Quality Circle und Lernstatt - Ein integrativer Ansatz (1989, 3. Auflage 1993)

Band 36 Rademacher, Michael: Arbeitszeitverkürzung und -flexibilisierung - Formen und betriebliche Auswirkungen (1990)

Band 37 Kaiser, Klaus: Kosten- und Leistungsrechung bei automatisierter Produktion (1991, 2. Auflage 1993)

Band 38 Müller, Hermann: Industrielle Abfallbewältigung - Entscheidungsprobleme aus betriebswirtschaftlicher Sicht (1991)

Band 39 Schörner, Peter: Gesetzliches Insiderhandelsverbot - Eine ordnungspolitische Analyse (1991)

Band 40 Bentler, Martin: Grundsätze ordnungsmäßiger Bilanzierung für die Equitymethode (1991)

Band 41 Brüggerhoff, Jürgen: Management von Desinvestitionen (1992)

Band 42 Bröker, Erich W.: Erfolgsrechnung im industriellen Anlagengeschäft - Ein dynamischer Ansatz auf Zahlungsbasis - (1993)

Band 43 Frankenberg, Peter: Transnationale Analyse US-amerikanischer und deutscher Jahresabschlüsse - Eine theoretische und empirische Untersuchung (1993)

Band 44 Kleinaltenkamp, Michael: Standardisierung und Marktprozeß - Entwicklungen und Auswirkungen im CIM-Bereich (1993)

Band 45 Pellens, Bernhard: Aktionărsschutz im Konzern - Empirische und theoretische Analyse der Reformvorschläge der Konzernverfassung (1994)

Band 46 Reckenfelderbäumer, Martin: Marketing-Accounting im Dienstleistungsbereich - Konzeption eines prozeßkostengestützten Instrumentariums (1995)

Band 47 Knittel, Friedrich: Technikgestützte Kommunikation und Kooperation im Büro. Entwicklungshindernisse - Einsatzstrategien - Gestaltungskonzepte (1995)

Band 48 Riezler, Stephan: Lebenszyklusrechnung - Instrument des Controlling strategischer Projekte (1996)

Band 49 Schulte, Jörn: Rechnungslegung und Aktienkursentwicklung - Erklärung und Prognose von Aktienrenditen durch Einzel- und Konzernabschlußdaten (1996) 
Band 50 Muhr, Martin: Zeitsparmodelle in der Industrie - Grundlagen und betriebswirtschaftliche Bedeutung mehrjähriger Arbeitszeitkonten (1996)

Band 51 Brotte, Jörg: US-amerikanische und deutsche Geschäftsberichte. Notwendigkeit, Regulierung und Praxis jahresabschlußergänzender Informationen (1997)

Band 52 Gersch, Martin: Vernetzte Geschäftsbeziehungen. Die Nutzung von EDI als Instrument des Geschäftsbeziehungsmanagement (1998)

Band 53 Währisch, Michael: Kostenrechnungspraxis in der deutschen Industrie. Eine empirische Studie (1998)

Band 54 Völkner, Peer: Modellbasierte Planung von Geschäftsprozeßabläufen (1998)

Band 55 Fülbier, Rolf Uwe: Regulierung der Ad-hoc-Publizität. Ein Beitrag zur ökonomischen Analyse des Rechts (1998)

\section{Band 1 - 55 erschienen beim Gabler Verlag Wiesbaden}

Band 56 Ane-Kristin Reif-Mosel: Computergestützte Kooperation im Büro. Gestaltung unter Berücksichtigung der Elemente Aufgabe, Struktur, Technik und Personal (2000)

Band 57 Claude Tomaszewski: Bewertung strategischer Flexibilität beim Unternehmenserwerb. Der Wertbeitrag von Realoptionen (2000)

Band 58 Thomas Erler: Business Objects als Gestaltungskonzept strategischer Informationssystemplanung (2000)

Band 59 Joachim Gassen: Datenbankgestützte Rechnungslegungspublizität. Ein Beitrag zur Evolution der Rechnungslegung (2000)

Band 60 Frauke Streubel: Organisatorische Gestaltung und Informationsmanagement in der lernenden Unternehmung. Bausteine eines Managementkonzeptes organisationalen Lernens (2000)

Band 61 Andreas von der Gathen: Marken in Jahresabschluß und Lagebericht (2001)

Band 62 Lars Otterpohl: Koordination in nichtlinearen dynamischen Systemen (2002)

Band 63 Ralf Schremper: Aktienrückkauf und Kapitalmarkt. Eine theoretische und empirische Analyse deutscher Aktienrückkaufprogramme (2002)

Band 64 Peter Ruhwedel: Aufsichtsratsplanungssysteme. Theoretische Grundlagen und praktische Ausgestaltung in Publikumsaktiengesellschaften (2002)

Band 65 Jens Thorn: Taktisches Supply Chain Planning. Planungsunterstützung durch deterministische und stochastische Optimierungsmodelle (2002)

Band 66 Dirk Beier: Informationsmanagement aus Sicht der Betriebswirtschaftslehre. Theoretische Ansätze und das Beispiel Mobile Business. (2002)

Band 67 Nils Crasselt: Wertorientierte Managemententlohnung, Unternehmensrechnung und Investitionssteuerung. Analyse unter Berücksichtigung von Realoptionen. (2003)

Band 68 Franca Ruhwedel: Eigentümerstruktur und Unternehmenserfolg. Eine theoretische und empirische Analyse deutscher börsennotierter Unternehmen. (2003)

Band 69 Andreas Bonse: Informationsgehalt von Konzernabschlüssen nach HGB, IAS und USGAAP. Eine empirische Analyse aus Sicht der Eigenkapitalgeber. (2004)

Band 70 Thorsten Sellhorn: Goodwill Impairment. An Empirical Investigation of Write-Offs under SFAS 142. (2004) 
Band 71 Bernd Slaghuis: Vertragsmanagement für Investitionsprojekte. Quantitative Projektplanung zur Unterstützung des Contract Managements unter Berücksichtigung von Informationsasymmetrie. (2005)

Band 72 Stephanie Freiwald: Supply Chain Design. Robuste Planung mit differenzierter Auswahl der Zulieferer. (2005)

Band 73 Rolf Uwe Fülbier: Konzernbesteuerung nach IFRS. IFRS-Konsolidierungsregeln als Ausgangspunkt einer konsolidierten steuerlichen Gewinnermittlung in der EU? (2006)

Band 74 Marc Richard: Kapitalschutz der Aktiengesellschaft. Eine rechtsvergleichende und ökonomische Analyse deutscher und US-amerikanischer Kapitalschutzsysteme. (2007)

www.peterlang.de 


\section{Die Kapitalschutzfunktion des Jahresabschlusses und Übernahme der IAS/IFRS für die Einzelbilanz}

Frankfurt am Main, Berlin, Bern, Bruxelles, New York, Oxford, Wien, 2005. $326 \mathrm{~S}$.

Europäische Hochschulschriften: Reihe 2, Rechtswissenschaft. Bd. 4182 ISBN 3-631-53856-1 · br. €56.50*

Ausgangspunkt der Arbeit ist die dem nationalen Gesetzgeber durch die so genannte IAS/IFRS-Verordnung vom 19.07.2002 gewährte Möglichkeit,

(1) Kapitalgesellschaften die Befolgung der IAS/IFRS im Einzelabschluss verbindlich aufzugeben. Der Autor untersucht die Eignung der IAS/IFRS unter dem Gesichtspunkt der europäischen und nationalen Kapitalerhaltungsregeln und vor dem Hintergrund des kapitalgesellschaftsrechtlichen Trennungsprinzips. Dabei kommt er zu dem Ergebnis, dass das geltende, in rechtspolitischer Hinsicht fundierte Kapitalerhaltungsregime, für dessen Bewahrung er eintritt, auf Grundlage der IAS/IFRS nicht aufrechtzuerhalten wäre.

Aus dem Inhalt: Der europäische Rechtsrahmen des Kapitalschutzes . Kapital als Instrument der Risikoverteilung zwischen Gläubigern und Unternehmenseignern - Handelsbilanzieller Bezugsrahmen des Kapitalschutzes . Einzelabschluss auf Grundlage der IAS/IFRS · Konsequenzen für das

(10 Jahresabschlussrecht

Frankfurt am Main - Berlin · Bern · Bruxelles · New York · Oxford · Wien Auslieferung: Verlag Peter Lang AG

Moosstr. 1, $\mathrm{CH}-2542$ Pieterlen

Telefax 0041 (0) 32/376 1727

*inklusive der in Deutschland gültigen Mehrwertsteuer Preisänderungen vorbehalten

Homepage http://www.peterlang.de 
Marc Richard - 978-3-631-75501-3

Downloaded from PubFactory at 01/11/2019 04:06:06AM

via free access 